\title{
KENYA GEOTHERMAL PRIVATE POWER PROJECT: A PREFEASIBILITY STUDY
}

\author{
Topical Report
}

October 1992

\section{DISCLAIMER}

This report was prepared as an account of work sponsored by an agency of the United States Government. Neither the United States Government nor any agency thereof, nor any of their employees, makes any warranty, express or implied, or assumes any legal liability or responsibility for the accuracy, completeness, or usefulness of any information, apparatus, product, or process disclosed, or represents that its use would not infringe privately owned rights. Reference herein to any specific commercial product, process, or service by trade name, trademark, manufacturer, or otherwise does not necessarily constitute or imply its endorsement, recommendation, or favoring by the United States Government or any agency thereof. The views and opinions of authors expressed herein do not necessarily state or reflect those of the United States Government or any agency thereof.

Work Performed Under Contract No. DE-FG07-89ID12850

\section{For}

U. S. Department of Energy Office of Industrial Technologies Washington, D.C.

By National Geothermal Association Davis, CA 95617-1350
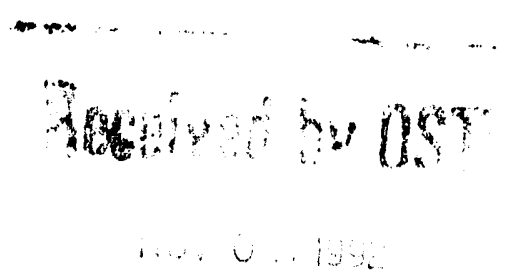
DOE/ID/12850-7

KENYA GEOTHERMAL PRIVATE POWER PROJECT:

A FEASIBILITY STUDY

\title{
Topical Report
}

October 1992

Work Performed Under Contract No. DE-FG07-89ID12850

\author{
Prepared for the \\ U.S. Department of Energy \\ Under DOE Idaho Field Office \\ Sponsored by the Office of the Assistant Secretary \\ for Conservation and Renewable Energy \\ Office of Industrial Technologies \\ Washington, D.C. \\ Prepared by \\ National Geothermal Association \\ P. 0. Box 1350 \\ Davis, CA 95617-1350
}




\title{
ACKNOWLEDGEMENTS
}

Mary persons and organizations have contributed to the preparation of this report. The U.S. Agenry for International Development, through its Office of Energy provided financial support, and the Kenya A.I.D. mission valuable assistance in liaison and communications. Thanks are especially to Mr. Ralph Burr for his great support of this effort and Dr. John E. Mock of the Deparment of Energy. Mr. Ross Pumfrey of the Office of Energy, and Mr. John Hammond and Mr. William Polen contractors to the Office of Energy were also very supportive. A.I.D. financial support was received through both the Office of Energy's Private Sector Energy Development Program and the Renewable Energy Applications and Training Project which originally suggested this prefeasibility study.

Kenya Power and Lighting Company, Ltd. was extremely helpful in providing information about its geothermal operations at Oikaria and Eburru, its transmission grid, and its development plans for the remainder of this decade, via intensive discussions and written documentation. Among others, thanks are extended to Mr. Samuel K. Gichuru, Managing Director, Kenya Power and Lighting Company; Mr. Edwin D. Wasunna, Chief Projects Development Manager, Mr. M.A. Gupta, Corporate Planning Manager, Mr. Julius M. Riungu, Geothermal Projects Manager, Mr. Laban Kariuki, Assistant Corporate Planning Manger; and Mr. Arun Goswami, Projects Engineer, Geologist William Okoth and geophysicists Daniel Kilele (of the Ministry of Energy) accompanied members of the project team in the field; their help was essential. Others at KPLC and staff of the Investment Promotion Centre of Kenya, too numerous to mention individually, are also thanked for their courtesy and assistance. Dr. Peter Dunkley and Dr. Martin Smith, of the British Geological Survey, were gracious in providing information on their work on the volcanology and geothermal manifestations of the northern Rift Valley. Their valuable help is acknowledged vith thanks. Mr. Gesta Gislason, associate of the United National Development Programme in Nairobi, proved to be indefatigable in leading the field trip for the geothermal team members and was very helpiul in discussing prior and possible future work under UNDP auspices.

The Ministry of Energy, through the Minister, the Honorable Nicholas Biwott, and the Permanent Secretary, Mr. C. N. Mutito, graciously allowed project members to purchase topographic and other maps and to discuss geothermal programs with Ministry staff. This is acknowledged with thanks.

Mr. Ian Campbell of Research and Planning Services, Lid., Nairobi, and his assistant, Mrs. Tameezan Wa Gathui, provided very valuable technical and logistical support to all team members. This is acknowledged with gratitude.

The main authors of this report are Mr. James Koenig and Dr. James McNitt of GeothermEx, Inc. Mr. Ben Holt and Mr. John Brugman of the Ben Holt Company, Mr. John Armstrong of Dorsey \& Whitney, Mrs. Karen Venable of Venable Associates, and Mr. Mike Jones, Consulting Economist-Consultant to Oak Ridge National Laboratory and Oak Ridge Associated Universities. Mr. William Polen of T. Head Company contributed to Section VI.

\author{
Prepared for the \\ The U. S. Agency for International Development \\ Office of Energy \\ and \\ U.S. Department of Energy \\ Assistant Secretary for Conservation and Renewable Energy \\ Under DOE Idaho Field Office \\ Energy Grant No. DE-FG07-89ID12850
}


TABIE OF CONTENTS

An Assessment of the status of Kenya's Power Sector and Implications of Private Power

for The Kenya Power and Iighting Company

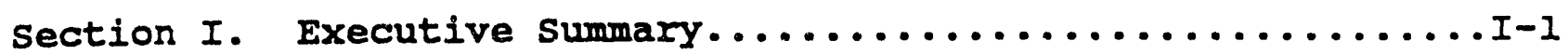

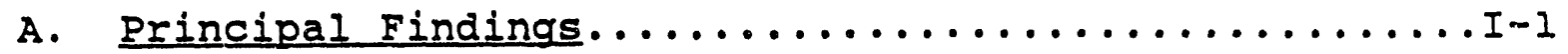

B. Recommended Plan of Action....................

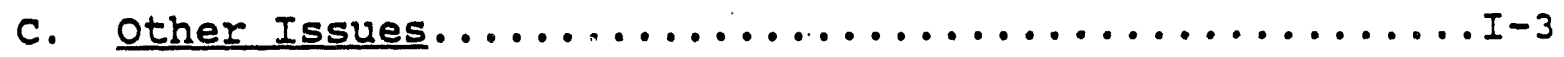

Section II. Introduction.......................... II-6

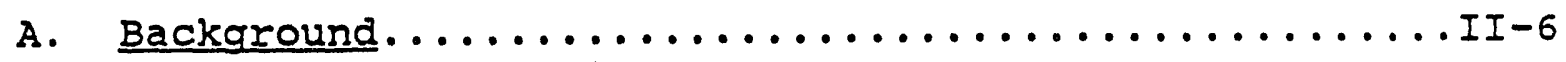

Section III. An Assessment of the Status of Renya's Power Sector and Implications of Private Power for The Renya Power and Lighting Company....................................III-I

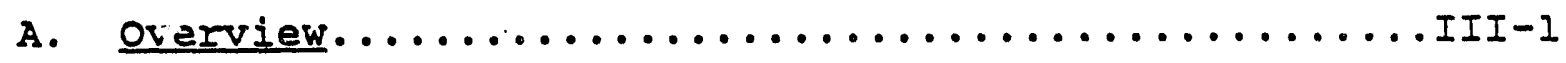

B. Power Demand and Supply....................... . . .

1. Current and Future Demand for Electric Power

2. Kenya Electric Power Supply

c. Kenya's Electricity supply Program...............II-8

1. Least-Cost Supply Plan

D. Comparison of KPIC and Private Power

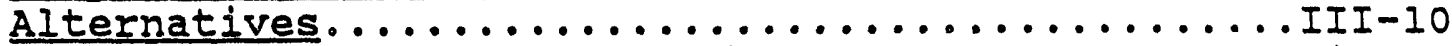

1. Methodology for Comparison of KPLC LCP and Private Power Alternatives

2. Comparative Analysis

Section IV. Renya Geothermal Program - Status and Issues Concerning Development............................IV-I

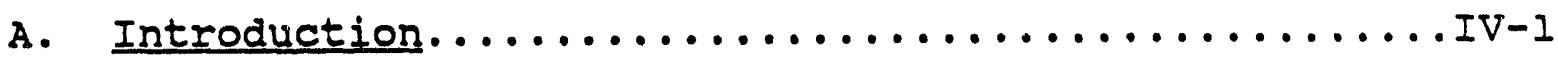

B. Geologic setting of the Kenya Geothermal Areas...... IV-2

c. History and Status of Geothermal Exploration and Development in Kenya................... IV- 
B. Philippines $\ldots \ldots \ldots \ldots \ldots \ldots \ldots \ldots \ldots \ldots \ldots \ldots$. $\ldots \ldots \ldots$

1. Electric Power System Overview

2. Private Power Legislation

3. Private Power Regulations

4. Private Power Projects

5. Private Power Investment Incentives

c. Pakistan.............................

1. Electric Power System overview

2. Private Power Legislation

3. Private Power Regulation

4. Private Power Incentives

D. Dominican Republic...................... VI-8

1. Electric Power System Overview

2. Private Power Legislation

3. Private Power Regulation

4. Private Power Projects

4. Private Power Incentives

Part 2. Setting a Price for Privately Generated Power

A. A Review of Methods for Pricing Private Power

Purchases.............................

1. Overview

2. Avoided Cost

3. Application of Avoided Cost Principles in Developing countries

Section VII. Private Power Project Financial Analysis

A. Investment Climate in Kenya................VII-I

1. Historical Overview

2. Economic Overview

B. Options for Private Power Development in Kenya...VII-2

C. Private power Financing Issues.............VII-4

D. Potential Role of Kenya Power and Lighting

Company, Ltd $\ldots \ldots \ldots \ldots \ldots \ldots \ldots \ldots \ldots \ldots$ VII -5

E. Financing options..................... VII-5

1. Traditional Sources of Capital

2. Local Sources of Funds

3. Other Sources of Funds

F. Financial Analysis.................... VII-7

1. The Financial Model

2. Financial Assumptions

G. Financial scenarios................... VII-8 
D. The Basis for Ranking Geothermal Prospects.........IV-I4

1. Background

2. Types of Assessment Methodologies

3. Detail of Application

E. Initial Prioritization of Geothermal Prospects

By Potential Size, Level of Exploration Risk

and Location...............................

1. Methodology

2. Possible Areal Extent

3. Prospect Descriptions by Risk Group

4. Initial Prospect Prioritization

F. Cost of Geothermal Exploration, Development

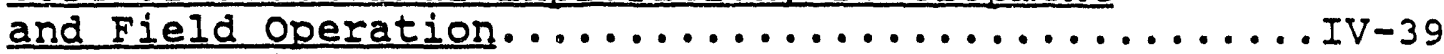

1. Description of Cost Factors

2. Exploration stage Costs

3. Developmental stage costs

4. Operation stage costs

G. Project Timetable......................

1. Exploration Timetable

2. Wellfield Development Timetable

3. Power Plant Construction Timetable

4. Summary

H. Project Recommendations..................... . . . . . .

1. Factors Controlling Project cost

2. Calculation of Cost Per Prospect

3. Favorable and Negative Aspects of Each Prospect

4. Project Recommendations

Section V. Capital Costs and Technical Characteristics of

Geothermal power Plants...........................v-l

A. Introduction...........................

1. Methodology

2. Results

3. Conceptual Design

4. Capital Cost Estimate

5. 0 \& $M$ Cost Estimate

6. Project cost summary

Section VI. Private Power Options, Experience and Review of Power Pricing Alternatives............................ VI-I

Part 1. Private Power: Experience in other Countries

A. Introduction........................... 


\section{A. PRINCIPAL FINDINGS}

Twenty-eight geothermal areas in kenya were evaluated and prioritized for development. The prioritization was based on the potential size, resource temperature, level of exploration risk, location, and exploration/development costs for each geothermal area. Suswa, Eburru and Arus are found to offer the best short-term prospects for successful private power development. It was found that cost per $\mathrm{kW}$ developed are significantly lower for the larger (50MW) than for smaller-sized ( 10 or $20 \mathrm{MW}$ ) projects. In addition to plant size, the cost per $\mathrm{kW}$ developed is seen to be a function of resource temperature, generation mode (binary or flash cycle) and transmission distance.

For the 3 sites with prospectively the most attractive development potential, estimated geothermal development costs range from about US\$2,538/kW (including interest during construction) for a $50 \mathrm{MW}$ plant to approximately US\$3,324/kW (including interest during construction) for a $20 \mathrm{MW}$ plant. Estimated cost per $\mathrm{kWh}$, based on sensitivity analysis of avoided costs, financing mix, tax concessions and plant size, are within the range of the Kenya Power and Iighting Company's (KPIC) own geothermal developinent costs. At these levels, returns from development appear to offer an attractive prospect for foreign investors.

KPIC sales of some $2,46 I$ GWh and peak demand of about 480 MW in 1988-89 will both double by about the year 2001-02. New capacity added during the period 1988-89 to 2001-02 will need to be equal in magnitude to all capacity already constructed. This expansion will impose not only a financial challenge but also a substantial logistical challenge for KPLC.

The purchase of additional or replacement capacity from private sources has a number of potential benefits for KPIC. These include such possible tangible and measurable benefits as lower prices for power, lower capital outlays for development, shorter development lead time and reduced workload for scarce KPLC projectmanagement personnel. Furthermore, numerous important uncertainties are reduced and risks are shifted by pursuing private purchases. These include reducing the risks and financial burden of geothermal exploration, reducing the risk of capacity or energy shortfalls due to project delays and higher-than-forecast energy or capacity growth, and reducing the burden of pursuing and acquiring rapital loans in a constrained financial market.

Private power development in Kenya could follow one of several models. One of the most common is the Build-Own-Operate-Transfer (BOOT) approach. Under this approach, private developers would explore, drill development wells, construct a power station and

$$
I-1
$$


H. Results of Financial Analysis Based on Project Structure and $\operatorname{Tax}$ Effects.................... VII-9

I. Analysis of Most Likely Prospects...........VII-10

J. Sensitivity Analysis of Kenya Power and Lighting company, Ltd. and Private Power.......VII-14

K. Conclusion...........................

Section VIII. Iegal Issues Relating to the Development and Sale of Private-sector Geothermal Power to the Public Sector in Renya

A. The Kenyan Legal and Regulatory Framework:

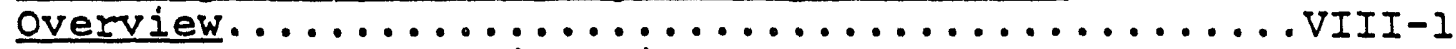

1. The Kenyan Legislative and Regulatory Approach

2. The Theory of Private Power Laws

B. The Private sector Perspective................ VIII-6

C. The General Agreement Framework...............VIII-7 1. Preliminary Agreements

2. Private-sector Power Agreements

3. Ancillary Agreements

D. Resource Rights........................ VIII-12

E. Power Purchase....................... VIII-16

F. Investment Laws and codes................

1. Overview

2. The Investment Laws and Regulations of Kenya

3. Investment Checklist

Appendices 
sell power to KPIC for an agreed period. The project would thereafter transfer to KPLC (Or KPC) at under mutually agreed terms. Another option is the Build-Own-operate (BOO) approach, under which no transfer of ownership takes place.

The Government of Kenya (GOK) has taken a number of actions to encourage private development of its geothermal resources and is aware of the critical role of foreign investment. In May 1990, the Geothermal Resources Act of 1982 was implemented, allowing private-sector geothermal development. The main assurances a private-sector developer would need are addressed, including rights to the resource, rights to sell steam or electricity and rights to repatriate income sufficient to meet debt burden and make a reasonable return on investment. Geothermal private power development requires the granting of a Geothermal Resources License and a license under tlie Electric Power Act, both to be granted by the Ministry of Energy (MOE); and in addition, a Mineral Lease consistent with the Mining Act of Kenya.

Nonetheless, since a private geothermal undertaking would be a first of its kind in Kenya, it would still impose substantial risks on the developer. These include political and economic risks; for example, ability to obtain an adequate price for power to allow a reasonable return on investment, risk regarding conversion of revenues into foreign exchange, risk of changes in government policy or new legislation, risk of changes in taxation or duties, or force majeure. For this reason and given the strong public interest in the project's success, strong support and encouragement from the GOK, MOE and KPIC is essential for such a venture.

In pursuing private power development in Kenya, the GOK would be able to benefit from the experience of many other developing countries, including Pakistan, the Philippines, Thailand, Indonesia, the Dominican Republic, Costa Rica and Turkey. Each of these countries has initiated policies and regulations encouraging private sector participation in their power supply plans. U.S. A.I.D would like to cosponsor with the Government of Kenya, a conference on opportunities for private investment in the power sector in Kenya.

\section{B. RECOMMENDED PIAN OF ACTION}

KPIC and MOE are invited to review and critique this report. The input and participation of both KPIC and MOE are critical to success of any private power effort. The team representing the U.S. geothermal industry which has prepared this report will respond to all comments, and will arrange to hold more detailed discussions with the GOK on geothermal private power development at the earliest opportunity. The report concludes that the development of a private geothermal project will require the 
1. Review of this report by KPLC and MOE, and revision of the report based on this review, followed by meetings to present findings and conclusions.

2. Agreement in concept by the KPLC and MOE to the development of a geothermal private power project in Kenya along the lines of this report, or as modified based on the considerations of KPLC and the GOK.

3. Completion of a Memorandum of Understanding (MOU) between the appropriate Kenya government agencies and a U.S. geothermal developer, and related agreements which include:

a. A joint-venture agreement, potentially with KPLC as a local joint-venture partner.

b. Granting of a Geothermal Resources License to drill, extract and utilize the resource, including confirmation of the availability of all concessions to the joint venture, and agreement on the general terms and conditions of a power sales contract; and a license under the-Electric Power Act.

c. Granting a Mineral Lease consistent with the Mining Act.

4. The U.S. geothermal developer will solicit and obtain funding for a full feasibility study, including any funds required for exploration ariling, with a reasonable contribution of funds, services or other support by the local joint-venture partner.

5. The U.S. developer and local joint-venture partner would present results of feasibility study and, following acceptance, would finalize the necessary development agreements (geothermal lease, power purchase agreement, and construction, management and operations agreement) and operational convenants (tax treatment, currency treatment, etc.) with the responsible kenya government agencies.

\section{OTHER ISSUES}

The successful development of private power in Kenya depends in large measure upon the degree to which KPIC and the MOE commit to the success of this approach and integrate the approach in KPLC's future capacity plans. one means of ensuring this commitment would be for KPIC to allocate a portion of its new capacity requirement to the private sector for development. This would signal a solid commitment by GOK and greatly facilitate establishing the local conditions necessary for successful project 
development.

Local participation in this type of project is important at all phases to ensure that it is designed and developed in a manner to serve the best interests of Kenya. Mobilization of local capital, potentially to participate through local currency in the long-term financing pool, is another area which GOK may wish to explore. 


\section{INTRODUCTION}

\section{A. BACKGROUND}

In June, 1988, during the preparations for a U.S. geothermal industry definitional trade and investment mission to Kenya, a strategy for development of a private power project in Kenya began to take shape. During that mission and later, the MOE and KPIC identified rapidly growing demand and capital constraints which jeopardized their ability to provide adequate new electricity supply. Subsequently, the MOE and KPIC agreed on the desirability of exploring private power alternatives, and developed implementing regulations for private geothermal development. Oak Ridge Associated Universities continued this initiative through the Renewable Energy Applications and Training Project of A.I.D., and sought U.S. industry involvement through the National Geothermal Association (NGA).

In mid-1990, funding was approved from the U.S. A.I.D., U.S. Department of Energy (DOS) and the U.S. Trade and Development Program (TDP) to perform this private power prefeasibility study. The study is intended to gather and analyze technical, firancial and institutional information, and help to define a private power approach to develop geothermal resources in Kenya. Specifically, the Kenya Geothermal private Power study is intended to evaluate various potential sites for geothermal development, evaluate the impact of private power development on the existing and future generation system, review the laws and regulations for private power development in Kenya, and generally to determine the legal and financial feasibility of a private geothermal project in Kenya.

The U.S. geothermal industry has been represented in this effort, by the NGA via its members GeothermEx, Inc. and the Ben Holt Company, and Venable Associates. Interest in Kenya arises from the desire of the U.S. industry to play a role in development of geothermal resources in Kenya, and because of the expressed interest on the part agencies of the GOK in pursuing this opportunity.

Report Format. The report which follows comprises a prefeasibility study for a private power development of a geothermal electric generation project in Kenya. Section III of the report provides a brief assessment of tire state of the Kenya power systems, the need for power, financial requirements, and the prospective benefits of private power development. Report section IV provides an assessment of the existing geothermal program and the geothermal resources of Kenya, along with a ranking of prospective sites for development. The costs for development are estimated in sections $I V$ and $V$ for a range of plant sizes; a financial analysis is performed in section VII on the potential 
rate of return to a private developer under a range of assumptions. Section VI of the report contains a brief review of the experience of a number of other countries with private power. A review of various methods for valuing private power and power pricing is also presented in section VI. section VIII contains a review of the local institutional and legal and regulatory framework for private power development and a discussion of the major legal issues pertaining to private power project development. 
III. An Assessment of the status of Renya's Power Sector and Implications of Private Power for The Kenya Power and Iighting Company

\section{A. Overview}

The power industry in Kenya is largely owned by the Kenya Government, and is comprised of 3 entities. These are The Kenya Power and Lighting Company (KPLI), The Kenya Power Company (KPC), and The Tana River Development Company (TRDC). The Kenya Power and Lighting Company is owned 498 by the Government of Kenya (GOK) and $9.7 \%$ by other Governmental institutions. The balance of shares are owned by Kenya residents $(34 \%)$ and non-residents $(7 \%)$. KPLC is responsible for the overall distribution of electricity in the country, owning the distribution network, as well as certain standby facilities such as Kipevu in Mombasa, and sevenal small diesels and hydro units.

The Kenya Power Company is owned entirely by the GOK and is responsible for the development of new hydroelectric and geothermal generation facilities and power purchases from Uganda. KPC is the owner of Tana river hydro facilities and the olkaria geothermal power stations. KPC is in the process of alquiring the Kiambere and Masinga stations of the Tana River Regional Development Authority (TARDA) and Turkwell power station from the Kerio Valley Development Authority. KPC is also undertaking the planning for the Sondu Miriu hydropower project. The Tana River Development Company is also wholly owned by GOK, and presently owns the Kamburu, Gitaru and Kindaruma hydro stations. TRDC selis in bulk to KPLC at cost.

The basic framework for power system planning in Kenya is the Kenya National Power Development Plan 1986-2006 (KNPDP), prepared by Acres International Itd in 1987. The KNPDP provided a new least-cost generation and transmission plan for Kenya. This plan represents the latest long-term development plan for the power sector available. Although the KNPDP has not been officially endorsed, it is believed to represent the best comprehensive basis for planning. This plan has been overcome by events in some areas, however, for example demand growth has been more rapid than forecast, and power development schedules have slipped. In this study we have therefore made adjustments in forecast demand, new capacity scheduling and costs, among other areas, based on input from KPLC, in order to reflect the current demand and supply situation and the best judgement of KPLC on various planning assumptions. 
Table III - 1 The Kenya Power and Lighting Company

Historic Sales of Electricity by Customer Category (GWH)

\begin{tabular}{|c|c|c|c|c|c|c|c|c|}
\hline Customer Category & 1984 & 1985 & 1986 & $1986 / 87$ & $1987 / 88$ & $1988 / 89$ & $1989 / 90$ & $\begin{array}{l}\text { Compound } \\
\text { Growth } \\
\text { Rate }(5.5 \text { yrs) }\end{array}$ \\
\hline $\begin{array}{l}\text { Domestic, Small Commercial } \\
\text { and Industrial }\end{array}$ & 514 & 545 & 292 & 634 & 678 & 729 & 780 & $7.9 \%$ \\
\hline $\begin{array}{l}\text { Medium Cormercial and } \\
\text { Industrial }\end{array}$ & 455 & 472 & 252 & 536 & 555 & 515 & 554 & $3.6 \%$ \\
\hline $\begin{array}{l}\text { Large comercial and } \\
\text { Industrial }\end{array}$ & 681 & 812 & 434 & 916 & 982 & 1041 & 1127 & $9.6 \%$ \\
\hline Off-Peak & 116 & 106 & 53 & 111 & 110 & 113 & 116 & $0.0 \%$ \\
\hline Street Lighting & 9 & .9 & 4 & 9 & 12 & 14 & 14 & $8.4 \%$ \\
\hline Total & 1,775 & 1,944 & 1,035 & 2,206 & 2,337 & 2,412 & 2,591 & $7.1 \%$ \\
\hline $\begin{array}{l}\text { Per Cent Increase } \\
\text { per Year }\end{array}$ & & $9.5 \%$ & & $8.8 \%$ & $5.9 \%$ & $3.2 \%$ & $7.4 \%$ & \\
\hline
\end{tabular}


B. Power Demand and Supply

\section{Current and Future Demand for Electric Power}

Historically the demand for energy and peak load power requirements in Kenya have grown rapidly, reflecting substantial growth in the industrial sector, as well as rapid urbanization of the country. Year to year fluctuations have also been significant as the affects of economic conditions flow through to power sales. In 1989 for example, energy sales growth dropped to $3.23 \%$ from $6 \%$ in the previous year. This was primarily due to a decline in sales to industry. Table III-l above summarizes the historic energy and power requirements met by the kenya power system.

Forecasts of future energy and power are extremely important in determining the plans for necessary new capacity. For purposes of this report, we have utilized forecasts prepared for KPIC by Ewbanks-Preece, covering the period 1985-86 to 2005-6. Forecasts incorporate estimates of total system sales, average losses, generation station internal use, system peak demand and system load factor. Table III-2 summarizes these data.

The basic picture given by the projections in Table III-2 is of a system with substantial continuing growth, about $5.4 \%$ in energy and peak demand. The implications of these forecasts is that sales of some 2,461 GWh and peak demand of about 480 MW in 1988/89 will both double by about the year 2001-2. Correspondingly, new capacity added during this period will need to be equal in size to all capacity already constructed to 1990. Given the higher prices for new capacity today, and the short time period during which this capacity will be needed, this expansion will impose not only a financial challenge but also a substantial logistical challenge for KPLC.

\section{Renya Electric Power Supply \\ a. Power Supply Characteristics}

The current electric power system in Kenya is made up of somewhat over 800 MW of installed capacity, with an effective generation capability of about $550 \mathrm{MW}$. Of this effective capacity, $375 \mathrm{MW}$ are hydroelectric, $130.5 \mathrm{MW}$ are oil-fired, and $43 \mathrm{MW}$ are geothermal. Due to the addition of $85.7 \mathrm{MW}$ effective capacity from the Turkwell hydroelectric plant in 1992-93, effective capacity rises to about $664 \mathrm{MW}$ in that year. Given current and projected energy demand, this capacity will be able to provide all capacity requirements (on an average hydru year basis) in 1992-93, but allowing only a $14 \mathrm{MW}$ reserve, where $95 \mathrm{MW}$ are required to maintain the $15 \%$ reserve margin desired by KPLC. 
Even with the optimistic assumption that Kenya will be able to add the Sondu Miriu and sererwa hydro projects for a total capacity of 49.4 MW by 1996-97, and geothermal capacity in the olkaria Northeast field of $64 \mathrm{MW}$ by 1994-95, the system by the year 2001-02 would still require an additional $165 \mathrm{MW}$ geothermal and 180 MW of coal. Table III-3 details existing capacity and capacity additions planned by fuel type. Table III-4 provides estimated generation from existing and planned capacity.

\section{b. Resource Cptions}

The geothermal resources of Kenya are among the best in the world and are described in some detail in section IV below. In addition to geothermal potential, Kenya is endowed with substantial hydroelectric resources. Identified undeveloped hydroelectric resources in Kenya total over 1,400 MW of capacity and 6,000 GWh of average energy. This potential is found in 5 major river systems, the Tana River basin with about $40 \%$ of the total, $30 \%$ in the Lake Victoria basin, and about $10 \%$ each in the Ewaso Ngiro North, Rift Valley and Athi River basins. After the Turkwell River project, about to be completed, the most attractive projects appear to be the Sondu Miriu and the sererwa projects, respectively.

The Sondu Miriu project is being prog:ammed for 1996-97, and would produce about $31 \mathrm{MW}$ firm capacity and average energy of 277.6 GWh. The Sererwa project would provide about 18.4 MW of power and an average of $157 \mathrm{GWh}$. Economics and feasibility of the sondu Miriu project are currently under final review. The sererwa project is essentially a peaking power plant which would operate only during system peak periods. The KNPDP reconmended further studies of this latter option. Apparently a feasibility study has recently been completed for sererwa, but was not obtained for purposes of preparing this report. Finally, consideration is being given to a $72.5 \mathrm{MW}$ third unit at Gitaru. The KNPDP did not incorporate this unit at Gitaru due to its high cost. Additional hydro potential at High Grand Falls, Leshota and Magwagwa was noted in the KNPDP, and further prefeasibility studies will apparently be undertaken on these areas in the future.

Kenya has no developed oil, gas or coal resources. It must therefore import all its fossil energy resources, and currently refines crude oil resources to provide for fuel for oil-fired generation, transport and industry, among other uses. Although coal-fired generation is recommended in the KNPDP, Kenya has no commercially exploitable coal resources, although nearby Tanzania and $Z$ imbabwe both have significant coal resources. Substantially expanded coal use in Kenya would require substantial investment in coal landling and storage at the port of Mombasa which have not been factored into the estimated cost of coal power generation included in this paper. 


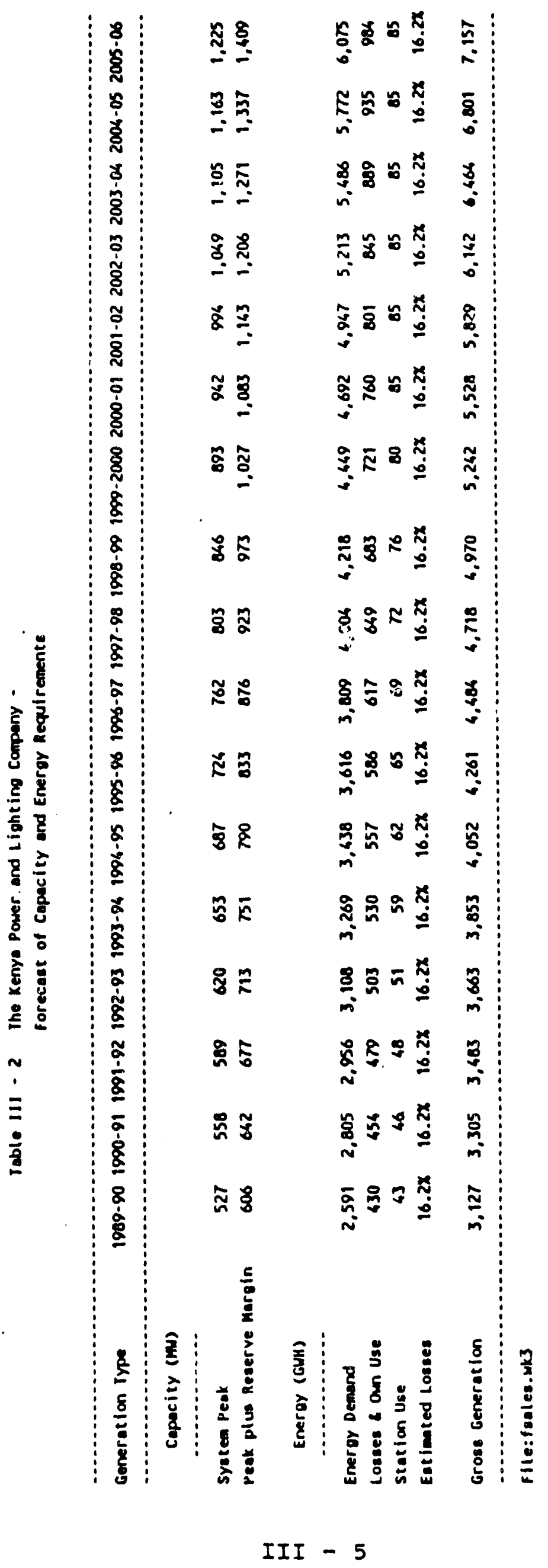




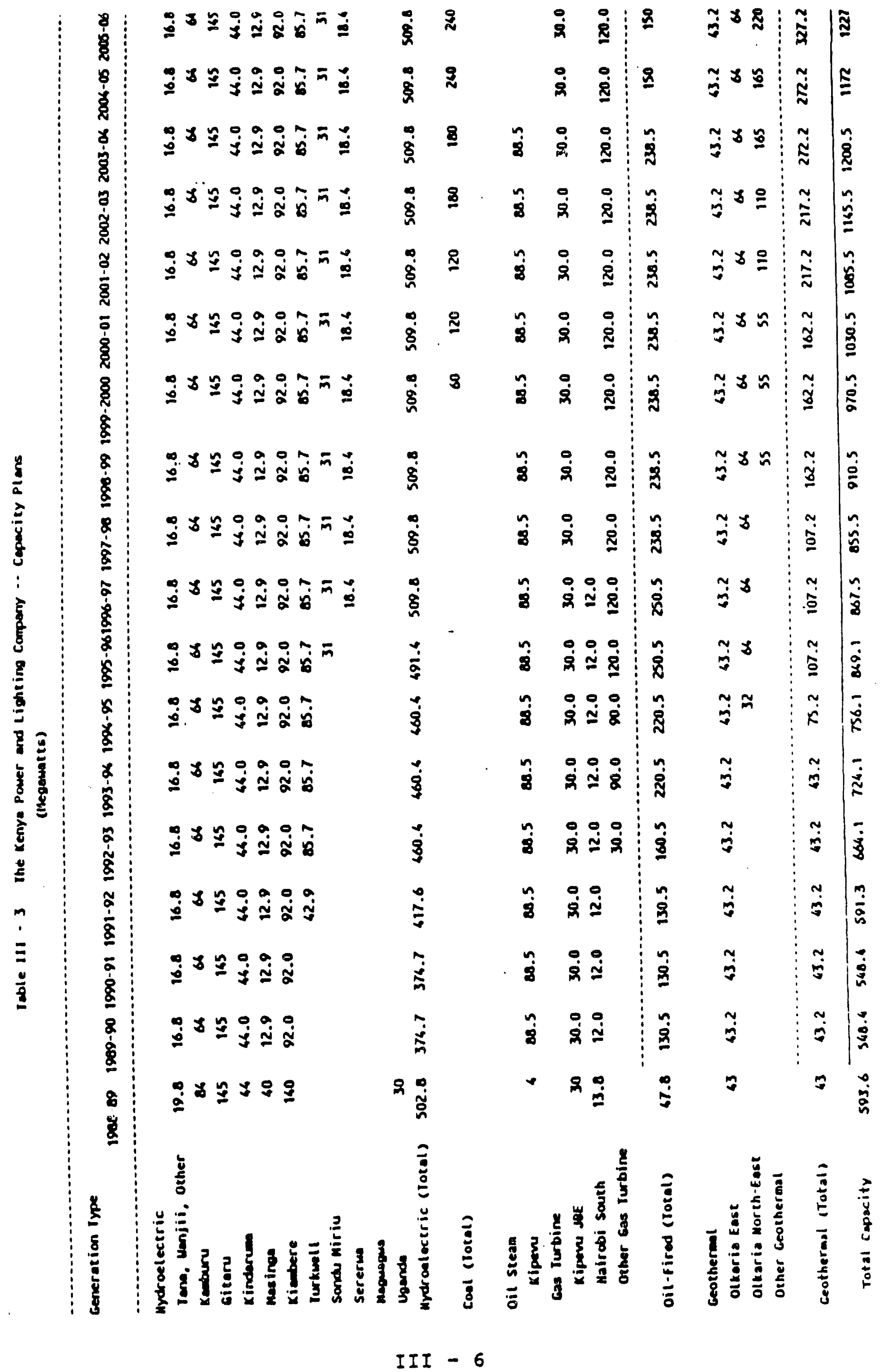




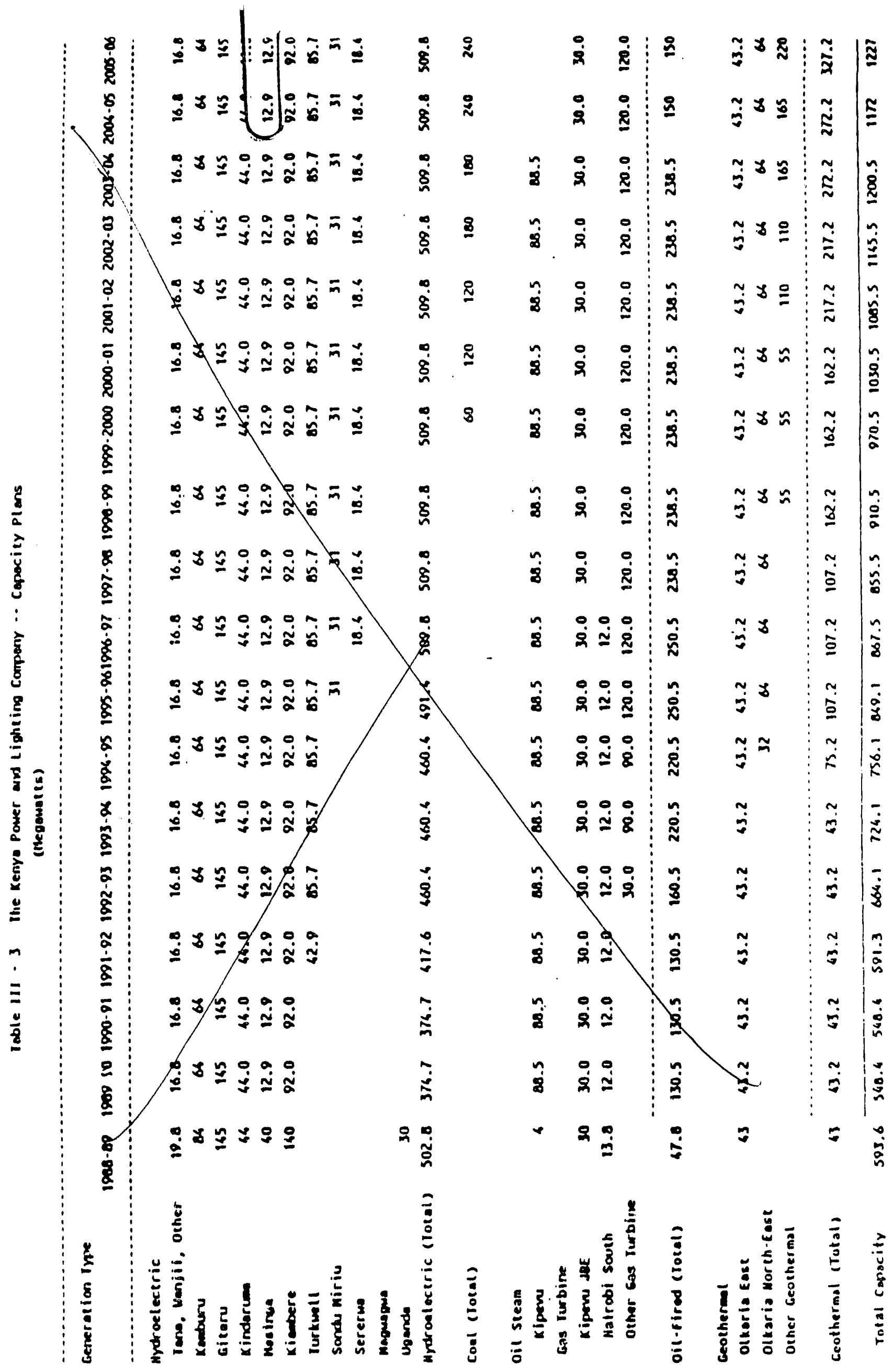




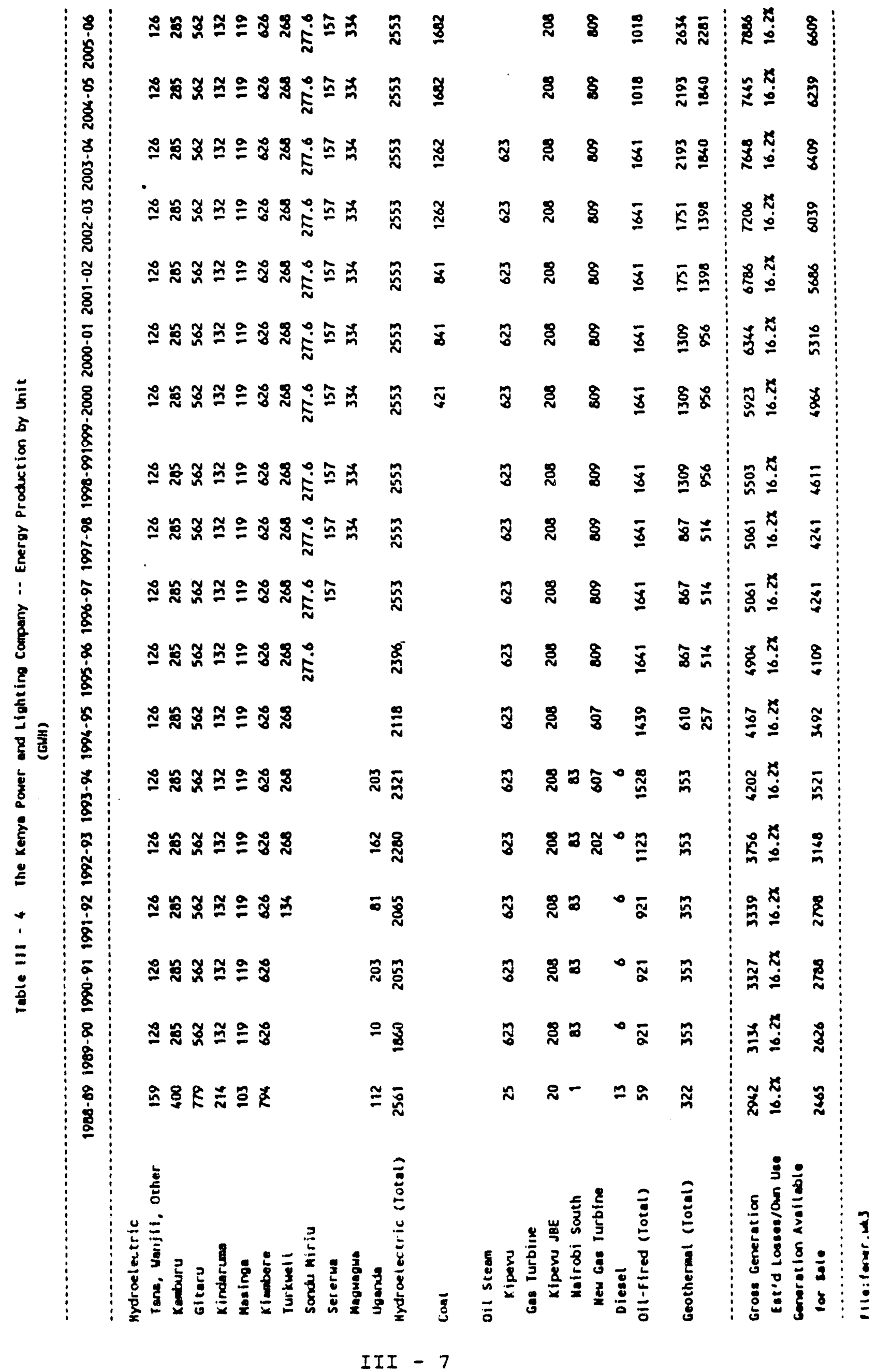




\section{c. Kenya's Electricity Supply Program}

\section{1: Least-Cost supply plan}

The KNPDP or so-called "Master Plan" for electric power development in Kenya completed in 1987, provides the basis for much of the planning for new generation today by KPIC and was used extensively for this prefeasibility study. Updates and additional analysis of the Kenya electricity supply program have been undertaken recently by Ewbanks Preece for KPLC due to changes in demand for energy, as well as changing costs of new capacity and other factors. KPLC itself and various other consultants continue to further refine these plans as part of the planning and feasibility work for various new generation projects. Any changes in the KNPDP (ACRES Report) have been incorporated in the prefeasidility study to the extent information was available.

\section{a Methodology}

It is important to understand the basic framework for supply planning in order to appreciate the comparison which will be presented later between private power alternatives and the KPLC planned generation program. This section presents a brief overview of the major considerations going into the planning process.

The basic supply plan of KPIC is designed to allow the requirements, while at the same time, minimizing the cost of providing this service. The planning process incorporates consideration of many factors, some of the technical factors include the reliability of equipment, maintenance needed and cost of new generation, and planning and construction requirements and lead times; and the other uncertainties, for example, as in future levels and geographic locations of electricity load growth, hydro conditions caused by dry weather, and fuel availability and cost. Given the uncertainties in these factors, sensitivity analysis is used to test various alternatives against these factors.

The limited analysis of supply alternatives in this study could not possibly duplicate or attempt to redo the supply plan of KPLC. However, this study did involve both a thorough review of the KNPDP and its various revisions. This review was basically intended to permit a better understanding of the economic and other implications of providing additional generation to KPLC through private means.

\section{b. Description of Plan}

The KNPDP consists of a mix of new generation, schedule for retirements, assumed purchases from Jganda, growth projections for

$$
\text { III - } 8
$$


energy and power, financial requirements and resulting reliability implications. The supply analysis in this report takes this information as given, as modified by the Ewbanks-Preece report, and analyses the implications of private power alternatives to this plan. The principal differences which are analyzed are: project cost, timing, and differences in oil generation requirements and unserved energy which result. Since both the KNPDP and the Ewbanks-Preece report assume that all energy requirements will be met, the analysis of unserved energy is for sensitivity analysis purposes to inform KPLC of the costs of not undertaking plans as scheduled, and the equivalent benefit if private power addi $=i o n s$ permit these hypothetical short-falls to be avoided.

\section{c. Planning Assumptions and Expansion Plans}

For this report we have attempted to be as consistent as possible with the planning assumptions used in the KNPDP and Ewhanks-Preece work. In general we have used the most recent data available, or in the case of several values have attempted to use the mean or most likely value, with sensitivity analysis used to evaluate the impact of divergence from this value. Table III-7 section presents the basic assumptions used for this analysis. These include capital and operating and maintenance costs, scheduled and forced outage rates, fuel costs, and fuel cost escalation (only for oil). Estimates for planned hydro output and costs are based KPIC's latest figures.

\section{d. Major Planning Issues and Uncertainties}

As part of both the general review of the KNPDP and subsequent analysis of expansion plans, the following major issues or uncertainties were identified which are the subject of analysis in this report:

1. Fuel prices and escalation rates

2. Energy and peak demand growth

3. Hydroelectric generation levels realized, and output and timing for additional hydro additions.

4. Geothermal development and production rates, economics and lead times; and lead times for other types of capacity (i.e. combustion turbines).

5. Generation financing (Section VI).

6. Unserved energy costs. 
D. Comparison of KPLC and Private Power Alternatives

1. Methodology for Comparison of KPLC LCP and Private Power Alternatives

The analysis in this section is intended to demonstrate the potential advantages of private geothermal development in terms of reducing costs and risks of higher energy demand than forecast, higher oil prices, delay in KPLC expansion plans and higher KPLC geothermal costs. Advantages are demonstrated primarily through a comparisons of economic costs and benefits. These relative costs and benefits depend ersentially on the costs of new capacity and directly associated transmission, and not on cost differences derived fron total system expansion analysis. The incremental costs and the various costed items in this analysis therefore are not equal to the total incremental crst for generation expansion, which would include overall transmission and distribution, and certain other items. Since overall system costs not related to new project costs are not significantly affected by the new projects reviewed here, this partial analysis should accurately reflect the main differences between the KPLC plan and private power project.

\section{a. Annual cost Curves}

In order to compare new generation capacity alternatives it is necessary to develop cnst relationships for each type of capacity which reflect both capital and operation cost. It is also nesessary to place costs which extend over a substantial period of time on a common footing. Cost relationships were developed for purposes of this report based on assumptions in the KNPDP, as revised in the Ewbanks-preece report, and through communication with KPIC staff. The two basic cost components associated with each technology are annual capital cost (including fixed o\&M costs) and annual operating and fuel cost.

Annualized capital cost used herein for analysis may be thought of as the cost of purchasing a unit of capacity on credit with repayment of principal and interest over the term of the loan. Variable cost depends on the number of hours the plant operates each year, and is rade up of operating and maintenance and fuel costs. Since capital equipment is not $100 \%$ reliable, capital costs for equipment rated at a nominal capacity are adjusted to reflect estimated output after applying planned and forced outage rates. Inflationary effects have been removed from costs to allow comparison on a constant "dollar" basis. Only for fuel costs which are assumed to escalate in the Euture at a rate $4 \%$ per year higher than general inflation, have adjustments been made to reflect this differential. Ail discour: sectors and other parameters in this analysis are on a so-called "real" terms basis. 
It was not feasible with the resources and data available for this analysis to run a system optimization model for KPIC to optimize plant dispatching and fully simulate a least-cost expansion plan for each case analyzed. Therefore in this report the basic least-cost expansion plan developed by ACRES International and KPIC, as modified by Ewbanks-Preece is used.

Figure III-l shows the total capital plus variable costs for each new generation type as its varies with capacity utilization. This figure demonstrates cost differentials by usage rate. It can be seen that geothermal is the lowest cost resource above $80 \%$ capacity factor (utilization at rated capacity), while coal is les: costly between 60\%-80\% capacity factor, with hydro (Sondu Miriu) being less costly below that level (but constrained by available water supply to only a capacity level of about 60\%). The advantages of greater utilization of baseload capacity due to its lower costs can be seen with both geothermal and coal (whose costs exclude the port and handling infrastructure required). These resources are substantially less costly per kWh than combustion turbine or oil steam options when operated at high baseload capacity factors. There generation is required either for standby or for intermediate or peaking duty only, it can also be seen that oil fired combustion turbine or other capacity would be more economic.

Hydroelectric generation alternatives are more complex to evaluate for several reasons. As the variable costs for hydro generation are very nearly zero, hydro unit cost shows very little sensitivity to the rate of capacity utilization. This can be seen for the Sondu Miriu and sererwa options in Figure l. (Also note the low maximum firm capacity levels for these two hydro options shown in the figure.) Hydro costs are generally very site specific, with a good hydro site likely to provide economic baseload energy. Where a site is poorer low water conditions cause energy and/or capacity to be constrained, or a low head may limit power output. Given the major impact of dry year conditions on hydro energy and capacity, hydroelectric generation often requires thermal back-up for reliability purposes, adding to real hydro costs. Due to the extensive hydro development in Kenya, additional hydro being contemplated is not necessarily more cost-effective than fossil alternatives.

\section{b. Comparative Analysis Description}

The basic economic comparisons provided in this report section consider three basic factors.

First, the relative cost for new additions is compared for the anticipated KPLC expansion plan (Base Case) versus private 


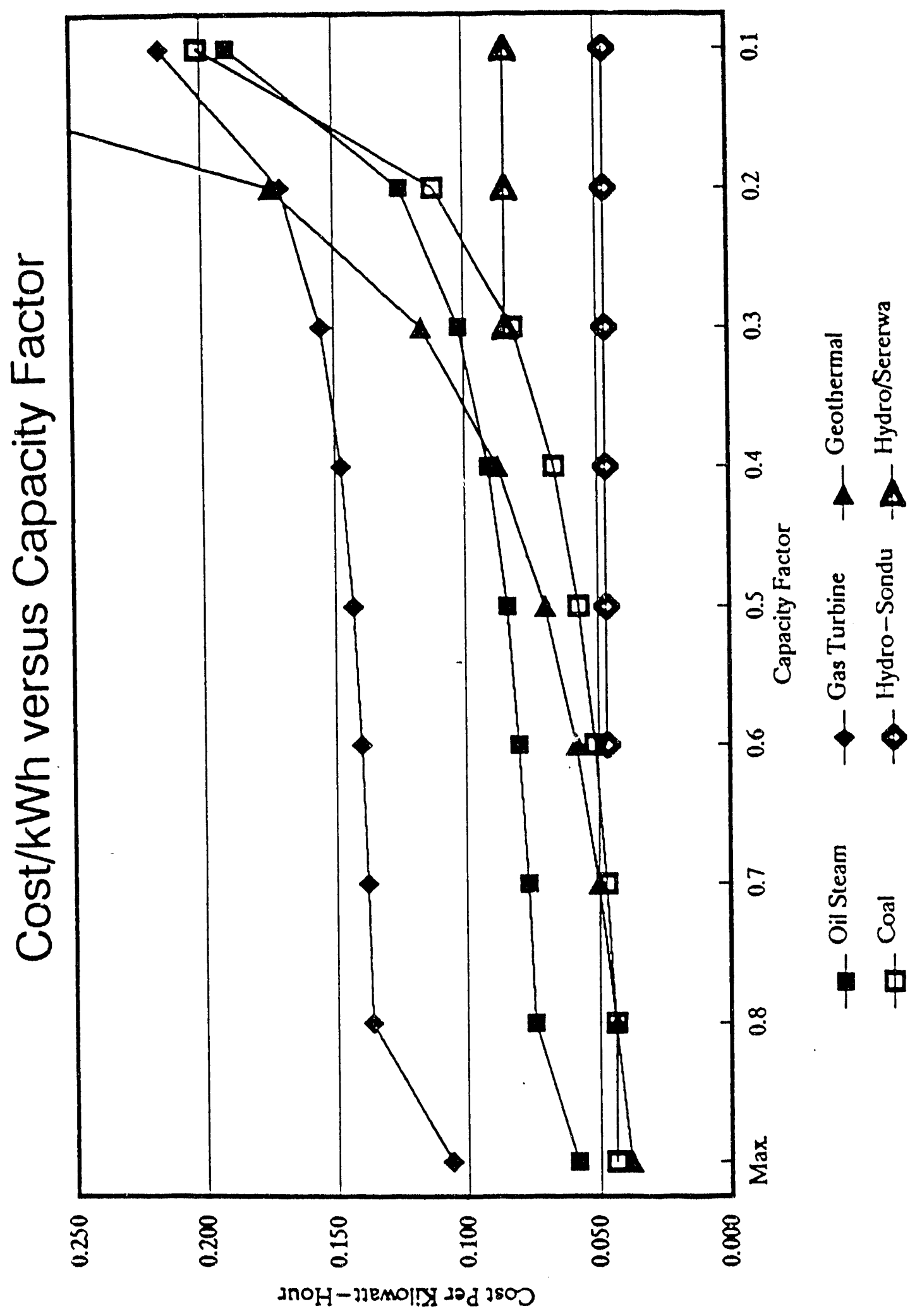

$I I I-12$ 


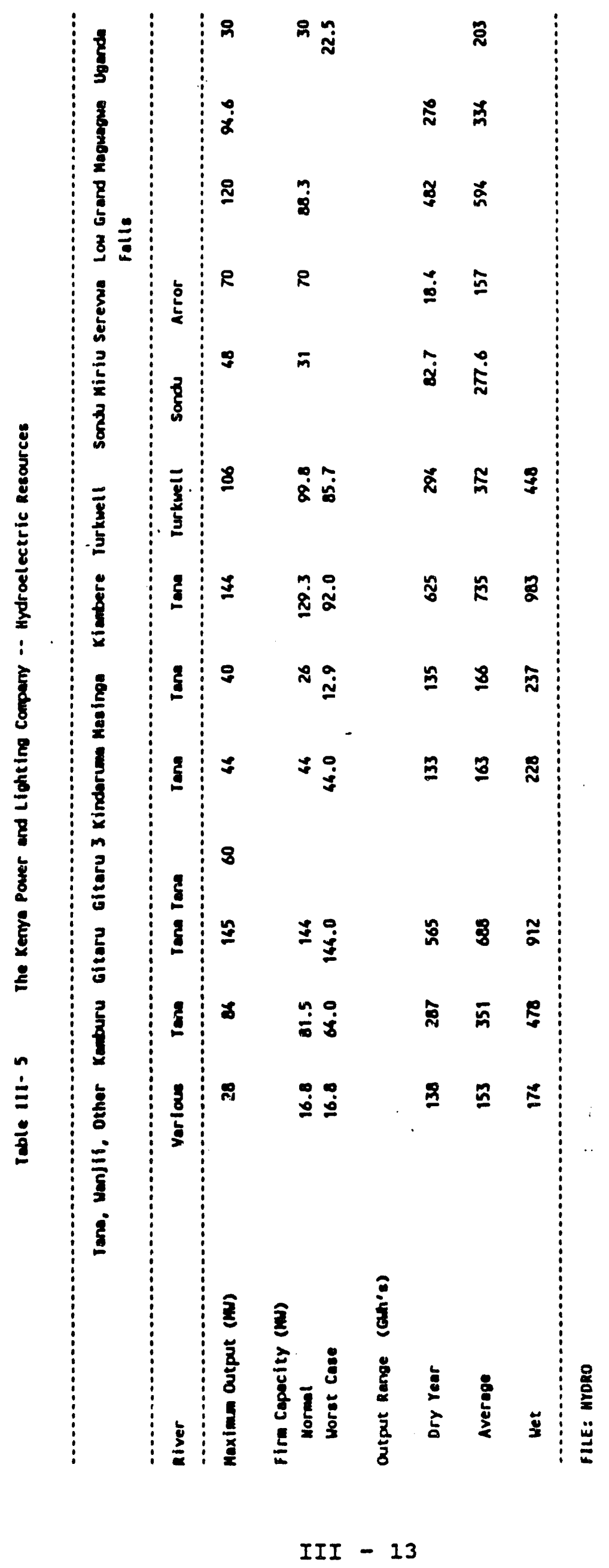


power alternatives in terms of annualized costs using the same discount factor ( $10 \%)$, in order to provide an approximation of relative economics.

Second, a reduction in the use of oil-fired capacity and costs is calculated, to account for the benefit from new capacity "backing-out" less economic combustion turbine or oil steam generation.

Third, benefits from a reduction in potentially "unserved energy" (if any) due to the private power generation is included. Both ACRES and Ewbanks Preece have made estimates of the cost to end-users of going without electricity. These estimates are about $\mathrm{Ksh}$. 15/ kWh, and we have used this value, or $\$ 0.65$ for sensitivity analysis.

2. - Comparative Analysis

a. KPIC Expansion Program

Shown in Table III-6 is the KPLC expansion program prepared as the Base Case for analysis in this report. The table presents, first, the initial capacity and energy balances or requirements. These are based on the system forecasts and assume no capacity additions beyond committed and facilities uncer construction. These figures form the baseline upon which additional capacity is added. This balance is not an expectation of the state of the system, only a representation of future requirements. Generation requirements in the Base Case include both station use and estimated losses, while capacity figures include a $15 \%$ reserve margin. Second, Table III-6 shows a revised balance after the planned KPIC expansion program, together with a summary of additions. Third, details of the expansion program are provided year by year to $2005 / 06$, including size in MW, average cost per kWh, cumulative generation, and annualized cost. Fourth, total annualized cost is calculated and shown together with incremental cost per kWh provided for each year.

1. In section VI, KPLC plans versus private power alternatives are compared in terms of specific project financing assumptions, to develop estimates of actual cash flows.

2. The importance of costing and including unserved energy becomes apparent when we consider the near to intermediate term period if KPIC has difficulty in installing adequate new capacity. By measuring the cost of unserved energy we are able to provide estimates of the impact of energy shortfalls, as well as the benefit of a potential private power project which might reduce the risk of unserved energy. 


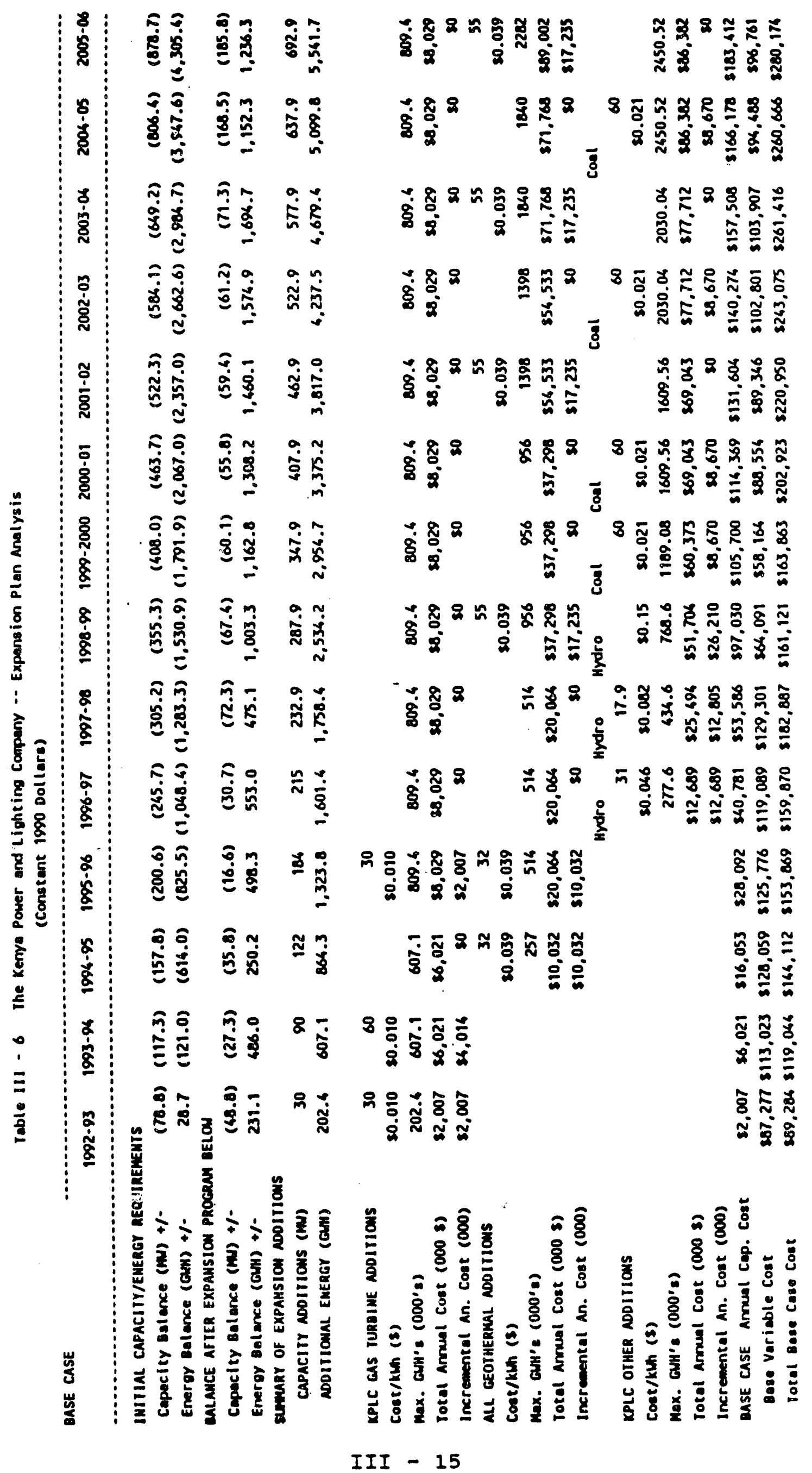


Table III - 7 Basic Cost Asaunptions for Analys is - Assumes Constant 1990 Dollars

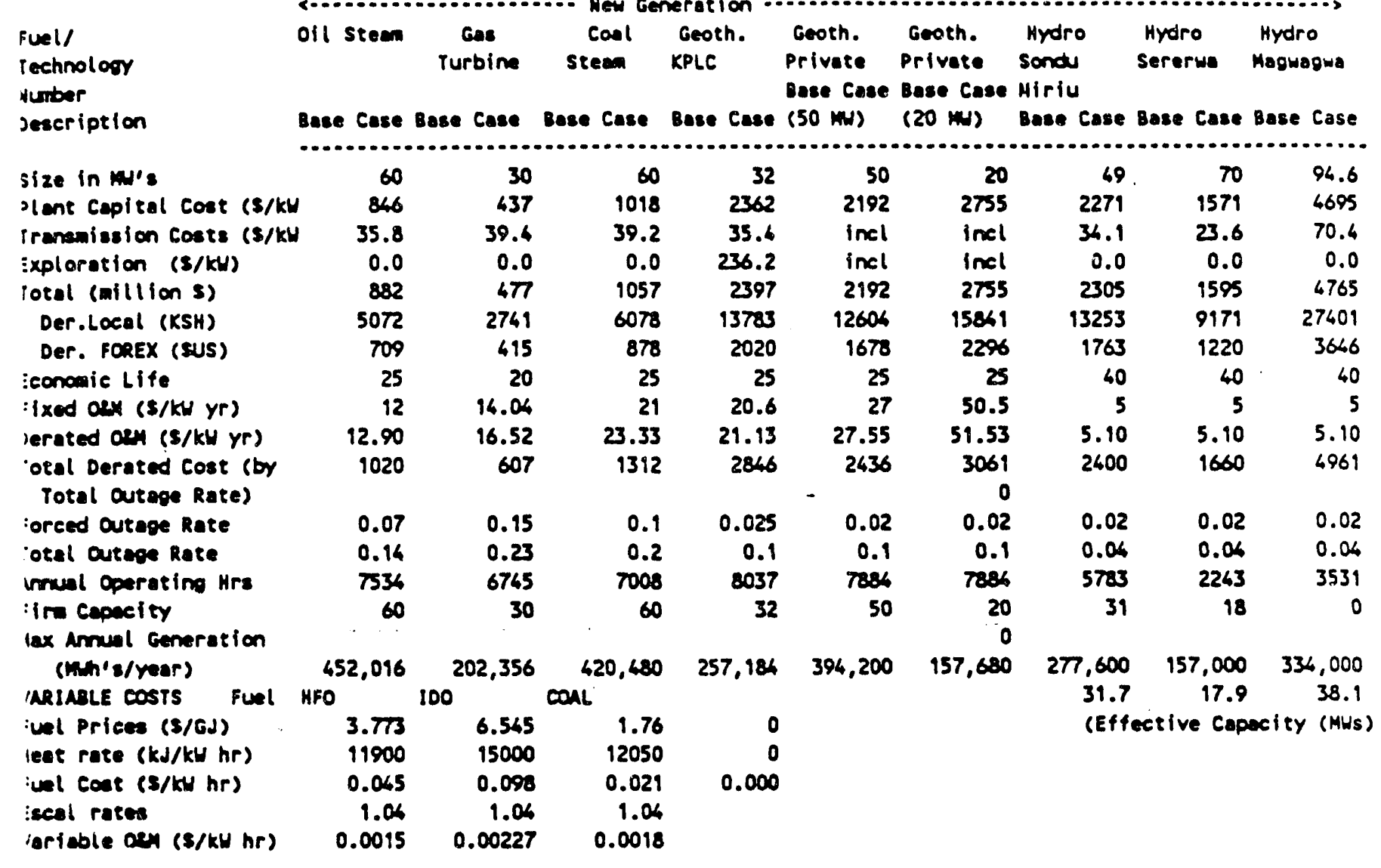


Capacity requirements in the Base case are about $80 \mathrm{MW}$ in $1992 / 93$ and grow to a total requirement of $875 \mathrm{MW}$ by 2005 . Energy requirements grow at a similar rate, increasing from $121 \mathrm{GWh}$ in 1993/94 to 4,305 $\mathrm{GWh}$ in 2005. Planned capacity additions to meet this demand (excluding Turkwell hydro plant soon to come on line), are about $740 \mathrm{MW}$. The after capacity expansion capacity balance shows that the planning reserve margin of $15 \%$ assumed in this report is not met after 1997/98, with reserves dropping to about $4 \%$ in 2005. Capacity additions will be made up of $120 \mathrm{MW}$ of combustion turbines, $284 \mathrm{MW}$ geothermal, $87 \mathrm{MW}$ (effective capacity) of additional hydro, and $240 \mathrm{MW}$ of coal. Total incremental costs vary by year due to capital and operating cost differences in generation capacity being added, with values dropping from $\$ 0.16 / \mathrm{kWh}$ in $1993 / 94$ to about $\$ 0.06$ in 2005/06. This picture reflects the fact that combustion turbine capacity must be added and oil capacity run more intensively in the short-run to meet loads before new baseload capacity can be brought on-line.

Total capital requirements in annualized amounts are shown in Table III-6, and demonstrate the tremendous increase in capital requirements of KPLC over the planning period. Requirements grow from about $\$ 2.0$ million for capital and $\$ 90$ million capital plus variable costs in 1992/93, to over $\$ 114$ million for capital charges and $\$ 200$ million in capital plus variable costs by the year 2000, reflecting the combination of combustion turbines, geothermal, new hydro and coal. These values which show the annualized costs for new capital additions, operating and maintenance costs and fuel costs, clearly represent a tremendous increase in revenue requirements.

\section{b. Sensitivity Analysis on KPIC Base -- The Implications of Adding Geothermal Private Power}

The purchase of additional or replacement capacity from private sources has a number of potential benefits for KPIC. These include tangible and measurable benefits such as possible lower prices for power, lower costs of development, shorter lead time and reduced workload for scarce KPLC project management personnel. Furthermore, numerous important uncertainties are reduced or risks shifted by pursuing private purchases. These include reducing the risks and financial burden of geothermal exploration, reducing the risk of capacity shortfalls due to new project del.ays, and reducing the risk of capacity or energy shortfalls from current or planned hydro generation. The sensitivity analysis below attempts to quantify and show the prospective costs to KPLC of these various tangible and intangible uncertainties. No attempt has been made to try and address the probability of occurrence for any of the above outcomes. It is likely that the best judge of the probability of any of the above eventualities will be KPLC staff themselves, and the purpose of this analysis it to provide a means for quantifying these judgments.

$$
I I I-I 7
$$


The sensitivities below involve a very large number of factors, years and assumptions. In order to try make this analysis understandable, while still meaningful, comparisons are shown in graphical form using percentage changes in average costs per $\mathrm{kWh}$ versus the original Base Case ( $4 \%$ growth forecast and $4 \%$ oil price escalation), for the various sensitivities. Average costs for a given year are the annualized capital cost for new generation for the plan for the respective year (total capital charges), plus total variable cost for that year, divided by total generation. Total costs, unserved energy costs, and total variable costs for each case can be found in the appendix.

\section{Alternative Scenarios}

six basic scenarios or sensitivity cases were analyzed to provide a rough approximation of the implications for KPLC of various uncertainties and the benefits of private geothermal. This results in 60 basic cases, all of which are very briefly described here and summarized in the figures which follow. Details are given in a set of 4 tables in the appendix to the report. In all sensitivities the KPIC Base Case in Case l refers to the original KPIC expansion plan, that is, with the base forecast and oil price escalation assumptions. The other case comparisons give results of the changes in sensitivity conditions described, with the system adjusting only in operating terms, all other factors equal. The results therefore represent an estimate of the maximum impacts which might be observed under these scenarios.

Sensitivity Analysis:

In order to understand both the impact of various contingencies on the KPIC system and the prospective benefits of private geothermal development, we have done a common set of sensitivity analyses for each of the cases listed below. Cases refer to alternative forecast and oil price assumptions, with sensitivity analysis referring to analysis of various different capacity timing and cost assumptions.

Basic Assumptions for the different cases are as follows:

Forecast Growth

$\begin{array}{ll}\text { Case 1: } & 4 \% \\ \text { Case 2: } & 6.7 \% \\ \text { Case 3: } & 4 \% \\ \text { Case 4: } & 6.7 \%\end{array}$

Case $4: \quad 6.7 \%$
Oil prices Price Escalation Base Increase (1992-93)
$4 \%$

$10 \%$

$4 \%$

$10 \%$

$6 \%$

$20 \%$

$6 \%$ $20 \%$ 
Case 1 consists of the basic sensitivity results compared under KPLC base case assumptions on forecast growth (Table III-2) and oil prices.

Case 2 consists of a set of sensitivities on a revised KPLC base case with a high forecast of load growth.

Case 3 again is a new set of sensitivities, this time with the original baseline forecast, but with oil price increasing more rapidly.

Case 4 shows the impact of sensitivities on a base case with both a high forecast and high oil prices.

The sensitivity assumptions which are examined in each case below are as follows:

Sensitivity

Number:

Figure III-2

Figure III-3

Figure III-4

Figure III-5
Description:

KPLC Base Case is modified by a delay in KPLC geothermal by 1 year. This forms the basic foundation for the analysis. Case 1-4 forecast and oil price assumption are then applied to this modified base period. Sensivitity analysis are shown for each case with the addition of 50MW of private geothermal, or alternatively $2 \times 20 \mathrm{MW}$ of private geothermal.

KPIC Base Case modified by a delay in KPIC geothermal by 2 years. Addition of 50MW of private geothermal, or alternatively $2 \times 20 \mathrm{MW}$ of private geothermal.

KPIC Base Case modified by a delay in KPLC hydro and coal additions by 1 year. Addition of $50 \mathrm{MW}$ of private geothermal, or alternatively $2 \times 20 \mathrm{MW}$ of private geothermal.

KPIC Base Case modified by a delay in KPIC hydro and coal additions by 2 years. Addition of 50MW of private geothermal, or alternatively $2 \times 20 \mathrm{MW}$ of private geothermal. 
KPLC geothermal capital costs increased by $25 \%$. Addition of $50 \mathrm{MW}$ of private geothermal to replace $32 \mathrm{MW}$ of KPLC higher cost geothermal.

KPLC Geothermal Delay. The impact of a delay in KPLC's overall geothermal plan by 1 year and 2 years, respectively are evaluated in Figures III-2 and III-3, in terms of the percentage change from the Base case. The impacts under the base forecast, high growth forecast, high oil price escalation (base forecast) and finally high growth together with high oil prices, are estimated. In the 1 year delay scenario (no other new KPLC capacity added), total costs rise by about $1.7 \%$ and average costs rise by about 2.48. Adding a 50Mw private geothermal project in the 1994-95 time period to compensate for this delay eliminates this cost increase and reduces average costs below the base case by $2.3 \%$ Alternatively, adding two smaller 20MW private plants, one in 199495 and the other in 1997-98, leaves total costs increasing about $1.9 \%$, while raising average costs slightly less than with the delay and no private generation scenario.

Another important feature of this scenario is the reduction in the total available capacity to meet reserve margin requirements. With capacity to meet a $15 \%$ reserve margin goal requiring about 100-140 MW over peak during the period 1992-93 to 1999-2000, shortfalls range from a high of 122 MW in 1998-99 (providing virtually a zero reserve margin) to $27 \mathrm{MW}$ in 1993-94 in this scenario. This contrasts with the Base Case with no delay, with a highest shortfall of $72 \mathrm{MW}$ (providing about a $6.5 \%$ reserve margin). Adding $50 \mathrm{MW}$ of private geothermal generation reduces the deficit in the delay case back to the base case level of about to 72 MW in 1997-98, and substantially lowers the average reserve deficit over the planning period.

KPLC Geothermal Delay -- High Forecast, High Oil Price and Combined High Forecast and High Oil prices cases. The above picture would greatly change in the case of higher than forecast growth, that is, if growth is raised from $5.4 \%$ to $6.7 \%$. In this case total costs of delay rise to $18 \%$ compared to the base case and average costs are $27 \%$ greater than the KPLC Base Case. The lower cost 50MW private geothermal plant in this situation lowers the total cost by $22 \%$ and shows only a $11 \%$ increase in average costs versus the KPIC Base case. These conclusions result from two primary factors, first, the higher use of oil required to meet greater energy needs with a geothermal delay and high forecast, second, substantial unserved energy, and third, the lower cost of private geothermal versus KPLC geothermal plart.

3. Deficit in this context refers not to an absolute shortfall in capacity to meet peak demand, but to a deficit in capacity required to meet a $15 \%$ reserve margin. 
Figure III - 2

KPLC - Geothermal Plan 1 Year Delay

(Percent Change in Cost from Base Case)

Case 1 - Base Growth \& Oil Price

$-10 \%$

Case 2 - High Forecast

Case 3 - High Oil Prices

Case 4 - High Oil \& High Forecast

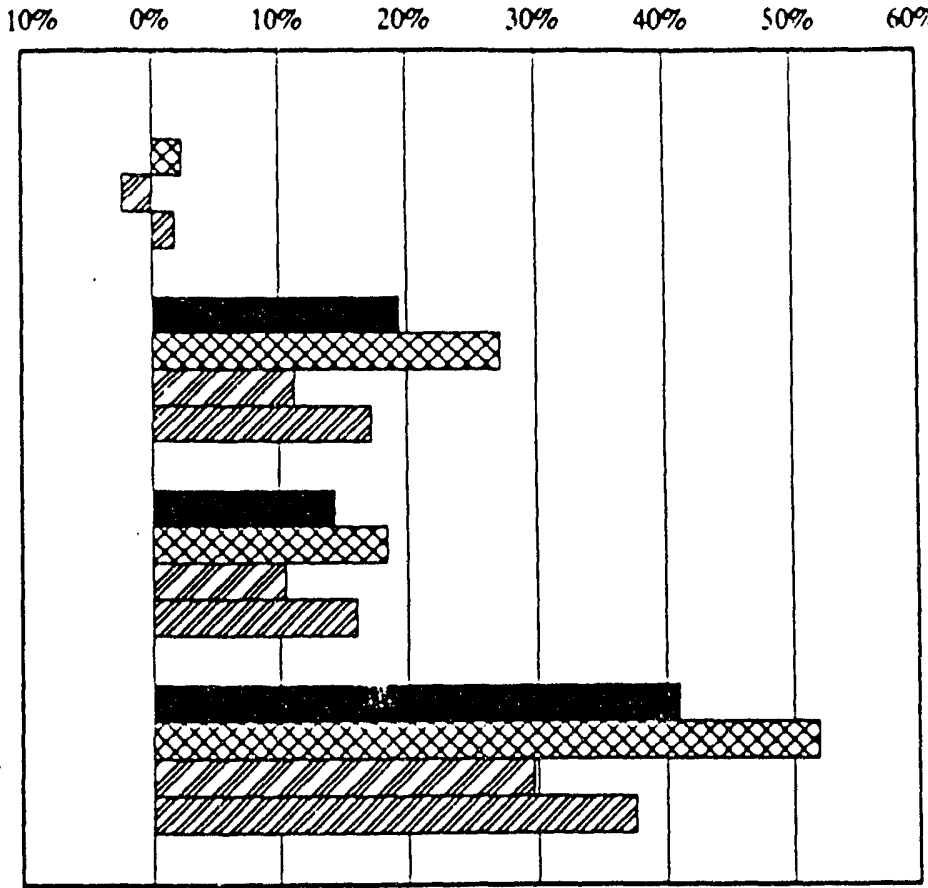

KPLC Plan (No Geothermal Delay)

KPLC Geotbermal 1 Year Delay

Ka KlC Geo. 1 Yr Delay + 50 MW Priv. Geo.

UIA KPLC Geo. 1 Yr Delay + 2x20MW Priv. Geo.

Figure III - 3 KPLC - Geothermal Plan 2 Year Delay

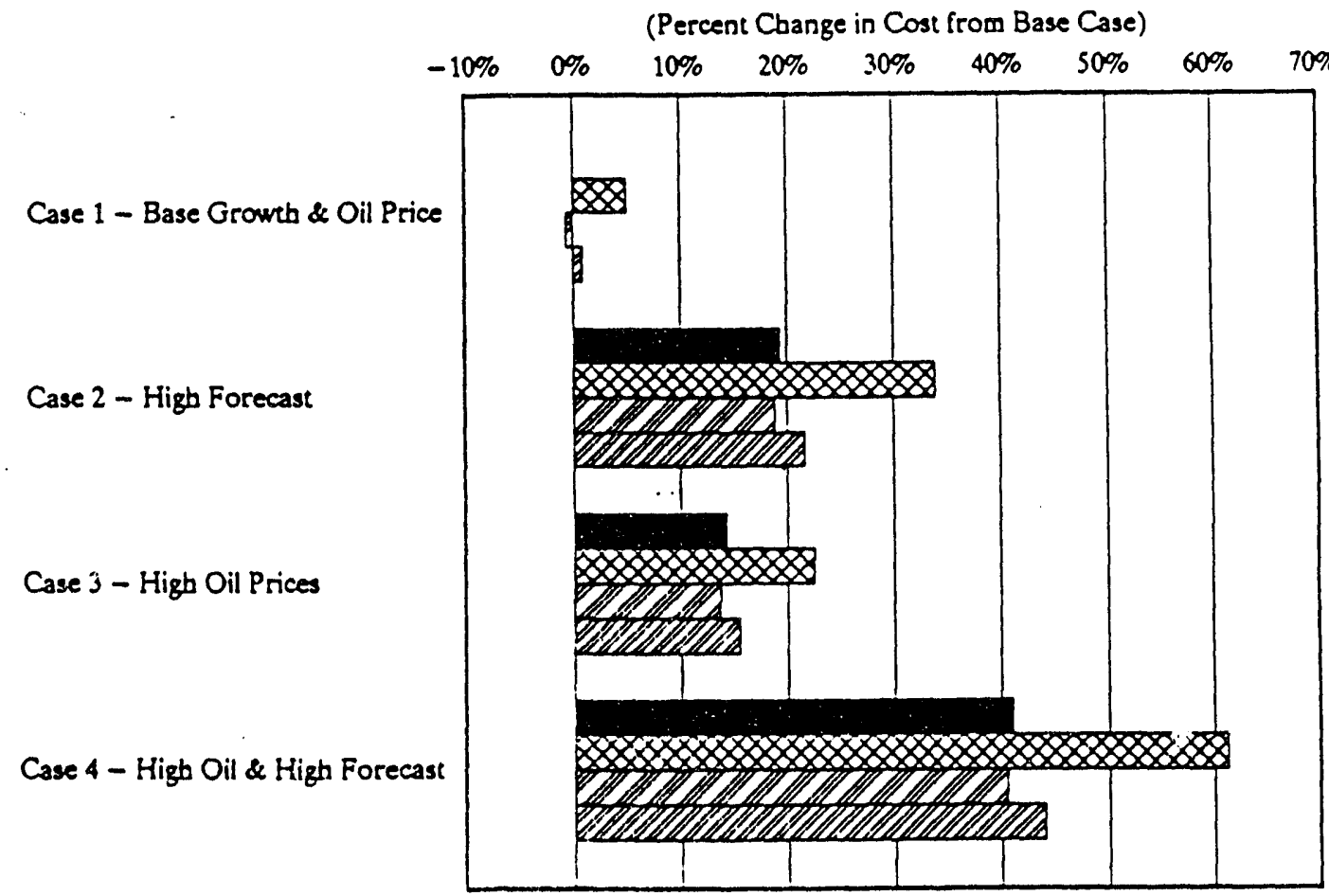

KPLCPlan (No Geothermal Delay)

K.PLC Geocherwal 2 Year Delay

KPLC Geo. 2 Yr Delay + $\$ 0 \mathrm{MW}$ Priv. Geo.

PIA KPLC Geo. 2 Yr Delay + 2x20MW Priv. Geo. 


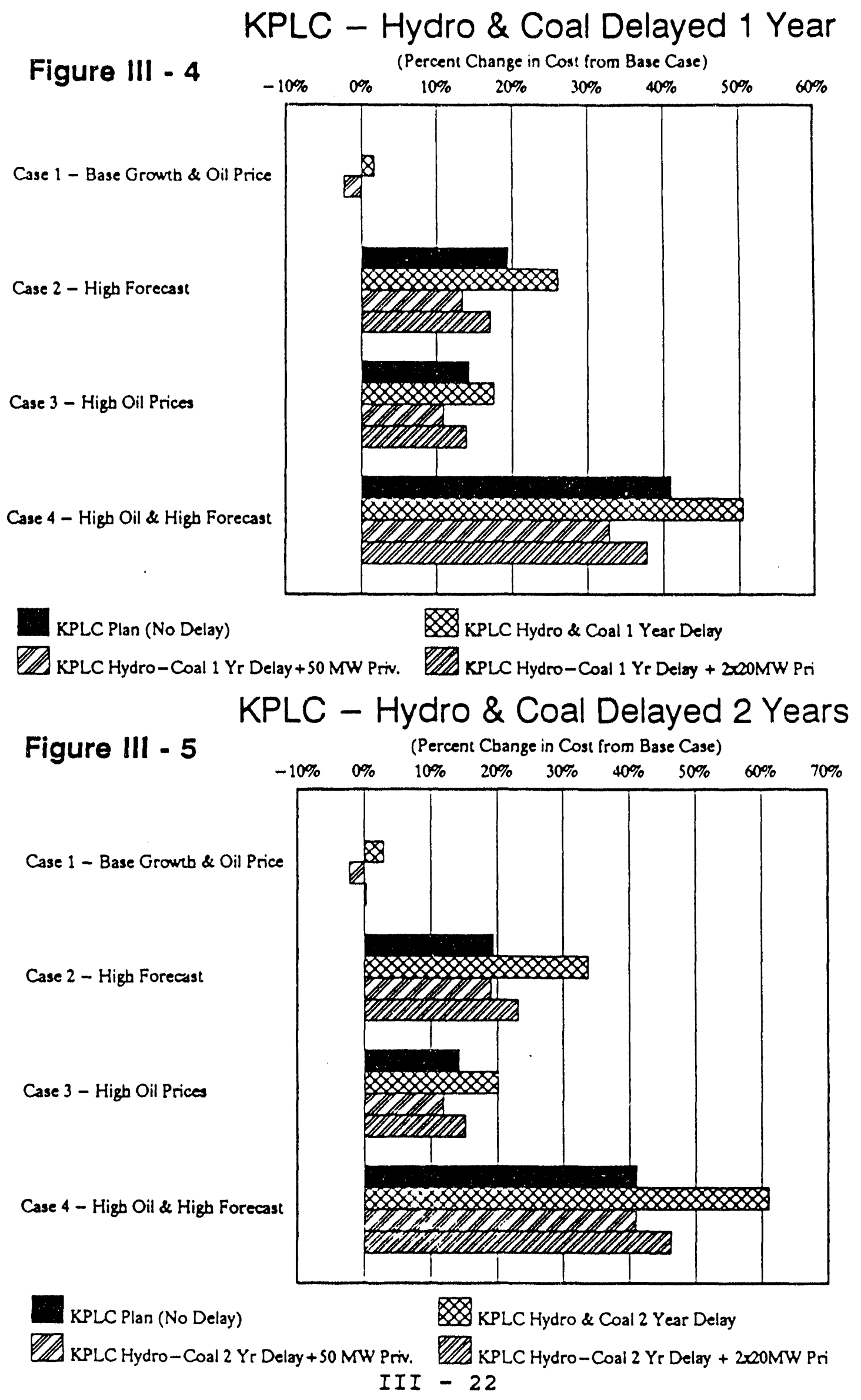


The impacts of higher oil prices with the base forecast are not so dramatic as with higher growth. Unserved energy is significant but only a small fraction of the high forecast case, and total costs rise only about $3 \%$ for the KPLC geothermal delay with no private geothermal, with average costs versus the KPIC Base Case rising by 18\%. Again the addition of $50 \mathrm{MW}$ of private geothermal significantly mitigates these higher costs. Total costs of the delay would be reduced by about $2.5 \%$ by adding private geothermal (50MW in 1994-95), and average costs would be only about $10 \%$ greater that KPLC Base Case.

Combining the higher forecast with higher oil prices produces a scenario similar to the high forecast case alone above, with similar relative benefits for addition of private geothermal (Figure III-2).

Figure III-3 shows the impact of a 2 year delay in KPIC geothermal and addition of private geothermal in two scenarios, the first case with 50MW added in 1995-96, and the second, two $20 \mathrm{MW}$ plants added, the first, in 1994-95 and the second, in 1995-96, respectively. The impacts of this case are similar in direction to the above 1 year delay case, however with the magnitudes of private power benefits increasing substantially.

KPLC Hydro and Coal Delay. - In order to test the sensitivity of the results to a delay in other aspects of the KPLC Base Case, two scenarios of delay in hydro and coal capacity were examined. In the first, each hydro and coal addj.tion is delayed by 1 year (Figure III-4), and in the second, hydro and coal are both delayed by 2 years (Figure III-5). Results are similar but costs increase are about one-half those of the above geothermal delay cases. Under the base assumptions on growth and oil prices, total costs rise by $1 \%$, and average costs versus the KPLC Base case rise by about $2 \%$. With the additional of 50 MW of private geothermal, total costs are reduced to slightly below the KPLC Base Case. Results obtained in the higher growth and higher oil price cases, as shown in figure. Figure III-5 shows the results for a two year delay in the KPIC hydro and coal plans.

KPLC Geothermal cost Increase. In order to understand the implications of higher than anticipated costs for KPLC geothermal on the system, a case was evaluated with an increase of $25 \%$ in KPLC capital costs. All other things equal, a 25\% increase in KPLC geothermal capital costs increases total system expansion costs by about 5\%, there is no change in unserved energy (no unserved energy), and reliability levels and ability to meet reserve targets do not change. 
Figure III - 6
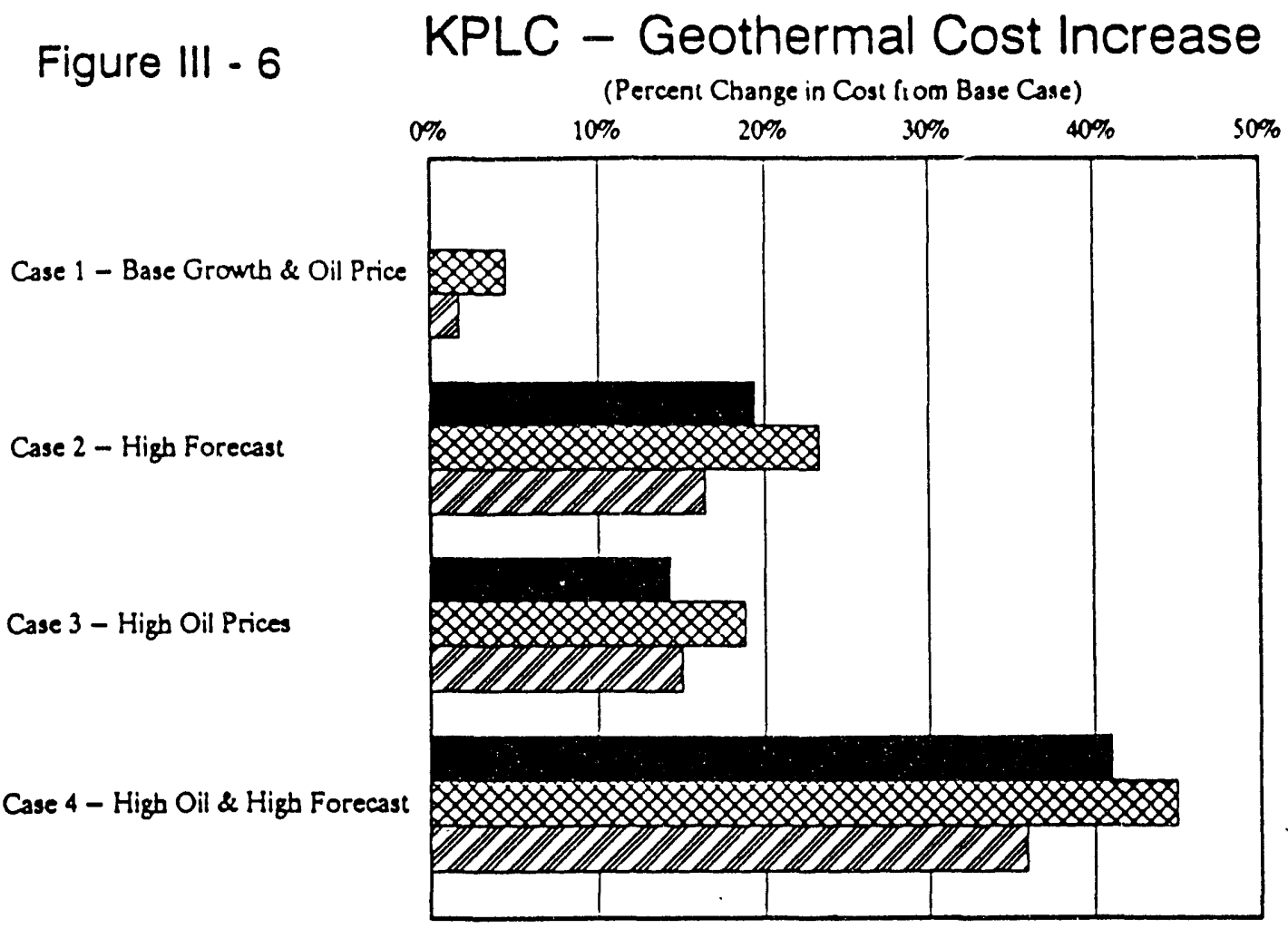

KPLC Plan (No Geo. Cost Increase) KPLC Geothermal 25\% Cost Increase

$\mathbb{D}$ KPLC Geo. Cost Incr. + 50MW Priv Geo.

The substitution of $50 \mathrm{MW}$ of private geothermal in the KPLC geothermal cost increase scenario, replacing $32 \mathrm{MW}$ of KPLC geothermal, produces substantial savings. Average costs remain above the no cost increase base case due to higher KPLC geothermal costs for remaining facilities, but overall the increase drops from $5 \%$ to $2.7 \%$. The average system cost increase of $4.5 \%$ drops to about $1.7 \%$. The impacts are more dramatic with high forecast scenario, with the total costs with private geothermal dropping by $6 \%$ from the KPLC Base Case with no cost increase. Average costs for the KPLC geothermal cost increase case with no private geothermal are 23\% over the KPLC Base Case, versus a only a $16 \%$ rise with private geothermal substituting for 32 MW of KPLC capacity. These higher costs are heavily influenced by increased unserved energy in the high forecast case; which in the case of a $50 \mathrm{MW}$ private plant versus $32 \mathrm{MW}$ KPLC plant, are reduced considerably. 


\section{Bibliography}

1. Republic of Kenya, "Economic Survey 1990," Centreal Bureau of Statistics, Ministry of Planning and National Development, May 1990 .

2. Electric Power Research Institute, "Technical Assessment Guide," July 1979.

3. Acres International, "National Power Development Plan for Kenya-1986-2006", July 24, 1987.

4. Ewbanks Preece, Various tables and data, 1990.

5. Kenya Power and Lighting Company, Personal Communication Various tables and data, August 17, 1990.

6. Kenya Power and Lighting Company, "Prices for Electricity Supplies," June 1990.

7. Kenya Power and Lighting Company, "Report and Accounts for the Year Ended 30th Jne, 1989.

8. National Geothermal Association, "Geothermal Resource Development opportunities in Kenya," December 1988.

9. Mohan Munasinghe, "Electric Power Economics," Butterworths, 1990 . 


\section{Section IV -KENYA GEOTHERMAI PROGRAM - STATUS AND ISSUES CONCERNING DEVELOPMENT}

\section{A. INTRODUCTION}

The objective of this section is to assess the geothermal resources of Kenya in terms of their size, logistics, development potential, and the time requirement and probable cost of exploring and developing tham. This information is to be used in decisions regarding private investment in the kenya geothermal industry, and in determining the terms and conditions of such investment.

This section is based both on original field work by the authors (McNitt and Koenig, of GeothermEx, Inc.), and on a review of published and unpublished work by others. Data on thermal manifestations and areas of youthful volcanism have been compiled and annotated, along with comments on the level of exploration previously achieved in each field or prospect. Estimates have been made of field or prospect area, depth and temperature. These estimates are based on the authors' experience in geothermal drilling in Kenya and elsewhere in the Rift Valiey of East Africa (Ethiopia and Djibouti), and on experience in comparable geologic settings elsewhere.

From these findings, estimates of reserves have been made for each field or prospect. These vary in precision from order-of-magnitude for several poorly known areas to moredetailed for the olkaria area and Eburru. Factors of topography and accessibility, distance from transmission lines, local markets, environment, and results of prior exploratory work have been considered, along with probable depth of drilling, possible drilling success rates and possible well yield, in a calculation of the cost of exploration and development. Where the estimate of reserves is considered sufficiently reliable, the total cost is converted into a cost per MW to develop.

The several fields and prospects have been ranked in order of attractiveness for future development. The ranking represents the authors' judgement as to where in Kenya investment in geothermal resources should take place during the remainder of this decade. Despite the experience of both authors in geothermal exploration and development, no warranty is offered or implied in the rankings presented herein. 
B.

Geslogically, Kenya consists of a Precambrian platform of metavolcanic and metasedimentary rocks, which regionaliy has been domed and uplifted, and both covered by younger rocks and sediment, and broken by younger structures (Figure IV-1). Precambrian rocks do not crop out in the eastern coastal plain or in the Rift Valley, but are exposed in the walls of the Rift and across much of central and western Kenya. Paleozoic rocks are present only in the southeastern coastal plain. Mesozoic rocks are more widespread, being exposed in the northeast and northwest as well as in the southern coastal plain.

However, the cover over the Precambrian basement is mainly of Cenozoic age: Miocene through Holocene sediment is distributed across the lowlands of eastern Kenya, and Oligocene through Holocene volcanic and sedimentary rock and unconsolidated sediment is present in the highlands of central and western Kenya and in the Rift Valley.

The Rift Valley (also known as the Eastern or Gregory Rift) is a broad trench that runs $\mathrm{N}-\mathrm{S}$ across western Kenya, extending on the $N$ into Ethiopia and on the $S$ into Tanzania (Figures IV-2 and IV-3). The Rift escarpment is well-defined in some segments, and more diffuse in others. similarly, its width varies from perhaps $25 \mathrm{~km}$ at the narrowest to over $100 \mathrm{~km}$ in its more diffuse segments. Not only are the Rift margins fault-bounded; faults of general N-S trend cut the Rift floor in numerous places, sometimes as major sub-parallel swarms and occasionaliy as discrete individual fractures (Figure IV-4). This has resulted in creation of numerous blocks bounded on both sides by faults (horsts and grabens), or only on one side (halfhorsts and half-grabens) with corresponding block rotation.

A second rift, the Kavirondo Rift, trends $\mathrm{E}-\mathrm{W}$ nearly normal to the Gregory Rift in western Kenya to Lake Victoria (Figure IV-4). The Kavirondo Rift cannot be traced across the lake into Uganda.

Volcanism, and associated lacustrine and alluvial sedimentation, has been very intense within and on the margins of the Rift. This has been explained by postulating that the generation of magma near the base of the crust, beginning late in oligocene time in response to movement of the African plate, in turn caused doming of the precambrian crust, rifting and volcanic erupticns on a massive scale. Lajes formed in domaropped basins and behind volcanic dams. Enormous quantities of lava, ash and sediment accumulated within the sist to depths ranging from a few tens of $\mathrm{m}$ on the Rift margins to several $\mathrm{km}$ within deeply downfaulted sections. 
Topographic elevation also varies along the Rift Valley floor, with the topographic high located in the vicinity of lake Naivasha (elevation about $1.8 \mathrm{~km}$ ), and with elevations decreasing by as much as $1.2 \mathrm{~km}$ to the $S$ at Lake Magadi and $1.5 \mathrm{~km}$ to the $\mathrm{N}$ at lake Turkana. The elevation difference is explained as being related to magmatic inflation of the Precambrian dome. Relief along major fault escarpments reaches or exceeds $1,000 \mathrm{~m}$ in several locations.

Thickness of fill within the Rift Valley has been calculated from gravimetric and seismic refraction surveys, and from geologic map interpretation. The fill varies from a calculated maximum of about $6 \mathrm{~km}$ beneath Lake Naivasha to minima of about $2 \mathrm{~km}$ beneath Lake Magadi and $1.5 \mathrm{~km}$ beneath Lake Bogoria. P-wave velocities suggest that Precambrian basement and Tertiary mafic intrusive rocks underlie the Rift valley fill. Although intrusions and local magma chambers are believed to exist (especially beneath certain active volcanoes, as discussed below), evidence is moot regarding a possible "axial intrusion" running the length of the Rift valley at a few $\mathrm{km}$ in depth.

However, the foregoing does not explain why many of the major Quaternary volcanoes of Kenya lie outside the Rift Valley (Figure IV-5), at distances of up to $200 \mathrm{~km}$. Diagrams showing the variation in chemical composition of the volcanic rocks versus time of eruption and location relative to the Rift valley have been prepared (Figure IV-6) in the attempt to explain this fact, without arriving at any convincing explanation.

What is demonstrated is that the more silicic volcanic rocks (rhyolite, comendites, pantellerites and their tuff and ash equivalents) are found most typically in the vicinity of the topographic center of doming in and adjacent to the Rift Valley. The more alkaline (nephelinite, trachyte, phonolite) and mafic (basalt) volcanics are distributed at the margins of the dome and beyond. Worldwide, there is a generalized association of producible geothermal systems with less-mafic or more-silicic volcanism, although this relationship is not without exceptions.

Several of the well-known volcanoes of latest Tertiary or Quaternary age are shown on Figure IV 7 , although several large eruptive centers, and smaller cinder cones, domes and mars too numerous to list do not appear. Thermal manifestations (springs, fumaroles, steaming ground, etc.) are associated with many of the major volcanic centers, such as silali, Paka, Longonot, Eburru and Suswa. However, many major volcanic centers, such as Shombole, Mt. Kenya, Rangwa and Lenderut are not known to have hydrothermal manifestations; these tend to be older than the fumarolically active volcanoes, and often are outside the main Rift Valley. Also, a very large number of thermal areas 
are not obviously associated with any major volcanic center, such as Lake Bogoria, Lake Magadi, Arus and Lorusio. These tend to be locally low points of elevation, and may represent outflow of thermal waters from reservoirs elsewhere.

In general, the principal thermal areas are found within the Gregory Rift. However, others are associated with the Kavirondo Rift (Homa Bay area) or are outside of the Rift Valley system (for example, Masamukye, SE of Nairobi, and Mwananyamala, $s$ of Mombasa). In general, again, the areas of known fumarolic activity, steaming ground and boiling springs are within the Rift Valley; those outside of it exhibit lower surface temperatures and/or appear to have lower temperatures at depth.

Both volcanic and seismic activity continue in the Rift Valley. Historic eruptions are reported for Teleki's Volcano, just $s$ of Lake Turkana (shown as Barrier on Figure IV-7), most recently in 1921-1922; Andrew's Volcano, just to the $S$ of Teleki's, appears to have been active within the past 100 years. Emuruangogolak has been dated by ${ }^{14} \mathrm{C}$ radiometry to have been active approximately 300 years before the present, and may have erupted as recently as the end of the 19 th Century.

Silali, to the $S$ of Emuruangogolak, may have been active during the past few centuriejs. Paka volcano, closer to lake Baringo, probably was active within the past few thousand years, and possibly within the past few centuries. It is located in the northern Rift valley about midway between lake Baringo and Lake Turkana.

Longonot, E of Olkaria, has yielded cultural evidence of an eruption sometime between 1858 and 1868 . Suswa, $S$ of Longonot, probably had its most recent eruption within the past 300 years. There is evidence that a magma chamber exists beneath Suswa, as well as beneath many of the other historic or quasi-historic volcanic centers. Shaitani and/or Chaimu, basaltic volcanoes located near the NW corner of Tsavo West National Park in southeastern Kenya, outside the Rift Valley, reportedly erupted in the 1850s, perhaps in 1855.

Several other major volcanoes, as noted above, are fumarolic; and many of these, including Menengai, yield evidence of eruption within the Holocene Epoch (past 10,000 years), and possibly within the last few hundred years. Basalt flows of the Elmenteita area, $S$ of Menengai, fall into this category also. In addition, numerous isolated cinder cones, domes and basalt lava flows probably are latest Pleistocene and Holocene in age; and some may have erupted, unreported, in historic time. 
Faulting probably has occurred in several major episodes to form the Rift Valley, and then to break the valley floor. Seismic activity continues, but is irregular in distribution both geographically and in time. Some very youthful volcanic features show fault offset (the slopes of Paka volcano, for example). This suggests fault movements into historic time. However, most investigators have concluded that seismicity (and therefore fault movement) is greatly diminished from Plio-Pleistocene time; and that most of the prominent, scarp-forming faults are inactive. However, seismic activity and fault offset can be expected to continue locally. The Kavirondo Rift is believed to be seismically inactive (a so-called "failed" rift). 
C.

\section{HISTORY AND STATUS OF GEOTHEFMAL EXPLORATION AND DEVELOPMENT IN RENYA}

During British colonial times, reconnaissance studies of geothermal manifestations were carried out by the Kenya Geological survey. These studies noted the presence and temperature of thermal springs and fumaroles, and related their distribution to faulting and volcanic activity within the Rift valley. In the 1930s speculation began on possible commercial utilization of the fumaroles of the Lake Naivasha region for electric power generation.

At Eburru, beginning in the early 140 s, steam from lowpressure fumaroles was condensed as a fresh-water source in an otherwise waterless volcanic upland. Steam also was used in small operations to process pyrethrum flowers as a source of high-quality natural insecticide. During the '40s and '50s several wells drilled for water in various parts of the Rift valley encountered hot water or steam.

Between 1956 and 1959 , as a result of further geological and geophysical reconnaissance in the Rift Valley. emphasis became focused on olkaria (then spelled orgaria). Beginning in 1956 and continuing into 1958, a consortium of private investors in Kenya and Great Britain, including Power Securities Corporation Limited and East African Power \& Lighting Co. Itd. (EAP\&L), drilled two exploratory holes within a few $\mathrm{km}$ of what is now the olkaria production field. Hole $x-1$ went to about $500 \mathrm{~m}$ and encountered temperatures over $120^{\circ} \mathrm{C}$ before being suspended. Hole $\mathrm{X}-2$ reached temperatures over $200^{\circ} \mathrm{C}$ by $940 \mathrm{~m}$. Despite repeated efforts, the wells could not be brought into sustained production for testing, and the project was abandoned.

In the mid-1960s, further geophysical surveys of the Rift Valley between Lake Bogoria and Lake Magadi again drew attention to the geothermal potential of the region. Anomalous areas of low electrical resistivity had been mapped previously at olkaria, Eburru and elsewhere. The olkaria anomaly covered between 50 and $100 \mathrm{~km}^{2}$ in area. Based on this renewed interest, the Government of Kenya requested United Nations assistance in 1969 for a geothermal exploration project. The project (KEN/70/525) began in October 1970, with EAP\&I (a parastatal organization) and the United Nations Development Programme (UNDP) named respectively as counterpart and executing agencies. The senior author of the present report, Dr. J. R. McNitt, was appointed project manager by UNDP.

Geological, geochemical and geophysical surveys were carried out at various scales across an extensive zone between Lake Magadi and a point $N$ of Lake Bogoria, but centering on olkaria, Eburru and lake Bogoria. Simultaneously, well $\mathrm{x}-2$ was cleaned out and brought into sustained production (1972),

$$
I \nabla-6
$$


discharging steam. Based on these surveys and tests, and calculations of the economics of drilling and development, olkaria was selected for exploration drilling and development.

Drilling at Olkaria began in 1973; by 1976, when the first stage of the UNDP project was completed, 6 welis had been drilled. Well $\mathrm{OW}-2$ was the first to indicate commercial productivity. Depths of the 6 wells ranged from 900 to $1,685 \mathrm{~m}$. Production zones were identified and tested between 650 and $900 \mathrm{~m}$ and between 1,100 and $1,300 \mathrm{~m}$. Steam was produced, with an increasing water percentage from deeper holes and from holes farther to the north. Temperature of the production zone was found to be approximately $245^{\circ} \mathrm{C}$, with higher temperatures found in the deeper and water-saturated zones. Teams of British and Icelandic consulting firms (including Merz and McLellan, and Virkir) determined by testing and data analysis in 1976 and again in 1977 that the field was suitable for commercial power generation.

Total UNDP expenditure under KEN/70/525 was approximately US $\$ 1.5$ million. EAP\&L expenditure is not known, but may have been approximately equal in amount.

The World Bank was then asked by the Government of Kenya to finance construction of the initial 30 MW power plant, $22 \mathrm{~km}$ of $132 \mathrm{kv}$ transmission lines, purchase of a drilling rig, completion of the development wellfield, construction of auxiliary facilities, and purchase of support materials. Late in 1979, an agreement was reached under which the Bank agreed to lend US\$40 million of the US\$89 million required to construct the two 15 MW power plants and other facilities at olkaria. Terms included a 20-year loan period, 5 years of grace, and $7.95 \%$ annual interest. The Commonwealth Development Corp. agreed to provide US\$20 million, with the remainder coming from Kenya Power Company (KPC), a subsidiary of EAP\&I, and from the Government of Kenya. KPC was appointed as the executing agency. Consulting firms from New Zealand, the UK and Iceland were employed in various capacities regarding drilling, resource assessment, power plant design and construction supervision.

At that time, 11 holes had been drilled. The first 15 MW plant went on-line in June 1981. By that time, 19 wells had been drilled, of which 14 wells were capable of supplying 34 MW. Various consulfing reports had estimated reserves to be $17 \mathrm{MW}$ within a $12 \mathrm{~km}^{2}$ area, and up to $1,400 \mathrm{MW}$ within the $100 \mathrm{~km}^{2}$ greater olkaria area.

Under the terms of an internal agreement within the Government of Kenya in 1979, the Ministry of Energy was given responsibility for all geothermal exploration and exploratory drilling within Kenya. EAP\&L was given responsibility for 
development and operation of the olkaria field and of any field subsequently discovered. EAP\&L in turn delegated responsibility for olkaria to its subsidiary, KPC.

Assistance in geothermal exploration/development also was provided by the Japan International Co-operation Agency (JICA) under a bilateral agreement signed by the Governments of Kenya and Japan in November 1979. The Ministry of Energy was appointed as the counterpart agency of JICA. Eburru, which along with Lake Bogoria and the Menengai and Longonot volcanoes had been identified in the UNDP project as highly attractive, was selected. Geological, geochemical and geophysical surveys were begun; however, the project was stopped late in 1981 before the anticipated completion period of 3.5 years. Temperature-gradient holes were not drilled, despite having been planned.

Planning for a follow-on geothermal exploration project began between the UNDP and the Government of Kenya in 1979. The geographic area and scope of work were decided upon after a reconnaissance assessment by the present junior author, $\mathrm{J}$. B. Koenig, late in 1980. The project, KEN/82/002, was approved in May 1982; after an offer of supplementary technical assistance from the Government of Italy was accepted by Kenya in 1984, a budget of US\$4.8 million (US\$3.4 million from UNDP and US\$1.4 milition from Italy) and Kenya Sh 28,000,000 (approximately US $\$ 2$ million at 1984 exchange rates) was approved. The UNDP and Ministry of Energy were appointed as executing and counterpart agencies.

In 1985, the Government of Kenya also entered into a bilateral agreement with the Government of the United Kingdom, under which the overseas Development Assistance would provide [575,000 (approximately US $\$ 700,000$ at 1985 exchange rates) for geological and related surveys of the central part of the Rift valley. Work was to proceed simultaneously with the UNDP-Italy project. In practice, a group from the British Geological survey condusted geological mapping and fluid geochemistry and isotopy in the Longonot-Suswa region, and regional hydrology of the lake Naivasha-suswa area; and a contractor provided by the Government of Italy (Geotermica Italiana) performed geological, geochemical and geophysical studies of the Menengai-Bogoria region, and Italian and Icelandic firms did geophysical surveys in parts of the iongonot-suswa area.

The second $15 \mathrm{MW}$ power piant was commissioned by Kenya Fower and Iighting Co. Ltd. (successor to EAP\&L) in December i982; and the third $15 \mathrm{MW}$ unit was Fiaced on-line in March 1985. Turioine-generators and associated electrical equipment were supplied by Mitsubishi lieavy Industries Ltd. Twenty-six wells had been drilled to supply the $45 \mathrm{MW}$ production, of which 22 weils were in use. Yieid per we:l averaged just over $2 \mathrm{MW}$. 
Drilling at locations elsewhere in the olkaria region began in the early '80s. Discoveries of potential commercial importance were made in northeastern and western olkaria. By 1986,13 wells had been drilled, of which 5 were considered to be commercially productive. Higher temperatures (over $300^{\circ} \mathrm{C}$ in several welis) were encountered in holes of 1,800 to over $2,400 \mathrm{~m}$ in depth, indicative of a water-dominated system. Driliing proved difficult in many cases, with several wells being suspended because of drilling or completion problems.

At the same time, pressure declines were observed in the olkaria production welis. Principal areas of upflow from the deep reservoiz were identified in NE and $W$ Olkaria, and the olkaria production field was identified as an outflow zone. This led to revisions of the olkaria field model, calculation of requirements for make-up drilling, dedication of an additional area of proven reserves for the $45 \mathrm{~kW}$ power plant, and the planning for expansion of electric power production into $\mathrm{NE}$ olkaria.

In 1984, the World Bank and the Government of Kenya signed IDA Credit 1486-KE, which provided for exploratory drilling of up to 8 wells at Eburru and further drilling in the olkaria region. This exploration project was funded by the Bank at SDR 23 million (US\$24.5 million at the May 1984 exchange rate), with Kenya Sh equivalent to US\$9.8 million also to be provided by KPC and the Ministry of Energy. Although the Ministry of Energy had been given responsibility for exploration outside of Olkaria, KPC was given responsibility for the Eburru drilling. New zealand project consultants (GENZI) were employed by KPC.

Subsequent to this, severe problems in drilling, and other extensive project delays, and overspending in various project rategories, led to a reassessment of project goals and operating methods. A subsequent IDA credit was agreed upon in 1988 between world Bank and Government of Kenya. This provided for reallocation of approximately US\$3.2 million from Credit 1486-KE to the new Credit 1973-KE to allow the delayed Eburru drilling to proceed, plus funds for a. new IDA loan to continue drilling and appraisal of the olkaria region, along with infrastructural support. Because of (a) subsequent reallocations between credits $1486-\mathrm{KE}$ and $1973-\mathrm{KE}$, (b) fluctuations in the dollar exchange rate of the SDR, Deutschmark (drilling contract so denominated), and kenya shiliing, and (c) allocation of part of the credit to non-geothermal activities, no dollar amount for credit $3973-\mathrm{KE}$ is provided herein.

Late in 1986, Acres International Iimited presented a report, "Kenya National Power Development Plan, 1986-2006", linder funding provided by World Bank and UNDP. This plan concluded 
that geothermal power represented the least-cost base-load alternative available to Kenya for power generation through the year 2006 . It recommended that $280 \mathrm{MW}$ of new geothermal generation be added, beginning with $30 \mathrm{MW}$ each in 1994 and 1995, and continuing with $55 \mathrm{MW}$ in 1998, 2001, 2003 and 2005 . Specific sites were not identified, but it was implied that the majority of this new geothermal generation would be installed in the olkaria region and Eburru.

Although the Acres report has not formally been adopted by the Government of Kenya, KPLC has acted informaliy to begin implementation of its geothermal recommendations. A feasibility study by Ewbank Preece Limited was completed in December 1989 for the northeast olkaria block, in which it was concluded that two 32 MW power plants were economically and technical feasible for commissioning in 1992 and 1993, and that the potential exists for a third $32 \mathrm{MW}$ power plant in the same area.

Work was extended under UNDP project $\mathrm{KEN} / 82 / 002$ into 1989, with additional financing. Recommendations submitted in 1989 by the principal consultant, Geotermica Italiana, included the drilling of 6 to 8 exploration wells in an area immediately $N$ of Menengai volcano (Olongai-olobanita caldera complex), and in the area S and SE of Olkaria field (mouth of Hell's Gate canyon and on lower flanks of Longonot volcano) to depths of 2,000 $\mathrm{m}$ or greater. If drilling and testing confirmed the existence of an exploitable reservoir, it was recommended that a non-condensing power plant be installed on one, two or 3 wells to demonstrate the technical and economic feasibility of large-scale development. Although size of the demonstration power plant was not specified, $5 \mathrm{MW}$ was discussed.

Since that time, there have been extensive communications between the Government of Kenya, the UNDP and the Government of Italy regarding possible bilateral (Kenya-Italy) and trilateral (Kenya-Italy-UNDP) projects. The sum of US\$25 million was discussed, although no firm cost figure was agreed upon. Most recently (February 1990), an Italian consortium of Ansaldo GIE (turbine manufacturer), Geotermica Italiana (resource consultant) and SICOM (driller) has proposed to KPIC that they be given a contract by KPLC in the amount of ECU 26.9 milizion (approximately US\$33 million) and Kenya Sh 75.4 million (US\$3.4 million) for drilling at either the Menengai or Longonot locations, followed by installation of a 5 MW turbine-generator. No Italian government financing was offered, but it was inferred that such support would be forthcoming following signing of a commercial contract between SPLC and the Italian group.

In 1988, the Government of the United Kingdom granted a 3-year, $\{833,000$ (US\$1.35 million at 1988 exchange rates) extension of its cocperative program, for detailed geological mapping and fluid geochemistry in the volcanic terrain of the 
northern Rift Valley by BGS. Work has focusec on the trachytic Korosi, Paka, Silali, Emuruangogalak and Namarunu volcanoes. It has in part utilized results of an earlier (1981-1984) cooperative geologic mapping project involving BGS and Kenya Mines and Geological Department (KMGD) scientists. Results of this earlier work were published in 1987 and 1988 by KMGD; the current results are to be released in late 1990 .

UNDP presently proposes to conduct environmental assessments of geothermal development in the greater Lake Naivasha region, and to provide miscellaneous support to the Ministry of Energy program. Approximately US $\$ 500,000$ may be authorized.

In 1987 , in response to continued operational problems at olkaria, KPC signed a technical assistance agreement with Petro-Canacia International Assistance Corporation (PCIAC). Under this grant agreement, PGIAC provided Canadian advisors in drilling and wellfield operating for a period of up to 3 years, for help at olkaria. GENZL's role was restricted to Eburru drilling. The agreement was valued at Kenya Sh 38.6 million (US\$1.9 million at 1987 exchange rates), and subsequently has been augmented and extended until at least early 1992. Drilling performance at olkaria has improved significantly.

An Act allowing for the licensing of private companies to participate in exploration and development of Kenya geothermal resources was approved in 1982. Under terms of that Act and Rules gazetted in 1990, companies from the United States and other countries have expressed interest in investment in the Kenya geothermal industry. Unocal Corporation, beginning early in 1988, conducted a reconnaissance assessment of geothermal prospects. Unocal informally has requested exclusive permission to explore Paka, Menengai and Lake Bogoria prospects; no action is known to have been taken by the Government of Kenya in response. A consortium of American companies, including Geothermex, Inc. and The Ben Holt Company, have held discussions with Magadi Soda Company Ltd. (a unit of ICI) regarding development of off-grid geothermal electric power to supply Magadi Soda's mining and processing operations at Lake Magadi.

Additionally, private and quasi-governmental companies in Iceland, Italy and Japan, and possibly elsewhere, have submitted unsolicited proposals to KPLC and/or Ministry of Energy regarding sale of goods and services to the Kenya geothermal program. The recent Italian proposal was discussed above. Mitsubishi Heavy Industries has suggested that KPLC request assistance from overseas Economic Cooperation Fund (OECF) of Japan in arranging financing for the planned two $32 \mathrm{MW}$ power plants at NE Olkaria. No action has been taken by KPLC. 
The world Bank has initiated discussions with KPLC regarding a possible future IDA credit, to cover the two $32 \mathrm{MW}$ plants, feasibility determinations for geothermal power plants at either W Olkaria or Eburru, exploration of an additional prospect, and technical and infrastructural support. Such a credit might be granted in mid- or late 1991 or early 1992. value could exceed us\$100 million.

Drilling at Eburru, under World Bank financing, finally began in 1989. Results of the first 4 wells have not been as encouraging as KPLC and its consultants GENZI had anticipated. Drilling of two more wells is underway now at Eburru. By contrast, the results of drilling at olkaria production field, and at $W$ and NE Olkaria have surpassed expectations. More than half the wells needed for the two $32 \mathrm{MW}$ plants at NE Olkaria have been drilled; and make-up wells sufficient for several years of operation have been completed at the main olkaria field.

Geoscientific research continues in the Rift Valley. This includes student theses, oil exploration surveys (no oil or gas has been found in Kenya), and scholarly research into crustal structure.

From 1970 to date, approximately US $\$ 170,000,000$ (in dollazs of those years) has beer spent in geothemal exploration and development by all parties, including the Government of Kenya and its agencies, the UNDP, the World Bark, the Governments of Italy, Japan and the UK and other governments, and miscellaneous research agencies and private companies. of this amount, perhaps one-quarter has been spent in kenya on local equipment, supplies and services. The largest overseas expenditures have been co purchase goods and services in:

Japan - turbine-generators and related equipment; exploration. services; vehicles and other equipment

New zealand - exploration and engineering services; management services; training services

Belgium - drilling contracts

United kingdom - engineering services; miscellaneous supplies ana equipment

Iceland - engineering services; individual consultancies; training services

Italy - exploration services; training services 
Perhaps $3 \%$ has been spent in the United States for wellfinld services and supplies, individual consultancies, and scientific equipment.

If, indeed, some $280 \mathrm{MW}$ of geothermal electricity will be added by 2005, a further expenditure of at least US\$600

million will be required for exploration, drilling, field development, power plant design and manufacture, and construction, as well as for purchase of equipment and supplies, and for training and infrastructural support. The percentages to be derived from international lenders and donors, the Government of Kenya and its agencies, and private investors cannot be estimated closely. 
D. THE BASIS FOR RANRING GEOTHERMAL PROSPECTB

\section{Background}

As described elsewhere, Kenya has extensive geothermal potential, estimated at several thousand $M W$ for 30 years. Few of these geothermal areas have been explored in detail, al though geological reconnaissance, cataluguing of thermal manifestations, and fluid geochemistry has been accomplished at many prospects. Reconnaissance or detailed geophysical surveys (principally gravity and electrical resistivity) have been run in the region between Suswa and Lake Bogoria. Drilling of geothermal welis has been accomplished only in Eburru and the greater olkaria area.

Therefore, a wide variation exists in the detail of exploration and level of knowledge for each prospect area. As the levels of knowledge increase through time, the ranking of each prospect can be expected to change, both absolutely and relative to other prospects. The ranking methodology must therefore be capable of processing unequal quantities of information on a common basis, so as to provide statistically reasonable projections that can be tested and revised in the future.

Further, the conditions of accessibility, the proximity to transmission lines and to market, and the technical complexity or degree of risk to be expected in developing the resource affect project cost and ease of financing, and ultimately help to determine which fields are developable. It would therefore be incorrect to establish ranking solely on the size of the resource. The present methodology attempts to utilize all the factors described herein.

\section{Types of Assessment Methodologies}

The simplest method of assessing a resource is by analogy. For example, calculations of $\mathrm{MW}$ per $\mathrm{km}^{2}$ of field routinely have been made by KPLC's consultants, on the basis of (a) size of the measured surface electrical and geochemical anomalies, (b) experience with geothermal fields elsewhere in comparible geological settings, and (c) inferences regarding data quality or reliability of the surface anomalies. Results typicaily are presented as a single best-estimate, or occasionally as an upper and lower estimate, without a percentage probalility for any estimated value. This method may be used before or after initial well drilling: it has been used at both oikaria and Eburru. Pre-drilling estimates made at Eburru by this method now seem to have been unrealistically high. 
Another method, often used after the initial round of drilling has been accomplished, but before there is an extensive history of well testing or production, involves calculation of the field volume, along with an estimation of the recoverable energy within that field volume. Volumetric calculations depend upon a knowledge of the distribution of field depth, thickness, areal extent, permeability and temperature, as well as fluid chemistry, and chemical and physical constraints on extraction. Here again, a single value or an upper and lower value typically are presented, without any calculation of the probability that the value(s) are correct. Volumetric calculations were utilized by the U.S. Geological survey in a series of published assessments of United States geothermal reserves, including numerous prospects that had not been drilled. subsequent drilling resulted in modification of many of these values.

There is inevitably some uncertainty over what value or range of values to assign for a given reservoir parameter in a volumetric calculation. To minimize this, reserves can be estimated in a probabilistic way, using a Monte Carlo simulation.

Even where there has been no drilling (or no significant drilling), Monte Carlo simulation can be done. The range and distribution of possible values is estimated for each critical parameter. The values of these uncertain parameters are sampled randomly, perhaps 1,000 or 10,000 times, using a specially designed Monte Carlo simulator. The results are used to calculate recoverable energy, as in other volumetric analyses, and are presented in terms of the percentage probability of any numerical value of reserves.

The advantages of this method are that it (a) provides a common basis for evaluation of prospects for which there is little information, as well as fields for which extensive well-test data are available, and (b) it allows a quantification of risk associated with exploration or development.

The principal disadvantage is that there is a tendency to use the same or similar values of reservoir parameters having to do with depth, thickness and permeability for all unexplored prospects, thus resulting in similar (or identical) reserve and probability values. A second difficulty is that a spurious level of confidence may result.

Once there are extensive well-test data or production histories, it is reasonable to perform numerical simulation modeling. This involves constructing a detailed 3-dimensional gridded model of the reservoir and, through multiple iterations, achieving a match between the model and the well-test or production data. The model thereupon can be used to forecast field operating conditions, operating costs, reserves and field life under various scenarios. This has been done for the main

$$
\text { IV }-15
$$


Olkaria field by KPLC's UK and Iceland consultants. Well-test data still are insufficient for meaningful numerical simulation modeling of West olkaria and Eburru. Well-test data are lacking for all other Kenya geothermal prospects.

After serious consideration, it was decided to use the simplest basis of comparative evaluation, analogy. There are insufficient data for many prospects of potentially large size, especially those of the northern Rift valley, to allow volumetric or Monte Carlo simulation methods to be used meaningfully. The tendency to use identical (or closely similar) values for important parameters for which no exploration data exist, makes volumetric and Monte Carlo values too unreliable in this setting. once the data collected in the northern Rift Valley by the BGS become widely available and are evaluated independently, it may be possible to perform a Monte carlo simulation with greater accuracy.

An alternative approach would be to treat each prospect separately, utilizing various methodologies to match exactly the level of data available. This would fail the first test of providing a common basis of analysis, without significantly improving the assessment for most prospects.

\section{Detail of Application}

The available data for each significant prospect have been reviewed, and are described and tabulated in section 5.0 . An assessment has been made of data quality, extent of coverage, and internal compatibility of results. Because much of this comes from unpublished or proprietary sources, the data cannot always be discussed in detail.

The likelihood of finding a geothermal field by drilling has been assessed for each prospect. The prospects are then grouped by risk (likelihood). Each prospect then is evaluated for probable size of field, using data developed at olkaria as a reference value.

Following this estimate of reserves, the costs of exploration, drilling, wellfield development, transmission-line construction, and power plant construction were applied, to obtain a final ranking. For many prospects, costs have been expressed in terms of dollars per MW $(\$ / M W)$ of developed resource at wellhead.

The prospects were then evaluated in terms of reserves (MW) and cost ( $\$ / M W)$, to provide the final ranking. These are then discussed, and recommendations are made for selection of one or more prospects. 


\section{E. INITIAL PRIORITIZATION OF GEOTEERMAL PROSPECTS BY POTENTIAL BIZE, LEVEL OF EXPIORATION RIBK AND LOCATION}

\section{Methodology}

The 28 geothermal prospects and one producing field (Olkaria) described in this section have been identified by the presence of some form of surface thermal activity, such as fumaroles, steaming ground and boiling or warm springs, or by hot groundwater or steaming conditions found in shallow wells. The prospects, identified by these thermal features, can be divided into 3 groups:

\section{Group 1:}

These are characterized by surface thermal features that are at the boiling point, and that are closely related geographically to areas of Holocene volcanic activity. Prospects with thermal features extending over areas of 24 to $40 \mathrm{~km}^{2}$ are classified is Group $1 \mathrm{~A}$, whereas those with areas of 2 to $12 \mathrm{~km}^{2}$ are classified as Group 1B. Probable reservoir temperature for Group $1 \mathrm{~A}$ and $1 \mathrm{~B}$ prospects is in the range of $240^{\circ}$ to $300^{\circ} \mathrm{C}$.

\section{Group 2:}

These are also characterized by surface thermal features at the boiling point, but the thermal features are not located close to areas of Holocene volcanic activity. Probable reservoir temperatures are likely to be in the range of $150^{\circ}$ to. $215^{\circ} \mathrm{C}$.

\section{Group 3:}

These are characterized by surface thermal features at temperatures significantly less than boiling, and which are not located close to areas of Holocene volcanic activity. Group 3A prospects have probable reservoir temperature of $100^{\circ}$ to $200^{\circ} \mathrm{C}$, whereas Group $3 \mathrm{~B}$ prospects have probable reservoir temperatures of $40^{\circ}$ to $150^{\circ} \mathrm{C}$, as determined from geochemical thermometry.

For several reasons, the chances of finding exploitable geothermal resources by drilling these prospects are greatest for the first group, decrease for the second, and are least for the third. There is a high probability that temperatures of Group 1 prospects will increase with depth along the boiling-point-fordepth curve, because temperatures already are at a maximum for surface conditions, and the presence of a nearby volcanic heat source implies proximity to a thermal fluid upflow zone. 
The absence of obvious volcanic heat sources close to the Group 2 prospects could mean that the surface thermal activity, although at the boiling point, may represent an outflow zone which, although high-temperature is cooler than its associated upflow zone. In addition, temperatures beneath outflow zones typically decrease with depth for some distance below the outflow.

Group 3 prospects, characterized by springs which are at less than boiling temperature and which are not associated with recent volcanism, often are related to deep, regional groundwater flow and tend to have lower reservoir temperatures than either upflow or outflow zones associated with a volcanic heat source.

Table IV-1 lists the geothermal prospects of Kenya grouped into the categories described above. The locations of these prospects with respect to access roads are shown on Figure IV-8, and with respect to power transmission and distribution lines on Figure IV-9. Although Olkaria is a field undergoing development, rather than a prospect, it was found useful to include olkaria in Table IV- 1 and Figures $I V-1$ and $I V-2$ for purposes of completeness and comparison.

Table IV-1 also gives estimates of possible field areas, reservoir temperatures and power generation capacities of the various prospect groups and sub-groups. The basis for these generalizations is discussed in the following section. 
Table IV-1: Classification of Ge: in Kenya by Level of

Listed in Groups fro:

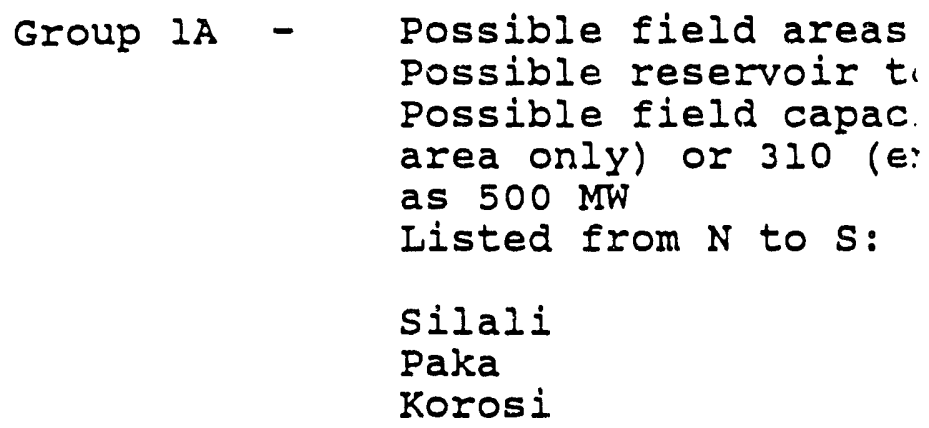


Table IV-2. Characteristics of Geothermal prospects

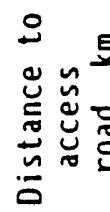

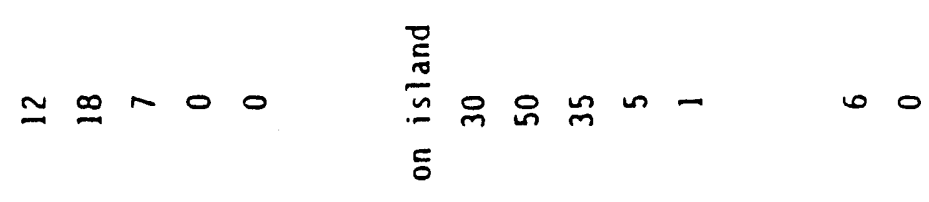

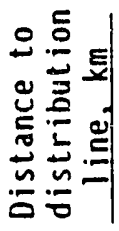

ก

옹을

$\approx$

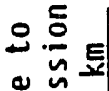

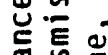

요요

유ㅇㅛㅛ요요 용

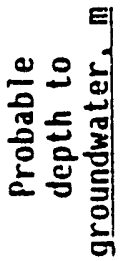

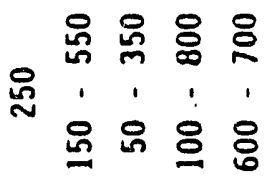

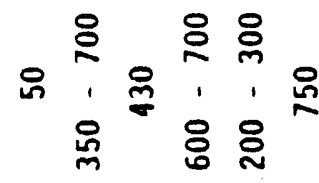

웅

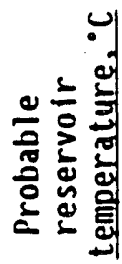

윤 윤 융 융 유

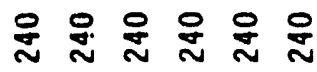

$\stackrel{n}{2}$

1 1

온으

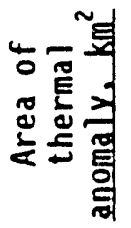

స

$::: \sim N \cong$

$-v$

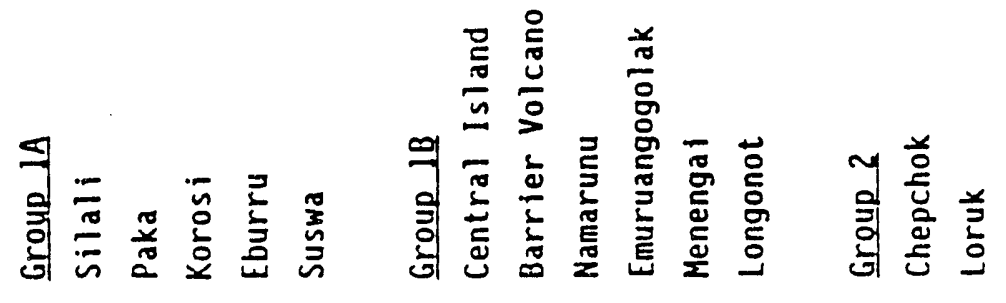

$I \nabla-20$ 
Table IV-2. Characteristics of Geothermal prospects (continued)

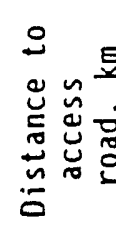

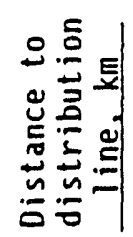

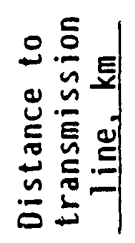

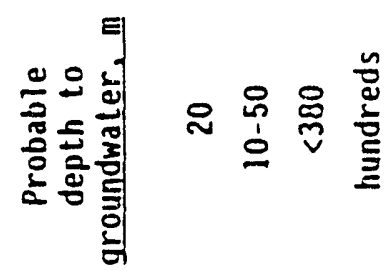

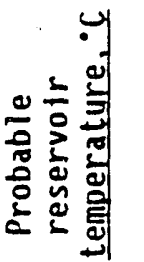

응

을

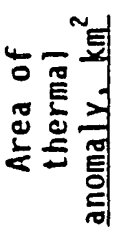

ณำ

-
$00-0$

$\because 28:$

8. 8.8

은윰으윰으

$\cong$ 용요

$\therefore$

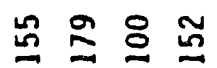

용무

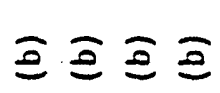

0
5
$\frac{a}{0}$

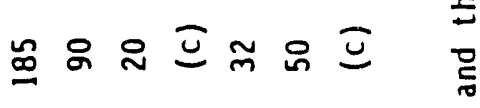

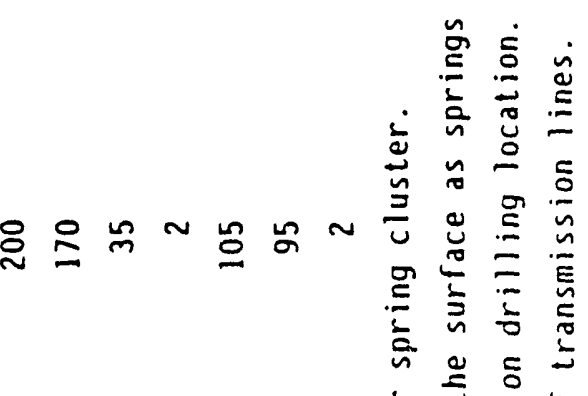

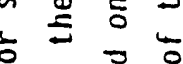

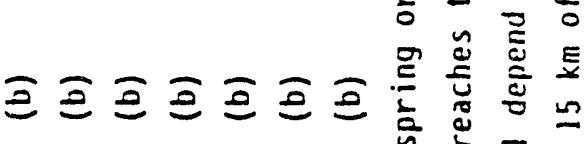

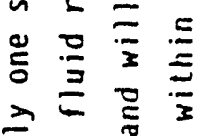

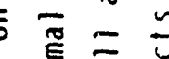

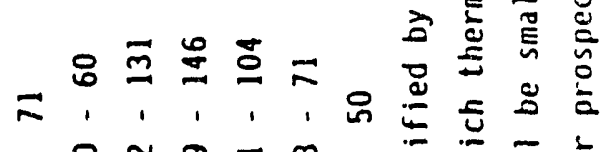

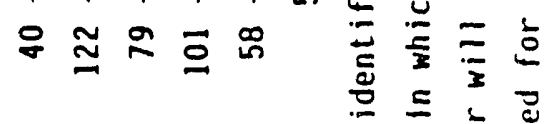

芯芯萼言言

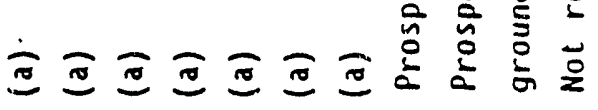

玉巨

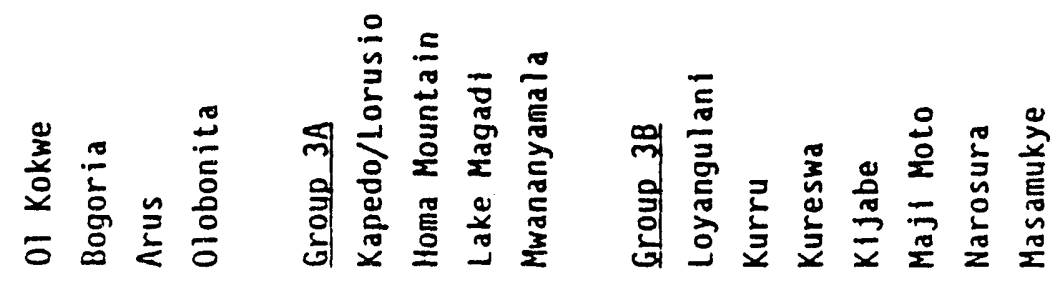

$I \nabla-21$ 


\section{Summary of Prospect Characteristics}

\section{a. Possible Areal Extent}

The possible maximum field size of $40 \mathrm{~km}^{2}$ shown in Table IV1 for prospect Group $1 \mathrm{~A}$ is the maximum area of fumaroles and steaming ground for any prospect in that group. The minimum area of fumaroles and steaming ground is $12 \mathrm{~km}^{2}$. The same maximum and minimum, figures for Group $1 B$ prospects are 2 and $12 \mathrm{~km}^{2}$.

This wide range of field areas estimated for Group $1 A$ and $1 B$ prospects reflects the uncertainty of these estimates. For example, at Paka, Korosi, olkaria and suswa, fumaroles and steaming ground cover 35 to $40 \mathrm{~km}^{2}$ at each prospect. Some of this ground, however, may be underlain by relatively cool, and perhaps undevelopable, outflow zones. At Eburru prospect, the central area of Holocene eruptive centers and craters is about 5 $\mathrm{km}^{2}$. The remaining area at Eburru might largely be outflow from the principal upflow zone. However, outflow zones often are developable commercially, either by use of flash-steam or binarycycle technology. Therefore, presumed outflow zones cannot automatically be excluded from this assessment of resource size.

Alternatively, some of the smaller thermal areas may be underlain by much larger reservoirs. The surface thermal area at the 2,000 MW Geysers field in northern California, for example, covers less than $2 \%$ of the area of the developed reservoir. Consequently, in some cases the surface-area values given in Table IV- 1 may be a better measure of the rate or intensity of heat release from the upflow zones than an approximate estimate of the areas of the underlying reservoirs.

Probable field areas have not been estimated for the prospects listed in Groups 2 and 3 that are characterized by hot springs, because hot springs are points of discharge from a reservoir and, as such, give no indication of the size or precise location of the reservoir. Three areas of steaming ground are included in Group 2: Chepchok, Loruk and Arus. These are relatively small prospects, each covering $1 \mathrm{~km}^{2}$ or less. As stated above, however, they may overly much larger reservoirs. The olobanita prospect is identified from wells which found hot water or which were dry but steaming, but because the wells are so few and so widely spaced, the extent of the prospect is highly uncertain.

\section{b. Probable Reservoir Temperatures}

Estimates of reservoir temperatures can be made prior to drilling by interpretation of the chemistry of hot spring waters and fumarole gases. Because of the generally great depth to groundwater in the Rift valley, most of tre thermal areas 
associated with the larger prospects consist of steaming ground and fumaroles rather than hot springs. The steam supplying the fumaroles has boiled off groundwater at depths ranging from a few tens of $\mathrm{m}$ to hundreds of $\mathrm{m}$. The steam carries non-condensible gases which, in some cases, can be used to estimate reservoir temperatures. The chemistry of hot springs can be used to estimate reservoir temperature for those prospects that are low enough in elevation for the groundwater table to reach the land surface.

Because of their height above the groundwater table, no hot springs, but only steaming ground and fumaroles occur at the Group 1 prospects and at 3 of the Group 2 prospects (Chepchok, Loruk and Arus). All the thermal activity associated with the Group 3 prospects, however, plus two Group 2 prospects, ol Kokwe and Bogoria, consists of hot springs and local patches of steaming ground.

The ranges of probable reservoir temperatures given for each group in Table IV-I are based on:

(a) the geochemical temperatures derived for a number of chemical parameters, which were then applied to all the prospects in their respective groups; and

(b) the assumption that Group 1 reservoirs will have temperatures comparable to those found at olkaria, which has the characteristics of a Group 1 prospect.

\section{c. Possible Power Capacities}

The range of power capacities estimated for the Group 1 prospects is given in Table IV-l. It is based on the results of numerical simulation of the olkaria reservoir, which has given a maximum unit-area power capacity of about $13 \mathrm{MW}$ per $\mathrm{km}^{2}$. The field area estimates for Group iA prospects range from 24 to 40 $\mathrm{km}^{2}$, and from 2 to $12 \mathrm{~km}^{2}$ for Group $1 \mathrm{~B}$ prospects. From these values, the power capacity for Group IA prospects using the above methodology is calculated to range up to $500 \mathrm{MW}$; the minimum calculated value may be as low as $65 . \mathrm{MW}$, if only the central volcanic structure is considered, or as high $310 \mathrm{MW}$, based on the areas of fumaroles and steaming ground. For Group 1 B prospects, the minimum and maximum power capacities are calculated by this method as being between 25 and $150 \mathrm{MW}$.

The power capacity estimates for Group 2 and 3 prospects (Table IV-I) are based in part on the extent of the area of thermal activity, and in part by analogy with developed fields located in similar geologic settings and which have similar reservoir temperatures. 


\section{Prospect Descriptions by Risk Group}

Following is a brief description of the individual prospects. The groups are discussed in sequence from the lowest risk group IA to the highest risk Group 3B. Within each group, however, prospects are listed from $N$ to $S$, a sequence which clearly has no bearing on the relative risk of finding an exploitable reservoir within the group.

\section{a. Group 1A}

These prospects are characterized by extensive surface thermal activity at the boiling point, and by a close association of this activity with recent volcanic centers. Boundary lines drawn around the scattered fumaroles and the broader patches of steaming ground enclose areas ranging from about 24 to $40 \mathrm{~km}^{2}$. The expected range of reservoir temperatures in this group is from $240^{\circ}$ to $300^{\circ} \mathrm{C}$, and the estimated power capacities range up to $500 \mathrm{MW}$. From $N$ to $S$, these prospects are silali, paka, Korosi, Eburru, Olkaria and suswa.

Silali This prospect extends over an area of about $24 \mathrm{~km}^{2}$ whose center is about $55 \mathrm{~km} \mathrm{~N}$ of the $\mathrm{N}$ shore of Lake Baringo, and about $12 \mathrm{~km} E$ of the nearest road access at the town of kapedo. The thermal activity, as mapped by the BGS, consists entirely of fumaroles and steaming ground at temperatures between $38^{\circ}$ and $97^{\circ} \mathrm{C}$. This activity mainly is concentrated within an enclosed, elliptically shaped caldera measuring $5 \times 7 \mathrm{~km}$. The floor of the caldera is at an elevation of $1,000 \mathrm{~m}$, whereas the lowest point on the caldera rim is at $1,200 \mathrm{~m}$. The water table, as indicated by the elevation of the hot springs at kapedo, is at an elevation of $740 \mathrm{~m}$ or slightly higher. Therefore, water rest-levels in wells drilled within the crater should be at a depth of about 250 m. If temperatures increase with depth along a curve of the boiling point with hydrostatic depth, temperatures on the order of $250^{\circ} \mathrm{C}$ could be expected between depths of about 600 to $700 \mathrm{~m}$. However, for purposes of conservatism, a minimum depth of $1,000 \mathrm{~m}$ below the water table is assumed as the likely driling depth for all prospects, based on the olkaria experience. Non-condensible gas samples have been collected by the BGS for the purpose of estimating the reservoir temperature; preliminary results were made available for this report. Data are expected to be released in final form at the end of 1990 or early in 1991.

Paka This prospect is located about $30 \mathrm{~km}$ NNE of the $\mathrm{N}$ shore of Lake Baringo, and is about $18 \mathrm{~km} \mathrm{E}$ of the nearest access road. The area of steaming ground and fumaroles, as mapped by the BGS, is about $4 \times 9 \mathrm{~km}$. The anomaly straddles the crater of Paka volcano, and its long dimension coincides with NNE-striking 
faults which offset the young lava flows. The elevation of the area of steaming ground ranges from about 1,000 to $1,400 \mathrm{~m}$, and because the elevation of the groundwater table probably is about $850 \mathrm{~m}$, the depth to ground water should range from 150 to $550 \mathrm{~m}$. The BGS has taken samples of non-condensible gas from these fumaroles, which were available for this report. Final data are scheduled to be released at the end of 1990 or early in 1991.

Korosi This prospect is located about $6 \mathrm{~km} \mathrm{~N}$ of the $\mathrm{N}$ shore of Lake Baringo and, like Paka, it is a $4 \times 9 \mathrm{~km}$ area of scattered fumaroles straddling the crater area of a young central volcano. The prospect is $7 \mathrm{~km}$ from the nearest road. The long axis of the anomaly parallels the NNE trend of the many faults crossing the volcano. The topographic elevation of the prospect ranges from about 1,000 to $1,300 \mathrm{~m}$, whereas the elevation of the groundwater table beneath the area is estimated to be $950 \mathrm{~m}$. Depth to groundwater, therefore, is estimated to range from 50 to $350 \mathrm{~m}$. Although there are no hot springs to be sampled to determine reservoir temperatures, gases from the fumarole have been sampled for this purpose by the BGS.

Olkaria The steaming ground associated with olkaria defines an irregularly shaped area covering about $35 \mathrm{~km}^{2}$ just to the $S W$ of Lake Naivasha. The thermal areas are associated with a number of recent domes and craters, as well as with $\mathrm{N}$ - and $\mathrm{NW-trending}$ fracture zones. It has been suggested these features are genetically related to a young caldera $8 \times 10 \mathrm{~km}$ in diameter. Forty-five MW of electric power are being produced from some 25 wells covering an area of less than $4 \mathrm{~km}^{2}$. The average productivity of olkaria wells is 2.5 to $3.0 \mathrm{MW}$. Exploration drilling has proven an additional $10 \mathrm{~km}^{2}$ of producible field to the $N$ and $N W$ of the existing well field. The southern part of the olkaria area, as defined by surface thermal features, appears to be an outflow zone, in which temperatures are cooler at depth than in the productive field, and which may prove to be largely unproductive.

Eburru The steaming ground and fumaroles defining the Eburru prospect extend over an area $8 \mathrm{~km} \mathrm{N-S}$ by $4 \mathrm{~km} \mathrm{E-W.} \mathrm{The} \mathrm{prospect}$ is located $12 \mathrm{~km} \mathrm{NW}$ of lake Naivasha and is easily accessible by road. On the $S$ (at 2,500 to $2,700 \mathrm{~m}$ elevation), the thermal areas are associated with several young craters on the top of Eburru volcano. Further north the thermal areas occur along $\mathrm{N}$-trending faults and young extrusion centers down to an elevation of $2,000 \mathrm{~m}$. Four deep exploration wells were drilled at Eburru during 1989: one in the crater area, one $S$ of the crater area, and $2 \mathrm{E}$ of the steaming, N-trending faults. The hole drilled in the crater area was successful, producing thermal fluid with a generating potential of about $2.5 \mathrm{MW}$. The other 3 holes were unsuccessful. Two additional wells were drilled in 
mid-1990 to the $N$ and $N W$ of the initial successful Eburru well. These were designed to test a chemical and geophysical anomaly of about $5 \mathrm{~km}^{2}$ in area. Preliminary temperature data suggest that one hole may be unsuccessful, whereas the second hole remains untested at this time. The large area of steaming ground located at lower elevation on the $\mathrm{N}$ flank of Eburru volcano (sometimes called Cedar Hill, Eburru station and the Badlands) has yet to be tested. It remains unknown if this lower-elevation zone is outflow from the main crater area, or represents a separate upwelling of thermal fluid.

Suswa The high-temperature fumaroles associated with suswa volcano define an area of $8 \times 5 \mathrm{~km}$. Suswa volcano, which is located about $50 \mathrm{~km} \mathrm{NW}$ of Nairobi, is unique in having a central ring structure which forms a deep, topographic trench which, in turn, surrounds a central "island" structure. The diameter of the island within the trench is about $5 \mathrm{~km}$. Many of the fumaroles associated with suswa volcano occur within the trench, but others occur within a larger outer caldera. The outer caldera is easily accessible by existing dirt tracks, but the island is difficult to reach, even by foot. The elevation of the outer caldera floor averages about $1900 \mathrm{~m}$. As the local elevation of the groundwater table is estimated to be about 1250 $\mathrm{m}$, the estimated depth to groundwater is 600 to $700 \mathrm{~m}$. Because of the depth to groundwater, no hot springs occur at suswa. Armannsson (1987), however, has calculated reservoir temperatures from $\mathrm{CO}_{2}$ gas discharging with the fumarole steam: fumaroles in the trench give temperatures in excess of $300^{\circ} \mathrm{C}$; the calderafloor fumaroles indicate temperatures a little below $300^{\circ} \mathrm{C}$; and the caldera rim fumaroles give temperature of $270^{\circ}$ to $290^{\circ} \mathrm{C}$.

\section{b. Group 1B}

The expected range of reservoir temperatures in this group is the same as for Group $1 \mathrm{~A}$ prospects, but the surface thermal anomalies associated with Group $1 B$ are significantly smaller than in Group $1 \mathrm{~A}$ (2 to $12 \mathrm{~km}^{2}$ as compared to 24 to $40 \mathrm{~km}^{2}$ ). Consequently, the probable potential of a Group $1 B$ prospect is in the range of 25 to $150 \mathrm{MW}$.

The Central Island, Barrier Volcano and Namarunu prospects are all located in the far $N$ of the Rift Valley; because of their remote location they have yet to be surveyed in detail. All that is known is that they contain fumaroles and steaming ground associated with young volcanic centers. They have been placed in Group 19 because it is believed that the areas of steaming ground extend over areas of only a few $\mathrm{km}^{2}$, but this assumption may be revised when betzer information becomes available. 
A brief description of the Group $1 B$ prospects, listed from $N$ to $S$, follows.

Central Island This prospect is located on Central Island in Lake Turkana. This is a volcanic island located $12 \mathrm{~km}$ from the western (nearest) shore of the lake. Although hot springs and steaming ground at boiling temperature have been reported, little else is known of the occurrence. No chemical analysis or geochemical temperatures have been reported.

Barrier Volcano This prospect is located at the $s$ end of lake Turkana where a young volcanic complex forms a topographic barrier between the lake on the $\mathrm{N}$ and the lower-elevation suguta valley on the $S$. From Silali volcano northward to the Barrier, a distance of $130 \mathrm{~km}$, the suguta Valley occupies the axis of the Kenya Rift. The Barrier is composed of 2 principal volcanoes, Teleki's volcano on the $N$ and Andrew's volcano on the $S$. Fumaroles are associated with both volcanoes. Teleki's volcano was active in historic time; Andrew's also may be active. The elevations of Teleki's and Andrew's volcanoes are about $650 \mathrm{~m}$ and $1,000 \mathrm{~m}$ respectively. By comparison, the probable groundwater elevation beneath the Barrier is at about $300 \mathrm{~m}$. Depth to groundwater, therefore, is expected to range from $350 \mathrm{~m}$ to $700 \mathrm{~m}$. No inferred reservoir temperatures from chemical geothermometry have been reported. The nearest-maintained road is $30 \mathrm{~km}$ from the prospect.

Namarunu This prospect is characterized by fumarole activity associated with Namarunu volcano, which is located in the suguta Valley about $40 \mathrm{~km} S$ of the Barrier volcanoes and $50 \mathrm{~km} \mathrm{~N}$ of Emuruangogolak volcano. Because of its extreme remoteness, the prospect has not been mapped in detail, and no accurate information is available concerning the extent of the fumarole field or the chemistry of the fumarole gases. The elevation of the volcano averages about $700 \mathrm{~m}$ compared to the elevation of the Suguta valley, directly to the $E$, at $270 \mathrm{~m}$. Depth to groundwater, therefore, would be about $430 \mathrm{~m}$.

Emuruangogolak This prospect is located $95 \mathrm{~km} \mathrm{~N}$ of the $\mathrm{N}$ shore of lake Baringo and is the most remote of those surveyed thus far by the BGS. Although a track passes within $8 \mathrm{~km}$ of the thermal area, the closest maintained road is $35 \mathrm{~km}$ to the $\mathrm{E}$. Thermal activity, in the form of fumaroles and steaming ground, occurs over a circular $7 \mathrm{~km}^{2}$ area located near the summit of a young volcano. Steam temperatures range from $47^{\circ}$ to $94^{\circ} \mathrm{C}$. As in the case with the thermal areas associated with the 3 volcanoes to the $S$, the BGS has recently collected gas samples at Emuruangogolak for the purpose of estimating reservoir

temperature. This information may be released late in 1990. The estimated range of depth to groundwater beneath the thermal area is 600 to $700 \mathrm{~m}$. 
Menengai Two fumarole fields have been described in Menengai caldera (McCall, 1967) ranging in temperature from $64^{\circ}$ to $90^{\circ} \mathrm{C}$. The extent of these fields has not been mapped, but evidently they are quite small compared to the size of the caldera itself, which is $8 \times 12 \mathrm{~km}$. The volcano appears to have been active within the past few thousand years. The caldera is located just $N$ of Nakuru, and the rim is easily accessible from the surrounding farm land. However, the caldera floor consists of a great expanse of slaggy lava flows which make the interior of the caldera difficult to traverse, even by foot. Terrain elevations within the caldera range from 1,800 to $2,100 \mathrm{~m}$. Although no wells have been drilled to determine depth to groundwater, it is estimated that the groundwater table in the caldera is at an elevation between 1,700 and $1,800 \mathrm{~m}$. Depths to groundwater, therefore, would range from 100 to $300 \mathrm{~m}$.

Longonot Longonot is a prominent central volcano located just $\mathrm{SE}$ of Lake Naivasha, and only $15 \mathrm{~km} \mathrm{E}$ of the olkaria geothermal field. Fumaroles, ranging in temperature from $47^{\circ}$ to $90^{\circ}$, occur along the inner rim of the summit crater of the volcano. The crater is $2 \mathrm{~km}$ in diameter, and is accessible only by foot because of the steep outer slope of the volcanic cone and the even-greater steepness of the inner crater rim. The steep cone of the volcano occupies the east side of a caldera which is $6 \mathrm{~km}$ in diameter. Four small areas of steaming ground, ranging in temperature from $43^{\circ}$ to $74^{\circ} \mathrm{C}$, occur on the $\mathrm{S}$ side of the caldera. It is unknown if these are related to outflow from a hightemperature zone to the $N$, or represent a separate zone of upwelling. The elevations of the top of the groundwater table and the top of geothermal fluid production may be at about the same elevation as at olkaria; that is, 1,600 m and 1,200 m, respectively. Because of the difficult terrain, directional drilling from outside the crater would be required to access the area beneath the crater. Assuming a maximum horizontal throw to depth ratio of 1:2, it would be difficult to find many drilling sites on the steep slope of the volcano that would be close enough to the crater to allow the drilling of targets located vertically beneath it. One such site, however, may exist on the NW side of the volcano at an elevation of about $2370 \mathrm{~m}$. Depth to groundwater from this site would be about $750 \mathrm{~m}$.

\section{c. Group 2}

The Group 2 prospects, like those in Group 1, are characterized by surface thermal feature at the boiling point. However, unlike the Group 1 prospects, those of Group 2 are not closely associated with recent volcaniz activity. Reservoir temperatures are estimated to range from $150^{\circ}$ to $215^{\circ} \mathrm{C}$, and power generating capacity from 10 to $50 \mathrm{MW}$. From $\mathrm{N}$ to $\mathrm{S}$, these prospects are: Chepchok, Loruk, ol Kokwe, Bogoria, Arus and iobanita. 
Chepchok This prospect consists of approximately $1 \mathrm{~km}^{2}$ of fumaroles and steaming ground, located $20 \mathrm{~km}$ NNE of the $N$ shore of Lake Baringo and $8 \mathrm{~km} S$ of the summit of Paka volcano. There are no recent volcanic centers at chepchok, but $N$ - to NNEtrending fault scarps are prominent. The thermal activity occurs along the bed of the komol river, at an elevation of about 1,040 $\mathrm{m}$. The Komol River separates Korosi volcano on the $S$ from Paka volcano on the $N$. The course of the river, therefore, is the lowest land surface between the two volcanoes. Because of chepchok's location on faults striking toward Paka volcano, and because of its relatively low elevation, it is possible that the thermal features at chepchok are related to southward outflow of thermal fluid originating from the paka upflow zone. The elevation of the groundwater table below chepchok is estimated to be about $900 \mathrm{~m}$, giving a depth to groundwater of about $140 \mathrm{~m}$. The prospect is about $6 \mathrm{~km} \mathrm{NW}$ of a maintained road.

Loruk This is a small area of steam and hot air vents located along the road paralleling the $W$ shore of Lake Baringo, about 5 $\mathrm{km} S$ of Loruk settlement. The vents issue from fractures in lava at an elevation of about $1,000 \mathrm{~m}$, which is about $40 \mathrm{~m}$ above the level of lake Baringo. The $W$ shore of the lake is about one $\mathrm{km} E$ of the thermal area. Temperatures up to $92^{\circ} \mathrm{C}$ have been measured in the vents. There is no obvious volcanic or structural feature controlling the location of discharge other than the $N$-trending fractures of the Rift valley floor.

ol Kokwe Hot springs and steaming ground, with a maximum temperature of $94^{\circ} \mathrm{C}$, occur on 01 Kokwe island in Lake Baringo. Although two basalt scoria cones occur on the $W$ side of the island, the thermal manifestations occur in older lavas on the $E$ side. ' Because the age of the basalt cones is uncertain, and because ol Kokwe island is not a major volcanic center comparable to those associated with the Group 1 prospects, the ol Kokwe prospect has been classified in Group 2. The silica and alkali geothermometers give reservoir temperatures between $175^{\circ}$ to $197^{\circ} \mathrm{C}$ (Allen et al., 1989). Depth to groundwater is about $20 \mathrm{~m}$.

Bogoria The most impressive discharge of hot springs in Kenya occurs along the $S, S W$ and $S E$ shores of Lake Bogoria. Most of the springs are boiling, some very vigorously, and some are associated with steaming ground. There are no young volcanic centers in the vicinity, and although the lake occupies a major half-graben structure, the location of many individual thermal features does not appear to be fault-controlled, because most of the springs are not on the faulted side of the half-graben. A possible explanation for the location of the springs is that lake Bogoria, at an elevation of about only $990 \mathrm{~m}$, is the first surface-discharge point for groundwater flowing northward in the Rift Valley from the vicinity of Menengai, located $40 \mathrm{~km}$ to the $\mathrm{S}$. Water infiltrating in the Menengai area could easily reach depths of several $\mathrm{km}$ before discharging at Bogoria. over this 
distance between points of recharge and discharge, the water could be heated either by shallow magmatic heat sources in the vicinity of Menegai, or by the high regional heat flow to be expected in this volcanically active part of the Rift valley. Because of problems in interpreting mixing ratios and times of mixing between thermal fluid, lake water and local groundwater, geothermometry results are ambiguous. Although the uninterpreted silica and alkali geothermometers give temperatures below $150^{\circ} \mathrm{C}$, gas thermometers and various mixing models give reservoir temperatures of $190^{\circ}$ to $200^{\circ} \mathrm{C}$. The latter are the more Iikely values, considering the vigorous boiling activity of the springs. As the springs are at lake level, the depth to groundwater would be only a few $m$ to a few tens of $m$, depending on the drilling site. A well-maintained road provides access to the $W$ shore of the lake. The road is maintained because the lake, which supports a large flamingo population, has been declared a Nitional Reserve. Because of this designation, development of the prospect will be environmentally sensitive.

Arus This prospect, located $16 \mathrm{~km} \mathrm{~W}$ of Lake Bogoria and $50 \mathrm{~km} \mathrm{~N}$ of Nakuru, consists of several strong fumaroles and boiling mud pools extending for a distance of several hundred $m$ along the $E$ bank of the Molo River. Although not entirely clear, it can be inferred from topographic relief that this section of the Molo river is following a fault scarp bordering the $w$ side of a narrow, E-dipping fault block. This fault, one of many on the Rift valley floor in the vicinity, is close to the central axis of the Rift. Although there are no young volcanic centers close to the prospect, a center from which Quaternary flood basalts were extruded is located at Goituimet, $9 \mathrm{~km} s$ of the prospect. Geochemical temperatures of $200^{\circ}$ to $215^{\circ} \mathrm{C}$ have been reported for the resarvoir. The fumaroles are at an elevation of $1,370 \mathrm{~m}$, which is $380 \mathrm{~m}$ above the level of Lake Bogoria. It is likely, therefore, that depth to groundwater should not exceed about 380 im. Except for the narrow canyon of the Arus river, the prospect is surrounded by flat terrain. The closest vehicle access is a dirt road located $2.5 \mathrm{~km}$ to the SE.

Olobanita The area of this prospect is poorly defined, because its location is not based on the presence of surface thermal activity, but instead on the distribution of a number of hot wells drilled in the rolling country $N$ of Menengai crater. The location of these wells has been described by several authors (McCall, 1967; Baticci, 1987; Geothermica Italiana, 1989). Not all of these descriptions agree in detail, because some of the older well locations cannot be verified, and some wells can no longer be entered. Nevertheless, there is general agreement that about 10 wells, drilled from 1 to $30 \mathrm{~km} \mathrm{~N}$ and NNW of Menengai, have encountered anomalously high temperatures ranging from $30^{\circ}$ to $98^{\circ} \mathrm{C}$. Few of the wells encountered water, and the hottest wells found steam under very low pressure. The area within which

$$
I \nabla-30
$$


the hot wells occur is about $10 \mathrm{~km} \mathrm{E-W}$ by $30 \mathrm{~km} \mathrm{N-S}$. The northernmost steaming well is at Mugurin, which is only $9 \mathrm{~km} \mathrm{SE}$ of the Arus prospect. There are no young volcanic features in the area; however, older, partially buried calderas have been mapped $N$ of Menengai. The area is easily accessible by many farm roads. The depth to groundwater is not known, but may range up to several hundred $\mathrm{m}$. Chemical geothermometry indicates reservoir temperatures in the range of $170^{\circ}$ to $190^{\circ} \mathrm{C}$ from the gases sampled in a well located $6 \mathrm{~km} \mathrm{NW}$ of Menengai crater.

\section{d. Group 3A}

Like Group 2 prospects, those of Group 3 are not closely related to recent volcanic activity; but unlike Group 2

prospects, surface thermal features are at temperatures less than boiling. Based on chemical geothermometers, the probable reservoir temperatures of Group $3 \mathrm{~A}$ prospects are in the range of $100^{\circ}$ to $200^{\circ} \mathrm{C}$. Based on analogy with developed fields in similar geologic settings, the probable power generating potential of Group $3 \mathrm{~A}$ prospects is estimated to be in the range of 5 to $50 \mathrm{MW}$.

There are 4 prospects that fall in to the $3 \mathrm{~A}$ category. Listed from $N$ to $S$, these are Kapedo/Lorusio, Homa Mountain, Lake Magadi and Mwananyamala. Brief descriptions of these prospects follow.

Kapedo/Lorusio Two hot spring areas, $9 \mathrm{~km}$ apart, are described herein as one prospect. Kapedo hot spring is located $12 \mathrm{~km} \mathrm{~W}$ of Silali volcano, and Lorusio hot spring is located $9 \mathrm{~km} N$ of Kapedo hot spring. Kapedo is directly accessible from a maintained road, and Lorusio by a motorable track from Kapedo. The maximum temperatures of these springs are $52^{\circ} \mathrm{C}$ at Kapedo and $81^{\circ} \mathrm{C}$ at Lorusio. The composition of Kapedo water is equivalent to the water of Lorusio diluted by an equal amount of very dilute, cold groundwater. Therefore, interpretation of the geothermometer data is ambiguous. Although alkali

geothermometers yield reservoir temperatures of $172^{\circ} \mathrm{C}$ for Lorusio and $155^{\circ} \mathrm{C}$ for Kapedo, silica temperatures are similar to measured surface temperatures, possibly because of mixing of the thermal water with cool, dilute surface water. The high Na/K ratio of both sprines supports the lower (silica) temperature

interpretauion. Whether these hot springs derive their heat from shallow magma beneath silali volcano, or from deep circulation in a area of high regional heat flow, is uncertain. satellite craters, located on the $w$ flank of silali, are as close $6 \mathrm{~km}$ from the Kapedo springs. Therefore, it is possible that the thermal water is outflow from a convecting upflow zone beneath these craters or beneath silali itself. 
Homa Mountain This prospect is located in the Kavirondo Rift of western Kenya on the shore of Lake Victoria, about $40 \mathrm{~km} \mathrm{SW}$ of Kisumu. Homa Mountain is a late Tertiary or early Quaternary carbonatite volcanic complex about $10 \mathrm{~km}$ in diameter. Three hot springs occur at the base of the mountain: Abundu and ongoro springs on the $\mathrm{N}$, and Nyabondo springs on the $\mathrm{S}$. The highest measured temperature is $90^{\circ} \mathrm{C}$ at the Abundu springs. Total flow from the springs is about $13 \mathrm{l} / \mathrm{s}$. Tole (1990) reported that quartz geothermometry gives reservoir temperatures in the range of $142^{\circ}$ to $179^{\circ} \mathrm{C}$, whereas a conservative interpretation of the alkali geothermometers indicates a temperature of $200^{\circ} \mathrm{C}$. These reservoir temperatures appear somewhat high in view of the possible Tertiary age of volcanism at Homa Mountain. The chalcedony geochemistry, which is applicable to low and moderate temperature water, indicates only $110^{\circ} \mathrm{C}$. It is possible that the unusual chemistry of the hot spring water (highly saline and alkaline sodium bicarbonate-chloride), itself probably a function of water:rock reactions within the old volcanic center, is causing the alkali geothermometer to give spurious temperature results.

Lake Magadi Numerous hot springs occur around the shores of lake Magadi, a highly saline lake located in the Rift valley about 80 $\mathrm{km} S W$ of Nairobi. The hottest springs occur at the $\mathrm{N}$ end of Iittle Magadi lake, a satellite feature immediately to the NW of Lake Magadi. The maximum spring temperature is $86^{\circ} \mathrm{C}$, and the rate of discharge from these high-temperature springs is approximately $50 \mathrm{l} / \mathrm{s}$. The surface geology consists of Pliocene(?) basalt flows, that have been broken into horsts, grabens and half-grabens by Pliocene-Pleistocene faulting. The grabens contain a thin layer of lacustrine and evaporite beds. There are no recent volcanic extrusions in the vicinity of the lake, and the springs emerge from a number of north-trending faults. Because there is a long history of mining trona from the lake, over the years there have been many studies concerning the origin of the hot springs and their relationship to the complex carbonate chemistry of the lake. Because of the probability of complex mixing and recirculation of lake water, groundwater and spring water, a clear picture of the origin of the springs has yet to be developed. There is general agreement, however, among the various interpretations of geothermometer results, that the temperature of the hot spring reservoir is in the range of $100^{\circ} \mathrm{C}$ to $140^{\circ} \mathrm{C}$, preferentially at the higher value. Because of the trona plant, a paved road is maintained from Nairobi to the central shore of the lake. From there, a motorable track reaches within $2 \mathrm{~km}$ of the $\mathrm{NW}$ shore of the lake where the hottest springs are located.

Mwananyamala This prospect is located in SE Kenya about $60 \mathrm{~km} \mathrm{SW}$ of Mombasa and consists of 4 hot springs distributed over an area of $9 \times 2 \mathrm{~km}$. The springs discharge from fractures and joints in Permian/Triassic sandstone. Dikes of Cretaceous age intruded 
into the sandstone appear to control the discharge area of two of the springs (Tole, 1990). Surface temperatures range from $55^{\circ}$ to $76^{\circ} \mathrm{C}$ with a total surface flow rate of less than 1 1/s. Quartz and most of the alkali geothermometers give reservol: temperatures in the range of $125^{\circ}$ to $180^{\circ} \mathrm{C}$. However, the $\mathrm{Mg}-$ corrected alkali thermometer yields a much-lower value. Because spring flow is so low, the effects of contamination by mixing with shallow groundwater is greater than otherwise, thereby complicating any interpretation.

\section{e. Group 3B}

This group of prospects is characterized by: (a) spring temperatures less than boiling; (b) non-association with young volcanic or intrusive centers; and (c) probable reservoir temperatures in the range of $40^{\circ}$ to $120^{\circ} \mathrm{C}$, as indicated by geochemical thermometry. Probable power-generating capacities of prospects in this group are only 5 to $10 \mathrm{MW}$.

Lovangalani This prospect is located on the SE shore of lake Turkana at the town of the same name. According to Tole (1990), the highest temperature of the springs is $39.8^{\circ} \mathrm{C}$ and the reservoir temperature, inferred from the quartz geothermometer is $71^{\circ} \mathrm{C}$. Our reappraisal of Tole's analysis suggests $40^{\circ}$ to $60^{\circ} \mathrm{C}$.

Kurru This prospect is located in central Kenya, about $80 \mathrm{~km}$ ENE of Archer's Post. Maximum measured temperature (Tole, 1990) was $42^{\circ} \mathrm{C}$. Inferred reservoir temperatures are $75^{\circ}$ to $105^{\circ} \mathrm{C}$ based on the several silica geothermometers, and $170^{\circ} \mathrm{C}$ on the bas is of the alkali geothermometer. Given the very high ratio of $\mathrm{Ca}: \mathrm{Na}+\mathrm{K}$ for the spring waters, the alkali geothermometer may be giving too high temperatures. The springs flow from crystalline basement rock, and are located about $20 \mathrm{~km} \mathrm{NE}$ of the nearest outcrops of young basalt flows.

Kureswa This prospect is located at the southern end of the Kerio valley, about $60 \mathrm{~km}$ SE of Eldoret. The Kerio Valley is a subsidiary part of the Rift Valiey system. The hottest spring (Tole, 1990 ) is $63^{\circ} \mathrm{C}$. The silica geothermometers give reservoir temperatures of $90^{\circ}$ to $122^{\circ} \mathrm{C}$, and the alkali geothermometer gives about $120^{\circ}-130^{\circ} \mathrm{C}$. The altitude of the spring is about 2,000 $\mathrm{m}$.

Kijabe This prospect is located $45 \mathrm{~km} \mathrm{NW}$ of Nairobi on the eastern escarpment of the Rift Valley. It consists of $43^{\circ} \mathrm{C}$ springs, with geochemically inferred reservoir temperatures in the range of $40^{\circ}$ to $146^{\circ} \mathrm{C}$. The springs discharge from a Rift Valley fault, from which it is inferred that the temperature anomaly is due to deep circulation of groundwater in an area of elevated temperature gradient.

Maji Moto This prospect is located in southern Kenya, $w$ of the Rift valley. The hot springs occur at the contact between 
Tertiary volcanic ash and underlying Precambrian metamorphic basement (Tole, 1990). Maximum discharge temperature is $57^{\circ} \mathrm{C}$, and the total flow rate for the spring group is estimated to be less than $1 \mathrm{l} / \mathrm{s}$. The quartz and most of the alkali geothermometers give reservoir temperatures of $101^{\circ}$ to $104^{\circ} \mathrm{C}$; however, chalcedony and $\mathrm{Mg}$-corrected alkali temperatures are about $60^{\circ} \mathrm{C}$.

Narosura This prospect is located $28 \mathrm{~km} \mathrm{SE}$ of Maji Moto. The maximum surface temperature of the warm spring is $31^{\circ} \mathrm{C}$ and its flow rate is estimated at about $2 \mathrm{l} / \mathrm{s}$. The quartz geothermometer gives an inferred reservoir temperature of only $58^{\circ}$ to $71^{\circ} \mathrm{C}$.

Masamukye This prospect is located near the Nairobi-Mombasa road, about $140 \mathrm{~km}$ SE of Nairobi. The springs rise in the bed of the Muooni river from fractures in Precambrian metamorphic basement. The prospect is $4 \mathrm{~m} \mathrm{~S}$ of outcrops of the pleistocene Ngun basalts (Tole, 1990). The highest spring temperature is $43^{\circ} \mathrm{C}$, and the reservoir temperature indicated by the silica geothermometers is between $45^{\circ}$ and $70^{\circ} \mathrm{C}$.

\section{Initial prospect prioritization}

An important aspect of the distribution of prospects in Kenya is that 7 of the 11 low-risk, potentially large fields are located $N$ of lake Baringo, where the distance to the nearest transmission grid is in excess of $90 \mathrm{~km}$. Distance to the transmission grid is an important criterion for establishing exploration priority; therefore, the criteria for selecting prospects distant from the grid will be somewhat different from the selection criteria for those fields closer to the grid. Mostly, the remote prospects must have a relatively large potential to justify the expense of constructing a long transmission line. To simplify the prioritization process, prospects first have been separated into categories defined by distance to the transmission grid.

The 29 prospects Iisted in Table IV-2 can be divided into 3 groups, those which are: (a) 2 to $60 \mathrm{~km}$; (b) 80 to $120 \mathrm{~km}$; and (c) 150 to $200 \mathrm{~km}$ from the transmission grid. If those prospects in the 150 to $200 \mathrm{~km}$ group (Central Island, Barrier Volcanoes, Loyangalani and Kurru) are eliminated from further consideration because of their extremely remote location; and if all of Group 3B prospects (which include two of the remote prospects), are eliminated because of their small potential (probably 10 MW or less), then the 19 remaining prospects can be grouped into two categories: 10 prospects located less than $60 \mathrm{~km}$ from the grid and 9 prospects located 80 to $120 \mathrm{~km}$ from the grid. 
Table IV-3: Initial priority Listing of Prospects Located Less Than $60 \mathrm{~km}$ from the Transmission Grid.

\begin{tabular}{|c|c|c|}
\hline & Prospect & Risk G \\
\hline 1. & Suswa & 1 \\
\hline 2 . & Eburru & 1 \\
\hline 3. & Arus & 2 \\
\hline 4. & Longonot & 1 \\
\hline 5 . & Menengai & 1 \\
\hline 6. & Lake Magadi & 3 \\
\hline 7 . & olobonita & \\
\hline 8 . & Homa Mountain & 3 \\
\hline$\theta$ & Mwananyamala & \\
\hline & Bogoria & \\
\hline
\end{tabular}

a. Initial prioritization of Prospects Located within $60 \mathrm{~km}$ of the Transmission Grid

Ten prospects are listed in Table IV-3 from highest to lowest exploration priority. The reasons for assigning these priorities are as follows.

Highest priority is given to suswa because of its probable high reservoir temperature, its probable large generation capacity and its easy accessibility. The main difficulty anticipated with development is the great depth to groundwater, estimated to be 600 to $700 \mathrm{~m}$. These great depths, assumed to be $1,000 \mathrm{~m}$ below the groundwater table, increase drilling costs and decrease power outplit, compared to wells collared at elevations closer to the water table.

Second priority is given to Eburru, where high subsurface temperature and the existence of a permeable reservoir already have been proven by drilling. Even though only 1 of 4 deep exploration holes has been successful, very little of the area of steaming ground to the $\mathrm{N}$ has been tested.

Third priority is given to Arus, even though it is in a higher- risk category (Group 2) than either Menengai or Longonot, because: (a) there is a potential for tapping a hot water body significantly larger than the prospect area; (b) wells may be as shallow as 1,000 to $1,500 \mathrm{~m}$; (c) the area is flat and easily accessible from both existing roads and the transmission grid; (d) land acquisition should not be costly because it is mostly low-productivity grazing land; (e) a drilling target could be chosen without extensive surface exploration; and (f) drilling water is readily available from the nearby Molo river. This probably would be the quickest and lowest-cost prospect of all to explore. 
Only fourth priority is given to Longonot, despite its proximity to olkaria. It is a category lB risk because finding suitable drilling sites from which to target wells beneath the summit crater will be difficult. Depth to groundwater also is great.

Fifth priority is given to Menengai, also a $1 \mathrm{~B}$ risi: prospect. Difficult ground access within the crater, and a relatively small area of active fumaroles are its main drawbacks. Its pluses include evidence of recent magmatism, probable high temperature, and proximity to major population centers and to transmission lines.

Sixth priority is given to Lake Magadi, because of its probable low reservoir temperature. Although this prospect is 80 $\mathrm{km}$ from the transmission grid, it is included with the group of prospects located within $60 \mathrm{~km}$ of the transmission grid because of the possibility of an off-grid market for electric power and by-product fresh water at the trona plant.

Lower priorities are given to the olobonita, Homa Mountain and Mwananyamala prospects, in spite of their large areas and favorable inferred reservoir temperatures, because drilling targets are not obvious, and major exploration programs, including gradient drilling to several hundred $m$, will be required at all 3 prospects before sites can be selected for deep exploration drilling. Even then, it might not be possible to prove the existence of a commercial geothermal reservoir with only one or two deep exploration wells.

Lowest priority is given to Bogoria, in spite of its large area and reasonably high inferred reservoir temperatures, because considerable opposition to development can be anticipated based on environment considerations and the existence of a national game preserve. If this opposition can be eliminated by means of agreements regarding land use and animal protection, the priority ranking given to Bogoria would change significantly.

Table IV-4: Initial priority listing of Prospects Located 80 to $120 \mathrm{~km}$ from the Transmission Grid

\section{Prospect}

1. Korosi

2. Paka

3. Silali

4. Chepchok

5. Kapedo/Lorusio

6. Loruk

7. Ol Kokwe

8. Emuruangogolak

9. Namarunu

\section{Risk Group}

$1 A$

$1 \mathrm{~A}$

$1 A$

2

$3 A$

2

2

IB

$1 B$ 
b. Initial Prioritization of Prospects Located 80 to $120 \mathrm{~km}$ from the Transmission Grid

Nine prospects are ranked in Table IV-4 from highest to lowest exploration priority. The reasons for assigning these priorities are as follows.

First, second and third priority are given to Korosi, Paka and silali, because all 3 are in the category of lowest exploration risk and highest probable generating capacity. Korosi is given first priority because it (a) may require the shallowest wells to develop, (b) is closest to the grid, and (c) requires the shortest length of new access road. Paka and silali are about equal in terms of priority, even though access into paka may be slightly easier than for silali, and the thermal features reportedly are more intense.

In contrast to this ranking, the BGS, based on the content of fumarole gases, have ranked the geothermal potential of Korosi behind that of Paka and Silali. We have not adopted the BGS ranking because: (a) the most diagnostic gases for identifying reservoir temperature $\left(\mathrm{H}_{2} \mathrm{~S}, \mathrm{CH}_{4}\right.$ and $\left.\mathrm{H}_{2}\right)$ were found in such low concentration that reliable interpretations of reservoir temperature could not be made, and (b) use of the less-diagnostic gases, such as $\mathrm{He}_{2}$, are considered too imprecise and theoretical for this application. Our priorities are based on probable drilling depths, distance from access roads, distance from the transmission grid, ard overall likelihood of finding a commercial geothermal reservoir.

Fourth priority is given to Chepchok. Even though the thermal anomaly is small in size, drilling should be relatively shallow $(1,000-1,500 \mathrm{~m})$ because of the low elevation of the prospect, and access should be relatively inexpensive because of comparatively level ground and proximity to an existing road.

Fifth priority is given to the Kapedo/Iorusio prospect mainly because of ease of access. However, if the thermal features are related to shallow outflow from silali, subsurface temperatures may be disappointing. Further, the large areal extent of the prospect makes the selection of exploratory drilling sites less simple and therefore somewhat riskier.

Sixth priority is given to Loruk. This area will require considerable exploration effort, because there is no obvious drilling target or identified controlling structure other than $\mathrm{N}-$ s-trending faults. However, access is easy, and exploration should be straightforward, emphasizing temperature-gradient drilling to several hundred $\mathrm{m}$. 
Lowest priorities are given to ol Kokwe, Emuruangogolak and Namarunu. In spite of the size and probable high reservoir temperature of Emuruangogolak and Namarunu, both prospects are very remote. Exploration, exploratory drilling and development would be expensive, slow and difficult. ol Kokwe is located on an uninhabited island in the middle of Lake Baringo. This isolated position makes drilling and development expensive and therefore unlikely. 


\section{F. COST OF GEOTHERMAL EXPLORATION, DEVELOPKENT AND FIELD OPERATION}

\section{Description of Cost Factors}

In this section, the costs associated with exploration, field development (including the production wellfield, steam gathering lines and transmission line, but excluding power plant and auxiliary structures), and field operation (including make-up well drilling, but excluding power plant maintenance) are discussed in general. They are discussed in further detail for specific prospects in section $G$.

Costs can be considered as a function of the following factors, both in an absolute sense and relative to other prospects:

Prospect accessibility: recessity for road construction; necessity to construct field camp; additional travel to/from prospect; additional time and cost of conducting field surveys in difficult terrain; uncertainty arising from incomplete field work in inaccessible parts of prospect; seasonal constraints on access

Prior investigation: level of completeness and utility of prior investigations; time and cost savings realized from use of prior work versus additional project risk (if any); need to repeat surveys or augment prior work

proximity to market and transmission lines: available line capacity (if any); construction of additional lines; possibility of local off-grid utilization of electricity; timing of incorporation into grid

Resource size: economies of scale; reward versus risk in large and small prospects; reserve capacity for contingencies

Resource characteristics: required depth of drilling; likely yield per well; geologic complexity as a factor in determining drilling success rates; chemical or physical constraints on resource utilization (scaling, corrosion, fluid enthalpy); anticipated rate of pressure drawdown.

Power plant: generation mode as a function of resource characteristics and size; fabrication and erection time as a function of generation mode and plant size.

Financing: financing sources, terms and conditions; availability of grants, soft loans and vendor credits; project insurance; terms of sale of electricity; repatriation of hard currency. 
Environment: constraints on access, drilling, construction, water consumption, and waste disposal; requirements for payment of compensation for damages; possible interruption of project activities.

Power plants and project finance are discussed by The Ben Holt Company in its report. We have used their cost numbers in evaluating the various prospects. Most of the resource areas are suitable for flash-steam generation; however, for a few, binarycycle generation is preferred. Distance from existing transmission lines has been noted for each prospect, and the cost of transmission lines is calculated in general terms for each prospect.

\section{Exploration stage Costs}

Exploration costs are dominated by the cost of exploratory drilling. The cost of exploratory drilling largely is a function of the precision of target-selection (risk), and the depth to the geothermal resource. Therefore, for fields of comparable depth, any field at which a discovery has been made by drilling will be less costly to develop than one which has not been drilled or at which driliing has resulted in no discovery. However, undiscovered fields at shallow depth may be less costly to develop than discovered deeper fields.

Because the passage of time represents lost financial opportunities, lengthier exploration programs typically become more expensive than shorter programs, even if the same work is accomplished in each. of course, there is a tendency to incorporate more work into a lengthy program, with greater expenditure. The possible advantage of having these additional data must be weighed against both the cost of collecting these data and the opportunity cost of lost time.

Remoteness of a prospect tends to add most to the cost of otherwise comparable programs. Roads and field camps may need to be constructed, and additional workers, supplies and equipment may. be needed. Access may be impeded seasonaliy. Water supplies may need to be developed locally via wells or pipeline; alternatively, expensive truck haulage may be required.

Geothermal exploration typically is built on 4 cornerstones:

1. An understanding of geologic structure and heat source: obtained from geologic mapping, gravimetry, and drilling.

2. Temperature distribution in the subsurface: obtained initially from fluid chemistry, and ultimately from temperature-gradient and exploratory drilling. 
3. Identification of a permeable and porous structure (the reservoir): inferred from geologic mapping, various geoelectrical methods, and fluid chemistry, and confirmed by results of drilling and well testing.

4 .

Recognition of fluid characteristics (phase, salinity, mixing patterns, flow directions): determined principally from fluid chemistry, drilling and well testing, and indirectly from geology and temperature data.

From this, an exploration program can be justified that begins with (or utilizes existing) geologic mapping, fluid geochemistry, and gravimetry. After this, typicaliy there are geoelectrical surveys and drilling of temperature-gradient holes. This is followed by construction of a conceptual geologic model, and the selection of exploration well sites, based on the model. other suites of information (seismic, petrochemical, infra-red, or aeromagnetic, for example) may be interesting, but usually are not essential to the program, and therefore cannot be justified on a cost or time basis except in exceptional cases.

Exploration costs, as noted above, will vary with the level of Drior work, the prospect location and accessibility, the geologic complexity as observed in work to date, and the size of the prospect. It is not possible to prepare detailed estimates of exploration cost for each prospect. However, based on the exploration principles described earlier, it is possible to generalize the costs of the main elements of an exploration program: geologic mapping, fluid geochemistry, gravimetry,

- electrical resistivity or magnetotellurics, and drilling of temperature-gradient holes, followed by conceptual modeling and drill-site selection (Table IV-5).

\section{Table IV-5: Exploration Costs at an Average Prospect}

Geologic mapping: Assume 4 man-months at US\$15,000 per month, plus US\$30,000 for support, printing and

miscellaneous. Total: US\$90,000 per prospect, where needed.

Geochemistry: Assume 3 man-months at US\$15,000 per month, plus US $\$ 50,000$ for support, chemical analyses, printing and miscellaneous. Total: US\$95,000 per prospect, where needed.

Gravimetry: Assume 2 crew-months at US $\$ 30,000$ per month, plus US\$30,000 for support, data processing, printing and miscellaneous. Total: Us $\$ 90,000$ per prospect, where needed. 
Geoelectrical surveys: Assume 3 crew-months at US\$35,000 per month, plus US\$20,000 for support, data processing, printing and miscellaneous. Total: US\$125,000 per prospect, where needed.

Temperature-gradient drilling: Assume 6 slim-holes to average $600 \mathrm{~m}$ depth, at US\$350 per $\mathrm{m}$, plus US\$75,000 for logging, data processing, printing and miscellaneous. Total: US $\$ 1,335,000$ per prospect, where needed.

Modeling and site selection: Assume 3 man-months at US\$15,000 per month, plus US\$20,000 for support, data analysis and printing. Total: US\$65,000.

In addition to the values given in Table IV-5, a project management function must be included, at an assumed cost of US\$40,000 per month while operations are underway. This function will involve varied aspects of liaison, negotiation and permitting, field supervision, budget management, materiel control, documentation and reporting, plus other tasks as required, all of which can be time-consuming and complex in Kenya. Based on an assumed 12 months for all aspects of exploration and drilling, through to selection of sites for the initial 3 deep wells, this comes to Us $\$ 480,000$.

Note, however, that some exploration work has been done at specific prospects, and that selected exploration steps may be omitted at various prospects, because of geologic or terrain factors. This may reduce time and cost of the exploration stage by up to 20\%. Also, for remote locations, costs will be increased by up to 20 or 25\%, reflecting additional time and cost for mobilization, supply, communications, etc.

Therefore, the exploration cost may range from US $\$ 1,820,000$ to 2,750,000 per prospect; depending upon the variables described above. This cost schedule has been applied to 15 prospects herein.

It is evident that the exploration cost per developed MW will be greater for small projects, and less for large developments. The exploration cost per project can be reduced by (a) selecting prospects that are less remote and less risky, (b) eliminating or reducing exploration steps, and (c) reducing the time requirements for exploration and drilling. Timetables for development are discussed in a subsequent section of this report. 


\section{Development stage costs}

are:

The items of greatest cost, in approximate descending order,

a. The power plant, including cooling towers, switching yard, and storage yard.

b. The wellfield, including production and injection wells, separators (if needed), steara gathering system and disposal lines.

c. Transmission line and substation.

d. Worker housing, offices, workshops, warehouses and related facilities.

e. Permanent water supply (wells, pipeline, storage tanks).

f. Road construction, site grading and other civil works.

g. Technical and economic feasibility studies, monitoring and testing, and design studies.

h. Preparation of specifications, selection of contractors, negotiation of agreements and permits, and supervision of contractors.

i. Environmental surveys and remedial work.

The power plant is discussed elsewhere. However, it should be noted that there are significant economies of scale in large developments; and that the enthalpy, chemistry, flow rate and pressure characteristics of the resource influence the type, size and cost of the power plant.

Experience at olkaria and Eburru has shown that the initial exploratory wells are, on average, deeper and more expensive than subsequent production wells, both in absolute terms and per $\mathrm{m}$ drilled. Drilling costs (1990 US\$) for wells of at least 6-inch bottomhole diameter are given in Table IV-6.

Table IV-6: Cost per Meter for Exploratory and Production Wells

Type

Exploration Production
Depth, I

$1,500-3,000$

$1,200-2,400$ $\underline{\text { US }} / \mathrm{m}$

$650-1,000$ $500-750$ 
This does not include the non-drilling costs of mobilization and demobilization (averages perhaps US\$100,000 per well for small programs, to perhaps US $\$ 40,000$ per well for programs of several wells), site preparation (about US $\$ 40,000$ per well), road construction (averages perhaps US $\$ 20,000$ per well for programs of several wells), or testing and data analysis (about US\$40,000100,000 per well, depending upon number of wells, location and reservoir complexity).

Additionally, it may be possible to obtain fluids from shallower depth at selected sites for binary-cycle generation. In such cases, production-well depth may average 300 to $800 \mathrm{~m}$, at a cost of US\$350 to 600 per $\mathrm{m}$, depending upon well diameter and pump requirements. In this report, however, no field is estimated to be shallower than 1,000 m in depth. Mobilization, site preparation, roads and testing are additional.

Certain standardized assumptions can be made regarding drilling success rates, well yield, standby reserves, and injection wells, as follows.

Even in lower-risk prospects of Group 1 and 2, only 1 of the initial 3 exploration wells is likely to be commercially successful. For the higher-risk prospects of Group 3 , and perhaps for certain others, the initial success ratio is likely to be 1 in 5 . After a discovery has been made, 4 of every 5 subsequent wells in any group is anticipated to be commercially successful.

Approximately 1 injection well will be required for disposal of fluids from every 2 production wells. To achieve this, approximately 1 of every 2 unsuccessful wells can be converted into an injection well, at an additional expenditure of about $10 \%$ of its original drilling cost. Because of these anticipated success rates, a $10 \mathrm{MW}$ development might require only 1 additional injection well; whereas, a $50 \mathrm{MW}$ field might need 5 or 6 specially drilled injection wells. The exact number would vary with both the drilling success rate, the well yield and the requirement for standb; reserve capacity.

A field cannot be operated safely for long without standby reserve capacity in wells. Otherwise, naturally occurring field pressure declines, or the need to shut-in a well for rehabilitation or repairs, would result in a reduction in power plant output. Typically, there should be standby reserve capacity equal to $10 \%$ of gross generating capacity or 1 additional well, whichever is a larger number of MW. 


\begin{tabular}{lccc} 
& \multicolumn{2}{c}{ Development Size, MW } & \multicolumn{2}{c}{50} \\
\cline { 2 - 3 } Production wells & 4 & 7 & 17 \\
Injection wells & 2 & 4 & 9 \\
Dry holes & 2 & 2 & 4 \\
Standby production wells & 1 & 1 & 2 \\
\cline { 2 - 3 } & 9 & 14 & 32
\end{tabular}

Table IV-7 gives the number of holes anticipated for a successful 10,20 and $50 \mathrm{MW}$ development, with suitable standby reserves, based on the assumption of a lower-risk prospect having an average yield of about 3 MW per well.

Table IV-7 shows a significant economy in scale for larger projects. The necessity to round fractional numbers to the nextlargest integer (there cannot be-1/3 or $1 / 2$ of a well), adds to this apparent benefit of scale.

Using an assumed average of $3 \mathrm{MW}$ per well, and the values given earlier for drilling cost (US\$650 - 1,000 per $m$ for exploration holes, and US\$500 - 750 per $m$ for production and injection wells, as a function of well depth), a generalized cost of drilling the exploration and production wellfield is given in Table IV-8 for 10,20 and $50 \mathrm{MW}$ developments for wells of 1,000 , $1,500,2,000,2,500$, and $3,000 \mathrm{~m}$ depth.

Based on Table IV-8, Table IV-9 presents the range of drilling costs per MW developed, in US\$/MW, again using $3 \mathrm{MW}$ per well as average yield. 


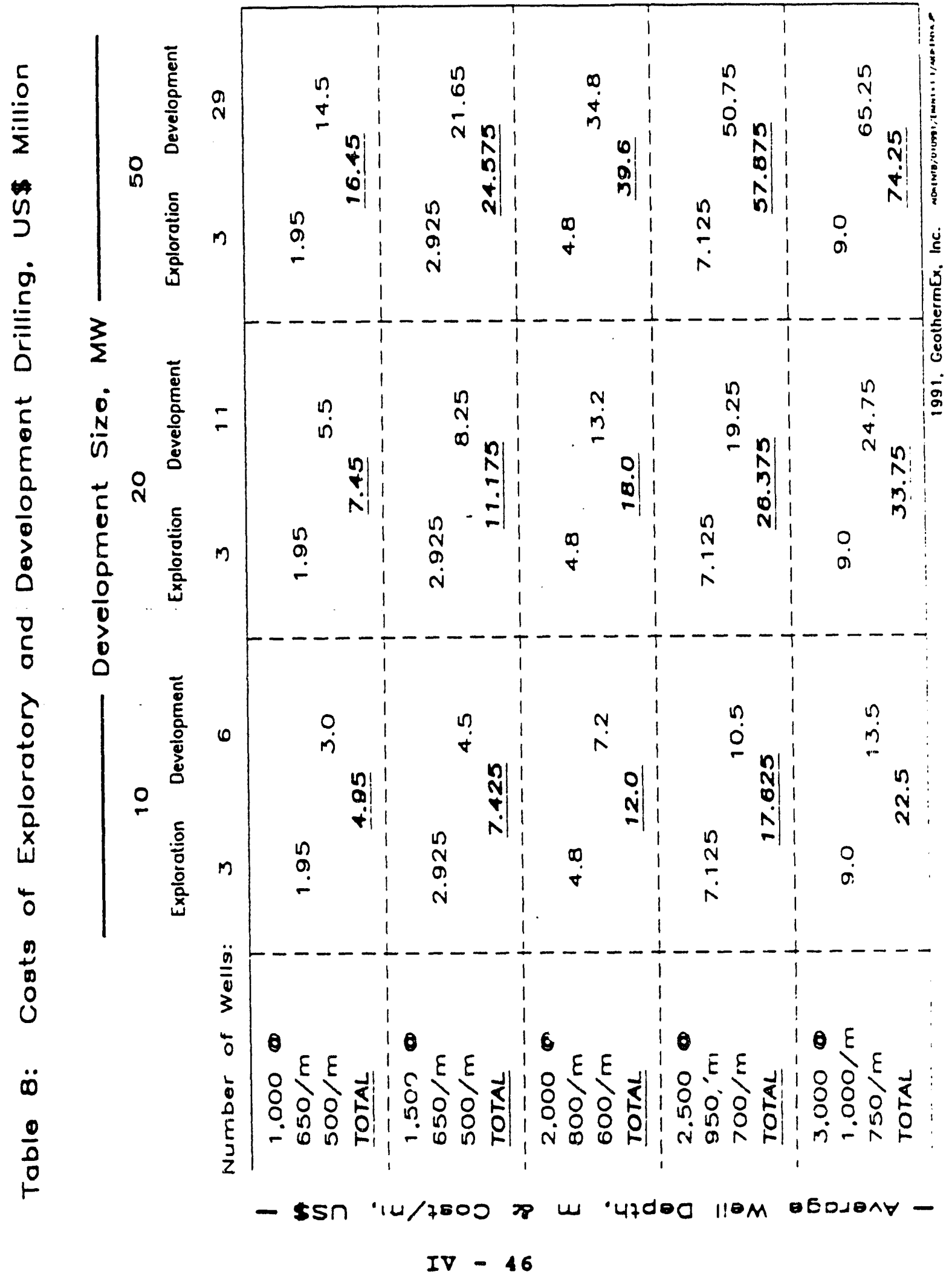


Table IV-9: Drilling Cost per MW Developed, at $3 \mathrm{MW} / \mathrm{We} 1 \mathrm{l}$ Average Yield, in USS/MW

Average Depth, m

1,000

1,500

2,000

2,500

3,000

10
450
743
1,200
1,763
2,250

Development Size, MW

20
373
559
900
1,319
1,688

50

329

429

792

1,158

1,485

Table IV-9 shows the great sensitivity of cost to well depth. It reinforces the desirability of developing a low-risk, large, relatively shallow prospect.

Water supply during the exploration drilling phase can be supplied by tank trucks from wells or rivers. During field development, either well(s) must be drilled on-site/close by, or a pipeline must be constructed from an existing permanent water source. A water well is estimated to cost about US\$100,000 including pump. Storage tanks cost perhaps another US\$100,000, erected. By contrast, a water pipeline may cost Us $\$ 100,000$ per $\mathrm{km}$, depending upon terrain, length and pumping requirements.

The testing and monitoring program necessary to prove the resource feasibility, plus the feasibility studies, and preparation of documents on system design bidding specifications, and contracts do not vary markedly by project size in the range 10 to $50 \mathrm{MW}$. For this report it is assumed that the cost increases by 0.2 for each $10 \mathrm{MW}$ increment above a basic $10 \mathrm{MW}$ unit size. Total cost therefore, is anticipated to be Us\$600,000 to 1,250,000 for projects of 10 to $50 \mathrm{MW}$ size.

Civil works, including road construction, pad and plant site grading, and construction of holding ponds, retaining walls and the like will vary widely with project size and location. Pad costs are about US\$20,000 per well; road construction is about US\$7,000 per $\mathrm{km}$ for unpaved, unsurfaced roads.

Environmental surveys and remedial work herein is budgeted at the same cost for every project, because the issues of erosion, waste discharges, change of land use, water consumption and loss of animal habitat are essentially similar across the Rift Valley. A cost of US\$100,000 is assumed for a $10 \mathrm{MW}$ project, increasing to about US\$250,000 for a $50 \mathrm{MW}$ project.

The pro rata costs of rig mobilization, water supply, site prepzation, road construction, environmental protection, and well testing and analysis operations ("non-drilling costs") are listed in Table IV-10. 
Table IV-10: Pro-Rata cost (USS) of Items Associated with Drilling ("Non-Drilling Costs") for 10,20 and $50 \mathrm{MW}$ Developments

\begin{tabular}{lc} 
Cost Item, USS & 10 \\
\cline { 2 - 2 } & \\
Mobilization & 700,000 \\
Site Preparation & 350,000 \\
Access Roads & 350,000 \\
Water Supply & 200,000 \\
Environmental & 100,000 \\
Testing \& Analysis & 600,000 \\
\cline { 2 - 2 } & \multicolumn{2}{c}{ Total } &
\end{tabular}

Number of holes drilled

Non-drilling cost

per hole

cost per $\mathrm{kW}$

\section{9}

255,000

230
Development size, MW

$\begin{array}{r}20 \\ 900,000 \\ 600,000 \\ 400,000 \\ 400,000 \\ 150,000 \\ 800,000 \\ \hline 3,250,000\end{array}$

50
$1,300,000$

$1,300,000$

500,000

750,000

250,000

$1,250,000$

$\frac{1,250,000}{5,350,000}$

These costs essentially are independent of reservoir depth and well yield. Applying these values to hypothetical 1,500 and $2,000 \mathrm{~m}$ deep reservoirs, with yields of $3 \mathrm{MW}$ per well, one obtains the total cost of wellfield for a prospect of average accessibility and complexity (Table IV-II).

Prospects located far to the north of Lake Baringo (including Namarunu, Emuruangogolak, silali and Paka of Group 1) will carry an additional cost penalty for road construction, rig mobilization, resupply and communications, and possibly for water supply. This cost penalty may range up to $20 \%$ to $50 \%$ of the nondriliing costs (again proportionately greater for the smaller developmer.t), which in turn ranges from under $12 \%$ to over $22 \%$ of total wellfield cost. By this methodology, a cost penalty of as much as $10 \%$ or $12 \%$ has been applied to development of the moreremote prospects.

Transmission-line cost will vary with distance and line voltage. In general, lines suitable to transport 50 to $100 \mathrm{MW}$ of electricity several tens of $\mathrm{km}$ at acceptable levels of loss ( 132 $\mathrm{kV}$ ) will cost about US\$70,000 per $\mathrm{km}$ (about $1.5 \mathrm{~km}$ of line and towers per US\$100,000 of budget). Lower voltage ines, suitable for smaller geothermal developments, will cost less: $62.5 \mathrm{kV}$ is about US $\$ 45,000$ per $\mathrm{km}$, and $33 \mathrm{kV}$ costs about US $\$ 30,000$ per $\mathrm{km}$. No provision is make for the costs to add or modify substations, to accommodate this electric power.

$$
\text { IV }-48
$$


Housing, offices, workshops and storage facilities will vary with project size, and to a lesser degree with the degree of project accessibility to other facilities. As a broad generalization, assuming $20 \mathrm{MW}$ as the basic unit size for development, the cost for every additional $20 \mathrm{MW}$ is assumed to be 0.25 additional to that of the basic unit cost. Thus, a $100 \mathrm{MW}$ development will require such support facilities at a cost 2.0 times that of a $20 \mathrm{MW}$ development.

Further, for remote fields, where no significant permanent settlement exists within about 10 or $15 \mathrm{~km}$, and where haulage and construction costs thus are higher, 0.5 has been added to the cost of support facilities for the first unit (Table IV-12).

\section{Operation Stage costs}

The cost of field operation consists of 5 major items:

a. Drilling of make-up or replacement wells, or the redriliting of existing wells: for a development of 10 to $50 \mathrm{MW}$ size, estimate one drilling operation every 3 years, at approximately Us $\$ 1,000,000$ per drilling for wells of 1,000 to $2,000 \mathrm{~m}$ depth, and perhaps Us $\$ 300,000$ for shallow (moderate-enthalpy) fields; there probably is some cost sensitivity to project size.

b. Maintenance of existing wells and gathering lines: for projects of 10 to $50 \mathrm{MW}$ size, assume US\$50,000 per well annually for labor, supplies and equipment to be used in testing, sampling, monitoring and routine maintenance operations; assume US\$100,000 per year for monitoring and maintenance of gathering and disposal lines; there probably is minor sensitivity to project size.

c. Office and warehouse operations: assume US\$200,000 per year for labor, supplies and equipment to be used in maintenance of documentation, telecommunications, reporting, and resupply; there is some cost-sensitivity to project size.

d. Connection of new wells into the system: again for 10 to $50 \mathrm{MW}$ development, assume US\$100,000 per well, once every 3 years.

e. Miscellaneous: exploration for ner resource areas; road maintenance; environmental or other remedial work; refurbishment of offices and equipment; purchase of vehicles and other equipment; assume US\$250,000 per year; there is some cost-sensitivity to project size. 
On the assumed basis of $3 \mathrm{MW}$ per well, allowing for injection and standby reserve wells and for minor costsensitivity as a. function of project size, a $10 \mathrm{MW}$ field operation would cost about US\$1.2 $\mathrm{mi}$. Iion annually, whereas a 50 MW field operation would cost approximately US\$1.6 million annually. 
Project time requirements will vary with location, accessibility, degree of prior work, complexity of reservoir, and development size. The time requirements can be evaluated best by dividing the project into 3 segments: exploration, wellfield development, power plant construction. Other factors, such as water-supply development, environmental protection, feasibility reporting, or construction of on-site housing, are carried out during one or more of the exploration, wellfield development and power plant construction phases.

It is not realistic to draw detailed chronograms showing step-by-step activities, because each prospect has unique characteristics that affect both time and cost. Some generalizations can be made, however, as follows:

\section{Exploration Timetable}

6 to 18 months will be required for all surface exploration, including the drilling of up to 6 slim holes for temperature observation purposes. The longer time will be required where access is difficult, no (or very limited) prior work has been accomplished, prospect area is large, and an obvious central focal point for drilling is lacking or obscured. In selected cases where access is good, existing data are adequate and drilling targets are clear, the temperature-gradient drilling can begin within one or two months of project initiation. In that situation, the smaller number ( 6 months) may be achievable. For the hypothetical average project, 10 months is used. If results are not encouraging, the project may be terminated at this point.

\section{Wellfield Development Timetable}

This stage may begin immediately upon completion of exploration, or may lag by some undetermined period of time, reflecting contingencies of permitting, finance and project management. An initial 3 wells will be drilled, to discover the resource and allow an initial quantification of the reservoir. This will be done regardless of ultimate project size. Depending again upon factors of location and accessibility, and presumed reservoir depth, a period of 8 to 12 months is estimated for siting and well design, road and pad preparation, selection of a driliing contractor, mobilizition, drilling, logging and testing of these 3 wells. Depending pon result, the project may be abandoned, or may continue into development driljing. However, it is assumed herein that we:lfield development will continue almost immediately after completion of the initial 3 wells.

Unlike exploration, development drilling is dependent upon the anticipated size of the power plant. Therefore, assuming hypothetical 10,20 and 50 N.W initial developments, at an average 
3 MW per well, the required time for all necessary drilling, testing and preparing feasibility reports is estimated to be as follows:

$$
\begin{aligned}
& 10 \mathrm{MW}: 12 \text { to } 18 \text { months (one rig) } \\
& 20 \mathrm{MW}: 24 \text { to } 36 \text { months (one rig) } \\
& 50 \mathrm{MW}: 34 \text { to } 50 \text { months (two rigs) }
\end{aligned}
$$

Concurrent with this, there may be construction of roads, the power plant site, housing for workers, and an office and workshop. There may be further surface exploration, or additional analytical studies. Prelininary power plant design, preparation of specifications, calls for bils on the power plant, and surveying transmission line right-of-way will begin long before the wellfield drilling is completed.

\section{Power plant construction Timetable}

Based on recent geothermal developments in the United States, Mexico and the Philippines, it is estimated that the final design, selection of manufacturer, manufacture, shipping, erection and acceptance testing of a power plant can be accomplished as follows:

$$
\begin{aligned}
& 10 \mathrm{MW}: 12 \text { to } 18 \text { months } \\
& 20 \mathrm{MW}: 18 \text { to } 24 \text { months } \\
& 50 \mathrm{MW}: 18 \text { to } 36 \text { months }
\end{aligned}
$$

This estimate is based on utilization of readily available ("offthe-shelf") and standardized power plants. No unusual design characteristics or unit sizes are anticipated.

The power plant stage would overlap broadly with the wellfield development, such that wellfield, transmission line, and other infra-structure would be completed essentially at the same time that the power plant is erected. Acceptance testing would follow immediately after the full interconnection of wells and plant.

\section{Summary}

From this outline, probable average timetables can be calculated (Table IV-13). It is assumed that wellfield development will follow immediately upon the exploration stage; and that the design and construction of a power plant will begin after 15 to 18 months of field development drilling, the exact time depending upon power plant size and reservoir complexity. 
Table IV-13: Anticipated Time Required for Average 10, 20 and $50 \mathrm{MW}$ Developments, Months

\begin{tabular}{|c|c|c|c|c|c|c|c|}
\hline \multicolumn{2}{|c|}{$\begin{array}{l}\text { Development } \\
\text { Size, MW }\end{array}$} & $\begin{array}{c}\text { Exploration, } \\
\text { months }\end{array}$ & \multirow{2}{*}{+} & \multirow{2}{*}{$\begin{array}{c}\begin{array}{c}\text { Initial } \\
\text { wellfield, } \\
\text { months }\end{array} \\
\frac{15}{15}\end{array}$} & \multirow{2}{*}{$\begin{array}{c}\text { Power } \\
\text { Plant, } \\
\text { months } \\
\begin{array}{c}15 \\
18\end{array}\end{array}$} & \multirow{2}{*}{$=$} & \multirow{2}{*}{$\begin{array}{r}\text { Total } \\
\text { months } \\
40 \\
51\end{array}$} \\
\hline 10 & $\begin{array}{l}\text { minimum } \\
\text { maximum }\end{array}$ & $\begin{array}{l}10 \\
18\end{array}$ & & & & & \\
\hline 20 & $\begin{array}{l}\text { minimum } \\
\text { maximum }\end{array}$ & $\begin{array}{l}10 \\
18\end{array}$ & & $\begin{array}{l}15 \\
18\end{array}$ & $\begin{array}{l}18 \\
24\end{array}$ & & $\begin{array}{l}43 \\
60\end{array}$ \\
\hline 50 & $\begin{array}{l}\text { minimum } \\
\text { maximum }\end{array}$ & $\begin{array}{l}10 \\
18\end{array}$ & & $\begin{array}{l}18 \\
21\end{array}$ & $\begin{array}{l}18 \\
30\end{array}$ & & $\begin{array}{l}46 \\
69\end{array}$ \\
\hline
\end{tabular}

These probable required times are not the absolute minimum values possible. That is, several months have been added into the welifield development phase beyond the absolute minimum, as a safety factor. Even with this safety factor, it is calculated that plants of $10 \mathrm{MW}$ can be brought on-line in 3-1/2 to 4 years from the initiation of exploration. Plants of $20 \mathrm{MW}$ size would be operating in under 5 years; and 50 MW plants would require less than 6 years from the initiation of exploration.

For prospects in advanced stages of exploration (such as Menengai or suswa) or exploratory driliing (Eburru) 6 to 20 months can be cut from these average time schedules.

It is assumed that the project will not be delayed because of regulatory, physical, environmental or financial constraints imposed within Kenya. Any undue constraints, relating to power pricing, land ownership, taxes or import duties, physical safety, or government decree could cause the project time to lengthen, perhaps significantly. Similarly, it is assumed that the project develnper is prepared to proceed from phase to phase without hesitation if results are favorable. 


\section{H. PROJECT RECOMMENDATIONS}

\section{Factors controlling Project cost}

Tables IV-3 and IV-4 assign priorities on the combined basis of potential resource size, risk, location and distance from transmission. Not surprisingly, Group $1 \mathrm{~A}$ prospects form 5 of the top 6 priorities in these tables, reflecting the importance assigned to (a) anticipated low risk and (b) potentially large resource size.

Each prospect has a different range of anticipated exploration/development costs, reflecting location and accessibility, anticipated resource characteristics, and degree of prior exploration. These costs are described in section 6 . In Table IV-14, the factors affecting cost are compiled for 15 of the 19 prospects listed in Tables IV-3 and IV-4 (4 very remote or environmentally protected sites are omitted). These factors are:

Size of possible initial power plant. There is great costsensitivity to power plant size. Therefore, those prospects having a resource potential of only $10 \mathrm{MW}$ are at a disadvantage to those having significantly greater resource potential, all other things being equal. In Table IV-14, a probable plant size $(10,20$ or $50 \mathrm{MW})$ is assigned to each of the 15 prospects on the basis of existing resource data. $50 \mathrm{MW}$ is anticipated for suswa, Korosi, Paka and Silali; Eburru, Longonot, Menengai, Arus, Olobonita and Chepchok are assumed to be $20 \mathrm{MW}$; all others are 10 MW.

Probable reservoir temperature. Prospects with probable temperatures of $180^{\circ} \mathrm{C}$ or less will be developed by binary-cycle methodology. Those with temperatures over about $210^{\circ} \mathrm{C}$ can effectively be developed by the flash-steam methodology.

Prospects having temperatures between about $180^{\circ}$ and $210^{\circ} \mathrm{C}$ can utilize flash-steam process, but at a distinct cost disadvantage relative to either higher-temperature (flash) or lowertemperature (binary) fields. Indeed, a $10 \mathrm{MW}$ binary-cycle plant for a reservoir of $165^{\circ}-180^{\circ} \mathrm{C}$ yielding about $3 \mathrm{MW}$ per well apparently is cost-competitive with $10 \mathrm{MW}$ flash-steam plants at reservoirs of up to $300^{\circ} \mathrm{C}$.

Drilling deptr. Yield per well and drilling success rates have been discussec previously. Because of very limited reservoir data, these factors are held constant for all prospects under consideration. Therefore, wellfield cost will vary principally with well depth. Probable drilling depths from 1,000 to 1,750 $\mathrm{m}$ have been assigned to each prospect. 
Transmission distance. As discussed previously, prospect distance from the KPLC grid varies from a few $\mathrm{km}$ to over $100 \mathrm{~km}$. Prospects on islands or at sites over $100 \mathrm{~km}$ from the grid have been eliminated from further consideration. At the lake Magadi prospect, the soda ash plant and local population is considered as a possible market for up to $10 \mathrm{MW}$; therefore, the transmission distance of only $15 \mathrm{~km}$ is used. All other prospects are assumed to supply the grid.

prior Exploration. The extent and effectiveness of previous exploration activities (geologic mapping, gravimetry, fluid geochemistry, logging of existing wells, drilling of temperaturegradient holes, etc.) has varied widely. A cost penalty has been charged against Korosi, Paka, Silali, Chepchok, Loruk, Homa Mountain, Mwananyamala and Kapedo/Lorusio. There has been a deduction from exploration cost at Eburru, Suswa, Longonot and Lake Magadi, where target selection can proceed rapidly and without much further work. Menengai, Arus and olobonita are not affected.

Remoteness of prospect. Prospects lacking road access, permanent water supply, or easy access to a town and/or supply facilities will experience increases in overall project costs. Additional roads, camps, and water tanks or pipelines will have to be built. Distance from towns, and especialiy from Nairobi, will result in costly additional travel on the part of all project workers and suppliers. Silali and Paka are penalized the most for remoteness, followed by Korosi, and then by Chepchok and longonot. Menengai, Eburru and Lake Magadi are given a cost deduction because of their close proximity to necessary facilities. Other prospects are unaffected.

operational complexity. A variety of factors that can make exploration, drilling and development more complex, and therefore more costly, includes geologic complexity, terrain roughness within the prospect, prospect size, and environmental constraints. The cost penalty principally reflects the additional months of operations necessitated by these factors. Suswa, Korosi, Paka and Silali in Group $1 \mathrm{~A}$, Longonot and Menengai in Group 1B, Olobonita in Group 2, and Homa Mountain, Mwananyamala and Kapedo/Lorusio in Group $3 \mathrm{~A}$ are penalized. 
Table IV-14. Factors Affecting Exploration and Development Cost
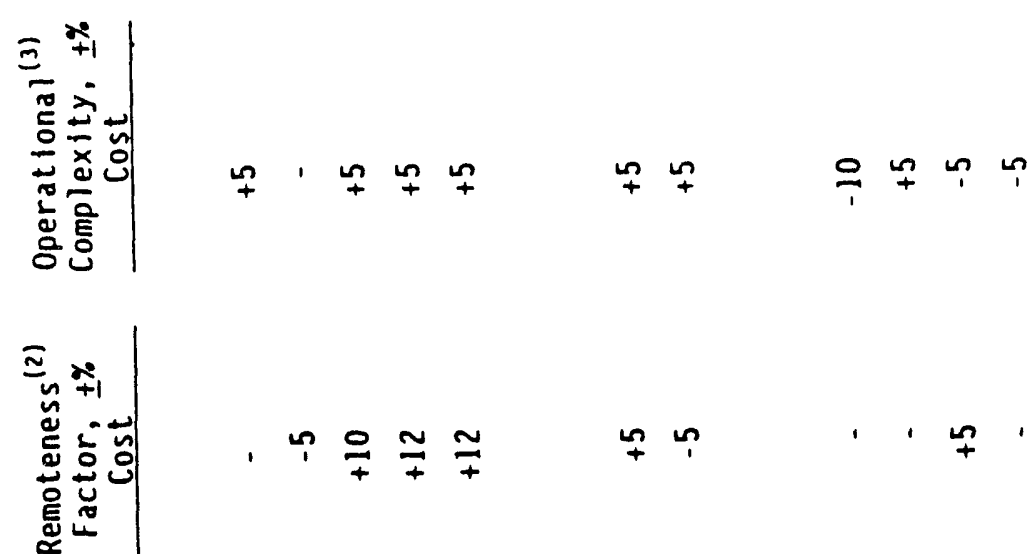

$\because \cong \cong \dddot{1}$

$\stackrel{n}{\sim}$

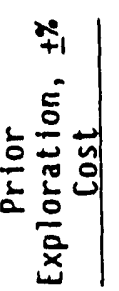

?. $1, \pm$

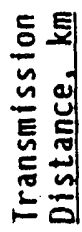

용ㅇㅇㅇㅛ 응

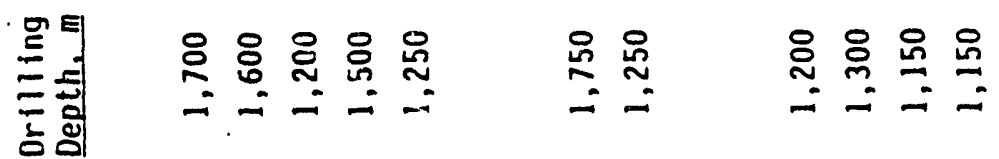

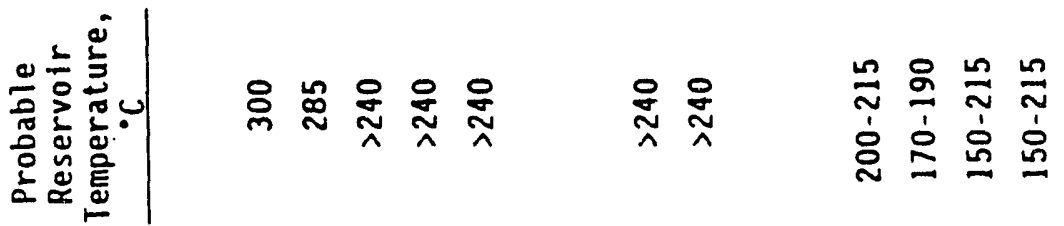

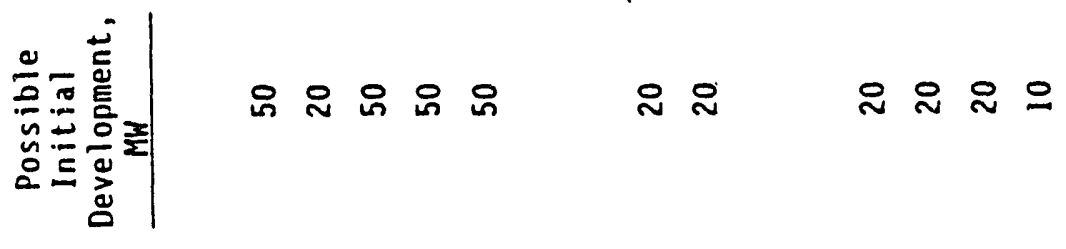

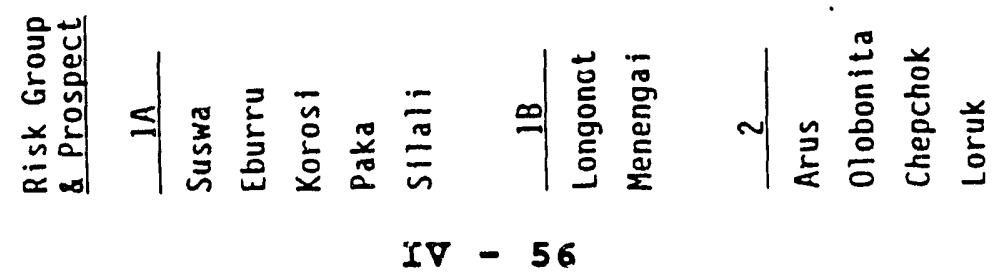


Table IV-14. Factors Affecting Exploration and Development Cost (continued)
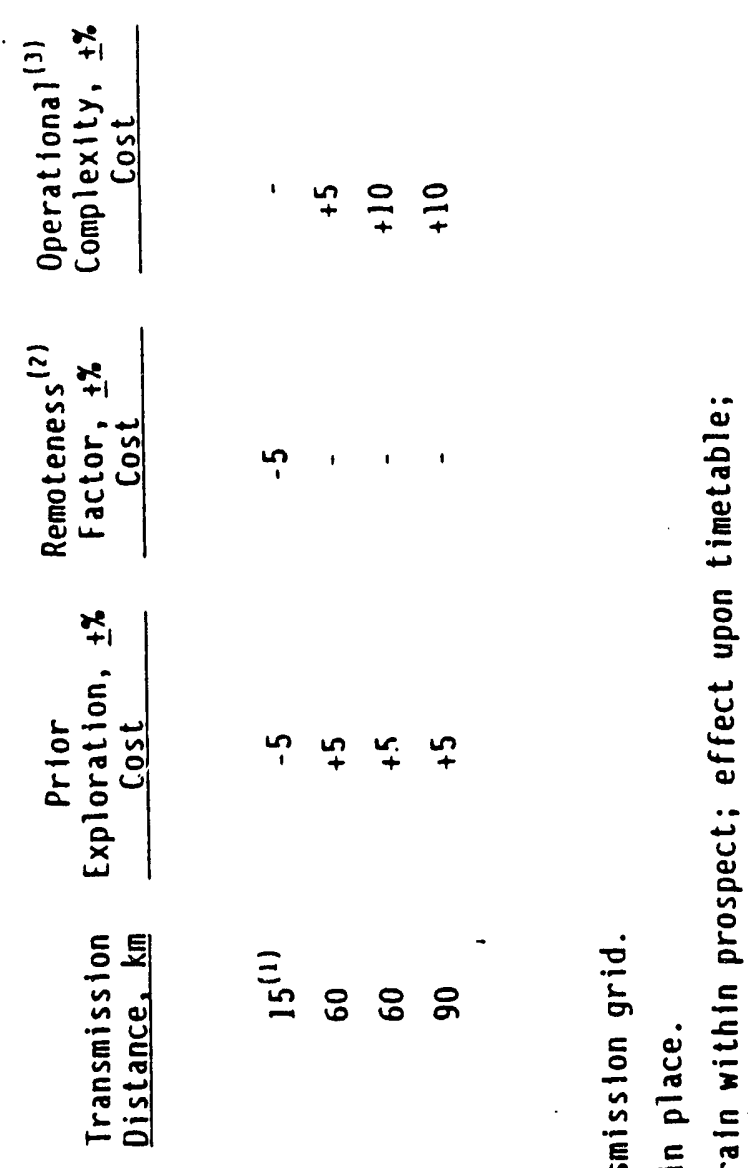

틈유
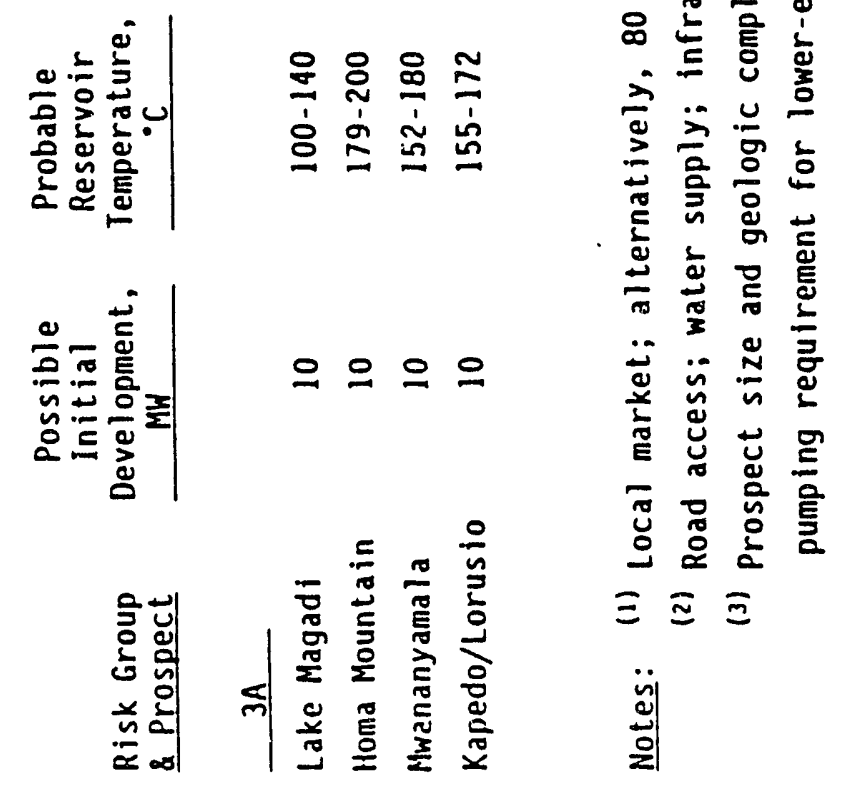

$$
I \nabla-57
$$




\section{Calculation of cost Per Prospect}

For each of the 15 remaining prospects, cost has been calculated on the following basis:

Exploration: The basic exploration cost (see section IV-E2) is applied to each prospect; this cost is increased or reduced to reflect prior exploration activity, as indicated in Table IV-14.

Wellfield Development: This includes drilling and non-drilling (roads, mobilization, well testing, etc.) components. Drilling cost is a function of project size $(10,20$ or $50 \mathrm{MW})$ and well depth, whereas non-drilling costs are a function only of project size (see section IV-E). All drilling is presumed to cost US\$650/m for the initial 3 exploratory wells, and US\$500/m thereafter, as shown in Table IV-8. To this is applied a penalty (or, in a few cases, a cost reduction) of up to $17 \%$ for prospect remoteness and operational complexity.

Power Plant Construction: Power plant cost, as determined by The Ben Holt Company, is a function of plant size, resource temperature and generation mode (binary or flash cycle). It is noted, however, that cost will vary widely for prospects in the temperature range $1800-2200 \mathrm{C}$ depending upon -generation mode. The present assumption is that flash-cycle generation will be used, because of the temperatures expected. If, however, fluids of $165^{\circ}-180^{\circ} \mathrm{C}$ are produced at certain prospects (Chepchok and Loruk for example), instead of $180^{\circ}-2100 \mathrm{C}$, power plant costs could be higher than those shown in these scenarios. Alternatively, if temperature reaches $215^{\circ} \mathrm{C}$ (for example at Arus), power plant costs may be reduced somewhat. These values, taken from Ben Holt, are summarized in Table IV-15.

Transmission Lines: Costs are based on average Kenya costs for a $132 \mathrm{kV}$ line, without regard to any special terrain or environmental factors. It is recognized that a $132 \mathrm{kV}$ line may not be needed initially at every prospect, but this is not factored into the cost estimate.

Gathering system: The cost of the steam-gathering and disposal pipelines, and auxiliary equipment, has been determined by The Ben Holt Company for 10,20 and $50 \mathrm{MW}$ power plants based on comparable developments in the United States and elsewhere.

Owner's cost and Financing charges: This includes project management cost, cost of constructing support facilities, permitting and licensing fees, and finance charges during wellfield and power plant construction. These cost data are provided by The Ben Holt Company. However, the costs of feasibility reports have already been included under wellfield development, and are not repeated herein. A cost penalty of

$$
I \nabla-58
$$


about 128 is applied to the more remote sites, for which additional lead-time (and therefore additional financing costs) are required.

Table IV-15. Cost of Power Plant, USS Million and USS/kW

\section{Power Plant Size, MW}

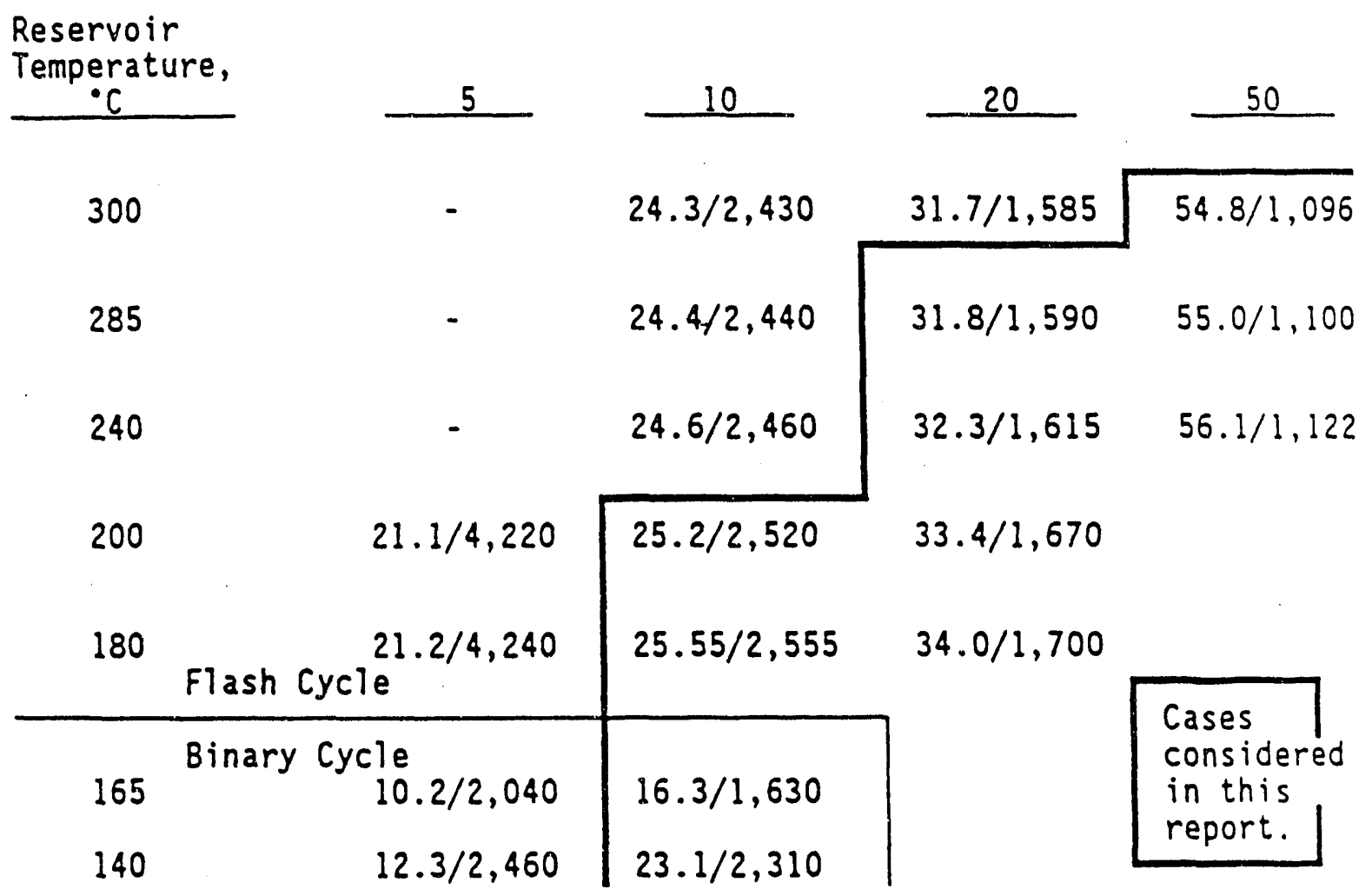


Table IV-16. Total cost (USS), Cost Per $\mathrm{kW}$ (USS/kW), and Ranking for Development
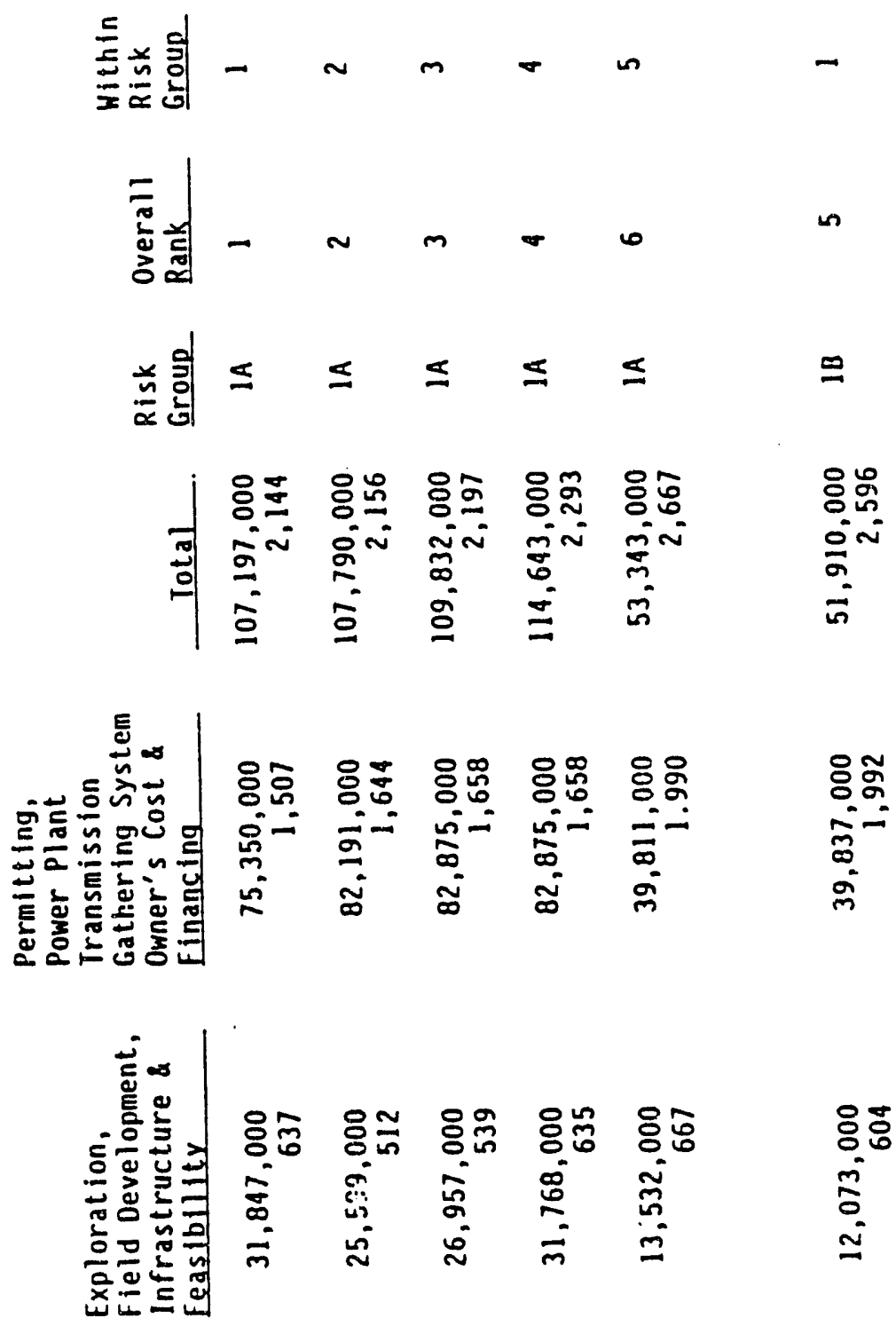

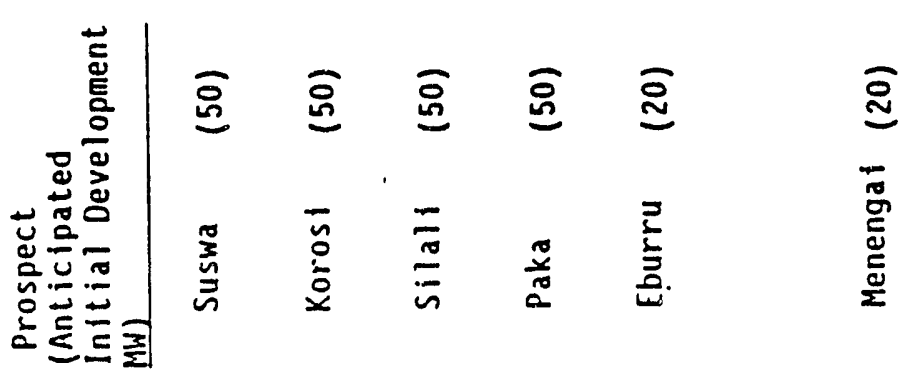


Table IV-16. Total cost (USS), Cost Per kW (USS/kW), and Ranking for Development (continued)
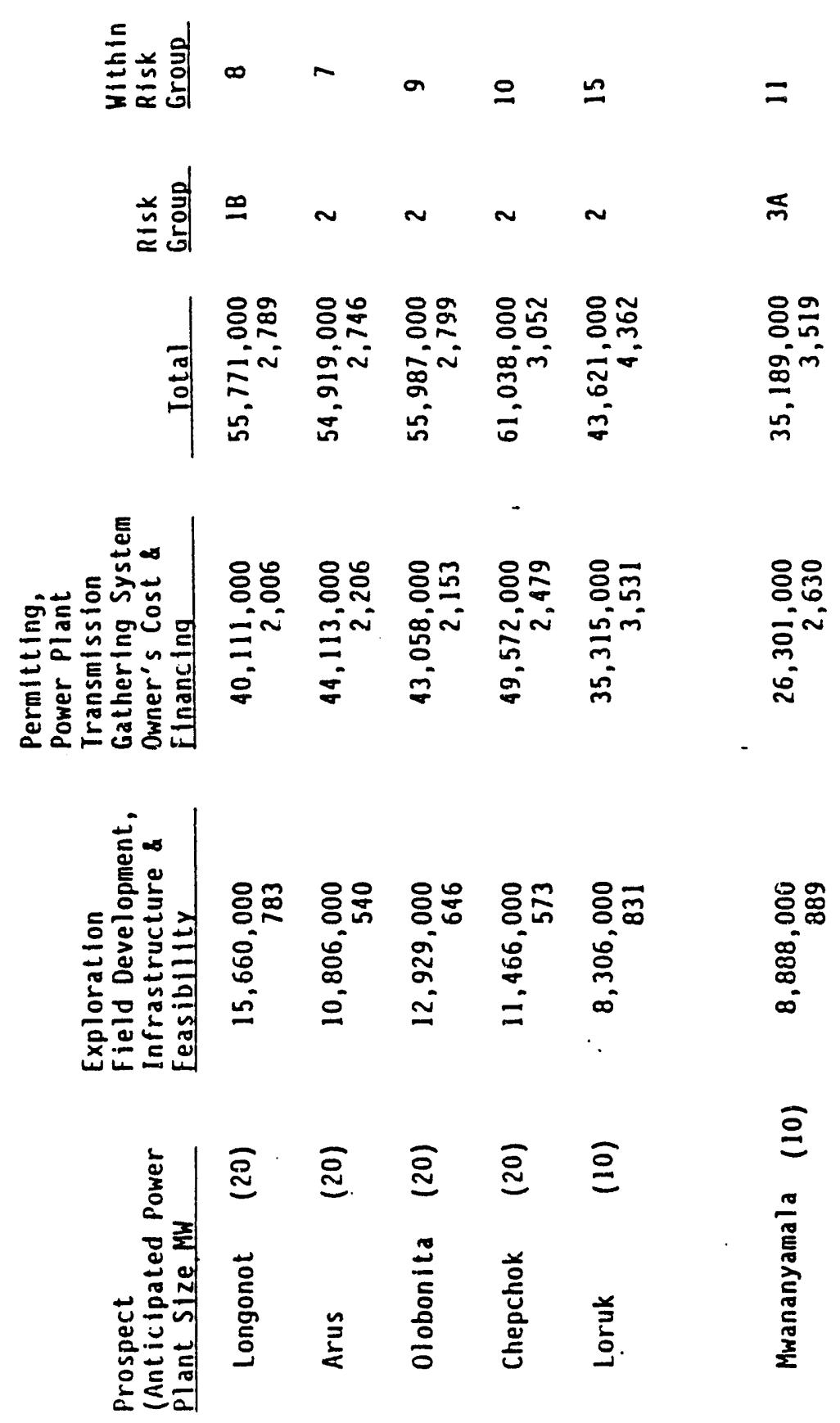
Table IV-16. Total cost (USS), Cost Per kW (USS/kW), and Ranking for Development (continued)
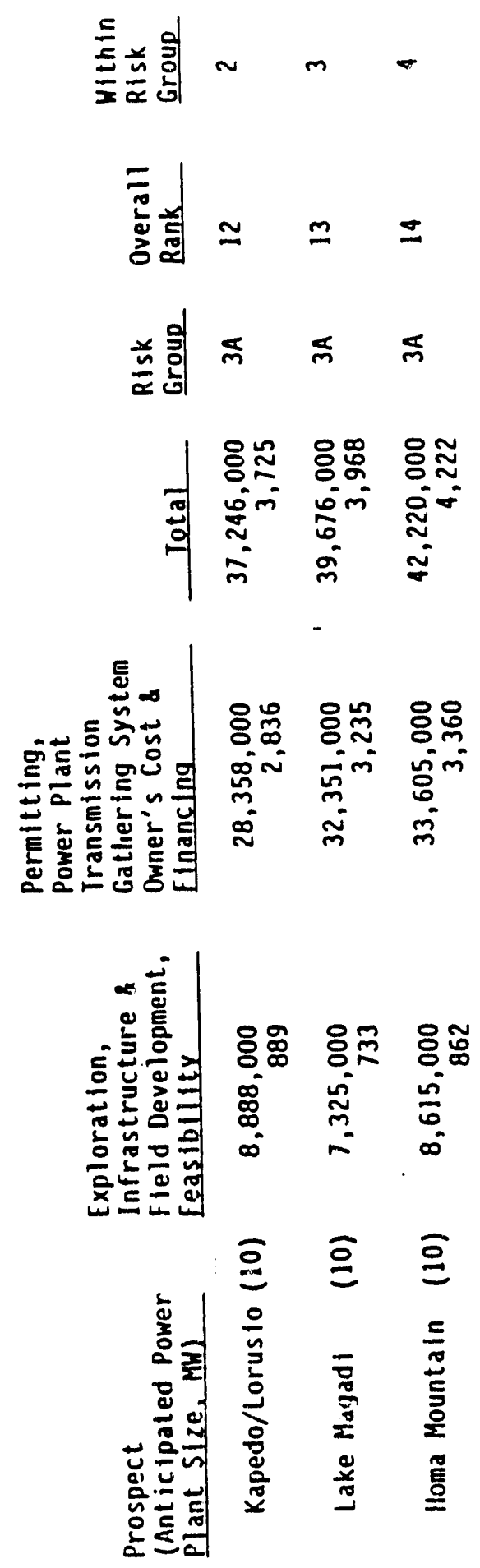
These costs have been tabulated for each of the surviving 15 prospects in Table IV-16, under 3 categories: (a) costs relating to exploration, wellfield development, infrastructural development and feasibility reporting; (b) costs of permitting and licensing, power plant, transmission line, steam-gathering and disposal system, project management and finance charges during construction; and (c) total project cost. Costs are expressed in millions of US\$ and as US\$ per $\mathrm{kW}$ installed, for the sizes of power plant determined in Table IV-15.

It can be seen that:

1. Costs per $\mathrm{kW}$ are significantly lower for $20 \mathrm{MW}$ than for $10 \mathrm{MW}$, and are lowest for $50 \mathrm{MW}$ projects. This places the smaller, riskier prospects of Group $3 \mathrm{~A}$ at a further disadvantage, and emphasizes the attraction of a potentially large resource.

2. Within each risk group (with the exception of Loruk, in Group 2), there is a maximum spread in cost per $\mathrm{kW}$ of about 25\%; most prospects fall within a cost range of about $10 \%$ within their risk group. This percentage probably falls within the range of uncertainty associated with sucil factors as well depth, or with the cost surcharges for remoteness and operational complexity. This means that within each risk group subjective preference (based on experience elsewhere) may be the determining factor in selecting a prospect for development.

3. The critical cost parameters appear to be transmissionline distance, well depth, and resource size and risk. Therefore, the riskier prospects within Groups 2 and $3 \mathrm{~A}$ can be considered only if well depth is anticipated to be shallow, and/or transmission distance is short.

4. The ideal prospect combines low risk (Group 1A or 1B) with large potential (50 MW power plant), shallow depth to reservoir and proximity to the transmission grid. No prospect fully meets these criteria. Suswa (lowest cost per $\mathrm{kW}$ ) may come closest.

5. A project may be abandoned short of completion, perhaps even before drilling a significant number of exploration wells. Therefore, a minimum-risk strategy involves selection of the prospect(s) having the lowest cost and least operational complexity through the exploration stage, or through the exploration and initial drilling phase. The projects having lowest exploration and initial drilling costs include lake Magadi, Arus, Eburru and (perhaps) Menengai. However, Lake Magadi is a small-size, low-temperature (to $140^{\circ} \mathrm{C}$ ) 
and high-risk prospect; Arus may be small and perhaps only of moderate temperature (to $215^{\circ} \mathrm{C}$ ); Eburru has had disappointing drilling results to date; and Menengai does not present an immediately recognizable drilling target, thus requiring further exploration.

6. Costs for the least expensive prospects appear to be compatible with those of major geothermal fields in the United states and elsewhere. Cost trade-offs occur from country to country over such factors as well depth, prospect accessibility, environmental sensitivity, well yield, and existence of support infrastructure.

7. Only in 1 case does a Group 2 prospect appear to have lower development cost than a Group 1 prospect: Arus appears to be slightly easier (and therefore cheaper) to develop than Longonot. Both developments are anticipated to be $20 \mathrm{MW}$.

\section{Favorable and Negative Aspects of Each Prospect}

The favorable and negative aspects of each prospect are summarized by risk group in the following table:

Prospect (MW)

Comments

Group 1 A

Suswa (50)

Korosi (50)

Lowest anticipated cost per $\mathrm{kW}$; accessible; probable very high-temperature resource; potentially very large; deep water table, therefore deep and costly drilling; no drilling target yet identified; moderate transmission distance; possible "fast-track" development timetable.

Low anticipated cost per $\mathrm{kw}$; remote and poorly accessible; probable high-temperature resource; potentially very large; probable moderate well depth; no drilling target yet identified; long transmission distance; not on "fast-track" timetable.

Silali (50)

Low anticipated cost per $\mathrm{kW}$; remote and poorly accessible; probable high-temperature resource: potentially very large; probable moderate well depth; no drilling target yet identified; very large transmission distance; not on "fast-track" timetable. 
Paka (50)

Eburru (20)

Group 1B

Menengai (20)

Longonot (20)

Group 2

Arus (20)

Olobonita (20)
Low anticipated cost per $\mathrm{kW}$; remote and poorly accessible; probable high-temperature resource; potentially very large; moderately deep drilling anticipated; no drilling target yet identified; very long transmission distance; not on "fast-track" timetable.

Moderate anticipated cost per $\mathrm{kW}$; accessible; largely explored; disappointing results in drilling; several drilling targets remaining, many at lower elevations; moderate to large resource potential; moderate to deep drilling; short transmission distance; possible "fast-track" timetable.

Moderate anticipated cost per $\mathrm{kW}$; accessible, but operationally may be complex; partially explored; probable high-temperature resource; moderate to large resource potential; probable moderate well depth; no drilling target yet identified; very short transmission distance; possible "fast-track" timetable.

Moderate anticipated cost per $\mathrm{kW}$; moderately accessible; probable high-temperature resource; moderate to large resource potential; probable great drilling depth; no drilling target yet identified; very short transmission distance; possibly on "fasttrack" timetable.

Moderate anticipated cost per MW; accessible; not operationaliy complex; probable moderate to high resource temperature; moderate resource potential; probable moderate drilling depth; drilling target easily identified; medium transmission distance; probable "fast-track" timetable.

Moderate anticipated cost per MW; accessible; possibly operationally complex; possible moderate to high resnurce temperature; moderate resource potential; probable moderate drilling depth; no drilling target yet identified; short transmission distance; probably not on "fast-track" timetable. 
Chepchok (20)

Loruk (10)

\section{Group 3A}

Mwananyamala (10)

Kapedo/Lorusio

Lake Magadi (10)

Homa Mountain (10)
Moderately high anticipated cost per MW; cost might be lower with binary cycle; remote and poorly accessible; probable moderatetemperature resource; shallow drilling anticipated; probable moderate resource size; no drilling target identified; very long transmission distance; not on "East-track" timetable.

Highest anticipated cost per $\mathrm{MW} ;$ cost might be lower with binary cycle; accessible, but poorly defined; probable moderate resource temperature; shallow drilling anticipated; resource size may be small; long transmission distance; not on "fast-track" timetable.

High anticipated cost per $\mathrm{kw}$; accessible, but not explored; potentially moderatetemperature resource; size may be small; drilling may be shallow; no drilling target yet identified; moderately long transmission distance; not. on "fast-track" timetable.

(10) High anticipated cost per kW; accessible, but probably operationally complex; potentially moderate-temperature resource; size may be small; drilling may be shallow; no drilling target yet identified; long transmission distance; not on "fast-track" timetable.

High anticipated cost per $\mathrm{kW}$; accessible and well explored; moderate to low-temperature resource; may be small in size; drilling probably shallow; drilling target easily identified; short transmission distance to local market; otherwise moderately long transmission; possible "fast-track" timetable for local market.

Very high anticipated cost per $\mathrm{kW}$; cost might be lower with binary cycle; accessible, but operationally may be complex; probable moderate- temperature resource; size may be small; probable shallow drilling depth; no drilling target yet identified; not on "fasttrack" timetable. 


\section{Project Recommendations}

Based in the foregoing, the following recommendations are offered, in approximate decreasing order of attractiveness:
a.
Suswa presents an attractive possibility of a large, rapidy explored and developable (but deep) resource.
b. Eburru offers an opportunity for inmediate drilling and development of a resource of moderate potential.
c. Arus offers an opportunity for immediate drilling into a potential resource of moderate potential.
d. Menengai presents a less-immediate but potentially attractive opportunity for discovery of a moderate to large resource. temperature resources, requiring costly and time- consuming efforts to discover and develop.
e. Korosi, Paka and silali probably are large, high-
f. No other site is immediately attractive for investment.
9. Lake Magadi would become attractive for immediate drilling if an adequate local market for electricity can be assured. 


\section{REFERENCES}

Allen, D. J., W. G. Darling and W. G. Burgess, 1989, Geothermics and hydrogeology of the southern part of the Kenya Rift Valley with emphasis on the Magadi-Nakuru area: British Geological Survey Research Report SD/89/1, Hydrogeology Series, $68 \mathrm{pp}+$ appendices.

Armannsson, H., 1987, studies on the Geochemistry of steam in the suswa and Longonot areas and water in the lake Magadi, Kedong Valley and Lake Turkana Areas, Rift Valley, Kenya: report prepared for United Nations Project $\mathrm{KEN} / 82 / 002$.

Baker, B.H., 1958, Geology of the Magadi area: Geological Survey of Kenya Report No. 42, 8I pp.

Baker, B.H., 1963, Geology of the area south of Lake Magadi: Geological Survey of Kenya Report No. 61, 27 pp.

Baker B.H., P.A. Mohr and I.A.J. Williams, 1972, Geology of the Eastern Rift system of Africa: Geological Society of America Special Paper 136, 67 pp.

Baticci, G, 1987, Thermal Conditions of the central-southern sector of the Kenya Rift Valley from the data collected in the boreholes drilled for water, report prepared for United Nations Project KEN/82/002, $41 \mathrm{pp}+$ appendices.

Bosworth, W. 1987, Off-axis volcanism in the Gregory Rift, East Africa: implications for models of continental rifting: Geology, vol. 15, pp 397-400.

Darling, W.G., D.J. Allen and H. Armannsson, 1990, Indirect detection of subsurface outflows from a Rift Valley lake: Journal of Hydrology, vol. 113, pp 297-305.

Dunkelman, T.J., J.A. Karson and B.R. Rosendahl, 1988, Structural style of the Turkana Rift, Kenya: Geology, vol.16, pp 258-261.

Geothermica Italiana srl, 1989, Geothermal exploration in the Kenya Rift Valley, areas of Menengai and Suswa-Longonot; synthesis and project development: report prepared for United Nations Project KEN/82/002.

Henry, W.J., J. Mechie, P.K.H. Maguire, M.A. Khan, C. Prodehl, G.R. Keller and J. Patel, 1990, A seismic 
Henry, W.J., J. Mechie, P.K.H. Maguire, M.A. Khan, C. Prodehl, G.R. Keller and J. Patel, 1990, A seismic investigation of the Kenya Rift Valley: Geophysics Journal International, vol. 100, pp 107-130.

Hackman, B.D., 1988, Geology of the Baringo-Laikipia area: Kenya Mines and Geology Department Report 104, 79 pp.

Key, R.M., 1987, Geology of the Maralal area: Kenya Mines and Geology Department Report 105, 93 pp.

Leat, P.T., 1984, Geological evolution of the trachytic caldera volcano Menengai, Kenya Rift Valley: Geological Society of London Journal, vol. 141, pp 1057-1069.

McCall, G.J.H., 1967, Geology of the Nakuru-Thomson's Falls - Lake Hannington Area: Geological Survey of Kenya Report No. $78,122 \mathrm{pp}$.

Mccall, G.J.H. and C.M. Bristow, 1964, An introductory account of Suswa Volcano, Kenya: Geological survey of Kenya Report No. 97.

Mcconnell, R.B., 1972, Geological Development of the rift system of Eastern Africa: Geological Society of America Bulletin, vol. 83, pp 2549-2572.

Morgan, P. and J. Wheildoll, 1979, Heat flow measurements across the Kenya rift: unpublished report, $24 \mathrm{pp}$.

Morley, C.K., 1989, Extension, detachments, and sedimentation in continental rifts (with particular reference to East Africa): Tectonics, vol. 8, pp 1175-1192.

ochieng, J.O., A.F. Wilkinson, J. Kagasi and S. Kimomo, 1988, Geology of the Loiyangalani area: Kenya Mines and Geology Department Report 107, $53 \mathrm{pp}$.

Thompson, A.O. and R.G. Dobson, 19.63, Geology of the Naivasha area: Geological Survey of Kenya Report No. 55, 80 pp.

Tole, M.P., 1986, Geochemical studies of low enthalpy geothermal areas of Kenya: report prepared for United Nations Project KEN/82/002.

Tole, M. P.: 1990, Chemical geothermometry and resource potential of low enthalpy geothermal systems in Kenya: Geothermal Resources Council Transactions, Vol. 14, part 1 , pp 187-193. 
Williams, I.A.J., 1969, Geochemistry and petrogenesis of the Kilimanjaro volcanic rocks of the Amboseli area, Kenya:

Bulletin Volcanologique, Tome XXXIII-3, pp 862-883.

Williams, I.A.J., 1970, The volcanics of the Gregory Rift Valley, East Africa: Bulletin Volcanologique, Tome XXXIV-2, pp $439-465$. 
Figure IV-1. Generalized Geologic Map of Kenya.

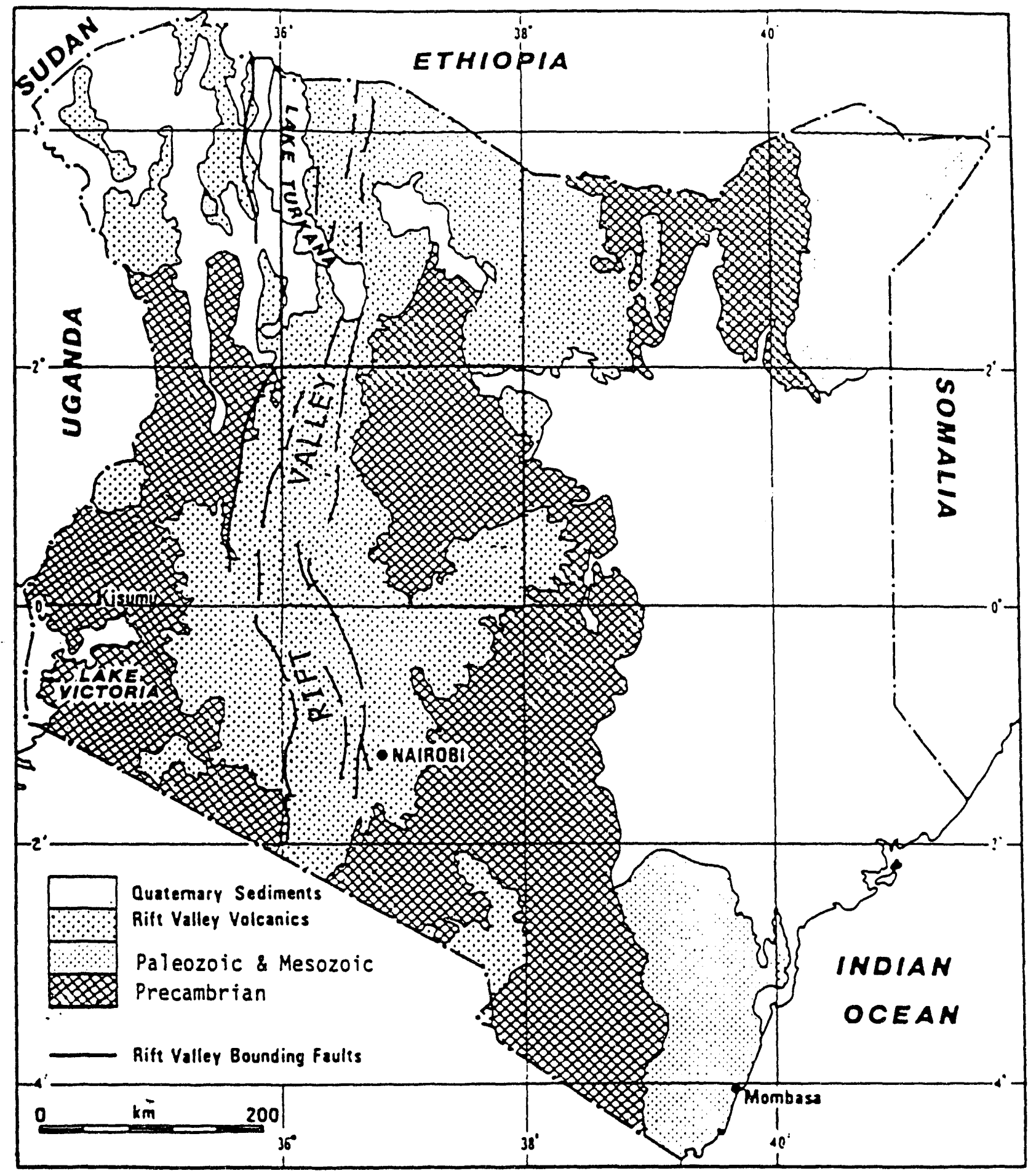


Figure IV-2. The East African Rift System.

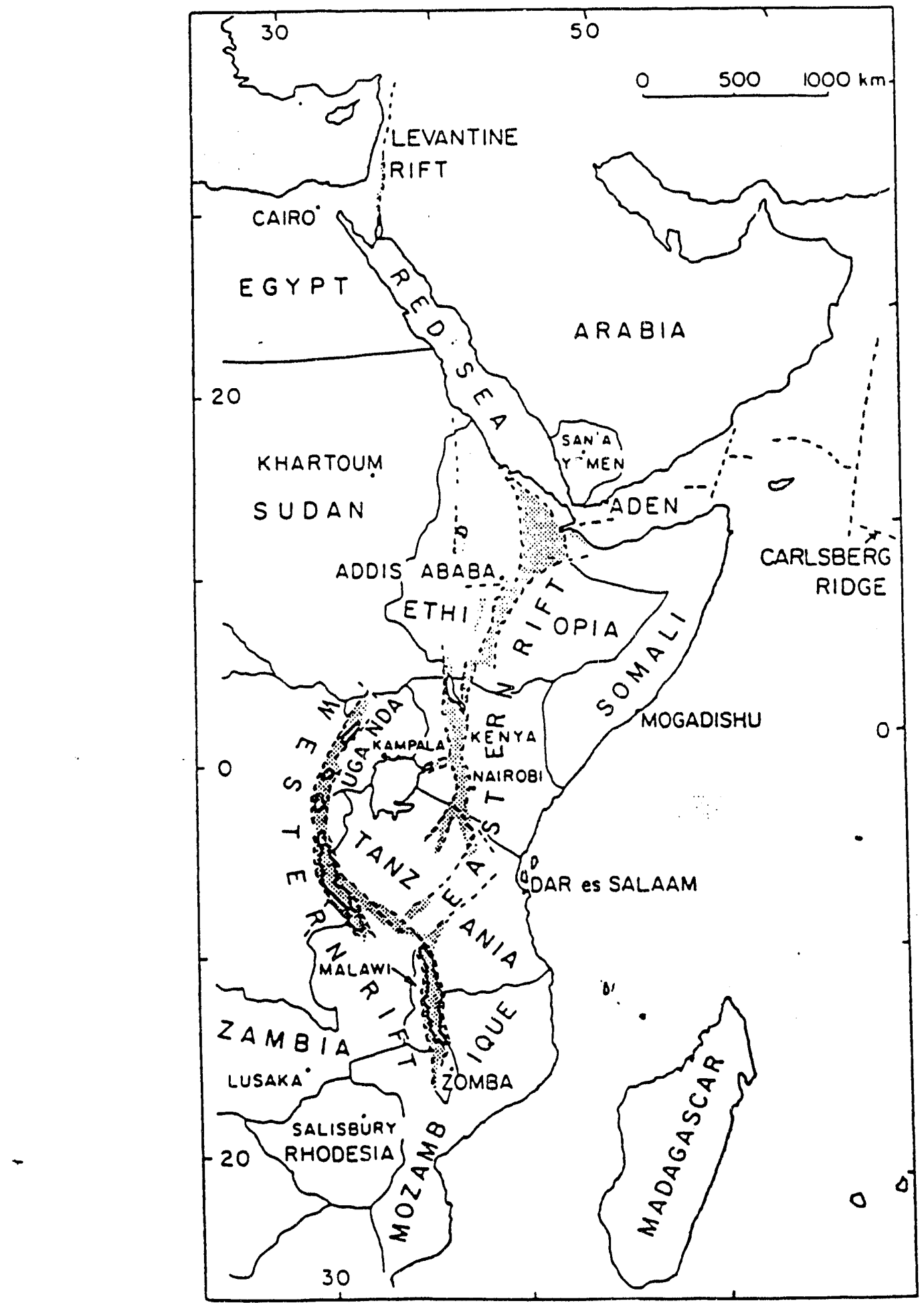


Figure IV-3. Geological Map of the Kenya Rift.

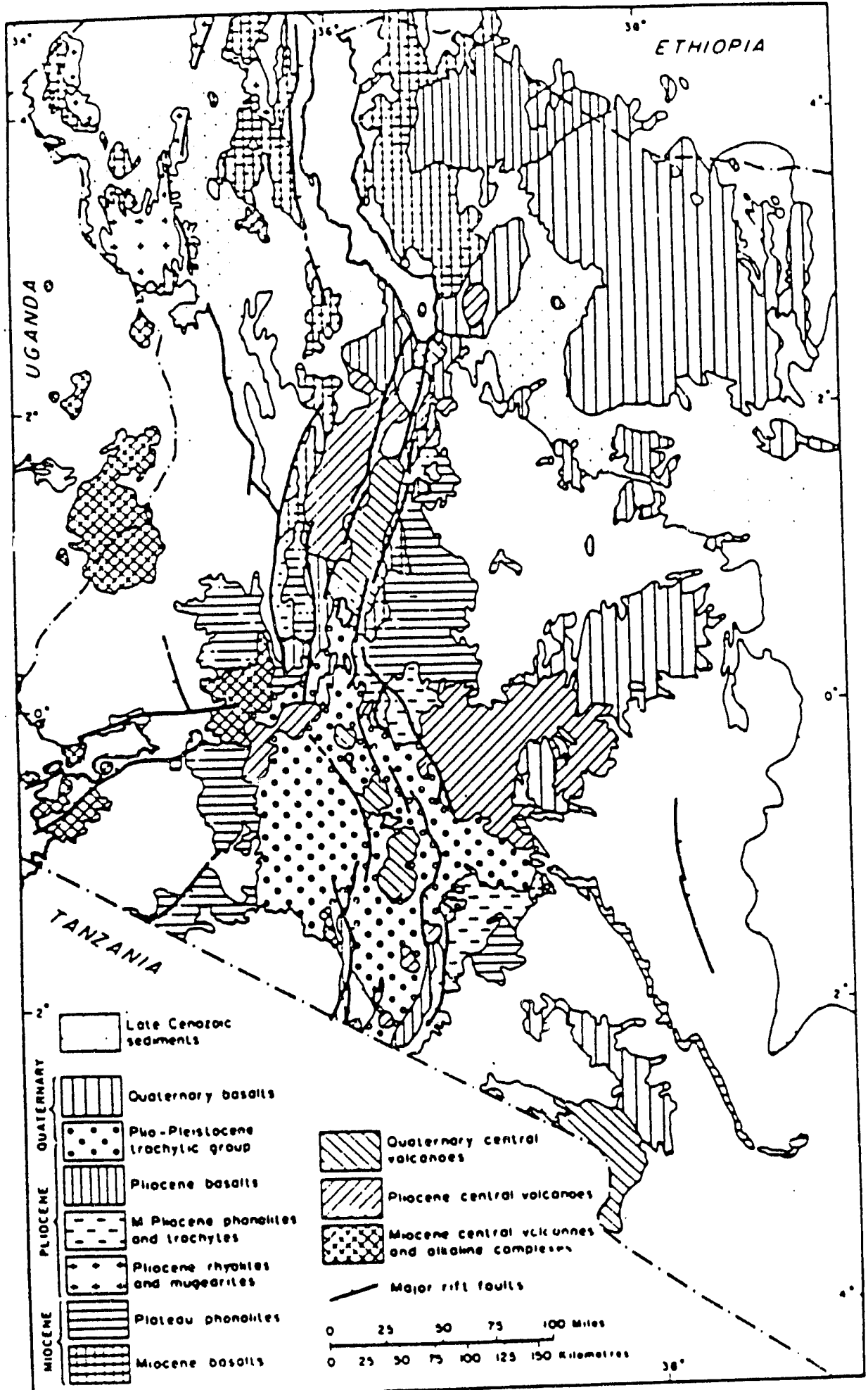


Figure IV-4. Fault pattern of the Rift Valley.

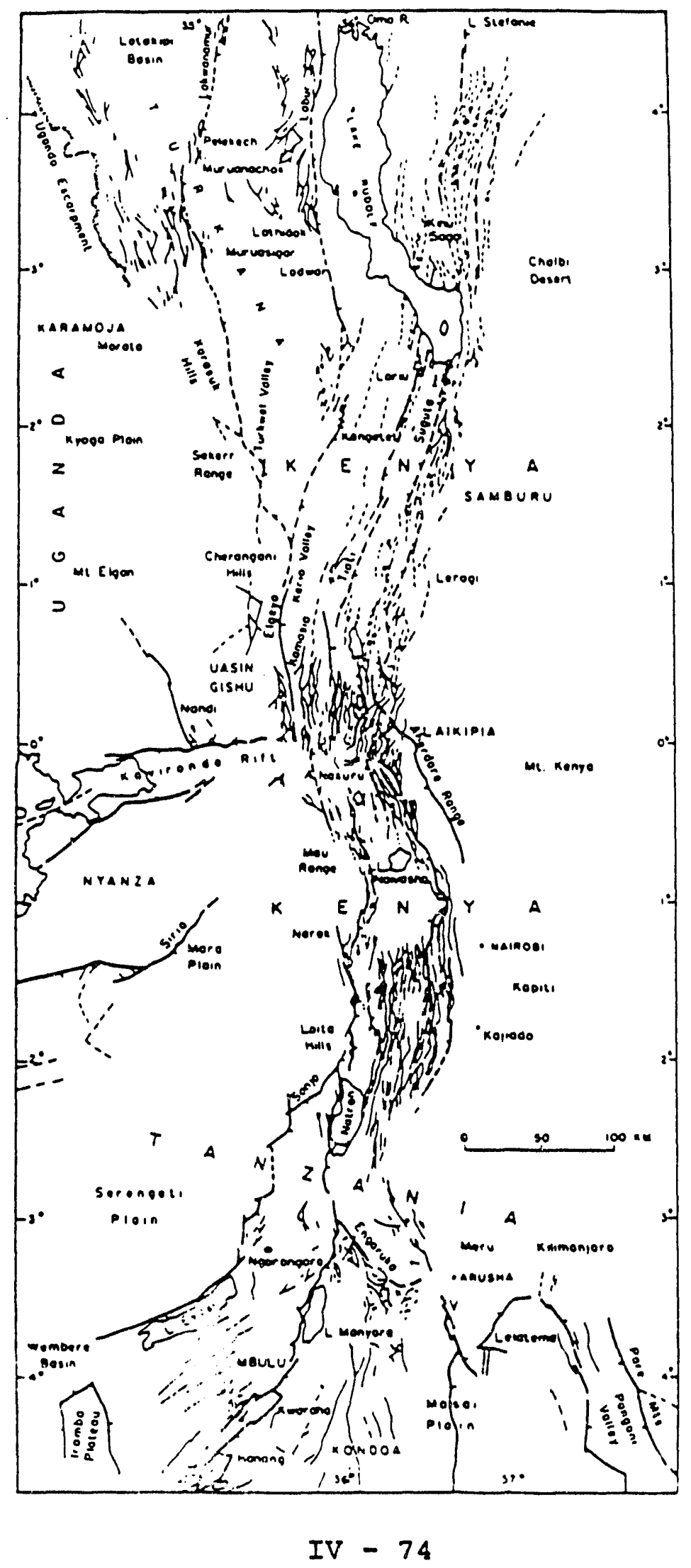


Figure IV-5. Map Showing the Distribution of the Main Volcanic Associations in Kenya, Eastern Uganda and Northern Tanzania.
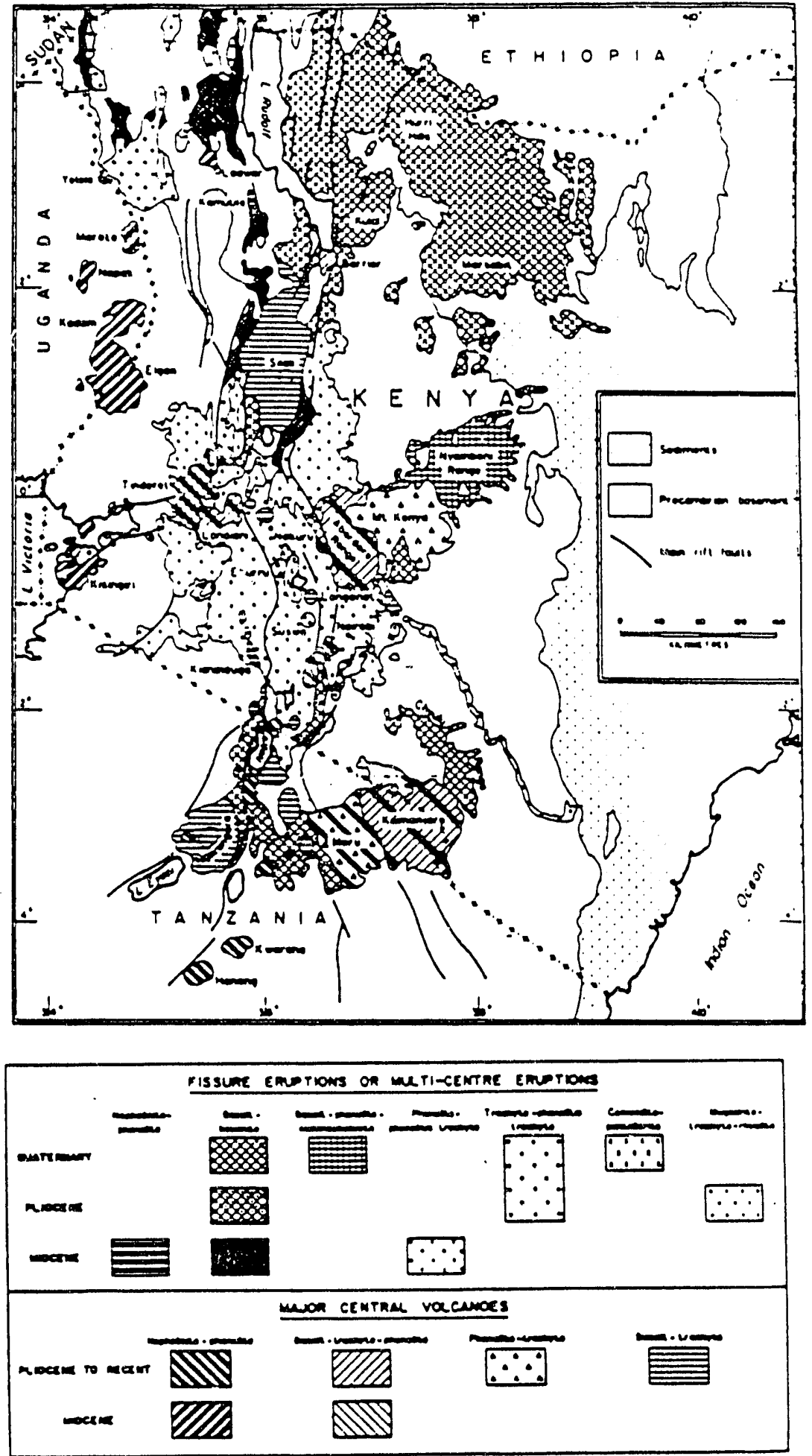

Map showing the distribution of the main volcanic associations in Kenya

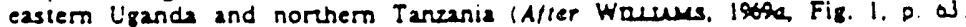
modified 10 distinguish Miocene, Pliocene and Quateranty voleanies). 
Figure IV-6. The Distribution In space and Time of Rift Volcanics.
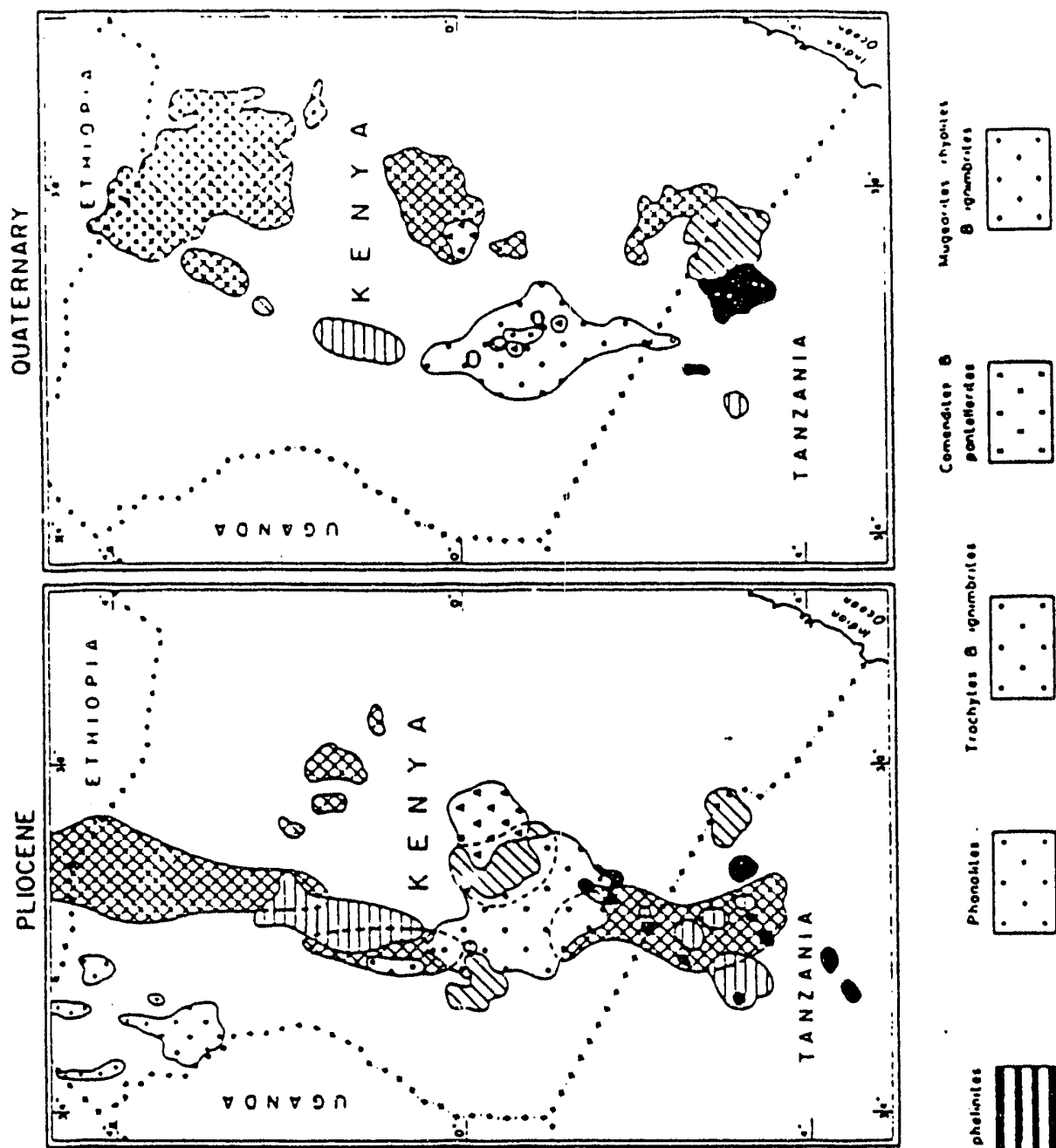

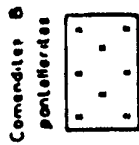
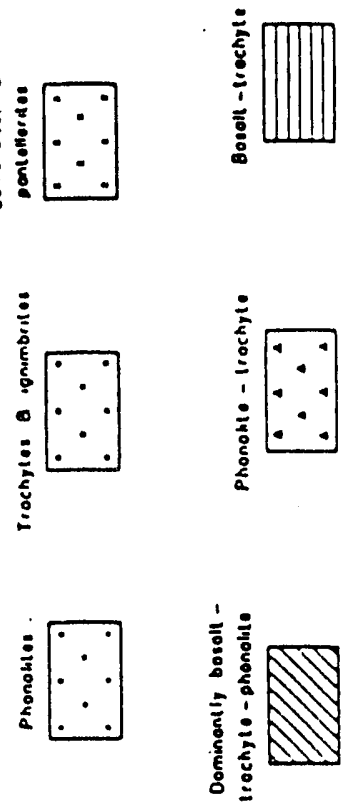

InI

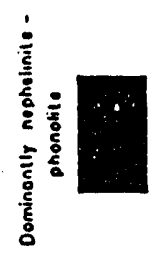

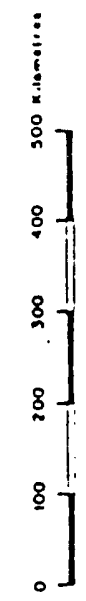
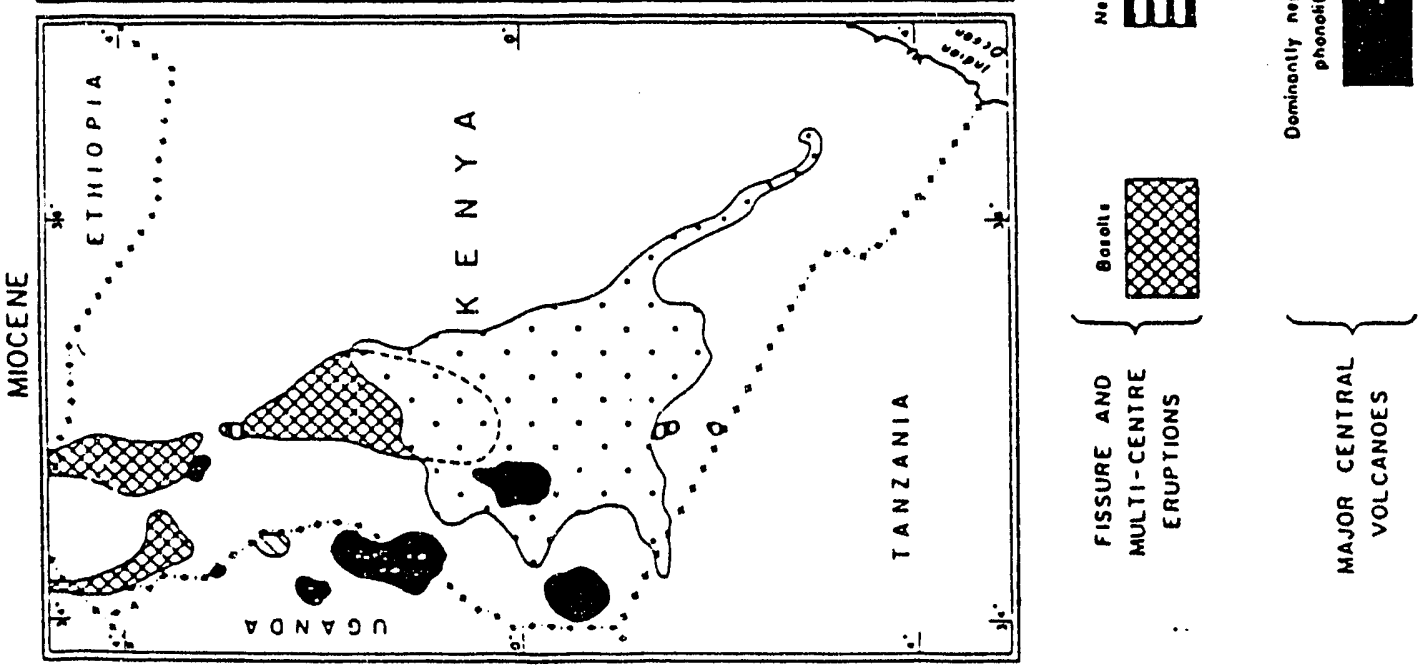
Figure IV-7. Major Late Tertiary and Quaternary Volcanoes.

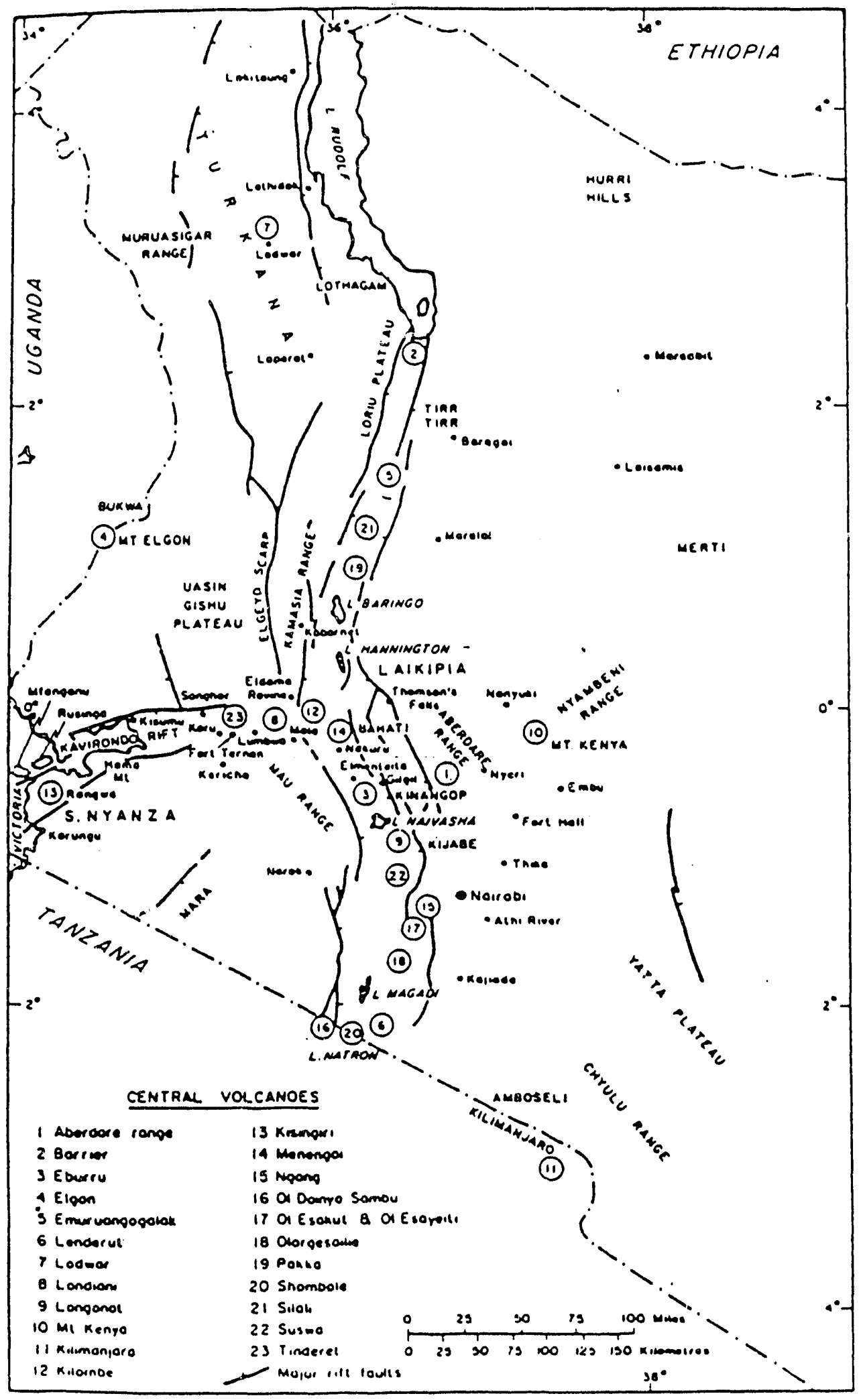


Figure IV -8 . Map of Geothermal Prospects and Roads, Kenya.

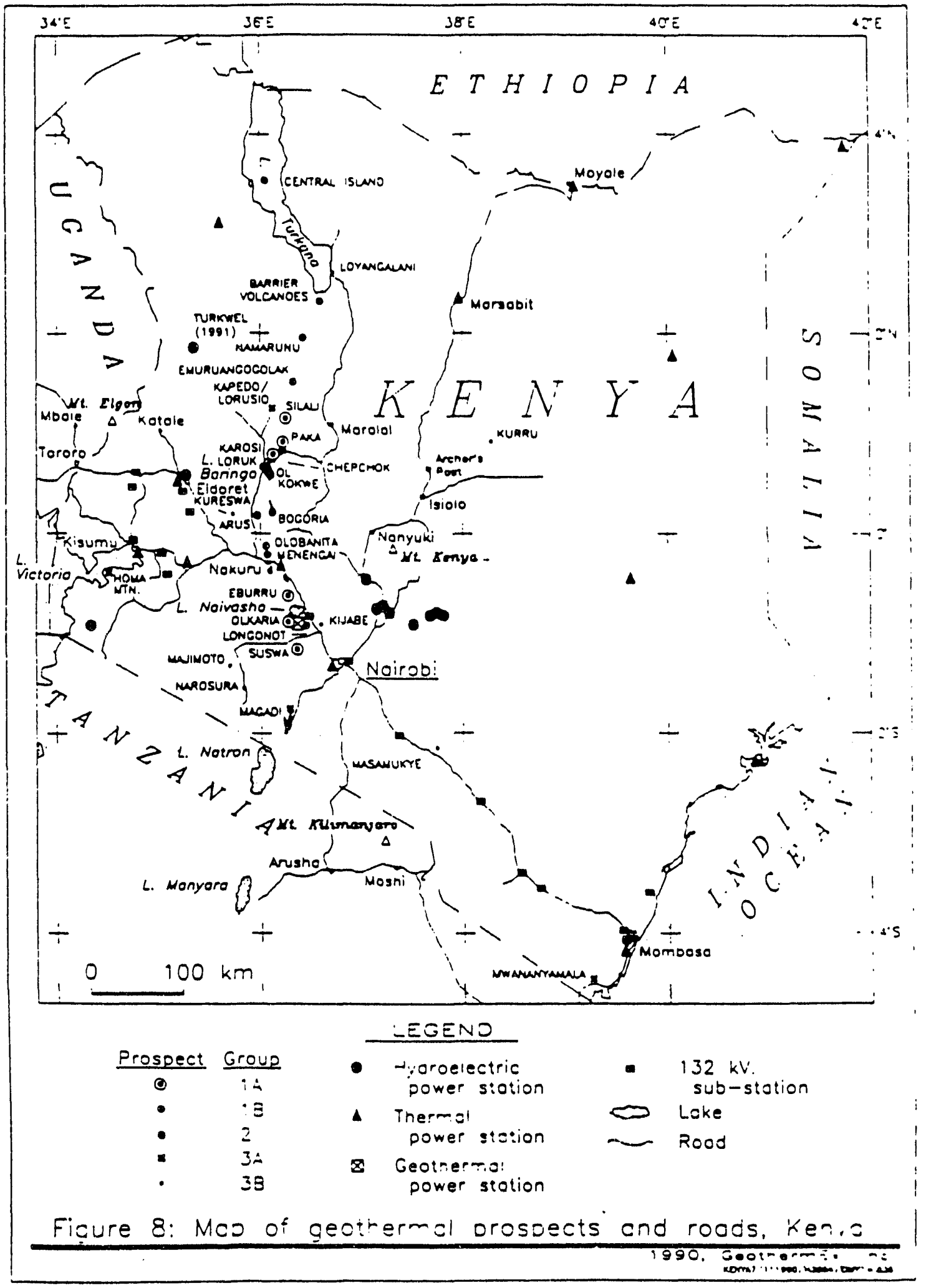


Figure IV-9. Map of Geothermal Prospects, Power Transmission Lines and Power Distribution Lines.

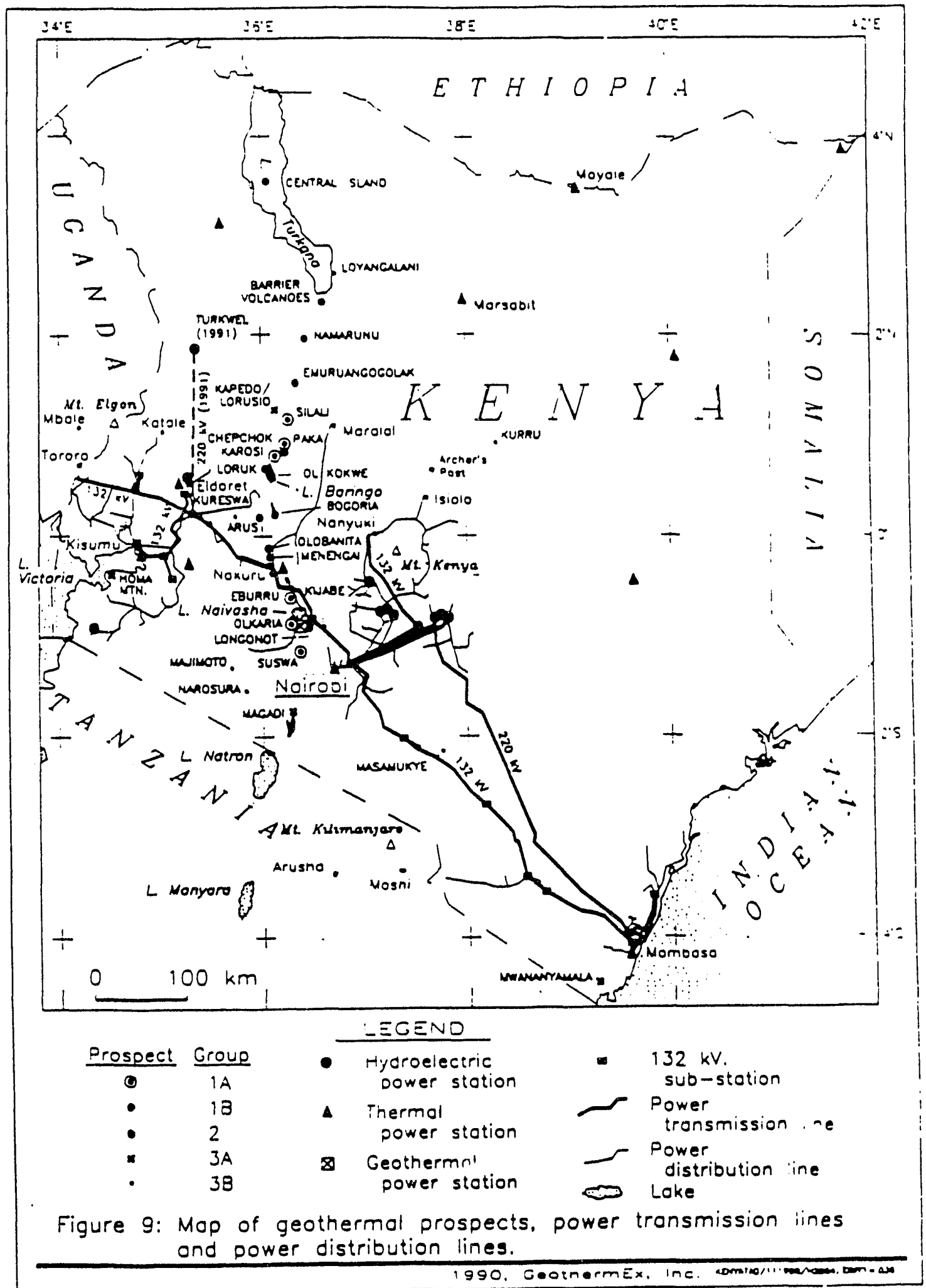


Section $v$.

CAPITAL COSTS AND TECHNICAL CHARACTERISTICS OF GEOTHERMAL POWER PLANTS

\section{A. INTRODUCTION}

The purpose of this section of the report is to estimate capital costs and $O \& M$ costs for the most attractive of the prospects identified in section IV of this report. Descriptions are also provided of the basic geothermal power generation options. This is followed by a financial analysis of the prospective sites and generation technologies in section VI.

\section{Methodology}

Section IV classified prospective resources in different ways. In Table IV-I they were classified by level of exploration risk. In Table IV-2, resource characteristics were set forth, including area, temperature, depth to groundwater, distance to transmission line, distance to distribution line and distance to access road. Table IV-14 lists the important factors affecting project cost for fifteen prospects. In Table IV-16, the 15 selected prospects were ranked according to cost-per-kilowatt to identify the most likely areas of future development.

These tables are referenced herein and serve as a useful basis for our work, (The Ben Holt Company). These tables are important in that they take into account key factors in an evaluation of a prospect: namely, size, depth, temperature and location.

To build upon this basis we have taken into account the following costs:

* Power plant costs as a function of size and resource temperature.

* Gathering and injection system costs as a function of plant size, resource temperature and well productivity.

* Transmission line and access road costs as a function of distance to a transmission line or main road.

* Project costs, including siting, financing and owner's costs during construction.

An effort has been made to develop both capital and 0 \& $M$ costs on a consistent basis in order to provide meaningful relative values. These costs were then added to exploration and well drilling costs developed by others. 
In general, at each prospect 3 plant sizes were investigated. For the steam flash prospects, $10 \mathrm{MW}, 20 \mathrm{MW}$ or $50 \mathrm{MW}$ plants were studied. For the binary cycle prospects, $5 \mathrm{MW}, 10 \mathrm{MW}$ and $20 \mathrm{MW}$ plants were used. For each case, a well productivity of $3 \mathrm{MW} /$ well was assumed. This value represer.ts the experience at the olkaria reservoir and assumes that state-of-the-art large diameter drilling. and completion technologies are able to increase productivities to a level comparable to other major resources. For the cases involving binary cycle plants, pumped wells were assumed. The productivity used was $1500 \mathrm{gpm} / w e l l$, a value typical for western U.S. reservoirs.

\section{Results}

Table $V-1$ is a detailed summary of the cases studied. There were 12 prospects suitable for dual-flash steam plants and three prospects suitable for binary plants. These represent the prospects shown on Table IV-16.

Figures V-1 through V-3 present the capital costs for projects of 50,20, and $10 \mathrm{MW}$ respectively as stacked bargraphs. AlI the cases shown in these figures assume well productivities of 3.0 MiN/well. From the figures, it can be seen that, for each plant size, the project costs, plant costs and gathering and injection system costs are nearly constant from one prospect to the next. However, the well costs, exploration costs, transmission line cost and access road cost vary from site to site. In the case of 50 and $20 \mathrm{MW}$ plants, the variation in well costs has the greatest impact on overall cost while for $10 \mathrm{MW}$ plants, the transmission line and access road costs are controlling.

Total costs and/or the cost per kW of a developed power plant can be seen to differ slightly from those given in Table IV-16, prepared by GeothermEx. These differences rarely exceed $4 \%$, and in some cases are less than 1\%. They reflect differences in treatment given to exploration and drilling costs and in costs of access roads, gathering systems and injection systems. The close similarity of values derived by different computations is encouraging, and suggests that these are useful values for development planning purposes.

Figure $V-4$ shows the variation of project unit costs with plant size. only dual-flash steam plants are shown. The line on the graph represents the average unit cost for each plant size. The "knee" of the curve occurs at about $15 \mathrm{MW}$. Below this point, unit costs tend to escalate dramatically.

Binary-cycle plants have been studied for 3 prospects; Iake Magadi, Mwananyamala and Kapedo/Lorusio. Binary plants are modular by nature and composed of multiple turbo-generators. They can be economically.built in sizes as small as 1 MW. However, the maximum module size for radial-inflow turbines is about $5 \mathrm{MW}$, and so a 50 MW plant would require 10 modules. This tends to put the modular plant at an economic disadvantage in the larger plant sizes. 
Table V-1. Capital and O\&M Costs for Selected Kenya Geothermal Prospects

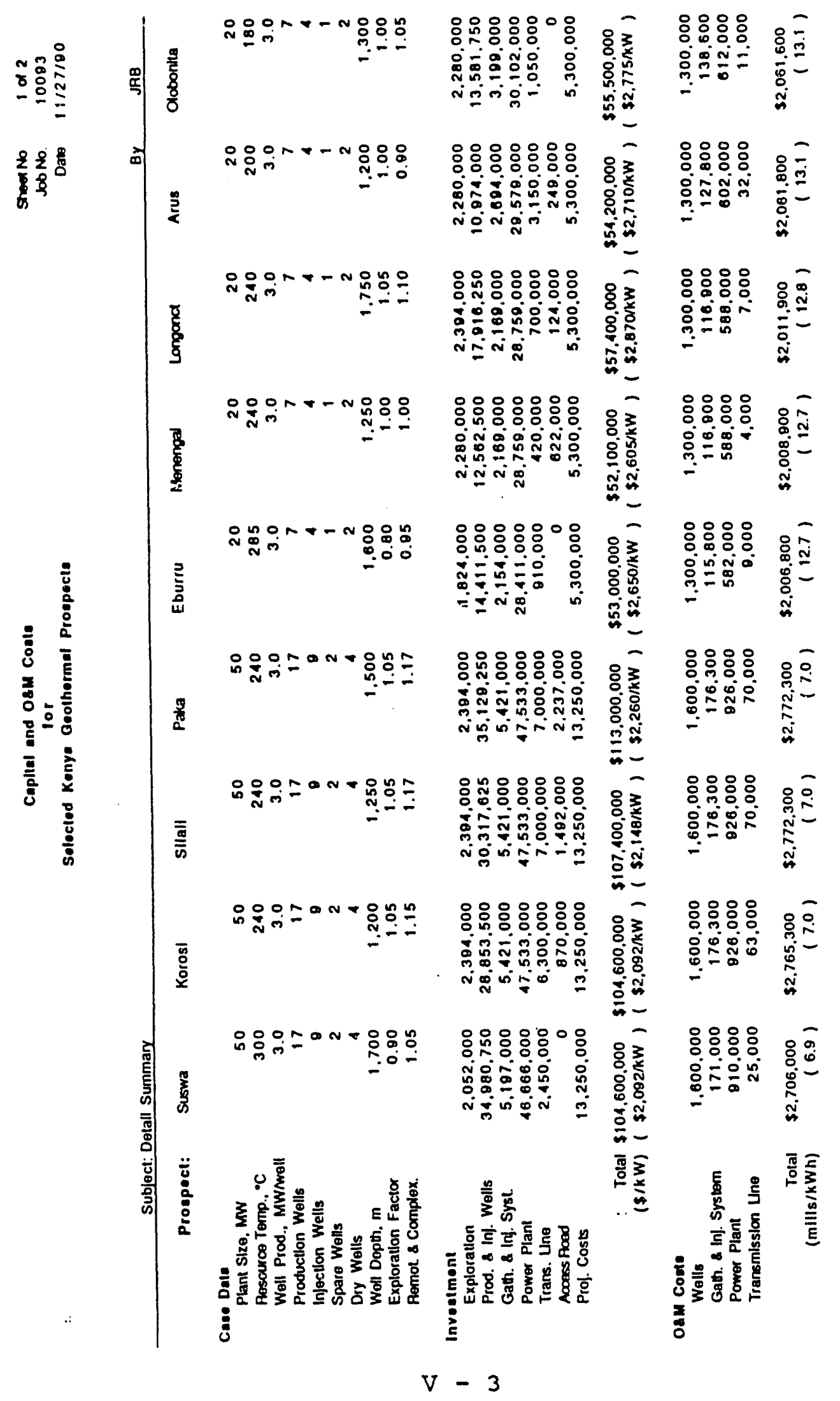


Table V-1. Capital and O\&M Costs for Selected Kenya Geothermal prospects (continued)

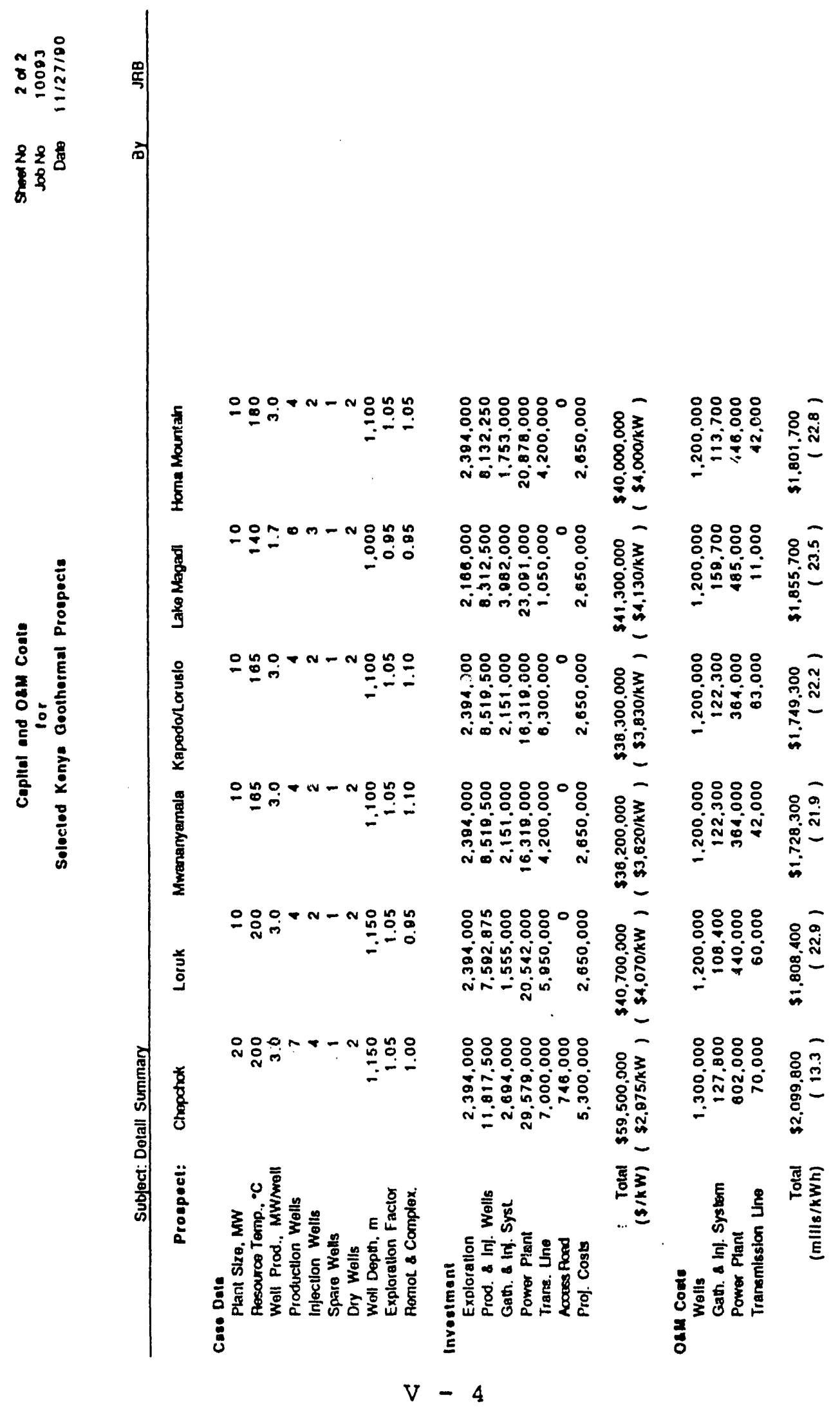


Fiqure V-1. Capital Cost Analysis, 50 MW Power Plants

Capital Cost Analysis

50 MW Power Plants

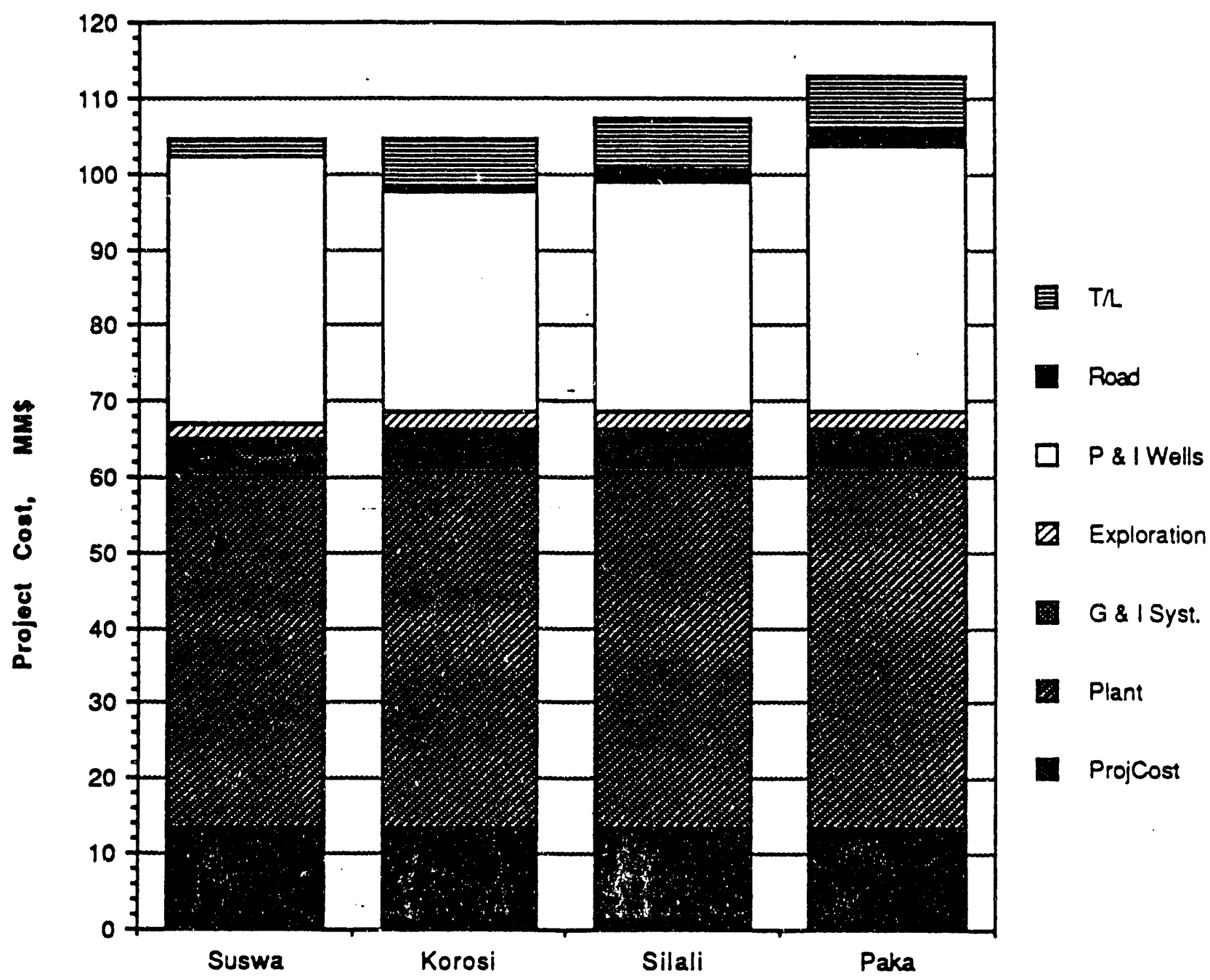

Prospoct

$v-5$ 
Figure V-2. Capital Cost Analysis, $20 \mathrm{MW}$ Power Plants

Capital Cost Analysis

20 MW Power Plants

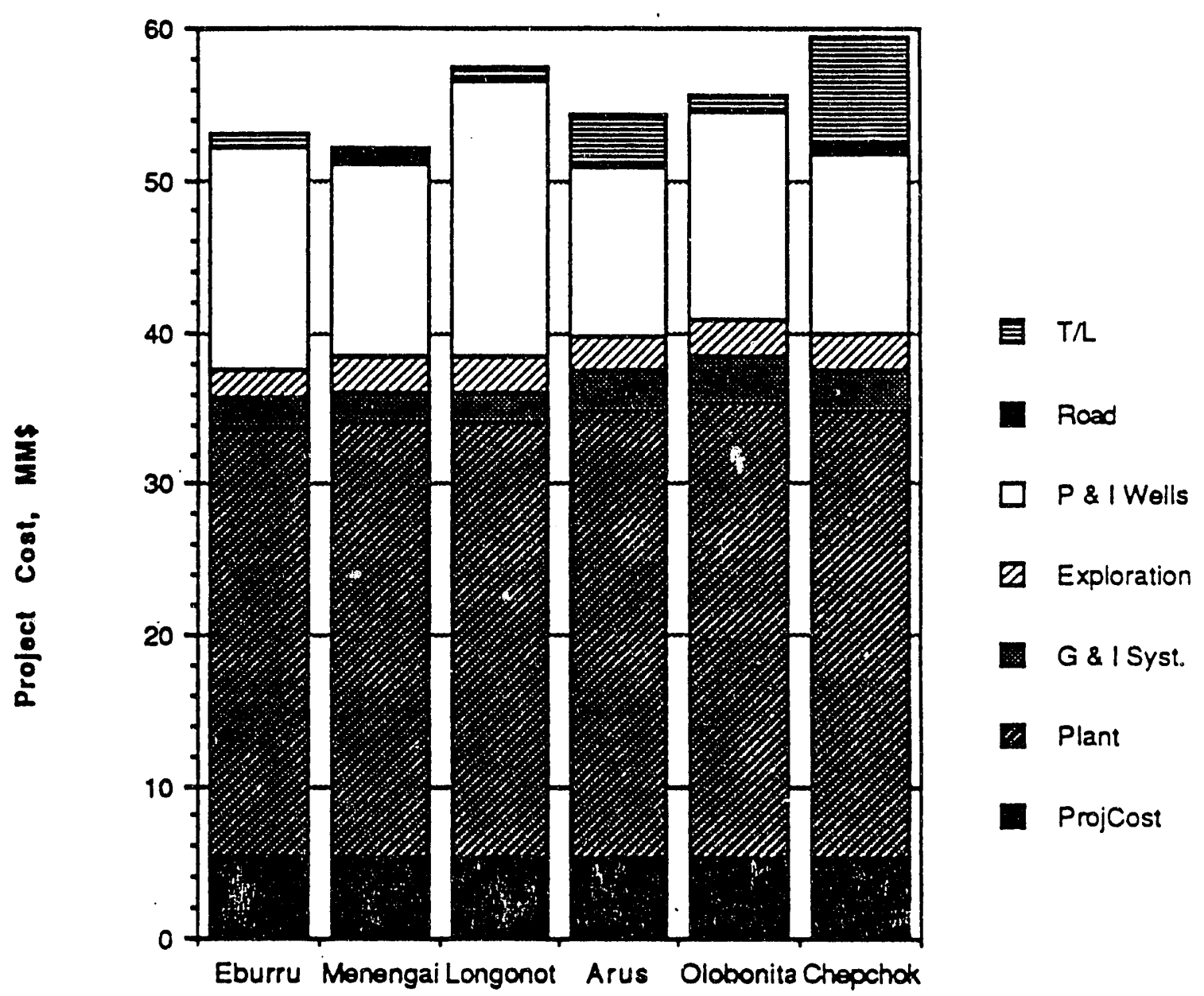

Prospoct 
Figure V-3. Capital Cost Analysis, $10 \mathrm{MW}$ Power Plants

\section{Capital Cost Analysis}

10 MW Power Plants

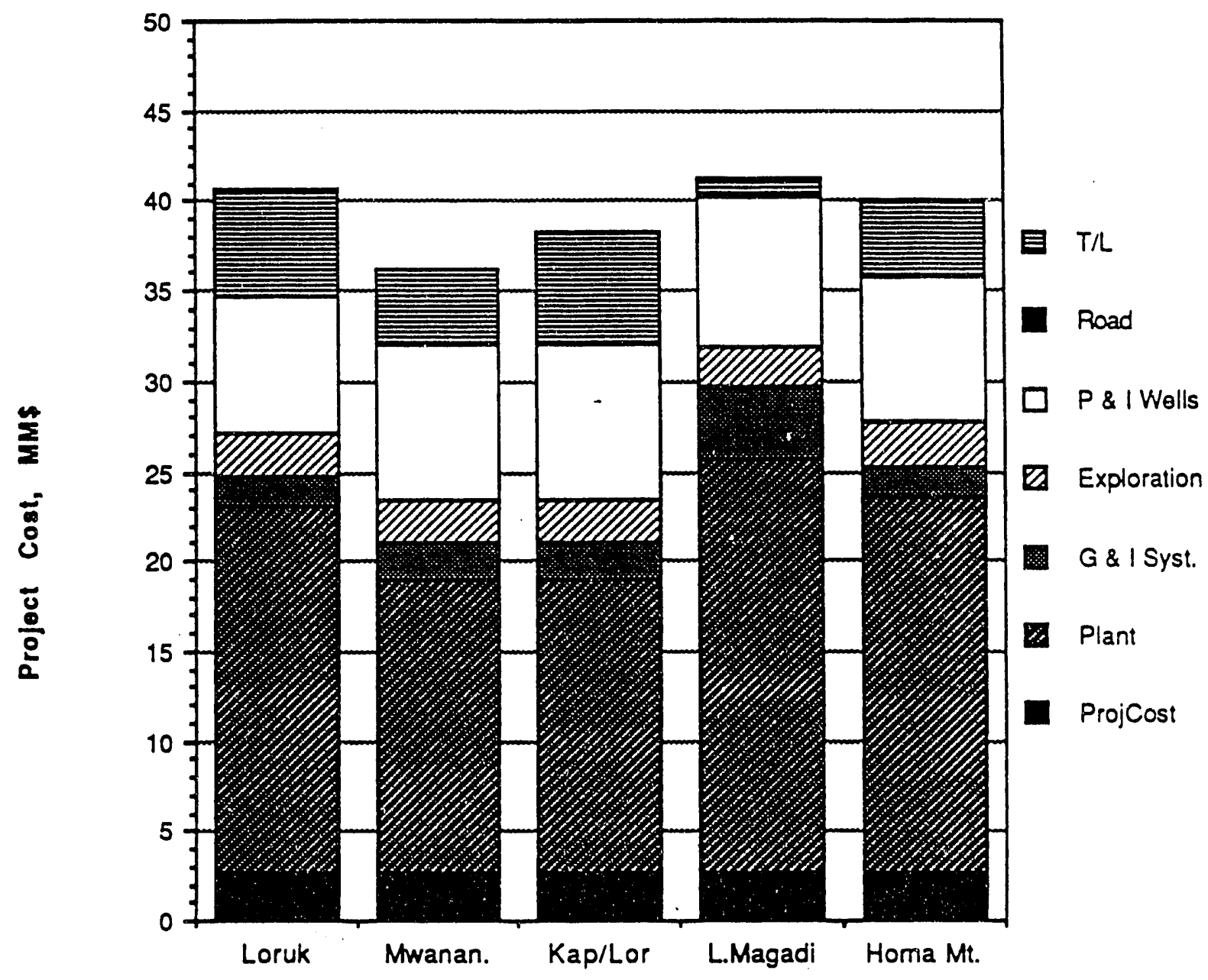

Prospect

$v-7$ 
Figure V-4. Plant cost vs. Plant size

\section{Plant Cost vs. Plant Size}

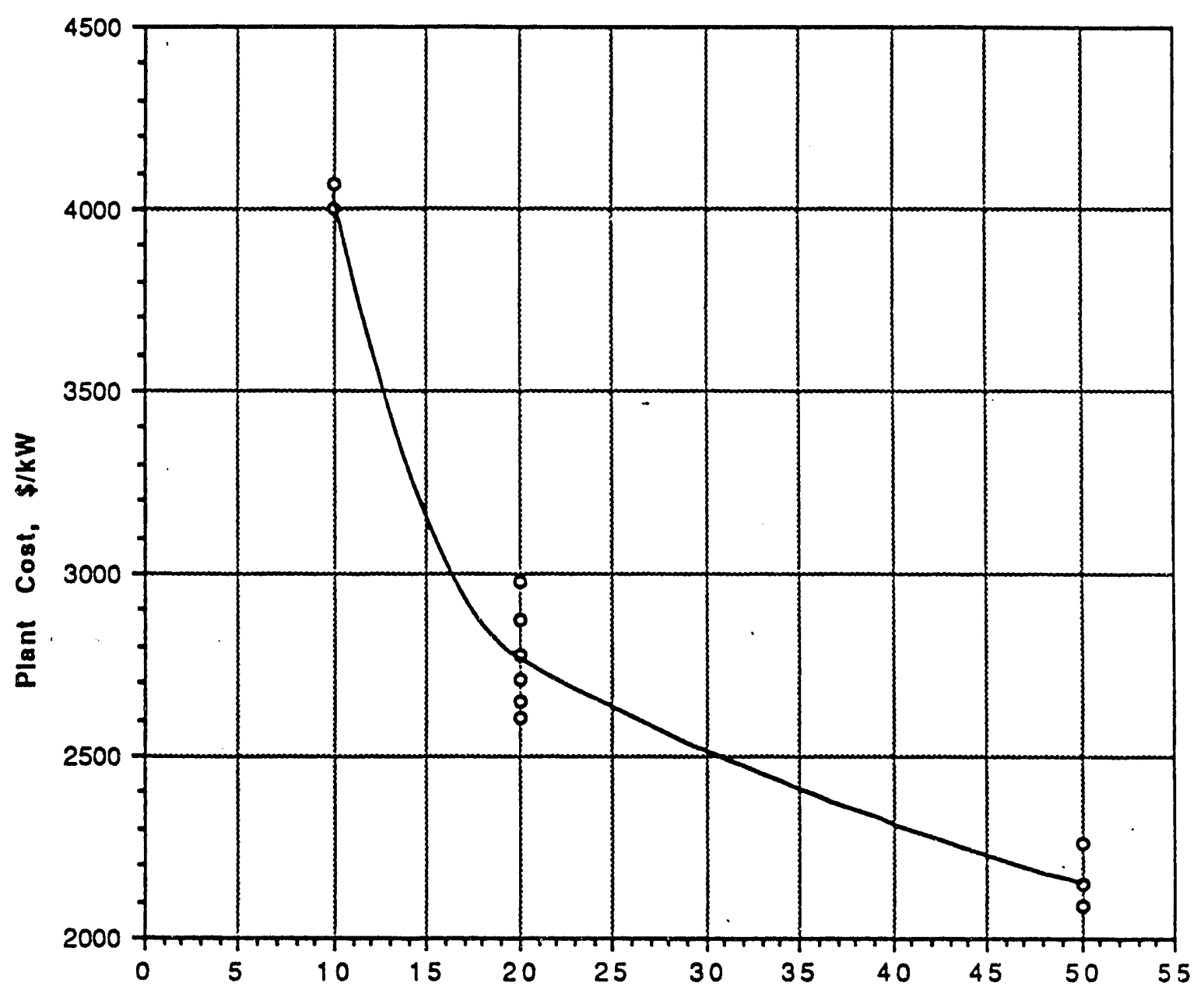

Plant Size, MW

$$
v-8
$$




\section{Conceptual Design}

\section{a. Dual Flash Steam Cycle}

Figure $V-5$ is a process diagram of the dual flash cycle. Geothermal fluid flows from the production wells to the high pressure separator where the steam and liquid are separated. The H.P.separator is located at the production pad adjacent to the production wells in order to minimize the length of two-phase piping. From there, the steam and brine are conducted to the power plant in separate pipelines. The low pressure separator(s) is located at the plant.

Both high and low pressure steam are fed to the dual pressure turbine which is a single case machine with either single or double flow depending on size. Exhaust steam from the turbine is condensed by cooling water in a direct contact condenser. The condensate plus cooling water is pumped by the hot well pumps back to the cooling tower.

The liquid from the L.P.separator goes first to the injection booster pumps and then by pipeline to the injection pads.

In order to accommodate the wide variety of reservoir conditions occurring at the various prospects included in this study, we have examined a number of cases for different plant sizes and resource temperatures. Figure $V-6$ is a chart of the 13 power plant cases which were examined.

The maximum H.P.flash pressure allowed was 100 psia. For the lower resource temperatures, lower flash pressures were used as appropriate. The L.P.flash pressure was kept above the ambient pressure of about 11.5 psia.

The turbine exhaust was maintained at 2 "Hga ( $\left.101^{\circ} \mathrm{F}\right)$. In $\mathrm{a}_{-1}$ cases, the combined turbine-generator efficiency was taken to be 75\% which is representative of current state-of-the-art for dua: pressure geothermal units.

The cooling tower size has calculated based on a design wet bulb temperature of $57^{\circ} \mathrm{F}$. This was the design temperature for the Dlraria plants. The required size is reported as a "size factor" which compares $t h e$ subject case with an existing tower $n=w$ in cperation ir a duis flash geothermal plant. A size factor of 0.25 means that the reguized cooling tower is one-fourth the size c comparison tower. It is assumed that the tower will have the ame height and irrigation rate (gpmift2) as the comparison tower

For each case, the various parasitic loads were calcuin::ea. These irolude the pumping loads of the hot well, brine booste. ind injection purps, the coo:irg towez fan load, transformer losser and 
Figure V-5. Dual Flash steam Cycle

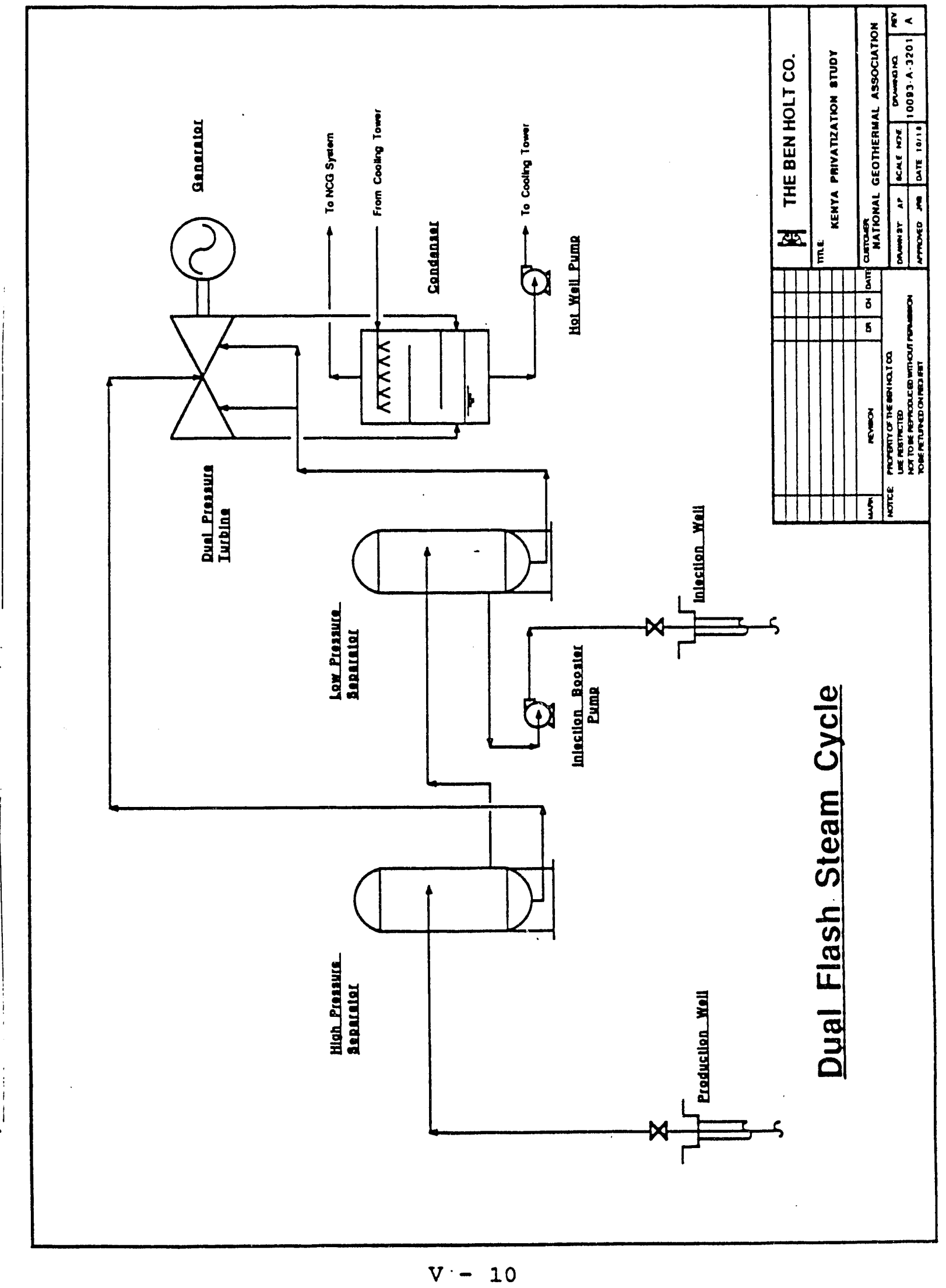


Fiqure V-6. Dual Flash steam Cycle Cases

Dual Flash Steam Cycle Cases

\begin{tabular}{|c|c|c|c|}
\hline $\begin{array}{lll}\text { Resource } & \text { Plant Size } \\
\text { Temperature } & & \\
\end{array}$ & $10 \mathrm{MW}$ & $20 \mathrm{MW}$ & $50 \mathrm{MW}$ \\
\hline $300^{\circ} \mathrm{C}$ & $x$ & $x$ & $x$ \\
\hline $285^{\circ} \mathrm{C}$ & $x$ & $x$ & $x$ \\
\hline $240^{\circ} \mathrm{C}$ & $x$ & $x$ & $x$ \\
\hline $200^{\circ} \mathrm{C}$ & $x$ & $x$ & \\
\hline $180^{\circ} \mathrm{C}$ & $x$ & $x$ & \\
\hline
\end{tabular}


miscellaneous loads such as lighting, instrument air and HVAC loads.

A typical example of the output of a steam cycle calculation is given in Figure $\mathrm{V}-7$.

\section{b. Binary Cycle}

Figure $V-8$ is a process diagram of the binary cycle. Geothermal fluid is pumped by a line shaft pump from the production well to the power plant. There it passes through the brine/hydrocarbon heat exchanger and to the injection booster pump from which it is pumped to the injection well. The geothermal fluid remains in the liquid phase through the entire cycle.

The hydrocarbon working fluid (in this case isobutane) is pumped through the brine/hydrocarbon exchanger where it is vaporized at high pressure. The vapors are then sent to a radial inflow expander. The exhaust vapor leaves the expander at low pressure and enters the shell-and-tube condenser. Cooling water from the cooling tower is used to return the hydrocarbon vapors to the liquid phase before they pass to the accumulator which feeds the circulating pump completing the cycle. The binary cycle is a completely closed loop for both the geothermal fluid and the working fluid and is particularly suitable in environmentally sensitive areas.

Two binary cycle cases were examined. At each of two resource temperatures, $165^{\circ} \mathrm{C}$ and $140^{\circ} \mathrm{C}$, a power plant of $10^{\mathrm{MW}}$ was evaluated.

The radial inflow expander was selected for this study based on its successful application in several existing plants. An expander efficiency of $79 \%$ was used based on the actual performance of existing units. Due to manufacturing limitations, expander size is limited to a maximum of about $5 \mathrm{MW}$ (gross). Therefore, the power plants consist of multiple units. Although there is a reduction in the economy of scale, the plants are more reliable since the loss of any one expander will result in only a partial loss of output from the plant.

The cooling tower for the plant was designed in the same way and with the same assumptions as given above for the steam plant. Binary plants have larger auxiliary loads than steam plants. The largest load is the hydrocarbon circulating pump. The next largest are the well pumps. Other loads include the cooling tower, cooling water pumps, injection booster pumps, transformer losses and miscellaneous loads as described above for the steam plant.

A typical example of the output of a binary cycle calculation is given in Figure $\mathrm{V}-9$. 
Figure V-7. Dual Flash steam Cycle

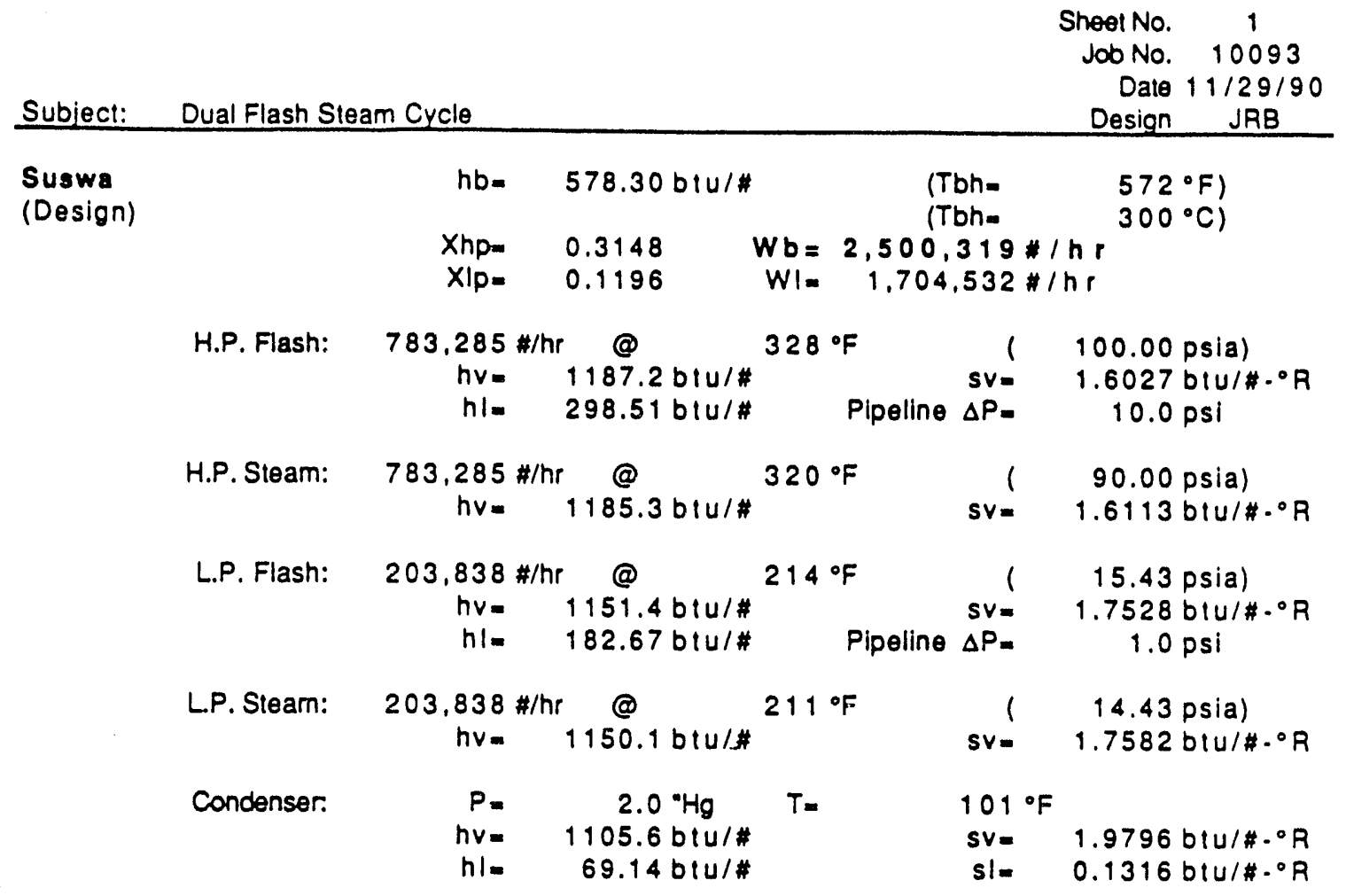

Turbine:

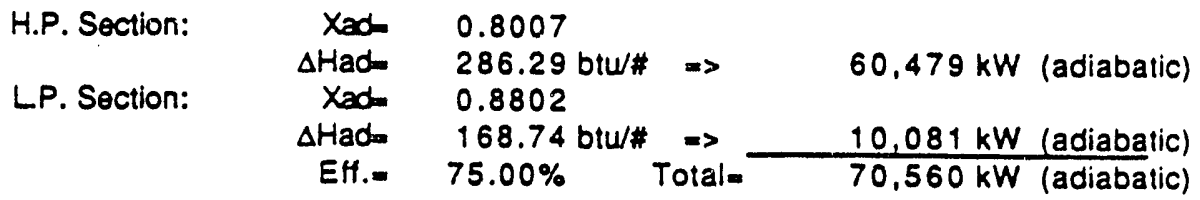

$$
\begin{aligned}
& \text { Total Req.= } \quad 70,560 \mathrm{~kW} \text { (adiabatic) } \\
& \text { Actual. } \quad 52,920 \mathrm{~kW} \text { (gross) } \\
& \text { Actual= } \quad 50,000 \mathrm{~kW} \text { (nel) }
\end{aligned}
$$

Parasitic Loads:

$\begin{array}{rr}\text { Hotwell Pumps } & 1169 \mathrm{~kW} \\ \text { Closed Loop C.W. Pumps } & 101 \mathrm{~kW} \\ \text { Inj. Booster Pumps } & 372 \mathrm{~kW} \\ \text { Brine Booster Pumps } & 38 \mathrm{~kW} \\ \text { Cooling Tower } & 791 \mathrm{~kW} \\ \text { Transformer Losses } & 265 \mathrm{~kW} \\ \text { Misc. } & 185 \mathrm{~kW} \\ & \\ \text { Total } & 2920 \mathrm{~kW}\end{array}$

NCG Removal:

$\begin{array}{rc}\text { NCG Contert- } & 0.50 \% \\ \text { Whog- } & 12.502 * / \mathrm{hr} \\ \text { Ejector Sleam- } & 62.508 \% / \mathrm{hr} \\ \text { Atm. Vent- } & 33.778 * / \mathrm{hr}\end{array}$

Brine Injection:

Spent Brine $=1,500,694 \# / \mathrm{hr}$

$$
\text { C.T. Blowdown= 5,485 } / \mathrm{hr}
$$

Total $=1,506,179 * / \mathrm{hr}$

$$
v-13
$$




\begin{tabular}{|c|c|c|}
\hline & & $\begin{array}{cc}\text { Sheet No. } & 2 \\
\text { Job No. } & 10093 \\
\text { Date } & 11 / 29 / 90 \\
\text { Desian } & \text { JRB }\end{array}$ \\
\hline Subject: & Dual Flash Steam Cycle & \\
\hline
\end{tabular}

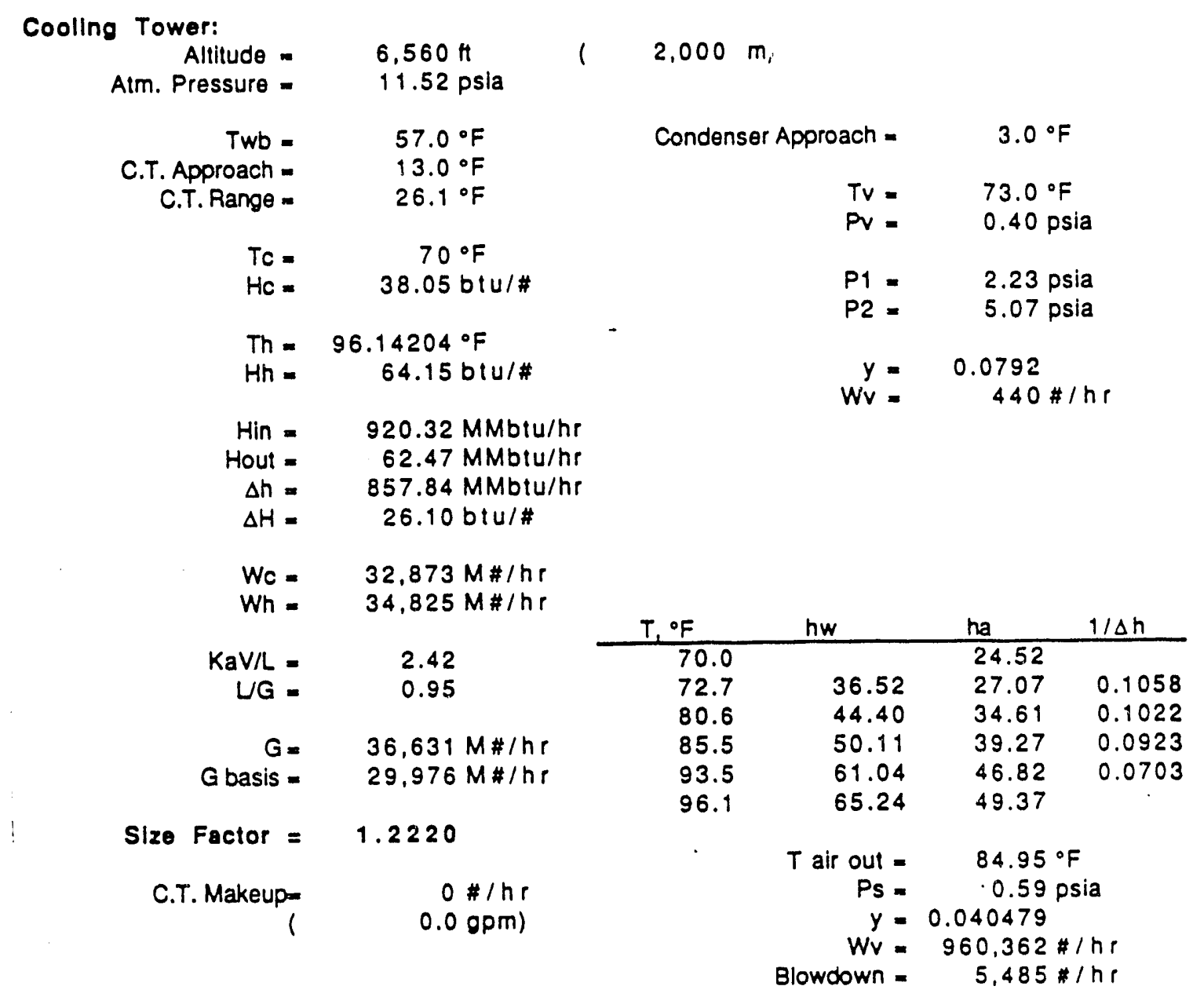


Figure $V-8$. Binary cycle

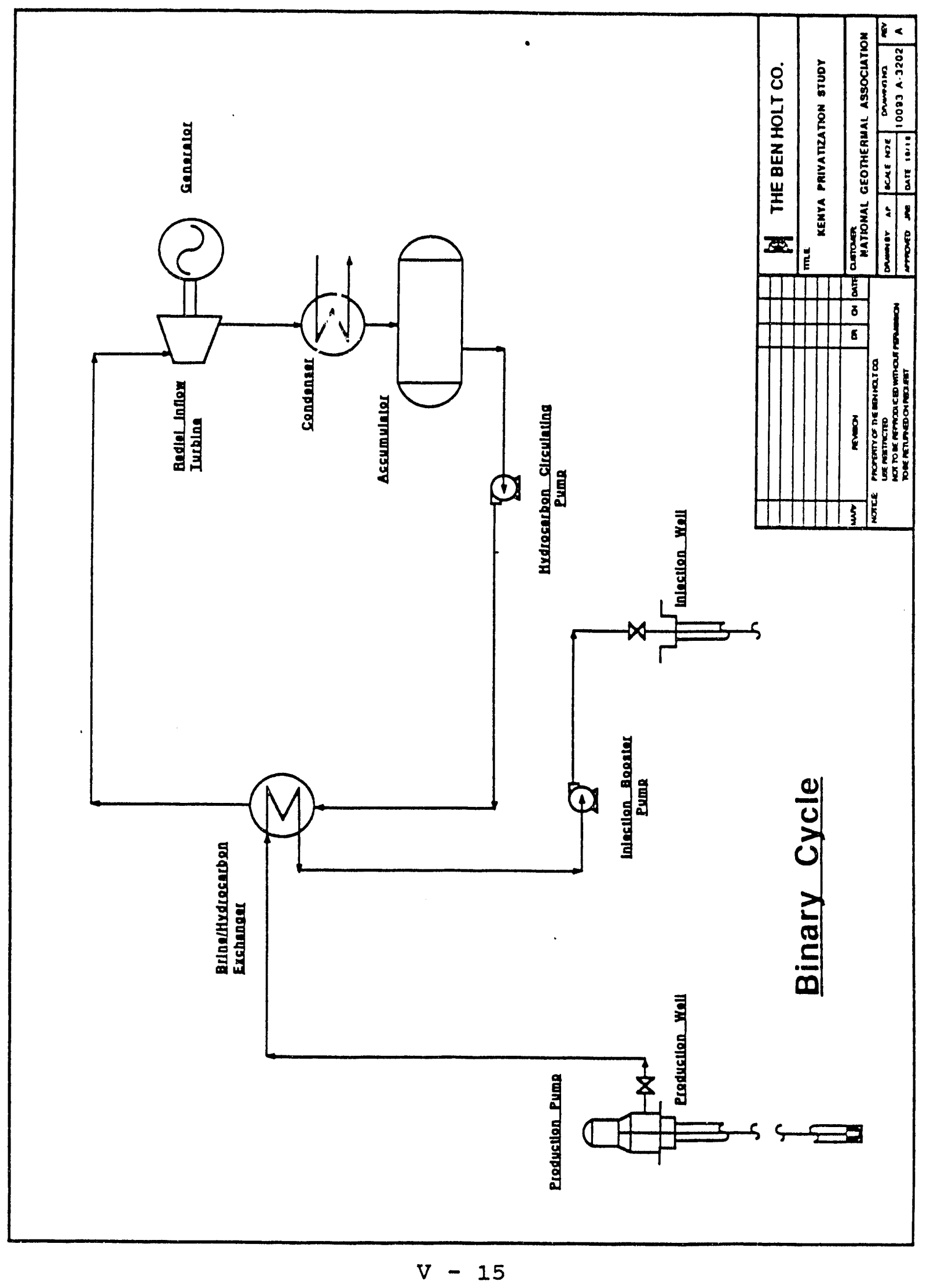




\section{Figure V-9. Binary cycle}

\begin{tabular}{|c|c|c|c|c|}
\hline Binary Cycle & & & & $\begin{array}{cc}\text { Sheet No. } & 1 \\
\text { Job No. } & 10093 \\
\text { Date } & 10 / 11 / 90 \\
\text { Design } & \text { JRB } \\
\end{array}$ \\
\hline \multirow[t]{4}{*}{$\begin{array}{l}\text { Mwananyamala } \\
\text { (Design) }\end{array}$} & $n b \cdot \mid n=$ & $299.75 \mathrm{btu} / \#$ & $\begin{array}{l}\text { (Tbh= } \\
\text { (Tbh= }\end{array}$ & $\begin{array}{l}\left.329^{\circ} \mathrm{F}\right) \\
\left.165^{\circ} \mathrm{C}\right)\end{array}$ \\
\hline & hb-out= & 146.50 blui \# & $\begin{array}{l}\text { (Tbh= } \\
\text { (Tbh= }\end{array}$ & $\begin{array}{r}\left.178.5^{\circ} \mathrm{F}\right) \\
\left.81.4^{\circ} \mathrm{C}\right)\end{array}$ \\
\hline & $\Delta h=$ & $153.255 \mathrm{blu} / \#$ & & \\
\hline & Wbr $=$ & $326,111 * / \mathrm{hr}$ & $\begin{array}{l}\text { Density = } \\
\text { Sp. Gr. = }\end{array}$ & $\begin{array}{l}56.43 \# / f 13 \\
0.905\end{array}$ \\
\hline
\end{tabular}

Turblne:

$\begin{array}{ll}\Delta h-g e n= & 25.3610 \mathrm{btu} / \# \\ \text { Actual }= & 14,551 \mathrm{~kW} \text { (gross) } \\ \text { Actual }= & 10,000 \mathrm{~kW} \text { (net) }\end{array}$

Parasitic Loads:

Brine Injection:

C.W. Circ. Pumps

H.C. Circ. Pumps

Inj. Booster Pumps

Well Pumps

Cooling Tower

Transformer Losses

Misc.

Total
$532 \mathrm{~kW}$

$1956 \mathrm{~kW}$

$591 \mathrm{~kW}$

$899 \mathrm{~kW}$

$315 \mathrm{~kW}$

$73 \mathrm{~kW}$

$185 \mathrm{~kW}$

$4551 \mathrm{~kW}$
Spent Brine $=2,326,111 \# / \mathrm{hr}$ C.T. Blowdown= $69,137 \# / \mathrm{hr}$ Total $=2,395,248 \# / \mathrm{hr}$

Wel! Pumps:

$\begin{aligned} \text { Brine V.P. } & = & 101.65 \mathrm{psia} \\ \text { Lift } & = & 365 \mathrm{fl} \\ \text { TDH } & = & 698 \mathrm{fl}\end{aligned}$




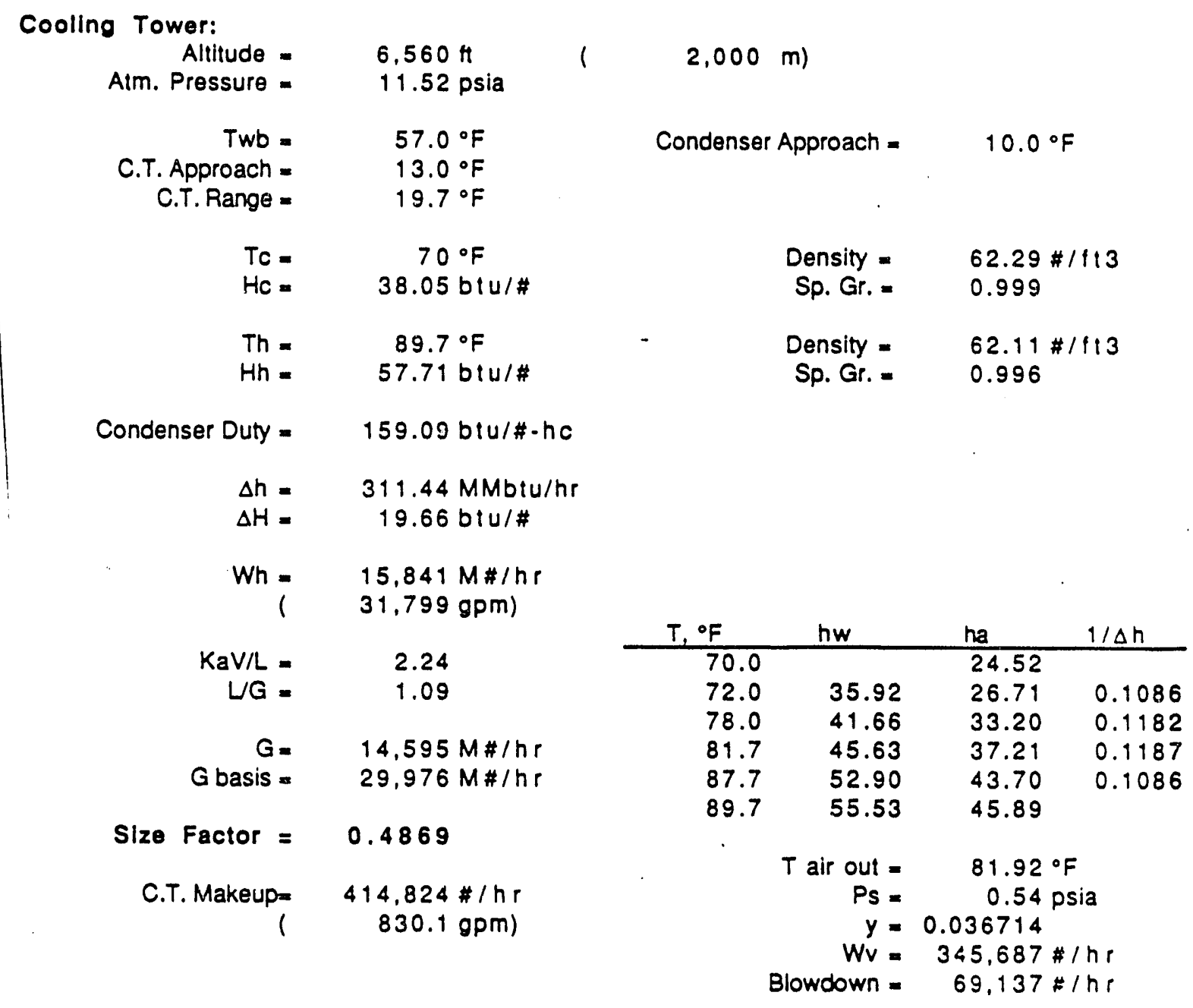




\section{c. Gathering and Injection system}

The gathering system consists of the piping and equipment necessairy to transport the geothermal fluid from the production wells to the power plant. The injection system serves the same function between the plant and the injection wells.

For the purposes of this study, it is assumed that each reservoir is capable of supporting a production rate of 5 MW per 40 acres and that the wells are spaced accordingly. Furthermore, it is assumed that the productive region is distributed along a fault system and that, therefore, the production field is long and narrow. The power plant will be sited at the approximate center of the production field in order to minimize the gathering piping. Each production pad will support three producing wells.

The H.P. separators are located at the production pads. The maximum capacity of a H.P.separator is $10 \mathrm{MW}$. Therefore, for wells of $5 \mathrm{MW} /$ well productivity there will be three separators per pad and for the other cases only one separator which will be shared by all three wells. Both the H.P.steam and the flashed brine will be sent to the plant in insulated pipelines. At the plant, the brine will be flashed again in the L.P.separators. The Iiguid from this flash will be sent to the injection wells.

It is assumed that there will be one injection well for every two production wells. These will be located in an injection field which will also follow the structure but be displaced laterally from the production field. The displacement ranges from about 1500 feet to $2500 \mathrm{ft}$ depending on the productivity of the production wells.

The steam lines were sized to minimize the pressure drop from the separators to the plant. In general, a maximum pressure drop of 10 psi was allowed. The steam lines are between 10 and 30 inches in diameter. The liquid lines for both the flashed brine and the injected brine were sized for a maximum liquid velocity of 8 fps. They range from 6 to 20 inches in diameter. The insulation thickness was 2.5 inches for gathering lines and 1 inch for the injection lines.

In addition to the pipelines, it was assumed that the well pad access roads as well as the electric power lines and instrument air lines would follow the pipeline routes.

Figure V-10 gives a typical example of the gathering and injection system design for each case. It aiso includes the cost of the pipelines, roads, etc. The cost of the separators and associated equipment is included elsewhere. 
Figure V-10. Gathering \& Injection System Design - Suswa 50 MW

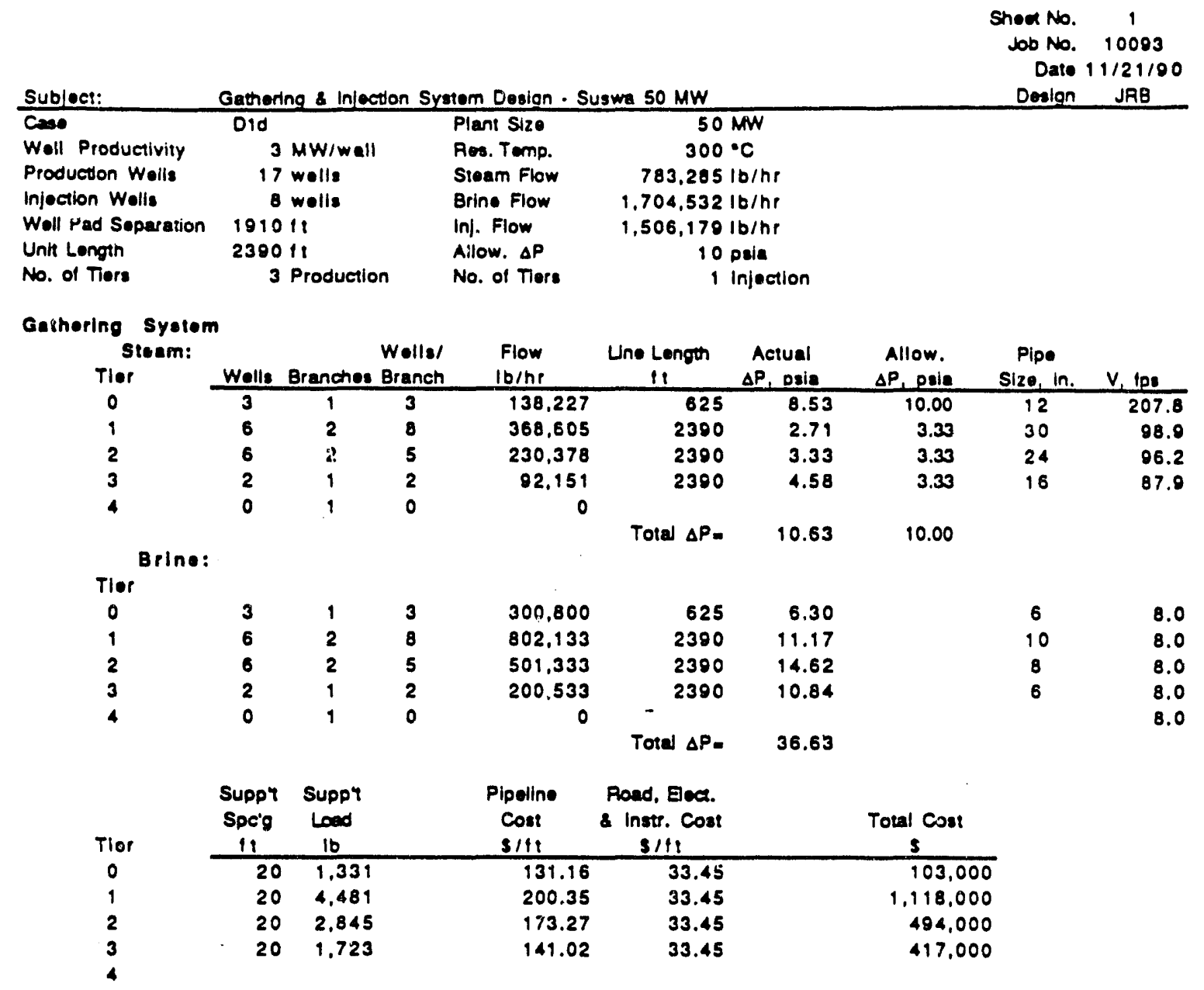

\begin{tabular}{|c|c|c|c|c|c|c|c|c|c|}
\hline \multirow{2}{*}{\multicolumn{2}{|c|}{ Injection Systom }} & & & \multicolumn{6}{|c|}{ Total $=\$ 2,132,000$} \\
\hline & & & \multirow[b]{2}{*}{$\begin{array}{l}\text { Brine } \\
\text { lo/he }\end{array}$} & \multirow[b]{2}{*}{ Une Length } & \multirow[b]{2}{*}{$\triangle P$ psia } & & \multirow[b]{2}{*}{$\begin{array}{l}\text { Pipe } \\
\text { Size, in. }\end{array}$} & \multirow[b]{2}{*}{$\begin{array}{l}\text { Allow. } \\
V, \text { tog }\end{array}$} \\
\hline Tier & Wolls & $\begin{array}{l}\text { Wolls por } \\
\text { Branch }\end{array}$ & $\begin{array}{l}\text { rolls po } \\
\text { Branch }\end{array}$ & & & & & & \\
\hline 0 & 3 & 1 & 3 & $1,506,179$ & 2390 & 9.43 & & 14 & 8.0 \\
\hline 1 & 5 & 2 & 3 & 564,817 & 2320 & 17.72 & & 8 & 8.0 \\
\hline 2 & 0 & 1 & 0 & 0 & & & & & 8.0 \\
\hline 3 & 0 & 1 & 0 & 0 & & & & & 8.0 \\
\hline \multirow[t]{3}{*}{4} & 0 & 1 & 0 & 0 & & & & & 8.0 \\
\hline & & & & & Total $\triangle P=$ & 27.16 & & & \\
\hline & $\begin{array}{l}\text { Suppy } \\
\text { Spc'o }\end{array}$ & $\begin{array}{l}\text { Supp't } \\
\text { Loed }\end{array}$ & & $\begin{array}{l}\text { Pipeline } \\
\text { Cost }\end{array}$ & $\begin{array}{l}\text { Roed, Eect. } \\
\text { \& Inetr. Cost }\end{array}$ & & Toral Cost & & \\
\hline Tlor & 11 & 16 & & $s / f 1$ & $5 / 19$ & & $\mathrm{~s}$ & & \\
\hline 0 & -20 & 2,124 & & 109.99 & 33.45 & & 324,000 & & \\
\hline 1 & 20 & 203 & & 89.10 & 33.45 & & 586.000 & & \\
\hline \multicolumn{10}{|c|}{0.000} \\
\hline \multicolumn{10}{|l|}{3} \\
\hline \multicolumn{10}{|l|}{4} \\
\hline & & & & & & Total= & $\$ 910,000$ & & \\
\hline & & & & & Grar & dotal= & $\$ 3,042,000$ & & \\
\hline
\end{tabular}

$V-19$ 


\section{Capital cost Estimate}

\section{a. Well costs}

For ihis study, we assumed that the unit drilling costs at each site were equivalent. Therefore, the only variable which affects the well cost is well depth. This was estimated for each prospect by others and reported in Table IV-14 of the Geothermex Report. The well cost is based on an estimated U.S. drilling cost of $\$ 650$ per meter for exploration wells and $\$ 500$ per meter for development wells. Well depths vary from 1,000 to $1,750 \mathrm{~m}$ with well costs ranging between $\$ 500,000$ to $\$ 1,137,500$ per well.

The number of production wells is determined by the plant size and the well productivity. The number of wells per case varies from 4 to 17 . The number of injection wells is half the number of production wells. In addition, spare wells are provided and an allowance is made for dry holes.

\section{b. Gathering and Injection system costs}

The cost of the gathering and injection pipelines was given in Figure $V-10$. The installed cost of the separators and associated equipment was based on the actual cost of similar equipment recently installed in the U.S. For each case, the number and size of separators was calculated. Based on recent experience, the installed cost of the facility was estimated to be about 4.5 times the cost of the major equipment.

\section{c. Power plant}

The capital cost of the power plant was based on the estimated cost of the major equipment. This included the turbine and generator, cooling tower, condenser, hotwell pumps, injection booster pumps, noncondensible gas removal system, L.P.separators, fire protection and other miscellaneous items. For each of the sixteen steam plant cases, the equipment was sized and priced based on equipment costs of recent geothermal construction projects. The same was done for the four binary cycle cases.

The direct construction costs such as concrete, piping, electrical, field supervision, etc., were also based on recent projects. Included were the cost of a construction camp and startup costs. No sales tax was included and a contractor's profit and contingency of $15 \%$ was used. This resulted in the cost to build the plant in the U.S. at a remote location. Figures $V-11$ and $V-12$ give exanples of the cost estimates for a dual flash steam case and a binary cycle case.

An additional 15\% was added to the U.S. price to account for the extra costs associated with overseas construction such as ocean freight and additional home office costs.

$$
V-20
$$


Figure V-11. Estimate summary Sheet, Kenya

ESTIMATE SUMHARY SHEET

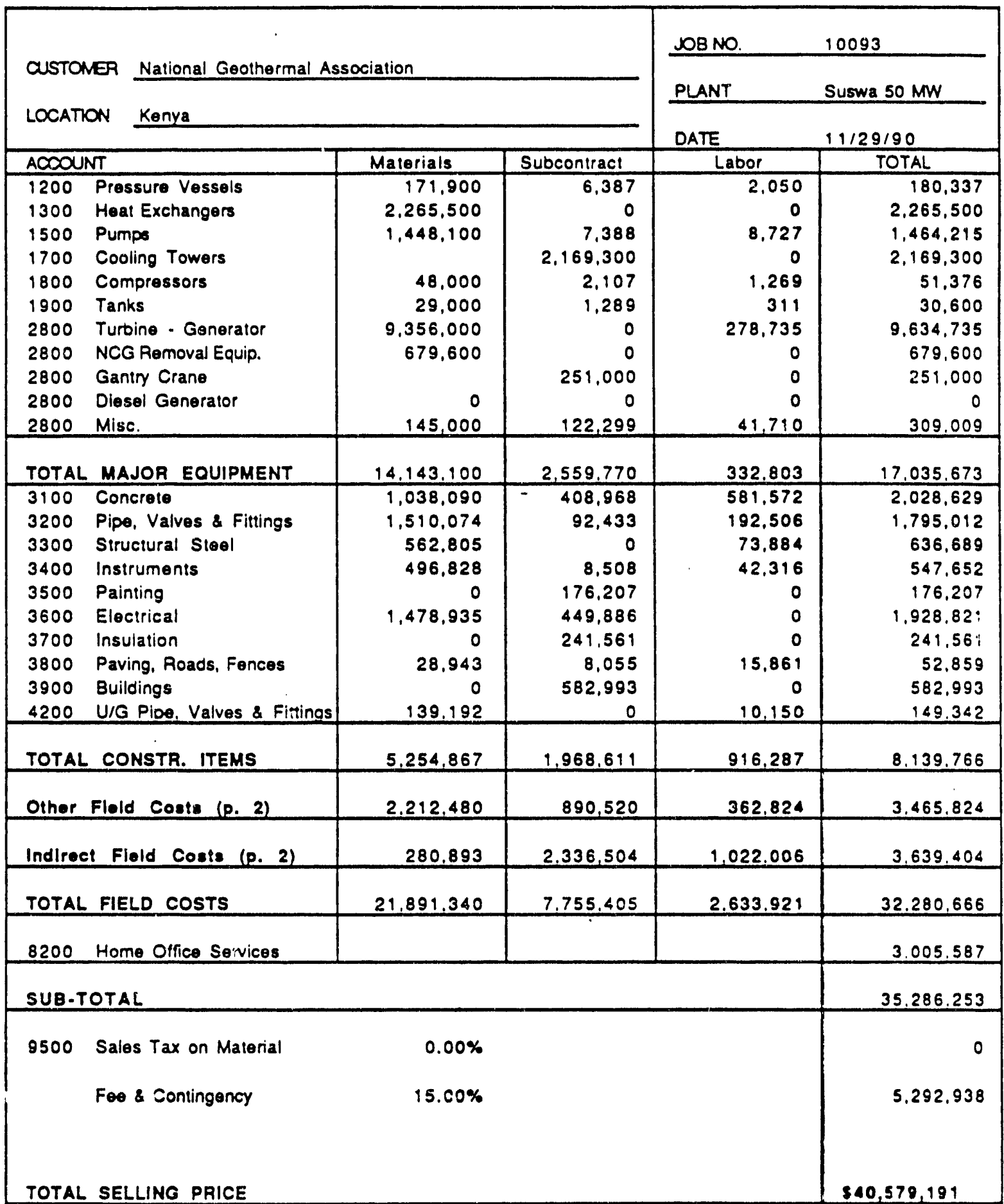


Figure V-11. Estimate Summary Sheet, Kenya (continued)

SUMMARY. FIELD COSTS

\begin{tabular}{|c|c|c|c|c|c|}
\hline \multicolumn{4}{|c|}{ Customer National Geothermal Association } & \multirow{3}{*}{$\begin{array}{l}\text { DOBNO. } \\
\text { PLANT }\end{array}$} & 10093 \\
\hline \multirow{2}{*}{\multicolumn{4}{|c|}{ QUSTOMER National Geothermal Association }} & & \multirow{2}{*}{ Suswa $50 \mathrm{MW}$} \\
\hline & & & & & \\
\hline LOCATION & nomya & & & DATE & $11 / 29 / 90$ \\
\hline ACOOUN & & Materials & Subcontract & Labor & TOTAL \\
\hline 6000 & Ocoan/Air Froight & 0 & 0 & 0 & 0 \\
\hline 6100 & Spare Parts & $2,132,532$ & 0 & 0 & $2,132,532$ \\
\hline 6200 & Catalyst \& Chemicals & 0 & 0 & 0 & 0 \\
\hline 6300 & Site Preparation \& Grading & 0 & 0 & 0 & 0 \\
\hline 6400 & Dismantling \& Demolition & 0 & 0 & 0 & 0 \\
\hline 6600 & Geotechnical Reports & 0 & 0 & 0 & 0 \\
\hline 7100 & Temporary Construction & 74,410 & 250,093 & 63,745 & 388,247 \\
\hline 7200 & Offsite Storage & 0 & 0 & 0 & 0 \\
\hline 7300 & Unallocable Labor - Craft & 3,021 & 0 & 93,964 & 96,984 \\
\hline 7600 & Supervision - Craft & 0 & 0 & 110,739 & 110,739 \\
\hline 8300 & Equipment Rentais & 2.517 & 640,427 & 94,377 & 737.321 \\
\hline TOTAL & OTHER FIELD COSTS & $\$ 2.212 .480$ & $\$ 890,520$ & $\$ 362.824$ & $\$ 3.465 .824$ \\
\hline 7400 & Start-up Services & 0 & $1,059,759$ & 0 & $1,059,759$ \\
\hline 7500 & Union Welfare Benefits & 0 & 0 & 0 & 0 \\
\hline 8100 & Field Staff \& Office & 0 & 55,379 & 684,086 & 739,465 \\
\hline 8400 & Small Tools & 75,160 & 0 & 0 & 75,160 \\
\hline 8500 & Consumable Supplies & 205,733 & 0 & 0 & 205,733 \\
\hline 8600 & Subsistence \& Lodgings & 0 & $1,221,366$ & 0 & $1.221,366$ \\
\hline 8700 & Field Transportation & 0 & 0 & 0 & 0 \\
\hline 9200 & Permits, Fees \& Licenses & 0 & 0 & 0 & 0 \\
\hline 9300 & Insurance, Payroll Taxes & 0 & 0 & 337.921 & 337,921 \\
\hline 9400 & Royalties & 0 & 0 & 0 & 0 \\
\hline 9700 & Duties, Customs, Etc. & 0 & 0 & 0 & 0 \\
\hline 9900 & Ouiside Engineering & 0 & 0 & 0 & 0 \\
\hline TOTAL & INDIRECT FIELD COSTS & $\$ 280,893$ & $\$ 2,336,504$ & $\$ 1,022,006$ & $\$ 3.639 .404$ \\
\hline
\end{tabular}


Figure V-12. Estimate Summary Sheet, Mwananyamala, Kenya

ESTIMATE SUMMARY SHEET

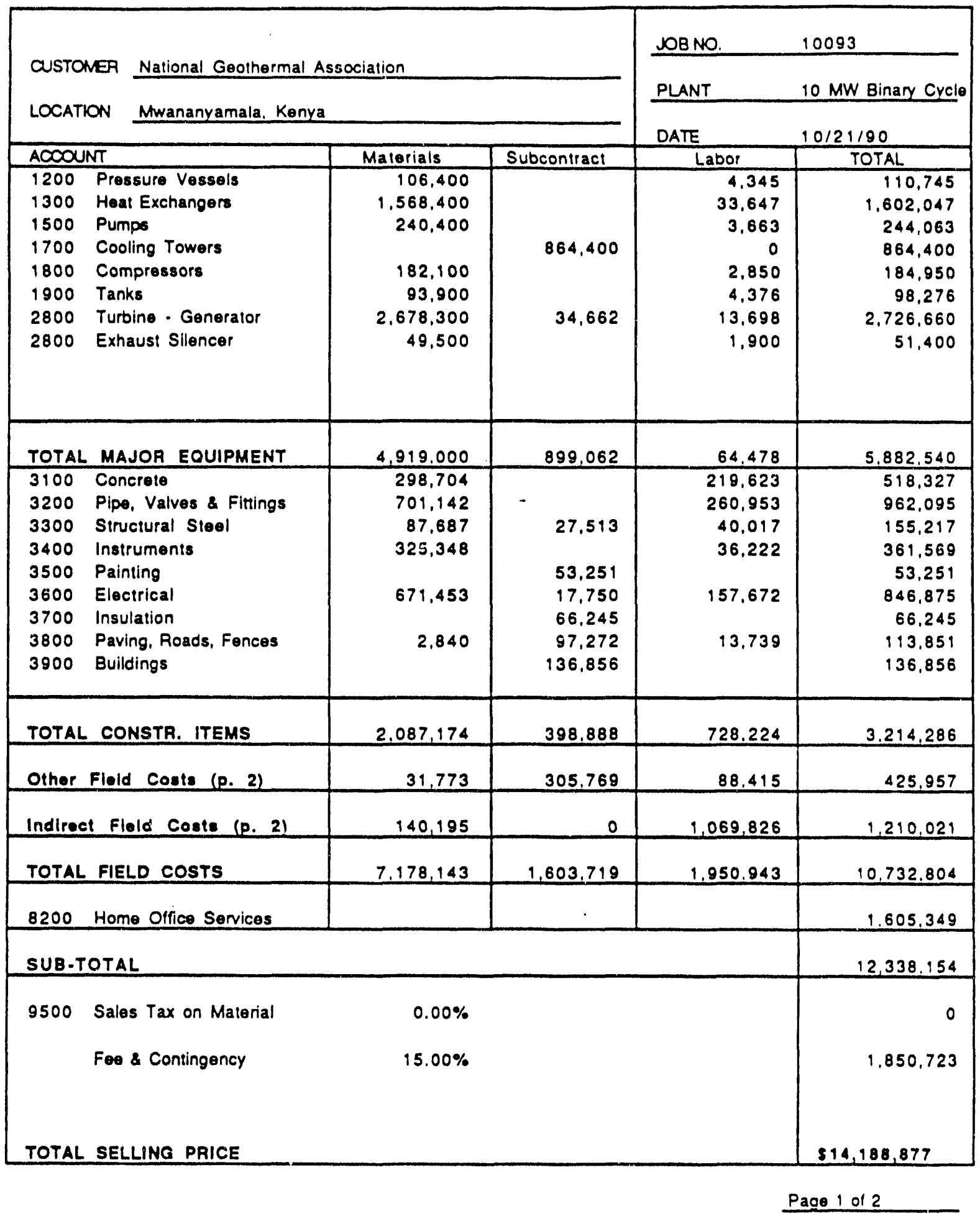


Figure V-12. Estimate summary sheet, Mwananyamala Kenya (continued)

SUMMARY. FIELD COSTS

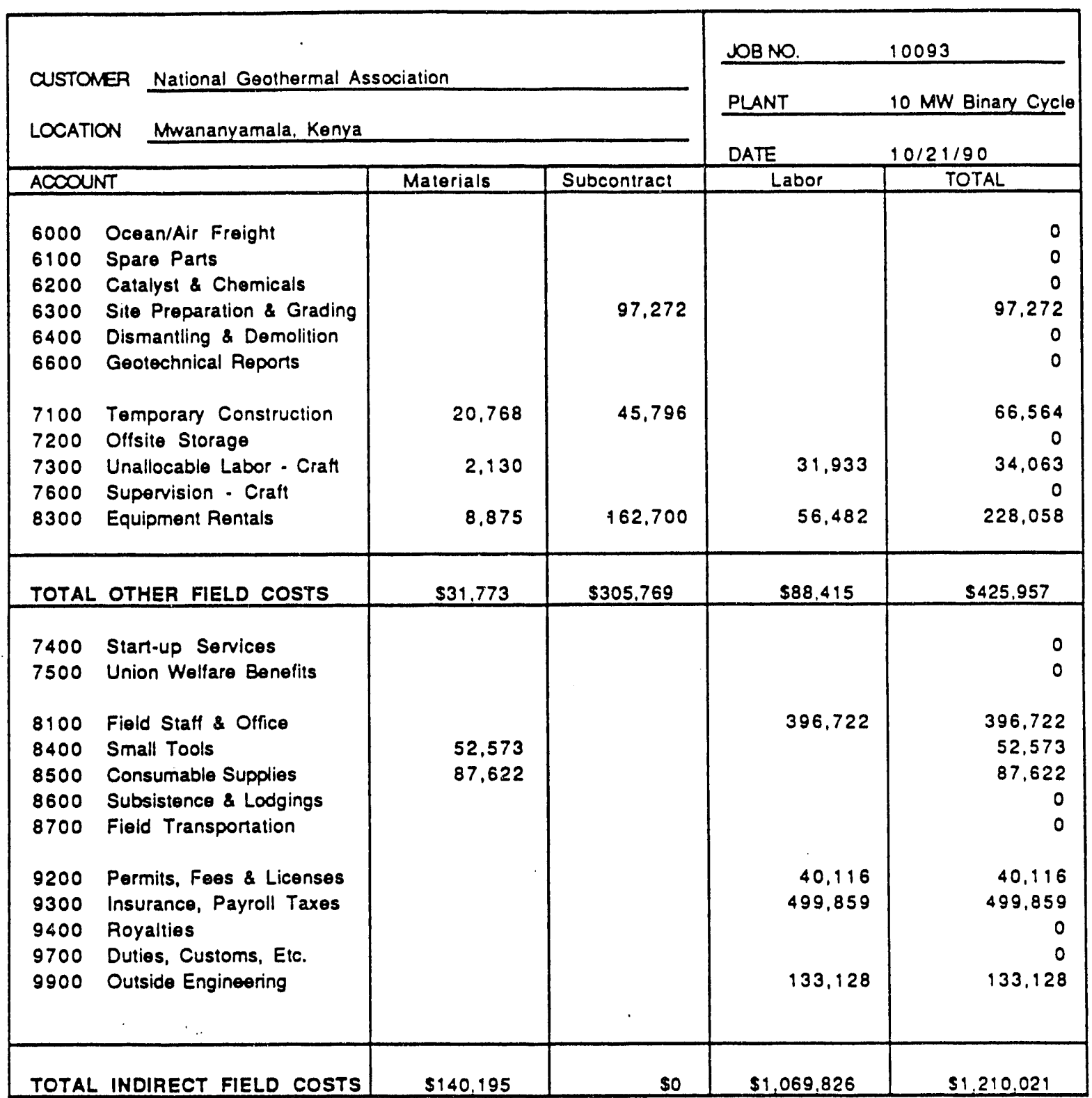




\section{d. Transmission Line}

The transmission line from the plant to the transmission grid operates at $232 \mathrm{kV}$. It is a cross country line supported by wooden H-frames. It is assumed that the transmission line corridor can take the most direct route between the power plant site and the closest approach of the nearest transmission line.

Based on U.S. costs, the transmission line is estimated to cost about $\$ 70,000$ per kilometer.

\section{e. Access Road}

For sites not currently served by an access road suitable for heavy equipment and construction traffic, the cost of an access road was included in the project capital cost estimate. The road is a heavy duty graded gravel road twenty feet wide. It includes drainage and culverts. No provision has been made for bridges, tunnels or extraordinary excavation or blasting.

The cost of this road is estimated to be about $\$ 125,000$ per kilometer.

\section{f. Project costs}

We have also estimated the amount of various intangible project costs. We have included $\$ 65$ per $\mathrm{kW}$ for siting and licensing as well as $\$ 100$ per $\mathrm{kW}$ each for financing costs and owner's costs during constructior.

\section{5. $O \& M$ cost Estimate}

\section{a. Tell costs}

The two main areas of operating and maintenance costs associated with the production and injection wells are well replacements and rework. It is assumed that over the life of the project, additional production and injection wells will be required either to replace damaged wells or to compensate for declining productivity.

In addition to well replacement, each well will require periodic, rework, cleaning, logging, etc. An amount of $\$ 100,000$ per year is provided for each well for this purpose. Overhead, warehousing and miscellaneous expenses add another $\$ 550,000$ per year. The total wellfield $0 \& M$ cost varies between $\$ 1,200,000$ and $\$ 1,600,000$ depending on project size. 


\section{b. Gathering and Injection system}

There will be three operators required for the gathering and injection system for a total of 12 hires. Based on a local labor rate of $8,000 \mathrm{kS} / \mathrm{mo}$, the annual cost is $\$ 70,000$ including overhead and benefits.

Maintenance costs include labor, materials and consumable supplies. The annual cost of labor and materials is equal to $1.6 \%$ of the facility capital cost. In addition, $0.2 \%$ is provided for supplies.

\section{c. Power plant}

There will be three operating positions required for the power plant for a total of twelve hires. As stated above, the annual cost will be $\$ 70,000$.

Annual maintenance costs are $1.6 \%$ of capital investment for labor and materials and $0.2 \%$ for supplies.

\section{d. Transmission Iine}

The allowance for the annual cost of O\&M for the transmission line is $1.0 \%$ of the installed cost.

\section{Project cost summary}

For each case, a project cost summary was prepared. Figure $\mathrm{V}-13$ is an example of the summary. Each summary contains the details of the capital and $O \& M$ cost estimates including the calculation of well, transmission line, access road and project capital costs and the calculation of the O\&M costs. 
Figure V-13. Geothermal Project cost summary, Kenya

GEOTHERMAL PROJECT COST SUMMARY

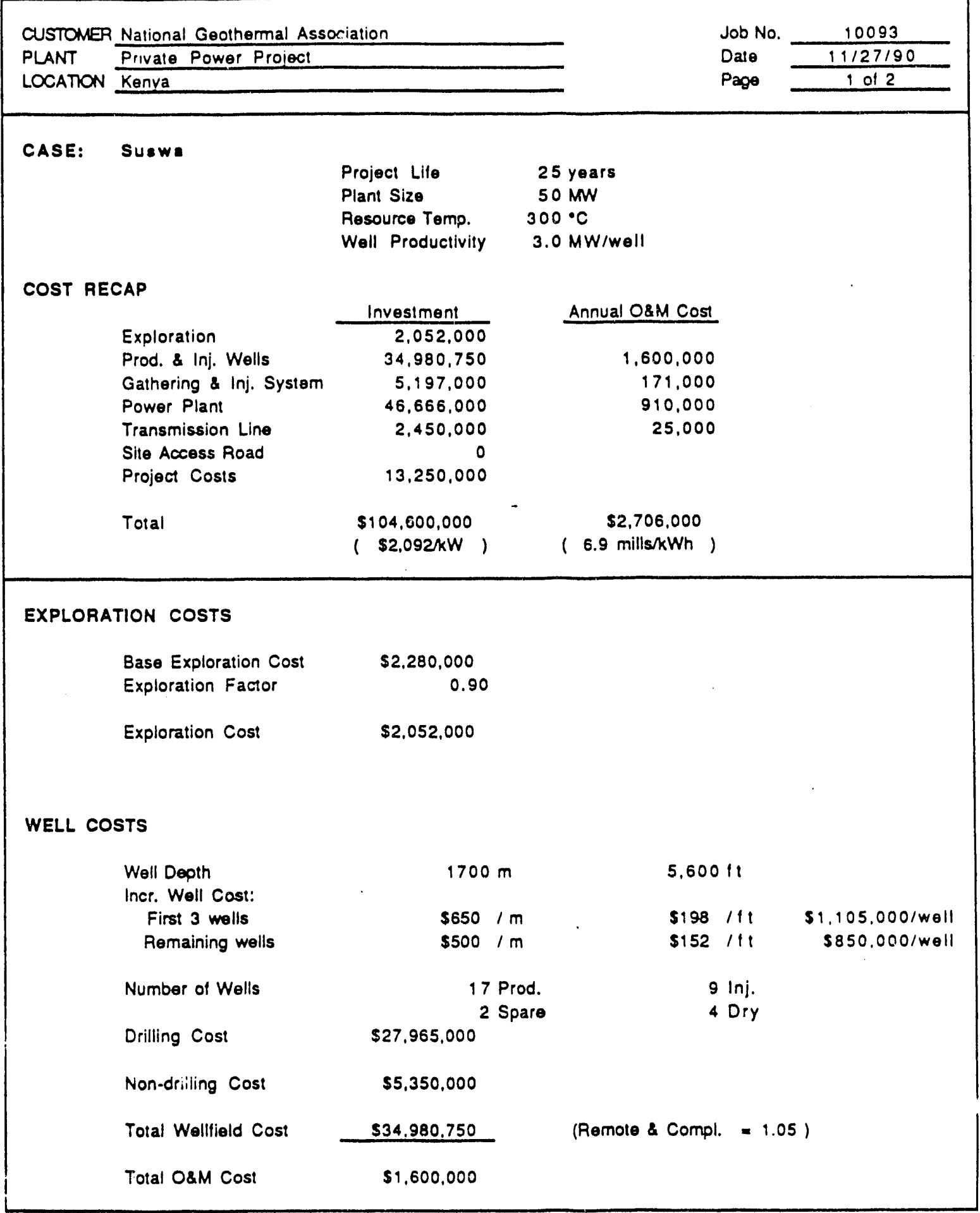


Figure V-13. Geothermal Project cost Summary, Kenya (continued)

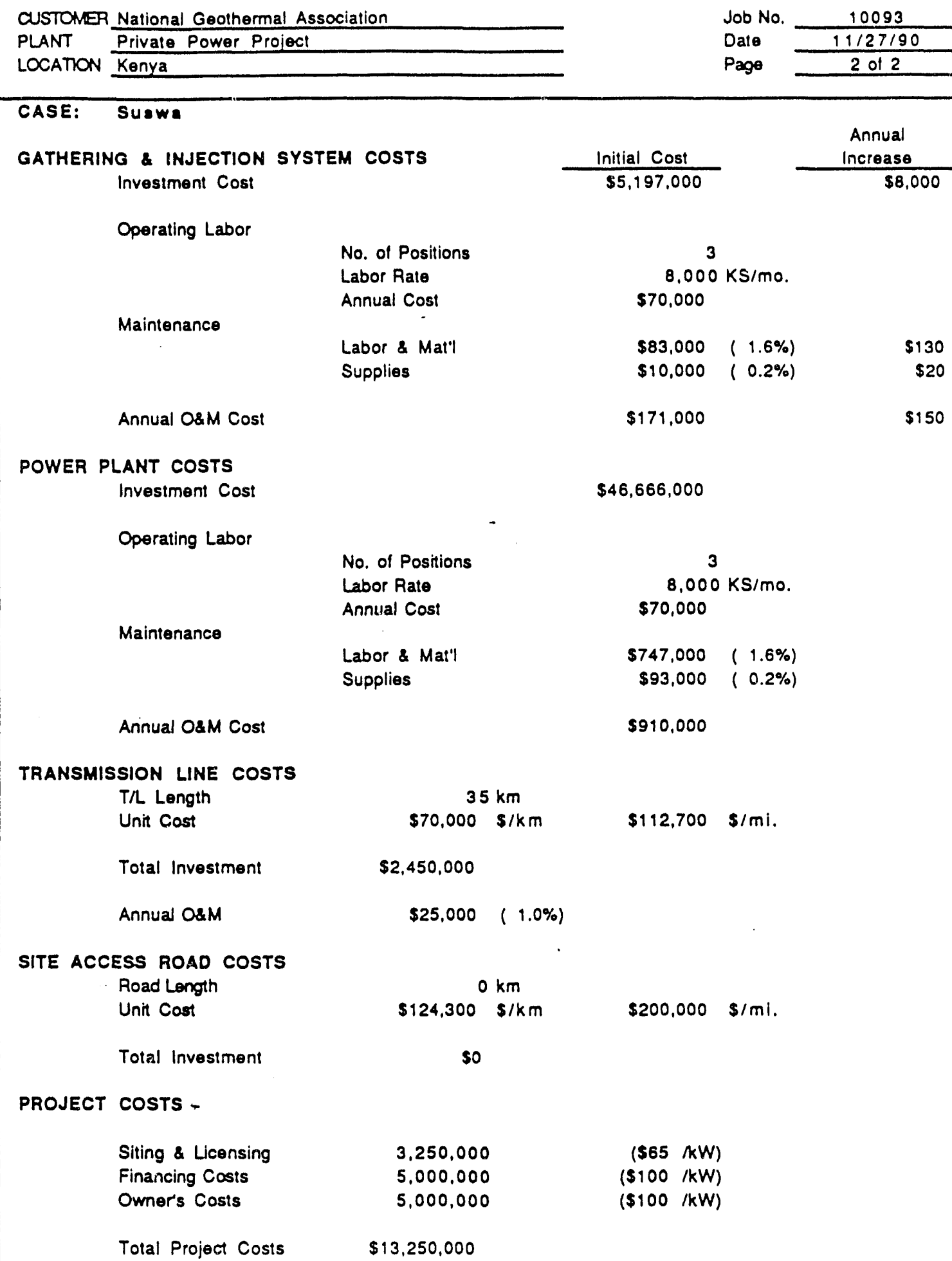

Total Investment

PROJECT COSTS -

Siting \& Licensing

Financing Costs

$3,250,000$

Owner's Costs

$\$ 13,250,000$ 


\section{A. INTRODUCTION}

Several developing countries with shortages of electric power have enacted or are considering enacting legislation permitting private financing, ownership and operation of discreet electric power generating facilities. These countries, which include the Philippines, the Dominican Republic, Pakistan, and India, are seeking to supplement the publicly financed expansion of their electric power systems through private participation. By doing so, they hope to attract new sources of capital that are not traditionally available to the power sector, and increase the efficiency of the sector by introducing competition.

Each country has followed a different although somewhat similar, legal and institutional approach to inviting private sector participation. Generally, the first step is to enact an enabling law or executive decree permitting private entry into tine power sector. This e:ther includes, or is followed by, a detailed set of implementation regulations that defines the institutional and procedural framework for soliciting, evaluating and implementing private power projects. In some countries the implementation regulations cite any incentives that the government is willing to provide to prospective project developers. In others, incentives are determined during negotiation of the power purchase and implementation agreements. purchase prices for electric power generated by the private sector are then established, and power purchase agreements are developed.

The purpose of this section is to briefly review the approash to private power taken by the Philippines, Pakistan, and the Dominican Republic. This section is not intended to provide a detailed analysis of the institutional, legal and financial structure that has been established to promote private power in each of these countries. Rather, it is intended to provide an overview of the approaches taken by each country.

\section{Phillipines}

\section{a. Electric Power system Overview}

The National Power Corporation, the government-owned national utility, has an installes generating aapacity of 5,788 MWs. The generating system is composed of 2,124 MWs of hydroelectric capacity, 894 MWs of geothermal capacity, 2,239 MWs of oil-fired steam turbine capacity, 126 MWs of diese? capacity, and 405 MWs of coal-fired capacity. 
During the ten year period 1989-1999, according to the World Bank, the Philippines will add 3,679 MWs of new capacity. The corresponding investment requirement for the new capacity, and transmission and distribution capacity additions is estimated to be $\$ 7.5$ billion. The World Bank estimates that only 28 percent of this investment requirement will be sourced domestically.

Although growth in demand for electricity has fallen from 9.4 percent in 1987 to 7.9 percent in 1989, demand is still outpacing the ability of NPC to construct new power plants. Moreover, recent droughts have reduced the reserve margin of the hydroelectric dependent utility. This situation has been compounded by frequent outages of thermal power plants. The result has been severe power shortages and increasingly frequent blackouts in Iuzon.

Anecdotal evidence suggests the cost of scheduled and unscheduled load shedding in the Philippines is high. Under a system devised in 1982 , over 1,500 industrial plants, representing nearly 75 percent of Manila's industrial output shut down once a week to conserve energy. In early 1990,365 of the largest commercial buildings in Manila temporarily established four day work weeks in hopes of receiving uninterrupted power during operating hours. Industry in the Philippines is estimated to lose $\$ 1.1$ million dollars daily due to a lack of reliable electric power.

\section{b. Private Power Legislation}

Concerned with the negative economic effects of the power shortages, the Government of Corazon Aquino enacted Executive order No. 215 in 1987 to allow the private sector to invest in electric power generating facilities. Among the provisions of its preamble, E.O. No. 215 recognizes that electric power generation is not a national monopoly, and further recognizes private participation in the energy sector as a means of increasing the nation's generating capacity without requiring financial assistance or guarantees from the government.

The Executive order establishes the types of energy facilities that the private sector may own and operate. These include cogeneration units, electric generating plants intending to sell all or part of its production to the national grid, and plants located outside the national grid system that may sell power directly to end users.

Most importantly, to simplify and expedite the process of private power project development, the Executive order required the National Power Corporation to develop a set of standard rules and regulations that define the responsibilities of the National power Corporation and the project developer in all stages of project development. These regulations were made a condition precedent for eracting in full, the Executive order. 


\section{c. Private Power Regulations}

The implementation regulations establish qualifying criteria for three categories of privately owned power facilities. These categories include: mini-private sector Generating Facilities -facilities under $1000 \mathrm{~kW}$ (later expended to $5 \mathrm{MW}$ ); Private sector Generating Facilities -- those facilities over $1000 \mathrm{~kW}$, but less than the largest NPC unit on the grid; and Block Power Production Facilities - facilities included on the NPC expansion plan, but that are developed and wned by the private sector.

Proposals for Mini-private sector Generating Facilities are submitted to the National Power corporation on an unsolicited basis, but must receive accreditation from the National power Corporation to certify that they meet the economic, ownership and engineering criteria established in the regulations. Mini-PsGF of less than $5 \mathrm{MW}$ may sell power to the National Power Corporation at various published rates depending on whether they offer firm capacity, are dispatchable, or offer "take or pay" arrangements. These rates are periodically published in national newspapers of the Philippines.

Proposals for PSGF, like mini-PSGF, are generally unsolicited, and must also receive accreditation from the National power Corporation. Upon accreditation, under the regulations, the National Power Corporation is obligated to interconnect with the facility and purchase power at the utility's avoided cost of generation. The methodology for calculating the avoided cost, and the avoided cost itself, is filed with the office of Energy Affairs, which serves to resolve disputes throughout the development and operation phases of a private project.

Proposals for Block Power production Facilities may be unsolicited, or may be submitted in response to a formal solicitation issued by the National Power Corporation. Iike MiniPSGF and PSGF, Block Power Production Facilities must also receive accreditation from the National Power Corporation. Power Purchase rates for Block Power Corporation Facilities are negotiated on a case-by-case basis.

\section{d. Private Power Projects}

In August, 1990, a $200 \mathrm{MW}$ gas turbine private power project began operation. The $200 \mathrm{MW}$ gas turbine project, was developed by Hopewell Project Management Company, Ltd., of Hong Kong, using the Build-operate-Transfer (BOT) development scheme. Under the BOT arrangement, Hopewell will own and operate the project for a period of 12 years, at the end of which time it will transfer ownership to the National Power Corporation. Revenue rrom the project originates from a two-part tariff, consisting of a capacity fee and a separate fee for energy delivered from the plant.

$$
V I-3
$$


The project was financed with equity from Hopewell, Citicorp, the Asian Development Bank (ADB) and the International Finance Corporation (IFC). Debt financing was provided by the ADB, the IFC, and a syndicate of commercial banks.

In August, 1990, NPC also awarded a consortium of Hopewell Holdings Iimited and Asea Brown Boveri the right to develop a 700 MW coal-fired Build-operate-Transfer power plant in San Juan Batangas on luzon island. NPC issued a request for proposals for the coa:-fired project in November, 1989, and had prequalified fourteen firms for bidding. The plant is scheduled for completion in July, 1993, and will be the second private power plant completed under E.O. 215.

\section{e. Private Power Investment Incentives}

The Government of the Philippines provided Hopewell Holdings, Ltd. With a number of investment incentives for the $200 \mathrm{MW}$ gas turbine project. Under the Philippines investment codes, the Hopewell project was certified a "pioneer" industry, which allows for $100 \%$ foreign ownership. The project was exempted from all revenue taxes for a period of six years, and was exempted from all import duties on capital equipment. Hopewell also received a $100 \%$ tax credit for locally supplied capital equipment, and a $100 \%$ tax exemption from the value added tax for local contractors associated with the project. The government also provided Hopewell with a vacant site for the project complete with access roads, water and telephone lines, and a transmission line to the nearest switching station.

Most importantly, the Government of the Philippines guaranteed the performance of the utility under the contract. Under the agreement, the government agrees to pay Hopewell, in the currency stated in the contract, any sum that the National Power corporation is late in remitting. This allowed the lenders to provide debt financing for the project without requiring a sovereign guarantee from the government.

\section{Pakistan}

\section{a. Electric Power System Overview}

The Water and Power Development Authority (WAPDA), the government-owned national utility, has an installed capacity of 5,115 MWs. The entire electric generating system of pakistan, including self production by the private sector, consists of $70 \mathrm{MWs}$ of nuclear capacity, 2,893 MWs of hydroelectric capacity, 1,703 MWs of oil-fired steam capacity, 847. MWs of diesel capacity, 500 MWs of gas-fired steam capacity, 865 MWs of combustion turbines, 600 MWs of combined cycle capacity and 12 MWs of coal-fired capacity.

$$
V I-4
$$


During the ten year period 1989-1999, according to the world Bank, the Government of Pakistan will require an additional 12,873 MWs of additional generating capacity. The corresponding investment requirement for new generation, transmission and distribution capacity is estimated to be $\$ 18$ billion. Approximately 46 percent is expected to be sourced domestically.

Demand for electric power has been rising at an annual rate of 11 percent since the early 1980s. The Water and power Development Authority (WAPDA), has had difficulty in keeping pace with the rapidly rising demand. The result had been the load shedding, once a seasonal phenomena, has become a year-round occurrence.

A study prepared for WAPDA and the U.S. Agency for International Development indicates that during the 1980s, load shedding in the industrial sector of pakistan resulted in an annual reduction of the value added of that sector of $8.2 \%$. The total direct and indirect costs of load shedding to the national economy represent a $1.8 \%$ reduction in gross domestic product.

\section{b. Private Power Iegislation}

Recognizing that private investment can supplement the traditional, government-financed expansion of the power sector, the Government of Pakistan was the first country to promote private power. Although it has not passed a formal law permitting private power, the Government of Pakistan has issued several policy pronouncements endorsing private power projects as a means of increasing the generating capacity of the country. In its seventh five year economic development plan (1988-1993)., the Government of Pakistan state that the private sector would contribute 2,000 of the 6,000 MWs called for in the electric power expansion plan.

A further indication of the commitment of the government to private power is the establishment of the private sector Energy Development Fund with assistance from the World Bank, the U.S. Agency for International Development and other bilateral donors including Japan, the United Kingdom, German, Canada and Italy. The Fund is designed to encourage private energy projects by lending up to 30 percent of the total project cost, which may include 50 percent of the foreign exchange costs. Loans may have a maturity of up to 23 years, with an eight year grace period. The current interest rate for loans from the fund is 14 percent.

\section{c. Private Power Regulation}

The Government of Pakistan has designated a regulatory and insticutional framework for private power. This framework, while not a formal regulatory statute, outlines the institutions responsible for the oversight of private power projects, and explains the procedures for submitting private power project

$$
V I-5
$$


proposals to the Government.

To facilitate private power development a Private Power cell was established in the Ministry of Water and Power to evaluate proposals for, and conclude agreements on, private power projects. A separate Private Power Cell was established in WAPDA to negotiate and enforce power purchase agreements.

Under the regulations, project companies must be incorporated in Pakistan. Twenty-five percent of the project capital must be in the form of equity. There is no limit to the amount of equity held by foreign entities.

Project developers may submit proposals to the PPC of the Ministry of Water and Power either in response to a request for proposals or on an unsolicited basis. Proposals submitted in response of a request for proposals are evaluated according to the following criteria:

* Qualifications of the project sponsors, contractors, and equipment suppliers;

* Ability of the proposed project to meet the required technical standards;

* Ability of the proposed project to meet the environmental guidelines and the occupational safety and health guidelines of the Govermment of Pakistan;

* Ability of the project to attract full financing; and

* Cost estimates presented as a basis for the sale of electricity are soundly based and reasonable compared with the costs that would be incurred if WAPDA were to undertake the project.

The winning proposals is issued in a letter of intent by the Ministry. The developer finalizes the proposal by preparing an implementation plan for the project, completing the environmental assessments, and closing any price reopener that were in the original proposal. The final step is to negotiate and sign a power purchase contract with the Private Power cell of WAPDA and an implementation agreement with the Ministry of Water and Power.

Unsolicited proposals are submitted to the PPC of the Ministry of Water and Power, where they are evaluated to determine if they:

* Are consistent with government policy;

* Form part of the least cost expansion plan of the utility;

* Do not conflict with government plans for solicited proposals.

If approved, the government issues a letter of interest to the developer, which permits him to undertake a feasibility study for the project. The feasibility study is submitted to the PPC of the 
Ministry, which evaluates the project using criteria similar to those used in the evaluation of solicited projects. If approved, the project is issued a letter of intent, enabling the developer to finalize the proposal and enter into contract negotiations.

\section{d. Private Power Incentives}

\section{Enhancement of Security Package}

Private power projects in Pakistan, as elsewhere, are financed on a limited recourse basis and, therefore, require a set of interlocking agreements to give security to lenders. To provide greater security to the lenders, the Government of pakistan is prepared to enhance the security package by assuming certain risks. The security enhancement package offered by the Government, and subject to negotiation on a case-by-case basis includes:

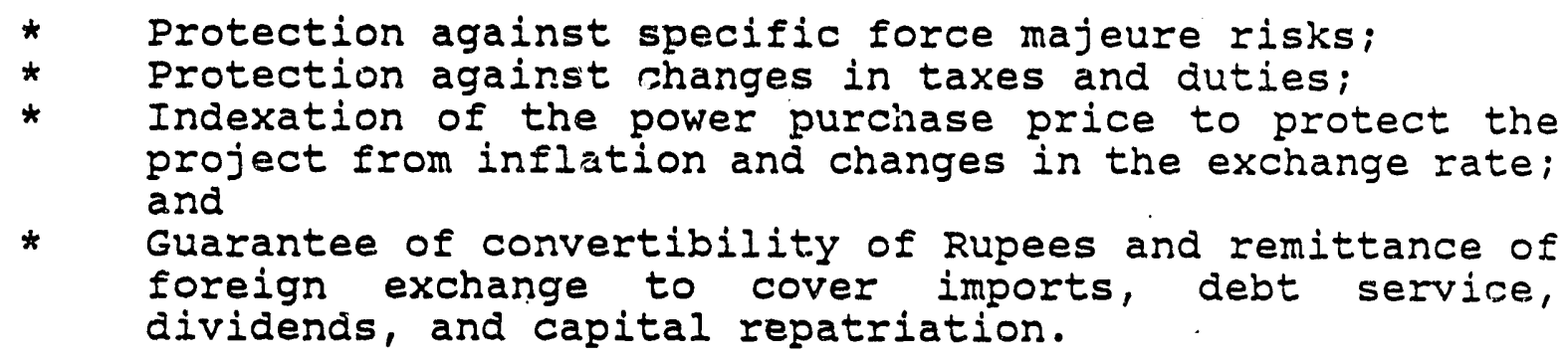

Most importantly, the Government guarantees the performance of WAPDA under the power purchase contract. If WAPDA fails to take the amount of power contracted for, the government will compensate the project company for the difference in the amount of power taken by WAPDA and the amount called for in the power purchase contract.

\section{Fiscal Incentives}

The Government of Pakistan provides the following fiscal incentives to project developers:

\footnotetext{
* Exemption from corporate income tax;

* Exemption of partial exemption from custom duties and sales tax on imports and machinery; and

* Makes available preferential loans for the purchase of locally manufactured machinery.
}

The project development company may also make use of the Private Sector Energy Development Fund.

3. Dominican Republic

a. Electric Power system overview

$$
V I-7
$$


The Corporation Dominica de Electricidad (CDE) is the government-owned utility, and has the obligation to provide the citizens, industry and commercial operations in the Dominican Republic with electric power. The CDE system has an installed generating capacity of 822 MWs. The entire generating capacity of the country, including self production by the private sector, consists of 205 MWs of hydroelectric capacity, 552 MWs of oil-fired steam turbine capacity, $14 \mathrm{MW}$ of diesel capacity and $219 \mathrm{MWs}$ of coal-fired capacity.

The country is currently suffering from a prolonged period of crisis in the electric power subsector. Much of the installed capacity is unavailable due to poor maintenance of the thermal plants. The transmission and distribution system is deteriorating, 30 percent system losses as a result. Blackouts occur from eight to twelve hours daily in some regions of the country.

The national utility currently accounts for approximately twothirds of the national debt. According to the World Bank, CDE will require $\$ 1.5$ billion during the period 1989-1999 for power generation expansion. An additional $\$ 500$ million will be required for transmission and distribution expansion. of this $\$ 2$ bililon, only 15 percent is expected to come from domestic sources. Private power is seen as a means of attracting new sources of capital to the power subsector.

\section{b. Private Power Legislation}

In 1988, President Balaguer issued an emergency decree calling for proposals for private power projects in the Dominican Republic. This followed in 1990 by formal passage of Law 14-90, which permits and encourages private investment in power generation facilities in the Dominican Republic. The purpose of the law is to promote and stimulate new electric power companies, both national and foreign, that contribute to the economic development of the country.

In its preamble, Law 14-90 states that electric energy is essential to the socioeconomic development of the nation. The preamble also states that the development of the electric power subsector will require substantial capital investments, and that the Government of the Dominican Republic is obligated to distribute its limited capital resources equitably among the many sectors of the economy that promote ...social and economic development. Therefore, to supplement it is inviting private investment to develop the electric power subsector.

\section{c. Private Power Regulation}

Law 14-90 creates a Directorate for the Development and Regulation of the electric power industry, which is charged with the regulation of the interaction between private electric power

$$
V I-8
$$


producers, $C D E$, and consumers. Under the law the Directorate is responsible for developing regulations to promote in an orderly manner, private investment in the electric power subsector.

The Directorate is composed of the Ministry of Industry and Commerce, the Ministry of Finance, the Technical Minister of the President, and the Governor of the Central Bank of the Dominican Republic. An Executive Director is appointed by the President to oversee the operations of the Directorate.

As stated in the law, the Directorate is responsible for the following:

* Establishing private power tariff rates;

* Defining the technical specifications of interconnection of private producers and CDE; and

* Supervision of contracts between private producers and CDE.

The Directorate also receives "petitions" from potential private power producers seeking approval of their projects and the granting of fiscal and other incentives provided under Law 14-90. As stated in the law, the "petitions" must contain the following information:

* Draft proposal with preliminary details on the engineering, cost, generation, and local participation;

* Technical and economic feasibility study;

* Investment document stipulating that the flow of funds will cover the amortization of the project;

* Itemization estimate of the dollar requirement for the period of the tax exemption will last (see incentives section below);

* Statement on the impact of the project on the national economy; and

* Study on the environmental impacts of the project.

The Directorate is charged, subject to the terms of reference to be developed under the regulations, with reviewing the "petitions" and granting approval of the project incentives.

\section{d. Private Power Projects}

The United States company, seaboard corporation, owns a $40 \mathrm{MW}$, barge-mounted diesel project that sells power to CDE. The project was developed by Transcontinental Capital corporation Itd. of Bermuda, a wholly owned subsidiary of jeaboard. The project was proposed under the emergency decree issued by president Balaguer in 1988 , and is estimated to cost $\$ 22$ million.

e. Private Power Incentives

$V I-9$ 
The Government of the Dominican Republic offers fiscal incentives to private power project developers. Under the legislation, the incentives are approved by the Directorate and may include the following:

* 100 percent tax exemption from income tax payments on revenue generated by private electric facilities;

* Exemption from tax on property purchased for private electric facilities;

* Exemption from taxes on the formation of private electric companies;

* Exemption from commercial patent taxes;

* Exemption from taxes on imported or domestically purchased fuels, materials, lubricants and other articles purchase for the construction, operation, and maintenance of private electric facilities; and

* Guarantee of the supply of U.S. Dollars required for the importation of goods and services, the amortization of project debt, and the repatriation of profits from private electric facilities.

The tax exemption period corresponding to each project is twenty years dating from the resolution of approval of the Directorate. This period may be extended an additional five years, provided that at least one-half of the capital of the project is held by Dominican Republic nationals at the conclusion of the initial twenty year exemption period.

Similar to the Government of Pakistan, the Government of the Dominican Republic also guarantees the contractual performance of its utility, $C D E$, regarding the sale and purchase of electric power, provided that the contract has been authorized by the Executive Power. 
B. SETTING A PRICE FOR PRIVATELY GENERATED POWER: AVOIDED COST

\section{Overview}

Experiences in other countries have shown that establishing the methodology for calculation of avoided costs is a very sensitive and time consuming issue. It is acknowledged and accepted by the private sector that the price paid and resources developed should promote the development of the least cost generation plan for Kenya. At the same time, given the risks of developing geothermal resources, development of the first-ever private power project in Kenya, foreign exchange and institutional and other risks, the price paid for power needs to offer adequate incentives to private developers. In principle, the method for determining the price to be paid should be simple to use, and permit adjustments over time for contingencies which might arise such as changing exchange rates, taxes, cost of doing business in Kenya, etc. It is critical that any agreement be adequate to satisfy the financial community that the project presents a reasonable loan risk. Several of the alternatives for determining the price, or establishing a basis for determining the price, of private power sold to Kenya Power and Lighting or Kenya Power Company is the subject of the discussion below.

\section{a. Avoided Cost}

One of the most common bases for determining price to be paid for purchased power is the so-called "avoided cost." In the United states following the implementation of the 1978 public utilities Regulatory Policy Act, electric utilities were required to purchase power from private generators at "avoided cost". These avoided costs consisted of two parts, an energy component, which was based on the short-run incremental operation cost of the utility less losses; and a capacity component, which was based on the marginal cost of new capacity. The basic objective of avoided cost pricing is to find a fair and readily implementable means for determining the value to the utility for additional private generation.

There has been substantial experience in the application of avoided cost principles in the United States, however determinations are always subject to negotiation. several key factors enter into the valuation of, and computation of price to be paid for private power purchases. The most prominent of which are:

* reliability--to what extent will the powor generated be available when needed and in the amount needed.

* energy and capacity value of power--how are the values for kWh's and kW's supplied to be determined. What costs are displaced by private power sources, are these merely

VI - II 
short-run operating costs (e.g. for cogenerators of small amounts of non-firm power) or do they include new capital investment by the utility.

* avoiding commitments to unnecessary capacity--how does the utility ensure sufficient capacity investment while avoiding overcommitting to private generation and therefore incurring excess costs.

* impact on subsequent generation expenditures and timing and valuation of these effects-how to determine the value of private power in terms of future deferral of new capacity or other expenditures.

* balancing incentives with consumer costs--ensuring an adequate incentive for the private developer while not burdening the system with unnecessary costs.

Many approaches have been applied to determination of avoided costs, and several are discussed briefly here for background.

1. Component Approach In this method short-run marginal operating costs of the utility are used for valuing energy supplied, and capital costs avoided are assumed to be equal to the costs of a new combustion turbine or other peaking facility. This approach is convenient and relatively easy to calculate. However, the approach also underestimates actual avoided cost, as the longrun costs of new baseload generation would obviously be higher than a peaking unit. other current and long-run system effects would also be excluded.

2. Differential Revenue Requirements Method This approach requires the modeling of the system over a substantial period of time, e.g. 25 years, with the development of a least-cost expansion plan for the period. Addition of the private power project into the plan is used to generate a revized least-cost plan, together with revized revenue requirements each year. Differences in revenues (savings due to the private project) are the amounts which could be paid the private generator. The complexity of this approach is the principal disadvantage, with the utility possibly the only party with access to all the data and capability to run the necessary model. The smaller the increment of capacity added by private generation in relation to the system, the less costeffective this approach. Nonetheless, with access to data, agreement on assumptions and openness regarding the methodology by the utility, this method is probably the closest approximation to the "correct" result.

3. Proxy Approach This approach is similar to the component approach in that it utilizes the capital and operation cost of an "avoidable" unit in the generation mix. Rather than only use a peaking unit however, it is more normal to use the next expected

$$
V I-12
$$


generation unit as the basis for estimated avoided cost payments for the private generator. The method is very simple, however it is likely to be only a rough estimate in that it does not consider other system effects or costs based on the planned dispatching of the "avoidable" unit, or project timing. Differences in reliability of the private versus utility generation are normally included.

4. Competitive Bidding This approach is meant to approximate the results of a free-market for capacity. It is normally based on the utility requesting offers according to type and size of capacity, timing, reliability, and baseloadintermediate-peaking needs. The utility would compute its avoided cost, e.g. utilizing the differential revenue method above, to establish a baseline for evaluating proposals. Based on the efficiency, cost of capital and other criteria of the bidder, the utility would hope to obtain power at or below its avoided cost. other factors than price would affect the evaluation, including the utilities judgement of the capability of the bidder, fuel type and future cost of fuels proposed, type of generation and perceived reliability and performance, etc. Furthermore, this method would only work with a substantial number of willing bidders, with the utility committed to purchase, and with the utility willing and able to facilitate arrangements once bids are accepted.

5. Alternative Approaches for special Situations where the size of individual projects is likely to be small, e.g. in systems with cogeneration of electricity and steam, or with initial small private projects, another option is the "standard offer". That is, after considering its avoided cost, the utility prepares a standard offer similar to a public tariff. This approach avoids costly negotiation and analysis by the private generator, and is likely to be very conducive to sales from small-generators. The offer will normally differentiate respectively, between only energy purchases, firm capacity supplied, dispatchable capacity, etc. This method can also be applied to larger generation units, although given the much greater capital requirements and risks involved, it is likely that such sales will always require substantial negotiation on price and terms in any event.

6. Incremental costs In tariff setting, the principle that rates should equal long marginal cost has been fairly-well accepted as economically correct. This basis should ensure that national economic resources are allocated efficiently within the power sector. This principle when applied to tariffs results in a fair allocation of costs amoung customers according to the costs they impose on the system, assures reasonable price stability and raises sufficient revanue to meet financial requirements of the utility. Applying this principle to power supplied leads to a similar result, that is, power supplied is worth the long-run incremental cost "avoided". The long-run incremental cost analysis therefore provides a result, on a kWh supplied basis, similar to the 
differential revenue analysis above. Long-run incremental cost however, is often calculated without explicit consideration of the multitude of financing methods for each unit of capacity, and therefore may give results somewhat different that a differential revenue analysis (based on a detailed financial model).

\section{b. Application of Avoided Cost Principles in Developing countries}

There are a number of critical differences in determining avoided costs in the developing country context that must be noted. The methodologies above all assume some estimation of the utilities revenue requirements utilizing the utilities normal financial model. Revenue would correspond closely to the actual financial costs. In using these methods in a developing country for power purchase pricing, however, substantial divergences in avoided cost theory occur, and require adjustment of terms. These occur for the following major reasons:

First, developing countries receive substantial subsidies in terms of grants and below market interest loans which do not reflect "econoinic" or free market values, nor certainly the cost of private development.

Comment: Since concessional or below-market rate loans (e.g. IDA financing) for power supply are normally strictly limited in total, deplacing these from the power sector into other development projects involves no loss to the country. In fact, since private foreign investment and often domestic private finance is scarce, additional capital offered as part of the private project is a net gain to the country.

second, large-scale power generation development is a risky undertaking, particularly so where actual resource exploration is required as with geothermal development.

Comment: It is necessa-y and appropriate to add to avoided costs in the differential reveneue calculation, the benefits of avoiding substantial risky or costly development expenditures such as with geothermal resources.

Third, there are great management and logistics and cash flow problems facing an electric utility growing at rates of 5-6\% per year, that is, with peak demand doubling in 12-14 years.

Comment: Introducing private financing, management and technical expertise as a complement to the utility, initially at low levels, is an excellent way for the utility to cope with high rates of growth, financial constraints and technical uncertainties. The U.S. example clearly demonstrates this principle, in fact between 1980 and 1985 more than 800 private power producers filed applications for over $24,000 \mathrm{MWs}$ of new

$$
V I-14
$$


capacity. Electricity production from private producers grew by $64 \%$ during this perlod, while total electricity production grew only $6 \%$.

Based on the revenue above it was determined that for purposes of this study, two basic comparisons would be most useful as a starting point. First, the results using the differential revenues methodology. And second, estimating the annual and average incremental cost of power. Given the linitations of this prefeasibility study we were not able to fully simulate the results using the differential revenue methodology. Nonetheless, judging this approach to be one of the best, we have attempted to approximate results of using this method in section $I$. our rough estimates we feel provide good representative values regarding differential annual revenues requirments with and without the private project. We have also provided estimates of annual and average incremental cost per $\mathrm{kWh}$ as another conventional basis for determining the value of private power. 


\section{References:}

1. Yves Albouy, "Guidelines for Marginal-Cost Analysis of Power Systems," World Bank Energy Department Paper No. 18, June 1984.

2. Pirooz Sharafi, "Implementing Requirements for Private Power," Seminar on Private sector Participation in the Energy/Power sector of Jamaica, September 10-12, 1990.

3. Mohan Munasinghe, "Electric Power Pricing Policy," World Bank, staff Working Paper.

4. Republic of Kenya, "Economic Survey 1990," Centreal Bureau of statistics, Ministry of Planning and National Development, May 1990.

5. Electric Power Research Institute, "Technical Assessment Guide," July 1979.

6. Acres International, "National Power Development Plan for Kenya-1986-2006", July 24, 1987.

7. Ewbanks Preece, Various tables and data, 1990.

8. Kenya Power and Lighting Company, Personal Communication Various tables and data, August $17,1990$.

9. Kenya Power and Iighting Company, "Prices for Electricity Supplies," June 1990.

10. Kenya Power and Lighting Company, "Report and Accounts for the Year Ended 30 th Jne, 1989.

11. National Geothermal Association, "Geothermal Resource Development Opportunities in Kenya," December 1988.

12. Overseas Private Investment corporation of the U.S., "Investment Finance Handbook", "Investment Insurance Handbook", 1990 editions.

13. Multilateral Investment Guarantee Agency, "Investment Guarantee Guide," World Bank, 1990 edition.

14. Export-Import Import Bank of the United States, "Program Selection Guide," January 1989.

15. Export-Import Import Bank of the United States, "Medium- and Iong-Term Export Loans and Guarantees," August 1988.

16. World Bank, "Pakistan:Private Sector Energy Development Project-Ioan and Project Summary," undated.

$$
V I-16
$$


17. Douglas J. Smith and Mona Reynolds, "Utilities Adapt to Growht of Independent Power," Power Engineering, May 1988.

18. Hagler, Bailly and Company, "Private-sector Power Generation in Thailand: Potential, Impediments, and Policy Issues," November 1986.

19. Mohan Munasinghe, "Electric Power Economics," Butterworths, 1990.

20. Scott Fenn, Susan Williams and Douglas Cogan, "Power Plays," Investor Responsibility Research Center, 1986. 
Section VII. PRIVATE POWER PROJECT FINANCIAL ANALYSIS

\section{A. INVESTMENT CLIMATE IN KENYA}

\section{Historical overview}

Since independence, the Government of Kenya has encouraged foreign and local private investment and has provided adequate measures to safeguard private enterprises. Kenya has followed a basic economic policy that emphasizes the role of the free market. Features of this system include the use of market-based pricing incentives, a liberal investment code, flexible exchange-rate management, and a fairly appropriate fiscal policy. Nevertheless, impediments to a free market economy still exist. The government is heavily involved in key sectors of the economy, and many parastatal organizations do not make efficient use of government funds. Foreign corporations in Kenya complain of excessive bureaucracy causing lengthy delays in obtaining government approvals for projects.

\section{Economic Overview}

Kenya's economic performance has been fairly strong during the past 5 years. The growth rate of the country's real Gross Domestic Product (GDP) averaged $5.1 \%$ per year between 1985 and 1989. The Government's major contribution to this success has been the provision of an enabling environment through trade liberalization, reduction of average level of tariffs, budget rationalization and appropriate monetary policies. In 1989, overall GDP, which had risen by $5.2 \%$ in 1988 , grew at a more moderate rate of $5.0 \%$.

There has been double-digit inflation in recent years. The rate of inflation was $10.7 \%$ and $10.5 \%$ in 1988 and 1989 respectively. A major cause of inflation was the increased cost of imported machinery and intermediate inputs (petroleum).

Kenya's main foreign exchange earners are tourism, coffee and tea. Kenya's US\$815 million export earnings the US\$1.5 billion (1989) imports leave a large deficit financed mainly by capital inflows, including foreign aid. Coffee and tea account for slightly over half of total exports. Horticulture, a rapidly expanding export item, provides over US\$50 million annually.

Kenya has a good transportation system and telecommunications network. Nairobi, the capital, and Mombasa, the largest Indian ocean port between Karachi and Durban, are the hubs of Kenya's infrastructure. Nairobi has an international airport served by more then 25 airlines. Kenya is considered to have generally dependable electric power, industrial fuel and water supplies. Inadecuate maintenance of the physical infrastructure, however, threatens

$$
\text { VII - I }
$$


industrial expansion. Kenya is represented by all major international development agencies and a number of foreign private banks.

\section{Government Attitude Toward Foreign Private Investment.}

The Kenyan government continues to publicly encourage foreign investment. In his 1988 and 1989 Government Budget speeches, the Minister of Finance testified to the Government's need to improve the investment climate. The government is aware of the critical role foreign investment plays in generating employment, new skills and foreign exchange. However, there remain difficulties related to the slow pace of removal of investment disincentives, such as excessive regulation, profit and dividend repatriation, restrictive industrial and banking laws, foreign exchange limitations, and rising levels of bureaucratic "red tape".

\section{B. OPTIONS FOR PRIVATE POWER DEVEIOPMENT IN KENYA}

There are many financial and corporate structures which accommodate the needs of the private investor, the local utility and the government in a private power project. Typically, a private developer sets up a foreign corporation in a joint-venture relationship with the local utility. The joint-venture corporation can provide off-balance-sheet financing, and is structured to share the risk and rewards of the project. Certain performance guarantees are required. These are usually obtained through contractual obligations, deficiency agreements or other similar agreements that ensure that the debt servise to the project will be paid. Such type of agreements are discussed in detail in section VIII of this report.

The most common structures for privately owned and financed projects are (a) the Build, Own and Transfer structure (BOT), (b) the Build, Own and operate (BOO) structure, with no transfer, and (c) the Build, operate and lease structure (BOI), where the private developer builds and owns the project but leases the plant to a government entity. Figure VII-I illustrates a typical BOT structure.

In a BOT, a private developer finances, builds, owns and operates a power plant, and selis power to the electric utility under a power purchase agreement for a prescribed term (which commonly varies from 10 to 15 years). After the agreed-upon term, the title to the power plant is transferred to the utility, and the utility assumes full responsibility for ownership and operations. Foreign exchange is used to service debt and pay a return to foreign joint-venture participants; and local currency is used to pay local returns and to fund construction, operating and maintenance costs. 


\section{Typical BOT Power Project Contractual Structure}

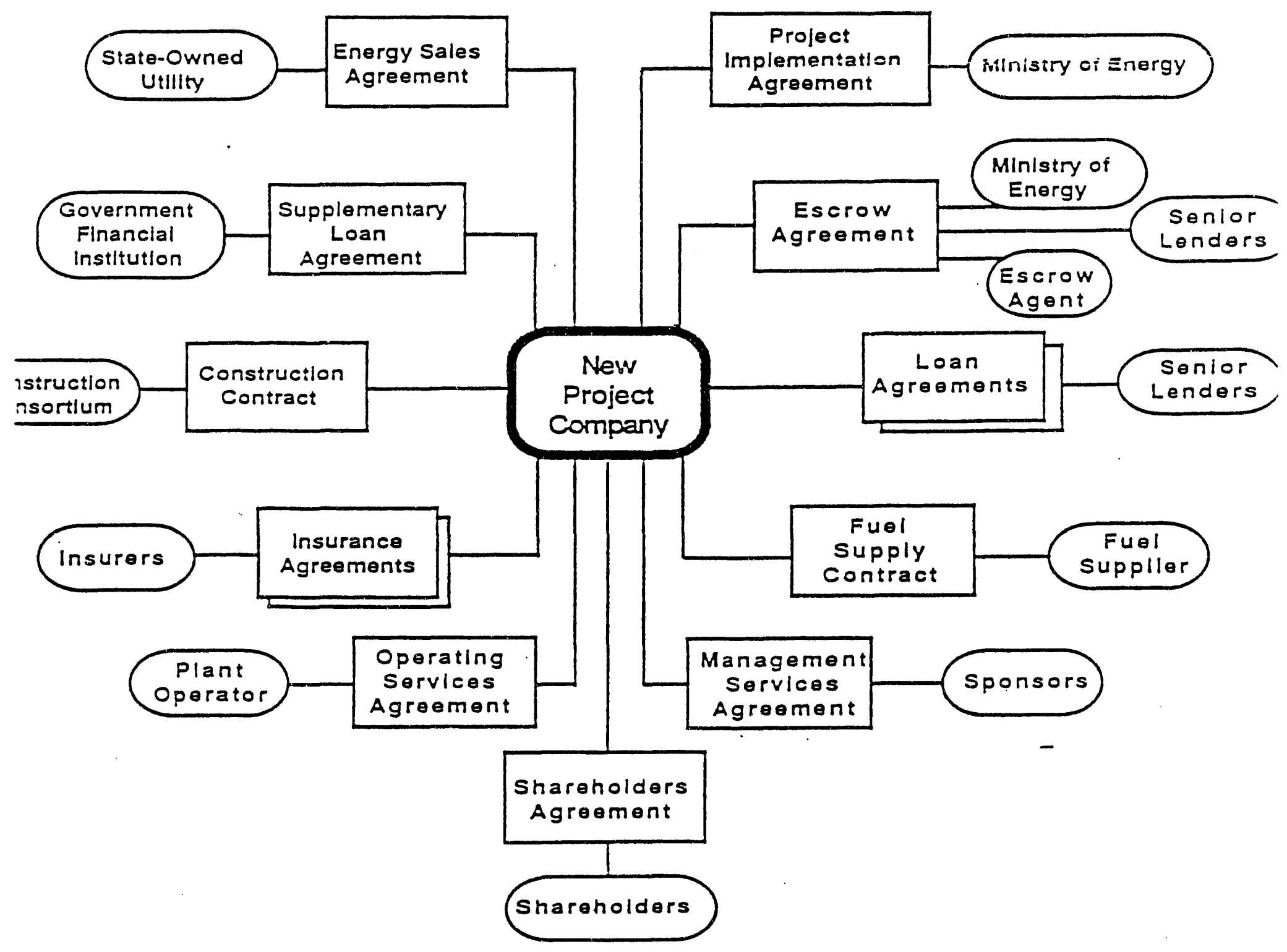


Typically, the following conditions are necessary for the successful implementation of a BOT project:

1. The project must be economically viable.

2. Investors and lending agencies will require adequate security/collateral, and a repayment stream in the currency of the investment in order to service its debts and provide an adequate return on investment.

3. The Government must be credit-worthy, and must agree to pay for the generated electricity at a realistic price for the term of the equity investment.

4. The foreign lenders and project sponsors need assurance that there will be no interference with the conditions and terms agreed upon in the contract during the operational phase of the project until project ownership has been transferred to the government. This includes such project management issues as removal of employment restrictions, tax and duty exemptions, etc.

\section{PRTVATE POWER FINANCING ISSUES}

The following issues are considered extremely important to financing agencies when considering funding a private power project:

1. Ability to negotiate necessary contracts: Government approvai must be timely and satisfactory to lending agencies.

2. Construction delays: Cost overruns, delays and contractor problems must be avoided. Therefore, the selection of the prime contractor is of extreme importance.

3. Performance output shortfalls: The size of the resource must be tested and proved by independent consultants.

4. Exchange rate fluctuations: Debt and return payments should match the currency of the lending agencies or should have escalation clauses or escrow accounts.

5. Environmental permitting problems: Environmental opposition can cause lengthy delays. Projects should be designed to avoid environmental issues.

6. Technical failure: Unexpected technica? problems, such as obsolete equipment or new, untested equipment, can cause delays. 
D. POTENTIAL ROIE OF KENYA POWER AND LIGHTING COMPANY, ITD.

Experience in other developing countries has shown that the utility company participation in the private power project leads to better acceptance of the project by the government and investors and to more effective project performance. Some of the potential roles of the foreign developer and local utility are:

I. Utility company responsibilities include:

-calculation of avoided costs.

-establishing standards for drilling, construction and operation phases.

-negotiating terms for power purchase contracts.

-establishing a system for reporting electric purchases.

2. Project sponsors responsibilities include:

-submitting proposals.

-conducting technical and economic feasibility studies.

-arranging financing.

-negotiating agreements with equipment suppliers, construction contractor's and other related services.

- negotiating terms for power purchase contracts.

-conducting drilling, field development and construction operations.

\section{E. FINANCING OPTIONS}

\section{Traditional sources of Capital}

a. Project sponsor.

The project sponsor is typically a party to the joint-venture, and normally contributes the equity or risk portion of the project's capital. This may include cash, capitalized equipment, technology transfer or in-kind services. project sponsors often provide overrun funding (subordinated loans) and completion guarantees.

\section{b. Commercial Banks.}

The principal advantages of obtaining loans from a commercial bank are the availability of funds ind funding flexibility. Commercial banks generally have medium terms (5-10 years) at a floating interest rate. It is common for a major project to obtain a syndicated loan, wherein the lead bank seeks participation from other large commercial banks to fund a sizeable portion of the project.

$$
V I I-5
$$




\section{c. Export Credit Agencies.}

The most common form of export credit support is provided by major government agencies of the suppliers' countries. This support can include direct loans, insurance, interest rate subsidies, and protection against inflation and exchange rate risk.

\section{d. Bilateral Aid.}

Projects in certain countries may be eligible for bilateral aid. This aid is usually highly concessionary (low interest rates and long grace and repayment periods). Such aid can be useful in providing technical assistance, funding feasibility studies or funding infrastructure. Disadvantages of bilateral aid are that it is generally not available in large amounts to any one country on a continuing basis, and it is frequently tied to procurement from the country providing the funds.

\section{e. Multilateral Development Banks.}

The multilateral development banks are a frequent source of funding for projects in developing countries. The major institutions in this category for sub-Saharan Africa are the world Bank (and its affiliated institutions, the International Development Association and the International Finance Corporation), and the African Development Bank. Development bank funding is divided into soft loan lending (low or zero interest rates and long maturities of 30-40 years) and hard lending (higher but stili below-market interest rates and shorter maturities of 15-20 years). In addition to providing financing, development banks can provide assistance in conducting feasibility studies, and infrastructure support.

\section{Iocal Sources of Funds}

Domestic capital markets in developing countries are often underutilized, and could provide local financing for a private power joint-venture. Kenya has recognized the importance of these markets and is seeking to expand them. In 1989, the Government of Kenya established a Capital Markets Authority. This Authority has been directed to create instruments and a trading mart for the development of an active, effective and efficient securities market in kenya. It is also expected to provide additional sources of investment financing, especially since the current long-term credit market is largely non-existent.

The Kenyan banking system consists of the Central Bank, 24 commercial banks (which include Kenya Commercial Bank, Barclays Bank, Citicorp, standard Chartered Bank, and National Bank of Kenya), and about 50 non-bank financial institutions. Two equity

$$
\text { VII - } 6
$$


capital companies, Industrial promotion Services Itd. (IPS), and Kenya Equity Capital, Itd., provide venture capital for mediumsized investments.

\section{Other Sources of Funds}

Current economic conditions in many developing countries have required creative financing methods for large, capital-intensive projects. Some of these are:
a. Private equity financing.
b. Debt-equity swaps.
c. Sale of power directly to the end user.
d. Joint venture with a local oil or gas company.
e. Lease options.
f. Expansion and development of local capital markets.
g. Debt-energy swaps.

All of the options listed above are potential financing mechanisms for use in a kenya private power project. The feasibility study for each specific geothemal project will address specific financing options for that project.

\section{F. FINANCIAL ANAIYSIS}

The first stage in the selection of one or more geothermal project sites consisted of screening the various prospects, ranking them and eliminating those that were clearly unattractive or uneconomical. Installed costs for the most attractive prospects were then computed. This revealed significant cost sensitivity in relation to the size of the geothermal power plant. The following financial analysis is based on the 3 most likely prospects (Suswa, Eburru and Arus) as outlined by Geotherm $\mathrm{xx}$ in Section IV. Installed cost and plant operating costs were taken from data provided in section $V$ prepared by the Ben Holt Company.

\section{The Financial Model}

A spreads-eet financial model was developed, using Lotus 123 softwar:. This model was used to analyze various scenarios based on difirent inancial assumptions and sensitivity. The model includes an $i:-$ eractive set of assumptions, an income and expense statemen=, sol-izes and uses of funds statement, and loan payment schedules. Fr:a this, cashflows were analyzed and internal rates of returs. (I:-: and net sresent vaiues (NPV) were calculated for each Frospect Jividends were not leve $: z e d$ or restzicted in this analysis. Cop :s of the spreadsheets for Suswa, Eiurru and Arus are included $\therefore$ Appendix IV. 


\section{Financial Assumptions}

a. Time Line:

-Construction periods (exploration, drilling and design) vary by plant size, location etc.

-Project life is 25 years.

b. External Economic Assumptions:

- Kenyan inflation rate is $8 \%$ per year.

- Kenyan shilling devalues vis-a-vis the U.S. dollar at an annual rate equal to the Kenyan inflation rate (assumed to be $8 \%$ per year).

- Exchange rate is $23 \mathrm{KSh} / \mathrm{US} \$$ in 1991.

- Kenyan corporate tax rate used in this analysis is $42.5 \%$.

c. Project Economics:

-Assumed capacity factor of $95 \%$ (plant is up and running 8,332 hours/year at rated capacity). -O\&M costs increase by $1 \%$ a year in KSh.

-Required payments are indexed to inflation.

-Project IRR's are calculated on after-tax cash flows for the length of the transfer period.

- Depreciation is calculated on a straight-line basis for this prefeasiblity study.

-Interest is capitalized during construction.

\section{d. Deal structure:}

-Project is financed by $20 \%$ equity, $80 \%$ debt. -No phase-in of equity takes place.

- Permanent financing takes place from a mixture of supplier credits, commercial bank loans and equity. Loan terms are varied in each scenario.

\section{G. FINANCIAI SCENARIOS}

Three scenarios have been developed for each geothermal prospect to calculate a payment that KPLC (or KPC) would make to the joint-venture company, based on various financing terms and a 20\% hypothetical IRR. These scenarios assume a 10-year BOT, a 15year BOT and a 25-year no-transfer BOO. Sensitivity analysis is 
performed for tax consequences assuming a 5-year tax-holiday and a no-tax-holiday example. The tax assumptions use a $42.5 \%$ rate (the corporation is not taxed by both governments) and, in the taxholiday example, taxes are not paid in the first 5 years of the project. Hypothetical financing terms are used throughout this analysis and the project is financed by $20 \%$ equity and $80 \%$ debt.

Scenario 1 - This scenario assumes a 10-year BOT structure. The $80 \%$ debt financing includes $60 \%$ supplier's credit (10-year term, $8 \%$ interest) and $40 \%$ commercial credit (7-year term, $12 \%$ interest). Interest is capitalized at $10 \%$ during the construction period and the grace period is equal to the construction period for each prospect.

Scenario 2 - This scenario assumes a 15 -year BOT structure. The $80 \%$ debt financing includes $60 \%$ supplier's credit (15-year term, $8 \%$ interest) and $40 \%$ commercial credit (7-year term, $12 \%$ interest). Interest is capitalized at $10 \%$ during construction and the grace period is equal to the construction period for each prospect.

Scenario 3 - This scenario assumes that no transfer of title occurs, and the plant is owned and operated by the joint-venture group for 25 years. The debt structure and interest rates are the same as those in Scenario 2.

The main difference in the 3 scenarios is that the IRR's are calculated on after-tax cashflows equal to the length of the transfer period ( 10 years, 15 years and 25 years).

H. RESUITS OF FINANCIAL ANALYSIS BASED ON PROJECT STRUCTURE AND TAX EFFECTS.

The information presented in Tables VII-1, VII-2 and VII-3 is based on payments required to satisfy a $20 \%$ IRR for each of the 3 prospects using scenario 1 - 3 assumptions. IRR's for each prospect are computed using after-tax cashflows based on the length of the transfer period. 
TABLE VII-1. SUSWA REQUIRED PAYMENT, BASED ON SCENARIO RESUITS AND RATE OF RETURN $\frac{\text { Required Payment, }}{\text { cents/kWh }}$

Scenario Description

10-Year BOT, Tax Holiday

10-Year BOT, No Tax Holiday

15-Year BOT, Tax Holiday

15-Year BOT, No Tax Holiday

25-Year BOO, Tax Holiday

25-Year BOO, No Tax Holiday \begin{tabular}{llllllll}
5 & 5.5 & 6 & 6.5 & 7 & 7.5 & 8 \\
\hline
\end{tabular}

\begin{tabular}{l}
$-\quad 924416392$ \\
\hline
\end{tabular}

- $-\quad 2101725$

$\begin{array}{lllllll}10 & 19 & 30 & 44 & 64 & 91\end{array}$

$\begin{array}{lllllll}6 & 11 & 16 & 22 & 28 & 35 & 43\end{array}$

$\begin{array}{lllllll}16 & 23 & 31 & 45 & 63 & 89\end{array}$

$\begin{array}{lllllll}13 & 17 & 21 & 25 & 30 & 36 & 44\end{array}$

TABLE VII-2. EBURRU REOUIRED PAYMENT, BASED ON SCENARIO RESULTS AND RATE OF RETURN

Reouired Payment, cents/kWh

Scenario Description

10-Year BOT, Tax Holiday

10-Year BOT, No Tax Holiday

15-Year BOT, Tax Holiday

15-Year BOT, No Tax Holiday

25-Year BOO, Tax Holiday

25-Year BOO, No Tax Holiday $\begin{array}{lllllll}7 & 7.5 & 8 & 8.5 & 9 & 9.5 & 10\end{array}$

$\begin{array}{llllll}- & 518 & 31 & 47 & 67 & 92\end{array}$

- - $\quad 6121825$

$\begin{array}{lllllll}18 & 27 & 38 & 52 & 71 & 96 & -\end{array}$

$\begin{array}{lllllll}11 & 16 & 20 & 24 & 30 & 35 & 43\end{array}$

$\begin{array}{lllllll}21 & 28 & 39 & 53 & 71 & 96 & -\end{array}$

$\begin{array}{lllllll}16 & 19 & 22 & 27 & 32 & 38 & 44\end{array}$ 
$\frac{\text { TABLE VII-3. ARUS REQUIRED PAYMENTS, BASED ON SCENARIO RESULTS }}{\text { AND RATE OF RETURN }}$

Required Payment, cents/kWh

Scenario Description

10-Year BOT, Tax Holiday

10-Year BOT, No Tax Holiday

15-Year BOT, Tax Holiday

15-Year BOT, No Tax Holiday

25-Year BOO, Tax Holiday

25-Year BOO, Tax Holiday

\begin{tabular}{lllllllll}
7 & 7.5 & 8 & 8.5 & 9 & 9.5 & 10 \\
\hline
\end{tabular}

$\begin{array}{rrrrrrr}- & - & 3 & 14 & 26 & 38 & 55 \\ - & - & - & - & 3 & 9 & 14 \\ 10 & 17 & 25 & 34 & 46 & 61 & 80 \\ 6 & 10 & 14 & 18 & 23 & 27 & 33 \\ 16 & 21 & 27 & 35 & 47 & 62 & 81 \\ -13 & 16 & 19 & 22 & 24 & 28 & 33\end{array}$

\section{ANAIYSIS OF MOST IIKELY PROSPECTS}

The following is a financial evaluation of suswa, Eburru and frus based on scenario results. Spreadsheet calculations for these prospects are included in Appendix IV.

Suswa. Suswa presents an attractive possibility of a large (50MW), rapidly explorable and developable resource. Its installed costs are US\$2,538/kW (interest during construction is US $\$ 546 / \mathrm{kW})$. It is estimated that exploration, drilling and construction can be completed in approximately 4 years. In Scenario 1 , the 10-year BOT, assuming a required $20 \%$ IRR, required payment for suswa ranges from $\$ .064 / \mathrm{kWh}$ to $\$ .077 / \mathrm{kWh}$ in the tax-holiday and, no tax-holiday examples. In scenario 2, the 15 -year BOT, the required payment ranges from $\$ .056 / \mathrm{kWh}$ to $\$ .064 / \mathrm{kWh}$ in the tax-holiday and no-tax holiday examples. In Scenario 3, the 25-year B0O, the required payment is $\$ .053 / \mathrm{kWh}$ and $\$ .059 / \mathrm{kWh}$ in the tax-holiday and no-tax holiday examples. Annual cashflow for suswa fluctuates in the first 15 years of the project due to loan-termination periods. In the 15-year BOT scenario, assuming a $\$ .056 / \mathrm{kWh}$ tariff, suswa has a positive net present value (NPV) using $10 \%, 12 \%$ and $14 \%$ discount rates. However, please note that IRRs will change for all candidate prospects once cashflows are levelized for debt-coverage payments and dividend restrictions. 
Eburru. Eburru offers an opportunity for immediate development of a resource of moderate potential (20MW). Its installed costs are US\$3,034/kW (interest during construction is US\$484/kW). Because of the advanced stage of exploratory drilling, it is estimated that construction can be completed in approximately 3 years. In scenario 1 , the 10-year BOT, assuming a required $20 \%$ IRR, the required payment ranges from $\$ .082 / \mathrm{kWh}$ to $\$ .096 / \mathrm{kWh}$ in the tax-holiday and no-tax-holiday examples. In scenario 2 , the 15-year BOT, the required payment ranges from $\$ .071 / \mathrm{kWh}$ to $\$ .08 / \mathrm{kWh}$ in the tax-holiday and no-tax-holiday examples. In the Scenario 3, the 25-year BOO, the required payment ranges from $\$ .069 / \mathrm{kWh}$ to $\$ .076 / \mathrm{kWh}$ in the tax-holiday and no-tax-holiday examples. Annual cashflows for Eburru fluctuate from year to year, due to loan-termination periods. In the 15-year BOT scenario, assuming a $\$ .071 / \mathrm{kWh}$ tariff, Eburru has positive NPV assuming a $10 \%, 12 \%$ and $14 \%$ discount rate.

Arus. Arus offers an opportunity for immediate drilling into a resource of moderate potential (20MW). Its installed costs are US $\$ 3,324 / \mathrm{kW}$ (interest during construction is US\$714/ kW). Because it is accessible and easily identified, it is estimated that construction can be completed in approximately 4 years. In Scenario 1 , the 10-year BOT, assuming a required $20 \%$ IRR, the required payment for Arus ranges from $\$ .087 / \mathrm{kWh}$ to more than $\$ .10 / \mathrm{kWh}$ in the tax-holiday and no-tax-holiday example. In Scenario 2, the 15-year BOT, the required payment ranges from $\$ .077 / \mathrm{kWh}$ to $\$ .086 / \mathrm{kWh}$ in the tax-holiday and no tax-holiday examples. In scenario 3, the 25-year BOO, the payment ranges from $\$ .074 / \mathrm{kWh}$ to $\$ .082 / \mathrm{kWh}$. Annual cashflows from Arus fluctuate from year to year, due to loan-termination periods. In the $25-$ Year BOT, assuming a $\$ .077 / \mathrm{kWh}$, Arus has a positive NPV assuming a $10 \%, 12 \%$ and $14 \%$ discount rate.

\section{Analysis of Transfer Period and Tax Holiday}

To illustrate the effect of transfer period on required return, suswa is used as an example in Figure VII-2. In the 10year BOT, 15-year BOT and 25-year BOO, no tax holiday scenarios, the required payments for suswa are $\$ .077 / \mathrm{kWh}, \$ .064 / \mathrm{kWh}$ and $\$ .059 / \mathrm{kWh}$ respectively. In the tax holiday scenarios, the required payments are $\$ .064 / \mathrm{kWh}, \$ .056 / \mathrm{kWh}$ and $\$ .053 / \mathrm{kWh}$ respectively. This indicates that length of transfer period can .. reduce required returns by more than $\$ .01 / \mathrm{kWh}$ (tax scenario case).

To illustrate the effact of tax concessinn on required return, using suswa's 15 -Year BOT as an example, Figure VII-3 illustrates the required payment based on a $20 \%$ IRR. These payments range from $\$ .064 / \mathrm{kWh}$ in the no-tax-holiday example to $\$ .056 / \mathrm{kWh}$ in the tax-holiday-example. This is almost $\$ .01 / \mathrm{kWh}$ less, due to elimination of tax payments for 5 years.

$$
\text { VII - } 12
$$


FIGURE VII-2. REOUIRED PAYMENT, SUSWA

Suswa (50MW)

1995 Payment for 20\% Project. IRR

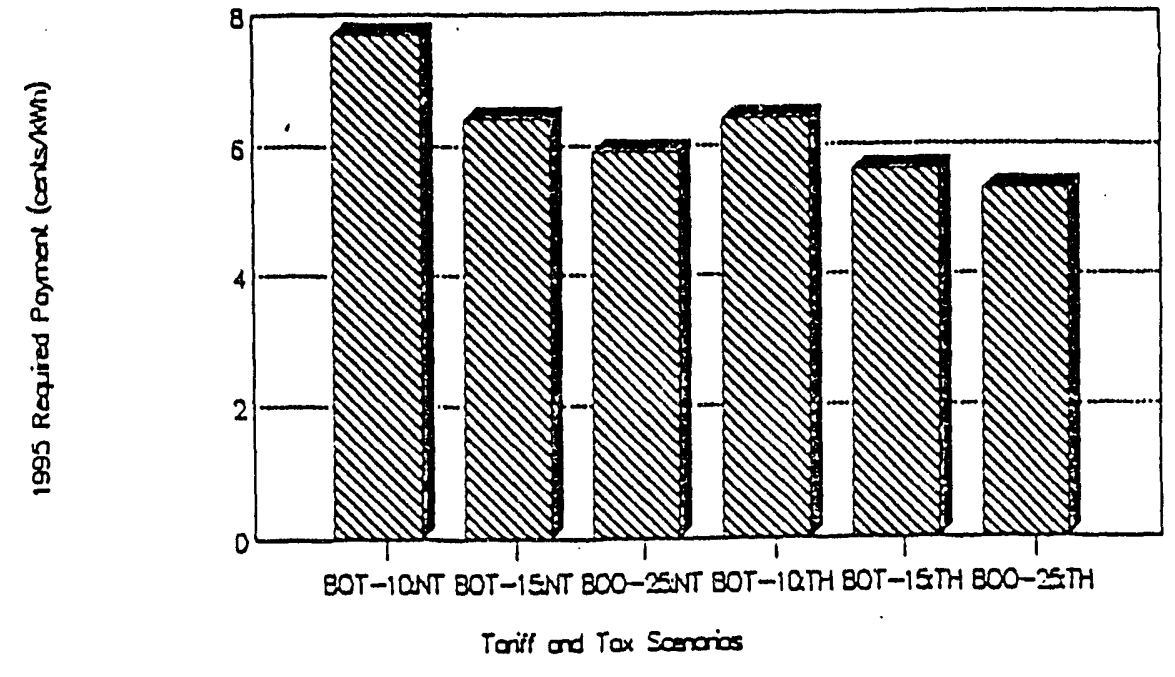

Legend: $\mathrm{NT}=$ no tax; $\mathrm{TH}=$ tax holiday.

EIGURE VII-3. SUSWA 15-YEAR BOT

Suswa 15-Year BOT

Tax Iffects

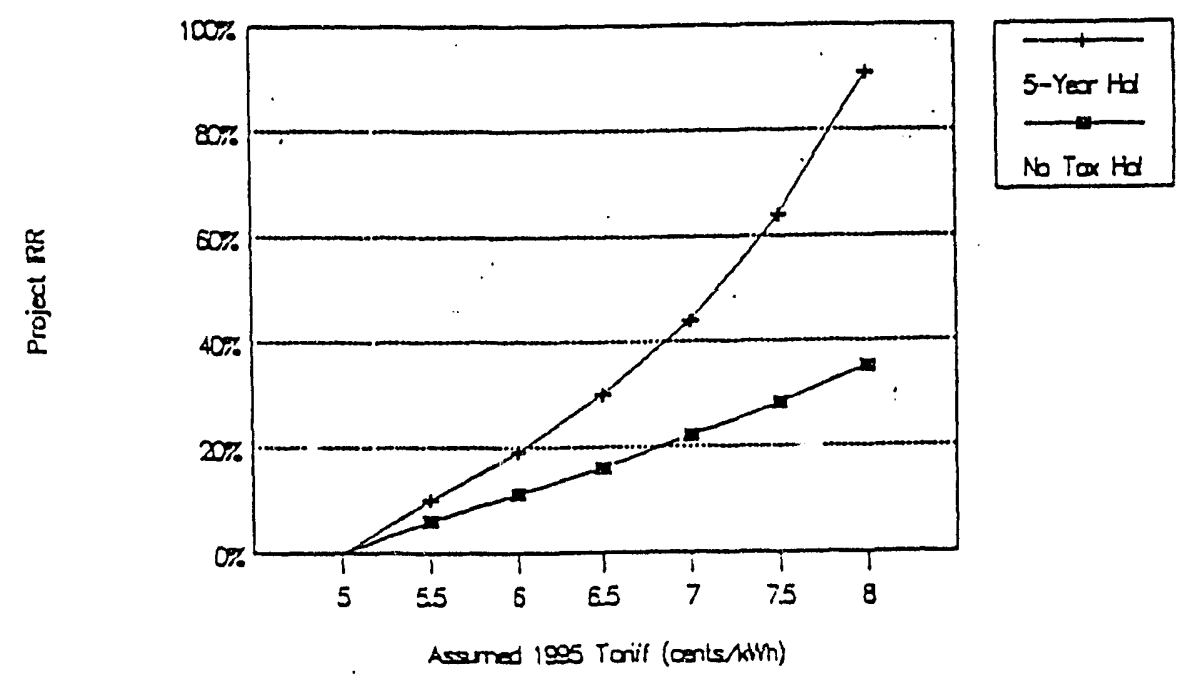

VII - 13 
J. SENSITIVITY ANALYSIS OF KENYA POWER AND IIGHTING COMPANY AND PRIVATE POWER PROJECT.

The following analysis was performed to derive a comparable KPLC cost to build a $32 \mathrm{MW}$ geothermal power plant. The assumptions used in this analysis were taken from information prepared in section III of this report.

\section{Assumptions}

Project size

Capital costs (includes US\$703/kW $O \& M$ interest during construction)

Capacity factor

Project life

Equity

Debt

Interest rate

Term

Construction period

Grace period

Kenyan tax rate

After-tax return on equity

Plant costs (US\$000)
32 MW

$\$ 3,065 / \mathrm{kW}$

$8 \mathrm{mills} / \mathrm{kWh}$

$80 \%$

25 years

$20 \%$

$80 \%$

$7.5 \%$

20 years

7 years

7 years

$39 \%$

$7.5 \%$

$\$ 98,080$

Based on these assumptions, KPLC's tariff, assuming $7.5 \%$ after-tax return on equity and a $7.5 \%$ interest rate on debt, is approximately $\$ .047 / \mathrm{kWh}$. Several qualifications are in order when comparing this figure to the required payments for a private power project calculated in this study. KPLC's capital cost per $M W$ is based on a $32 \mathrm{MW}$ plant, and the private power projects are based $20 \mathrm{MW}$ and 50MW plant size. Additionally, KPIC's cost of capital and return on equity are substantialiy lower than marketbased rates for this type of project.

\section{Sensitivity Analysis}

The following cases present sensitivity analysis demonstrating terms which would make a private power project's costs more comparable to KPIC's project costs assuming various capacity factors, rates of return and interest rates. Unless stated otherwise, the information presented herein assumes KPIC has an $80 \%$ availability factor, a $7.5 \%$ return on equity and a $20-$ year loan ( $7.5 \%$ interest rate). The private power project assumes a $95 \%$ availability factor, $40 \%$ commercial loan (7-year term, $12 \%$ interest rate), $60 \%$ suppliers' loan (15-year term, $8 \%$ interest rate) and a $20 \%$ IRR. Both KPIC and the private power project capital cost per $\mathrm{kW}$ include interest during construction ( $8 \%$ and $10 \%$ respectively). 
CASE 1 - Capacity Factor

Private Project: KPLC has no tax-holiday, $7.5 \%$ ROE, 25-year project life.

Suswa has a 5-year tax-holiday, $20 \%$ IRR, 15-year and 25-year project life.

Public Project: KPLC has no tax-holiday, $7.5 \%$ ROE, 20-year loan term, 25-year project Iife.

Suswa has no tax-holiday, 20\% IRR, 20-year loan term, 15-year and 25-year project life.

CASE 2 - Rate of Return

Private Project: KPIC has no tax-holiday, $80 \%$ capacity factor, 25-year project life.

Suswa has a 5-year tax-holiday, 958 capacity factor, 15-year and 25-year project iffe.

Public Project: KPIC has no tax-holiday, $80 \%$ capacity factor, 20-year loan term, 25-year project life.

Suswa has no tax-holiday, $95 \%$ capacity factor, 20-year loan term, 15-year and 25-year project life.

CASE 3 - Interest Rates

Private Project: KPIC has no tax-holiday, $7.5 \%$ ROE, $80 \%$ capacity factor, 15-year loan term, 25-year project life.

Suswa has a 5-year tax holiday, 20\% IRR, $95 \%$ capacity factor, 15-year loan term, 25-year project life.

Public project: KPIC has no tax-holiday, $7.5 \%$ ROE, $80 \%$ capacity factor, 20-year loan term, 25-year project life.

Suswa has no-tax holiday, $20 \%$ IRR, 95\% capacity factor, 20-year lcan term, 25-year project life. 
Table VII $\cdots 4$. COST COMPARISON OF TARIFFS FOR PRIVATE VERSUS PUBLIC PROJECT

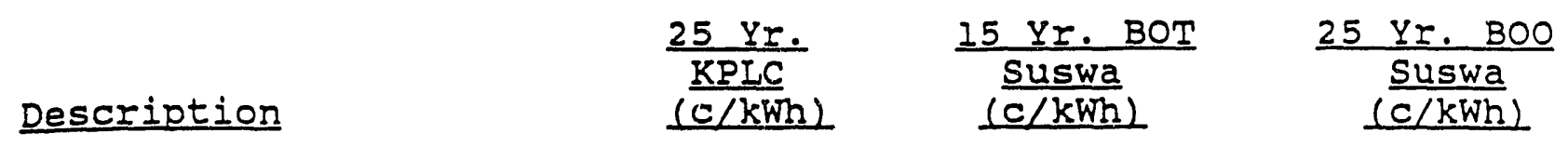

CASE 1 - Capacity Factor. Rate of return is held constant and capacity factor is analyzed.

$\begin{array}{lllll}\text { Private Project }-\quad 80 \% & 5.3 & 6.5 & 6.3 \\ & 85 \% & 5.1 & 6.2 & 6.0 \\ 90 \% & 5.0 & 5.8 & 5.6 \\ 95 \% & 4.9 & 5.6 & 5.4 \\ \text { Public Project }-\quad & & & 5.2 \\ & 80 \% & 5.0 & 5.4 & 4.9 \\ 85 \% & 4.8 & 5.1 & 4.7 \\ 90 \% & 4.5 & 4.8 & 4.5\end{array}$

CASE 2 - Rate of Return. Capacity factor is held constant and rate of return is analyzed.

$\begin{array}{lrrrr}\text { Private Eroject }-7.5 \% & 5.4 & 4.8 & 4.0 \\ 10 \% & 5.6 & 5.0 & 4.4 \\ 15 \% & 7.2 & 5.3 & 5.0 \\ 20 \% & 8.1 & 5.6 & 5.4 \\ \text { Public Project }-\quad 7.5 \% & 5.0 & 4.0 & 3.6 \\ 10 \% & 5.3 & 4.1 & 3.8 \\ 15 \% & 5.7 & 4.4 & 4.1 \\ & 20 \% & 6.2 & 4.7 & 4.5\end{array}$

CASE 3 - Interest Rate. Capacity factor and rate of return vary and interest rates are analyzed.

$\begin{array}{lllll}\text { Private Project }-\quad 7 \% & 5.0 & 4.8 & 4.6 \\ 8 \% & 5.2 & 4.9 & 4.7 \\ 9 \% & 5.4 & 5.1 & 4.9 \\ 10 \% & 5.6 & 5.3 & 4.5 \\ \text { Public Project }- & 48.8 & 4.5 & 4.4 \\ & 7 \% & 5.0 & 4.7 & 4.5 \\ 8 \% & 5.3 & 4.9 & 4.7 \\ 98 & 5.5 & 5.0 & 4.9 \\ 10 \% & & & \end{array}$


Table VII-4 illustrates different tariffs for a private versus public project based on sensitivity analysis of capacity factors, rates of return and interest rates. This information is also presented graphically in Figures VII-4, VII-5 and VII-6.

In Case 1, capacity factor sensitivity, rate of return is held constant and capacity factor is analyzed. In the private project example, at an $80 \%$ capacity factor, KPIC's tariff of $\$ .053 / \mathrm{kWh}$ is closest to suswa's 25-Year BoO project, $95 \%$ capacity factor ( $\$ .054 / \mathrm{kWh})$. KPLC's costs are lower in this example due to its lower required return. In the public project example, KPLC's 80\% capacity factor tariff is comparable to suswa's 25-Year BOO required payment at $85 \%$ capacity (\$.05/kWh vs. \$.049/kWh). At $95 \%$ capacity factor however, suswa's required payment becomes less than KPIC's tariff at an $80 \%$ capacity factor, in both the 15-Year BOT and 25-Year BOO projects. Financing costs are lower in the public project example but KRIC's higher capital cost $(\$ 3,065 / \mathrm{kW}$ vs. $\$ 2,538 / \mathrm{kW}$ ) make private power less expensive. Comparing capacity factor sensitivity between the public and private projects, the most likely comparison, we find KPLC's $80 \%$ capacity factor tariff is most comparable to suswa's 25-Year Boo required payment, $95 \%$ capacity factor ( $\$ .05 / \mathrm{kWh}$ vs. $\$ .054 / \mathrm{kWh}$ ), based on required returns of $7.5 \%$ and $20 \%$.

In Case 2, rate of return sensitivity, capacity factor is held constant and rate of return is analyzed. In the private project example, KPLC's tariff, assuming a $7.5 \%$ return, is comparable to suswa's 25-Year BoO required payment assuming a $20 \%$ rate of return ( $\$ .054 / \mathrm{kWh}$ vs. $\$ .054 / \mathrm{kWh})$. In the public project, KPIC's tariff, assuming a $7.5 \%$ rate of return, is greater than Suswa's 15-Year BOT and 25-Year 300 required payments assuming a 208 rate of return. This is due to KPLC's lower availability and higher capital costs. If KPLC's project were privately financed and a $20 \%$ IFs were required, YPLC's tariff could be as high as $\$ .081 / \mathrm{kWh}$.

In Case 3, interest rate sensitivity, assuming base case capacity factors and required returns, the effect of different interest rat is on project cos -3 are analyzsd. At an 808 capacity factor and $7 . j \%$ required retL $: n$, KPIC's tariffs are similar to the private : ver project reo..ired payments $(95 \%$ capacity factor, 20 IRR) in $:$ th the private and public examples (only loan terms are varied). Losts become comparable in this case due to FiRI's bigher capitz 1 cost and private power projects increased availabilit: lower capital costs and higher reguired retura. Interest rate sensilivity is an important factor in this analysis because private power financing cannot compete with KPIC' subsidized rates. Based or the type of equipment firancing obtained, ard, if either donor funds aud/or grants are obtained, private power's financirg terms can compare favorably to KDIC's interest rates. 
This analysis demonstrates that given highe availability (efficiency), lower capital costs (reduced construction time) and interest rates which are comparable to KPLC's (this implies a portion of the financing could be either donor financing or grants), a private power project can compete with KPLC's subsidized costs for a planned or proposed geothermal project. It should also be mentioned that based on accepted methodologies for computing avoided costs, KPIC's systemwide avoided costs would be higher than the amounts listed above (geothermal plant costs are only one component of this calculation). Methodologies for computing avoided costs are discussed in detail in section VI, Part 2 .

\section{FIGURE VII-4. COST COMPARISON PRIVATE VERSUS PUBIIC PROJECT, CAPACITY FACTOR}

\section{Private vs. Public}

Capacity Factor

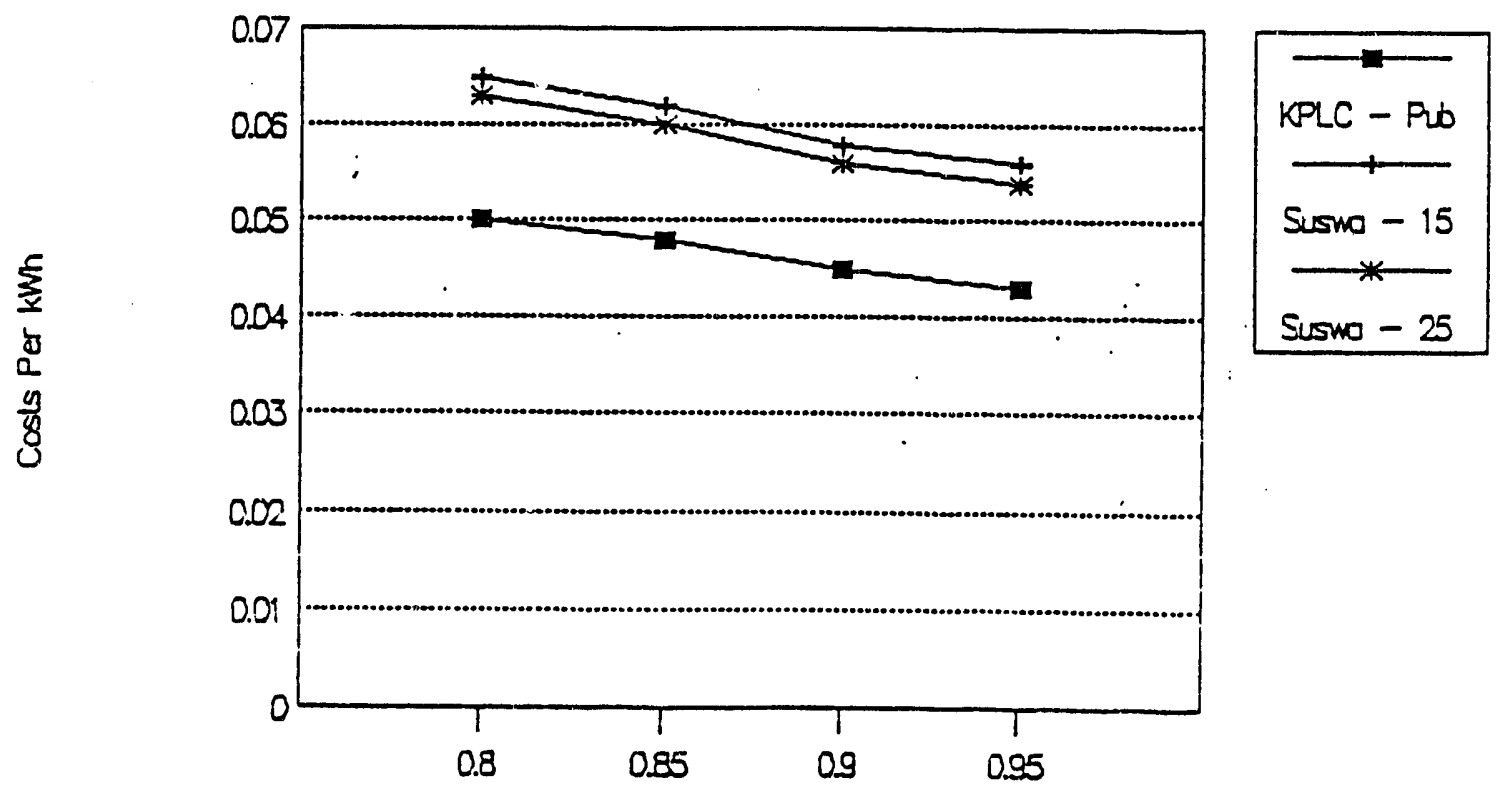

Copodity Fater 
EIGURE VII-5. COST COMPARISON PRIVATE VERSUS PUBIIC PROJECT, RATE OF RETURN

Private vs. Public

Rate of Return

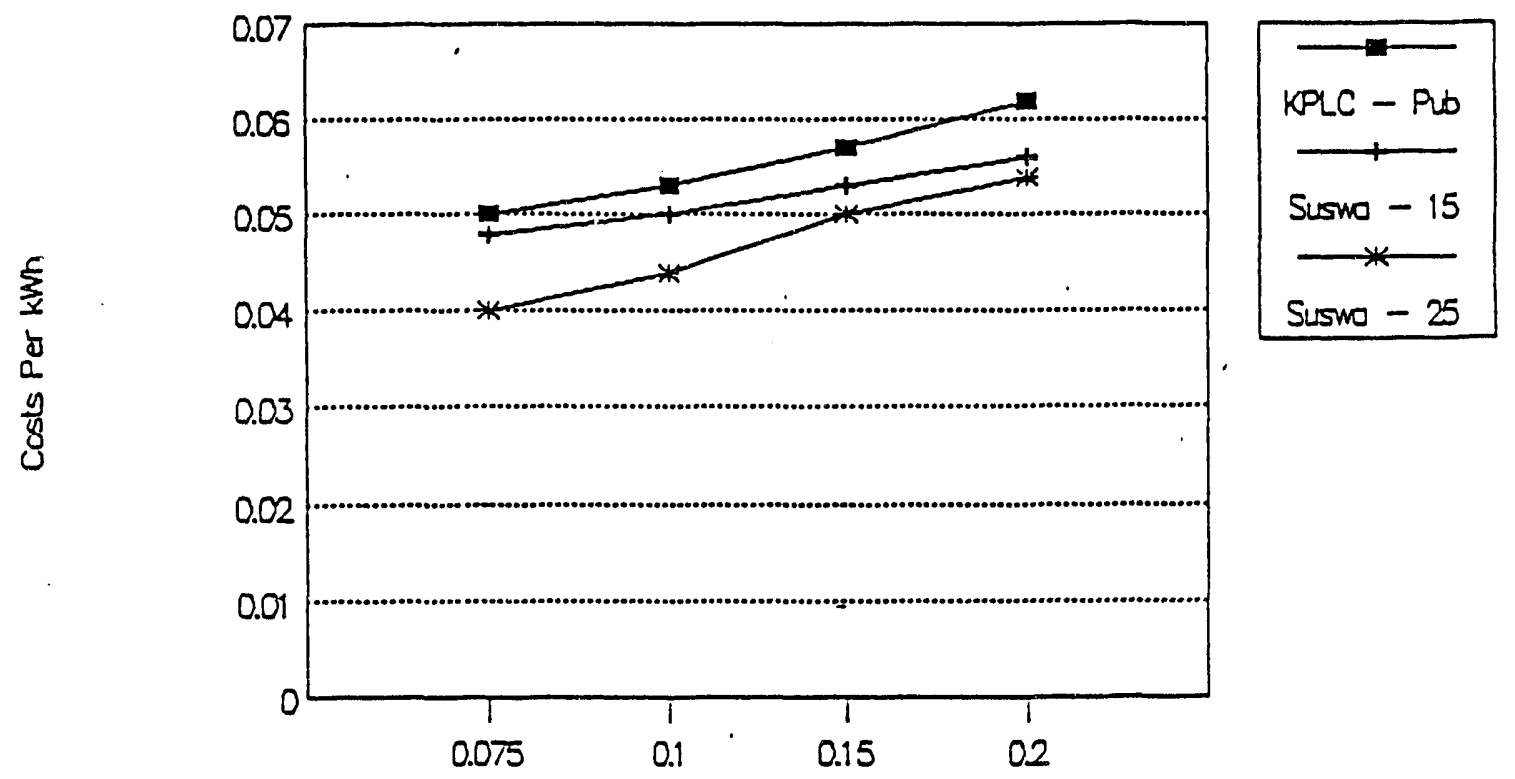

Rote of Reburn

EIGURE VII-6. COST COMPARISON PRIVATE VERSUS PUBIIC PROJECT, INTEREST RATES.

Private vs. Public

Interest Rate

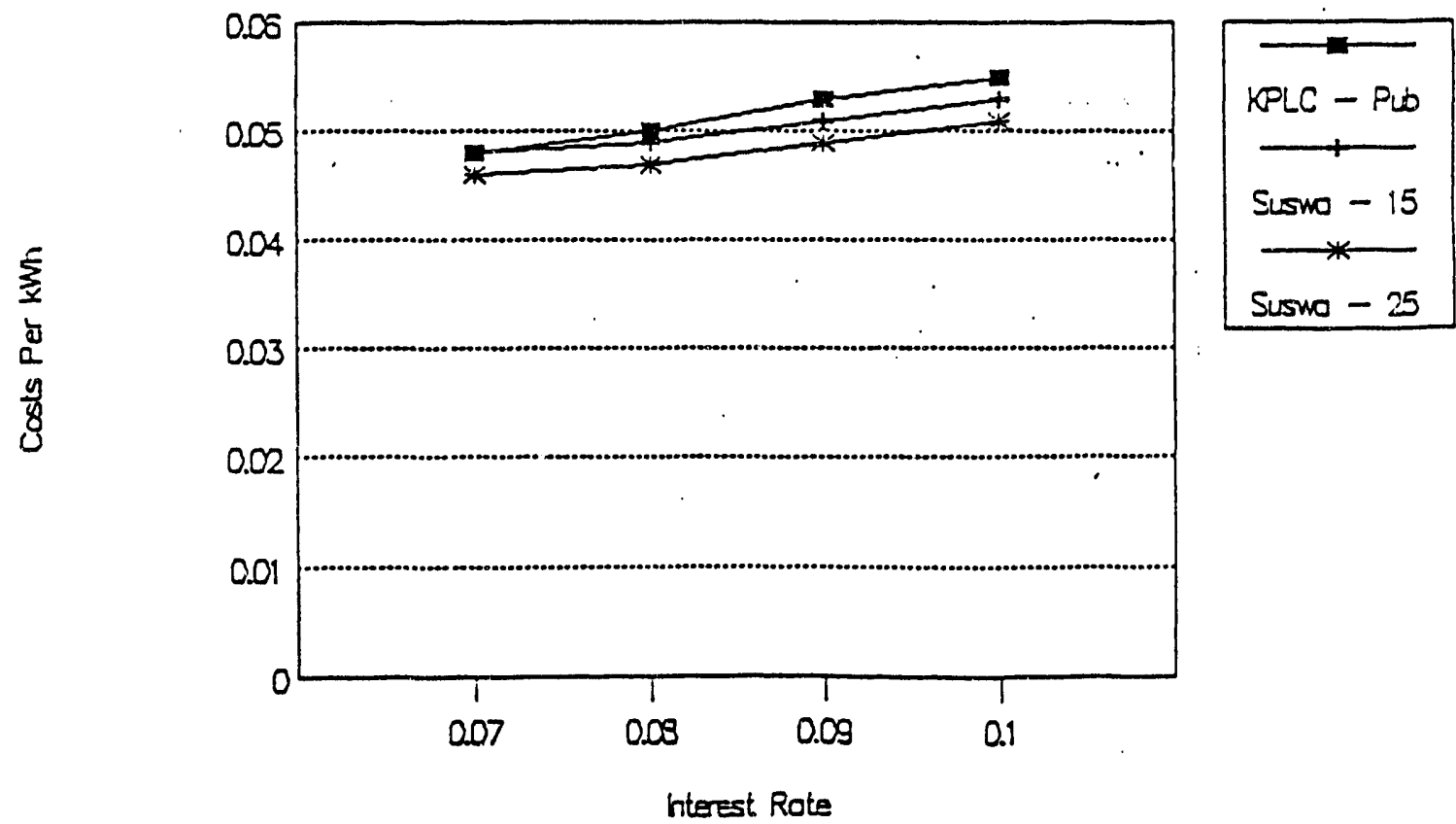




\section{R. CONCLUSION}

This prefeasibility study has attempted to demonstrate the advantages of a private power project, and look at the returns an international investor would require in order to finance this type of project. The advantages of private power are many. private power developers (1) arrange for and assume all the risk of financing and constructing the power project, (2) provide offbalance-sheet financing, (3) establish an avoided cost for future projects, (4) help improve efficiency standards for other power projects, and (5) provide technology transfer for new products and services. In terms of financing costs, private power projects cannot compete directly with KPLC's highly subsidized rates. Private power can, however, free KPIC Iimited capital for use on other projects. Other favorable factors which make costs more comparable include increased availability and reduced construction time. Also, when considering the limits on availability of concessionary financing to KPLC, and the constraints being imposed by concessionary lenders, the price disparity between a public and a private power project becomes less both in amount and in importance. 


\section{BIBIIOGRAPHY}

Acres International, Kenya National Power Development Plan 19862005. Joint UNDP/World Bank EnergY Management Assistance Program, June, 1987.

Charles Cicchetti, some Thoughts on Why and How to Initiate Private Power Projects in Pakistan. Thailand, November, 1988.

William Dykes, opportunities for Private Electric Power Generation and Energy Conservation in Developing countries. 12 July. 1989 .

Economic Survey 1990 , Central Bureau of Statistics, Ministry of Planning and National Development.

Ewbank Preece, Tables and Geothermal Data, 1990.

1898 Foreign Economic Trends Report, American Embassy Nairobi, August 7,1989 .

IFC, A Guide to Investment in the Development World,

International Finance corporation.

Investors Guide to Kenya, Vol. I, II and IV, Investment Policies, Procedures and opportunities. Investment Promotion Center, May, 1989.

Phillip Iiebman, Innovative Financing strategies and Technioues, Ideas, Examoles and Timing, National Geothermal Association, February, 1989 .

Kodiat Samadikum, Seventh Conference on Electric Power Industry, The Build, operate and Transfer (BOT) Concept, New Financing Approach for Asean Utilities. Brisbane, october, 1989.

Seminar on Private Power Generation Theory, Build-operateTransfer, OEA-USAID-TTEM-PCCI, October 5, 1988, Manila.

U.S. Export Council for Renewable Energy, Private Finance for the Power sector: The Renewable Energy Option, June, 1989.

USFCS Nairob EV 1990, Country Marketing Plan, September, 1989.

World Bank Cofinancing of Medium-sized Private Sector Enterprises -the Export Credit Enhanced Leverage ('EXCEj') Program.

World Bank Financing of the Energy Sector in Developing Countries, April, 1989. Working Paper No. 14.

World Bank Expanded Cofinancing Operations (ECOS) January, 1990

$$
\text { VII - } 2 I
$$


Section VIII. IEGAI ISSUES RELATING TO THE DEVELOPMIENT AND SAIE OF PRTVATE-SECTOR GEOTHERMAL POWER TO THE PUBLIC SECTOR IN KENYA

\section{A. THE KENYAN LEGAL AND REGULATORY FRAMEWORK: OVERVIEW}

Power supply projects in Kenya are undertaken to meet both economic and social objectives, and, historically, have been the responsibility of the Government. In 1990, the Government of Kenya, realizing that the rate of growth of power demand is exceeding its ability to construct new generating capacity, opened the possibility for the private sector to participate in power supply--specifically power supply from geothermal sources. The basis for geothermal power supply is established in the Geothermal Resources Act, 1982. I The law vests all geothermal resources in the Government, ${ }^{2}$ and establishes a regulatory framework, pursuant to which a private-sector developer may be licensed to enter a geothermal field, and drill, extract, generate and sell the resource.

This law was executed by the Minister of Energy eight years subsequent to its passage, and came into effect simultaneously with the promulgation of implementing regulations on May $1,1990$.

1 The Geothermal Resources Act, 1982, Law No. 121982 (Date of Assent 8 July 1982, Date of Commencement, by Notice). Full text appears in Appendix $V$.

2 Id. Part I, $\$ 3$.

3 The Geothermal Resources Act, 1982, Commencement, Iegal Notice 225, April 24, 1990, Kenya Gazette, Supp. 33, 262 (May 25, 1990); The Geothermal Resources Regulation, 1990, Legal Notice 206, April 24, 1990, Kenya Gazette, Supp. 33, 262-283 (May 25, 1990). Full text appears in Appendix VI. 
These implementing regulations make clear that transnational (foreign), private-sector corporations are eligible applicants for authority from the Government of Kenya to explore for geothermal resources and to be granted a license to drill and utilize geothermal resources, including utilization of the resources for the production of power. ${ }^{4}$ It should be noted, however, that neither the law nor the regulations sets forth an express policy of encouraging private-sector development of geothermal resources. The statutory framework affords a discretionary mechanism which allows private-sector participation in geothermal power production, but stops shy of clearly endorsing policy of private-sector geothermal resource development. 5

\section{The Renyan Legislative and Regulatory Approach}

The Geothermal Resources Act, 1982, establishes a series of steps which the transnational geothermal developer must follow: (1) the Minister of inergy must first authorize all resource exploration; (2) a "geothermal resources license" must be obtained from the Minister in order for the developer to drill, extract, and utilize the resources, 7 and (3) if electricity is to be produced the developer must obtain a license under the Electric Power Act, 8 or if commercial by-products are reclaimed, the geothermal resources license must include a mining lease consistent

4 The Geothermal Resources Regulations, $\S 1,7,18$.

5 See, e.g., the statement of the Philippine government in setting forth the Act Authorizing the Financing, Construction, Operation and Maintenance of Infrastructure Projects by the Private sector: "It is the declared policy of the state to recognize the indispensable role of the private sector as the main engine for natural growth and development and provide the most appropriate favorable incentives to mobilize private resources for the purpose." (Republic Act, No. 6957, July 9, 1990).

6 Geothermal Resources Act, supra note 1 , at $\S 36$. Such grant is for five years.

7 Id. \$ 7. Such grant is for 30 years, renewable for five years.

8 Id. $\$ 14 ;$ Electric Power Act, Ch. 314, Law of Kenya 2-213 (1986). Power sajes under the Electric power Act and the laws of Kenya is a somewhat complicated issue. For a detailed analysis, see Appendix VII. 
resources license must include a mining lease consistent with the Mining Act.

The Geothermal Resources Regulations, 1990, set forth a model license which establishes the basis for negotiating the arrangements for obtaining the rights to the Kenyan Geothermal resources Iicense -- a "model Geothermal Resources License". 10

This Model Geothermal Resources Iicense provides that the right to take and use geothermal resources may be based in part on a geothermal contract, incorporated into the license by reference. The license establishes a scheduln of payment for land rental and royalty for the sale of steam or electricity. It provides for the forfeiture of the license in the event of either unauthorized inactivity on the part of the developer or breach of the geothermal laws, regulation or license. The Model License mandates a reporting system and establishes an incentive system whereby the Minister of Energy undertakes to secure a number of investment incentives (for the most part preexistent in other legislation) for the licenses.

\section{The Theory of Private Power Laws}

Private development of public power resources is a relatively new innovation worldwide. The underlying rationale for introducing this approach into Kenya in 1990 deserves careful examination - the theory underlying the law may determine not only the direction of future geothermal license/contract negotiations, but also whether the concept of private geothermal development is viable in KenYa.

There are two fundamental reasons for a country to promote private power development, project financing and lower rateholder costs.

9 Geothermal Resources Act, supra note 1, at $\$ 8(2)$; Mining Act, Ch. 306, Laws of Kenya.

10 Geothermal Resources Regulations First Schedule Model Geothermal Resources License $\$ 3(1)$. The Geothermal Resources Regulations provide that a geothermal resources license

... may be accompanied $b_{y}$, or conditioned upon, the execution of a contract (to be known as a "geothermal resources contract") between the licensee and the relevant government departments or other body designated by the minister for the utilization of the geothermal resources. 
* Private-sector financing is a viable alternative to public-sector financing in an era in which worldwide power demands will outstrip the availability of funds from traditional public-sector financial sources.

* Private-sector power projects, must be run on a costeffective basis, producing the maximum possible power from available resources in the shortest possible time in order to be competitive and commercially viable. Thus, the successful private-sector project by its own internal, self-selection process will, in theory, generate lower-cost electricity for the benefit of the ratepayer.

Thus, the Kenyan legal, regulatory regime may properly be judged by the extent to which it creates incentives which will place the private power developer on equal footing with the public-sector developer of power. This issue is especially sensitive with respect to geothermal power. geothermal power, by its nature, is site specific. Unlike oil, it is not generally an exportable commodity. It has only one market -- the state utility monopolies. Therefore, the imposition of lease payments, royalties, customs duties and taxes will be passed along through the utility to the ratepayers. If a government does not levy such charges against the public-sector power developer, but does levy them against the private-sector developer, the private-sector developer is forced to absorb an unequal burden. At the outset of a private project these charges must be met by debt and equity contributions. Subsequently they must be met from operating revenues. In turn, repayment of principle and interest as well as on-going government charges must be met by the utility. Moreover, risk capital or equity must have a predictable return at least as high as investment in a industrial-nation banks Certificates of Deposit plus, an upside commensurate with the investment risk, if equity investment is to be attracted.

Consequently, a private-sector geothermal power development project cannot be compared with, or regulated as though it were, an industrial project or a mineral-development project. To do so ignores the fact that the nation is properly promoting both an alternative financing mechanism supplementary to public financing and a low-cost rate to the ratepayer.

on the other hand, the Government of Kenya holds geothermal resources in trust for all the people of Kenya. To the extent that it provides resource rights, land use, and incentives, it is providing quantifiable things of value. Thus, the people of Kenya are making an investment in private-sector power development in the same way that banks and private investors are making an investment. A fair and equitable method of repayment of the kenyan investment must be built into any legislative and regulatory scheme. 
The Build, Own, operate and Transfer or "BOOT" model is one such method. In the BOOT model, the private-sector developer furnishes $100 \%$ of the financing. After the private-sector developer repays its debt burden and makes a reasonable return on its investment, by pre-agreement, the assets of the project are transferred to the Government for integration into its power production system. The fewer Government charges against income levied on the project during its private-sector phase, the sooner the transfer. One variation on this approach is to vest ownership of the project in the Government on an on-going basis. Fcr example, a percentage of the corporation can be transferred to the Government by transferring stock ownership in lieu of royalties and lease payments. Thereby, from project initiation, the Government can participate in profits on a coequal basis with the other equity investors. 


\section{B. THE PRIVATE GECTOR PERSPECTIVE}

From the perspective of a private-sector, transnational developer, the legal requirements prerequisite to undertaking steam and power production in a foreign country are relatively straightforward. The private-sector developer must:

(1) be assured of its right to the resources,

(2) be assured of its right to sell steam or electricity, and

(3) be assured of its right to earn and repatriate income sufficient to meet debt burden as well as to make a reasonable return on investment.

Knowledgeable financial experts have amplified on these three basic preconditions. They have stated that, as a general rule before governments and prospective private sponsors embark on private-sector energy projects, three conditions must exist: First, the host government must be firmly committed to putting the responsibility for the creation and operation of the new generating capacity into the hands of the private sector. Second, the host government must understand private-sector incentive mechanisms and be realistic in its risk-reward sharing expectations. And, third, the host government must be seen by the project sponsors and lenders to have a credible commitment to concluding a deal."

Thus, even the relatively simple prerequisites of the privatesector power developer, must be understood and evaluated in the more sophisticated context of international financial imperatives. In this light, the following discussion examines the issues of the general agreement framework, resource rights, power purchase arrangements, and (D) economic incentives.

11 See, e.g.. Stevenson, william A., "The Turkish BOT Power Experience," U.S.A.I.D. Report No. 89-i4, summary Report of the Philippine seminar and Round Table on private Power Generation through Build-operate-Transfer (BOT), (MaY 1989). 


\section{THE GENERAI AGREEMENT FRAMEWORK}

The Geothermal Resources Regulations, 1990, contemplate that a private-sector geothermal power project will be defined by a geothermal resources license into which will be incorporated a geothermal resources contract. ${ }^{12}$ The Regulations appear to contemplate a single omnibus agreement, although there is no statutory or regulatory prohibition against dividing the agreement into sub-agreements in order to handle discrete issues more manageably. These sub-agreements may be incorporated into the geothermal resource contracts by reference. Agreement-management will depend greatly upon the parties to the agreement. If the power purchase agreement is between a private-sector developer and the utility, such a prerequisite agreement might be better negotiated separately and incorporated by reference into the Government's geothermal resources contract. Moreover, if it is determined to establish private/public joint ventures, such joint venture arrangements might also be separately negotiated.

The Power Purchase Agreements set forth below, plus any joint venture agreements, will form the core of a private-sector investment in a geothermal power plant in Kenya. However, depending upon circumstances, the parties may find that other agreements are useful in memorializing their intentions. This section describes some of the agreements which may be executed separately, or folded into a single, omnibus agreement. ${ }^{13}$

As discussed in section II $D$ below, in view of the unique public nature of a private-sector power project, it may be in the long term interests of all parties to have the geothermal resources contract package approved and passed into law by parliament.

\section{Preliminary Agreements}

Depending upon the circumstances, a number of preliminary agreements may be executed.

\footnotetext{
12 $3(1)(2)$.

Geothermal Resources Regulations, supra note 4 , at $\$$
}

13 Id. at $\$ 3(2)$ provides that a geothermal resources contract between the licensee and the government may accompany the Geothermal Resources License. Thus, such an omnibus agreement is authorized. This section and those following provide examples of the content of such an agreement. Id. supra note 4 , at $\$ 14(1)$. 


\section{a. Non-Disclosure Agreement}

A non-disclosure or confidentiality agreement may be executed to preserve the integrity and confidentiality of information disclosed among joint venturers and to establish a schedule, a team and a procedure for pursuing further agreement. This concept is consistent with the Kenyan regulations. The Kenya Geothermai Resources Regulation, $\$ 14(1)$ provides that "all information supplied to the [Minister of Energy] by the licensee shall be kept confidential and shall not be disclosed except with the consent of the licensee." 14

\section{b. Letter of Intent of Memorandum of Understanding}

Memorandum of Understanding ("MOU") and letters of intent identify the parties engaging in the negotiations and, in general terms, the objectives which they seek to achieve. The objectives covered should include the type of entity to be created and what its function will be. It should include a stipulation of the intended level. of capitalization for the new entity as well as the anticipated percentages of ownership and control to be assumed by the parties. It should address the intention of the parties as to the agreements which will form the geothermal resources contract (e.q., geothermal lease, power purchase, joint venture, construction, management, operations, etc.).

\section{Comment}

At this early stage of negotiations, the parties are often not far enough along to address specifics, nevertheless it is useful if significant provisions can be addressed.

A memorandum of understanding should identify the general responsibilities of each party during the start-up phase of the project, and should address a schedule by which certain procedures and acts should be complete in order to get the venture completed by a specific date. 


\section{Private-sector Power Agreements}

\section{a. Geothermal Resources Agreement}

The Geothermal Resources License envisioned by Kenya establishes the relationship between the government and the joint venture corporation or individual foreign corporation. The mineral lease issues associated with Geothermal Resources License are discussed in detail in section II $B$, below.

\section{b. Joint Venture Agreement}

The Joint Venture Agreement establishes the relationships among the private offshore developer, the public and private domestic partners and with the Government itself. The prevailing form is the equity joint venture agreement. In an equity joint venture, a new entity such as a corporation or a partnership is created specifically to achieve the joint venture objectives. The corporation format frequently used for international joint ventures. If no joint venture is contemplated the offshore developer will typically retain its domicile. If a joint venture with a private domestic corporation is contemplated, a neutral situs or the host country situs is common. In joint ventures with governmental entities, incorporation in the host country is generally mandated.

\section{c. Construction, Operation and Maintenance Agreement}

The construction, operation and maintenance agreement may be incorporated into the omnibus geothermal resources contract or may be addressed in the form of a separate agreement.

Assuming that the joint venture is, for example, between the offshore developer and a wholly government-owned entity such as the Kenya Power Company or a partially government-owned entity like Kenya Power and Iight Company, 15 the joint entity is placed in a situation in one of its principals--the U.S. investor--will function as prime contractor for construction and subsequent operation and maintenance of the facility. It would appear prudent from the perspective of all parties to negotiate the construction, operation, and maintenance agreement in context of, and simultaneously with, the geothermal resources contract in order to ensure internal consistency.

In a joint venture arrangement in which the contractor is an equity participant, the tendency of the contractor will be to ensure an adequate return on investment through management/operating payments, payable off the top from gross income rather than through profits shared by the host investor.

15 see text at section II $C$, below.

$$
\text { VIII - } 9
$$


It is to the investor's interest to ensure that whatever formula is agreed--"costs plus percentage costs," guaranteed maximum, incentive contracts with mixed lump sum/cost plus--the host country owner (especially if it is a government) perceives that an equitable method of ensuring its fair share of income is formulated.

\section{d. Power sales Agreement}

The electricity buyer and seller must have well-defined power contracts stating the amount, reliability and length of time (i.e., months, downtime, and time of day) that the energy producers will supply electricity. The power sales Agreement is discussed in detail in $S$ II $C$ below. Kenya has had no need to institute the complex regulatory regime as exists, for example for regulated utilities in the United states. Thus, a power sales agreement with KPLC is likely to be among the first of its kind. Therefore, this agreement may be free of certain regulatory constraints and may be drafted and negotiated as if the agreement were between two whollyprivate entities. offshore developers, however, are cautioned to ensure that their Kenya project activities are in compliance with the laws of their domicile.

\section{Ancillary Agreements.}

Ancillary agreements may be useful to:

* implement, on a more detailed basis, the transfer of information, technical skill and equipment;

* protect the transferred information, equipment and technical data; and

* distribute responsibilities of the parties.

a. Examples of Ancillary Agreements

The list of ancillary agreement may include:

(1) an administrative services agreement,

(2) a supply agreement,

(3) a purchase agreement relating to equipment and machinery,

(4) an agreement related to indirect issues, e.g. the use or upkeep of the transmission and distribution system, 
(5) an employee training agreement, and

(6) a technical assistance and licensing agreement.

b. Recourse/NonRecourse Agreements

In certain circumstances, especially those in which the transnational joint venture company arranges for host country financing, recourse and non-recourse financial agreements may be included in the package. 


\section{RESOURCE RIGHTS}

The international private-sector geothermal developer is accustomed to entering into geothermal leases which typically permit the exclusive and discretionary right to explore and develop the leasehold and to erect commercial facilities in exchange for rent or royalty payments. The term of the lease is long enough to allow development and is automatically extended if the lessee is successful. The lease is short enough to allow reversion to the lessor in the event the lessee is inactive or unsuccessful. In Kenya, the geothermal resources license contemplates many of the issues traditionally covered by a geothermal lease. Nevertheless, some legal authorities might argue chat the authority to use land pursuant to license is not perfected until a written lease is passed from lessor to lessee. In the final analysis, it is the financial investor or lender who must be comfortable that its investment is secure. The five following operative provisions are standard in geothermal leases, and may serve as a point of departure for a Kenyan formulation. They also illustrate the norms by which the land-use sections of the Kenya regulatory scheme may be evaluated by the international private sector developer. 


\section{EXAMPLE GEOTHERMAL LEASE}

1. EXCLOSIVE DEVELOPMENT RIGHTS. The Lessee shall have the sole and exclusive 'right to explore for, drill for, produce, extract, remove, store, utilize, treat, process, convert and sell, geothermal steam, hot water, and related products during the term of the lease and any extension thereof. The rights of the Lessee in such uses shall include the right to construct, use and maintain a power-generating facility, roads, pipelines, utility and power lines and other structures and improvements which may be necessary or convenient in the operations under the lease.

2. CONSIDERATION. The consideration paid by the Lessee shall be (one or more) of the following:

a. Annual rental in the amount of per acre [or hectare] for the entire land area of the leasehold estate;

b. Royalty of percent of the proceeds from the sale by Lessee of geothermal resources, less any taxes imposed on the sale of such geothermal resources and less the cost to Lessee of any transmission to the point of sale.

3. COMMERCIAI DEVELOPMENT. At such time as Lessee shall have drilled and completed wells within the leasehold which shall indicate to the satisfaction of the Lessee a sufficient commercial potential, and at such time as the Lessee has obtained a market for the geothermal resources, Lessee may construct facilities for the commercial sale of products from the leasehold.

4. TERM. The lease shall remain in force for a period of years and thereafter so long as geothermal resources are produced or the Lessee is engaged in drilling operations or the construction of facilities for the commercial sale of products.

5. DISCRETION. The Lessee shall conduct its operations with reasonable diligence, but shall have no obligation to explore for, develop or produce geothermal resources for the leased land. 
The approach which Kenya proposes to use is set forth in the Model Geothermal Resources License. ${ }^{16}$

(1) The Iicense grants a Licensee (the lessee) broadly stated exclusive rights to explore for, extract and utilize geothermal resources for a term of thirty years.

(2) Consideration is a yearly advance rental per hectare plus a royalty of a negotiated percentage of the value of each kilowatt hour.

(3) This license requires the Licensee actively to develop the geothermal field or be subjected to forfeiting its rights.

In its basic conceptual approach, the Model Geothermal Resources Iicense is consistent with international geothermal resource standards. The deviations from industrialized country norms appear justifiable.

\section{COMMENT}

Pursuant to the terms of the Model License, if the licensee ceases work for six months, it may lose its license unless the previous written consent of the minister is obtained. It is common for developing countries to require an expenditure commitment or an obligation to drill. The penalty levied by the government of Kenya--forfeiture of the license in the event of inactivity by the Licensee--is not necessarily an onerous penalty to be imposed by a government charged

16 First Schedule, Model Geothermal Resources License, The Geothermal Resources Act, 1982 (No. 12 of 1982) and the Geothermal Resources Regulations, 1990, Kenya Gazette, Supp. 33, 269-276 (May 25, 1990) (hereinafter "Model Iicense").

17 Id. $\$ 1-2$. The thirty-year term is renewable for two further periods of five years each.

Id. $\$ 3$.

19 Id. Section 7(1). "The Minister may, by notice to the Iicensee, declare this licensee to be forfeited [inter alia] if the licensee wholly ceases work in or under the license and during a continuous period of six months, without the written consent of the Minister." 
with developing electrical resources for its people, provided that administrative authorization for delay caused, for example, by business contingencies is not unreasonably withheld. There may be some justifiable criticism of the six-month provision. Considering the delays endemic to international transactions, grace period may be unreasonably short.

Regarding consideration, the advance yearly rental plus a production royalty is straightforward. The Government should be aware that in higher risk exploration areas, it is customary for the lessor to waive or reduce initial rental fees until the area proves commercially productive--thereby encouraging exploration of unexplored sites. The Government might also consider crediting or applying rentals paid to the Government to royalties payable (or to become payable) on actual production: The key to successful cooperative development of energy resources by the private sector is elimination of penalties to risk taking--i.e., economic incentives.

The Model License does not specifically allow a deduction from royalty payments. of any taxes. This omission might be perceived by investors as a loophole allowing the Government unilaterally to raise the amount of royalty payments by exercising its powers to tax. such perceptions should be addressed by the Government, by contract or regulation. Otherwise, silence on the subject may frustrate the ability of developers to raise loan and equity contributions. 
E. POWER PURCHASE

For private-sector power generation to be attractive as an investment to the private sector, certain economic and contractual requirements are necessary to increase investor benefits and

thereby encourage development with the resultant public-sector benefits. From the private-sector developer's perspective, it will need a firm, power-purchase contract with the concomitant guaranteed electricity prices and reasonable guarantees of payment, investment security and system integrity.

It is useful to examine an outline of a standard power purchase agreement (the international norm) in context of the legal framework in Kenya. 
EXAMPLE GEOTHERMAL PURCHASE AGREEMENT

1. OVERVIEW

1.1 BASIC AGREEMENT. The basic document is a single contract between a company and a Utility where the company contracts to design, build and operate for 24 hours a day, " $x$ " days a year for " $y$ " years, a facility producing "z" megawatts.

\section{COMMENT}

* It is presently contemplated that the company would be majority owned by the off-shore investor, in a joint venture arrangement with one or more Kenyagovernmental entities could be Kenya Power company (KPC) or Kenya Power and Light Company (KPLC). KPC is a $100 \%$ government-owned company responsible for ongoing development of geothermal resources. It owns, inter alia, the olkaria geothermal plant and associated transmission lines. KPLC has majority government ownership and control, but also has approximately $30 \%$ private ownership. KPC and the other government-owned companies which own generating stations have agreements with KPLC vesting responsibility for operations and maintenance of the power facilities with KPLC. KPLC thus functions as the sole power utility in kenya. It is also recognized that KPC and KPLC have identity of management and staff. KPC is a paper company which KPLC personnel staff.

* The prospective private-sector investor and the Government of Kenya (including KPC and KPLC) will need to analyze the relative merits of identifying KPC and/or KPLC as a joint venture partner. The following analysis identifies the issues which may be identified by a hypothetical private-sector investor. The actual conclusions may differ, but this analysis is illustrative of the approach.

Under the circumstances set forth the above, the private-sector investor may conclude that there is very little functional difference whether the Kenyan partner is KPC or KPIC. It is arguable that KPC (as a $200 \%$ government-owned entity charged with geothermal development) may enjoy the greater stability of the two and that there is less of a potential for conflict of interest if the utility is not in a posture of contracting a geothermal resources agreement with itself. On the other hand, one could argue with equal force that it is

$$
\text { VIII - } 17
$$


relatively easy to penetrate the corporate veil and that the two entities are indistinguishable.

From the perspective of the private-sector partner, the determining factor is which of the two entities establish sufficient credibility in the eyes of the international investment community to attract the requisite debt and equity capital. It is probable that both public and private foreign, lending institutions will require majority ownership and control to be in the hands of their own nationals and that as much of the host country ownership as possible be in the hands of the Kenyan private sector. This predisposition, coupled with the established operational track record of KPLC, argues that, on balance, KPLC may prove the most likely Kenyan partner.

The private-sector investor will have to ensure that the articles of incorporation and by laws of the Kenyan joint venture partner as well as the laws and regulations governing the operations of those entities allow them to enter a joint venture with a foreign partner:

* A joint venture agreement between the partners will be one element of the agreement package.

* The Keryan joint venture partner will be in the best position to assume responsibility for obtaining all requisite Government approvals.

1.2 .

MAJOR DEFINITIONS. The following summarizes the key definitions:

"Agreement" means this Geothermal Resources Power Purchase Agreement.

"Annual Period" means any one of a succession of consecutive 12-month periods.

"Buyer" means Kenya Power and Iight company (or "KPLC)". 
"Buyer's system" or "System" mans the Buyer's electrical system. serving Kenya, Including Buyex's. Electrical Interconnection Facilitios, beginning at the point(s) of Delivery.

"Date of Initial Compercial Servioe" means the day the seller designates as the inttial date of production of electricity by sellex at lts Faollity.

-Electrical Interconnection Facilities" means those faclilties required for the receipt: or delivery of Electrlcity of any polnt (s) of Delivery requilrad to connect Buyer's syaten to the Facility in order to effectuate the purposes of this Agreement.

"Electricity" means the total amount of electricity producible by the Facility and avaliable for oale.

"Force Majeura" a force such as (1) aots of. Godi (11) war, inqurrection, rlot, civil disorder or disturbance; (iii) Impact of national emexgency; (iv) defaults of subcontractors and suppliers) (v). change of law, and (vi) strikes.

"Geothermal Resources Iicense" means the Geothermal Resources Ilcense granted the __ day of $19 \ldots ;$ by the Minister of Energy to seller.

"Jolnt Venture Agreament" means the agreenent entered between and among

"kịh" means kilowatts of aleotricity per houx.

"kw" means kilowatts of electricity.

"Points of Delivery" means any points where the seller's Electrical Interconnection Facilities connect to the Buyer's Ilectrical Interconneation Facilities.

"seller" means the foint venture entity producing eleotrical power.

comogers

* These derinitions are 1llustrative only. 
2. TERM, Thirty years (plus two extensions of tivo years each).

\section{conacings}

- The teirms of sale to the grfa must be incorporated into the contract. To the extent that it is contemplated that the racility be transferred back to Govermment ownershlp-a bulld, own, operate, transter or "BooT" arrangement, a formuls may be devlsed whereby, after the debt is pald and the Company receives an agreed return on investment, the faclilty may be transferted for an agxaed sum. If the Government wants to axpodite transfer, it will offar Inoontives to allow high retention of gxose income (perhaps forteiting foyalty and thereby vesting itselt with an irioreasing share of the oorporate ownership), and be prepared to buy out of the company eariy. If the Government wishes to mintmize cash outlay, a long term contract, such as that apparentiy envisioned by Kenya, can usually allow transfer for a token sum of money.

\section{GAIE OP' HOFLICITY}

3.1 Seller shall sell and Buyer shalf buy all Electricity to be produced by Seller's Iacility.

3.2 HOWIHLY ELECIRICIFY ARRGH. BUYer shall pay sellar, in United states Dollars, a monthly electriclty chargo equal to (i) the capacity charge, calculated on a $\mathrm{kw}$ basts, plus (11) tho product of the energy prioe for the applicabie calendax year, and the monthiy quantity of Electrioity on a kWh basis.

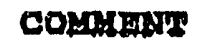

* This approach 1o 11lustrative. Thexe are a number of .. formula which have proven effective. The economics of the project and the goals of the parties should dictate a result which can bo expressed by formula.

* The $\mathrm{kW}$ basis and the energy.price fox the calendar year are at the heart of the agreement and therefore the subject of negotiations and formula set forth. In separate append 1 xes.

All parties must agree apon an electriclty pricing Iormula which guarantees prioes to the selier. This formula should account for varfous factors such as system 
reliability, production costs to the private sector producer, avoided costs to the Buyer for oil, coal, natural gas, hydropower, etc., and generation capability. If reliable power is supplied by the seller, the full avoided costs (energy plus capacity costs) are part of the criteria for seliing the electricity transfer price which is also moderated by system reliability and capacity. From an economic perspective, avoided costs should reflect incremental or long run marginal costs of electricity production. These are the costs to the Seller for installing and operating the least-cost option.

* Hard currency payment is essential. Financial institutions will not loan the private sector project funds without hard currency repayment.

Furthermore, since infrastructure projects such as power production facilities do not generate hard currency, financial institutions may require Government guarantees. In some of the developing countries, the Government guarantees only the power-purchase payments; it does not necessarily guarantee the loan. Should Kenya opt for this approach, the Government would only guarantee that payments will be made for the electricity it receives, not for the debt of a facility whether it succeeds or not.

\section{DOTIES OF THE PARTIES}

4.1 SELLER. Seller shall obtain all material government approvals. Seller shall own, operate and maintain all Electrical Interconnection Facilities necessary for the delivery of electricity from its Facility to the points of Delivery. Seller shall endeavor to provide uninterrupted delivery of Electricity to Buyer's system.

4.2 BUYER. Buyer shall own, operate and maintain all Electrical Interconnection Facilities necessary for the receipt of electricity from Points of Delivery to its system. Buyer shall purchase Electricity.

\section{MEASUREMENT, METERING AND ORERATING SCHEDULE}

5.1 UNITS OF MEASUREMENT. For the purposes of this Agreement Electricity shall be measured in $\mathrm{kW}$ and $\mathrm{kWh}$.

5.2 MEASUREMENT EQOIPMENT. Seller and Buyer shall each maintain electrical measuring, equipment. Seller's meters shall be used for quantity measurements. Testing, corrections of measuring equipment and

$$
\text { VIII - } 21
$$


maintenance shall be as mutually agreed.

5.3 OPERATING SCHEDULE. Seller and Buyer shall keep each other informed as to the operating schedule and condition of their respective facilities and equipment.

\section{COMMENT}

* Measurement provisions, with the requisite checks and balances must be carefully honed. Confidence of seller and Buyer in the measurements must be scrupulously maintained if the Agreement is to be effective during the operating years. This issue, if not set forth with specificity at the outset of the relationship, may prove to be a major cause of friction in the relationship.

\section{BIILINGS AND RECORDS}

6.1 MONTHLY BILI TO BUYER. Seller shall bill Euyer for the amount of Electricity actually delivered ti seller during the preceding month.

6.2 PAYMENT. Buyer shall pay seller in U.S. dollars for all amounts billed pursuant to Article 6.1 within thirty (30) days of the receipt of seller's statement.

6.3 RECORDS. Both Seller and Buyer shall maintain such records as mutually agreed which shall be available for inspection by either Party upon reasonable notice.

\section{COMMENT}

* Certainty of payment underlies project financing. Interest penalties for late payment are normally part of these provisions.

7. TAXEs. Seller shall be solely responsible for any income taxes relating to the Facility. Buyer shall be solely responsible for any sales, use, property, income or other taxes relating to the Buyer's system, as well as any taxes imposed on the sale to the Buyer of Electricity produced by the Facility.

8. REPRESENTATIOI 3 AND WARRANTIES

8.1 REPRESENTATIONS AND WRRRANTIES OF BUYER. Buyer hereby represents and warrants to seller as follows:

$$
\text { VIII - } 22
$$


A. Buyer is a corporation duly organized and existing in good standing under the laws of Kenya and is duly qualified to do business in Kenya.

B. Buyer possesses all requisite power, authority, including regulatory authorities and financial capability, to enter into and perform this Agreement and to carry out the transactions contemplated hereunder.

8.2 REPRESENTATIONS AND WARRANTIES OF SELLER. SeIler hereby represents and warrants to Buyer as follows:

A. Seller is a joint venture duly organized and existing under the laws of and is duly qualified to do business in Kenya.

B. Seller possesses all requisite power and authority to enter into and perform this Agreement and carry out the transactio: ; contemplated hereunder.

\section{COMMENT}

* In most international transactions, particularly where there is a direct foreign investment of the type contemplated here, an initial decision to be made concerns the type and nationality of the entity which will actually engage in the activity.

Factors which are usually considered in making such selection include foreign and domestic taxation, methods of financing the operation, credit risks and concerns, trade incentives, risks concerning injury to person and property, local licensing and permitting public relations, etc.

* There is no requirement under the Geothermal Resources Act and its implementing regulations that the licensee be a Kenya corporation. The contemplated joint venture, however, would be with KPC or KPIC. Whether either of those corporations are permitted (i) to enter into a joint venture with a foreign company (in a partnershiptype joint venture), or (ii) to become shareholders in a foreign company (by forming a new corporation with an offshore situs), is a question which needs to be examined. On such examination, it is probable that the joint venture seller must have a Kenya situs by virtue of the KPC or KPLC tie-in.

If a Kenya situs for the joint venture is selected the Government must assure the joint venture that it may

$$
\text { VIII - } 23
$$


continue to take advantage of the economic incentives established by the License. For example, Article 17 (2) of the Model Geothermal Resources License mandates that the Licensee appoint an attorney resident in Kenya to supervise operations under the license. ${ }^{20}$ clearly, this and similar such provisions contemplate an off-shore, foreign Iicensee. Consequently, one of the incentives to the Licensee, for example contained in Article 16(1)(e) of the Model License, is the ability freely to repatriate abroad all proceeds from the Iicensee's geothermal operations, including the proceeds from power sales. If a Kenya situs is elected for the venture, the Model License will have to be carefully drafted to recognize and to accommodate the fact that the licensee is in part foreign, in part domestic.

In the event of mixed foreign/domestic ownership, the provisions of the License should conform its legal language so that the spirit of the incentives remains intact and expresses the intent of the Ministry.

9. INDEMNIFICATION. Each Party agrees to protect, indemnify and hold harmless the other party and its directors, officers, shareholders, employees, agents and representatives against any and all loss on account of injury to persons, or for damage to property arising out of that Party's operation of facilities, except if such injury or harm is caused by the negligence of the other Party.

10. INSURANCE. The Buyer and the seller shall each obtain and maintain in force comprehensive general liability insurance in agreed amounts.

11. ARBITRATION. Arbitration shall be under the convention for the settlement of Investment Disputes between states and Nationals of other states.

\section{COMMENT}

* Most private-sector investors consider it of particular importance in contracts with government entities to specify clearly what jurisdiction's laws will be applied in the interpretation and enforcement of the contract, to specify where disputes will be resolved and how disputes will be resolved (arbitration is the generally preferred n.ethod). Each party to the Agreement will normally want the laws of its own domicile to apply and

This requirement is probably inserted to ensure an adequate nexus between a foreign-owned corporation and Kenya.

$$
\text { VIII - } 24
$$


for the dispute to be settled by a tribunal located in its domicile.

* In electing an arbitral tribunal, special care should be taken to ensure that Kenya has officially recognized that forum. The following list sets forth the major arbitral tribunals.

a. ICsID. The Convention on the settlement of Investment Disputes between States and Nationals of other states ("ICSID") establishes the International Center for Investment Disputes. This convention has the unique adrantage of providing that each contracting state shall recognize and enforce an ICSID award as though it were a final judgment of the country's courts. ICSID is limited to disputes arising between a state party to the convention and a national of another state and must arise from an investment dispute. Kenya is a member of ICSID, and contemplates the use of ICSID in the Model License.

b. The New York Convention. The 1958 United Nations Convention on the Recognition and Enforcement of Foreign Arbitral Awards (the "New York Convention"), ratified by approximately 10 countries, provides that an international award-rendered in a country party to the Convention may be enforced in another convention country.

c. UNCITRAI. This model set of rules was unanimously approved by the U.N. They are of particular interest because arbitrations administered by the London court of Arbitration and The American Arbitration Association can be carried out using these rules.

d. ICC. The International Chamber of Commerce rules have the advantage of being internationally recognized (unlike those of the American Arbitration Association).

e. AAA. The American Arbitration Association rules are perhaps more effective than others, provided that the contracting parties are citizens of countries which have ratified the New York Convention, as its procedures generally involve less delay and expense.

12. BREACH OF CONTRACT. This provision sets forth the events which are deemed to create a breach of contract and the remedies for such breach.

COMMENT

* Liabilities such as penalties for default on contracts are important to the utility (KPLC) vis-a-vis future

$$
\text { VIII - } 25
$$


* Of overriding importance are the breach of contracts envisioned under the kenya regulatory scheme. Since a breach results in forfeiture of rights, the Government will have enormous leverage over the joint venture seller.

13. MISCELLANEOOS. These provisions addresses notice, service successors and assigns, third party reneficiaries, confidentiality governing law, language, currency, effective date, amendments and other such significant issues.

\section{ECONOMIC INCENTIVES}

The private-sector investor in a Kenya geothermal power plant will take a careful look at of the institutional and legal framework in making a determination as to whether to invest in Kenya. The income produced by electricity sales is only one component of the analysis. For example, to the transnational sector investor, time is money. The time eaten up by inordinate government administration may be the difference between profit and loss, and is often a key element in deciding whether to place risk capital in a given country. This section will define its subject "economic incentives" in the broalest possible meaning of the term and examine the multitude of interrelated issues from the legal perspective which, in sum total, constitute the Kenya economic incentive package. 


\section{Overview}

In general, in order to regulate foreign investment and joint ventures on their territories, most countries have enacted "investment laws" or "investment codes" whose purpose is to create a legal framework for the entry and operation of foreign capital. Some countries have enacted a network of laws rather than a general investment law which, though complex, serves the same purpose. Few countries view a foreign investment project, in and of itself, as a good thing. A foreign investment project is desirable if it has desirable effects on the host country's economy. Every project will have both benefits as well as costs and risks. A geothermal power project will have both. Therefore, Kenya may view a private-sector geothermal power facility as a mixed blessing with costs as well as benefits. Consequently, the objective is to strive for agreements which will structure such a facility project so as to maximize benefits and minimize the costs to both sides. However, as has been discussed, in $\S$ I.B above, a private infrastructure project has a unique public element, and incentives designed for the proverbial "widget manufacturer" need to be evaluated with their application to a private-sector power project.

\section{The Investment Laws and Regulations of Kenya}

Since Kenya achieved independence in 1963, the Kenyan government has pursued a policy of creating a mixed economy in which the public and private sectors play a role.

\section{a. Constitution}

The Constitution of Kenya establishes fundamental due process protection from the deprivation of private property:

No property of any description shall be compulsorily taken possession of, and no interest in or right over property of any description shall be compulsorily acquired ... unless provision is made by a law applicable to that taking of possession or accuisition for the prompt payment of fuli compensation. 2 I

21 Kenya Constitution, Art. 75, para. (1). Full text appears in Appendix VIII. 


\section{COMMENT}

This provision in the Kenya constitution is similar to standard provisions in most investment laws which make guarantees, in varying degrees, against nationalization or expropriation. such language, although extremely significant, may be viewed by the international financial community (which has witnessed abuses) as being of limited usefulness. However, in any eventual investment dispute resulting from expropriation, it may provide support for an adequate standard of compensation, e.g., "prompt, adequate and effective."

\section{b. Investment Iaw}

The primary investment law of Kenya is the Foreign Investments protection Act. 22 The Foreign Investments protection Act is a classic mix of checks and balances. It controls the formation and operation of investment while it simultaneously encourages foreign investment primarily by offering foreign investors and joint ventures a variety of incentives.

Under the Kenya statutory scheme, foreign investors may apply for and be granted certificates if it is determined that the enterprise would "further the economic development of, or would be of benefit to Kenya." Importantly, a certificate holder "notwithstanding the provisions of any other law for the time being in force," may transfer out of Kenya the approved foreign currency, at the prevailing official rate of exchange. This includes after tax profits, equity investment and the principal and interest of loans. 23

\section{COMMENT}

* The language of the statute is clear that any investment variations must be certified, thus the private-sector investor must diligently update its certificate.

* Repatriation of foreign currency may be delayed (not stopped -- but delayed) by administrative processes, outside the statutory framework, This issue should be scrutinized by the prospective investor.

22 The Foreign Investments Protection Act, Ch. 518 (Dec. 15, 1964 ) as revised by the Foreign Investment protection (Amendment) Act, 1988, Kenya Gazette No, No. 50, 58-60 (Aug. 11, 1988). Full text appears in Appendix IX.

23 Id. \& 3. 


\section{c. Investment promotion Center}

The Investment Promotion Center was created by the Government of Kenya under an Act of Parliament to serve as the primary contact point for companies and entrepreneurs, both local and foreign, wishing to explore investment opportunity in Kenya. ${ }^{24}$ The Center functions to streamline application and approval procedures--"one stop" shopping. According to the Center, "recent policy statements have indicated that the Government expects the private sector to play an increasingly important role in the provision of goods and services. Foreign investment is welcomed...."

\section{COMMENT}

The Center is a relatively new government organization, since installation of a private-sector power facility would represent the implementation of a major policy issue, the private-sector investor may find that the Center would augment investment efforts with the relevant government ministry and agencies, but would not relieve the investor of the primary burden of proceeding. As noted in the overview to this chapter, a geothermal power-production facility is more properly viewed as an integral part of the Government's power infrastructure than as an offshore developer of a Kenyan manufacturing facility.

\section{d. Geothermal Investment}

The Geothermal Resources Act and its implementing regulations represent a special investment law for the geothermal energy sector. The incentives are spelled out contractually in the Model Geothermal Resources License. These incentives (section numbers in parentheses) include:

(1) Entry. Facilitated entry permits for technicians and managers. ( $\$ 14$ )

(2) Import. Facilitated permits for import relating to operations, exempt from all customs duties, and, when certified by a representative of the Ministry of Energy, waiver of approval of import license and

24

See Investors' Guide to Kenya, Vols. I to IV (May 1989). In President Moi's 1982 inaugural address, he stated, "... The private sector will in the future play an increasingly large role in development, through both domestic and foreign investment. The Government will do everything in its power to encourage both domestic and foreign investor." 
waiver of exchange control approval. (\$ 15(1)(2)(3))

(3) Household Goods. Facilitated permission for expatriate employees to import exempt from all customs duties. ( $\$ 15(4)$ )

(4) Resale. Licensee, contractors and expatriate employees may sell imported items no longer needed for operations. (\$ $15(5))$

(5) Export. Licensee, contractors and expatriate employees may export previously imported articles free of all export duties. ( $\$ 15(6)$ )

(6) Foreign Bank Accounts. Maintain external accounts inside Kenya, and foreign bank accounts outside Kenya. ${ }^{25}$ (\$ $16(1)(\mathrm{a})$ )

(7) External Disposition. Receive and retain foreign currency outside Kenya. ( $\$ 16(1)(8)$ )

(8) External Payments. Pay directly outside Kenya for goods and services in Kenya. ( $\$ 16(1)(c))$

(9) Payroll. Pay expatriate employees in foreign currency outside Kenya. (\$ $16(1)(d))$

See Exchange Control Notice No. 3; Exchange Control Act CAP. 113 (1988). 
(10) Repatriation. Fully repatriate abroad all proceeds from the licensee's geothermal operations in Kenya, including but not limited to proceeds from the sale of assets (i.e., Electricity). (\$ $16(1)(e)$ )

\section{COMMENT}

* Query. Would this provision expand on the repatriation provisions of the Foreign Investments protection Act?

(11) Most Favored Investor. Rates of exchange would be not less favorable than those granted to any investor.

(12) Central Bank Approval Waired. Licensee could enter all contracts without prior approval of Central Bank (or any another Government agency), subject to giving preference to Kenyan goods. (\$ 16(3))

(13) Certification. Facilitation of the obtaining of a Foreign Investment, Protection Act Certificate of Approved Enterprise (with the amount recognized by the certificate equaliing the amount set forth in the Iicensee's books of accounts). ( $\$ 16(4)$ )

\section{COMMENT}

* The Minister is excused of all contractual obligations in the event of force majeure--by definition, an occurrence beyond the reasonable control of the Minister which prevents performance of obligations.

Consequently, the effective result is that the incentives set forth in the Model Iicense represents a good faith, best efforts undertaking by the Minister, excusable in force majeure circumstances--disputes over which would be settled by reference to ICSID arbitration.

* The term "force majeure" requires careful definition.

* The certainty of the incentives set forth in the model Iicense is somewhat diluted by the fact that the Minister cannot act ultra vires. Thus, a conflicting law or regulation might govern in the event of a conflict between the contractual license and such law or regulation. In view of long term nature of the license contemplated ( 30 to 40 years), it would seem to be in the interest of both parties for the agreed-on license to be enacted into law by the Parliament. There appears to be precedent for

$$
\text { VIII - } 31
$$


such special legislation in Kenya which has been established by practice in the area of petroleum development contracts.

\section{Investment Checklist}

Most transnational corporations will ask a time-proven series of questions prior to making an investment. Many of these have been addressed elsewhere in this chapter. Where previously covered, this list provides a convenient summary. Where not otherwise covered, they provide a mechanism to identify and to address the issue.

a. Ground Rules. What are the host country procedures, customs and regulations regarding foreign excilange, customs, and insurance?

The model Geothermal Resources License provides a mechanism for "most favored investor" exchange rates; however, the issue of whether and how the utility, KPLC, will pay the power producer in hard currency is not addressed. The Model License waives the most onerous customs duties. The issue of whether KPLC will be able to obtain the insurance remuisite under the power purchase agreement is linknown.

b. Import Restrictions. Will the venture be allowed to import or purchase necessary raw materials or components, or will there be prohibitivel? high tariffs?

The Model License resolves in the affirmative the question of whether the venture will be allowed to import or purchase components. Approved projects may obtain the privilege to import capital goods, spare parts at reduced tariff rates or without the payment of any customs duty at all. The issue of raw materials is not expressly addressed by the kenya regulations, but may be a de minimus issue for the geothermal power producer. Due to high customs duties prevailing in Kenya, such customs exemptions are extremely important to the commercial feasibility of the project.

c. Financial Ability. What are the regulations affecting the ability of the joint venture to pay for imported goods, e.g., ability to use letters of credit and other forms of payment, availability of dollar funds located outside the importer's country? Does Kenya law establish financial criteria--such as guidelines for the amount of capitalization or funding to be made by a U.S. partner to a local business entity?

In general, the Model License allows a viable financial scheme. No legal regulations exist for participation by Kenya nationals in foreign-owned ventures. The government may use its economic power to provide various guarantees of foreign loan, guarantees from the central bank to provide hard currency for debt 
servicing, and guarantees by government agencies to purchase the surplus production at a minimum price, thereby assuring a certain degree of profitability.

d. Labor Law. Does Kenya law regulate the number of foreign nationals which may be employed? Does it regulate management or director appointments?

Minimum wiges are prescribed by law and vary according to type of job and locality. They are increased periodically and published in the Kenya Gazette. In Nairobi, average wages paid in practice at the beginning of 1988 were about ksh 800 per month for an unskilled worker and Ksh 1300 per month for a skilled worker. overtime is paid at one and a half times the normal hourly rate, and at two times wages on holidays.

Legal maximum working hours are 52 in a six-day work week. However, in practice a 45 hour, six-day work week is generally observed. Employees are legally entitled to 24 days annual paid vacation after ore year of continuous employment. There are a total of 11 paid public holidays during the year.

Total fringe benefits, include social security and health insurance, amount to about 30 percent of the basic wage. In practice, an employee is entitled to 60 days of sick leave per year: 30 days on full pay and 30 days on half pay. Women are enticled to maternity benefits for two calendar months, forfeiting annual paid vacation.

In normal circumstances, an employer must give one month's notice of termination. On actual termination, the employer must pay one month's wages in lieu of dismissal notice, any accrued holiday pay, and severance pay if the employee has worked for more than five years.

A number of trade unions are registered under the Trade Union Act. They are organized by craft, rather than industry, and belong to a central group, The central organization of Trade Unions (COTU). The modern sector work force is highly unionized. However, Kenya has a well developed system of industrial relations and labor relations are generally friendly. Union membership is not compulsory in any industry.

e. Incentives. What are the incentives to attract foreign investment including remittability of profits, interest, and royalties?

The major instrument of guarantees for foreign investments is the Foreign Investment Protection Act. Under the Act the Minister of Finance issues a certificate of Approved Enterprise to foreign nationals who invest in approved sectors in foreign currency or re-invest their retained earnings in Kenya. This allows investors

$$
\text { VIII - } 33
$$


* Profits, after tax, including retained profits which have not been capitalized

* The original equity investment, plus retained profits which have been capitalized

* Principal of foreign loans and interest as specified in the certificate

Capital gains arising from the sale of foreign assets not permitted to be transferred out of Kenya are required to be invested in Government securities at market rates. The income from the Government securities in which the capital gains are invested may be transferred out of Kenya when received. In addition, the capital gains may be repatriated at the end of five years in the same manner applicable to the original equity investment.

Kenya has not established a tax-benefit program to attract investors. Nearly all host countries manipulate their tax and fiscal systems in order to attract foreign investment. one of the most common incentive is the "tax holiday" which exempts the enterprise--and sometimes the investor--from local income and other taxation for a specified period of years. The host country may also grant exemptions from taxes on dividends, royalty payments, interest payments, property taxes and numerous other charges and fees for which the project, its investors, creditors, contractors, and subcontractors would otherwise be liable. A variation on the tax holiday is "tax stabilization" which guarantees that the approved project will pay no more than a specified maximum tax exemption or relief to the joint venture's foreign employees. Nonetheless, the issue of a tax holiday might be explored with the Kenya government.

In negotiating tax incentives, the investor should take great care to understand Kenya's tax system, especially how its tax laws are applied in practice, so that the incentive obtained will contribute a meaningful benefit. Moreover, it is important to determine precisely when the tax holiday begins. Ideally, in a semi-public infrastructure enterprise taxation should be delayed so that principle and interest payments may be met and, if possible, accelerated.

Rather than to grant outright tax exemptions, many countries achieve the same result--i.e, increasing after-tax cash flow--by allowing the project to take increased tax deductions for accelerated depreciation.

f. Organization of Businesses. Which local form of business VIII - 34 
association is best suited to a geothermal power operation? If under local law a joint venture is necessary, what are the standards to be applied in the selection of foreign partners, distribution of control and operations?

These questions are more contractual than legislative and need to be addressed in context of the prospective joint venture agreement.

9. Corporation/Companies Law. Does Kenya law prohibit the conduct of the relevant business activity by a business entity other than one created under the law of the host country? Does it require government approval of the relevant business?

Foreign investors need to apply for and obtain a certificate of Approved Enterprise if they wish to avail guarantees provided under the Foreign Investment Protection Act. Other special licenses and approvals may be required for particular types of businesses. Employers must register with the tax authorities and the National Social security Fund. Finally, plans for any buildings or other facilities of a permanent nature must be submitted to the concerned local authority for approval.

The principal forms of business enterprise in Kenya are:

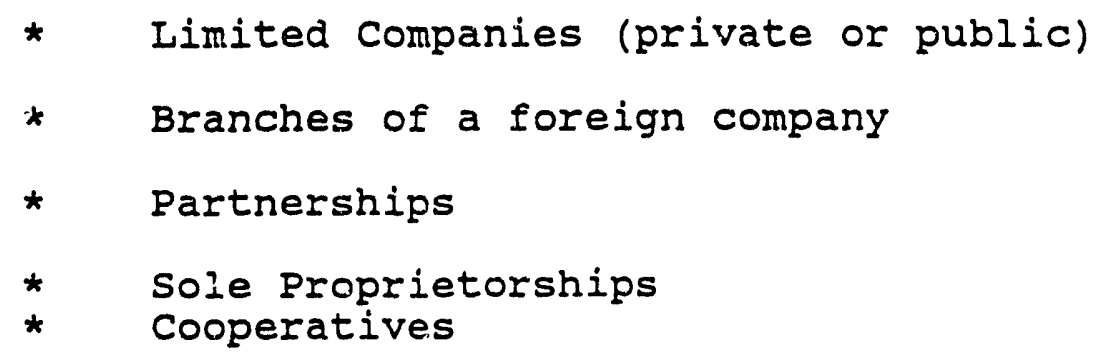

Investors are advised to retain local legal counsel to carry out the steps necessary to establish a company in Kenya. Kenya's legal system is based on English law and practice. The Investment Promotion Center can provide a list of lawyers with experience in dealing with the legal and commercial aspects of investment, both foreign and local.

Foreigners who intend to work in Kenya are required to obtain work permits. Such work permits are issued by the Immigration Department, which is under the office of the President. Work permits are generally issued for an initial period of two years. Work permits for top-level managers and technical personnel should be carefully agreed on in advance.

h. Taxation. What is the interrelationship of the tax laws of the domicile of the foreign investor and local taxation, including tax treaty implications and availability of foreign tax

$$
\text { VIII }-35
$$


credit for foreign taxes paid?

- Corporate Income Tax. Locally registered and incorporated companies, both foreign and local, pay corporate tax at the rate of 45 percent of taxable income. Branches of foreign companies pay income tax at the rate of 52.5 percent, a corporate tax burden comparable to European levels. There are no provincial or municipal income taxes, but local authorities may levy property taxes. No other corporate income taxes or surtaxes exist.

Businesses which suffer losses can carry forward such assessed tax losses to be set off against subsequent taxable profits. Losses may be carried forward until adequate profits have accrued to absorb carried forward losses.

Personal Income Tax. Income tax is charged on the income earned in Kenya by any person resident in Kenya. A wife's income is assessed independently of the husband, and is taxed at the same rates as the husband. Expatriates working in regional offices located in Nairobi are exempted from income tax on one-third of their earnings if such earnings are paid from offshore sources. Expatriates employed in Kenya are allowed to remit in foreign currency part of their earnings.

Personal income tax rates are levied in the following manner:

\begin{tabular}{ll}
\multicolumn{1}{c}{ Ksh } & $-\frac{\%}{10}$ \\
$1-39,600$ & 10 \\
$39,601-79,200$ & 15 \\
$79,201-118,80$ & 25 \\
$158,401-198,000$ & 45 \\
over 198,000 & 50
\end{tabular}

Housing, allowances, cars and other perquisites are imputed at specified rates and added on to taxable income. As long as these items continue to be $d$ at less than $100 \%$ of the foreign jointventure corporation may view these items as incentive benefits to its employees.

sales and withholding Taxes. Sales tax is levied on all manufactured goods produced in or imported into Kenya. The ad valorem rate is 17 percent on most goods, with higher rates levied on drinks, cigarettes and luxury items.

Withholding tax is deducted from payments of dividends, $\operatorname{VIII}-36$ 
interest, royalties, and other unearned income to nonresidents. Rates of withholding tax (1990) are as follows:

Type of Payment

Management/Professional Fees

Royalties

Rent

Dividends

Interest

Pensions and Annuities
Withholding Rate (percentage)

- Tax Treaties. Comprehensive tax treaties are in force with Canada, Denmark, the Federal Republic of Germany, Malawi, Norway, Sweden, the United Kingdom, and Zambia. These tax treaties generally provide for avoidance of double taxation and reduce or waive the withholding taxes outlined above.

i. Dispute Resolution. What is the usefulness of arbitration agreements under local law, treaties and international rules? Does Kenya law require that disputes in regard to local activities be resolved in the courts of Kenya and governed by the laws of Kenya?

Kenya is a member of the International center for settlement of Investment Disputes, ICSID, and, thus, disputes may be settled exterior to the courts of Kenya. The applicable law appears to be a matter to be resolved by agreement.

j. Ownership Law. Who may own or use geothermal resources? How is access to the power grid regulated? Who owns the transmission lines? How and to what degree of efficiency are utility bills collected and to what extent is the utility subsidized?

The Government owns the geothermal resources, development authority rests with KPC, but KPLC is the monopoly utility.

The issue of efficient collection of utility bills will be at the heart of the power purchase agreement.

k. Currency. Does Kenya law regulate the repatriation of capital, the importation of foreign currency, or the rate at which the local currency may be converted into U.S. dollars upon repatriation of profits or other distributions to the United States? Does it regulate the economic return on the U:S. partner's investment which may be repatriated from che year to the next?

A Certificate of Approved Enterprise to foreign nationals who VIII -37 
invest their retained earnings in Kenya this allows investors to transfer:

* Profits, after tax, including retained profits which have not been capitalized

* The original equity investment, plus retained profits which have been capitalized

* Principal of foreign loans and interest as specified in the certificate

Capital gains arising from the sale of foreign assets not permitted to be transferred out of Kenya are required to be invested in Government securities at market rates. The income from the Government securities in which the capital gains are invested may be transferred out of Kenya when received. In addition, the capital gains may be repatriated at the end of five years in the same manner applicable to the original equity investment. 


\section{LEGAL BIBLIOGRAPHY}

\section{Constitution}

KENYA CONSTITUTION, Laws of KenYa, 2-95 (1987).

\section{statutes}

The Companies Act, ch. 486, Laws of Kenya, 2-571 (1978).

The Customs and Excise Act, ch. 472, 1 Laws of Kenya, 2-389 $(1984)$.

The Customs and Excise Act, ch. 472, 2 Laws of Kenya, 2-188 $(1984)$.

The Electric Power Act, ch. 314, Laws of Kenya, 2-213 (1986).

The External Loans and Credits Act, ch. 422, Laws of Kenya, 2-3 $(1979)$.

The Exchange Control Act, ch. 113, Laws of Kenya, 2-60 (1988).

The Foreign Investments Protection Act, ch. 518, The Kenya Gazette Supplement, 2-5 (1964).

The Foreign Investments Protection (Amendment) Act, 1999, No. 14 of 1988, The Kenya Gazette Supplement no. 50 (Acts No. 4), $58-60(1988)$.

The Geothermal Resources Act, 1982, Legal Notice No. 12 of 1982 , 47-58 (1982) date of assent, July 8, 1982, date of commencement, by notice, commencement, May 1, 1990, Legal Notice No. 205 of 1990, 262 (April 24, 1990).

The Kenya Citizenship Act, ch. 170, Kenya Gazette Supplement No. 21, Legal Notice No. 66, 125-130 (1976).

The Immigration Act, ch. 172, Laws of Kenya, 2-67. (1984).

The Immigration Act, ch. 172, Kenya Gazette supplement No. 35 , Legal Notice No. 108,189 (1986).

The Income Tax Act, ch. 470, Laws of Kenya, 1-184 (1986).

The Restrictive Trade Practices, Monopolies and Price Control Act, 1988, No. 14 of 1988, Kenya Gazette Supplement No. 87 (Acts No. 10), 213-271 (1988).

The State Corporations Act, ch. 446, Kenya Gazette Supplement No. 33, Legal Notice No. 199, 257 (1990). 


\section{Books, Pamphlets and Unpublished Material}

K.-H. Bockstiegel, Arbitration and State Enterprises (1984).

T. Brewer, R. David, \& L. Lim, Investing in Developing Countries

$(1986)$.

C.J. Cicchetti, Meeting the Nation's Future Energy Needs: Cogeneration, Competition and Conservation (Nov. 1988), (paper presented at looth convention of National Association of Regulatory Utility Commissioners) (available from Asian Institute of Technology).

D. Goldsweig, Joint Venturing Abroad (1985).

Investment Promotion Centre, 1 Investors Guide to Kenya (1989).

Investment Promotion Centre, 2 Investors Guide to Kenya: Investment policies, procedures, and opportunities (1989).

Investment Promotion Centre, 4 Investors Guide to Kenya, statistical Tables and opportunities (1989).

Investment Promotion Centre, Project Application Form IPC/IFC/001.

Office of Energy Bureau for Science and Technology United States Agency for International Development, Potential for private Investment in Rice Residue Power Generation, Rpt. No. 88-05 (1988).

Office of Energy Bureau for Science and Technology United States Agency for International Development, Report on Roundtable for Private Participation in the Electrical sector of the Dominican Republic, English Version, Rpt. No. 88-20 (1988).

Office of Energy Bureau for Science and Technology United States Agency for International Development, Summary Report of the Philippine seminar and Roundtable on private power Generation through Build-operate-Transfer (BOT), Rpt. No. 89-04 (1989).

United Nations Industrial Development organization, United Nations, Guidelines for contracting for Industrial projects in Developing Countries (1975).

United States Agency for International Development office of Energy Bureau for Science and Technology and Bureau for Asia and the Near East, Summary of the International workshop on opportunities for Private sector Power Generation in Indonesia RET. No. 89-17 (1989).

The World Bank/International Finance Corporation, Philinoines 
Rural Electrification sector Study: An Integrated Program to Revitalize the sector (August 10, 1989) (Draft Report No. 8016$\mathrm{PH})$. 
Methodology for section III Sensitivity Analysis

Appendix I 


\section{Sensitivity Analysis:}

In order to understand both the impact of various contingencies on the KPLC system and the prospective benefits of private geothermal development, we have done a common set of sensitivity analyses for each of the cases listed below. Cases refer to alternative forecast and oil price assumptions, with sensitivity analysis referring to analysis of various different capacity timing and cost assumptions. The sensitivity assumptions which are examined in each case below are as follows:

Sensitivity

Number:

1.

2 .

3.

4 .

5 .

6 .

7 .

8 .

9 .

10.

11.
Description:

KPLC Base Case

KPLC Base Case, except that all geothermal additions are delayed by 1 year.

Same as -2 , except that 50 MW of private geothermal are added in 1994-95.

Same as 2, except that $40 \mathrm{MW}$ of private geothermal are added, 20 MW each, respectively, in 1993-94 and 1997-98.

KPLC Base Case, Except that all geothermal additions are delayed by 2 years.

Same as 5, except that 50 MW of private geothermal are added in 1995-96.

Same as 5, except that $40 \mathrm{MW}$ of private geothermal are added, 20 MW each, respectively, in 1995-96 and 1998-99.

KPLC Hydro and coal new capacity is delayed by 1 year in all instances.

Same as 8 , except that $50 \mathrm{MW}$ of private geothermal are added in 1996-97.

Same as 8 , except that $40 \mathrm{MW}$ of p-ivate geothermal are added, $20 \mathrm{MW}$ each, respectively, in 1996-97 and 1997-98.

KPLC Hydro and Coal new capacity is Appendix I - 2 
12 .

delayed by 2 years in all instances.

Same as 11, except that $50 \mathrm{MW}$ of private geothermal are added in 1996-97.

33 .

Same as 11, except that $40 \mathrm{MW}$ of private geothermal are added, 20 MW each, respectively, in 1996-97 and 1998-98.

14 .

KPLC Base Case, except that all KPLC geothermal capital costs are increased by $25 \%$.

15 .

Same as 14, except that $50 \mathrm{MW}$ of private geothermal are added in $1994-95$ as a substitute for 32 N.T of KPLC geothermal.

Case 1 consists of the basic sensitivity results compared under KPLC base case assumptions on forecast growth (Table III-) and oil prices.

Case 2 consists of a set of sensitivities on a revised KPLC base case with a high forecast of. load growth.

Case 3 again is a new set of sensitivities, this time with the original baseline forecast, but with oil price increasing more rapidly.

Case 4 shows the impact of sensitivities on a base case with both a high forecast and high oil prices.

Basic Assumptions for the different cases are as follows:

Forecast Growth

Case 1: $4 \%$

Case 2: $6.7 \%$

Case $3: \quad 4 \%$

Case 4: $6.7 \%$
Oil Prices

$$
\text { Price Escalation Base Increase }
$$

$\begin{array}{ll}4 \% & 10 \% \\ 4 \% & 10 \% \\ 6 \% & 20 \% \\ 6 \% & 20 \%\end{array}$

As noted above reserve margins realized varied considerably in the sensitivities, and in general showed significant reserve 
deficits in most cases, even when KPLC plans were realized as planned with the base case forecast. Furthermore, unserved energy became an extremely high figure in several of the sensitivities, particularly under the high forecast. This result perhaps even understates the potential danger, as it is assumed that the KPLC plan is realizable (except for the explicit sensitivity delays, etc.), and due to other contingencies not modeled such as drier than average years, failure to realize combustion turbine plans as expected, lower than expected energy or capacity from Turkwell, etc. 
System cost scenario Results for section III

\author{
Appendix II
}


Appendix II

\section{system cost scenario Results for section III}

\section{Case 1 - Base Case Forecast and Oil Price Escalation Rates}

\begin{tabular}{|c|c|c|c|c|c|c|c|c|}
\hline & $\begin{array}{l}\text { Case } 1 \\
\text { Base Case/forecast and } \\
\text { oil Price Escalation }\end{array}$ & $\begin{array}{l}\text { Total Amual } \\
\text { Capital Cost } \\
\text { (000s) }\end{array}$ & $\begin{array}{l}\text { Unserved } \\
\text { Energy } \\
\text { (000s) }\end{array}$ & $\begin{array}{l}\text { Variable } \\
\text { Costs } \\
\text { (000s) }\end{array}$ & $\begin{array}{l}\text { Total } \\
\text { Costs } \\
\qquad(000 s)\end{array}$ & $\begin{array}{c}\text { Change } A t \\
\text { From Base } \mathrm{C} \\
(x)\end{array}$ & $\begin{array}{l}\text { Averege } \\
\text { Cost } \\
\qquad(0005)\end{array}$ & $\begin{array}{l}\text { Chanoe } \\
\text { From Base } \\
\qquad(x)\end{array}$ \\
\hline & KPLC Base Case & $\$ 1,242,616$ & so & $51,400,641$ & $\$ 2,643,257$ & & 50.037 & $0.00 x$ \\
\hline 2 & KPLC Geothermal-1Yr Delay & $51,953,614$ & 54,510 & $\$ 1,530,223$ & $\$ 2,688,347$ & $1.71 x$ & $\$ 0.037$ & $2.36 x$ \\
\hline 3 & Geo. I Yr Delay+50mu Priv. Geo. & $\$ 1,314,606$ & so & $\$ 1,289,432$ & $\$ 2,604,039$ & $-9.48 x$ & 50.036 & $-2.30 \%$ \\
\hline 4 & Geo. I Yr Delay+2x20mH Priv. Geo. & $\$ 1,295,253$ & so & $\$ 1,397,448$ & $\$ 2,692,701$ & $1.87 x$ & $\$ 0.037$ & $1.7 \pi x$ \\
\hline 5 & KPLC Geothermal-2Yr Delay & $\$ 1,081,846$ & $\$ 14,950$ & $\$ 1,655,863$ & $52,752,660$ & $4.14 x$ & 50.038 & $4.94 \%$ \\
\hline & Geo. 2 Yr Deloyt5amu Priv. Geo. & $51,229,423$ & 54,510 & $51,391,766$ & $\$ 2,625,698$ & $-0.66 x$ & $\$ 0.036$ & $-0.63 x$ \\
\hline & Geo. 2 Yr Delay+2x20MW Priv. Geo. & $\$ 1,236,975$ & so & $\$ 1,421,591$ & $\$ 2,658,567$ & $0.58 x$ & $\$ 0.037$ & $0.86 \%$ \\
\hline & KPLC Hydro \& Cool-IYr Delay & $\$ 1,156,236$ & so & $\$ 1,520,251$ & $\$ 2,676,485$ & $1.26 \%$ & \$0.037 & $1.73 x$ \\
\hline 9 & Hydro Coal Delay+50MH Priv. Geo & $\$ 1,290,395$ & so & $\$ 1,304,665$ & $\$ 2,595,059$ & $-1.82 x$ & $\$ 0.036$ & $-2.25 x$ \\
\hline 10 & Hydro \& Coal Delay+2x20Mn Priv. Geo & $\$ 1,284,384$ & so & $\$ 1,363,675$ & $52,648,060$ & $0.18 x$ & $\$ 0.037$ & $-0.01 x$ \\
\hline 11 & KPLC Hydro \& Coal-2Yr Delay & $\$ 1,069,853$ & so & $\$ 1,626,323$ & $\$ 2,696,176$ & $2.00 \%$ & $\$ 0.038$ & $2.93 \%$ \\
\hline 12 & Hydro \& Coel Delay+50m, Priv. Geo & $\$ 1,204,013$ & so & $\$ 1,375,076$ & $\$ 2,579,089$ & $-2.43 \%$ & 50.036 & $-2.30 x$ \\
\hline 13 & Hydro \& Coal Delay+2x2OMH Priv. Geo & $\$ 1,198,003$ & so & $51,443,452$ & $\$ 2,641,455$ & $-0.07 x$ & 50.037 & $0.28 \pi$ \\
\hline 14 & KPLC Geothermal 25\% Cost Rise & $\$ 1,373,546$ & so & $51,400,641$ & $\$ 2,774,187$ & $4.95 \%$ & 50.038 & $4.50 x$ \\
\hline 15 & KPLC Geo. Cost Rise+50MH Priv Geo & $\$ 1,384,061$ & so & $51,331,595$ & $\$ 2,715,657$ & $2.74 x$ & $\$ 0.037$ & $1.69 \%$ \\
\hline
\end{tabular}

\section{Case 2 - High Forecast Demand Growth and Base Oil Price Escalation Rates}

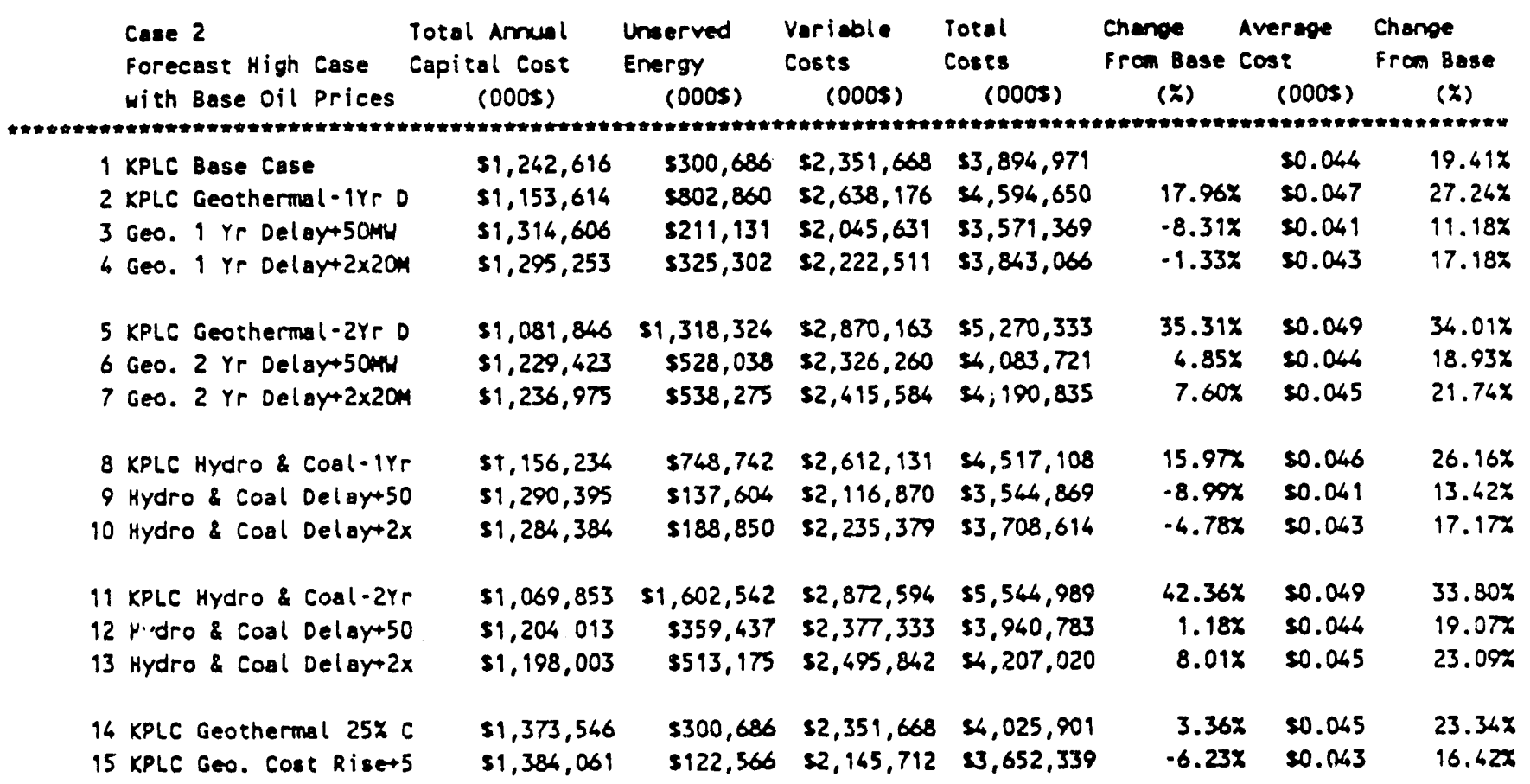




\section{system cost 8cenario Results for section III (Continued)}

\section{Case 3 - Base Case Forecast and High Oil Price Escalation Rates}

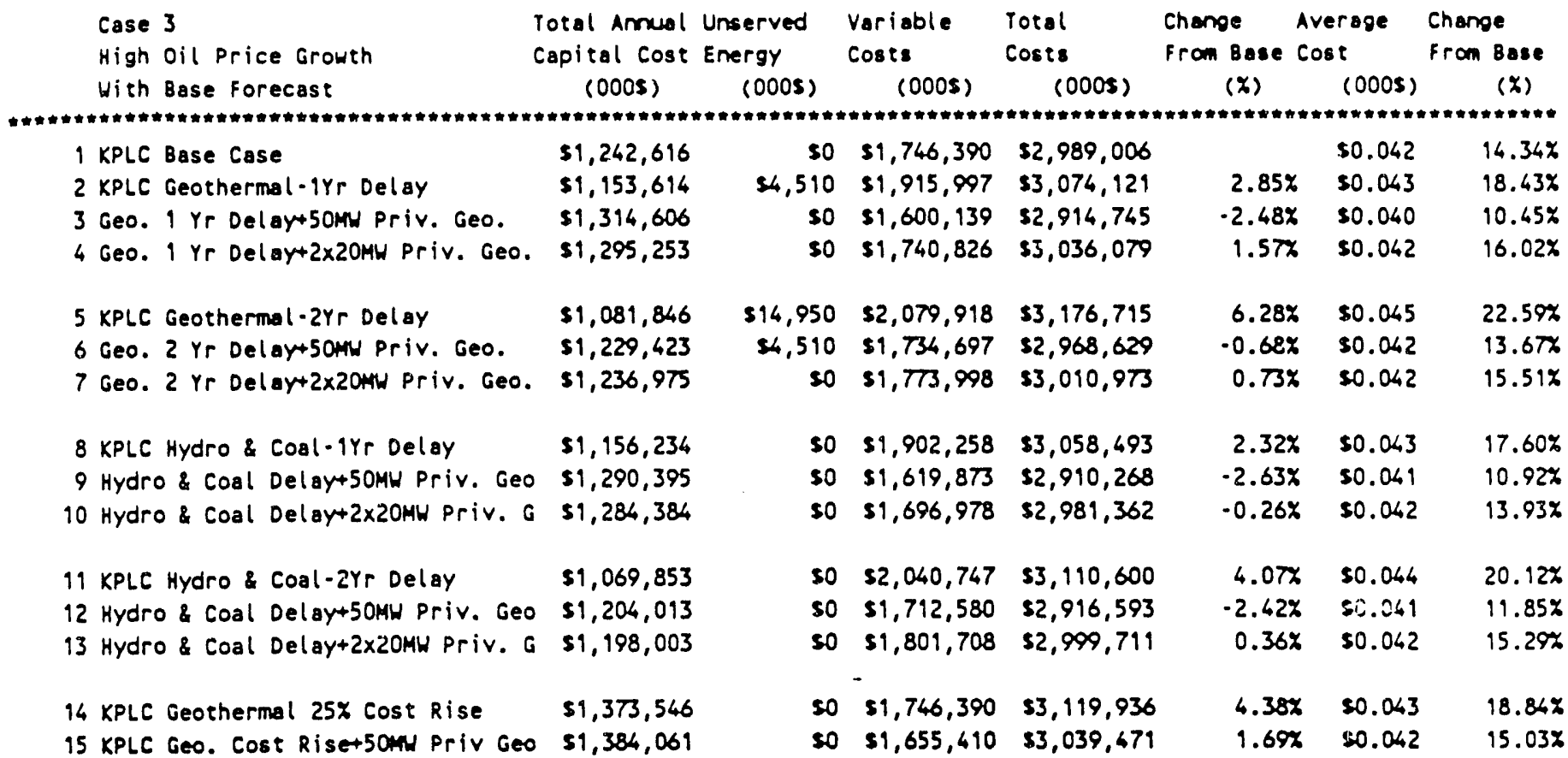

\section{Case 4 - High Porecast Demand Growth and Bigh Oil Price Escalation Rates}

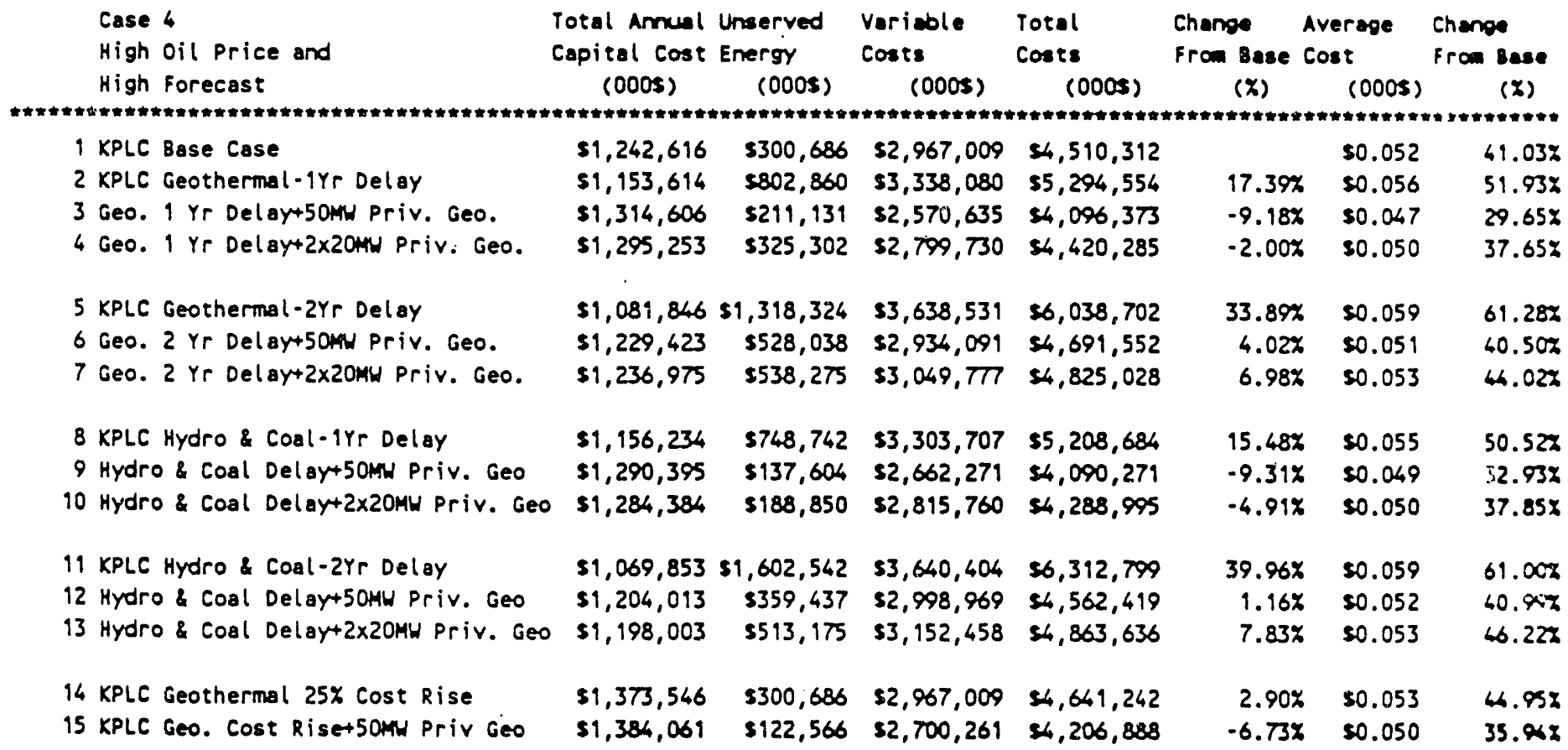


Levelized costs for various capacity Alternatives

(Base Oil Prices and Other Assumptions)

\begin{tabular}{|c|c|c|c|c|c|c|c|}
\hline & & & apital & Fuel & Varieble Coet & Torel Cor & \\
\hline Oil steen & $\begin{array}{l}\text { Ler. Amul } \\
\text { Amull Ler. }\end{array}$ & $\begin{array}{l}\text { Cap Cost } \\
\text { Busbar Cost }\end{array}$ & $\begin{array}{r}117.09 \\
0.015\end{array}$ & $\begin{array}{r}466.37 \\
0.062\end{array}$ & $\begin{array}{l}11.30 \\
0.003\end{array}$ & $\begin{array}{r}592.76 \\
0.080\end{array}$ & $\begin{array}{l}s / k w / y r \\
s / k w h\end{array}$ \\
\hline Gas Iurbine & $\begin{array}{l}\text { Lev. Amuel } \\
\text { Amusl Ler. }\end{array}$ & $\begin{array}{l}\text { Cap Cost } \\
\text { Busber Cost }\end{array}$ & $\begin{array}{l}81.57 \\
0.010\end{array}$ & $\begin{array}{r}909.12 \\
0.135\end{array}$ & $\begin{array}{l}15.31 \\
0.005\end{array}$ & $\begin{array}{r}1006.00 \\
0.150\end{array}$ & $\begin{array}{l}s / k w / y r \\
s / k W h\end{array}$ \\
\hline Geothermal & $\begin{array}{l}\text { Lev. Amual } \\
\text { Amual Ler. }\end{array}$ & $\begin{array}{l}\text { Cap Cost } \\
\text { Busbar Cost }\end{array}$ & $\begin{array}{r}317.89 \\
0.039\end{array}$ & $\begin{array}{l}0.00 \\
0.000\end{array}$ & $\begin{array}{l}18.90 \\
0.005\end{array}$ & $\begin{array}{r}336.79 \\
0.044\end{array}$ & $\begin{array}{l}s / k w / y r \\
s / k w h\end{array}$ \\
\hline Cool & $\begin{array}{l}\text { Ler. Amull } \\
\text { Amual Ler. }\end{array}$ & $\begin{array}{l}\text { Cap Cost } \\
\text { Busbar Cost }\end{array}$ & $\begin{array}{r}152.25 \\
0.021\end{array}$ & $\begin{array}{r}204.04 \\
0.028\end{array}$ & $\begin{array}{l}12.61 \\
0.006\end{array}$ & $\begin{array}{r}368.91 \\
0.055\end{array}$ & $\begin{array}{l}s / k w / y r \\
s / k w h\end{array}$ \\
\hline Sondy & $\begin{array}{l}\text { Lev. Amual } \\
\text { Amual Ler. }\end{array}$ & $\begin{array}{l}\text { Cap Cost } \\
\text { Busber Cost }\end{array}$ & $\begin{array}{r}264.13 \\
0.046\end{array}$ & $\begin{array}{r}0.00 \\
0.000\end{array}$ & $\begin{array}{l}0.00 \\
0.001\end{array}$ & $\begin{array}{r}2156.13 \\
0.067\end{array}$ & $\begin{array}{l}s / \mathrm{kw} / \mathrm{Yr} \\
\mathrm{s} / \mathrm{kwm}\end{array}$ \\
\hline Sererwa & $\begin{array}{l}\text { Lev. Amuel } \\
\text { Amual Liev. }\end{array}$ & $\begin{array}{l}\text { Cap Cost } \\
\text { Busbor Cost }\end{array}$ & $\begin{array}{r}184.35 \\
0.082\end{array}$ & $\begin{array}{r}0.00 \\
0.000\end{array}$ & $\begin{array}{l}0.00 \\
0.002\end{array}$ & $\begin{array}{l}1136.35 \\
0.084\end{array}$ & $\begin{array}{l}\text { s/kw/yr } \\
s / \mathrm{kLh}\end{array}$ \\
\hline Magwegue & $\begin{array}{l}\text { Lev. Amuel } \\
\text { Amual Lev. }\end{array}$ & $\begin{array}{l}\text { Cap Cost } \\
\text { Busbar cost }\end{array}$ & $\begin{array}{r}560.68 \\
0.155\end{array}$ & $\begin{array}{l}0.00 \\
0.000\end{array}$ & $\begin{array}{l}0.00 \\
0.001\end{array}$ & $\begin{array}{r}5100.66 \\
0.156\end{array}$ & $\begin{array}{l}s / k w / y r \\
s / k w h\end{array}$ \\
\hline Private Geo Susmo & $\begin{array}{l}\text { Lev. Amual } \\
\text { Amual Lev. }\end{array}$ & $\begin{array}{l}\text { Cap Cost } \\
\text { Busbar Cost }\end{array}$ & $\begin{array}{r}287.20 \\
0.036\end{array}$ & $\begin{array}{r}0.00 \\
0.000\end{array}$ & $\begin{array}{l}24.30 \\
0.007\end{array}$ & $\begin{array}{r}319.50 \\
0.063\end{array}$ & $\begin{array}{l}s / k w / y r \\
s / k w m\end{array}$ \\
\hline Privere Geo $\sin l l$ & $\begin{array}{l}\text { LeV. Amulal } \\
\text { Amual LV B }\end{array}$ & $\begin{array}{l}\text { Cap Cost } \\
\text { usbor Cost }\end{array}$ & $\begin{array}{r}410.34 \\
0.046\end{array}$ & $\begin{array}{l}0.00 \\
0.00\end{array}$ & $\begin{array}{l}45.45 \\
0.013\end{array}$ & $\begin{array}{r}0.55 .79 \\
0.058\end{array}$ & $\begin{array}{l}s / k u / y r \\
s / k w h\end{array}$ \\
\hline
\end{tabular}

Levelized Annual Capacity Costs (IIC)

Levelization Formula:

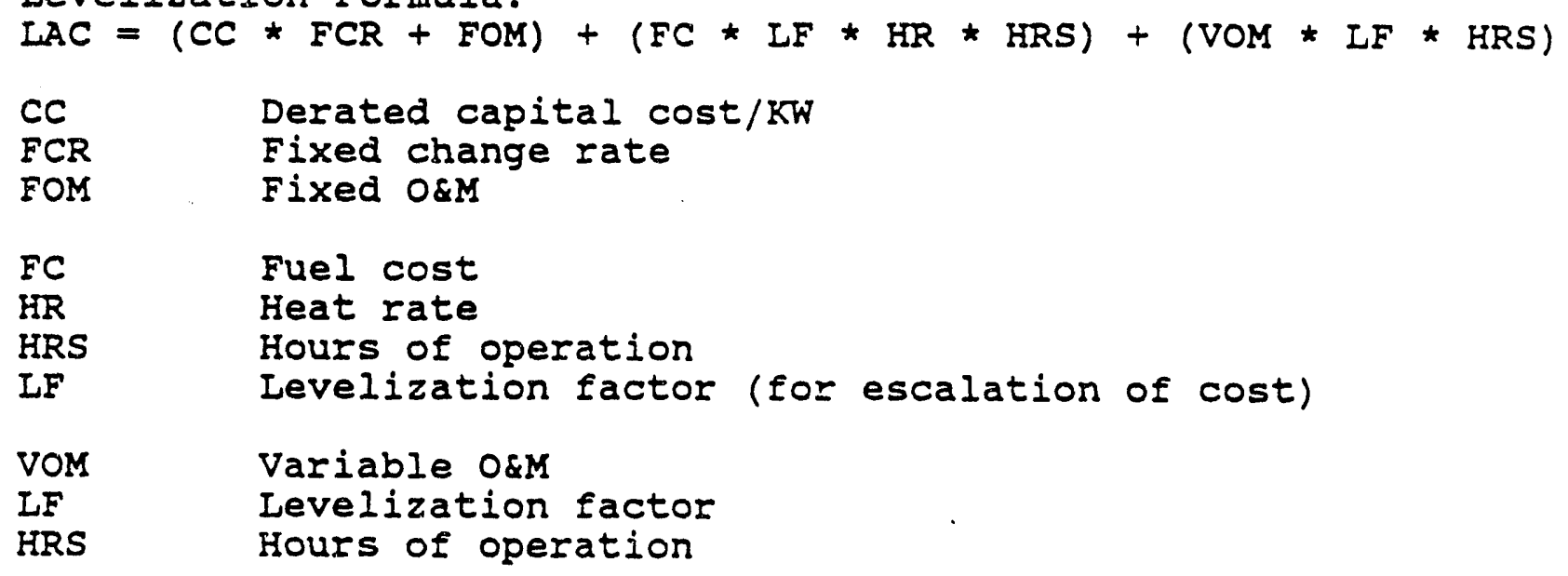

\section{Notes:}

1. Derated capital cost/KW = capital cost/(1-forced outage rate)

2. FCR based on economic life, discount rate of $10 \%$

3. LF modifies constant $\$$ amounts for effects of real price escalation (differential vs. other commodities)

$$
\text { Appendix II - } 3
$$


Expense Plan Scenario Tables for Base Case section III

Appendix III 


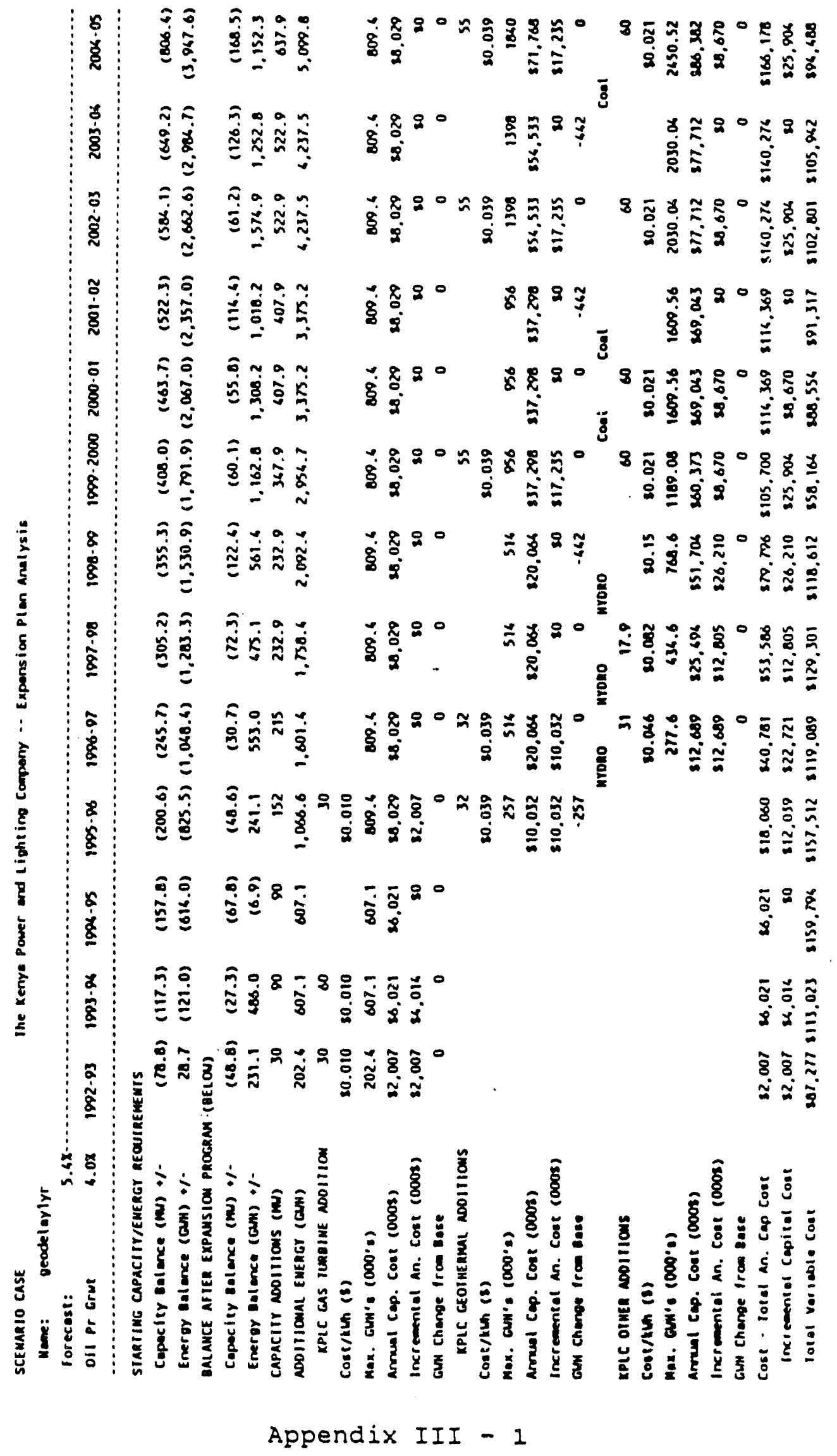




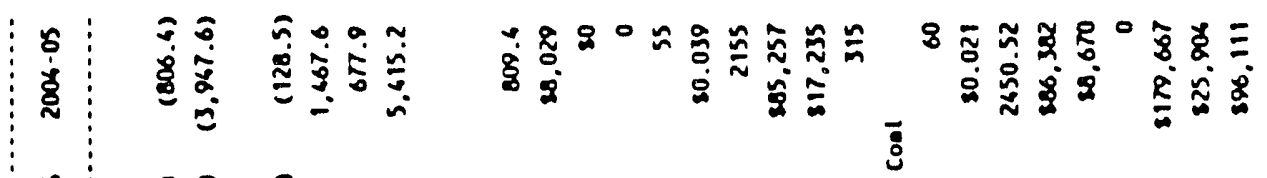

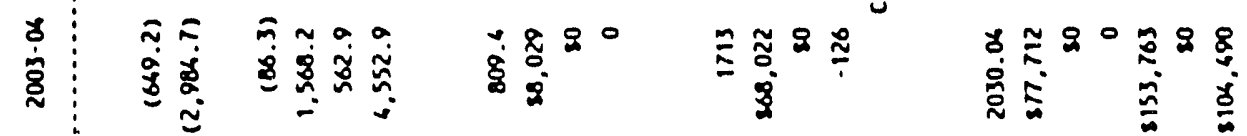

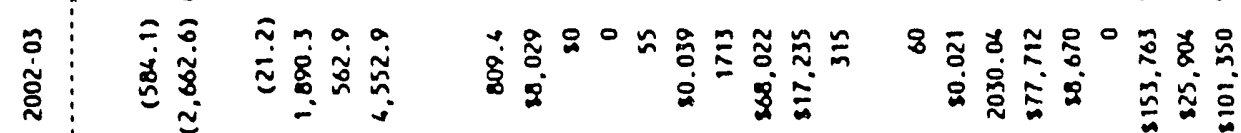

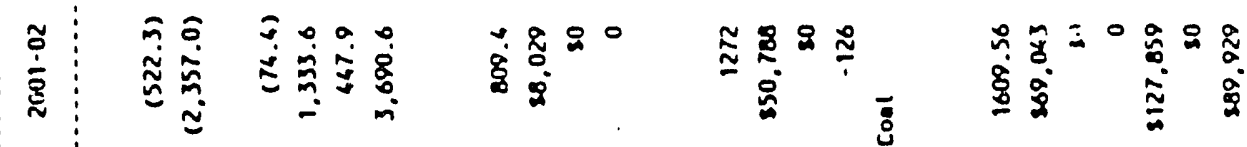

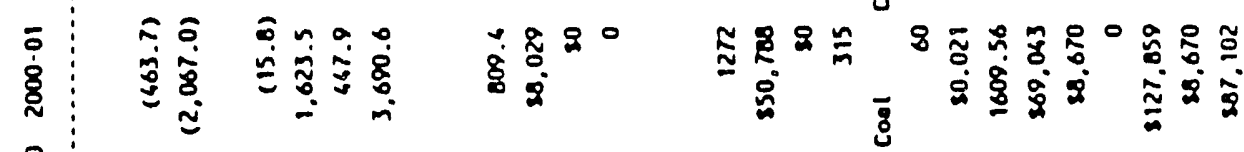

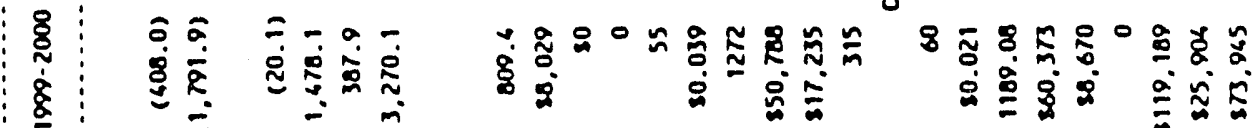

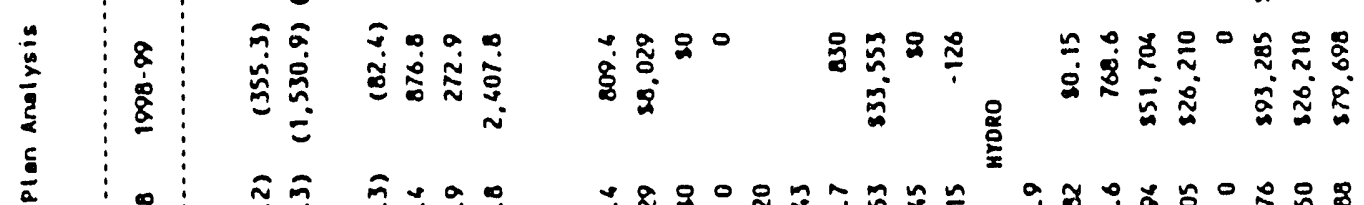

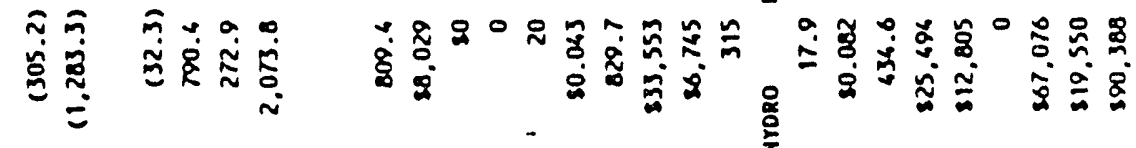

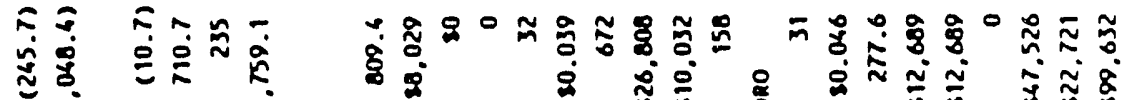

$$
\begin{aligned}
& \text { 苍 亭 }
\end{aligned}
$$

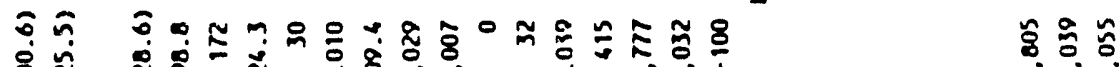

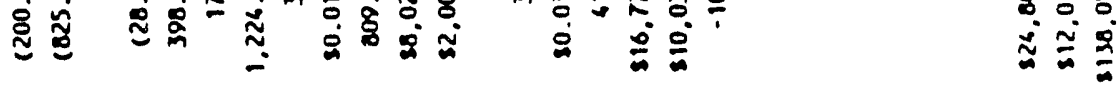

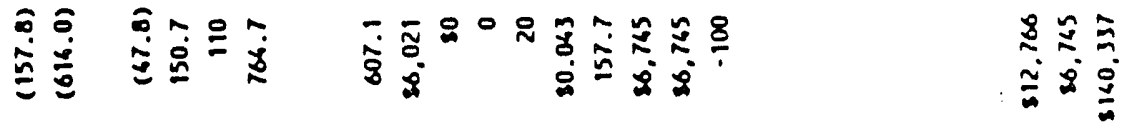

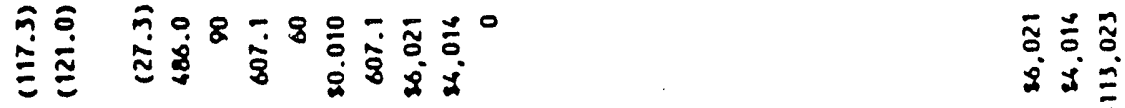

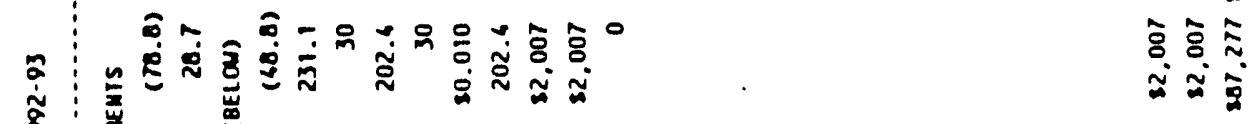

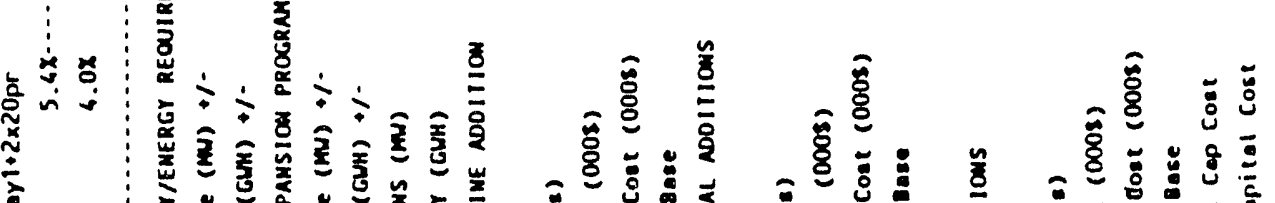

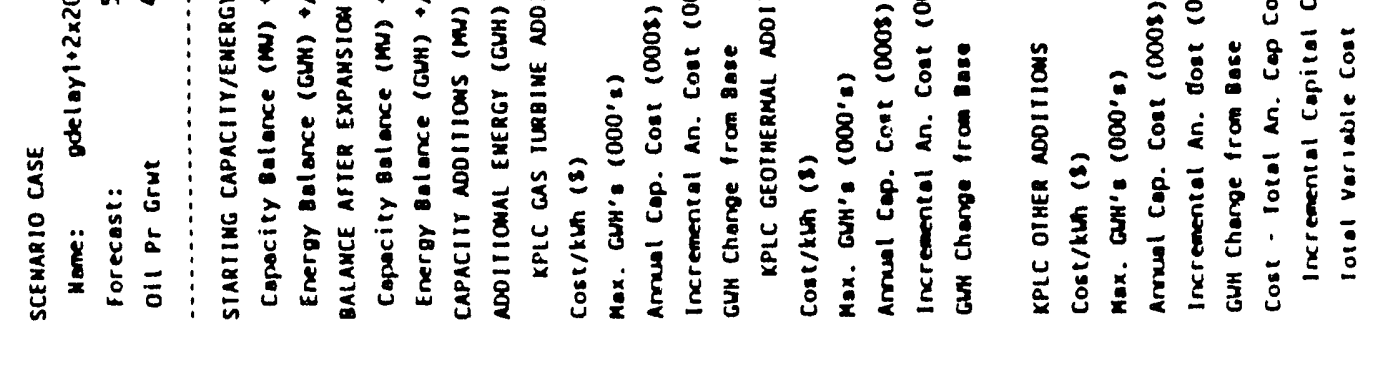

$$
\begin{aligned}
& \text { Appendix III - } 3
\end{aligned}
$$




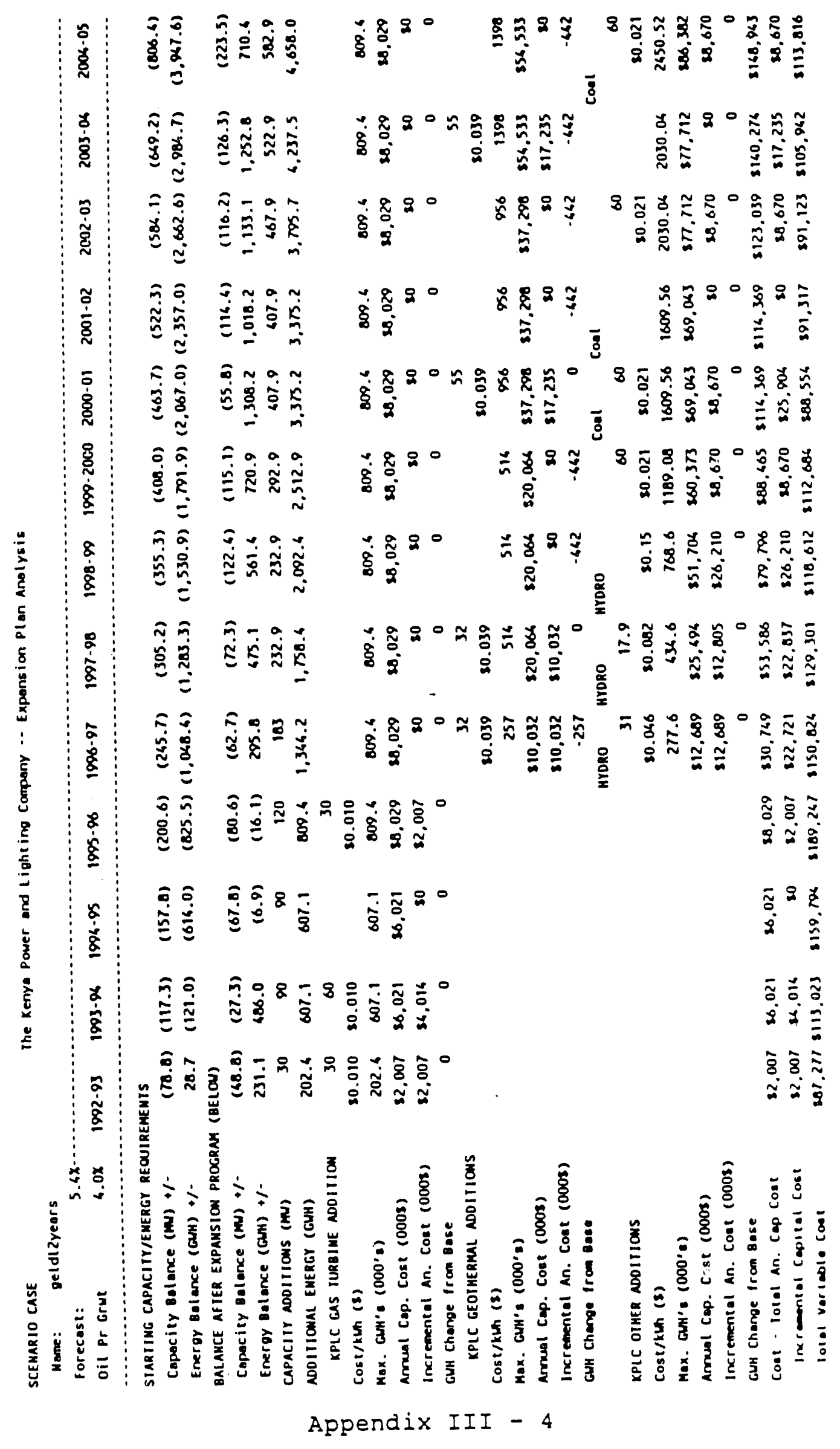




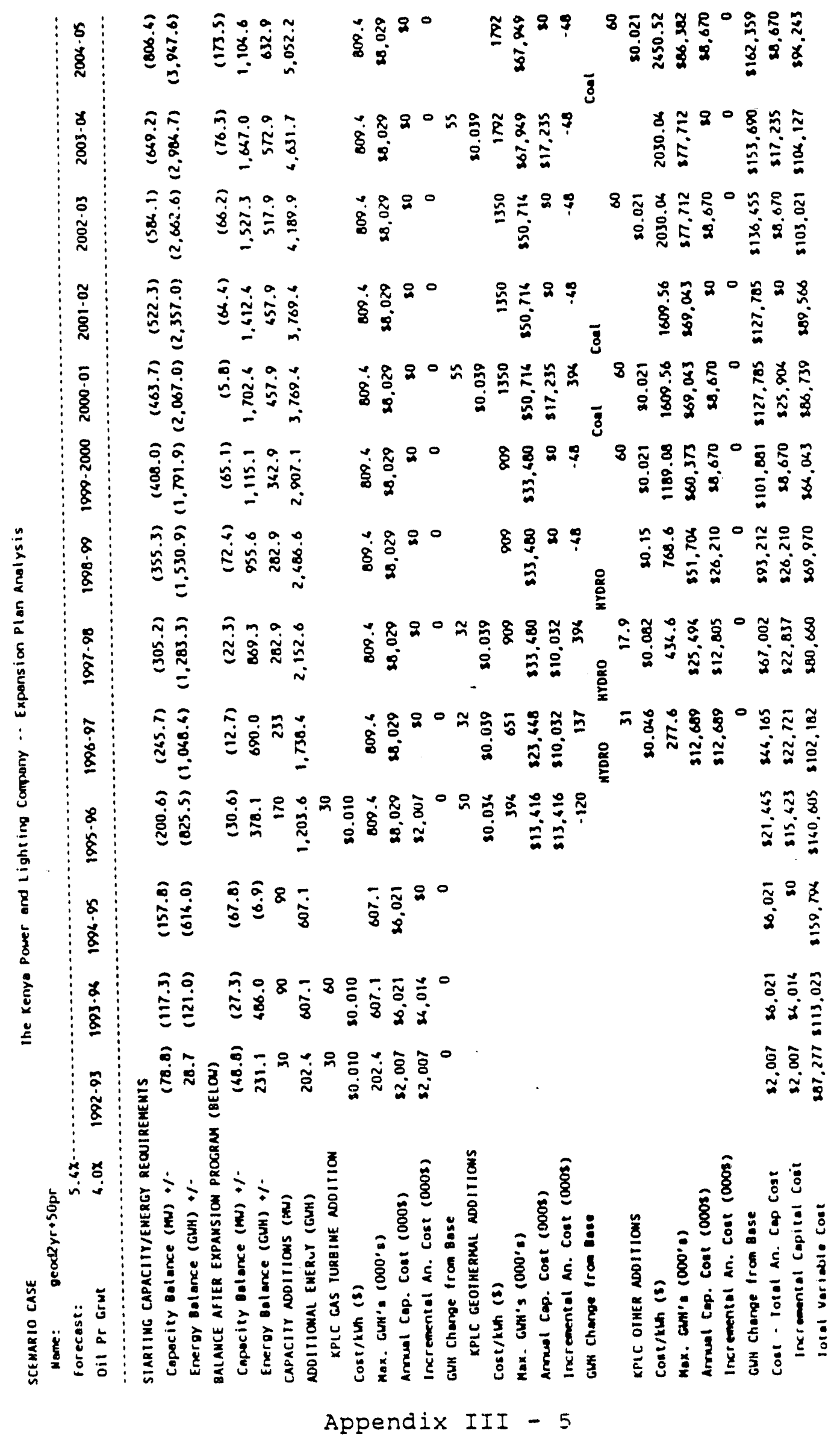




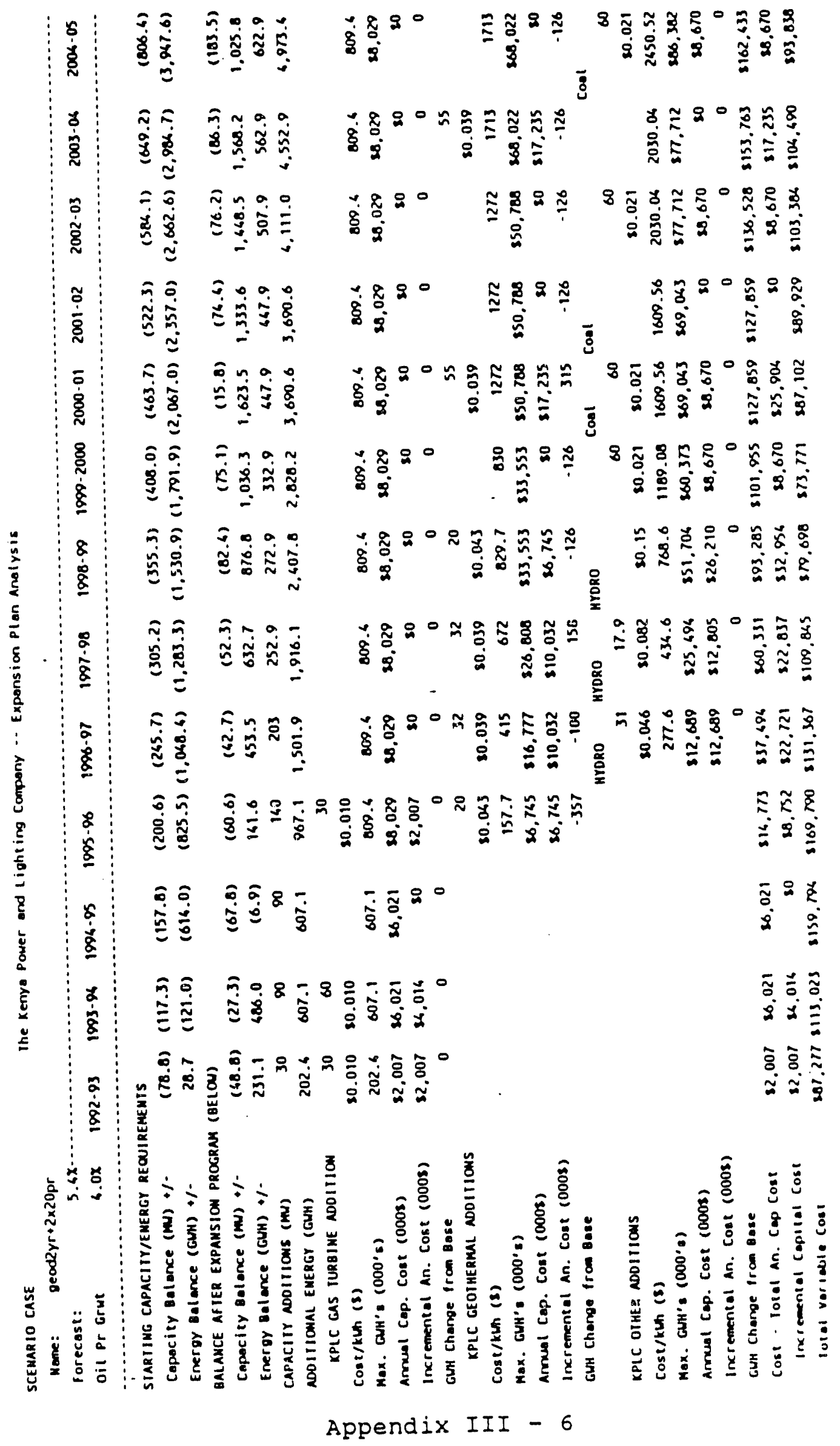




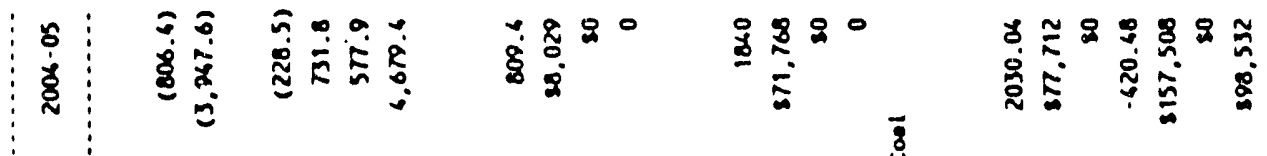

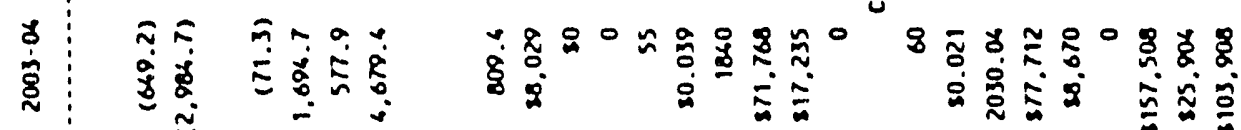

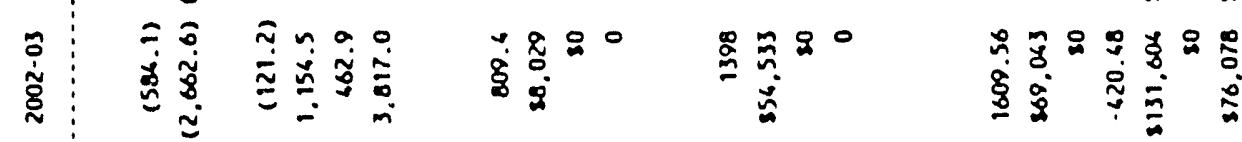

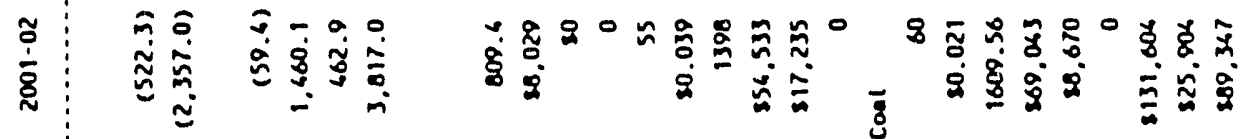

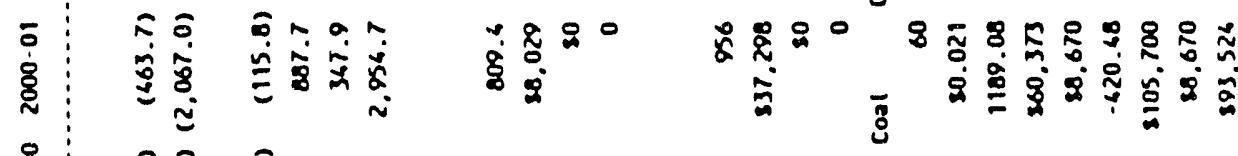

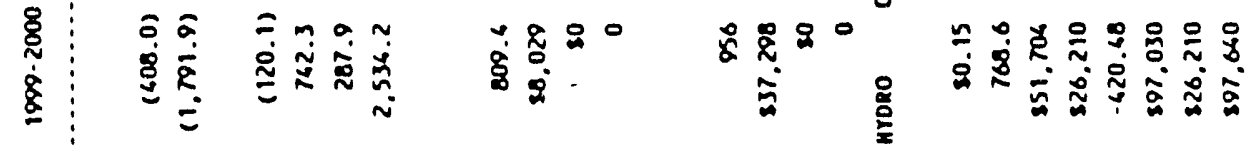

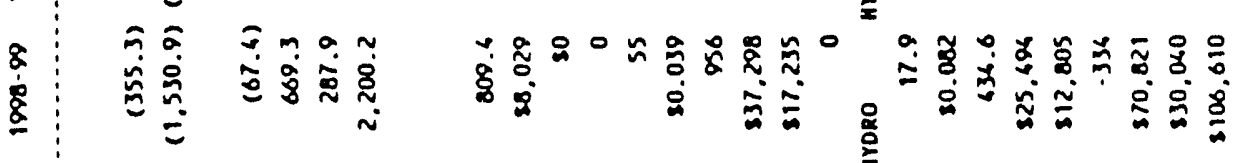

$$
\begin{aligned}
& \text { 定 }
\end{aligned}
$$

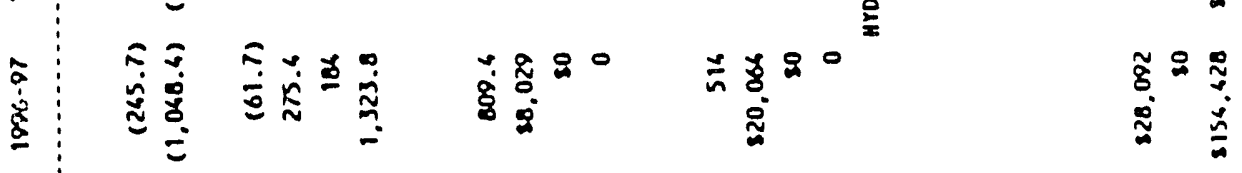

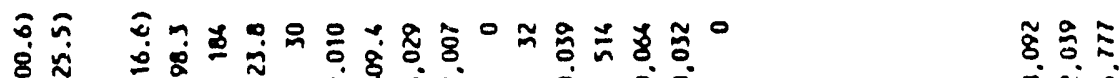

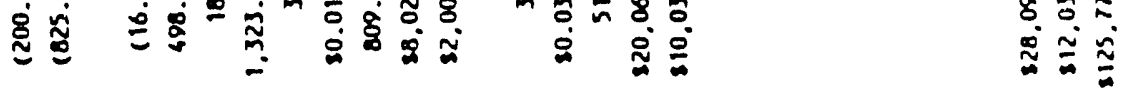

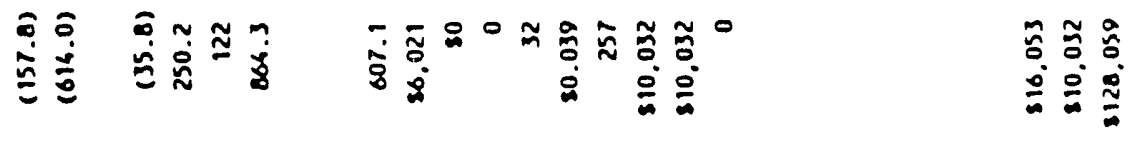

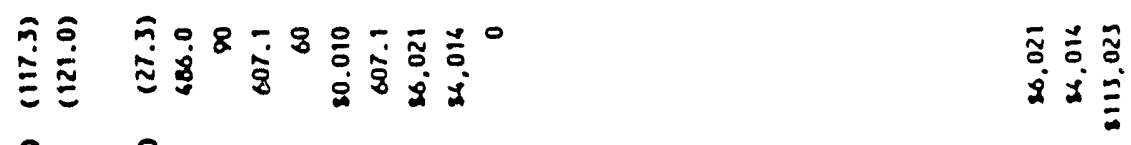

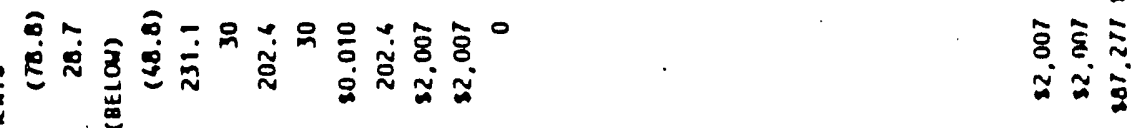

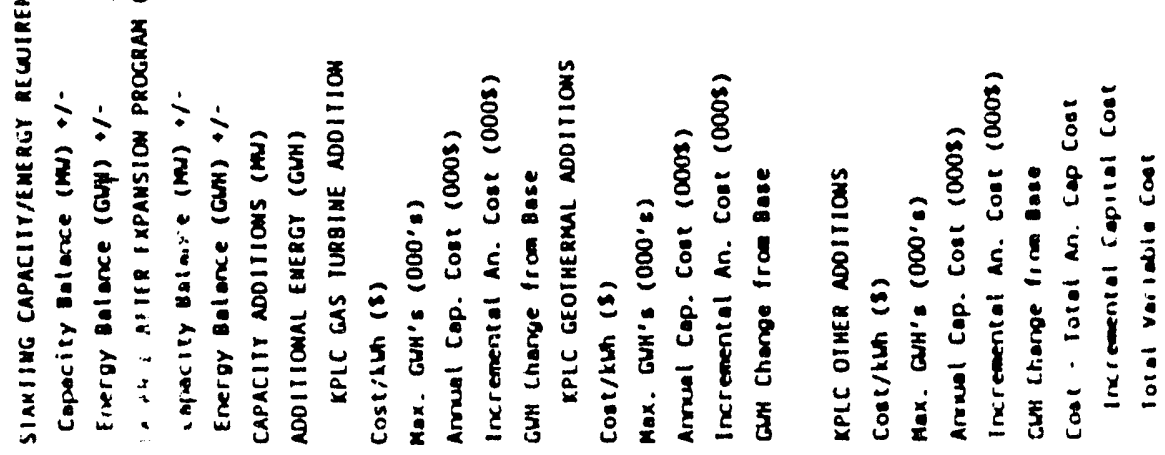

$$
\begin{aligned}
& \text { Appendix III - } 7
\end{aligned}
$$




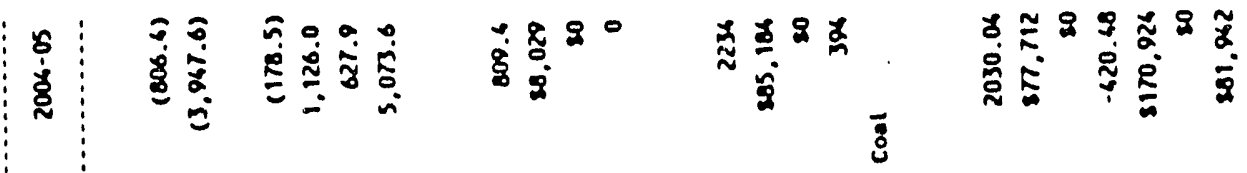

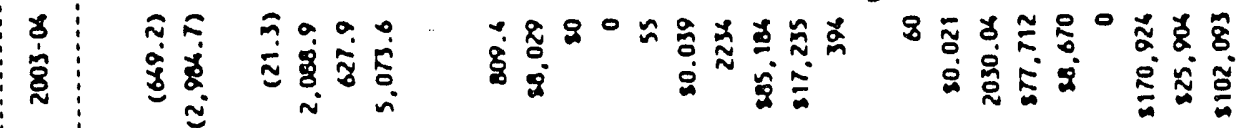

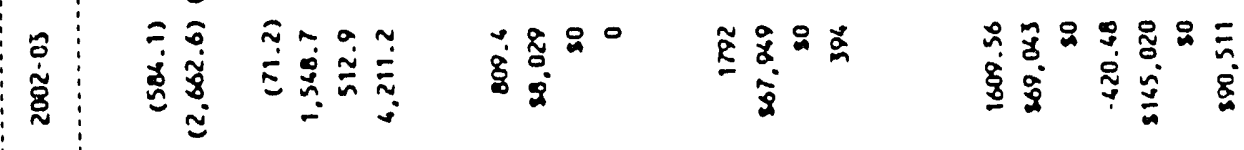

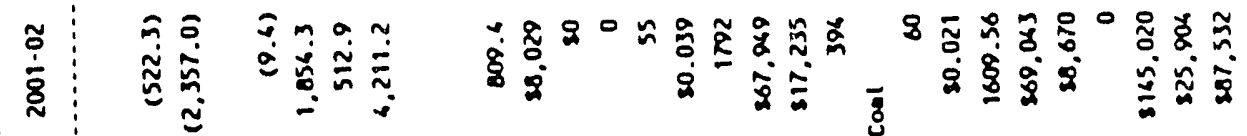

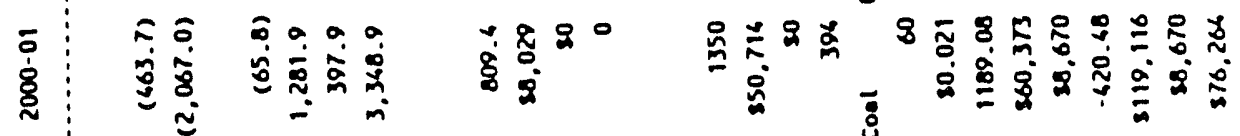

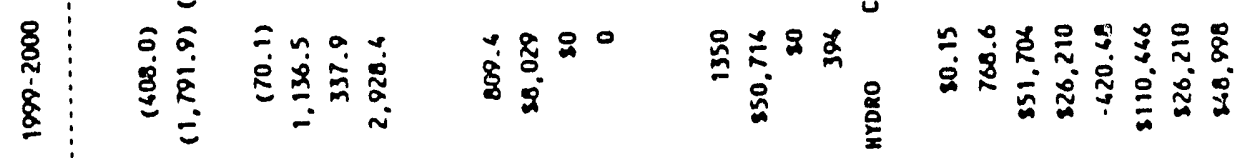

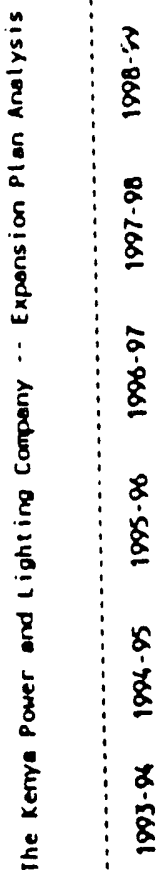

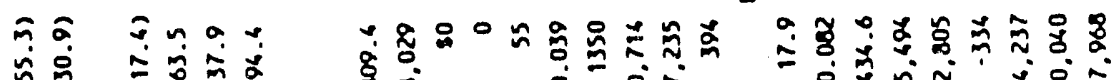

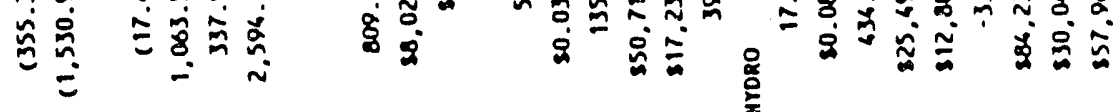

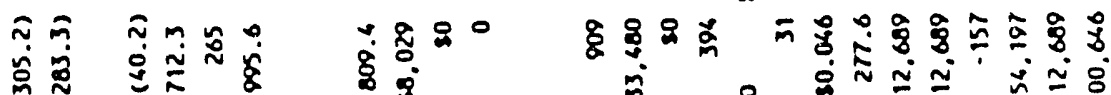

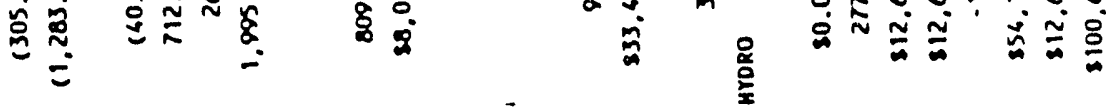

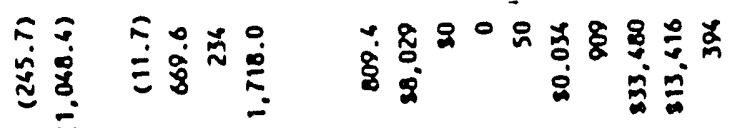

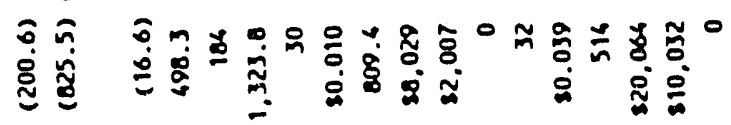

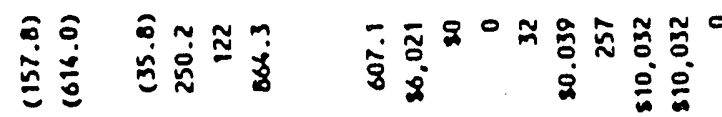

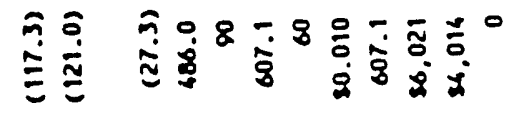

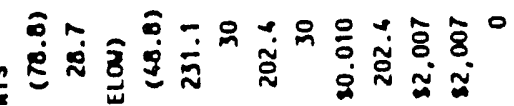

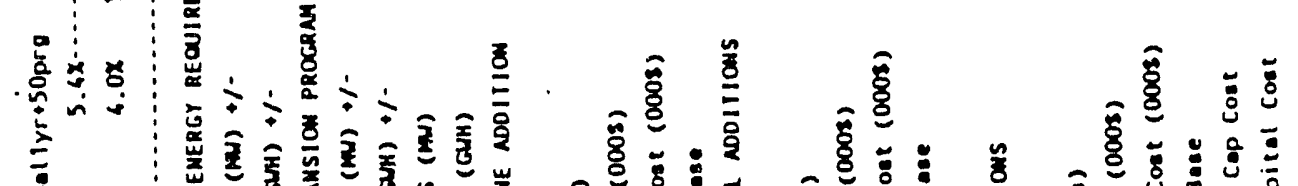

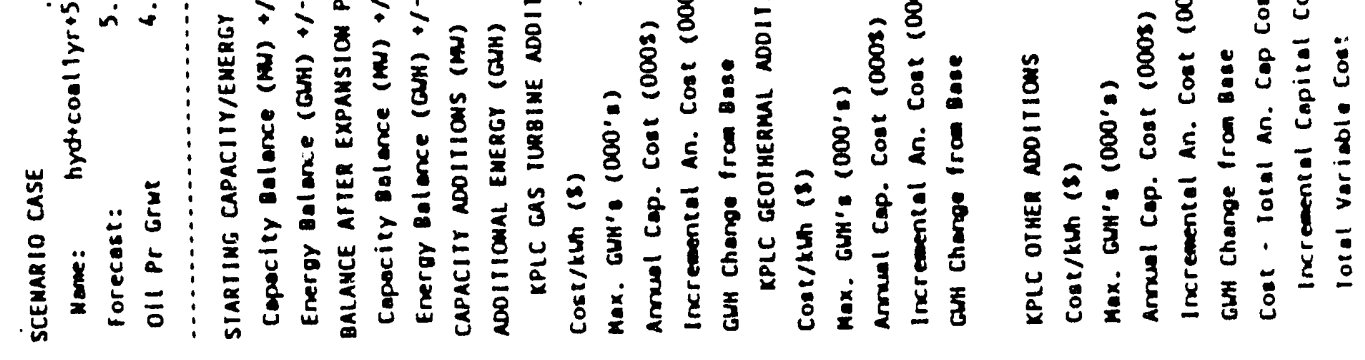

$$
\begin{aligned}
& \text { Appendix III - } 8
\end{aligned}
$$

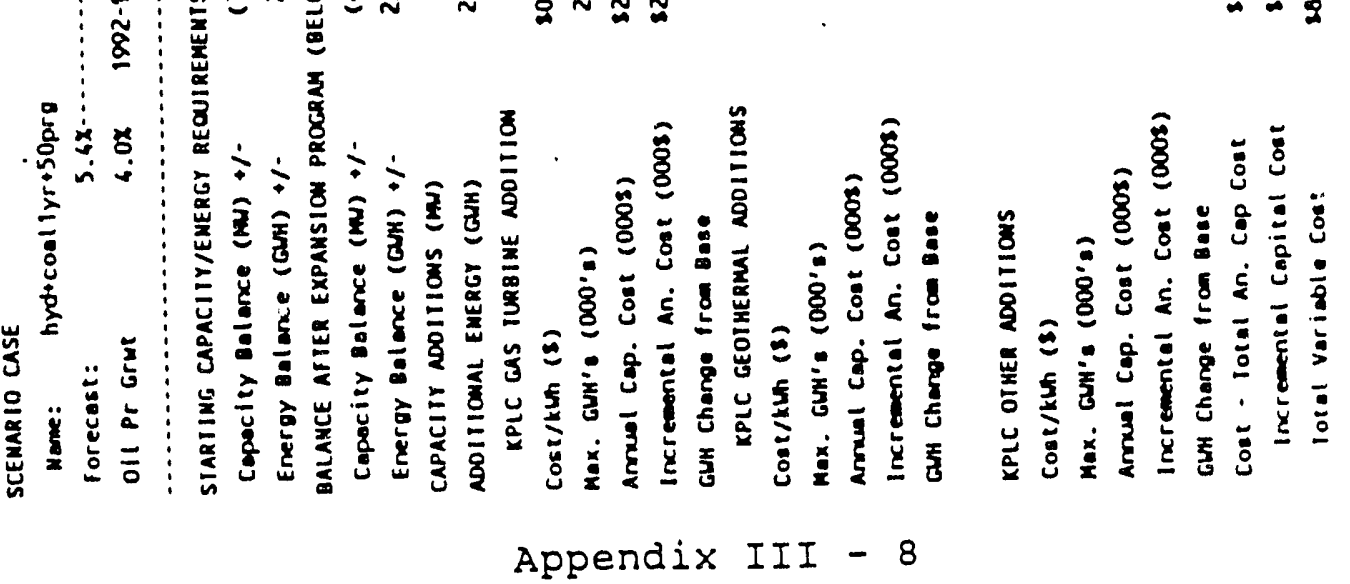




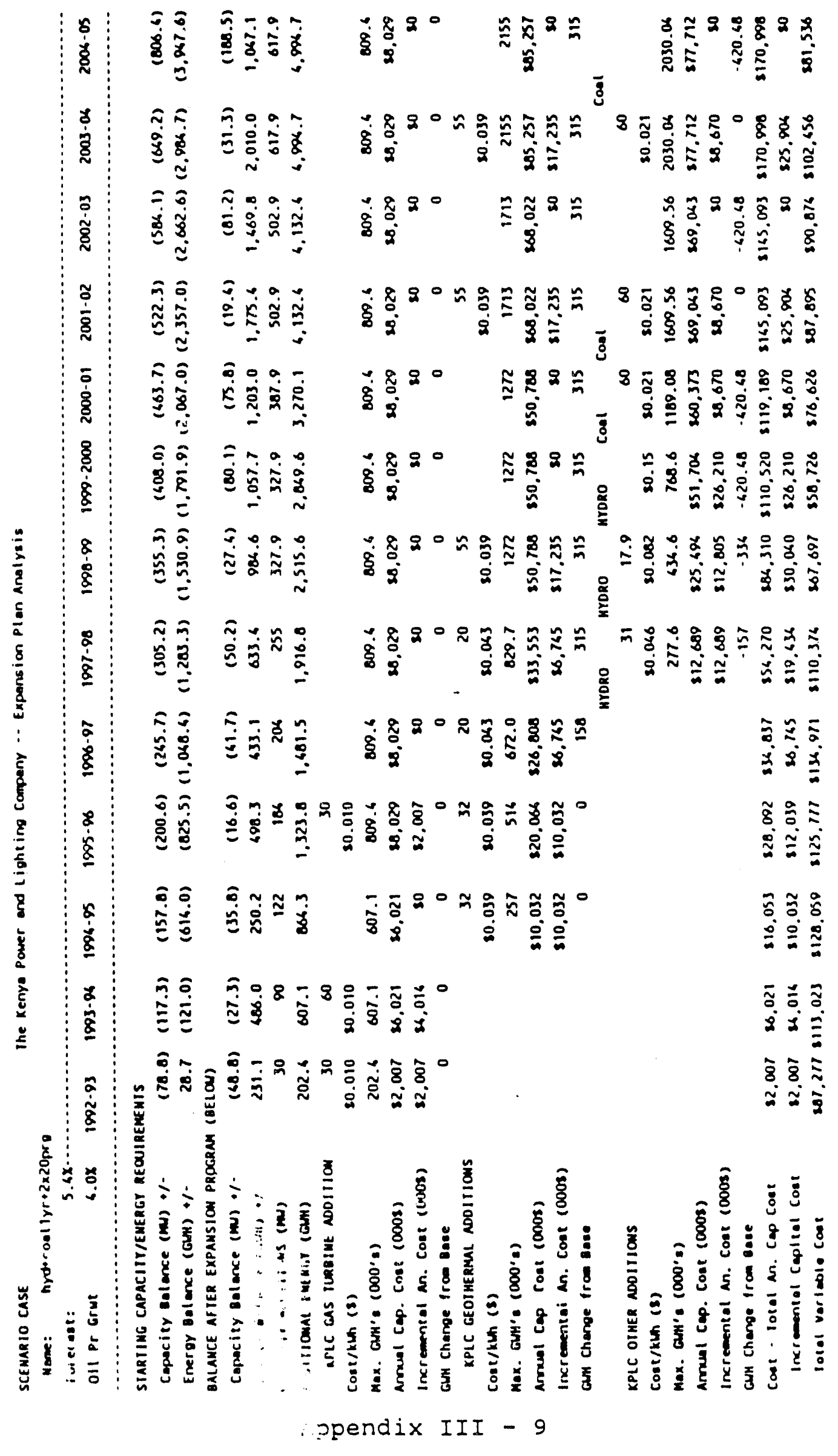




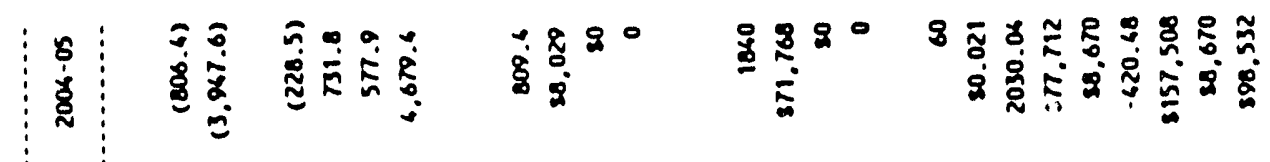

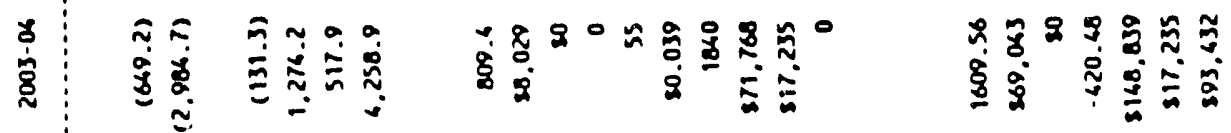

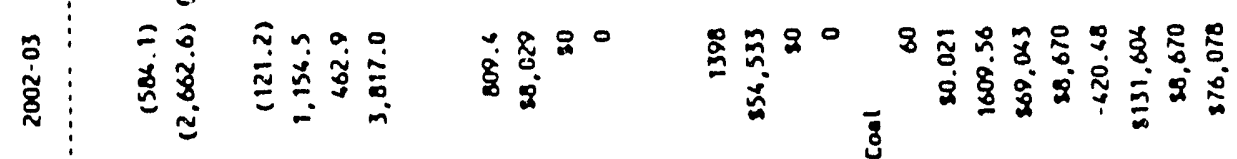

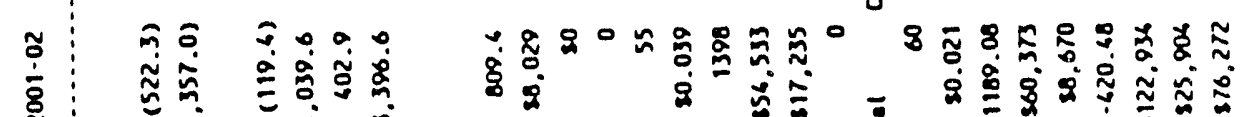

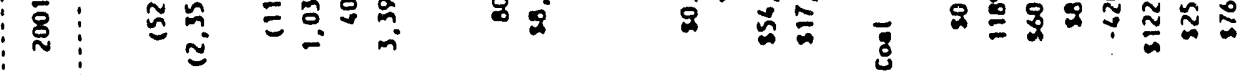

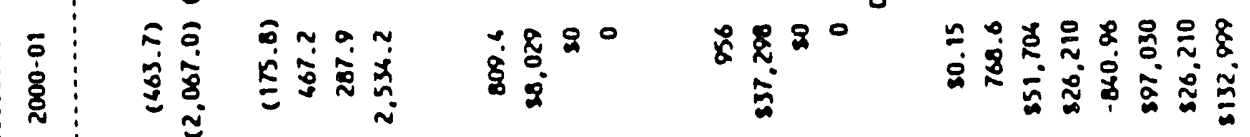

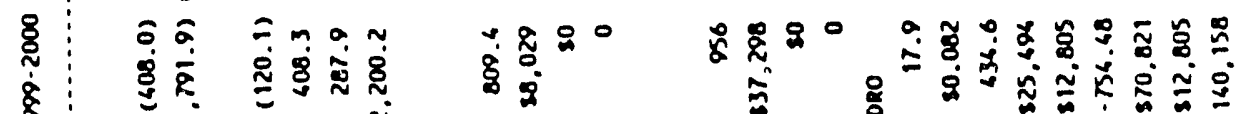

$$
\begin{aligned}
& \text { \& }
\end{aligned}
$$

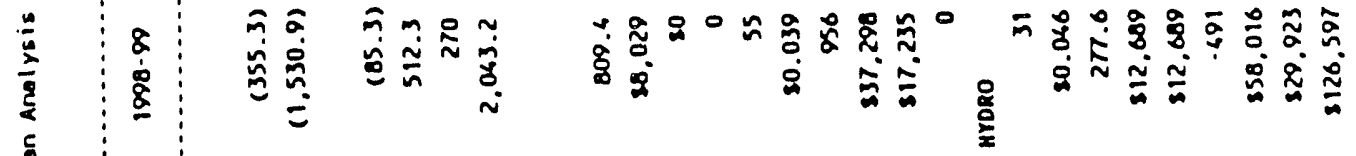

$$
\begin{aligned}
& \frac{\frac{5}{2}}{\frac{\delta}{2}}
\end{aligned}
$$

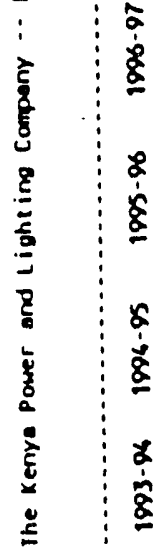

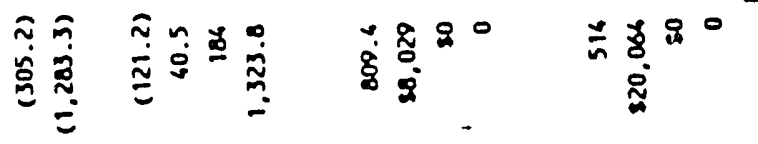

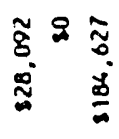

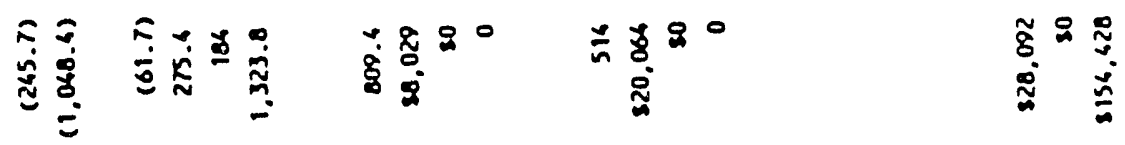

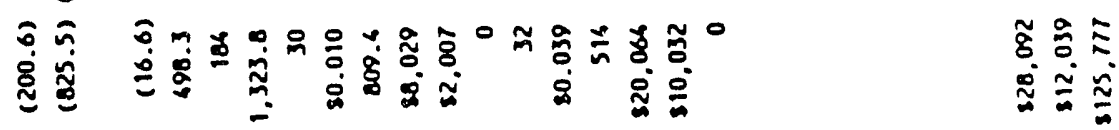

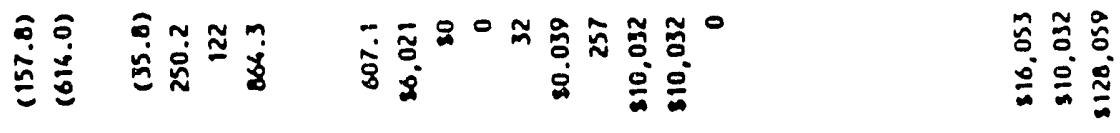

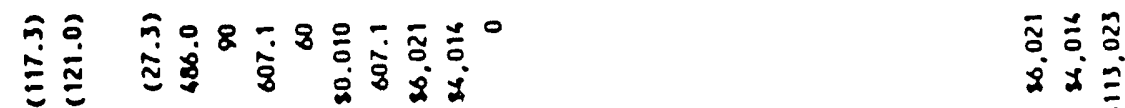

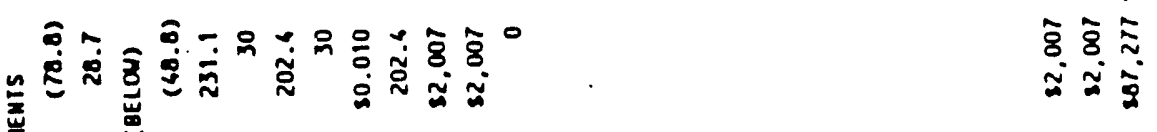

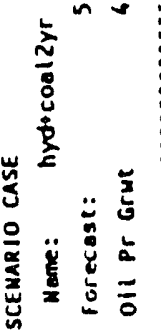

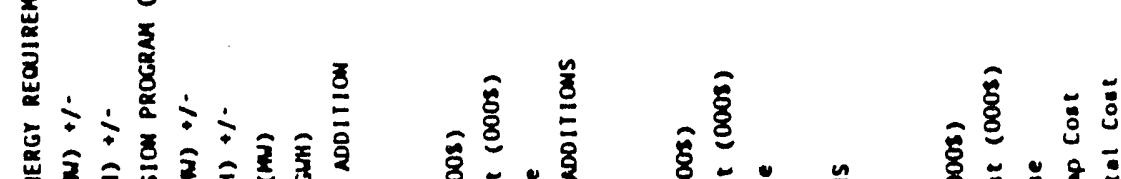

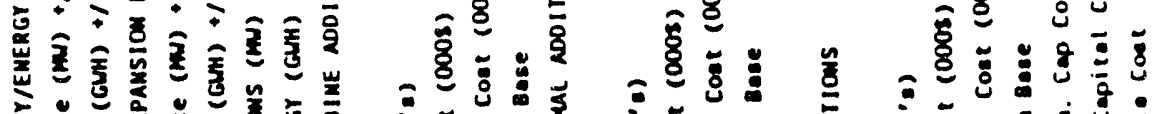

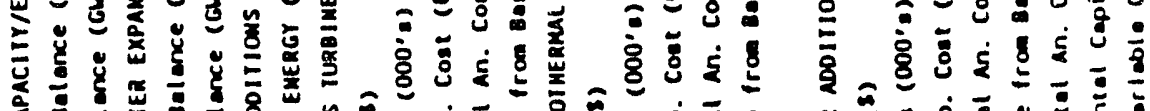

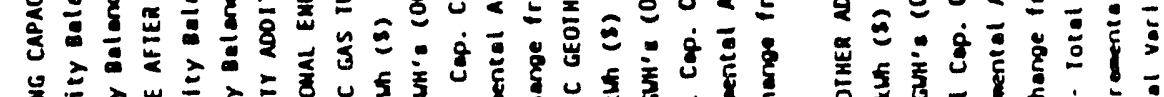

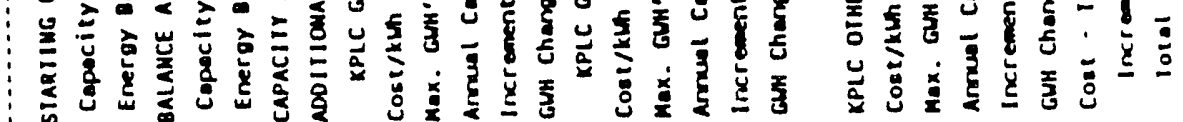

$$
\begin{aligned}
& \text { Appendix III - } 10
\end{aligned}
$$




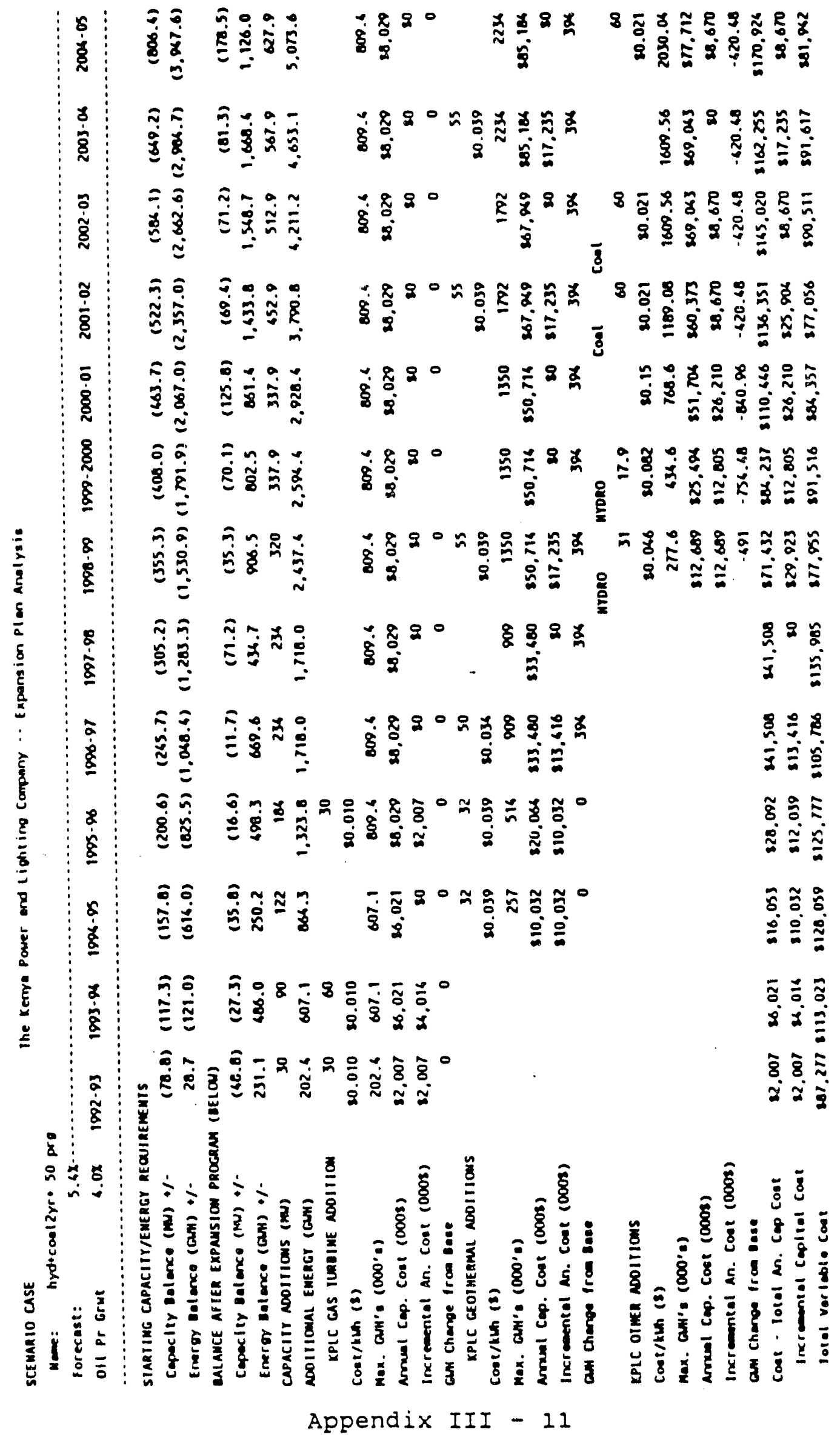




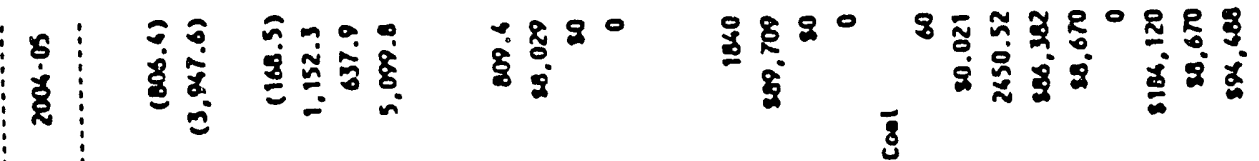

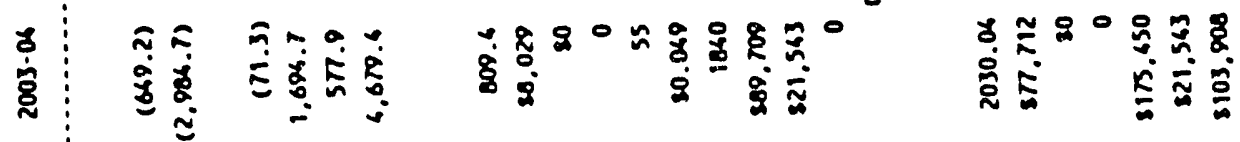

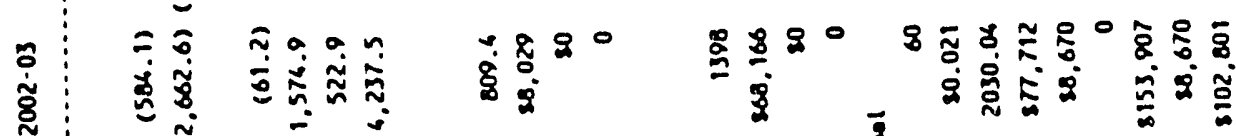

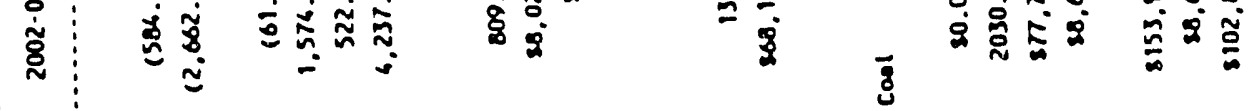

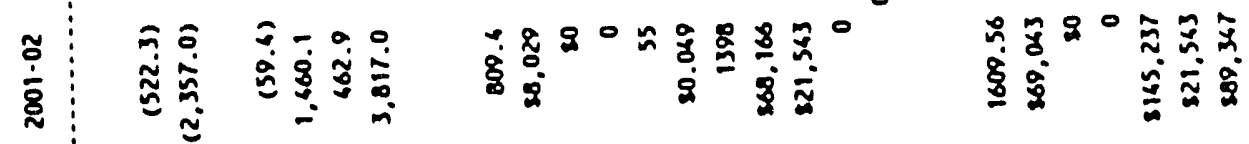

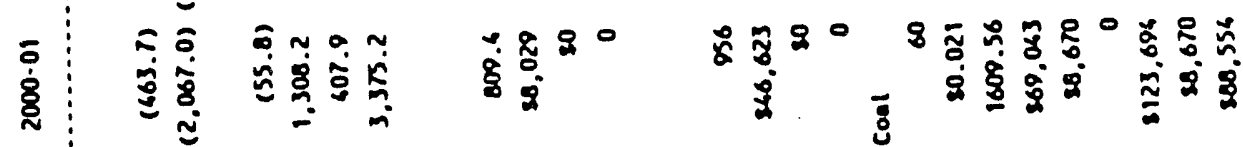

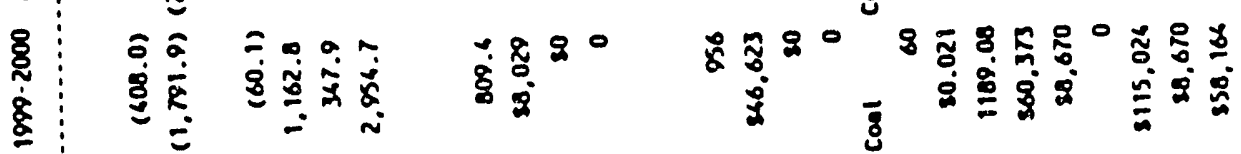

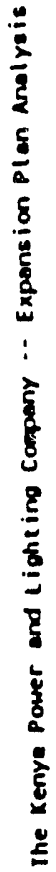

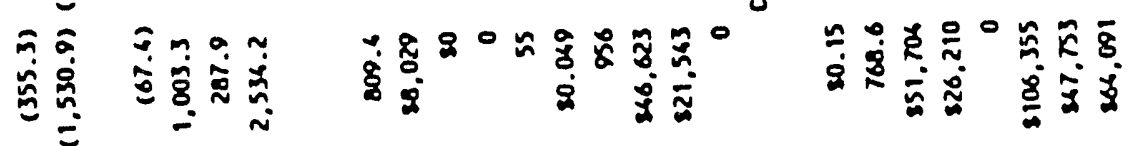

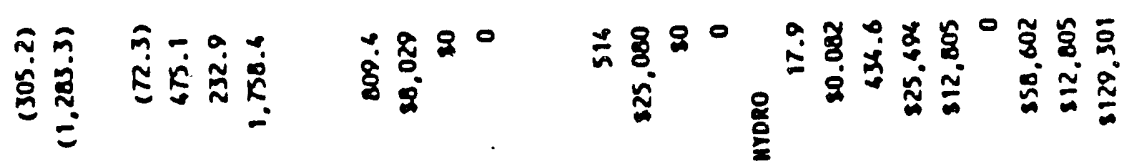

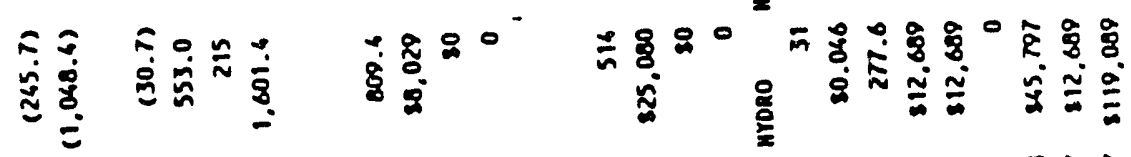

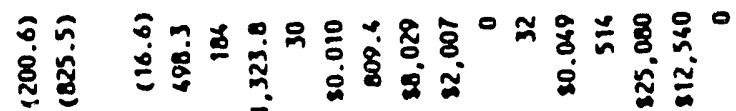

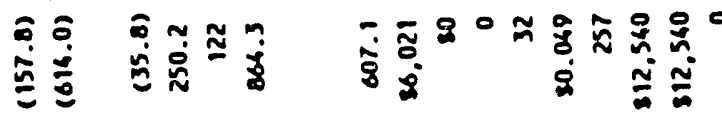

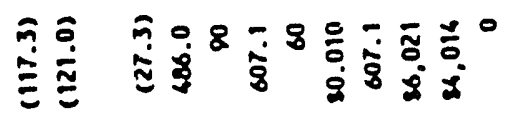

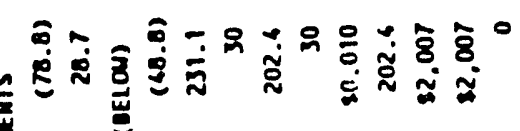

$$
\begin{aligned}
& 85 \\
& \text { 言芒 }
\end{aligned}
$$

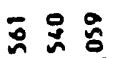

$$
\begin{aligned}
& \stackrel{\circ}{\square} \\
& \overline{0} \\
& \dot{s} \\
& \text { ชิ } \\
& \text { ष्ष }
\end{aligned}
$$

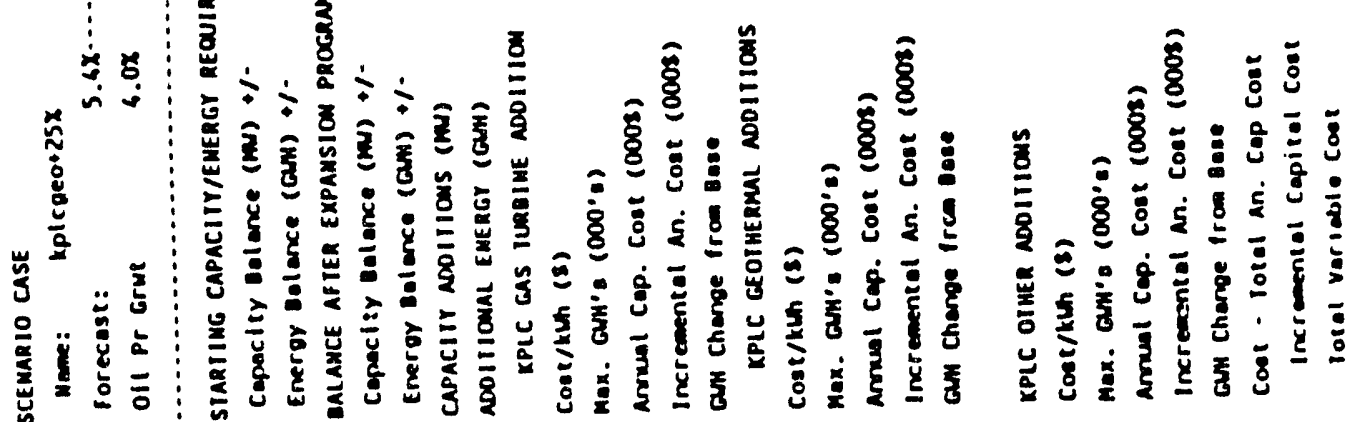

$$
\begin{aligned}
& \text { Appendix III - } 13
\end{aligned}
$$


Spreadsheets for Suswa, Eburru and Arus

Appendix IV 


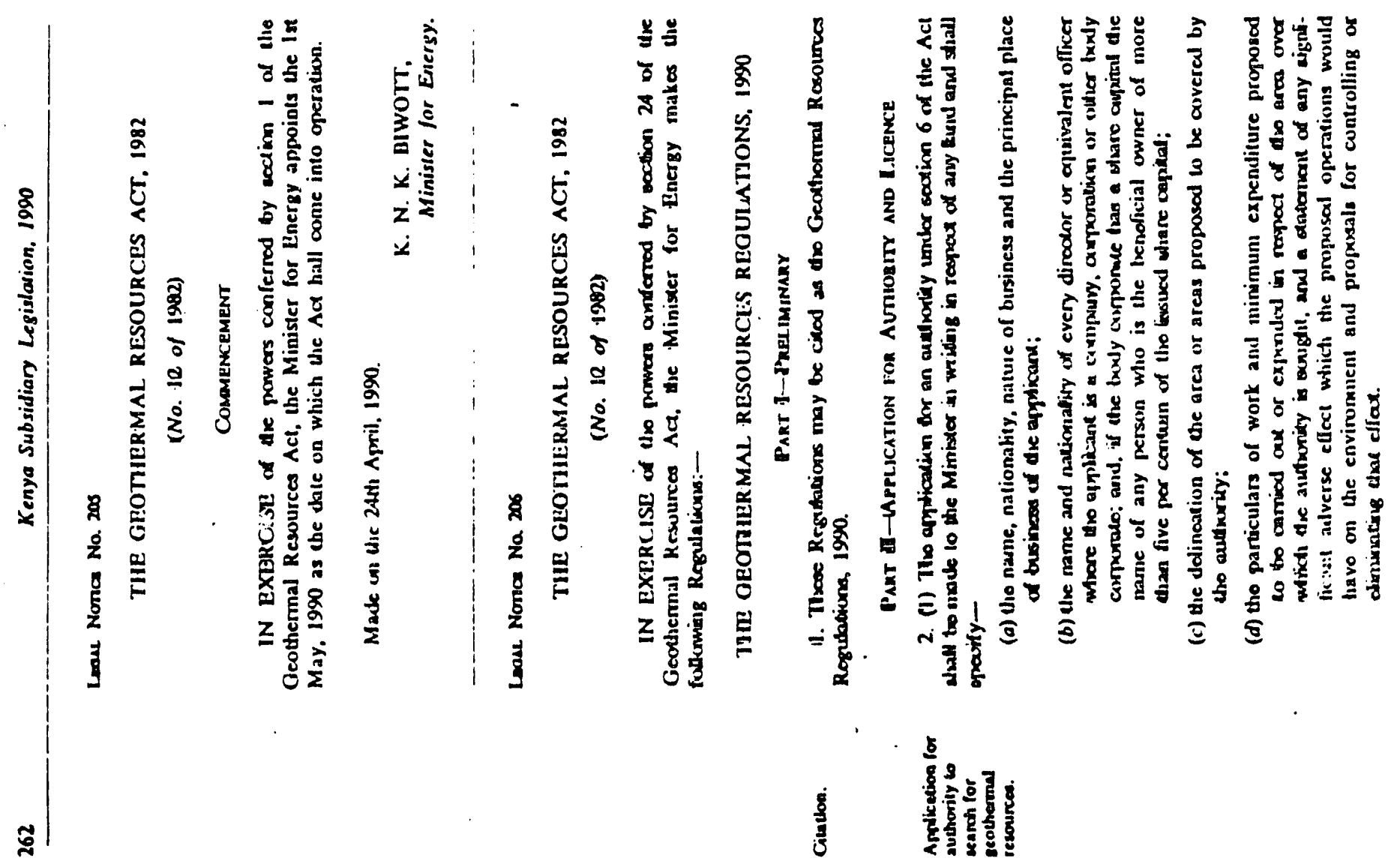




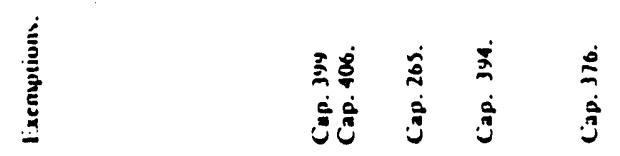

$\stackrel{\square}{8}$
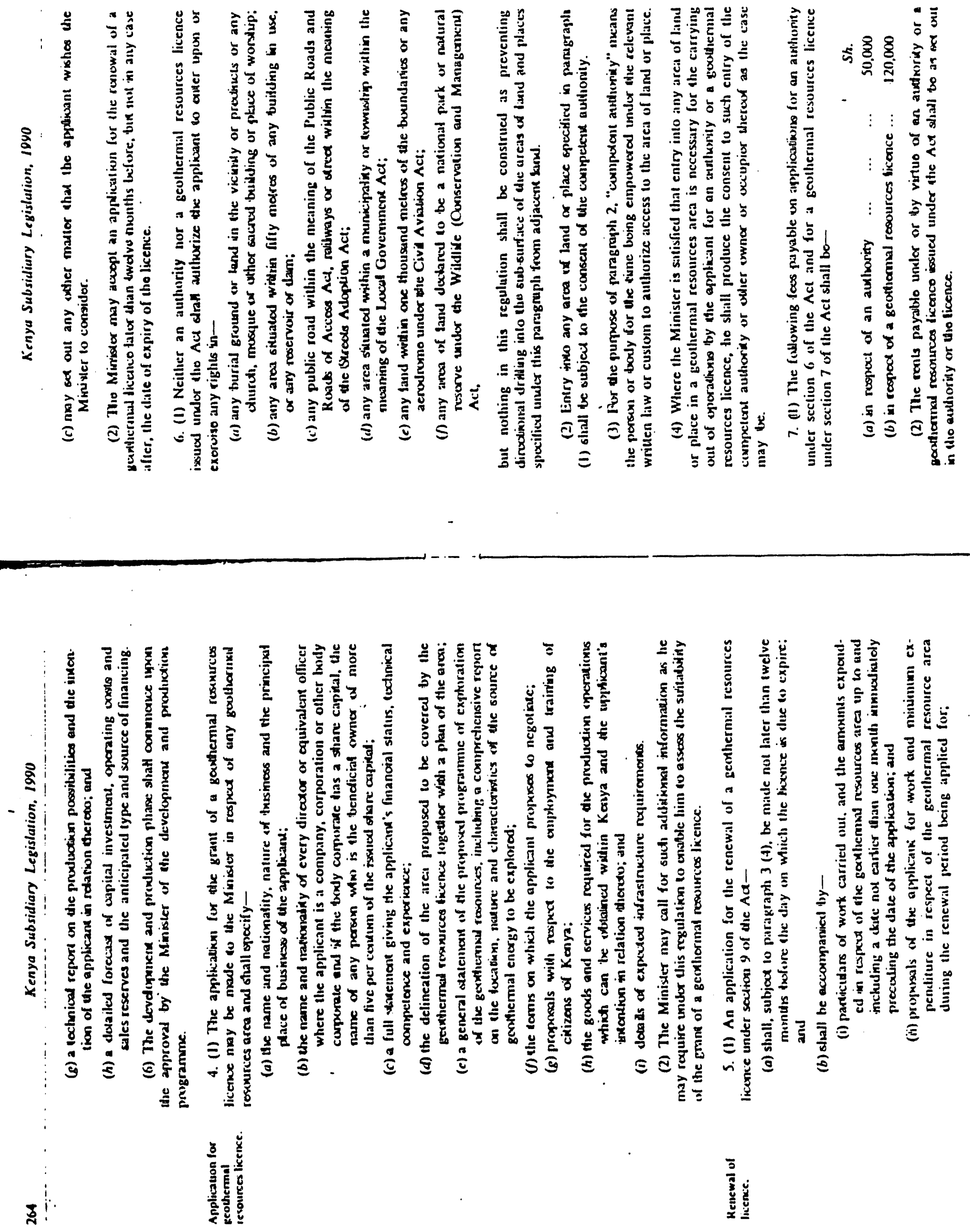
苞

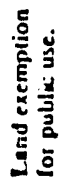
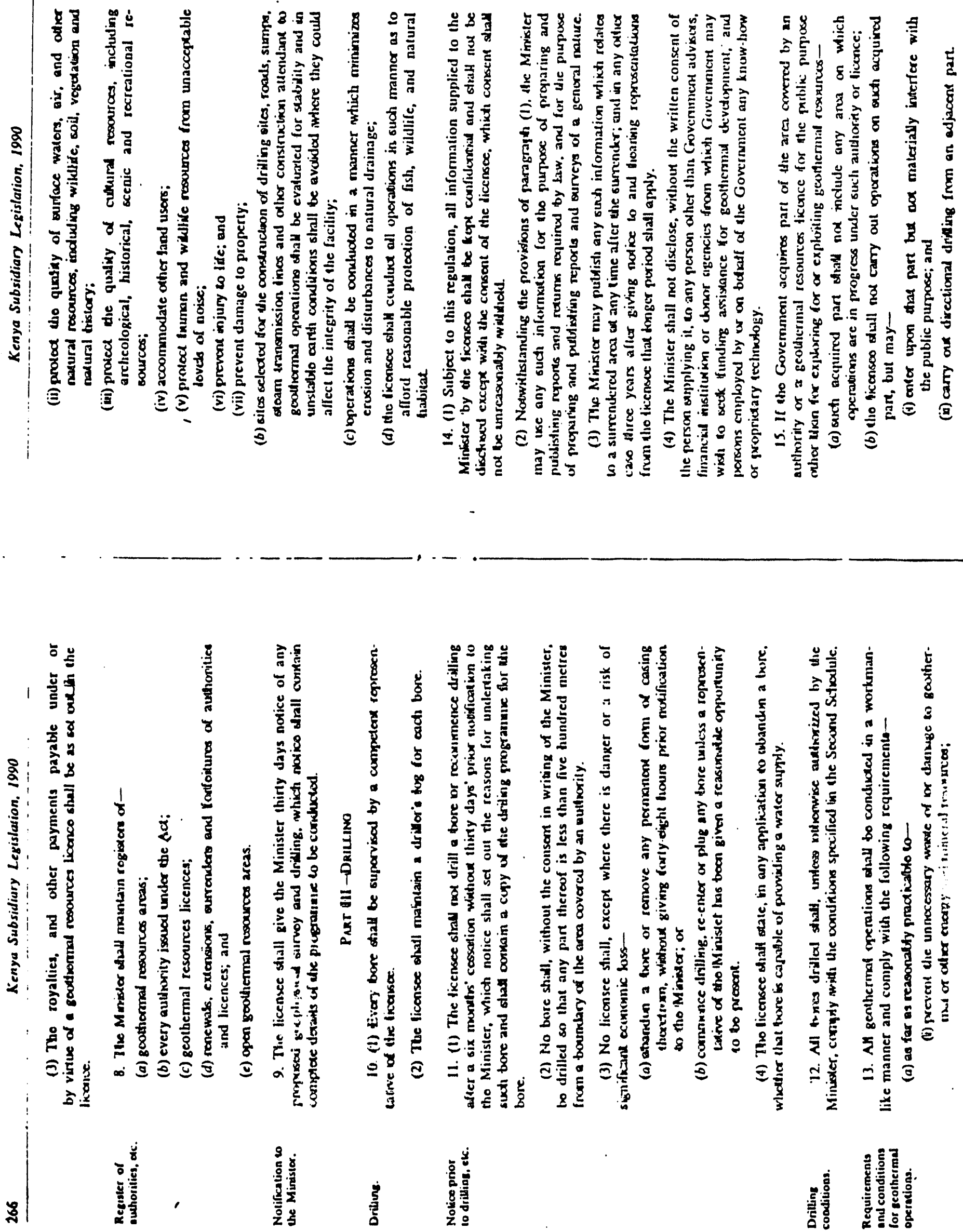

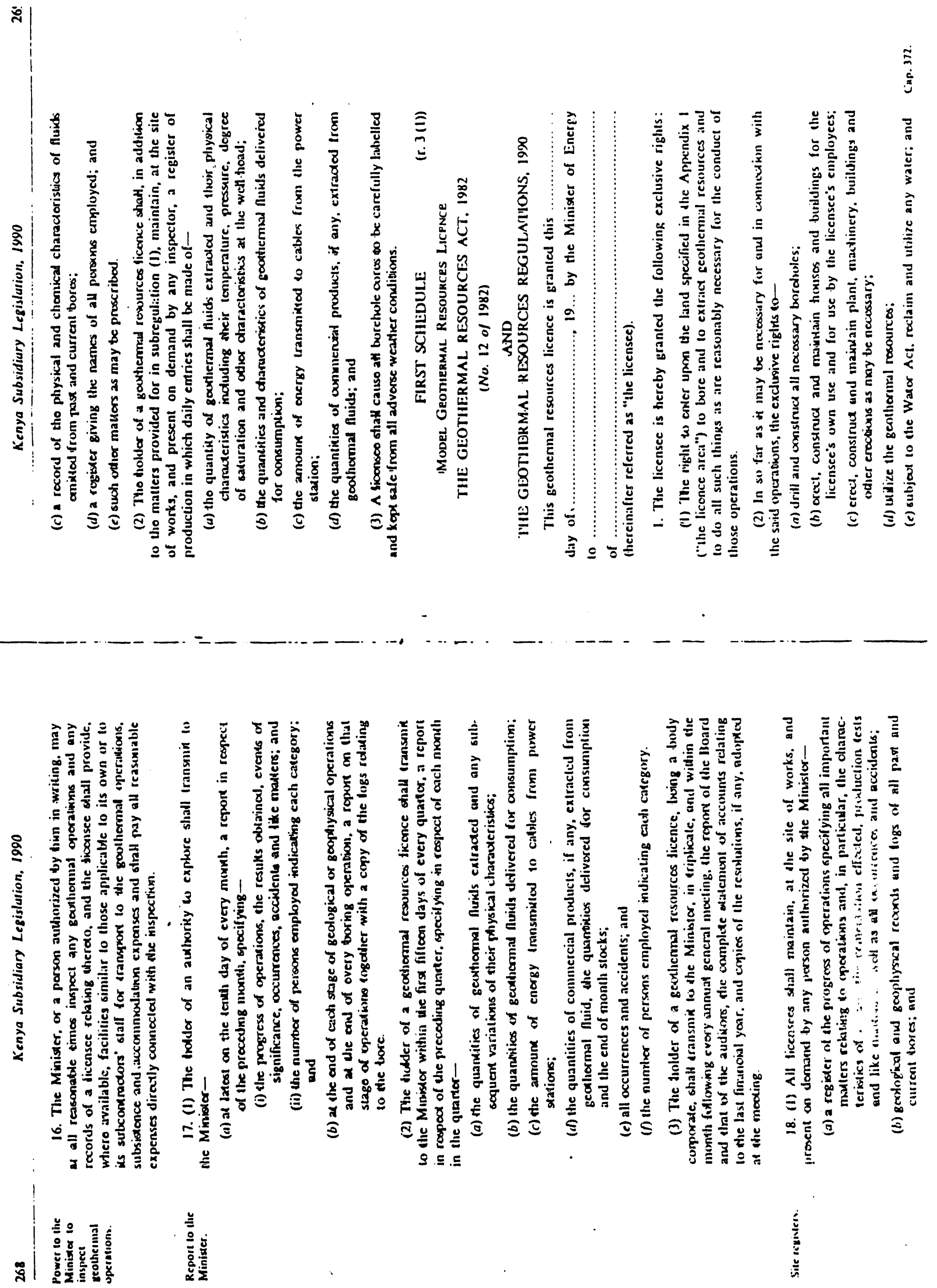

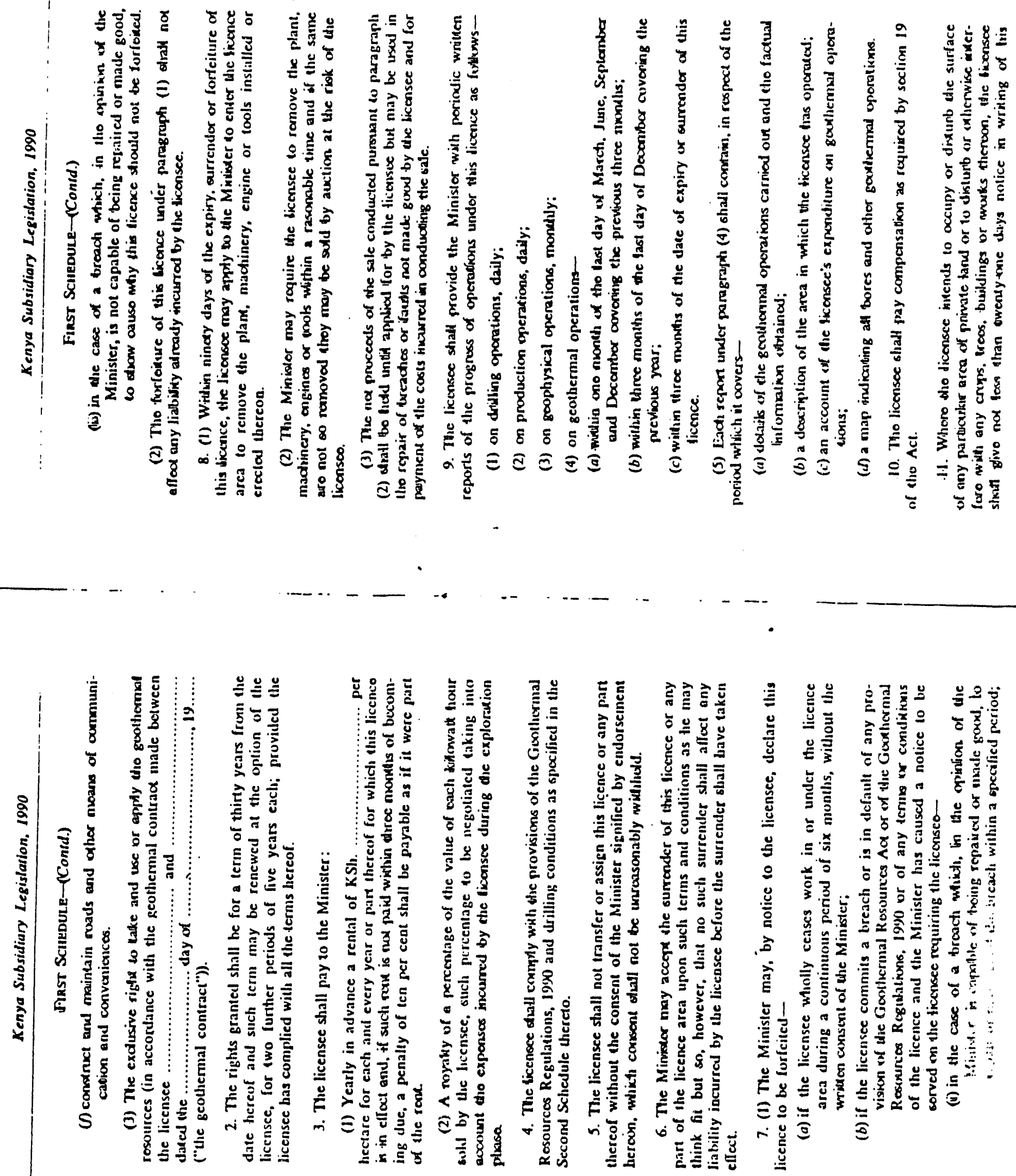


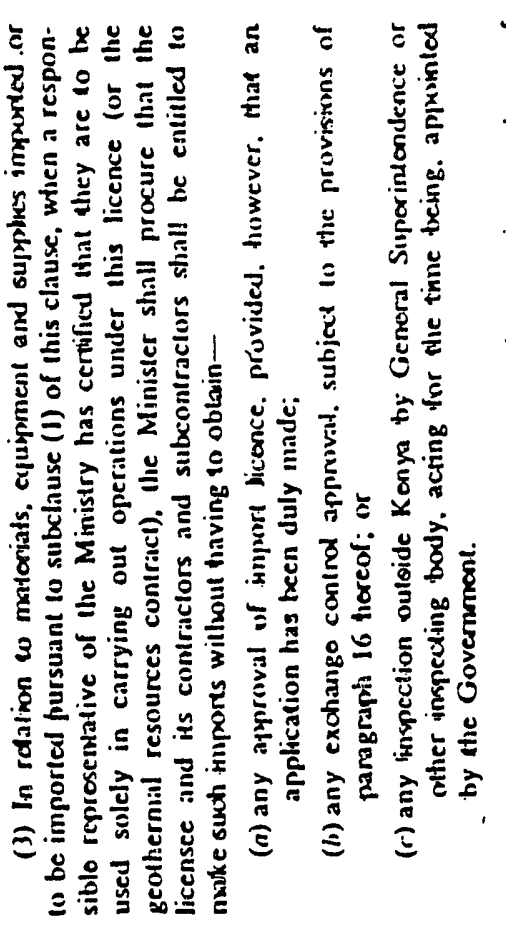

\section{§.}

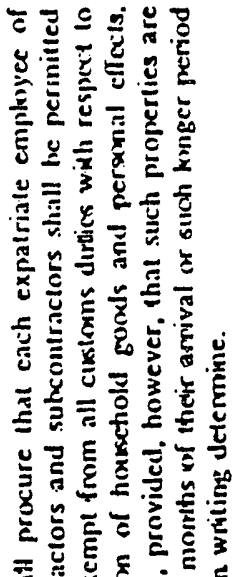

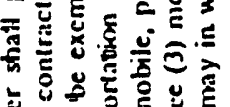

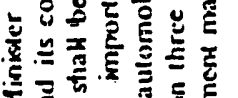

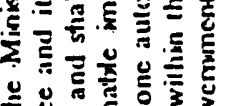

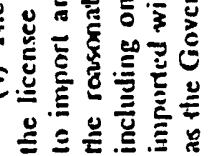

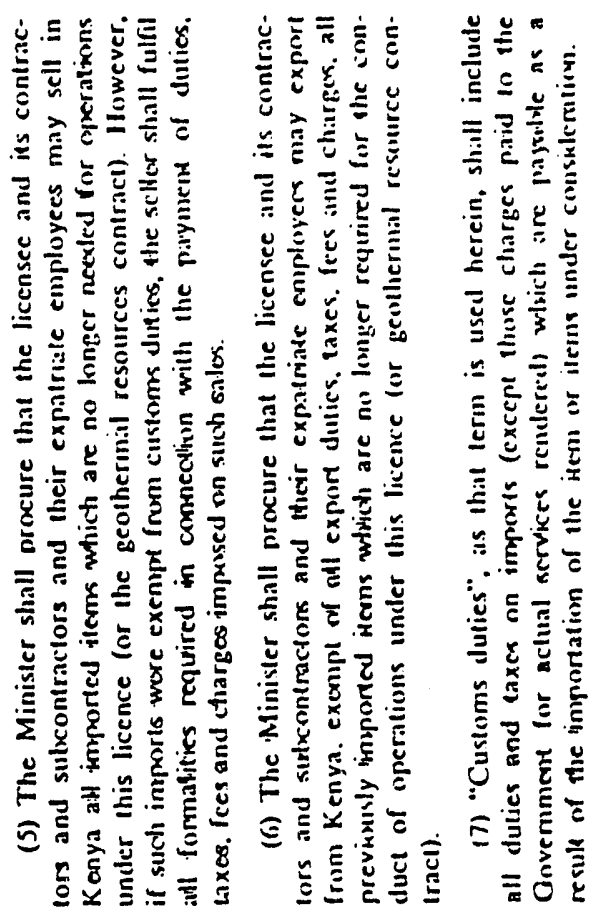

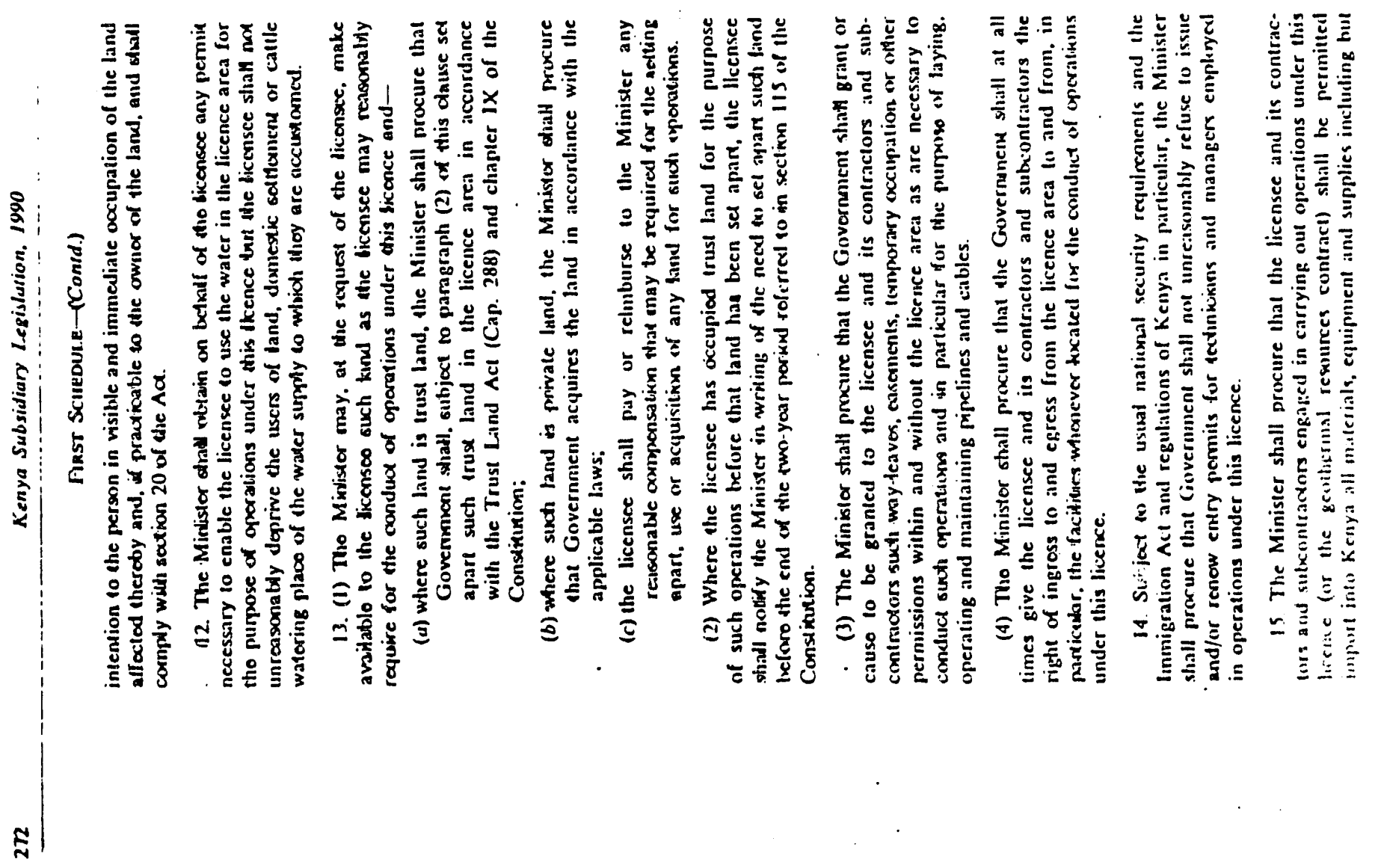




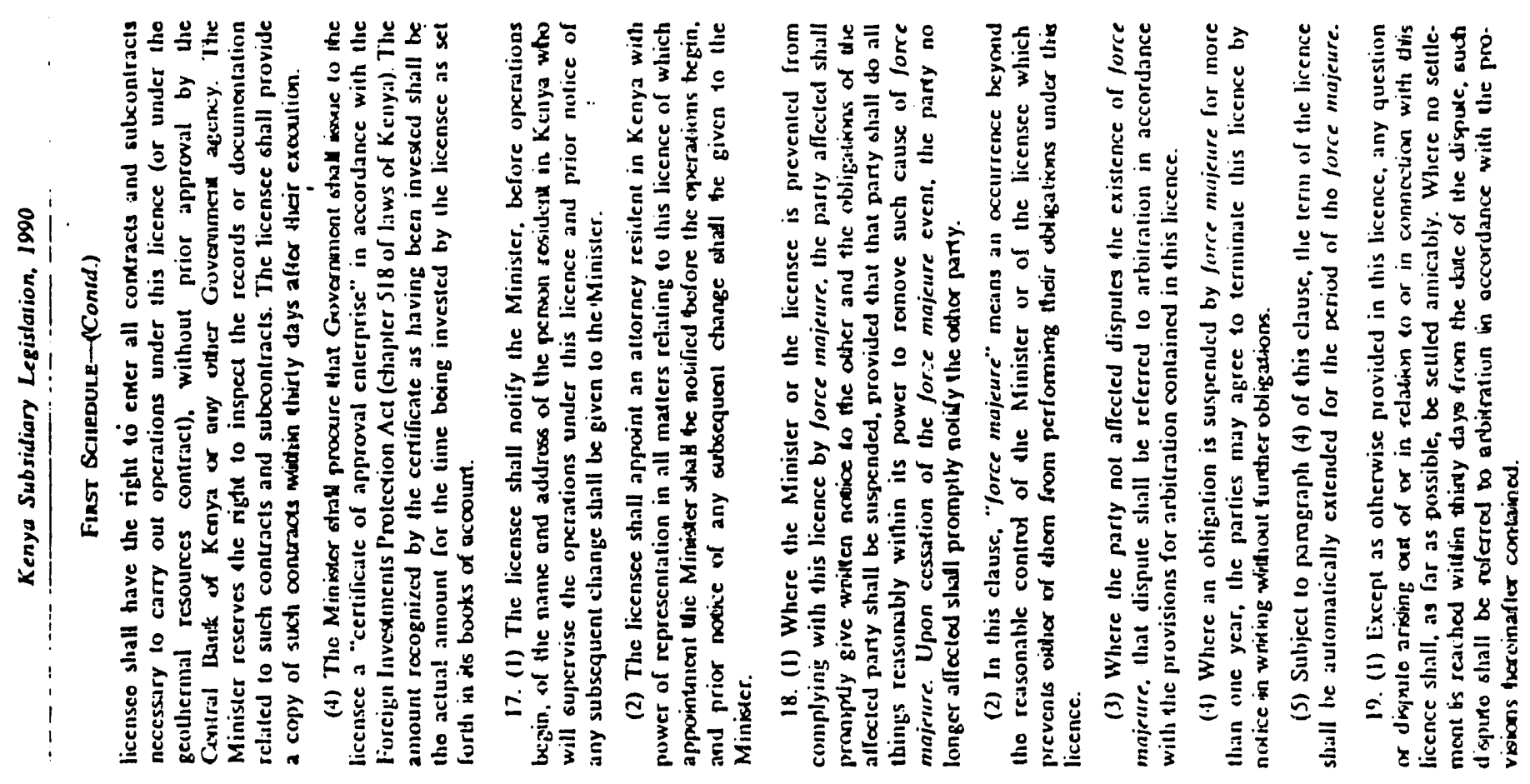

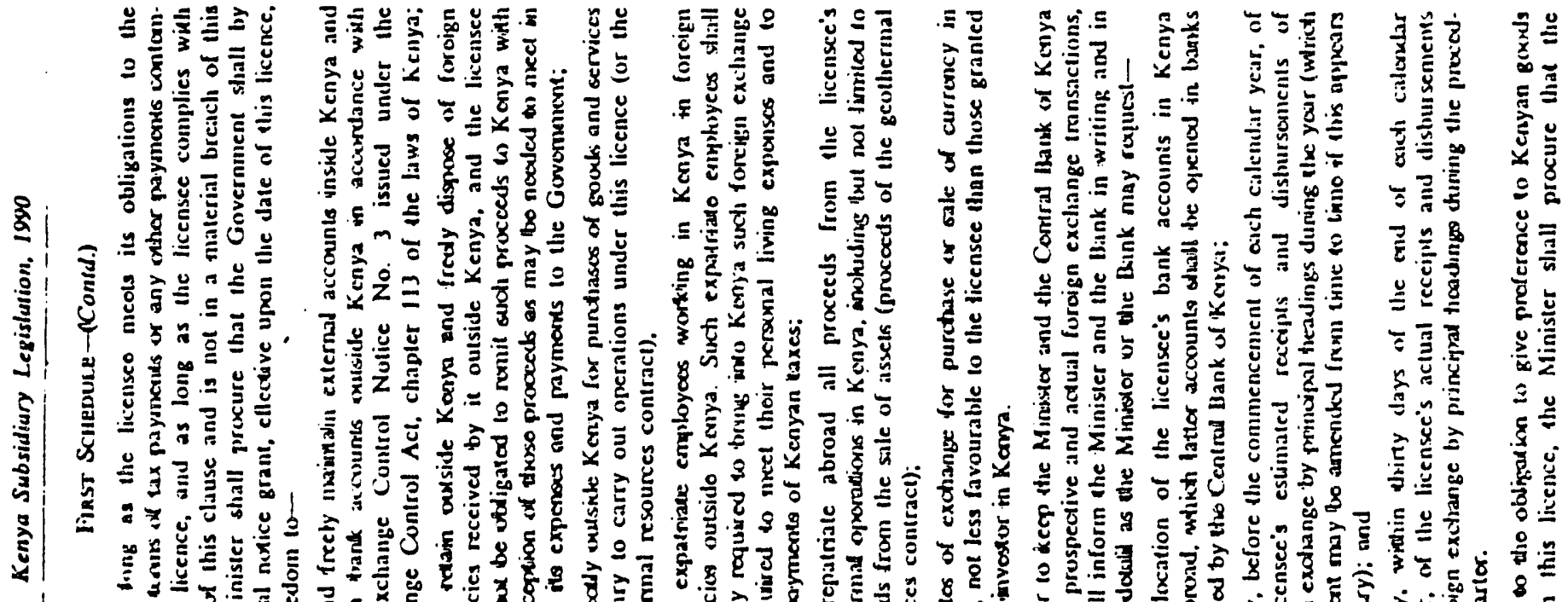

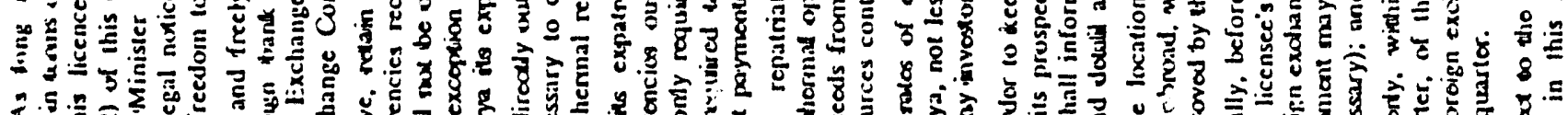

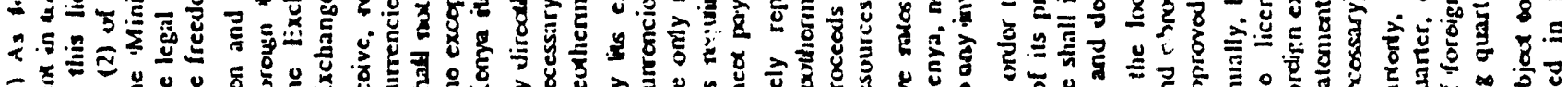

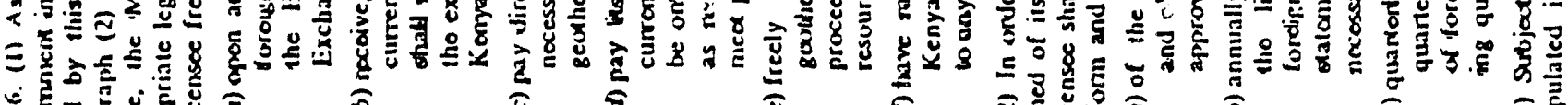

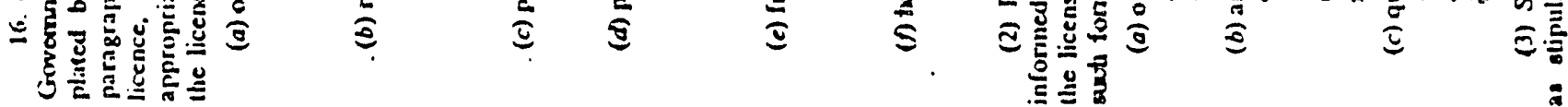



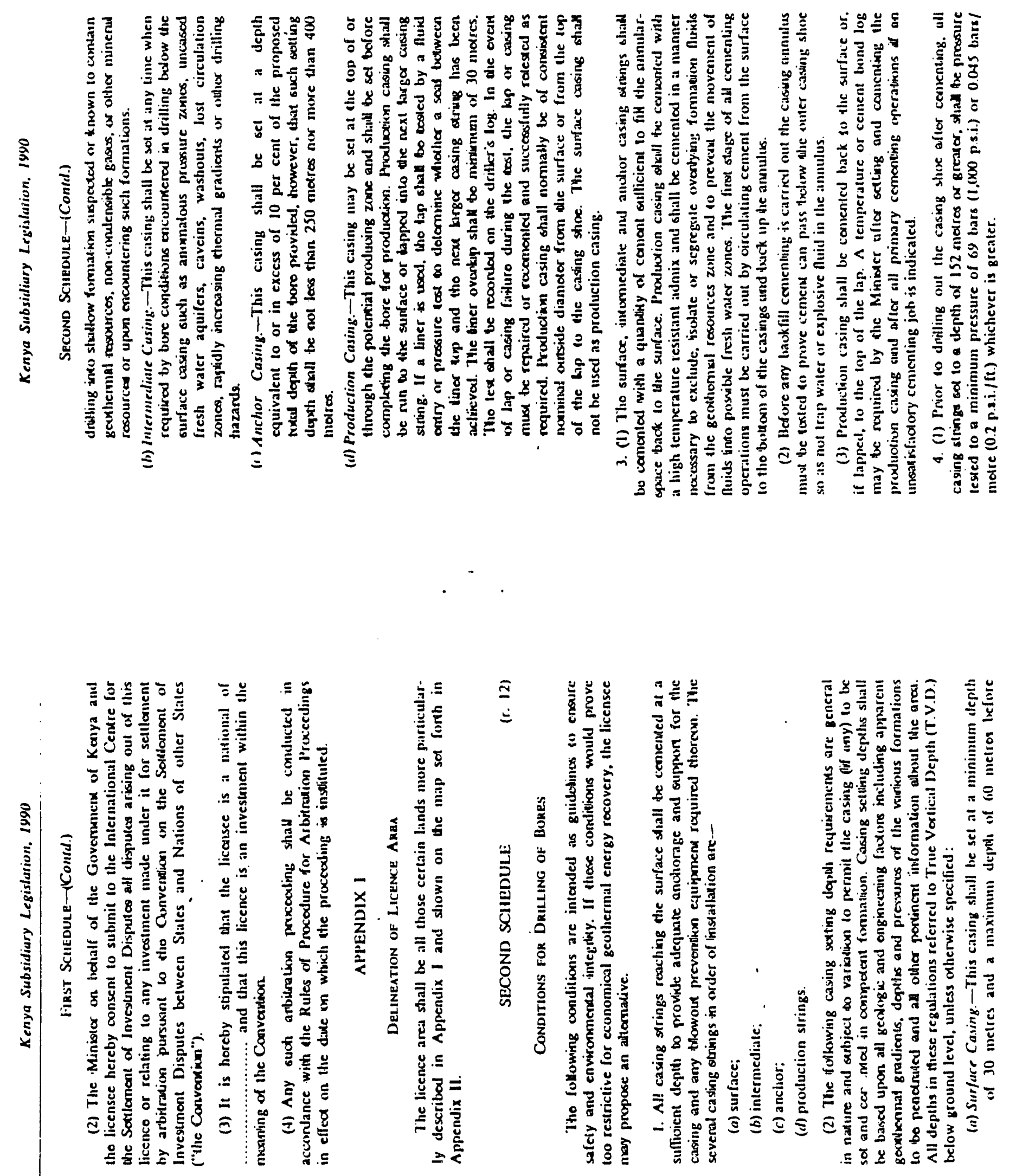
$\stackrel{2}{2}$
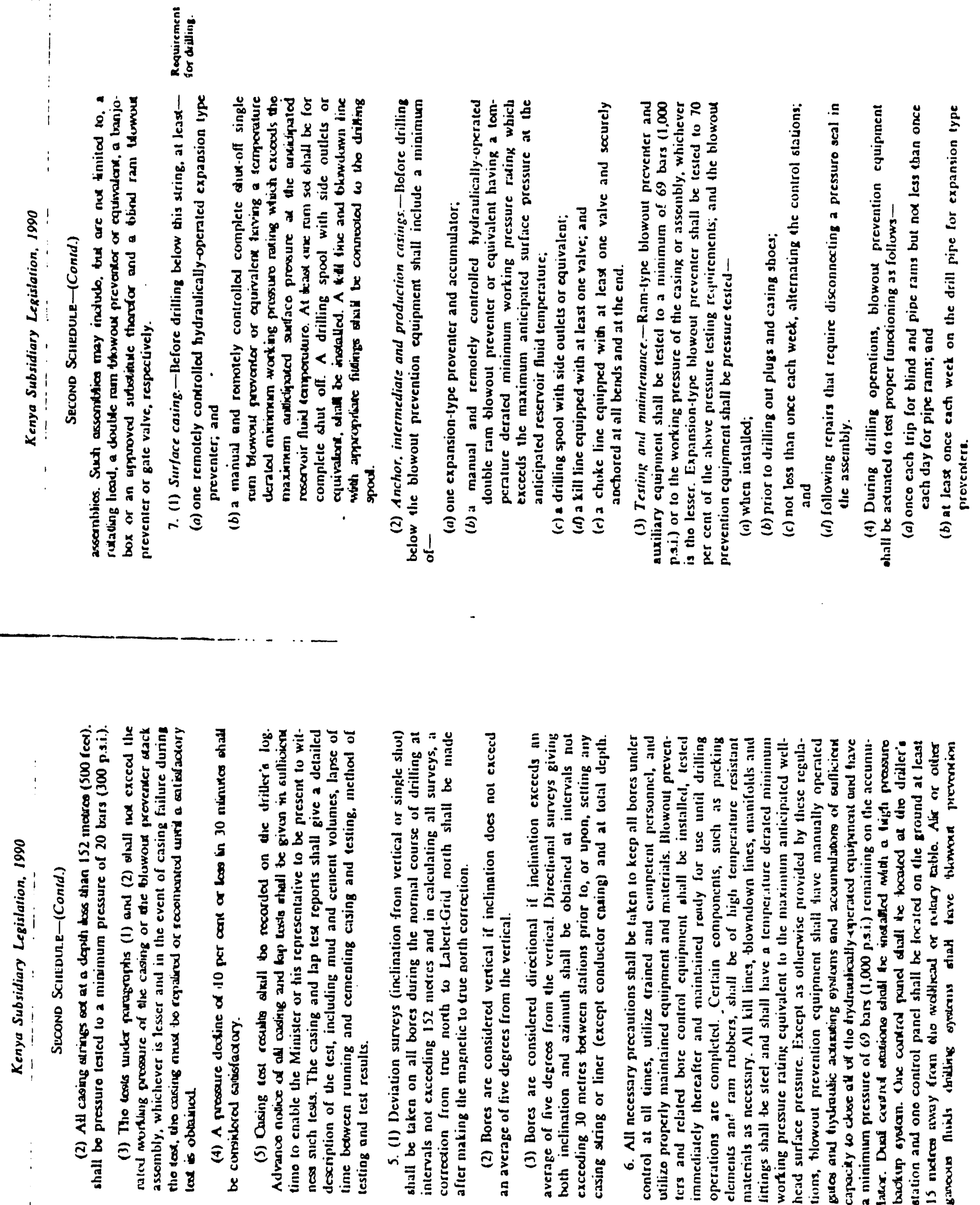

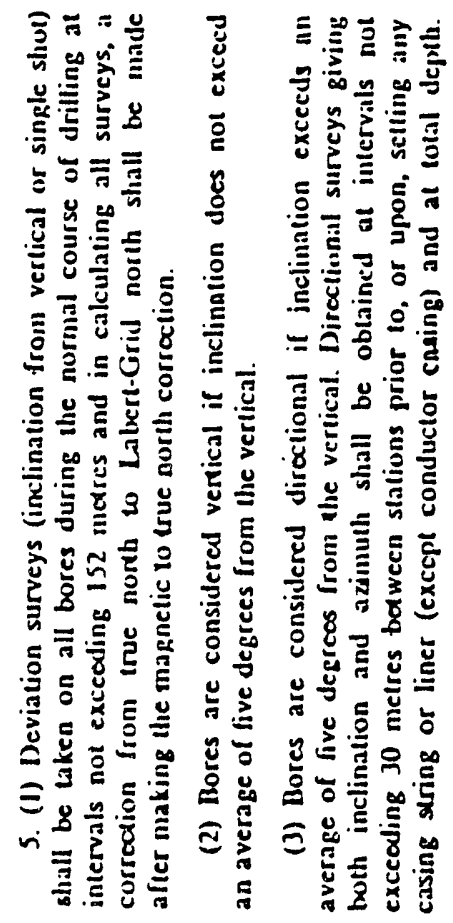

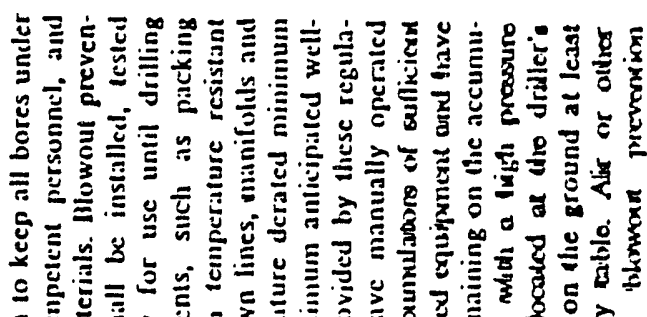

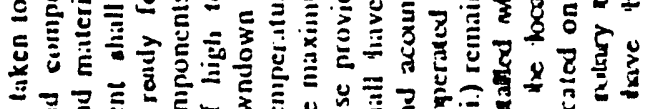

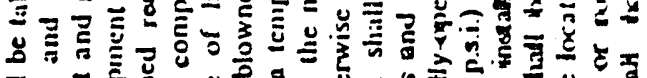

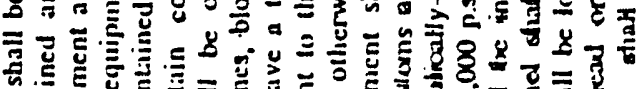

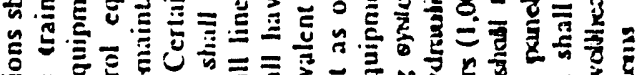

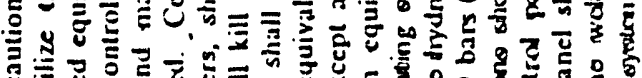

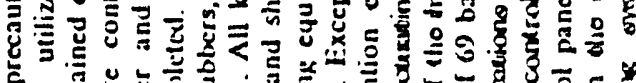

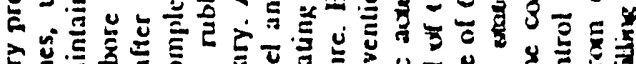

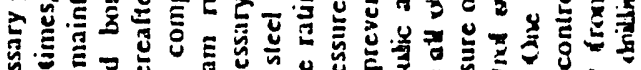

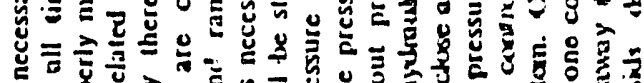

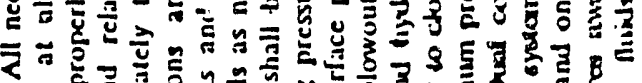

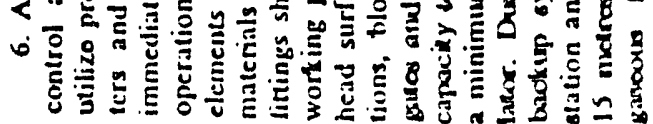




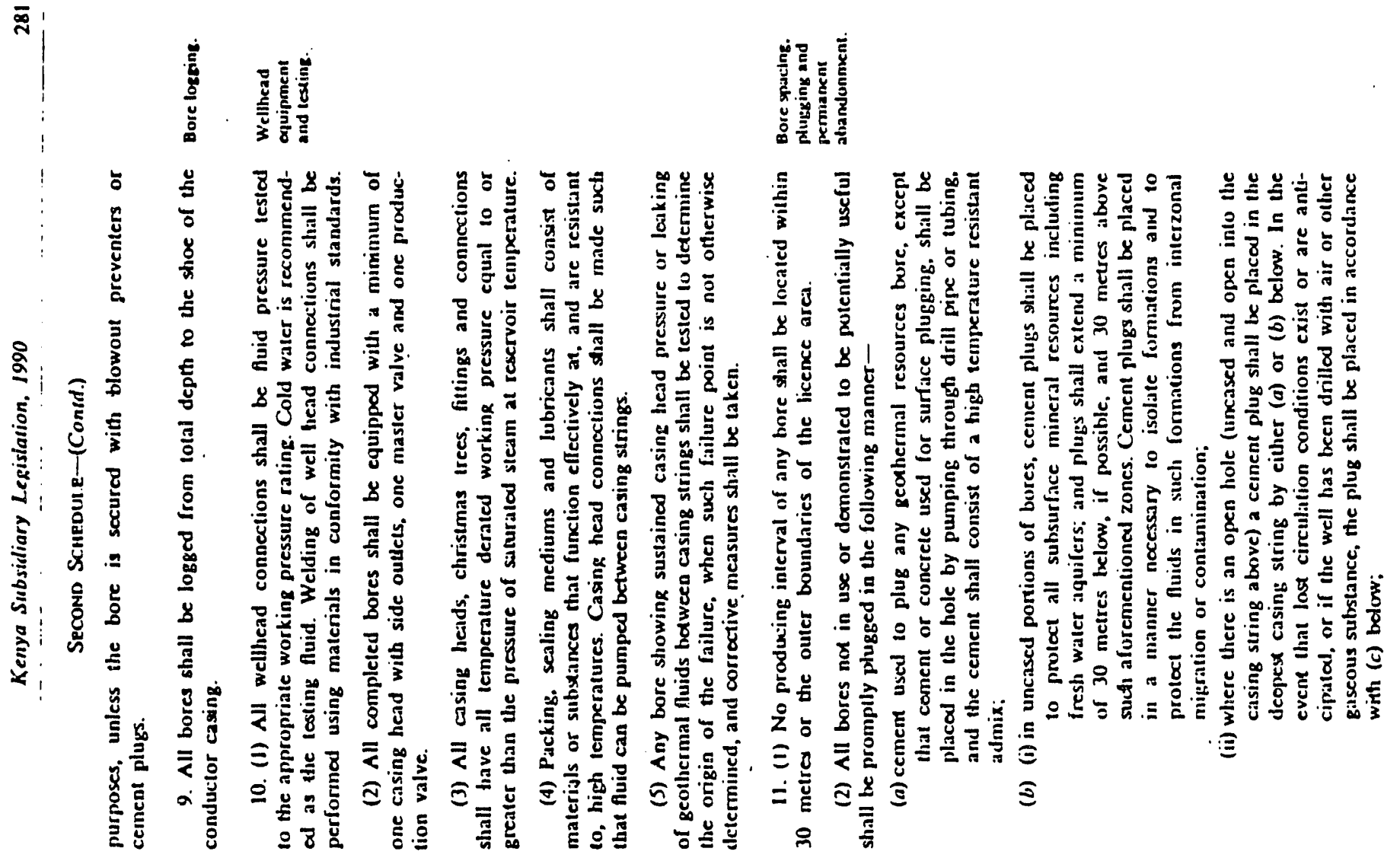

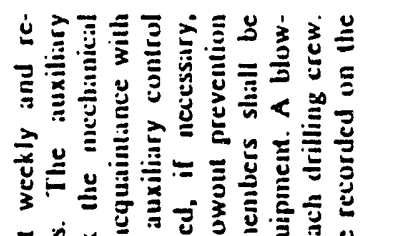

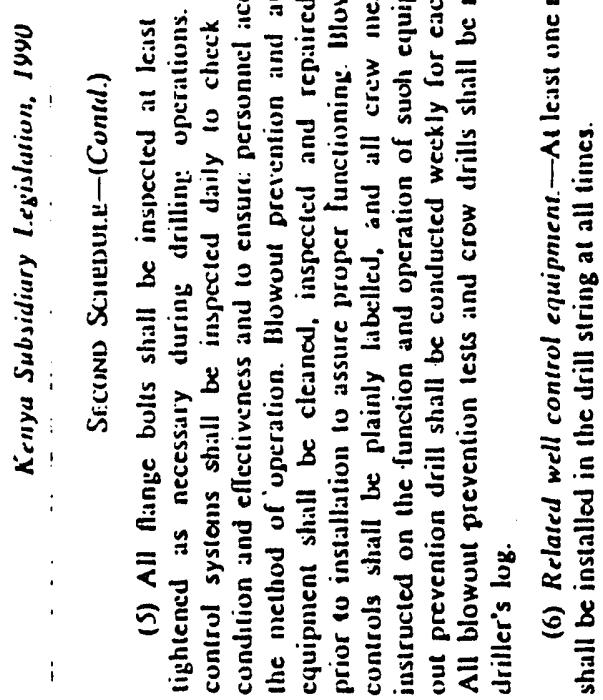

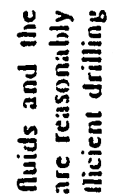

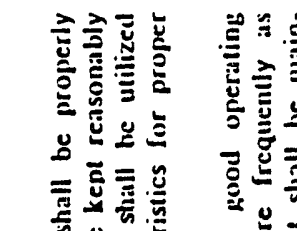

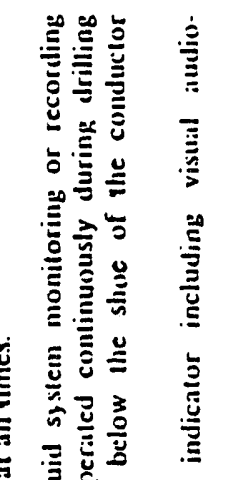

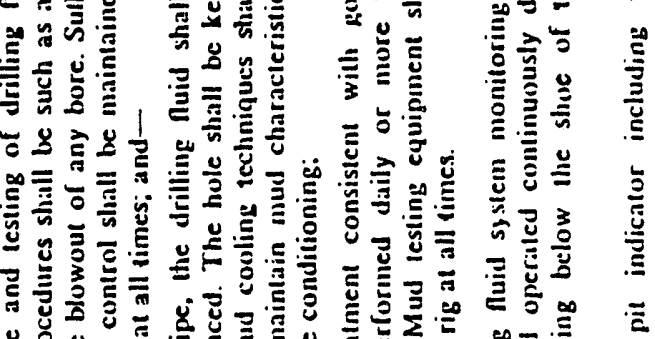

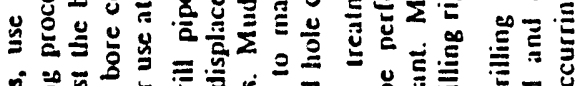

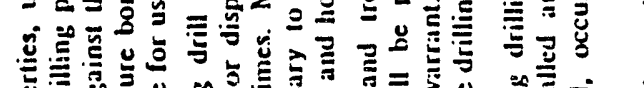

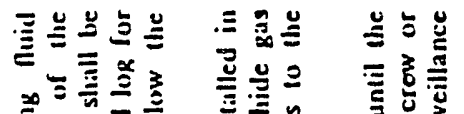

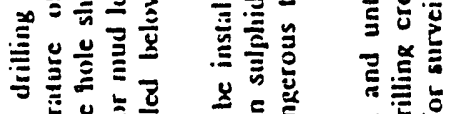

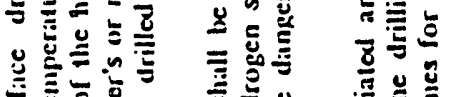

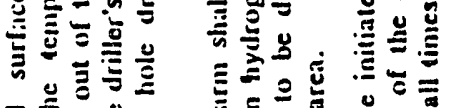

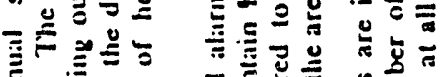

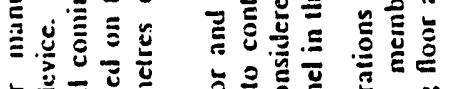

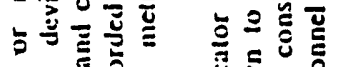

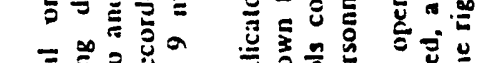

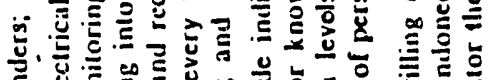

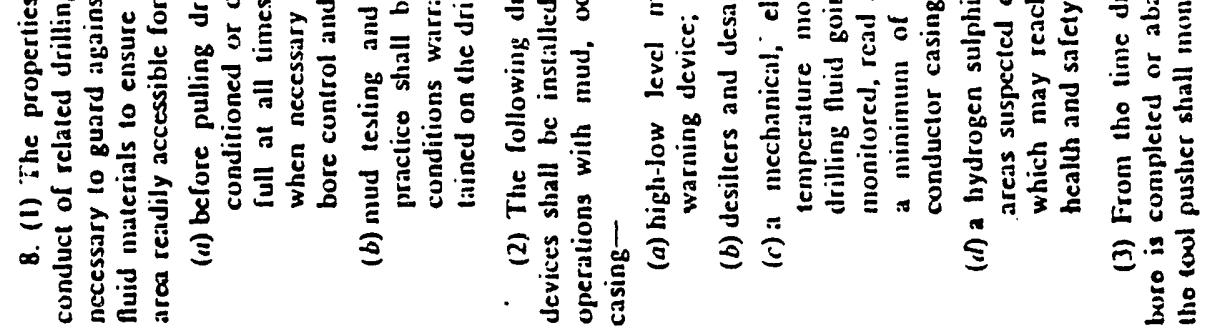



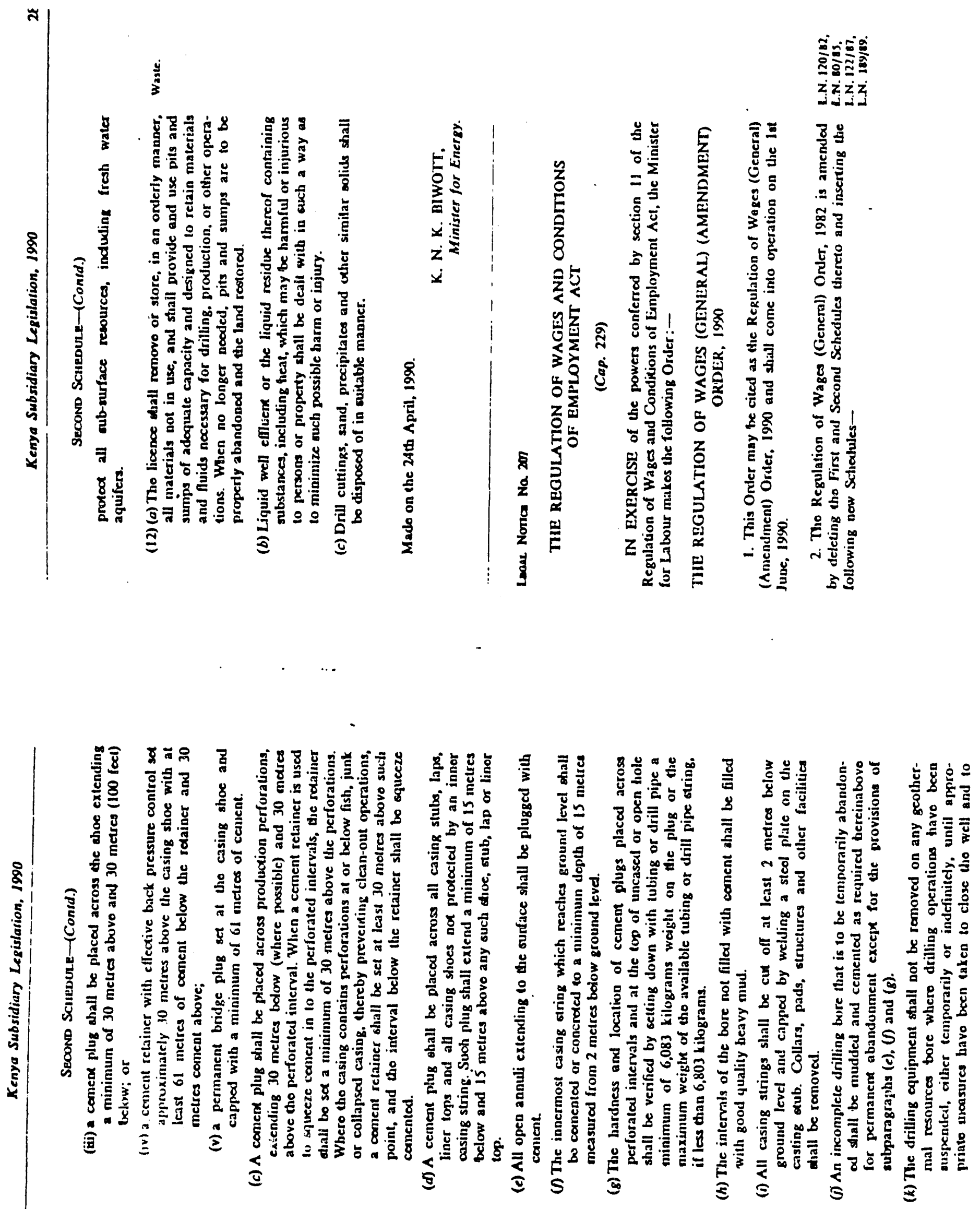
The Geothermal Resource Regulations

Appendix VI 
THE GEOTHERMAL RESOURCES ACT, 1982

No. 12 of 1982

Date of Assent: 8th July, 1982

Date of Commencement: By notice

ARRANGEMENT OF SECTIONS

Section

Part I-PMenogrusy

1 Sbor tile and comorenceoneas.

2-Inerprezision.

3-Goothersal resouroes vested in the Governoweal

$\leftarrow$ Declaration of geoblermal resources spea.

5 Uasurborized use of sootbermal resources protibited.

PARt II-Explottatton of Grotresull Rusources

$\leftarrow$ Minister to authorize cearch for reothermal resources.

7-Miairter may grasl a 800 hermal resoureor licence.

8 -Rights uoder licasce.

O-Reoewal and surreoder of lieence, are.

10-Transfer of beesce.

11-Forfinire of becoce.

12-Reat ad peaaliy for noo-paymeat of reat

13-Lieeasee to re-ealer under cerrais condivions.

14-Powers of heessee in tespect of the geactaion of eloctricity.

15-Austorities, ex. to be registered.

PATT UULSATETY AND ACCDERTS

16-Sufery of persons.

iT-Miajsei may require bore wo be closed.

Put IV-Muscenureous Provistons

18-Compeosacion for injury or damage 10 laod.

19-Paymeal of cocopeasation to had owners and cocupien.

20-Norice is respect of privace hod.

21-Charges pajzble for exrzetion of zeciberral resources for ceris purpoces.

22-Ofiecos.

23-Pendioa

24-Requincioss

! 
Sbo:t jide and cormeosement.

In:e:pre:2:jos.
As Act of Parliament to control the exploitation and ase of geothermal resources and vest the resources in the Government and to provide for conoected purposes

E.X.ACTED by the Parliament of Kenya as follows:-

\section{PART 1-PRELLSTINARY}

1. This Act may be cited as the Geotbermal Resources Act, 1982, and sinall come into opeation on such day as the Minisier may, by ootice in the Gazette, appoint.

2. In this Act, uniess the context otheruise requires-

"bore" means a tiell, hole, pipe or excavation of any kind witich is bored, drilled, sunt or made in the ground for the purpose of investigating. prospecting for, ob:aining or providing geotberanal resources; and includes any reacsivaced or converied bore previously capped and abandoned which is employed for re-injecting geothermal resources or their residues:

"geotbermal resources" means any producr derived tom and produced within the earth by nasural heat; and includes steam. water and water vapour and a mixure of any of them that bas been beated by natural heat whether as a direct product or resulting tom otber material ingoduced artifcially into an underground formation and beated by namal beat:

"georbermal resources area" means an area which is declared to be a geothermal resources area uoder secrion 4:

"land" includes land covered with water:

"licence" means a georbermal resources licence granted undei section 7:

"licensee" means the public or local authority, company or body of persons to whom a licence is granted.

"the Minister" means the Minister for the time being responsible for matters connected with energy. 
3. All unextracted geothermal resources under or in any land sball be vested in the Government subject to any rights which, by or under any writted law, have been or are granted or recognized as being vested in any otber person.

4. The Minister may, by notice in the Gazette, declare that any area $\alpha$ land where geothermal resources bave been discovered or which is a source or is believed to be a cource of geothermal resources shall be a geothermal resources area.

5. Notuithstanding anything to the contary in any written law or instrumeat of title, no person shall sink a bore. isp or take and use or apply geothermal resources for any purpose unless be is firsi granted an authority or licence under this Act.

\section{Part II-ExploItation of Geothermul Resoltrces}

6. (1) For the purposes of and subject to this Act, the Minister may authorize any person (including a public officer), in uriting, to male survey's, investigations, lests and measurements in searcb of geothermal resources and for that purpose the authorized person may-

(a) ealer upon any land spesified in the aubority with such assistants. gear, appliances, and equipmeat as be thinks fit:

(b) sinl any boie on the land:

(c) make geologica! survey's and geophysical survej's on the land; and

(d) generally do all things necessan in connection Rith the survey, investigation, test or measuremeni.

(2) Hibeo practicable. reasonabie notice of the inteation 10 enter upon any land shall be given to the owner or occupie: of the land.

(3i) Ever: person who is authorized in uriting uoder subsection (1) to ealer upon any land shall produce his authority when required to do so by the ok'ner or occupier of the land on which he intends to enter or bas entered.

on wich he intends to eacer or bas entered. 
No. 12

(4) Every aubhority granted under this section shall be subject to-

(a) the condition that every bore made pursuant to the authority shall be-

(i) kept under close supervision:

(ii) maintained in a safe condition;

(iii) finally lett in a condition of lasting safety;

(b) such otber conditions as the Minister may impose eitber at the time of granting the authority or subsequeatly at the time of the closure of the bore.

(5) An authority granted under this section shall not be transferable, and shall be in force for a period of one vear for the date of issue, but may be reaewed for a period of one year from the date of expiration thereof or from the expiration of any renewal.

(6) An aubority granted under this section may be revoked by the Minister on any of the following grounds-

(a) that the person to whom the authority is granted bas not complied with any requirement or condition of his authority;

(b) that operations being carried on under the authority are, in the opinion of the Minister, affecting derimentally otber specified bores or the supplies of geotbermal resources for other specified purposes:

(c) that it is in the public interest that operations being carried on under the authority should cease.

Miniver ary

coner a rocuber.

ond resurtes

7. (1) The Minister may, on application being made to licoos. him in respect of any land, grant a licence (to be known as a "geochermal resources licence") over part or the pihole of a geothermal resoures area under such terms and conditions as be may determide.

(2) An application for a licence to be issued under this section shall be in the approved form and be accompanied by the prescribed fers.

(3) A liceace may be granted under this section for such term, not exceeding thirty years, as the Minister may deter. mine and sball be in the prescribed form. 
8. (1) A licence shall, subject to this Act, confer upon the license the right-

(a) to enter upon the land being the subject of the lisena to bore and wo extract geothermal resourcer and to do all such things as are reasonably nocessary for the conduct of tbose operations:

(b) in so far as it may be necessary for and in connection with the operations referred 10 in paragrapb (a)-

(i) to drill end construct all necesary boreboles;

(ii) to erect, construct and maintain bouses and buildings for his own use and for use by his employees:

(iii) 20 erect, construct and maintain plant, machinerg. buildings and other erections as may be neces cary:

(jv) to utilize the geothermal resources;

(v) subjoct to the Waler Act, to reclaim and atilize any hater; and

(vi) to construct and maintain roads and other means of communications and convesiences;

I 6 ' to take and use or apply the geotbermal resources for any purpose specified is the licence.

(2) Where an! by-product oblained in the production of geotbermal resources may be reclaimed for furiber use or sale and is a mineral withio the meaning of the Mining Act, the licence may be modified so as to allow for the inclusion of a mining lease to enable recover; of that by-product.

9. The Minister may-

lal reper a licence for a lerm not exceeding five years subject to such terms and conditions as be thinks Gt:

(b) Hibolly or partly remit all or any of the terms and condicions contaired is an liceace where, oning to special circumsiances, in his opinion, compliance therenith would be impossible or greal bardship would be inflicted upon the licensee: 
No. 12

(c) extend ti:e to the licensee for complying with the lerms and conditions of any licence upon such terms and conditions as be may thint fir:

(d) acseph, whecher with a view to the renewal or re-grant of any licence or otberrise the surrender of any licence or any part of the area comprised thereia upon such terms and conditions as be may thint 6 i. but so botiever that no sucb surrender shall affect any liability incured by the licensee before the sureader shall bave takea effect.

Thestros of insese.

Foresis:s of Lix:x.
10. The license sball not transfer or assign bis licensee or azy par thereof ritibout the conseat in writing of the Min'sier signined by ezdorsement thereon.

11. (1) The Minister may, by notice to the licensee, dec. lare a licence to be forfeited-

(a) if the licensee wholly ceases work in or under the land the subject of the licence during a continuous period of six months, without the aritten consent of the Minister:

(b) if the licensec commits a breach or is in default of any provision of this Act or of the regulations made thereunder or of any terms or conditions of the licence and the Minister has caused a notice to be served upon the licensee requiring bion-

(i) in the case of a breach which, in the opinion of the Minister, is capable of being repaired or made good, to repair or make good the breach vithin a speficied period:

(ii) in the case of a breach which, in the opinion of the Minirer, is not capible of being repaired or made good. Lo show cause within a specified period why his licence should not be forfeited.

(2) The forfeirure of a licence under subsection (1) shall not affect any liability alseady iacurred by the liceasee.

(3) The forfeiture of a liceace under subsection (1) shall be published in the Gazette. 
12. The licensee shall in respect of his licence pay yearly in advance such rent as may be preseribed by the Minister and. if the reat is not paid within three mosths of becoming due a peaalty of ten per centur sball be payable as if it were part of the reat.

13. (1) Any licensee whose licence has expired or has been surreodered or forfeited may, within nioery days of the date of the expiry, surrender or forfeiture, apply to the Minister to enter the land which was oomprised in the licence to remove the plant, machinery, engines or tooks installed or erected on the land.

(2) The Minister may require the licensee to remove the plant machinery, encines or tools within a reasonable time. and if the planh machiners; engines or tools are not removed within a reasonable ime they may be sold by auction at the rist of the licensee.

(3) The Det proceeds of the sale conducted pursuant to subsection (2) sball be beld until applied for by the licensee but may be used in the repair of breaches or fauls not made goot by the bicensee and for the payment of the costs incurred in conductiog the sale.

14. The holder of a licence under the Electric Pou'si Aat ma! fo: the purpose of generatiag. transmiring or supply: ing elsci:izal porer-

(a) extrast, tale, use and apply geothernal resources on o: under any land which is the subjert of the licencs:

(b) eresi. construct. provide and use suct works and appliances as may be necessa.? fo: the purpose of generating electricing, and in conoxction rith the trasmission. use, supply and sale of electricin:

15. Every authoring and licence issued under this Act sinali be registered in the prescribed manne?.

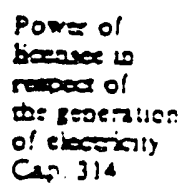

\section{PART III-SAFETI AID ACGIDENTS}

16. A licensee shall be liable for any loss. damage or

Selay $\alpha$ iniury to any person or property resulting from his works or operations. Whether as a result of negligedce or otherwise: 
No. 12

Miaiser mat require bore

io be doaed.
Georhermal Resources

1982

17. (1) Notwjthstanding any other provisions of this Act, the Migister may, at any time. order a bore to be closed after ziving aotice 10 any person in accordance with subsection (2) Ja iny of the following grounds-

(a) that the bore is a source of danger to persons or property in the vicinity:

(b) thai : he bore is, in the opinion of the Minister, affect. ing de:rimentally other specified bores or a specified tourist arraction or the supplies of geothermal resources for orher specified purposes:

(c) that the bore is a quisance in law or that it is otherwise in the public interest that the bore should be closed:

(6) inat the bore is no longer necessary for operation in accordance witb plans approved by him:

lel for the protection of the envisonment includiag ground h'ater against contamination; or

(j) in the interest of conservation of the geothermal resoures.

(2) Notice to close a bore may be given under this section by the Mijnister to the licensee entitled to use or apply the geothermal resources from the bore for any purpose and if there is no licence granted under this Act the notice may be given to any of the following -

(a) the person authorized by the Minister to make the bore:

(b) a person who made or assisted to make the bore without any authority:

Ici the ovines of the land if be permitted the bore to be made without the authority of the Minister.

(3) No compensation resulting from the closure of any bore shall be payable by the Governmeat but the Minister may consider the refund of part of the fees which may bave been paid in respect of any autbority or licence in relation to a bore which be has ordered to be closed under this secion, except that no refund of any part of fees shall be made in respect of asy bore made wihout the authority of the Minister. 
Part IV-Miscellaneous PROVISIONS

18. (1) Except as otherwise provided in this Act every person who-

(a) has an interest in any lasd injuriously affected by che exercise of any of the powers conferred by this Act or confersed by any authority or licence granted under this Acti or

(b) suffers any damage from the exercise of any powers so conferred,

shall be entitled to compensation, determined by the Minister. for the loss, injur and damage sufferted by him.

(2) Any person aggrieved by a determination of the Minister under subsection (1) may appeal against such determination to the High Court.

19. (1) Mthenever, in the course of searching or boring for geothernal resources, any disturbance of the rights of the ourer or occupier of any land or a nuisance or damage 20 tha: land or 10 any crops, trees, buildings, stock or w'orks ibereon is caused. the holder of the authorin or licence under which such opeations are carried out sbal! pay to the orze? o: ossupier a fair and reasonable compensation for such disturbance. nuisance or damage.

(2) If the person referted to in subsection (1) fails to pay sumpensaition o: if an ou'ner or ocsupier is discarisfied with the comfensation offered to him. the oune: or oceupier may' within one month of the demand having been made refer the maner 10 the Higb Court which sball assess and determine the amount of corspensation to be paid.

20. 11i there a licenses intends 10 occupy or disturb the surface of any paricular area of private land or to disturb or otherhise interfere with ajy cTops, trees, buildings or works thereor. be stall give Dot less than twenty-one day's notice in prisie land writing of bis inten:ion 10 the person in visible and immodiate recupation of the land affected thereby and, if pracricable, :o the ouner of the laod.

Pryouel of compeasion on hod ancers and acomians. 
ง.o. 12

(2) When the occupation, disturbance or interference refersed to in subsection (1) has concioued for a period of - hiriy conserutive days, the owner or occupier of the land affected may require the licensee to give security, in sucb sum and by such means as the Minisier may direct, for meeting any sompensation payable under section 19 to the ouner or Wivufier of the land.

i3) In this section "oviner" means-

(a) in case of unst land the county council in which the land is vested:

E. : :8:

(b) in the case of land ouned by group representatives under the Land (Group Representatives) Acr, that group:

I6l in the case of other land. ine iegistered owner. lessee or srasiee.

4) In the case of land ow'ned by group representanives unde: the Land (Group Representatives) Act, the notice required under subsection (1) to be given to the owner of the land may be sent by post addressed to the posial address of the group representarives or delivered personally to the office of that group.

Carzes pay. able for exrasion of seotarement resourses for cerain puposes. Otexces.

Peozi:tes.
21. The Minister shall levy the prescribed fees, rentals and royalties for the extraction of geothermal resources for indusirial or commercial purposes and for any orber purposes which may be determined by the Minister

22. (1) Every person who sinks any bore or who extracts, takes. uses or applies geothermal resources in contravention of this Act shall be guilty of an offeace.

(2) Every person who removes, damages, destroys or ocherwise interferes with any survey pegs or beacons placed on the ground in connection with any survey lawtully carried on under this Act or any valve or instrument being used in conzection with any such survey or with any bore sball be guilty of an offence.

23. Any person who is guilty of an offence under this Act sball be liable to a fine not exceeding ten thousand shillings and if the offence is a continuing one, to a further fine not exceeding one thousand shillings for every day or par of a day during which the offence contiaues. 
24. (1) The Minister may make regulations necessary for cartying into efect ibe provisions of this Act.

(2) Regulations ma! be made under this section for the following purposes -

(a) prescribing any forms that may be required for the purposes of this Act:

(b) prescribing conditions upon or robject to which autborities and licences may be applied for, granted or reaewed:

(c) providiog for the keeping of records and the turaish. ing of information and reruras by persons auborized by or under this Acr and prescribing the native of the reconds, information, and returns and the form. manoer and time in which they shall be kept or furnished:

(d) prescribing matters in respect of which fees, rents and royalties are to be payable under this Act and the amount of the fees and rents, and persons liable to pay them:

(e) authorizing the refund of fees, reats or remission, in sucb circumstances as the Minister thints tit, of any fees or reacals payable under this Act;

(f) pressribing the responsibilities of licensees and persons io ahom authorities are granted by or under this Act, and the operations to be carried out under licosces;

(g) prescribing the qualifcations of persons in charge of the waling and closing of bores, and in paricular. of persons exployed as bore managers, and providing for the examination of any grast of certifiates to qualified persons.

(hi preventiog or abaing nuisances in or about bores and industries using geothermal resources;

(ii prescribing safer. precausions in the making and atret the compieting of bores. and the treament of the ground above any bore and of narer above and below the ground. and preventing waste or loss of geotbermal resources;

(i) prescribing drilling machinerg. materials, and casting to be used in making of bores and to be arailable 
No. 12

to cope with any emergency in connection with any bore, and probibiting the use of ocher classes of materials thereof:

(k) probibiting or regulating the making of bores near other bores;

in regulating the sessation of boring operations and the abandonment and closing of bores and prescribing precautions against loosening the earth in the vicinity of any bore:

imi providing for bores to be made with due diligence and by safe and saisfactory methods;

(n) generally regulating the making of bores;

(0) providing for the exemption of licensees and persons to whom authorities have been granted under this Aci either wibolly or parcially, and eitber absolutely or conditionally, from any of the requirements of their liceaces or authorities or of regulations made under this secuion. 
Kenya Electric Power Act

Appendix VII 


\section{Note: Kenya Electric Power Act}

The Geothermal Resources Act 1982 states inter alia that the holder of a geothermal resources' license may "take and use or apply the geothermal resources for any purpose specified in the license. I/ The Act further states that the holder of a license under the Electric Power Act "may for the purpose of generating, transmitting or supplying electrical power ... erect such facilities as necessary for the purpose of generating, transmitting and selling electricity." $2 /$ The Geothermal Resources Regulation 1990 further provides in its first schedule (the Model Geothermal Resources Licenses) that exclusive right to "take and use or apply" the geothermal resources shall be in accordance with the geothermal contract made between the licenses and such other parties to the contract. 3 /

It is within the context of this geothermal resources legal, regulatory and contractual system that the issue arises of how a geothermal licensee is permitted to generate electrical power. Pursuant to the terms of the Geothermal Resources Act, in order for the geothermal resouices licensee to be able to generate, transmit or supply electrical power a license under the Electric Power Act $4 /$ must be issued.

The Electric Power Act provides that in order for a public or local authority, company, person, or body of persons to generate electricity, such entity must hold a bulk supply license or a local generating iicense under this Act.5\% The Act also provides for exceptions to the licensee rules which are not pertinent in the instart matter. 6 /

1/ The Geothermal Resources Act 1982, Laws of Kenya, Law No. 12 $1982, \S 8(1)(c)$.

2l Id. $\$ 1 \hat{z}$.

3/ The Geothermal Resources Regulation, 1990. Legal Notice 206, April 24, 1990, Model Geothermal Resources License, $\$ 1(3)$.

4/ Electric Power Act, Ch. 314, Laws of Kenya 2-213 (1986).

5/ Id. $\$ 4(1)$.

6/ Id. $\$ 4(1)$ to $(4)$. 
Two types of licenses may be issued: a bulk supply licenst and a local generating license.

The Minister of Energy may grant a bulk supply license to any company to supply electrical energy in bulk to bulk supply licensees or authorized distributors within any area prescribed ir: such license. I/ such a bulk supply license under this Act conveys to the licensee the right to generate, transmit and suppl: electrical energy over, through or within the area defined by the license.8/ Such license may be for any period not exceeding 50 years. 2 '

A "bulk suppli: license" means a license granted to a public or local authority, :ompany, person or body of persons to generat: and supply electrical energy to other bulk supply licensee or authorized distributnrs within a defined area. The bulk supply license is in contrast to a "local generating license" which basically is a license authorizing an authorized distributor to generate electrical energy. The locai generating license is issu: by the Minister of Energy after determining that the holder of tr.: distributing license cannot obtain a supply of electrical energy from a bulk supply licensee, or that the distributing licensee wi: : be able to generate electrical energy at the lowest price at whicr. such electrical energy could be supplieci by a bulk supply licensee. $10 /$

Thus, the geothermal resources licensee will most likely b. required to obtain a bulk supply license to generate and sell electricity.

I/ Id. $\$ 10(1)$.
s/ Id. $\$ 10(5)$.
I/ Id. $\$ 10(2)$.
I0/ Id. $\$ 2$.


The Constitution of Kenya, Article 75

Appendix VIII 
Pivie.tion firan linumign ierairient.

Piverion ficim geprivation

of fioperiy.

is of $197 i$, s. 3. of the sentence or order of a court, is reasonably necessary in the interests of bygiene or for the main. tenance of the place at which be is detained:

(c) labour required of a member of a dispiplined force in pursuance of his duties as such ot, in the case of a pcrson who has conscientious grjections to service as a member of an armed force, lahour that that person is required by law to perform in place of such service:

(d) labour requiked during a period when Kenya is at war or an order/under section 85 is in force or in the event of any other emergency or calamity that threatens the life on well-being of the community, to the extent that/he requiring of the labour is reason. ably justifiable, in the dircumstances of a situation arising or gxisting during pat period or as a result of that oxher emergency or calamity. for the purpose of dealing with that situation, or

(c) labour/reasonably required as part of reasonable and normal comminal or other civic obligations.

74. (1) No person shall be subject to yorture or to inhunanor degrading punishment or other treakment.

(2) Nothing contairied in or done under the aluthority of any law shall be held to be inconsistent with or in contravention of this section to the extent that the law in question auchorizes the infliction of any description of punishment that was la wiul in Kenya on 11 th December, 1963.

75. (1) No property of any description shall be compulsorily taken possession of, and no interest in or right over property of any description shall be compulsorily acquired. except where the following conditions are satisfied-

(a) the taking of possession or acquisition is necessary in the interests of defence, public safety, public order, public morality, public bealth, town and country planning or the development or utilization of pro. perty so as to promote the public benefit; and

(b) the necessity therefor is such as to afford reasonable justification for the causing of hardship tha: may result to any person baving an interest in or right over the property; and

(c) provision is made by a law applicable to that taking of possession or acquisition for the prompt payment of full compensation. 
Rev. 19871:

(2) Every person baving an interest or right in or over property which is compulsorily taken possession of or whose intcrest in or right over any property is compulsorily acquired shall have a right of direct access to the High Court for-

(a) the determination of his interest or rigbt, the legality of the taking of possession or acquisition of the property, interest or right, and the amount of any compensation to which be is entitled; and

(b) the purpose of abtaining prompt payment of that compensation:

Provided that if Parliament so provides in relation to 3 malter referred to in paragraph (a) the right of access shall be by way of appeal (exercisable as of right at the instance of the person having the right or interest in the property) from a tribunal or authority, other than the High Court, having jurisdiction under any law to determine that matter.

(3) The Chief Justice may make rules with respect to the practice and procedure of the High Court or any otber tribunal or authority in relation to the jurisdiction conferred on the High Court by subsection (2) or exercisable by the other tribunal or authority for the purposes of that subsection (including tules with respect to the time within which applications or nppeals to. the High Court or applications to the other tribunal or authority may be brought).

(4) and (5) (Deleted by 13 of 1977, s. 3.)

(6) Nothing contained in or done under the autbority of any law shall be beld to be inconsistent with or in contraven. tion of subsection (1) or (2) -

(a) to the extent that the law in question makes provision for the taking of possession or acquisition of property-

(i) in satisfaction of any tax, duty, rate, cess or other impost;

(ii) by way of penalty for breach of the law, whether under civil proces: or after canviction of a criminal offence under the law of Kenya;

(iii) as an incident of a lease, tenancy, mortgage, charge, bill of sale, pledge or contract:

(iv) in the execution of judgments or orders of a court in proceedings for the determination of civil rights or obligations: 
(v) in circumstances where it is reasonably necessary so to do because the property is in a dangerous stale or injurious to the bealth of buman beings. animals or plants;

(vi) in consequence of any law with respect to the limitation of actions; or

(vii) for so long only as may be necessary for the purposes of an examination, investigation, trial or inquiry or, in the case of land, for the purposes of the carrying out thereon of hork of soil conservation or the conservation of other natural resources or work relating to agricul. tural development or improvement lbeing work relating to the developneut or improvement that the owner or occupier of the land has been required, and has without reasonable excuse refused or failed, to carry out).

and except so far as that provision or, as the case may be, the thing done under the authority thereof is shown not to be reasonably justifable in a democratic society; or

(b) to the extent that the law in zauestion makes provision for the taking of possession or acquisition of-

(i) enemy property:

(ii) property of a deceased person, a person of unsound mind or a person who has not attained the age of eighteen years, for the purpose of its administration for the benefit of the persons entilled to the beneficial interest therein;

(iii) property of a person adjudged bankrupt or a body corporate in liquidation, for the purpose of its administration for the benefit of the creditors of the bankrupt or body corporate and, subject thereto, for the benefit of other persons entitled to the beneficial interest in the property; or

(iv) property subjec: to a trust, for the purpose of vesting the property in persons appointed as trustees under the instrument creating the trus! or by a court or, by order of a court, for the purpose of giving effect to the trust.

(7) Notbing contained in or done under the authority of an Act of Parliament shall be held to be inconsistent with or in contravention of this section to the extent that the Act in 
question makes provision for the compulsory taking possession of property or the compulsory acquisition of any interest in or right over property where that property, interest or right is vested in a body corporate, establisbed by law for public purposes, in which no moneys have been invested other than moneys provided by Parliament.

76. (1) Except with his own consent, no person shall be subjected to the search of bis person or his property or the entry by otbers on bis premises.

(2) Nothing contained in or done under the authority of any law shall be held to be inconsistent with or in contra. vention of this section to the extent that the law in question makes provision-

(a) that is reasonably required in the interests of defence. public safety, public order, public morality, public health, town and country planning, the development and utilization of mineral resources, or the development or utilization of any other property in such a manner as to promote the public benefit:

(b) that is reasonably required for the purpose of promoting the rights or freedoms of other persons:

(c) that authorizes an offeer or agent of the Government of Kenya, or of a local government authority. or of a body corporate established by law for public purposes, to enter on the premises of a person in order to inspect those premises or anything thereon for the purpose of a tax, rate or due or in order 10 carry out work connected with property that is lawfully on those premises and that belongs to that Government, authority or body corporate, as the case may be; or

(d) that authorizes, for the purpose of enforcing the judgment or order of a court in civil proceedings, the entry upon premises by order of a court.

and except so far as that provision or, as the case may be. anything done under the autbority thereof is shown not to be reasonably justifiable in a democratic society.

77. (1) If a person is charged with a criminal offence, then, unless the charge is withdrawn, the case shall be afforded a fair hearing within a reasonable time by an inde-

Prolection against arhilrary search or eritry. pendent and impartial court establisbed by law.

Provisions to recure prolection of law. 
The Foreign Investment Protection Act

Appendix IX 


\section{CHAPTER 518}

35 of 1964, 6 of 1576.

Inlerprelation. 6 of 1976, Sah.

Foreign inveciors may aiply for and

lie sianicd

itrilieaies. 6 of $1976, \mathrm{Scb}$

\section{THE, UREIGN INVESTMENTS PROTECTION ACT}

Commencement: 15th December 1964

An Act of Parliament to give protection to certain approved foreign investments and for matters incidental thereto

1. This Act may be citeu as the Foreign Investments Protection Act.

2. (1) In this Act, except where the context otherwise requires-

"approved" in relation to any enterprise, foreign currency, period, sum or amount means any enterprise, currency, period, sum or amount specified in the relevant certificate issued under section 3;

"foreign ässets" includes foreign currency, credits, rights, benefits or property, any currency, credits, rights, benefits or property oblained by the expenditure of foreign currency, the provision of foreign credit, or the use or exploitation of foreign rights, benefits or property, and any profits from an investment in an approved enterprise by the holder of a certificate issued under section 3 in relation to that enterprise;

"foreign national" means a person who is not a citizen of Kenya, and includes a body corporate which was not incorporated in Kenya.

(2) For the avoidance of doubt it is declared that assets shall not cease to be foreign assets by reason of their being assets in some other part of the Commonwealth, and that currency shall not cease to be foreign currency by reason of it being in Kenya as well as in some place outside Kenya, so long as, in the case of currency, the relevant sum originates from outside Kenya.

3. (1) A foreign national who proposes 10 invest foreign assets in Kenya may apply to the Minister for a certificate that the enterprise in which the assets are proposed to be invested is an approved enterprise for the purposes of this Act.

(2) The Minister shall consider every application made under subsection (1) and, in any case in which he is satisfied that the enterprise would further the economic development 
of, or would be of benefit to, Kenya, he may issue a certificate to the applicant.

(3) Foreign nationals who have already invested foreign assets in Kenya shall be entitled' to the grant of a certificate on application:

Provided that a certificate may be withheld if the Minister is not satisfied that the enterprise is of bencfit to Kenya.

(4) Every certificate shall state-

(a) the name of the holder,

(b) the name and a description of the enterprise;

(c) the amount of the foreign assets invested or to be invested by the holder of the certificate in the eaterprise divided as between-

(i) capital, being deemed to be a fixed amount representing the equity of the holder in the enterprise for the purposes of this Act and which shall be expressed in the certificate in, and shall for the purposes of this Act be in, Kenya currency; and

(ii) any loan, which may be expressed in, and may for the purposes of this Act be in, either Kenya currency or the relevant foreign currency:

(d) the relevant foreign currency;

(e) if the assets have not yet been invested, the value therenf and the period within which they shall be invested;

(f) such other matters as may be necessary or desirable for the purposes of this Act.

4. The Minister may amend a certificate granted under section 3-

(a) in any case in which he is satisfied that some other foreign national has succeeded to the interest in the enterprise of the holder of the certificate, by substierrificale. tuting for the name of the holder the name of his 6 ol 1976, sch. successor:

Provided that the Minister shall riut substitute the name of any person who has acquired the 
Foreig̣n assets lo be hrought in during

afproled period.

Cirmpliance with Cilp. 113.

Tiansfer of pratiss. els. o i1 1976, Scb. interest of the holder by the expenditure, directly or indirectly, of assets other than foreign assets;

(b) in any case where an interest in the enterprise passes to any other person on the death of the holder;

(c) in any case where the name of the enterprise is altered, by substituting the name as so altered;

(d) in any case in which new foreign assets are invested or are to be invested in the enterprise by the holder, or the holder has withdrawn or been paid, in accordance with this Act. any part of his investment by varying the approved amount in accordance therewith;

$(e)$ in any case where the investment consists of the acquisition of shares or stock of a body corporate, and new shares or stock are acquired otherwise than by the investment of assets which are not foreign assets, by amending the number or amount and the descripion thereof;

(f) with the written consent of the holcler of the certificate. by varying the approved foreign currency;

(g) by extending the period during which foreign assets are to be invested; and

(h) subject to these foregoing provisions and to the written consent of the holder, in such other manner as may be necessary or desirable.

5. If, at the time at which a certificate is issued under this Act. any foreign assets or part thereof to which the certificale relates have not been invested in the approved enterprise. they shall be so invested within the approved period. and. if not so invested within that period, the certificate shall be deemed to have been revoked.

6. Nothing in this Act shall affect the obligation of an investor other than an investor from one of the scheduled territories to comply initially with the requirements of the Exchange Conirol Act.

7. Notwithstanding the provisions of any other law for the time being in force. the holder of a certificate may, in respect of the approved enterprise to which the certificate 
relates, transfer out of Kenya in the approved foreign curtency and at the prevailing official rate of exchange-

(a) the profits, after taxation, arising from or out of his investment of foreign assets:

Provided that any increase in the capital value of the investment arising out of the sale of the wholc or any part of the capital assets of the enterprise shall not be deemed to be a profit arising from or out of the investment for the purposes of this Act;

(b) the capital specified in the certificate as representing and being deemed to be the fixed amount of the equity of the holder of the certificate in the enter. prise for the purpose of this Act:

\section{Provided that-}

(i) where any amendment or variation is made in the amount of the capital under the provisions of section 4 , the amended or varied amount shall be substituted for the original amount; and

(ii) no additional amount or sum shall be added to the capital specified in the certificate (as amended or varied) to represent any in. crease in the capital value of the investment since the issue of the certificate or since the last amendment or variation of the certificate; and

(c) the principal and interest of any loan specified in the certificate.

8. No approved enterprise or any property belonging thereto shall be compulsorily taken possession of, and nn interest in or right over such enterprise or property shall bc compulsorily acquired, except in accordance witb the provisions conceming compulsory taking of possession and acquisition and the payment of full and prompt payment of compensation contained in section 75 of the Constitution and reproduced in the Schedule to this Act.

9. The Minister may make regulations or give directions generally for the better carrying out of the purposes of this Act and prescribing the manner in which applications shall be made for certificates under this Act, and the information which sball accompany those applications. 


\section{THE FOREIGN INVESTMENTS PROTECTION (AMENDMENT) ACT, 1988}

No: 7 of 1988

Date of Assent: 11th August, 1988

Date of Commencement: 19th August, 1988

\section{An Act of Parliament to amend the Foreign Investments Protection Act}

ENACTED by the Parliament of Kenya as follow's:-

Short tille.

Application.

A nendmant ol sestion 3 of Cilp. 518.
1. This Act may be cited as the Foreign Investments Pro. tection (Amendment) Act, 1988.

2. The provisions of this Act shai! apply to investments in respect of which a certificate of approved enterprise is granted or amended by the Minister after the commencement of this Act.

3. Section 3 of the Foreign Investments Protection Act. in this Act referred to as the principal Act, is amended-

(a) by repealing subsection (3);

(b) in subsection (4) -

(i) by deleting paragraphs (c) and (d) and inserting the following new paragraphs-

(c) the amount of the foreign assets invested or to be invested by the holder of the certificate in the enterprise divided as between-

(i) capital, being deemed to be a fixed amount representing the equity of the holder in the enterprise for the purposes of this Act and which shall be expressed in the certificate in, and shall for the purposes of this Act be in. either Kenya currency or the relevant foreign currency; and

(ii) any loan, which may be expressed in. and may for the purposes of this Act be in, either Kenya currency or the relevant foreign currency; 
(d) the foreign currency invested or to be invested;

(ii) by deleting paragraph (e);

(c) by inserting the following new subsection-

(5) If the foreign assets thave not yet been invested a conditional certificate shall be issued stating. in addition to the details specified in subsection (3). the period in which they shall be inverted.

4. Section 4 of the principal Act is amended by deleting puragraph (d) and inserting the following new paragraph-

(d) in any case in which new foreign assets are invesied or are to be invested in the enterprise by the holder. or the bolder has withdrawn or been paid, in accordance with this Act, any part of his investment by vary. ing the approved amount in either Kenya currency or the relevant foreign currency in accondance therewith.

5. Section 7 of the principal Act is amendod by deleting paragraph (a) and inserting the following new paragraph-

(a) the profits, including relained profits which have not been capitalized, after taxation, arising from or out of his investment in foreign assets:

Provided that any increase in the capital value of the iovestment arising out of the sale of the whole or any part of the capital assets of the enterprise or revaluation of capital assets shall not be deemed to be probt arising from or out of the investment for the purposes of this Act.

6. The principal Act is amended by inserting the follow. ing new soction immediately after section 8 -

Invertorent of procoods.

8A. Any proceeds realized from the sale of foreign assets which may not be transferred out of Kenya in the manner provided for under section? shall be invested in Government securities for a period of five years:

Provided that-

(i) the income from the Government securi. ties in which the proceods are invested
Amendmeat of coctios 4 of Cap. 318.

Ameortmeat of section 7 of Cap. 518.

Losertion of Dew soction $B s$ in Cap. 518 . 
No. 7

Foreign Investments Protecrion (Amentment) 1988

may be transferted out of Kenya under the same terms as interest under para. graph (c) of section 7; and

(ii) the capital may be transferred out of Kenya at the end of five years on the same terms as other funds in the manner providod for under soction 7. 


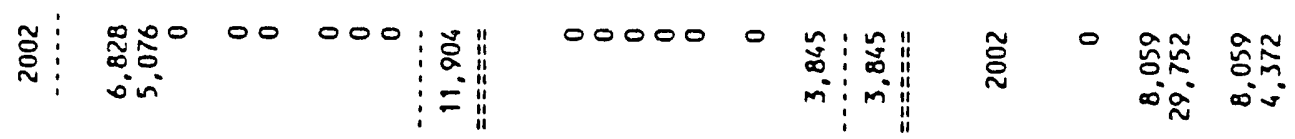

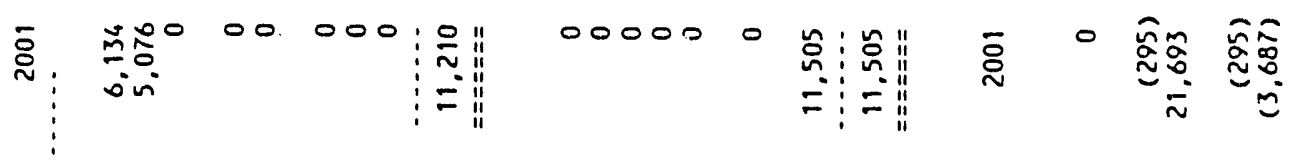

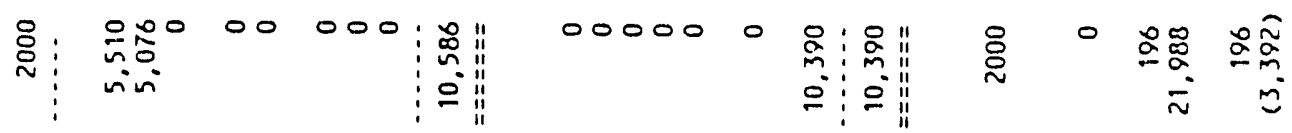

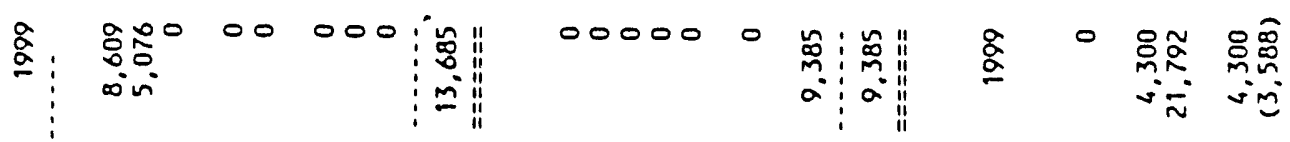

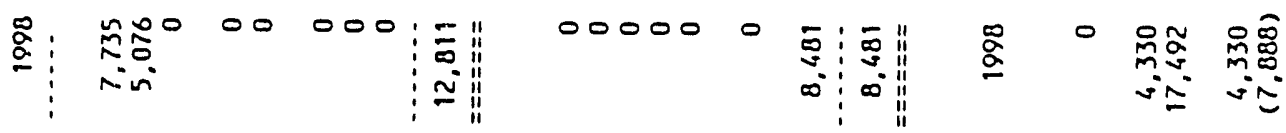

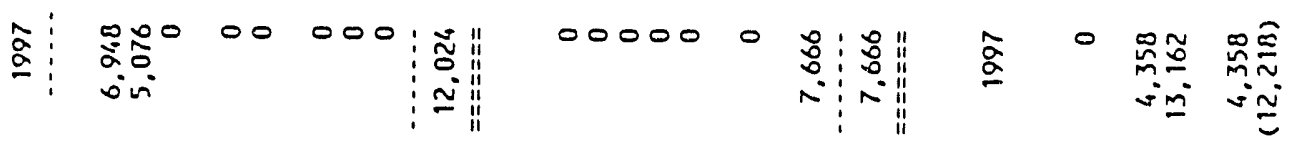

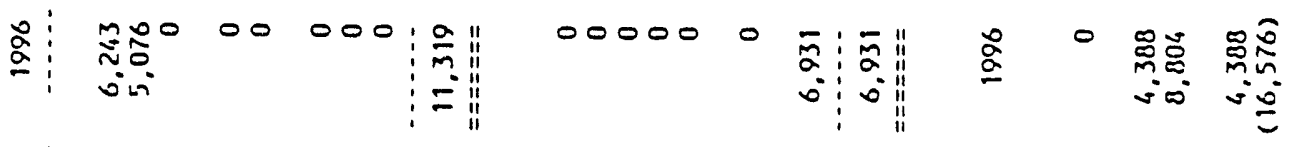

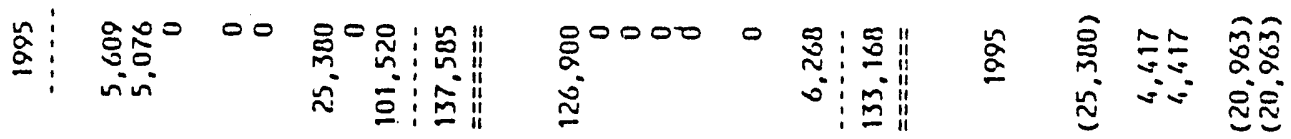

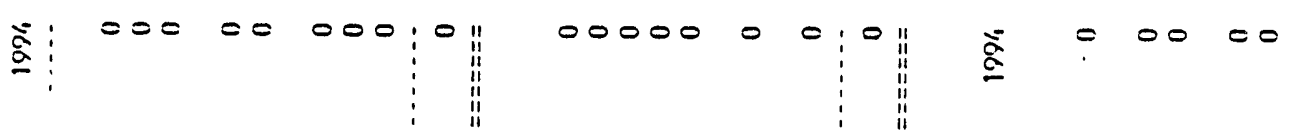

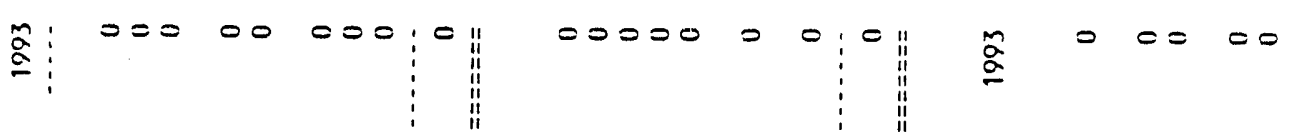

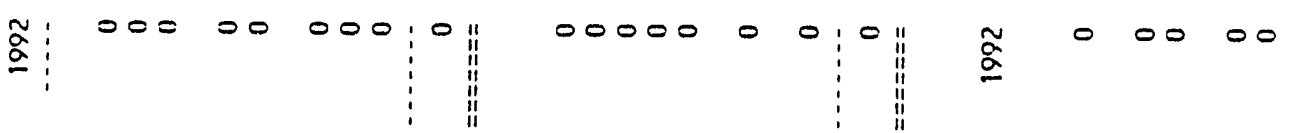

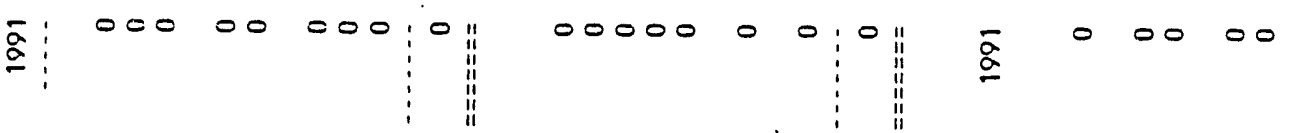

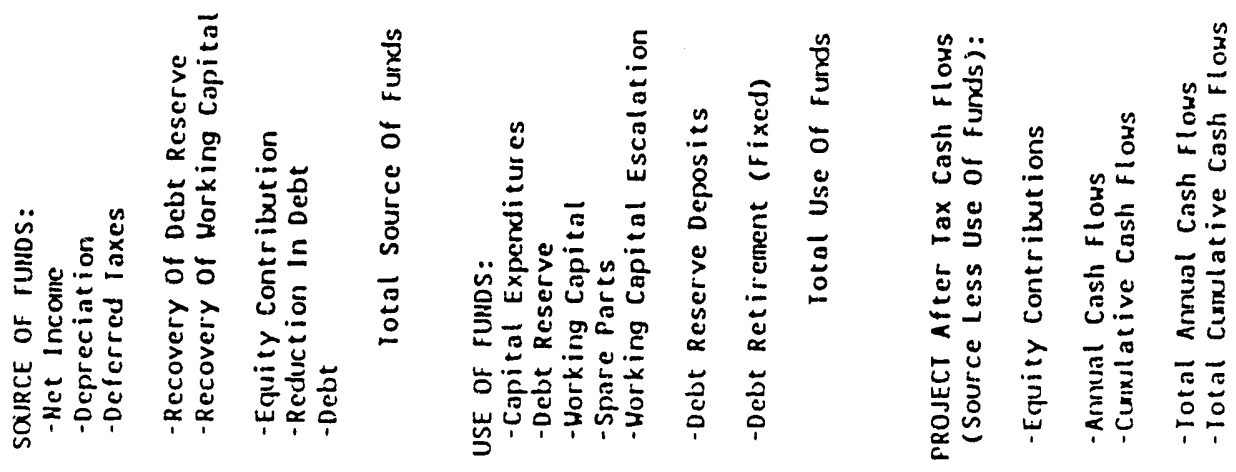




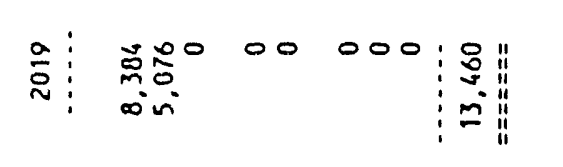

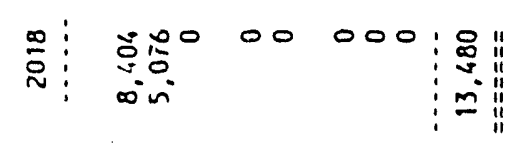

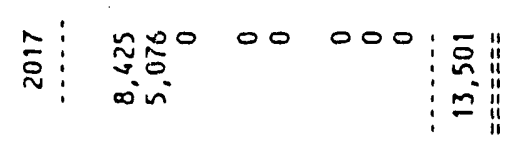

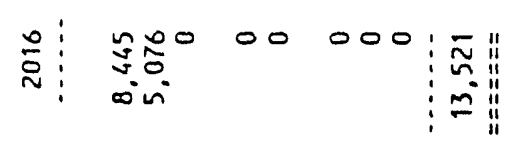

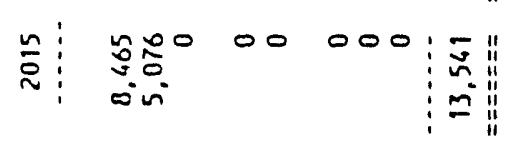

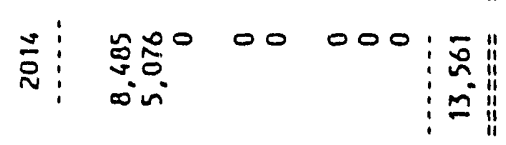

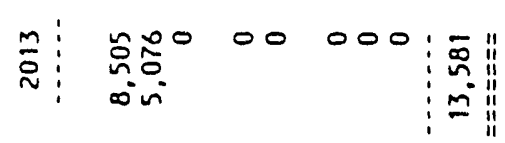

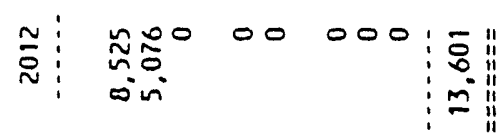

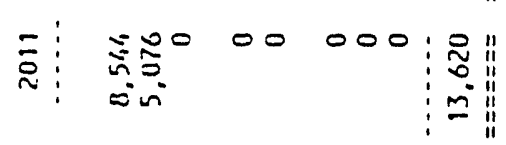

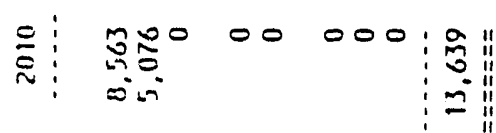

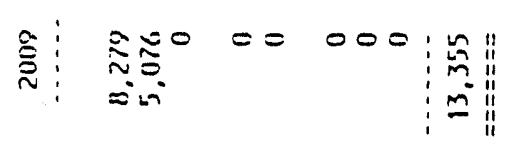

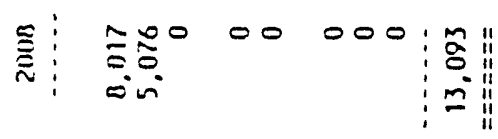

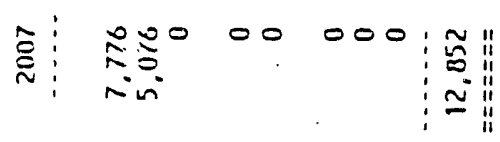

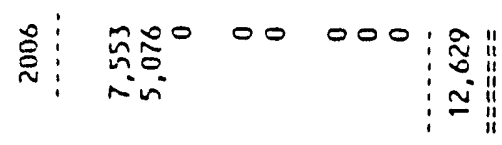

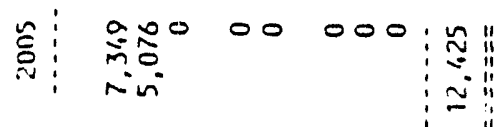

雚

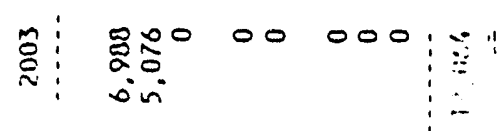

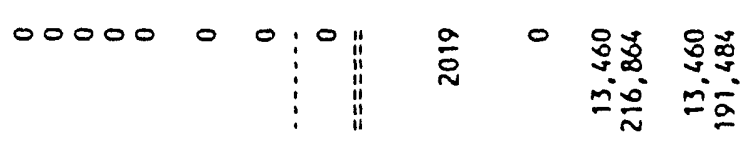

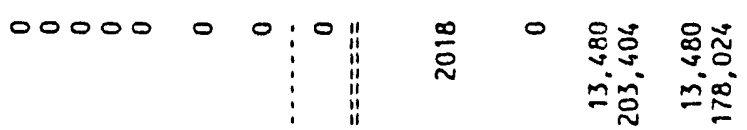

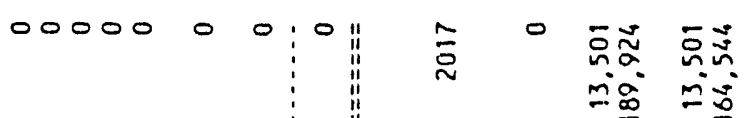

$0000000.011000 \%$

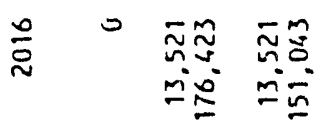

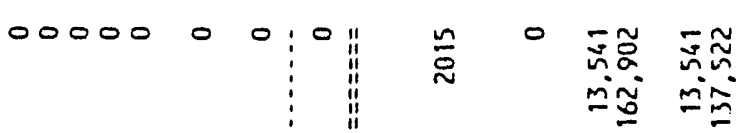

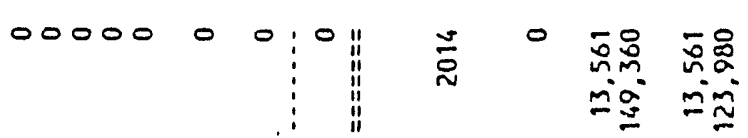

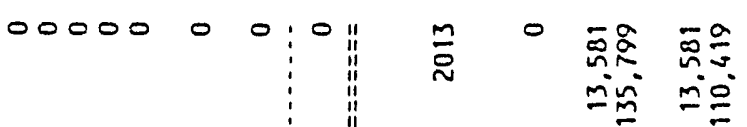

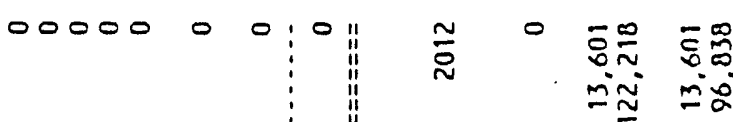

0000000.011

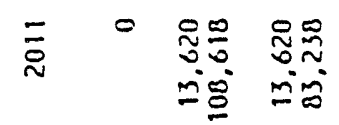

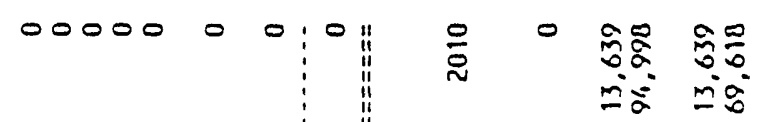

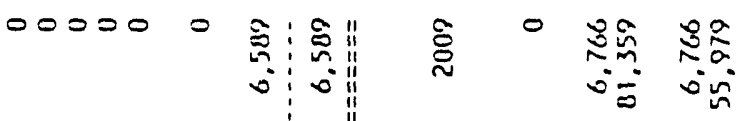

00000 o

00000 o

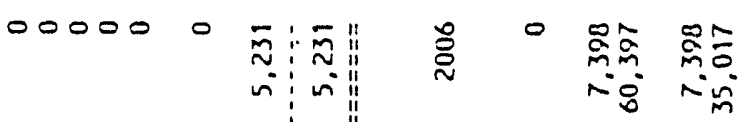

00000 0 m:

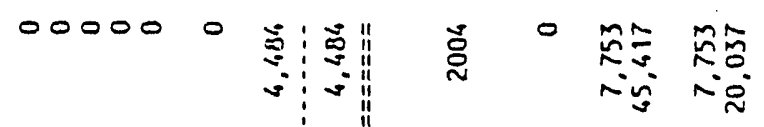

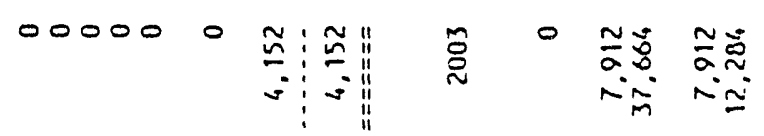



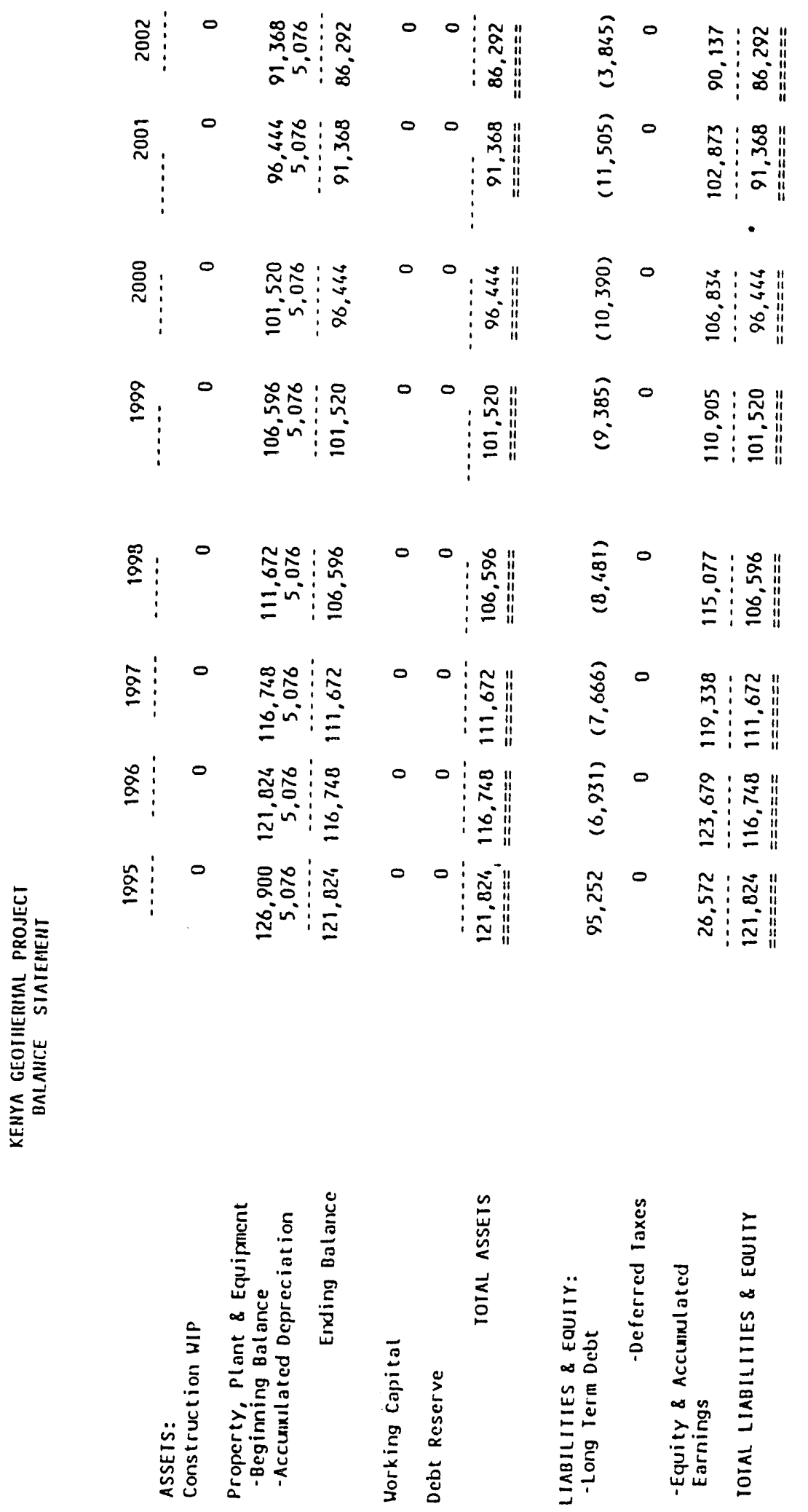


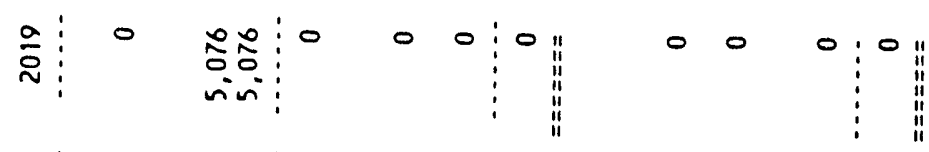

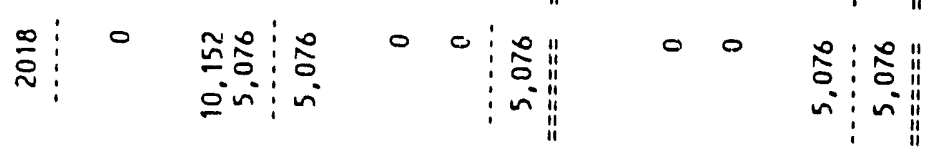

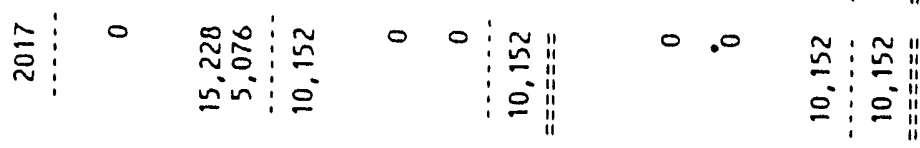

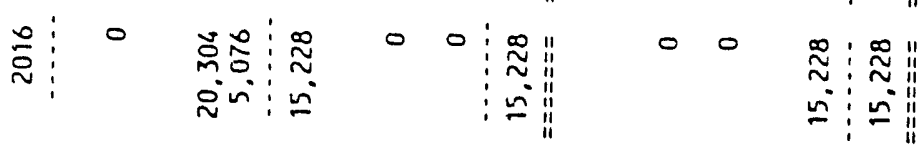

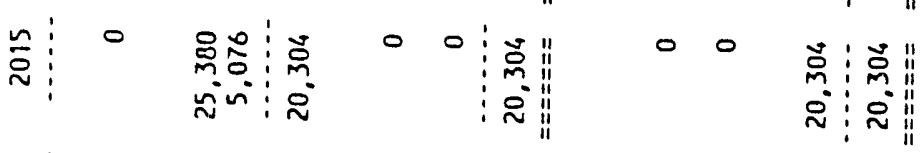

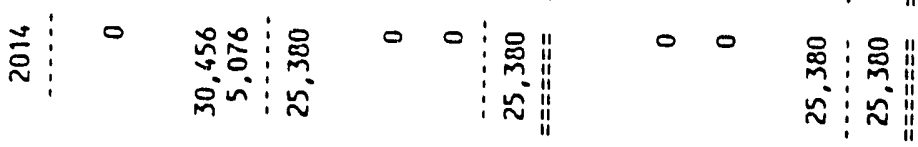

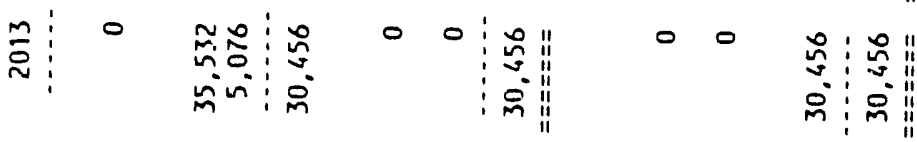

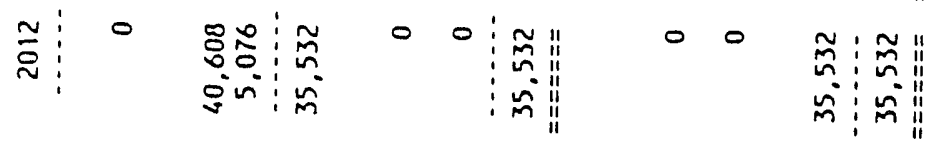

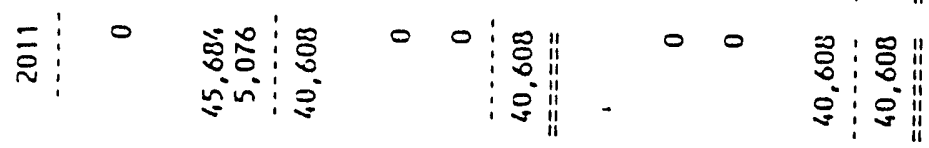

$$
\begin{aligned}
& \text { 东 } \\
& \text { 总 } \\
& \text { 玩 }
\end{aligned}
$$

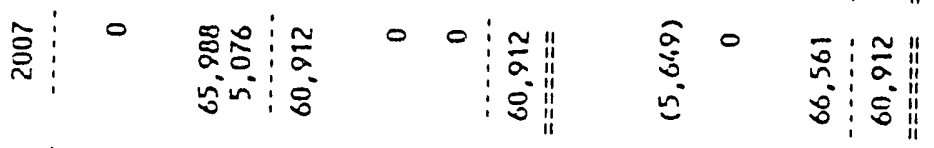

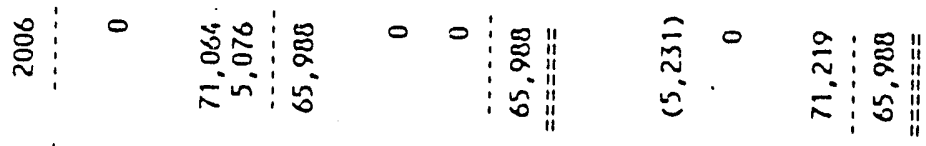

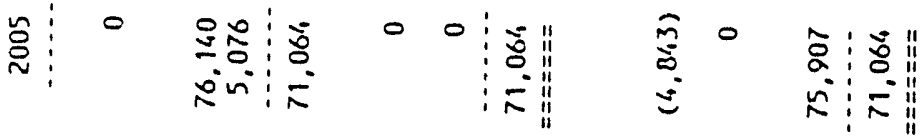

$$
\begin{aligned}
& \text { 总 }
\end{aligned}
$$

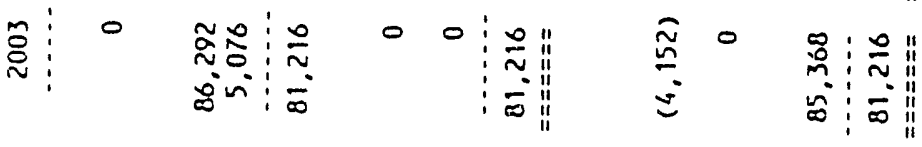




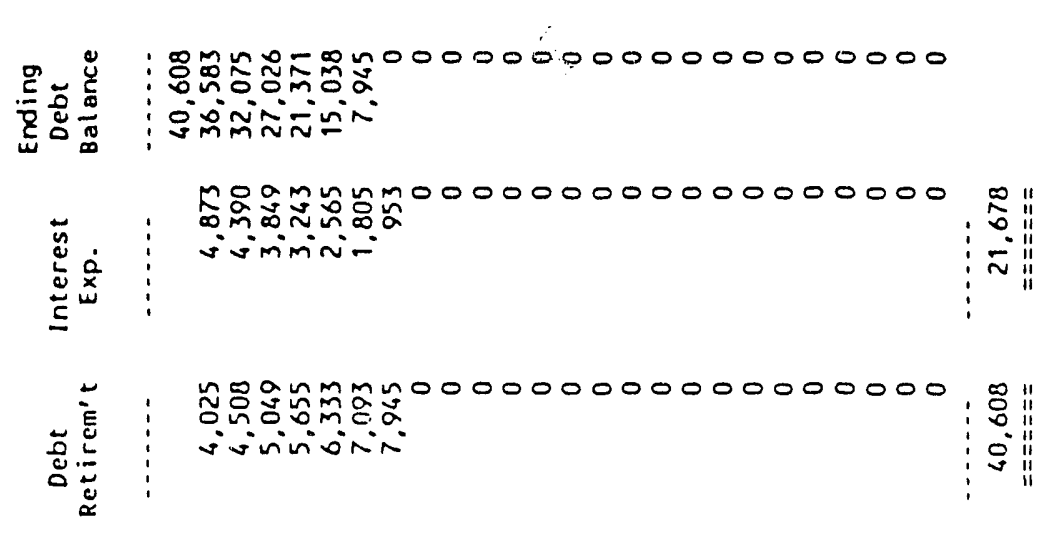

:

过苍造

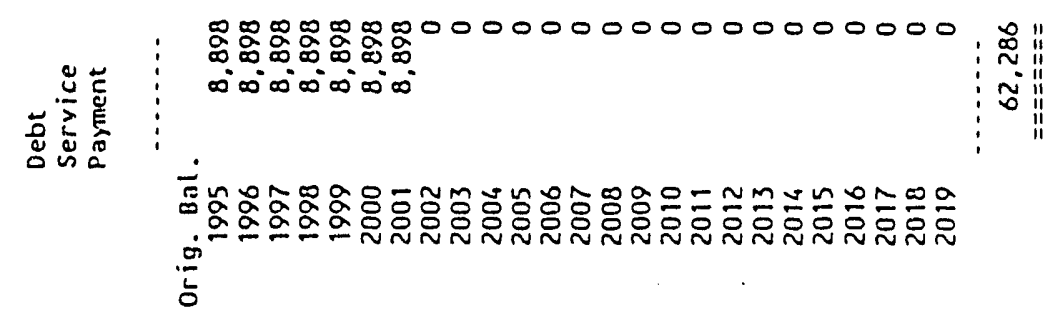

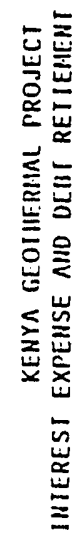
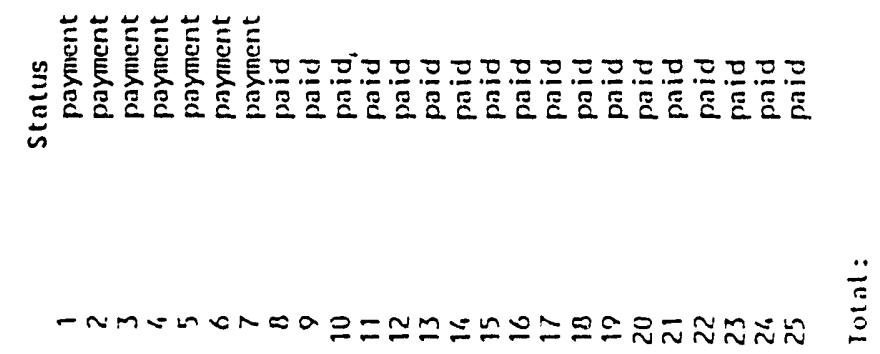

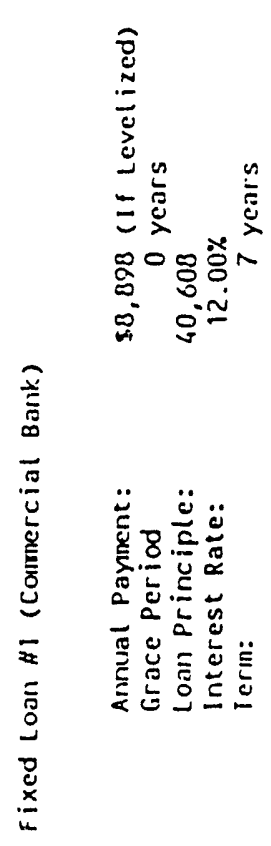

Appendix IV - 5 


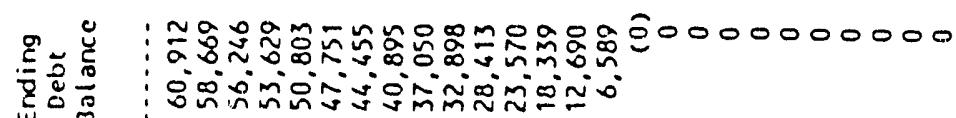

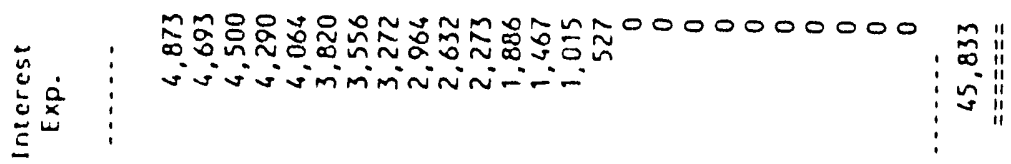

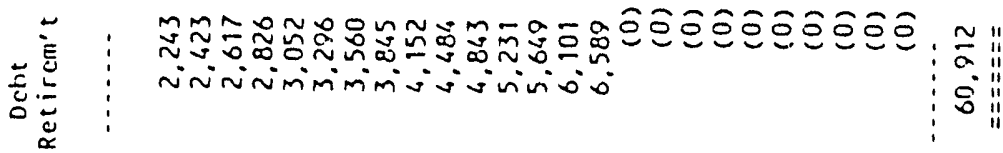

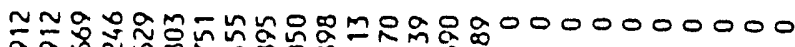

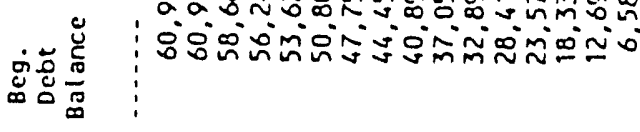
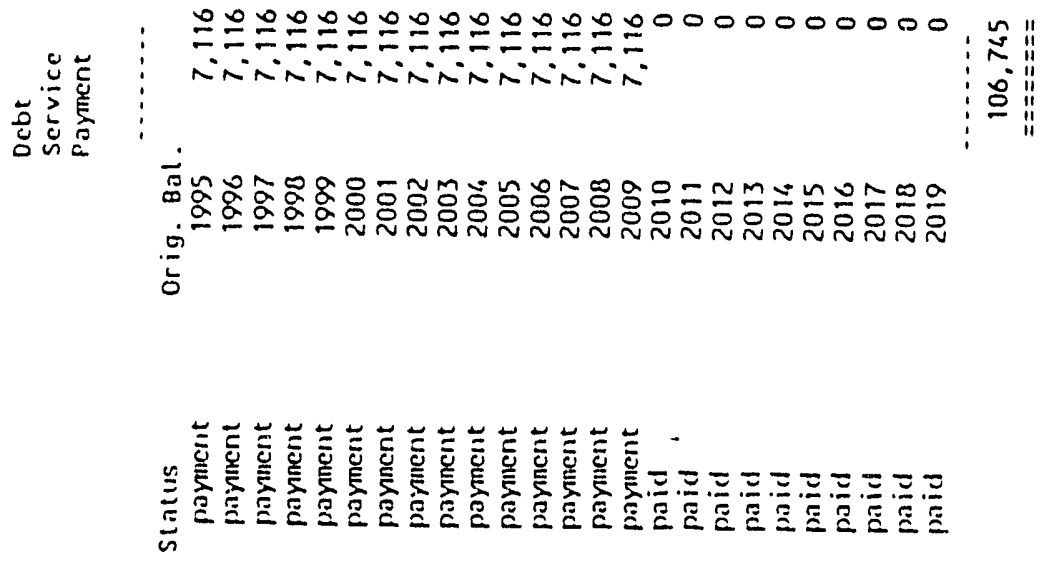

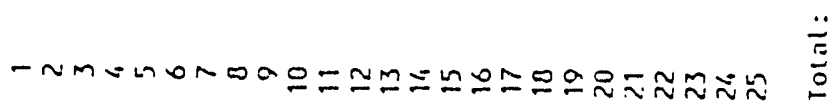
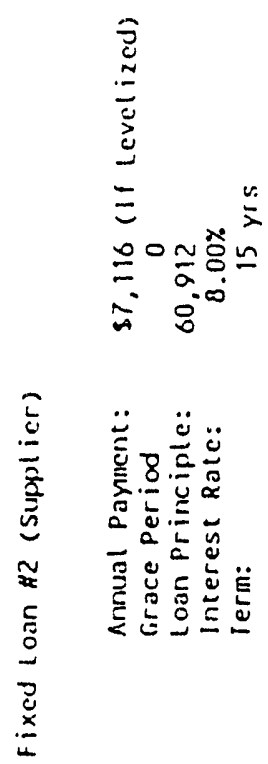

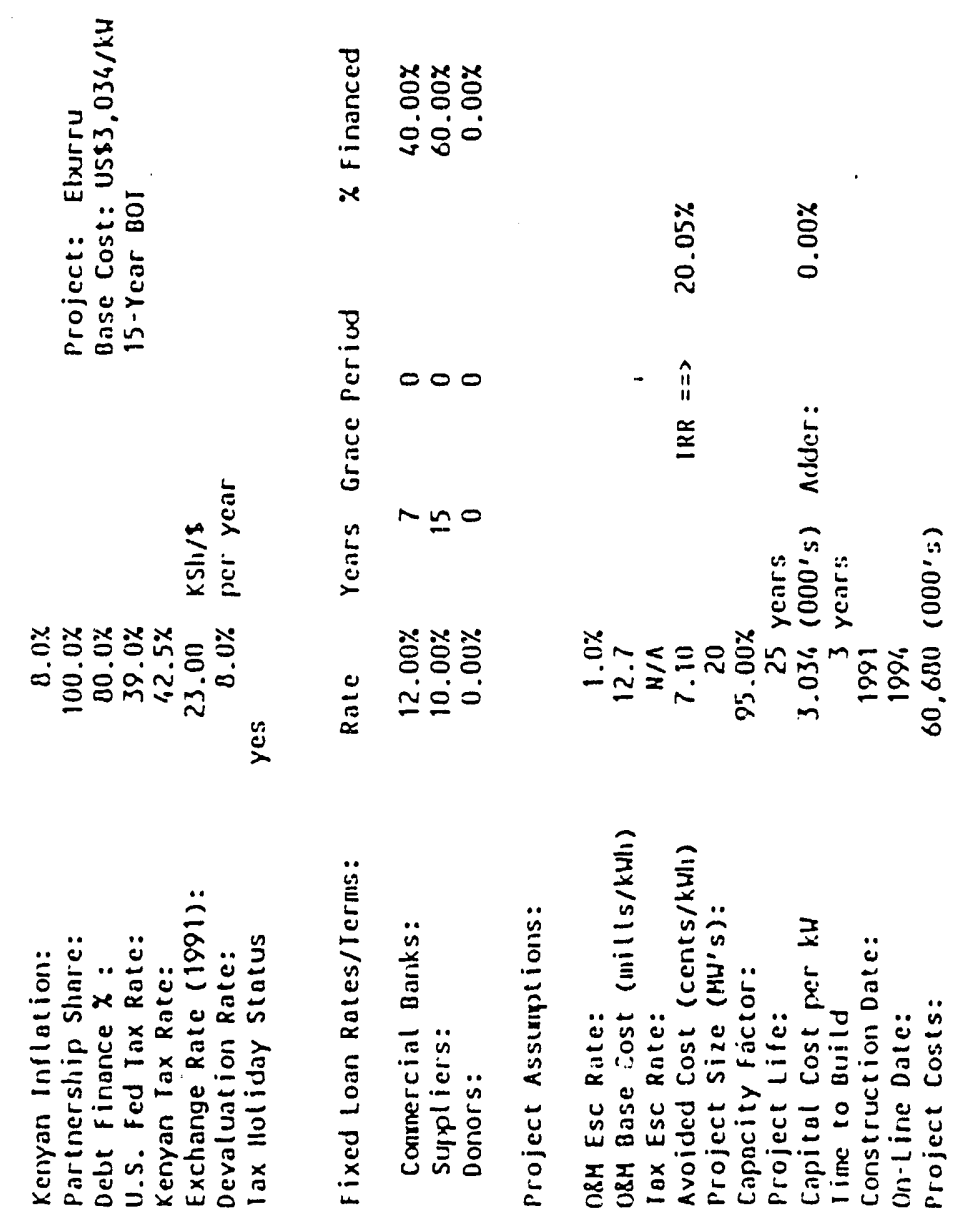


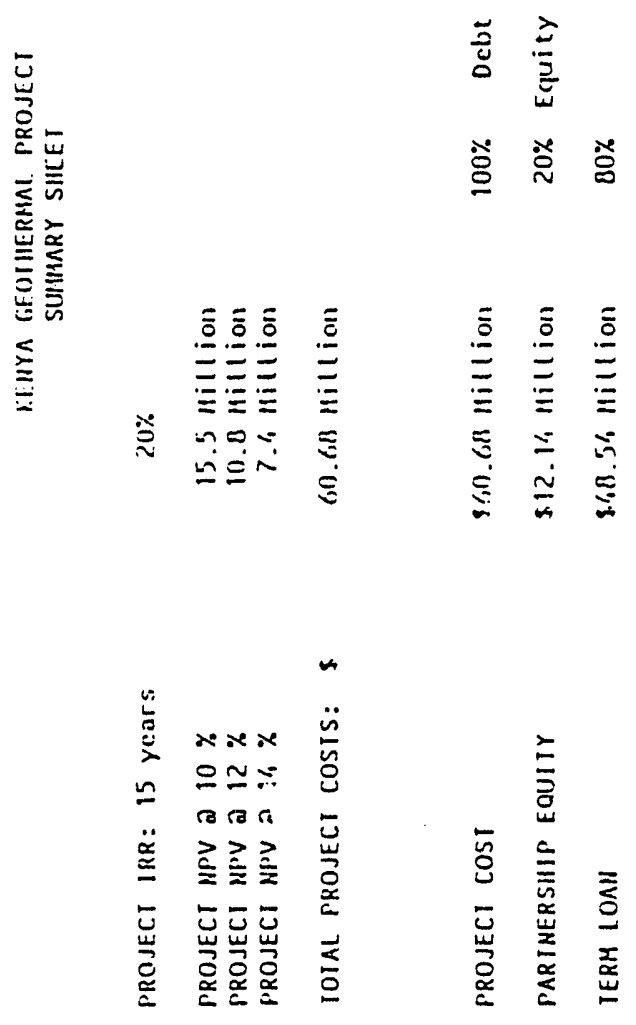

Appendix IV - 8 


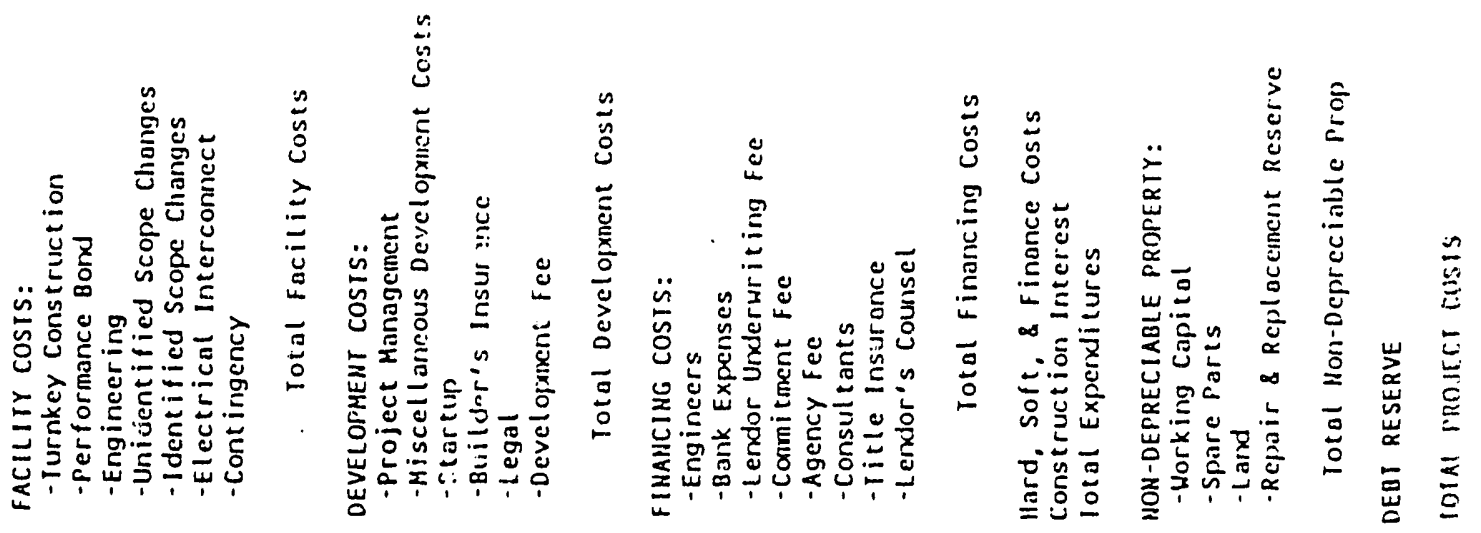




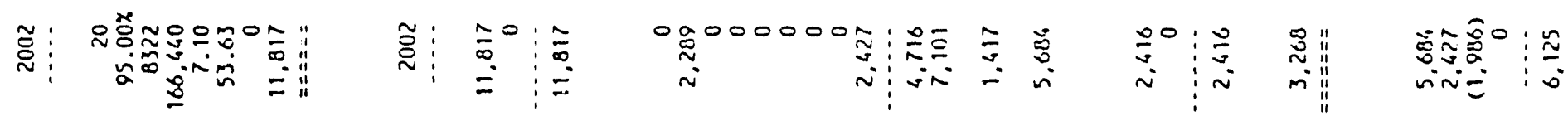

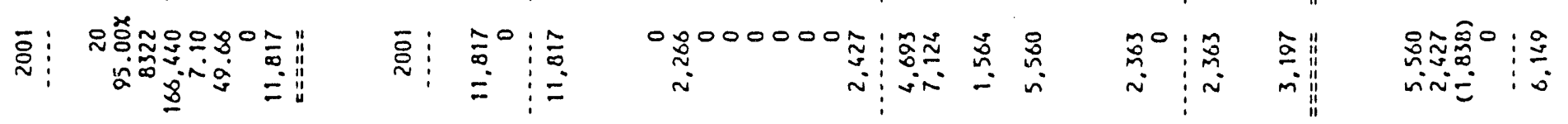

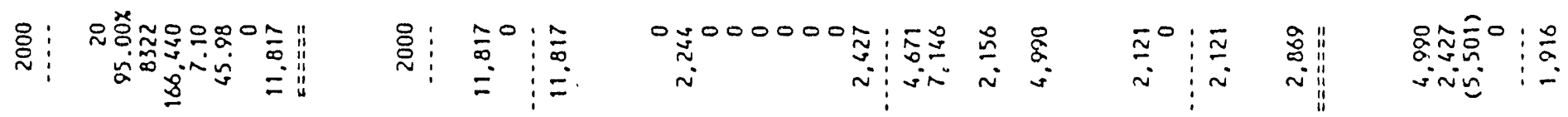

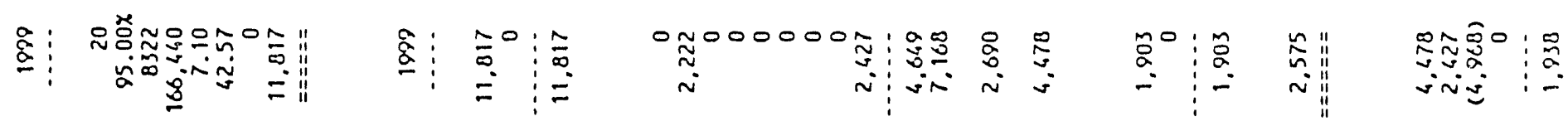

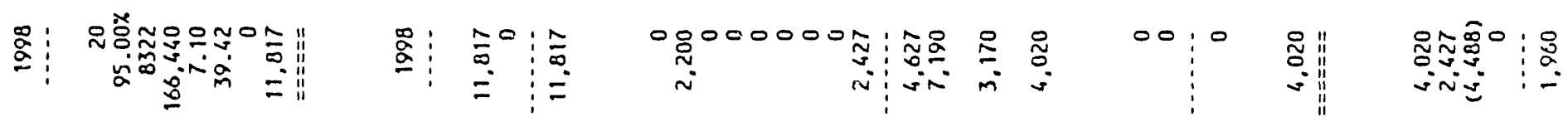

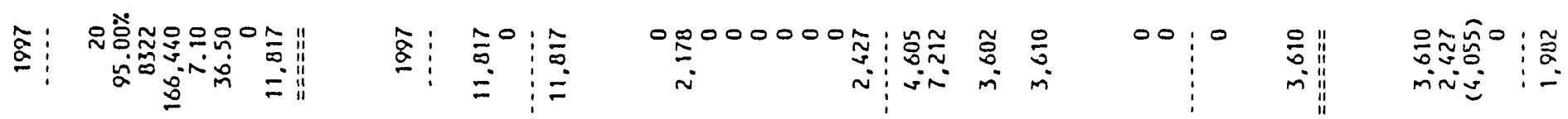

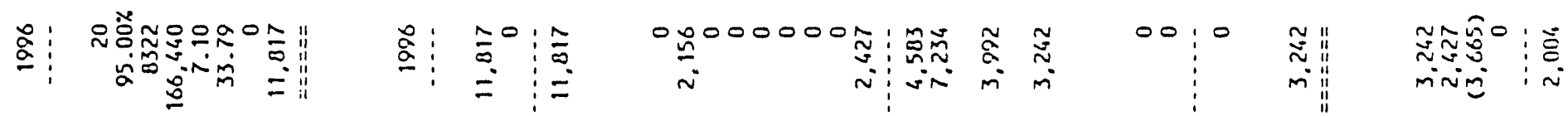

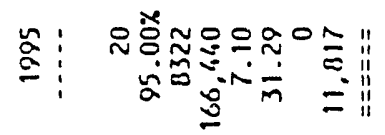

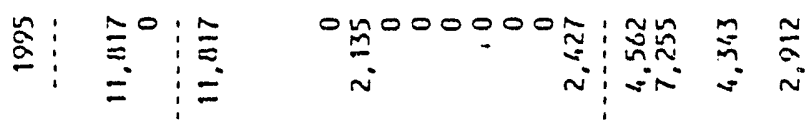

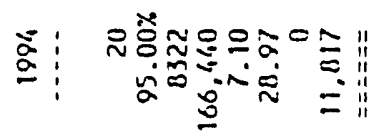

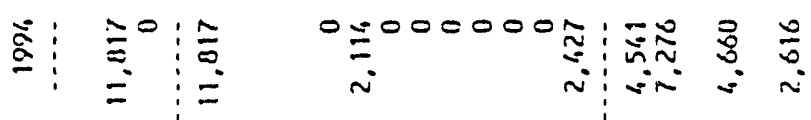
$\infty 0: 0 \quad \simeq$

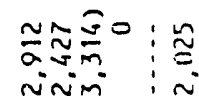

ڤ: $\quad 00000 \cong 00 \|$

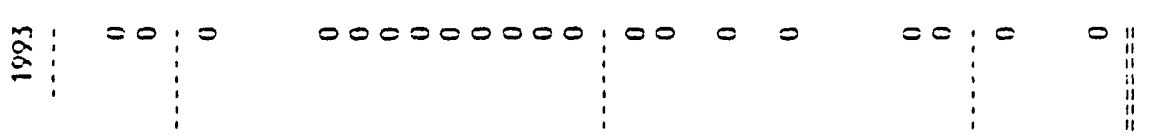

$\approx 00000 \ddot{E}^{0}=0$

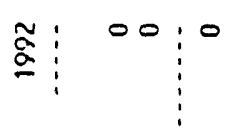

$0000000001000=$

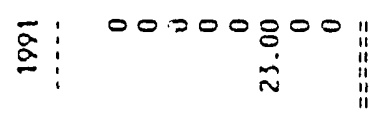

$\bar{\Sigma}: \quad 00: 0$

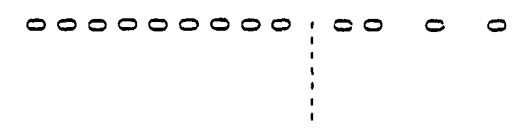

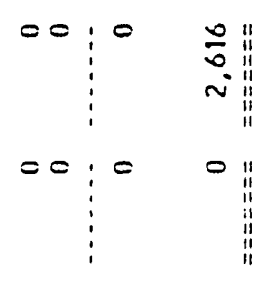

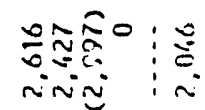
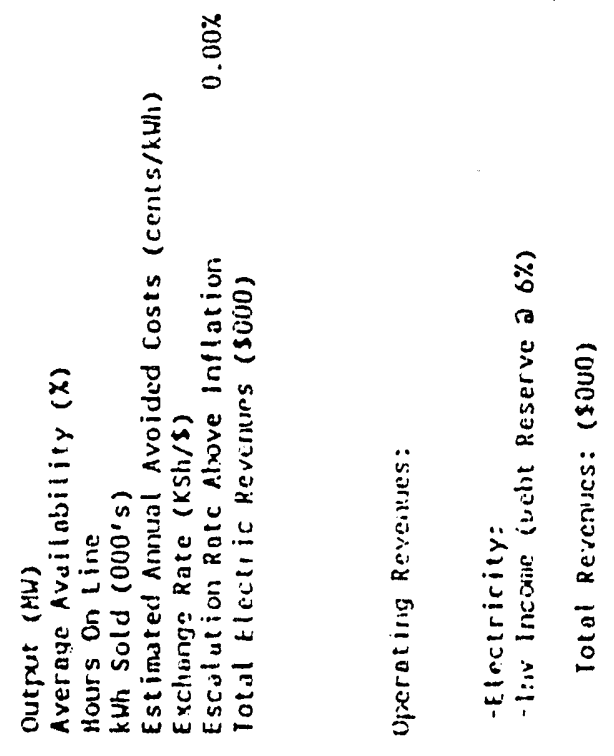

ํㅜㅇ
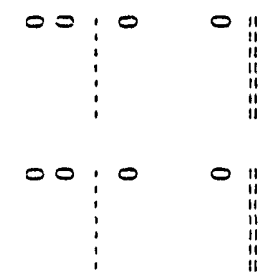


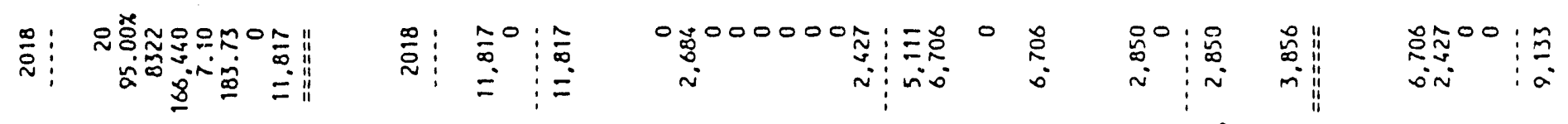

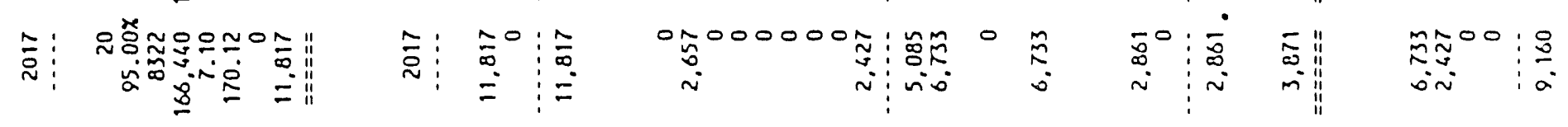

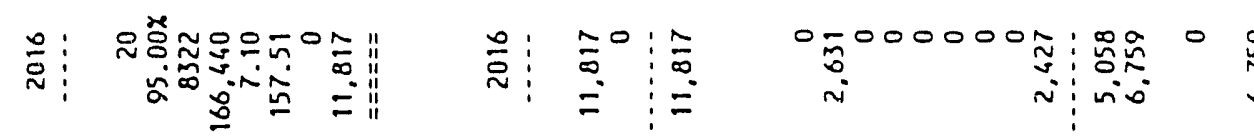

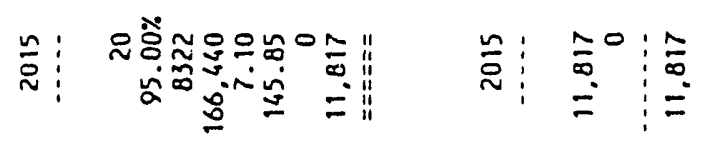

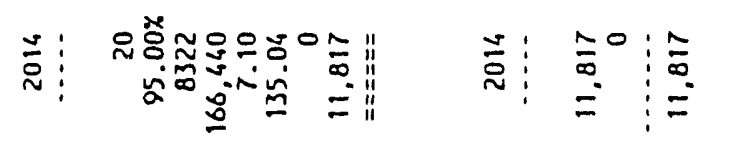

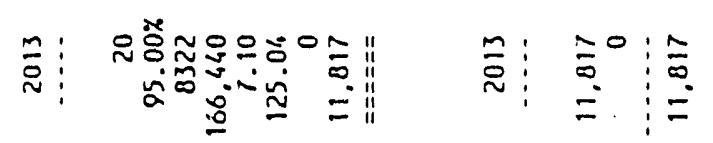

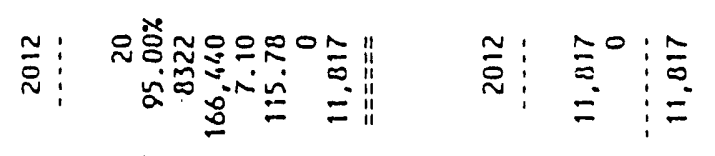

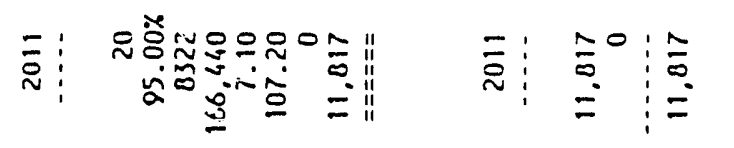

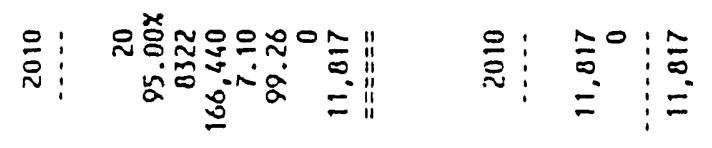

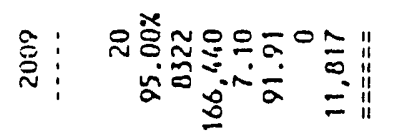

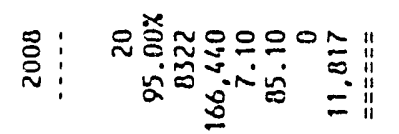

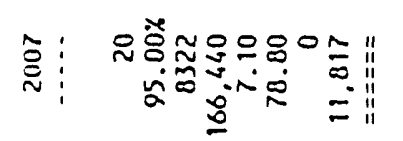

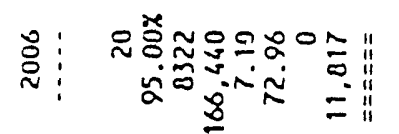

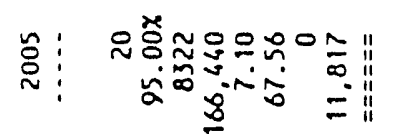

亮:

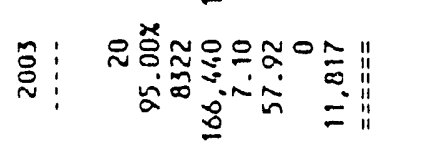

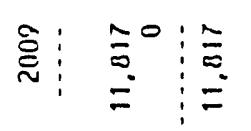

密:

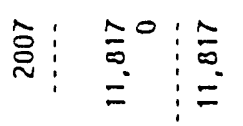

雚:

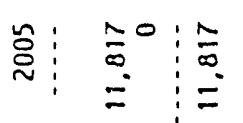

总:

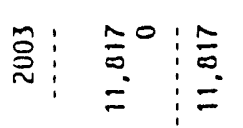

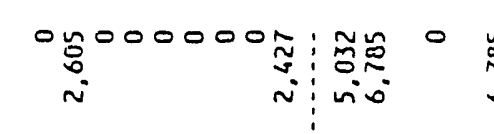

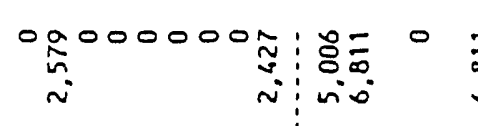

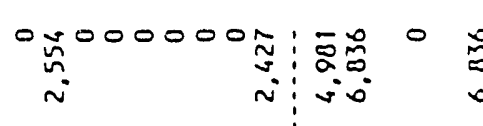

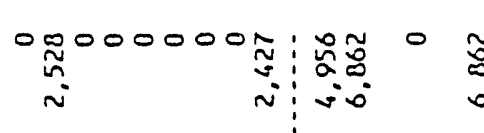

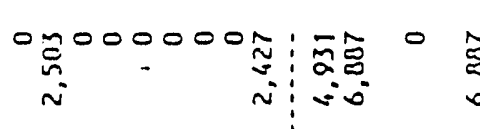

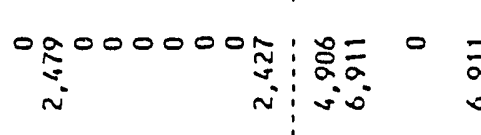

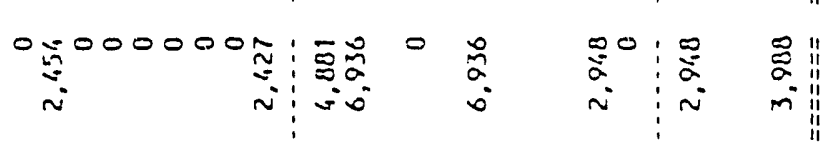

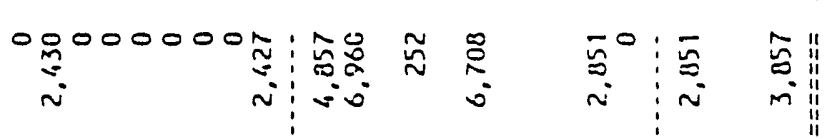

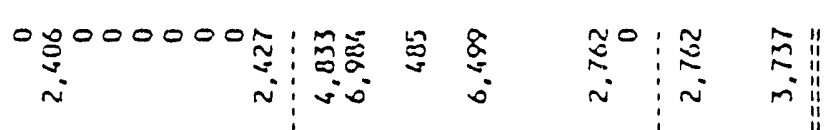

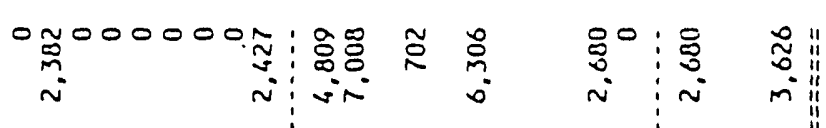

总000000空:

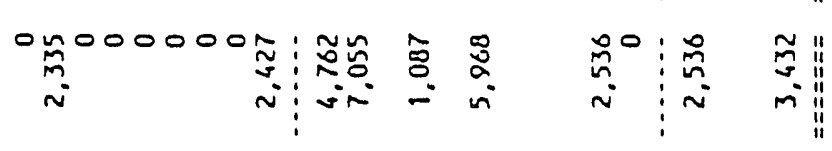

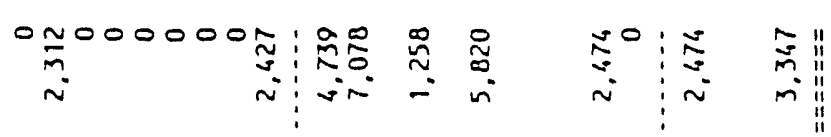

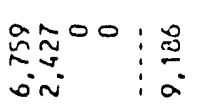

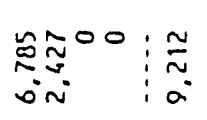

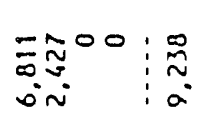

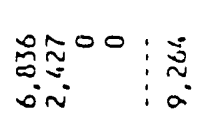

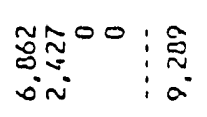

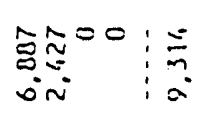

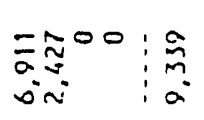

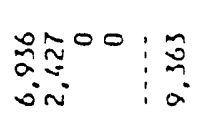

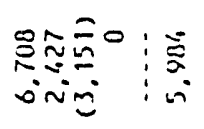

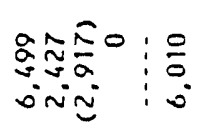

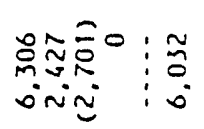

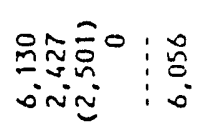

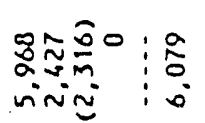

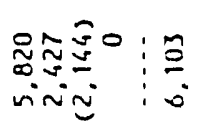




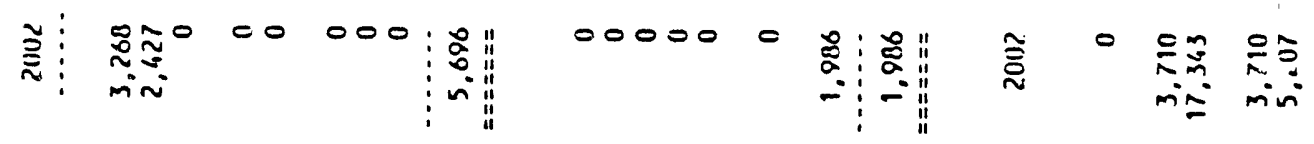

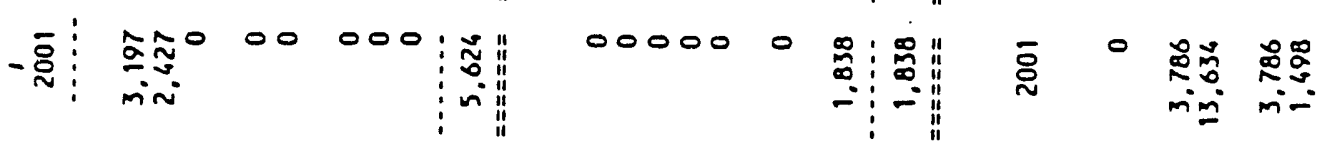

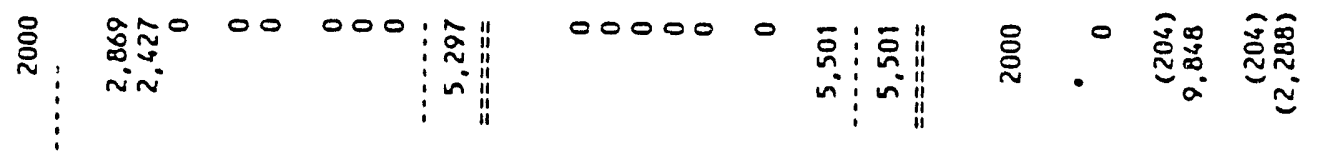

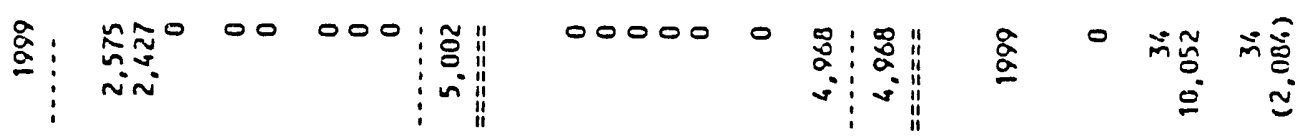

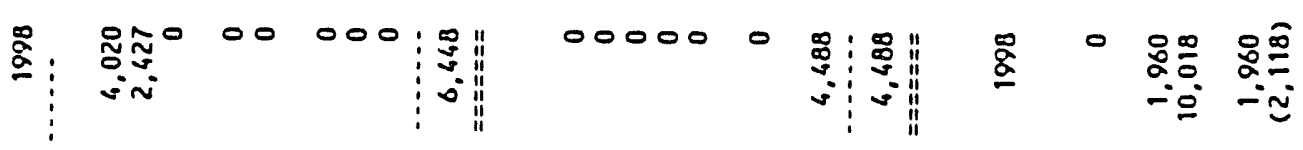

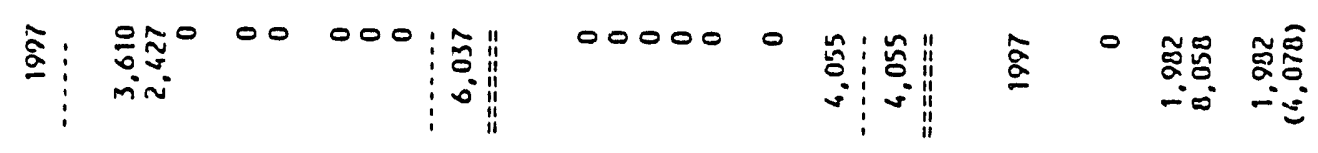

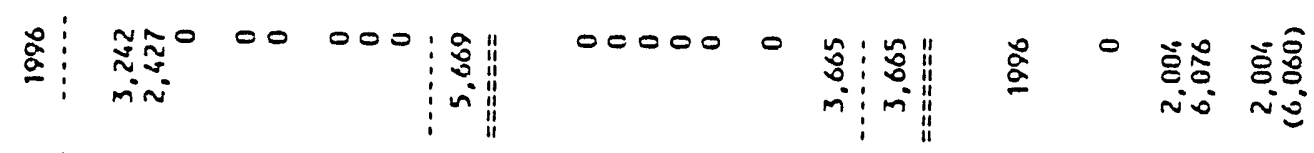

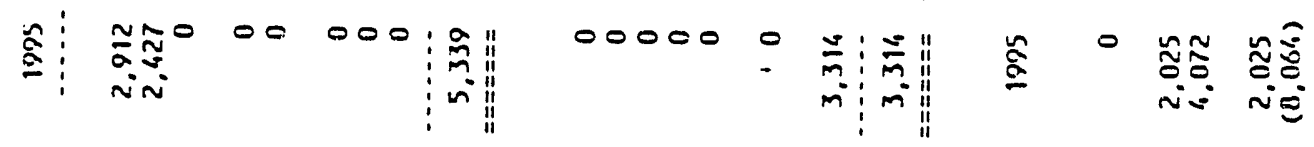

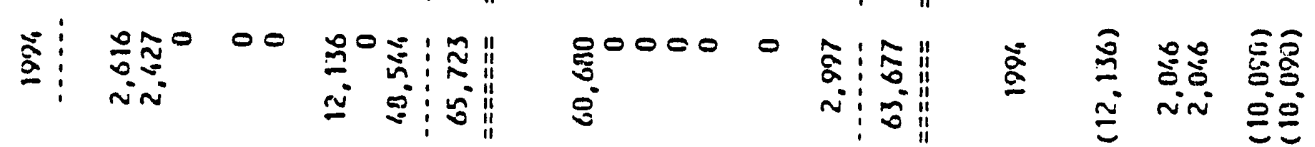

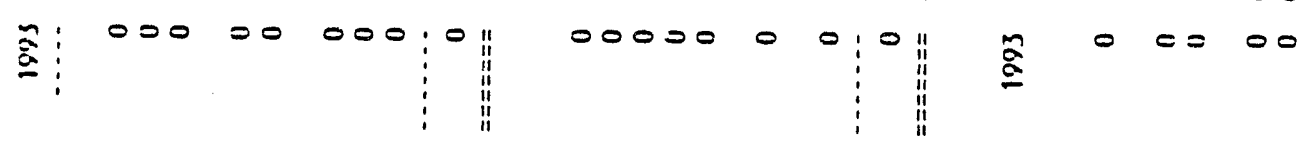

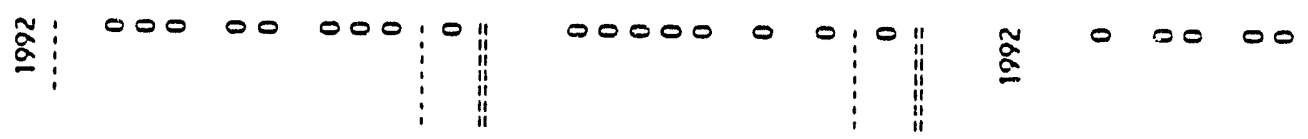

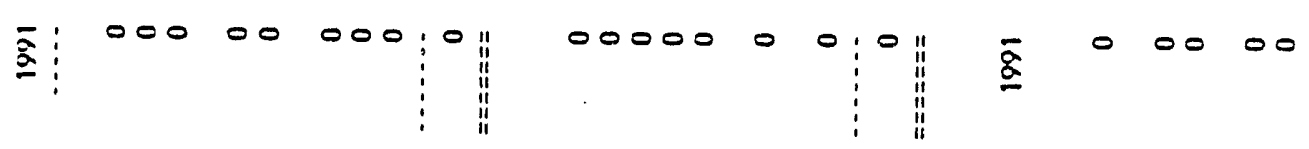

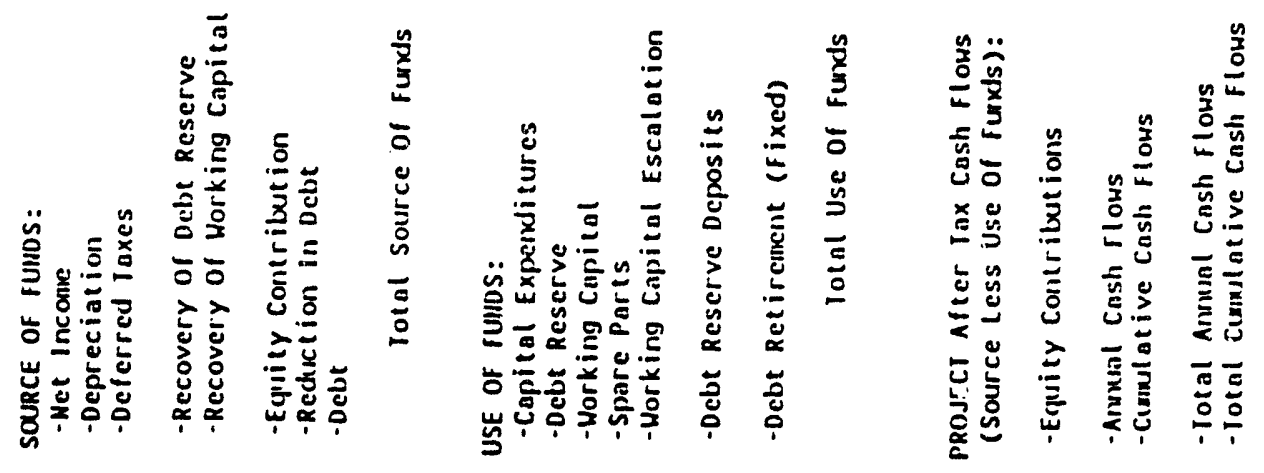




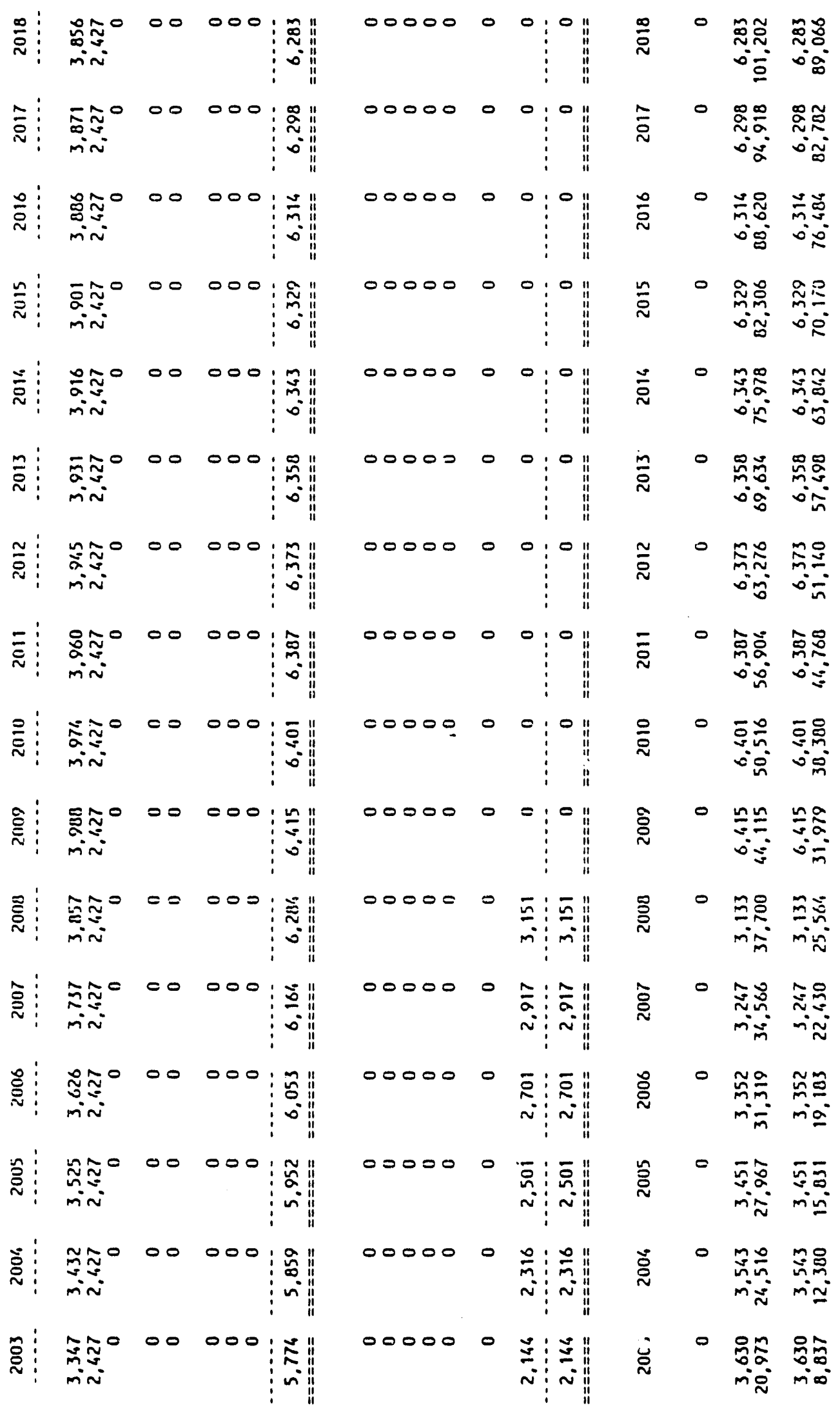




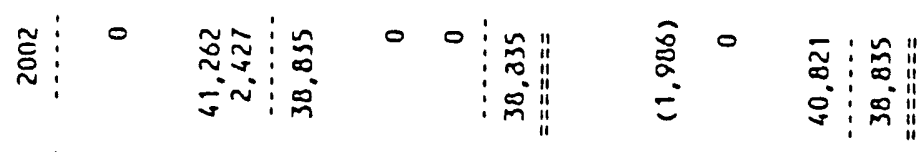

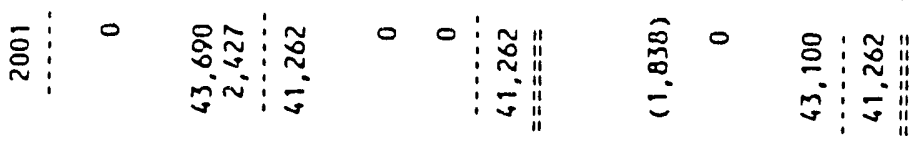

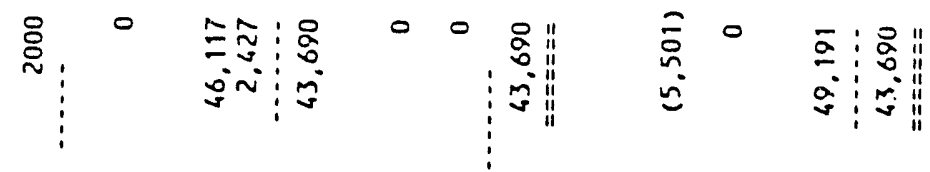

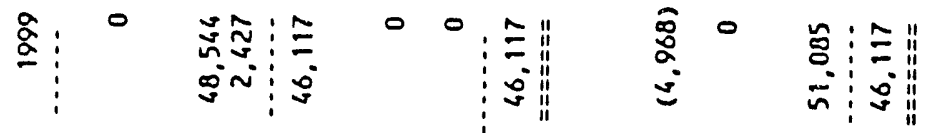

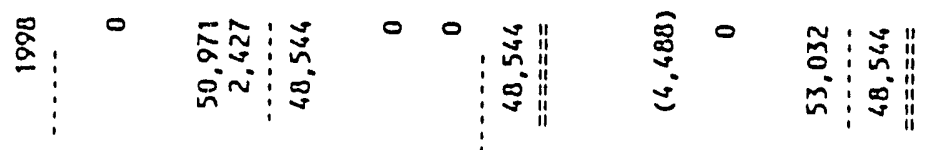

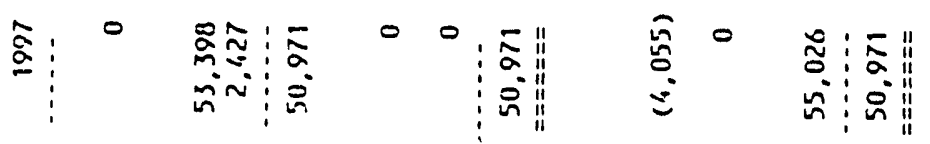

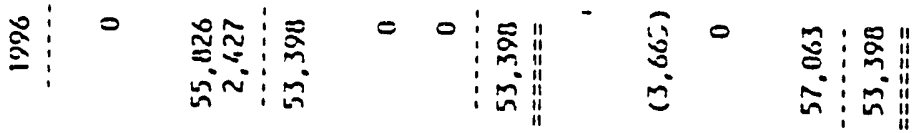

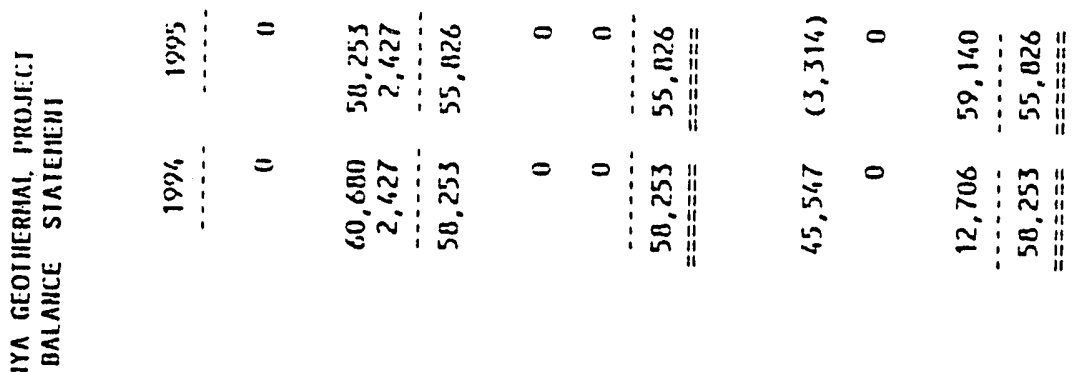

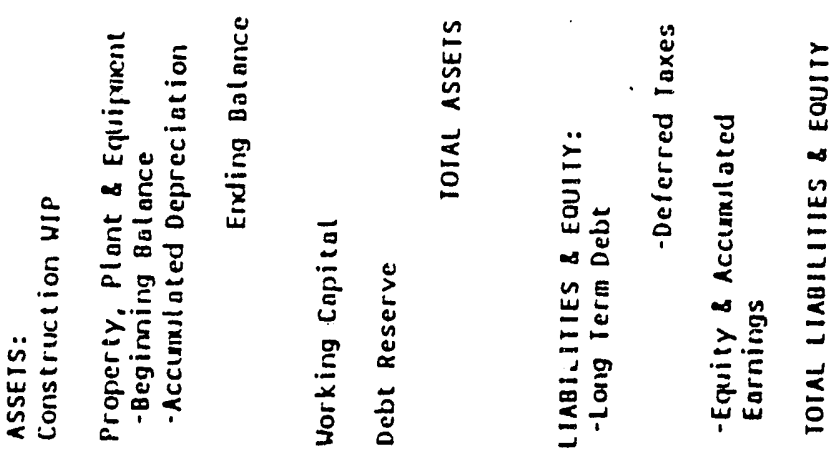




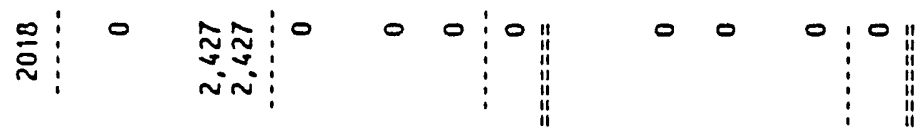

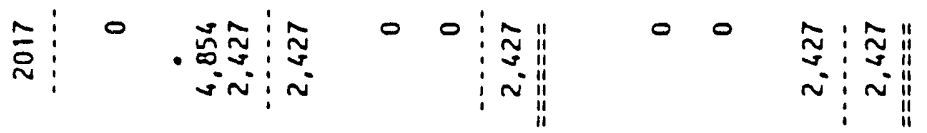

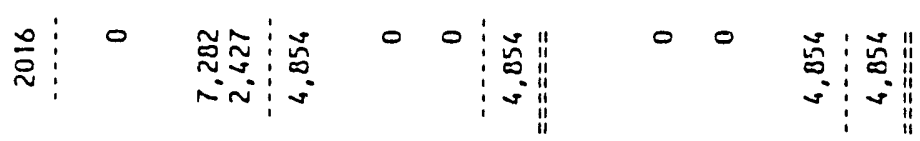

$$
\begin{aligned}
& \text { 立 }
\end{aligned}
$$

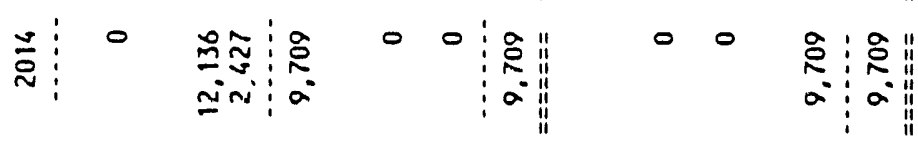

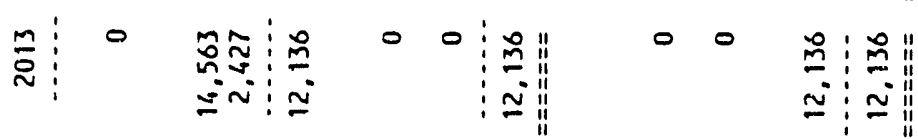

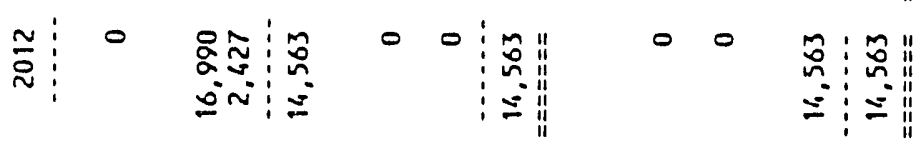

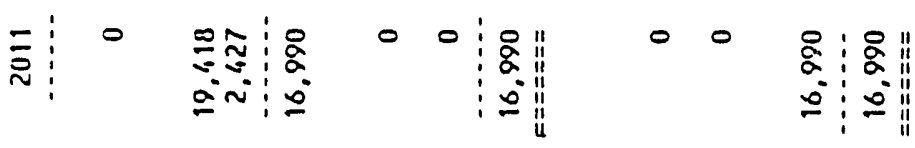

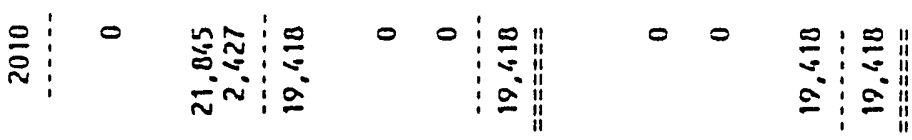

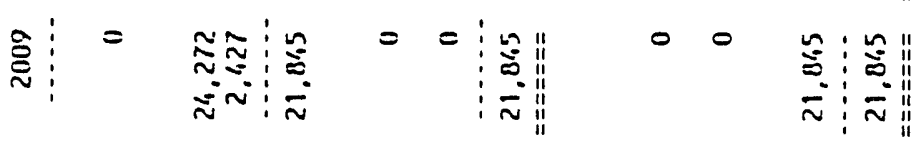

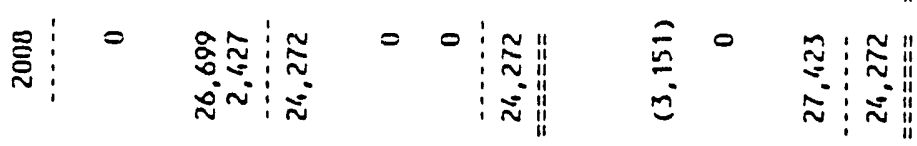

$$
\begin{aligned}
& \text { 立 }
\end{aligned}
$$

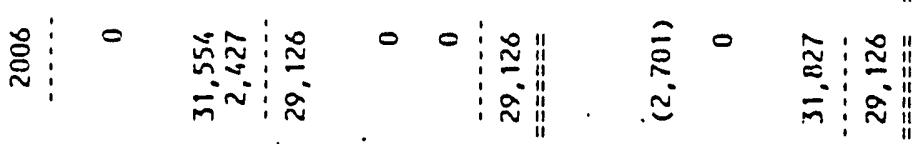

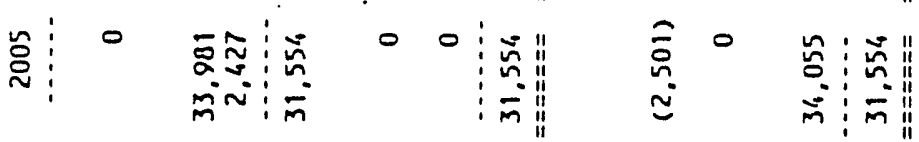

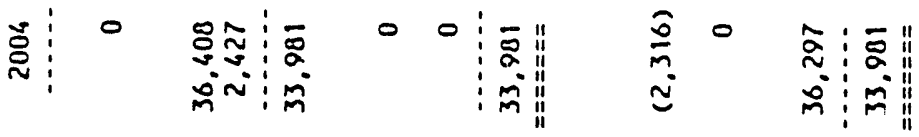

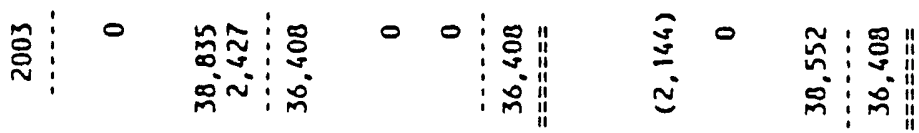




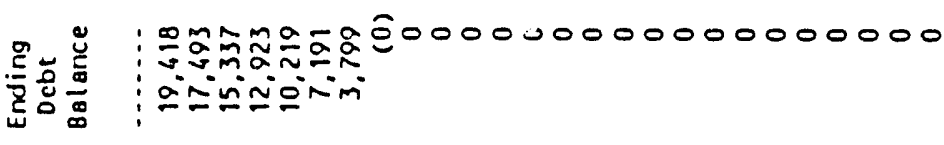

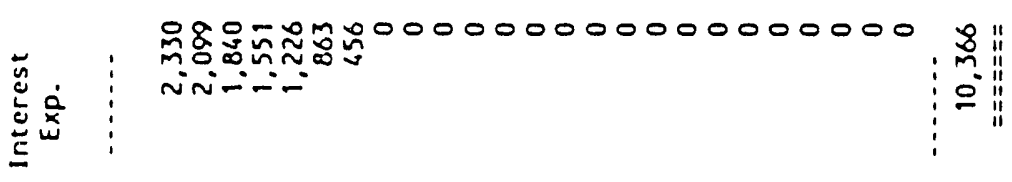

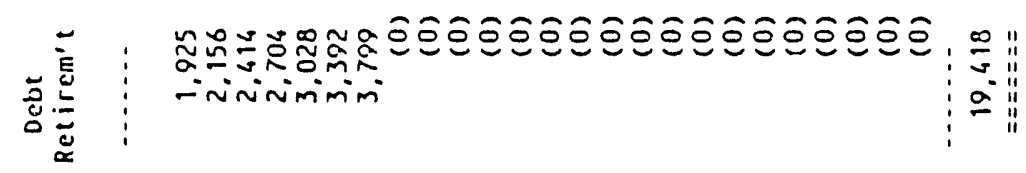

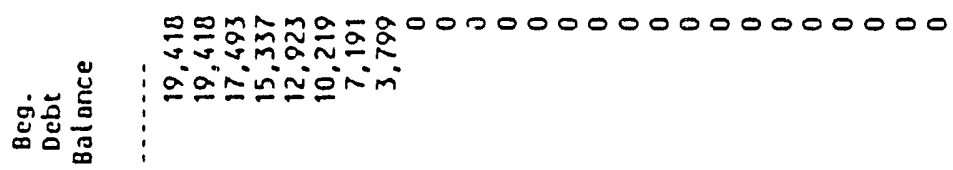

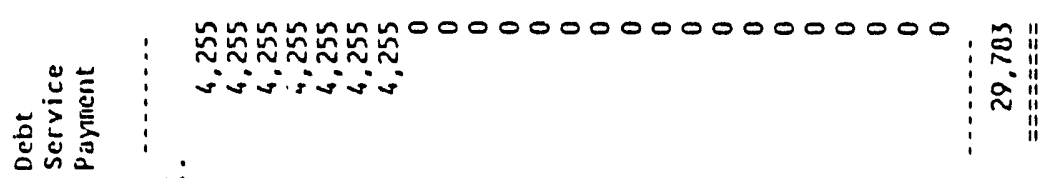

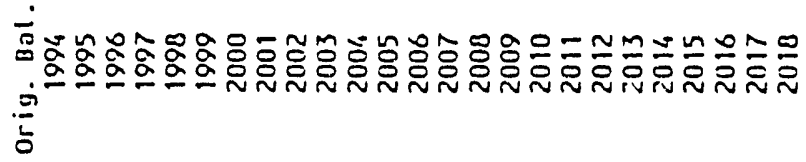

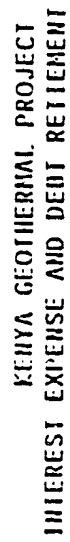
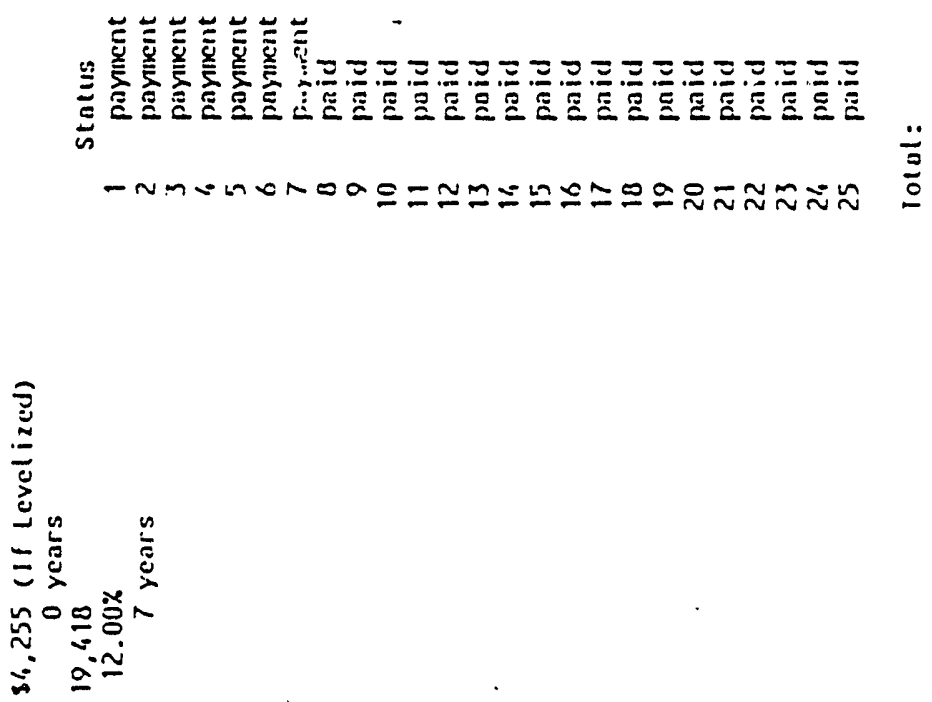

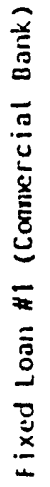

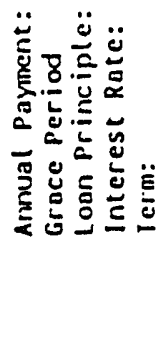

Appendix IV - 16 


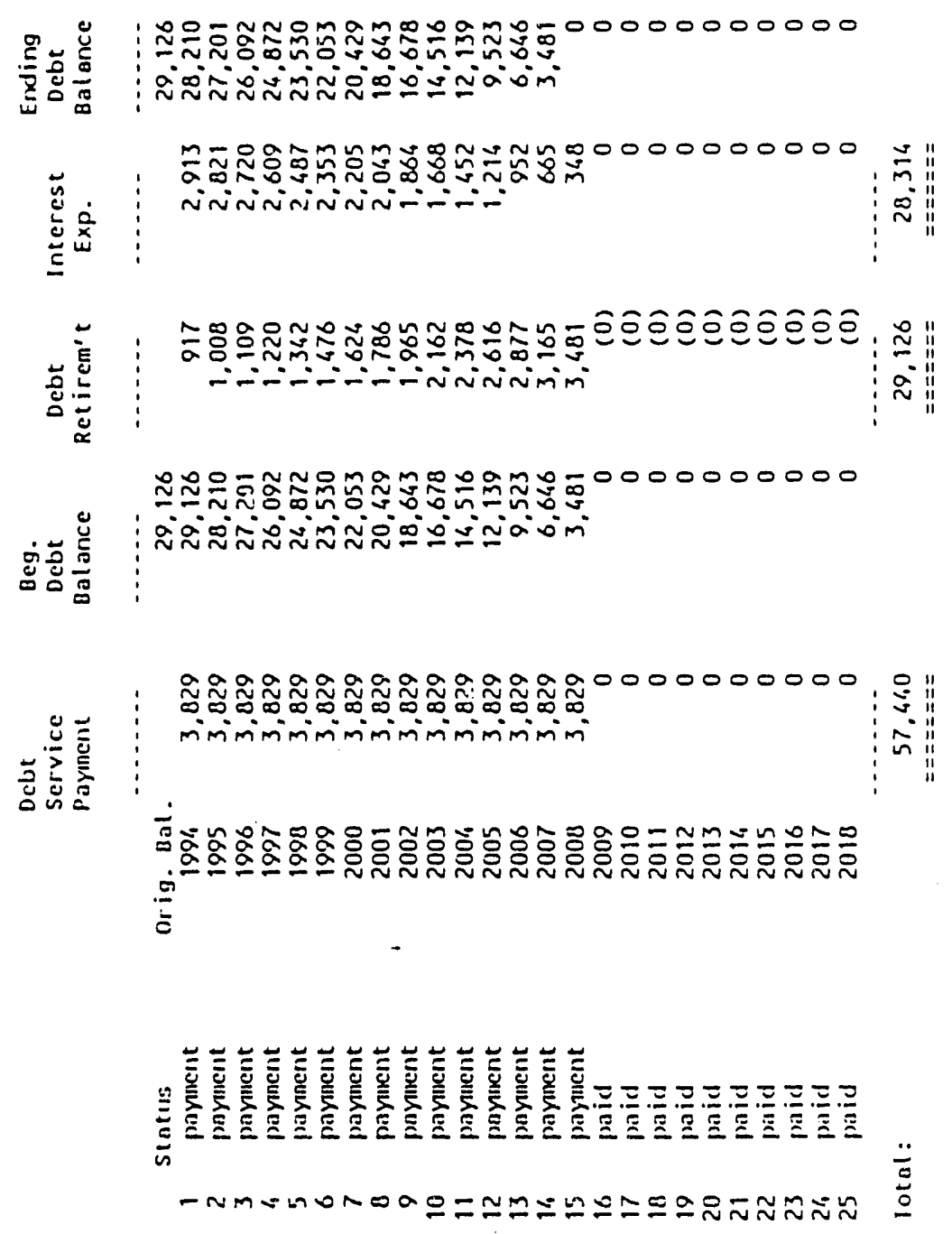

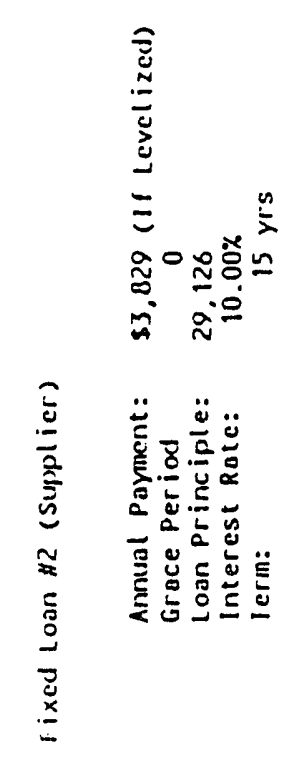



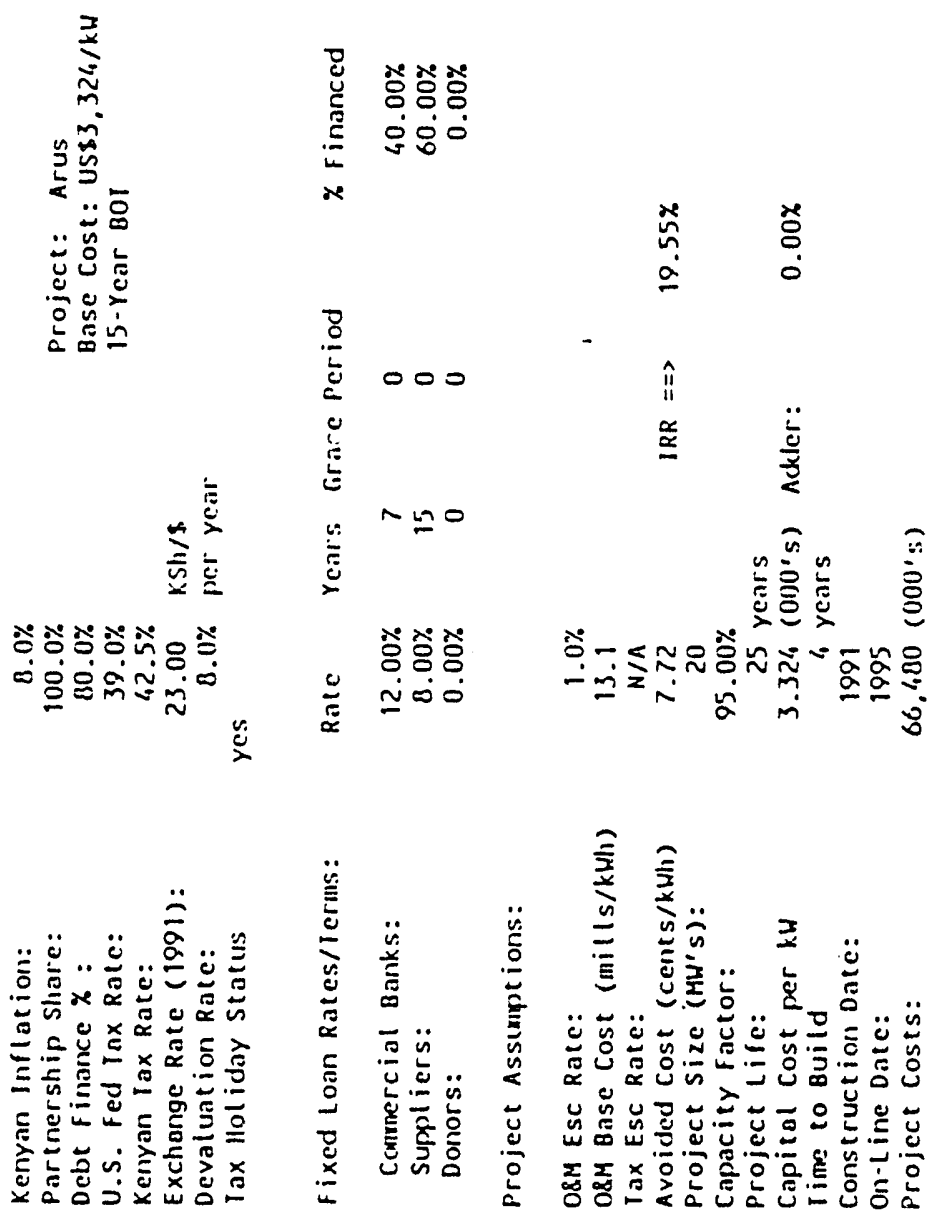

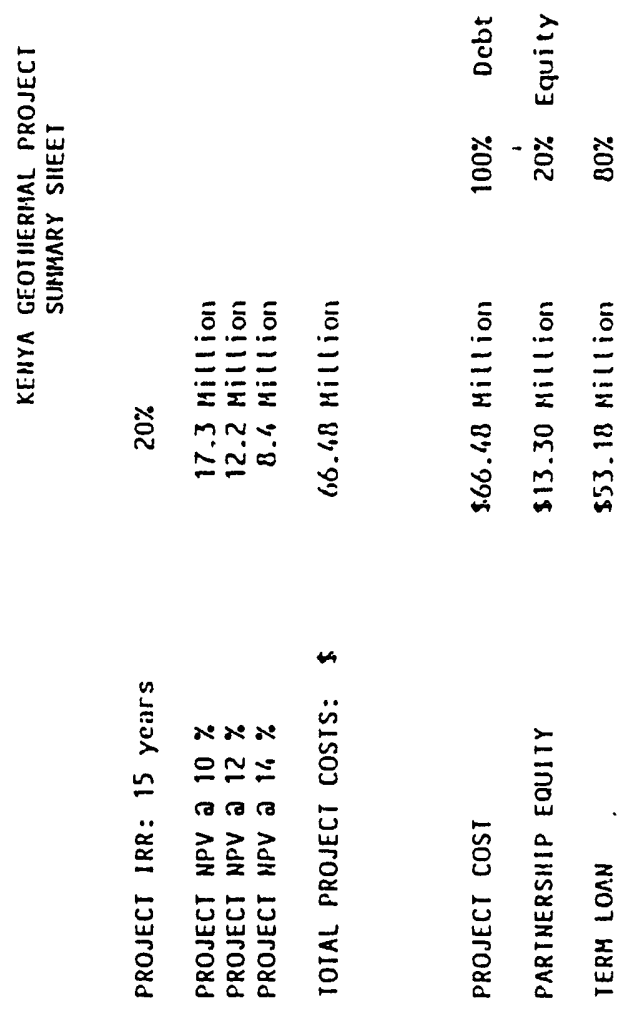

Appendix IV - 19 


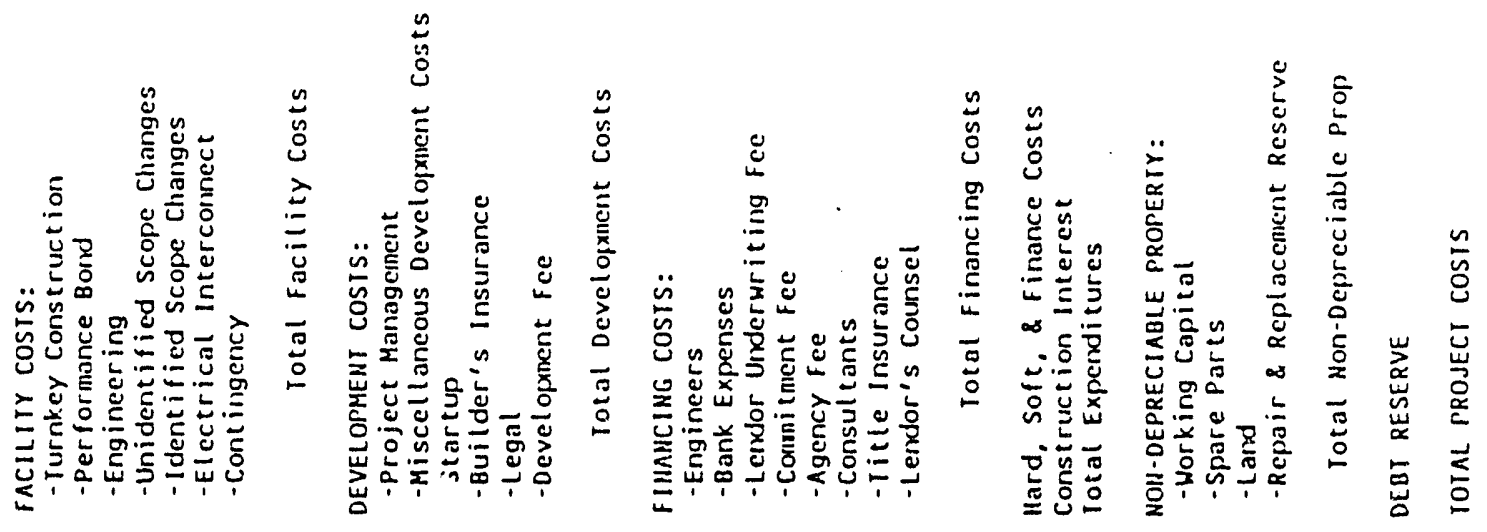




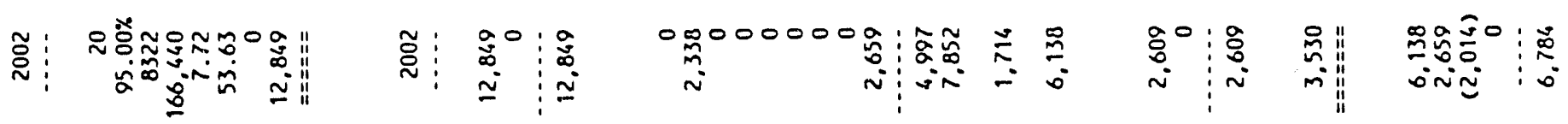

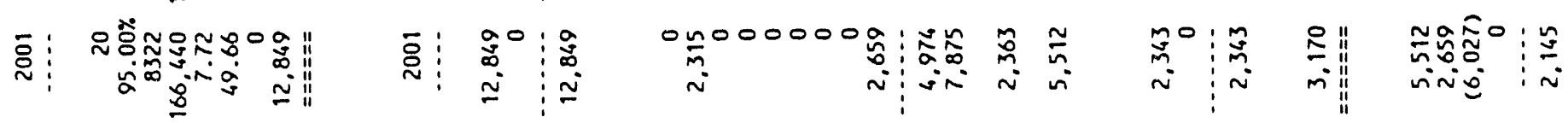

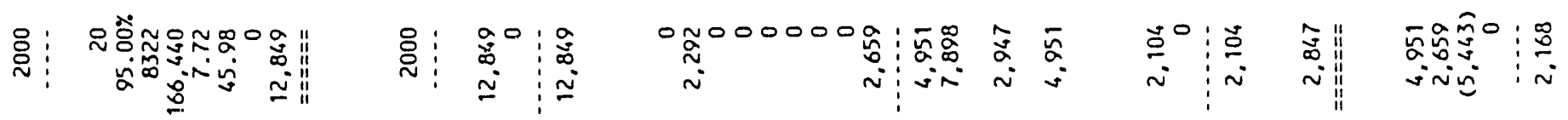

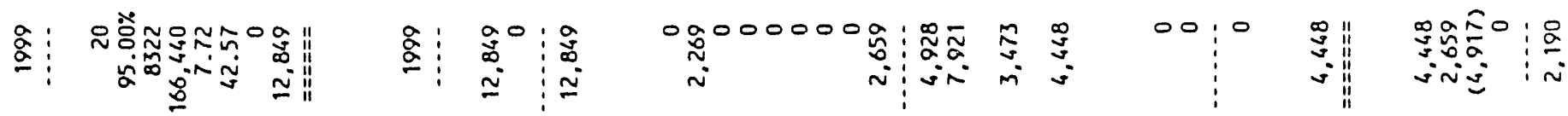

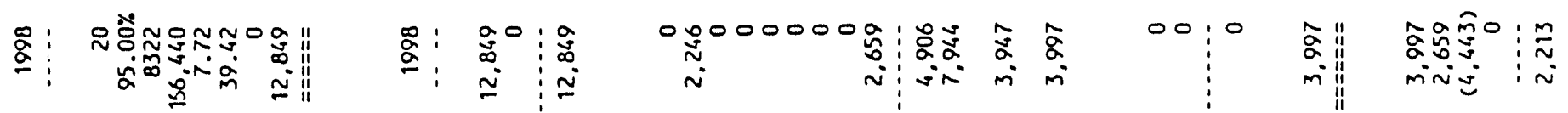

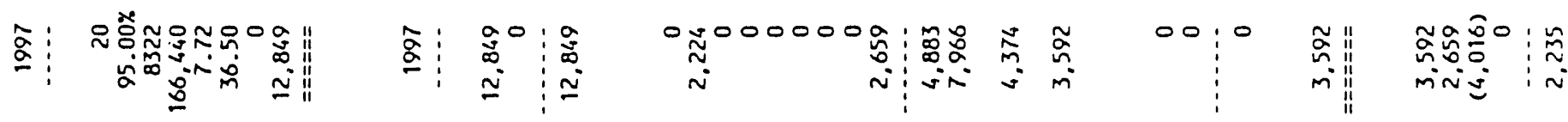

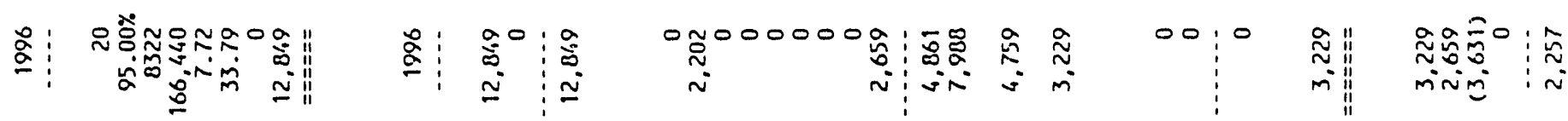

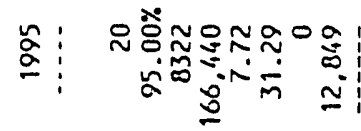

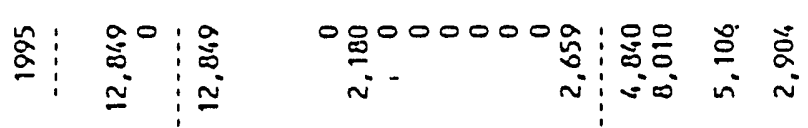

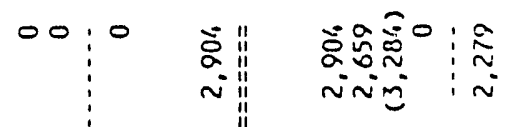

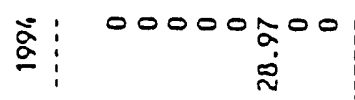

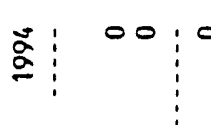

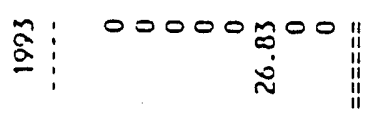

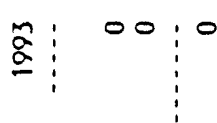

$\approx 00000 \stackrel{0}{\approx}: 00$

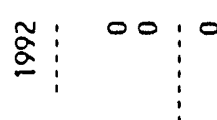

$\bar{\Sigma}$ $00000800 \|$
$\tilde{\sim}$
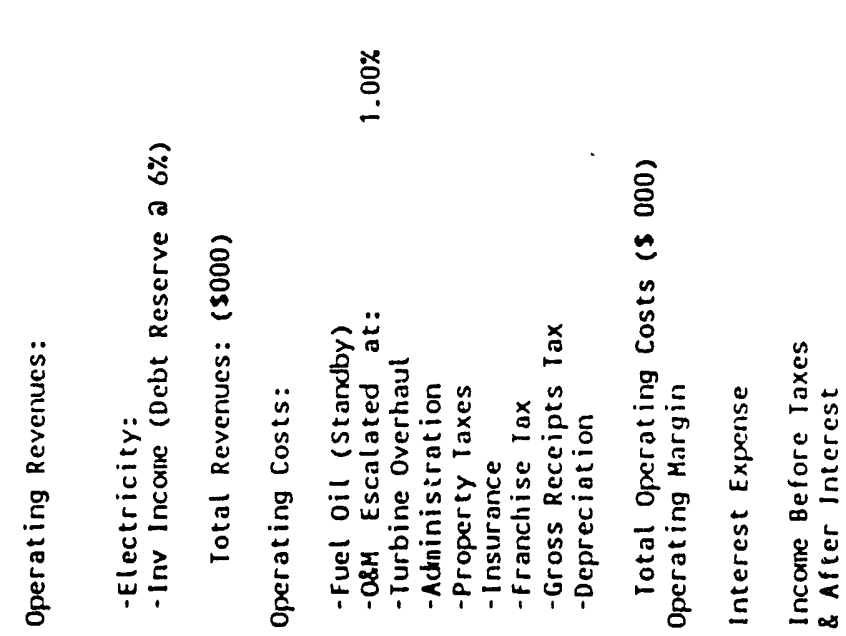

$\stackrel{\stackrel{\sim}{0}}{\stackrel{\sim}{\sim}}$

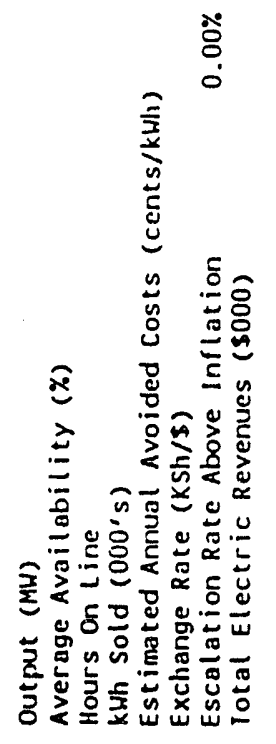

Appendix IV - 21 


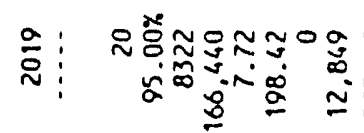

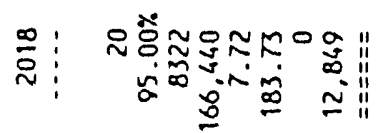

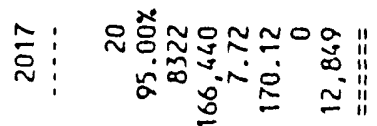

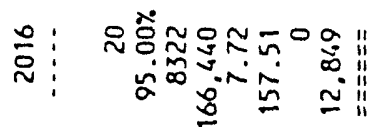

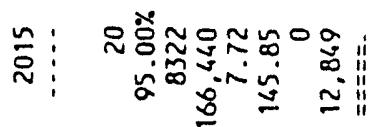

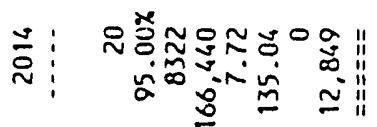

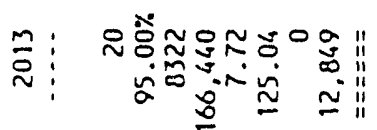

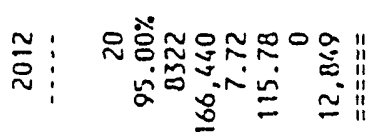

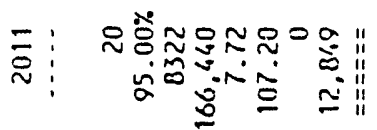

呈:

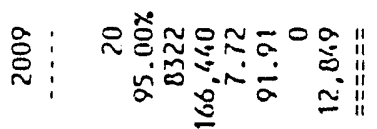

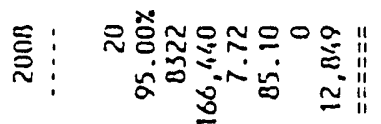

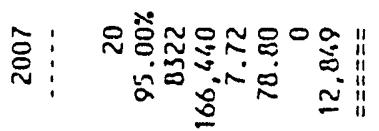

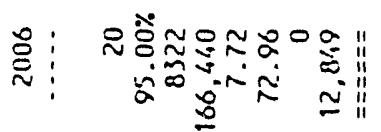

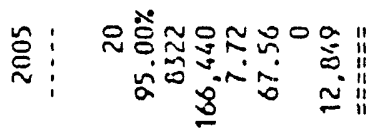

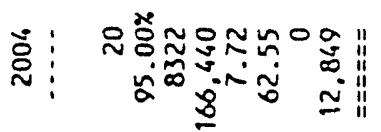

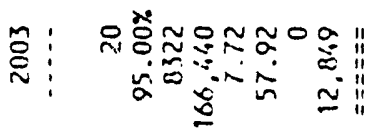

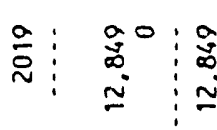

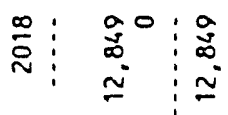

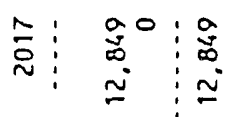

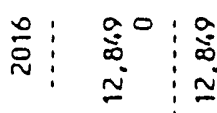

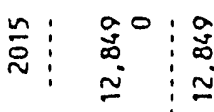

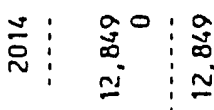

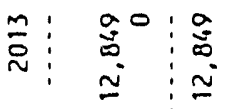

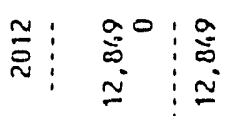

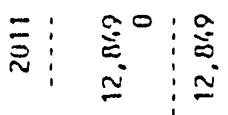

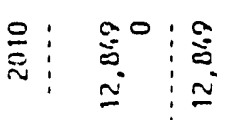

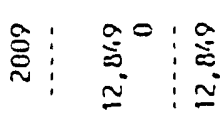

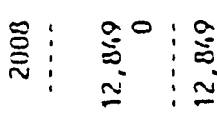

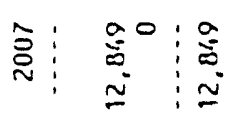

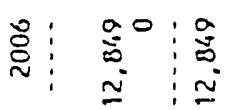

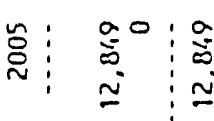

总

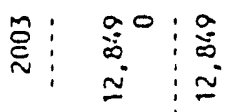

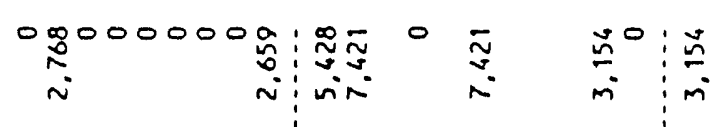

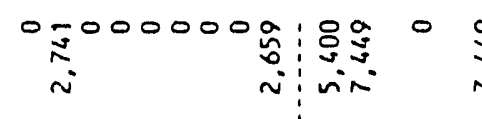

婇

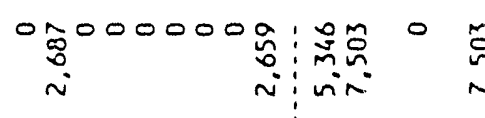

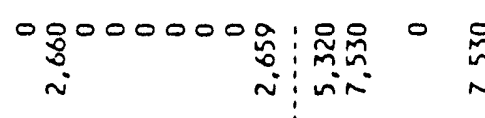

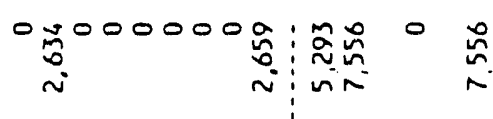

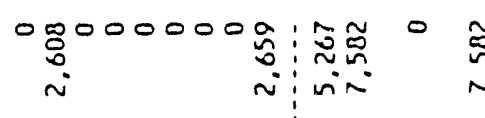

颉

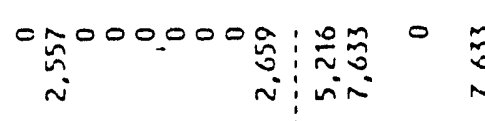

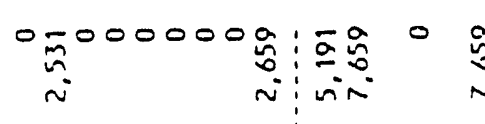

总

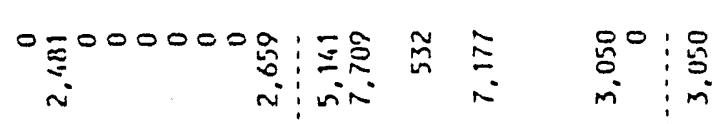

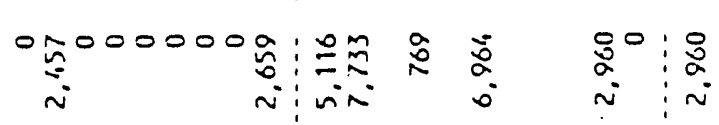

咩0000000

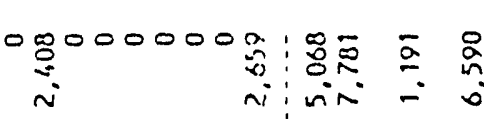

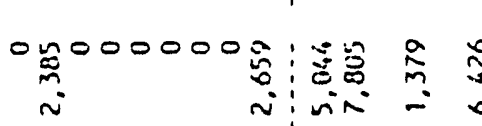

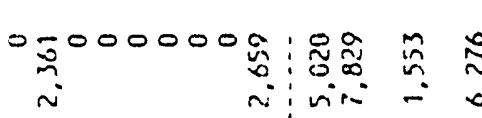

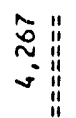

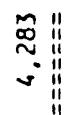

\begin{tabular}{l:l}
$\hat{s}$ & $\hat{=}$ \\
\hdashline & $m$
\end{tabular}

c.

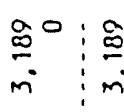

s.t.

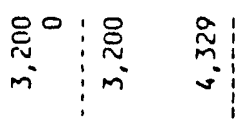

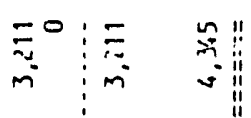

$\begin{array}{l:c}\tilde{N}_{m}^{0} & \approx \\ m^{*} & \sim\end{array}$

品"

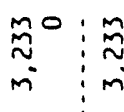

c:

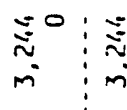

:

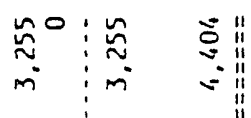

总

․:

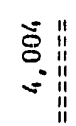

管

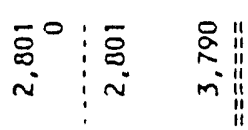

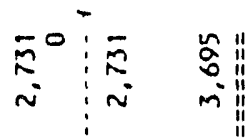

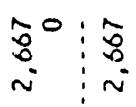

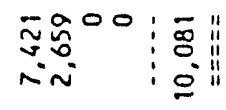

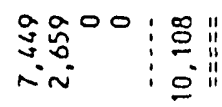

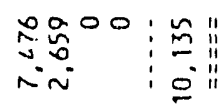

享忩00

品忩00

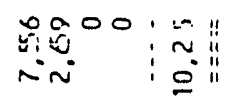

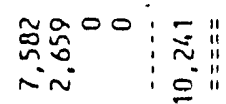

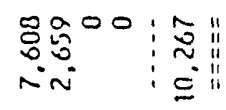

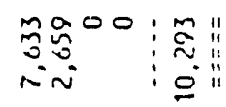

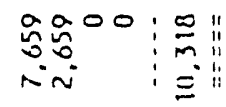

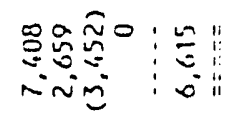

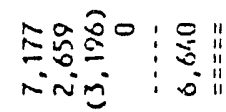

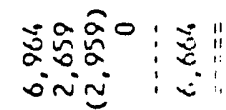

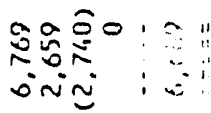

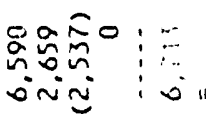

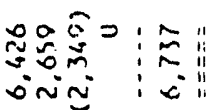

우ำำ: 


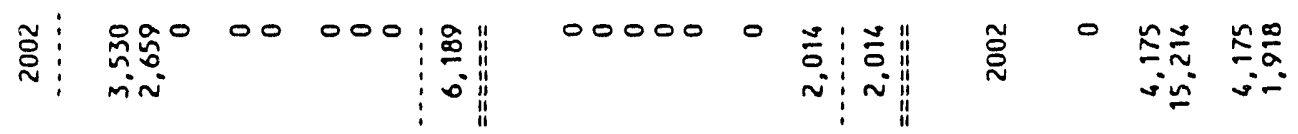

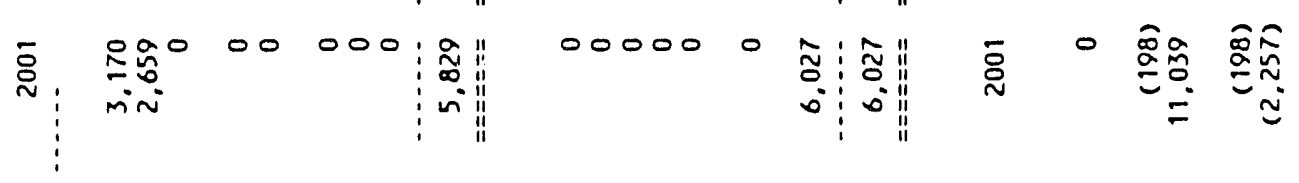

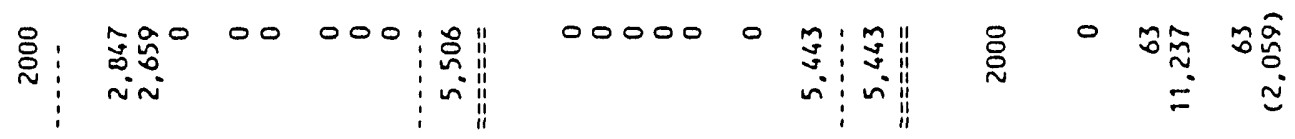

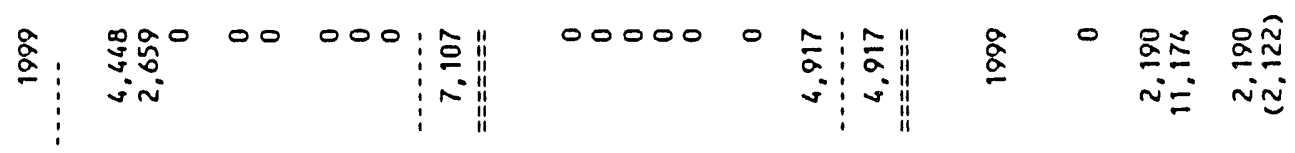

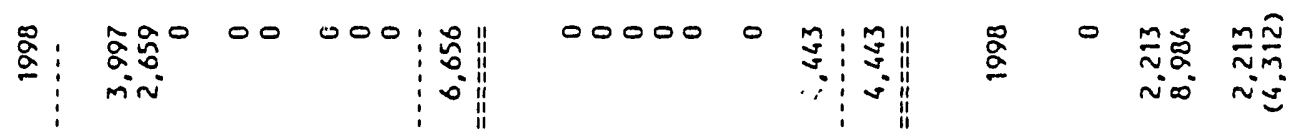

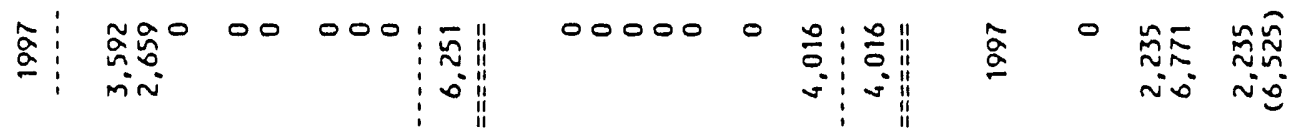

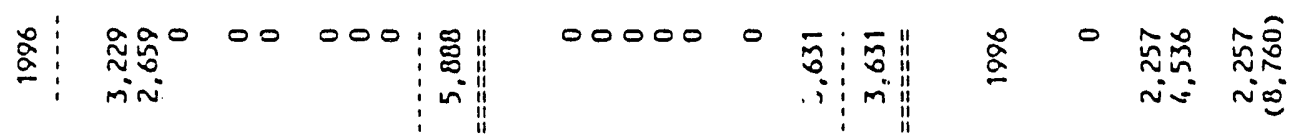

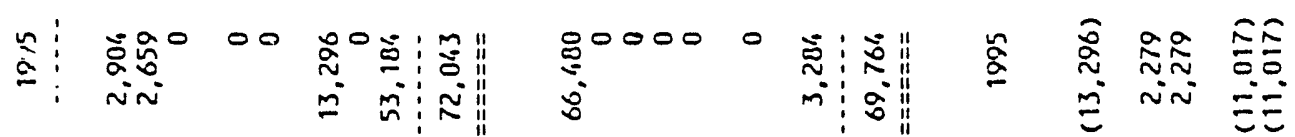

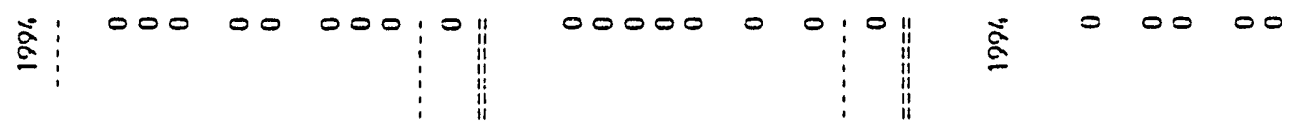

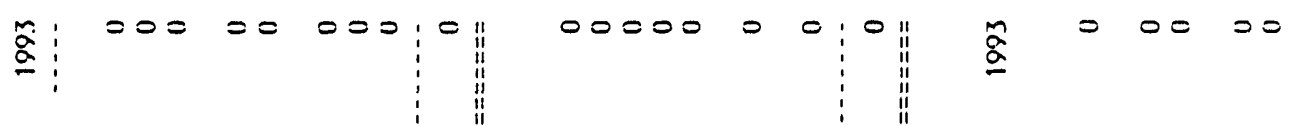

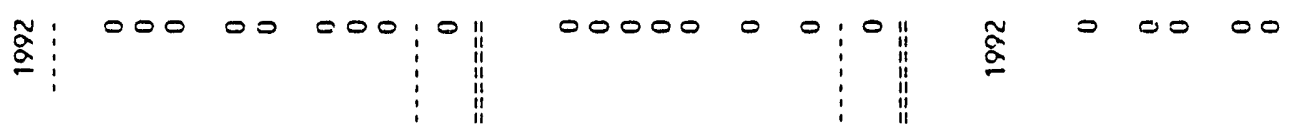

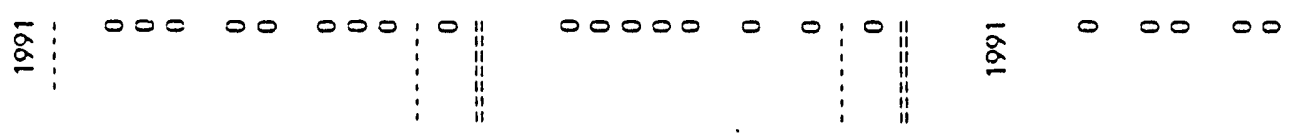

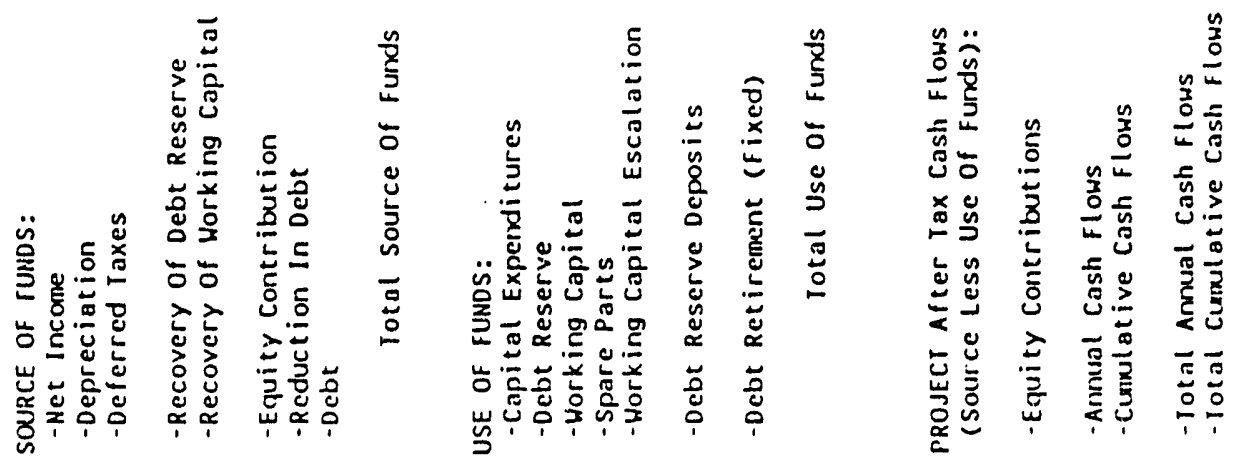




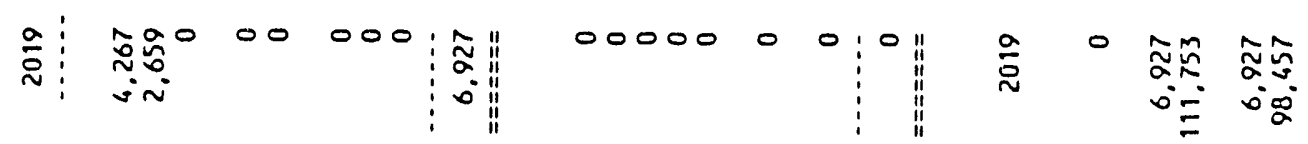

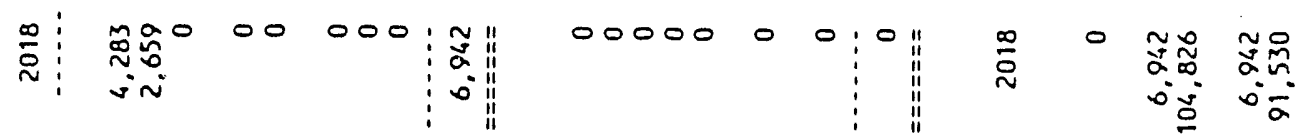

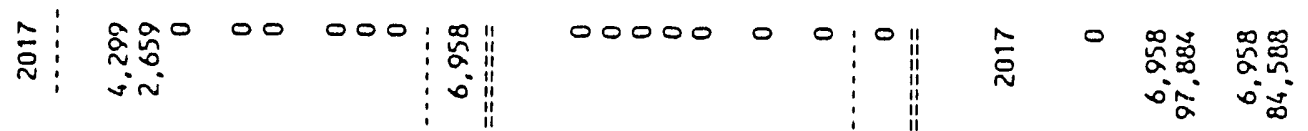

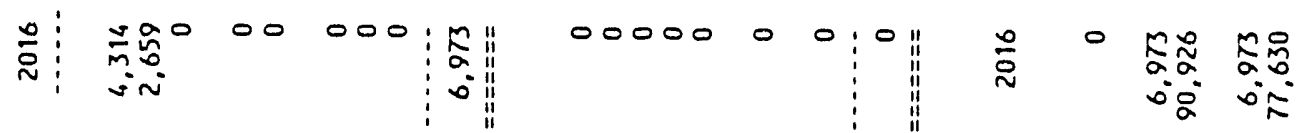

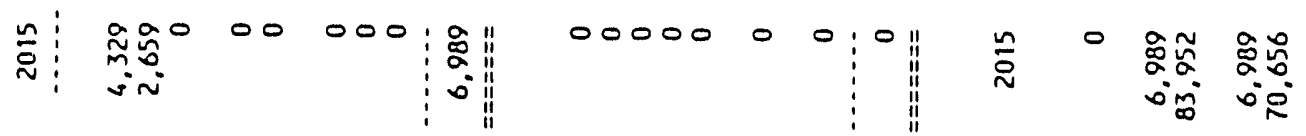

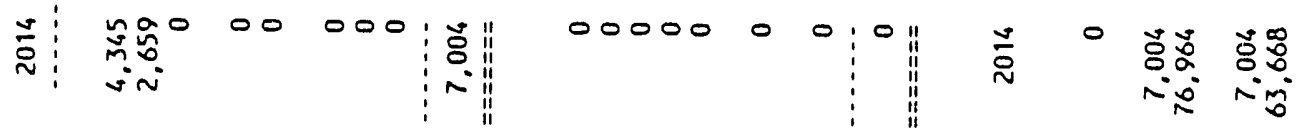

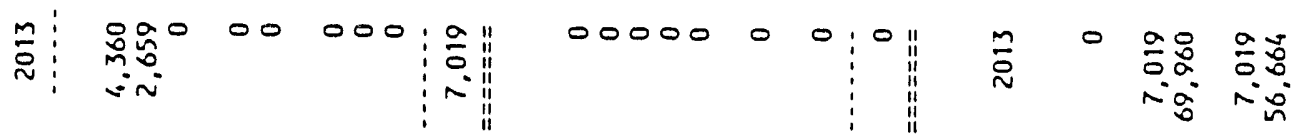

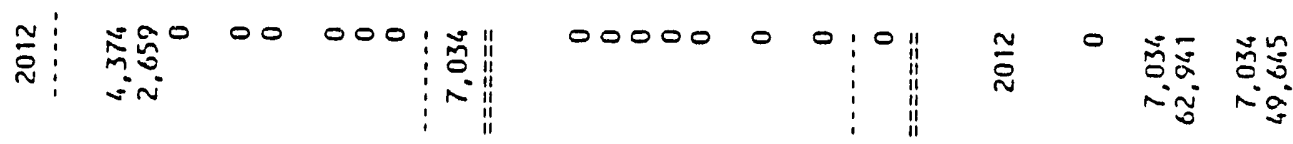

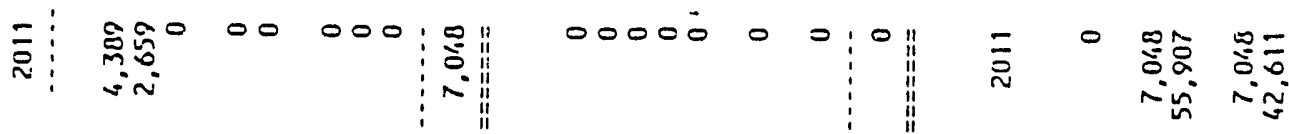

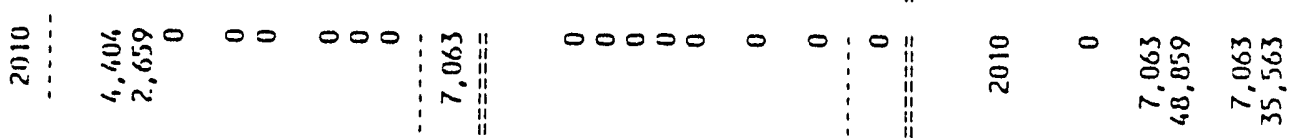

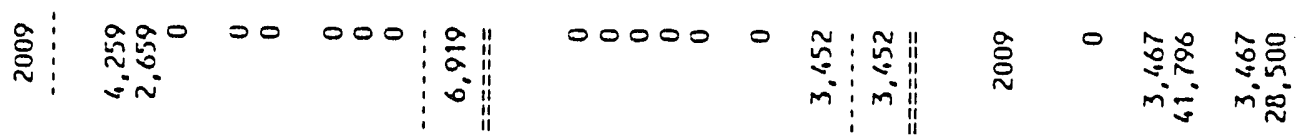

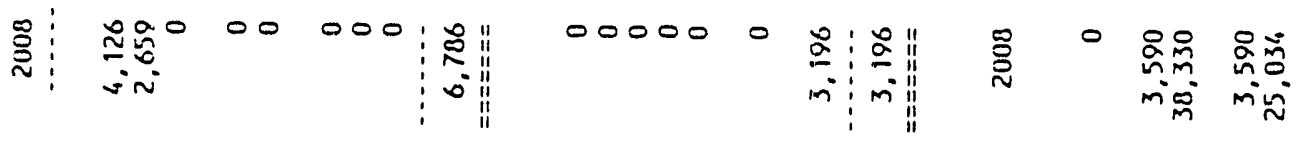

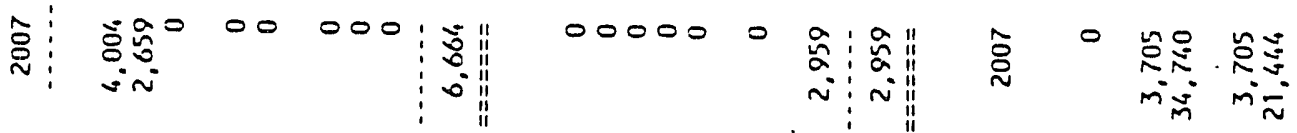

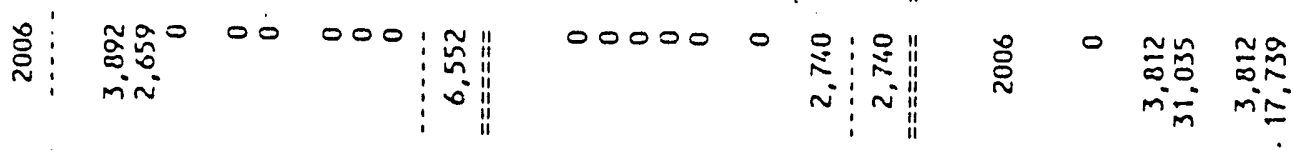

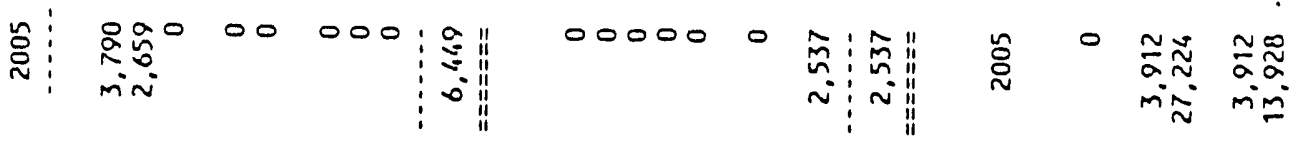

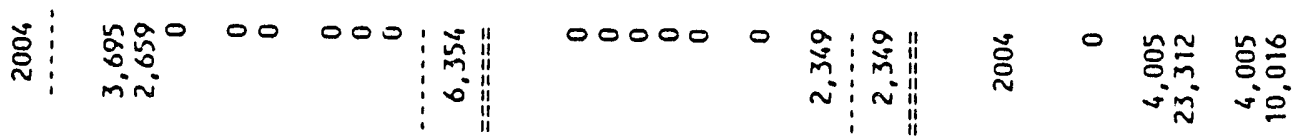

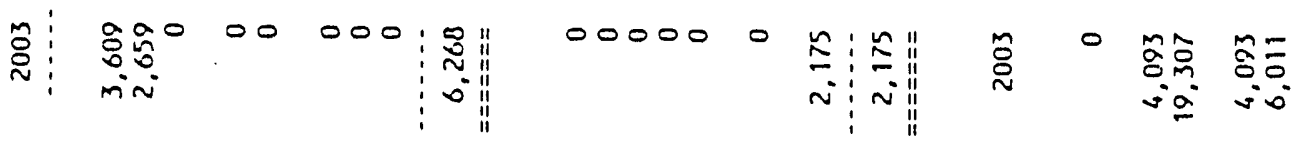




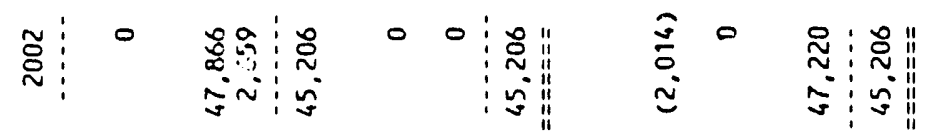

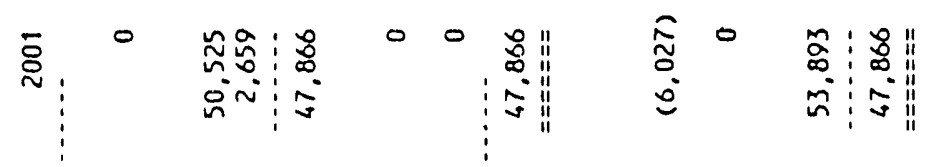

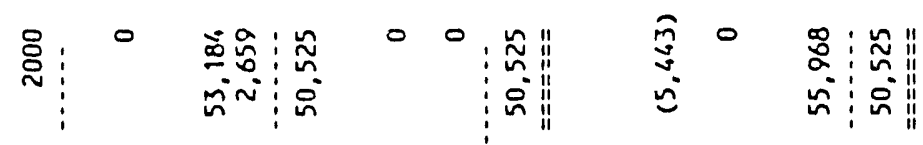

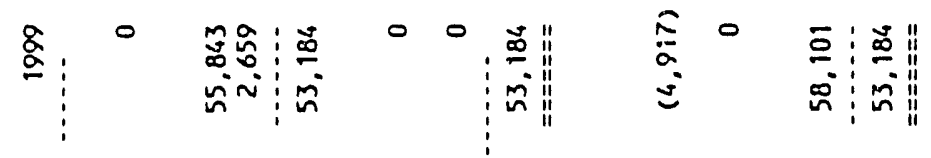

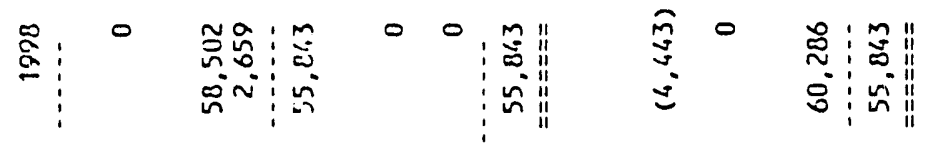

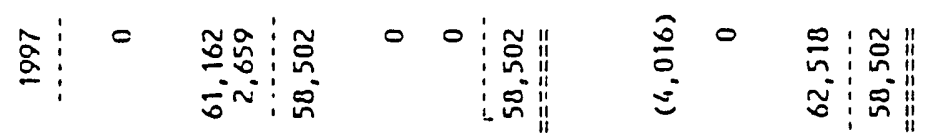

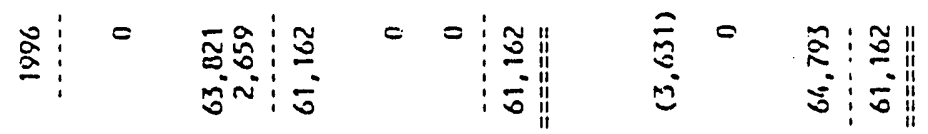

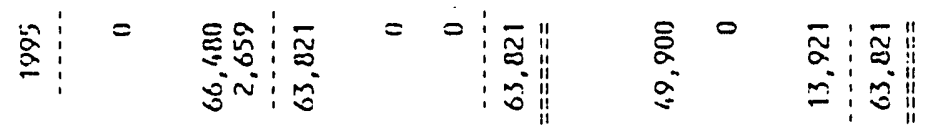

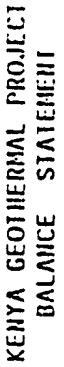

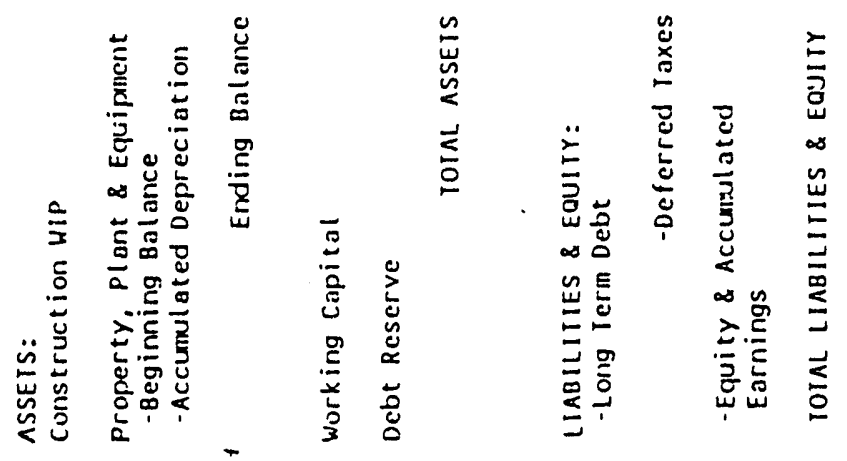




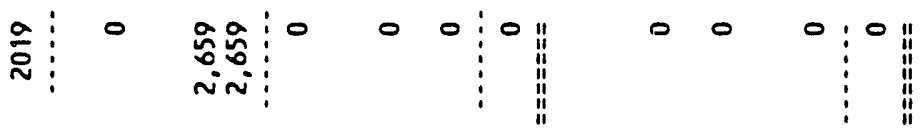

$$
\begin{aligned}
& \text { 里家 }
\end{aligned}
$$

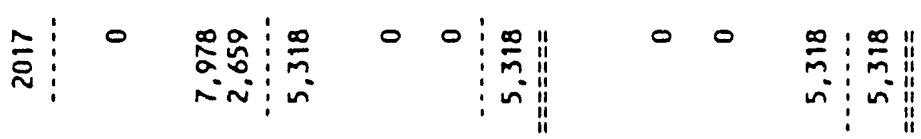

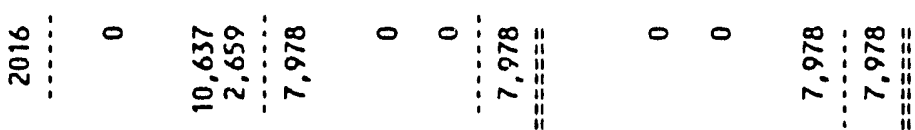

$$
\begin{aligned}
& \text { 高 }
\end{aligned}
$$

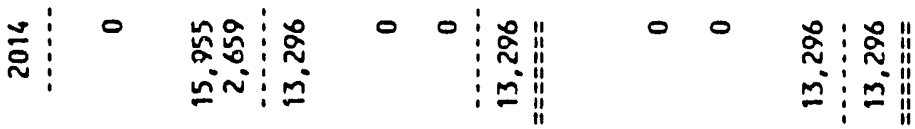

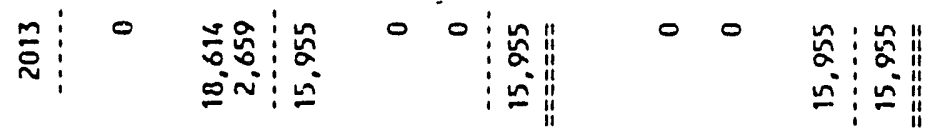

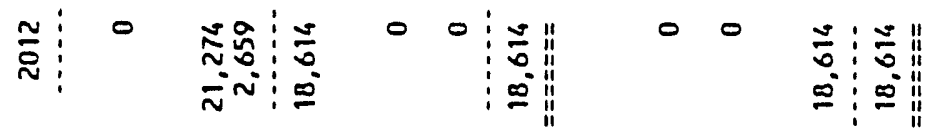

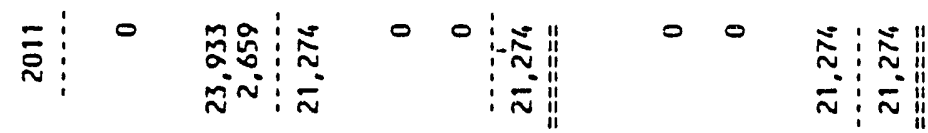

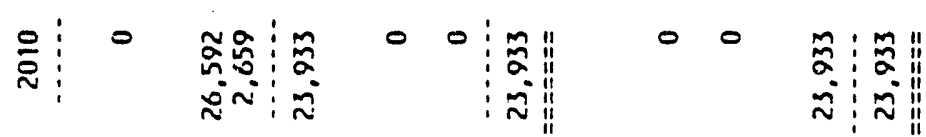

$$
\begin{aligned}
& \text { 言 } \\
& \text { 悹 }
\end{aligned}
$$

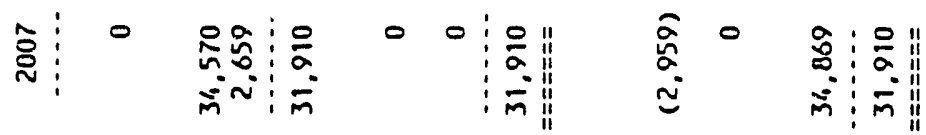

$$
\begin{aligned}
& \text { 实 }
\end{aligned}
$$

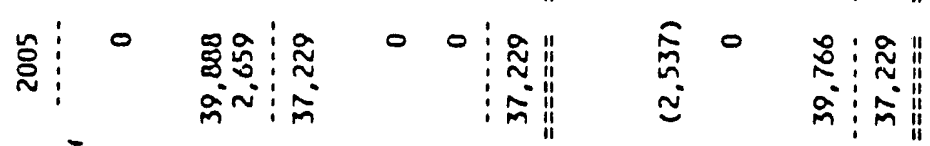

$$
\begin{aligned}
& \text { 竎 }
\end{aligned}
$$

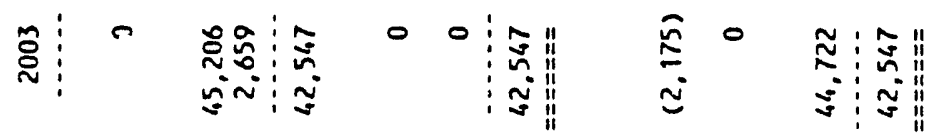




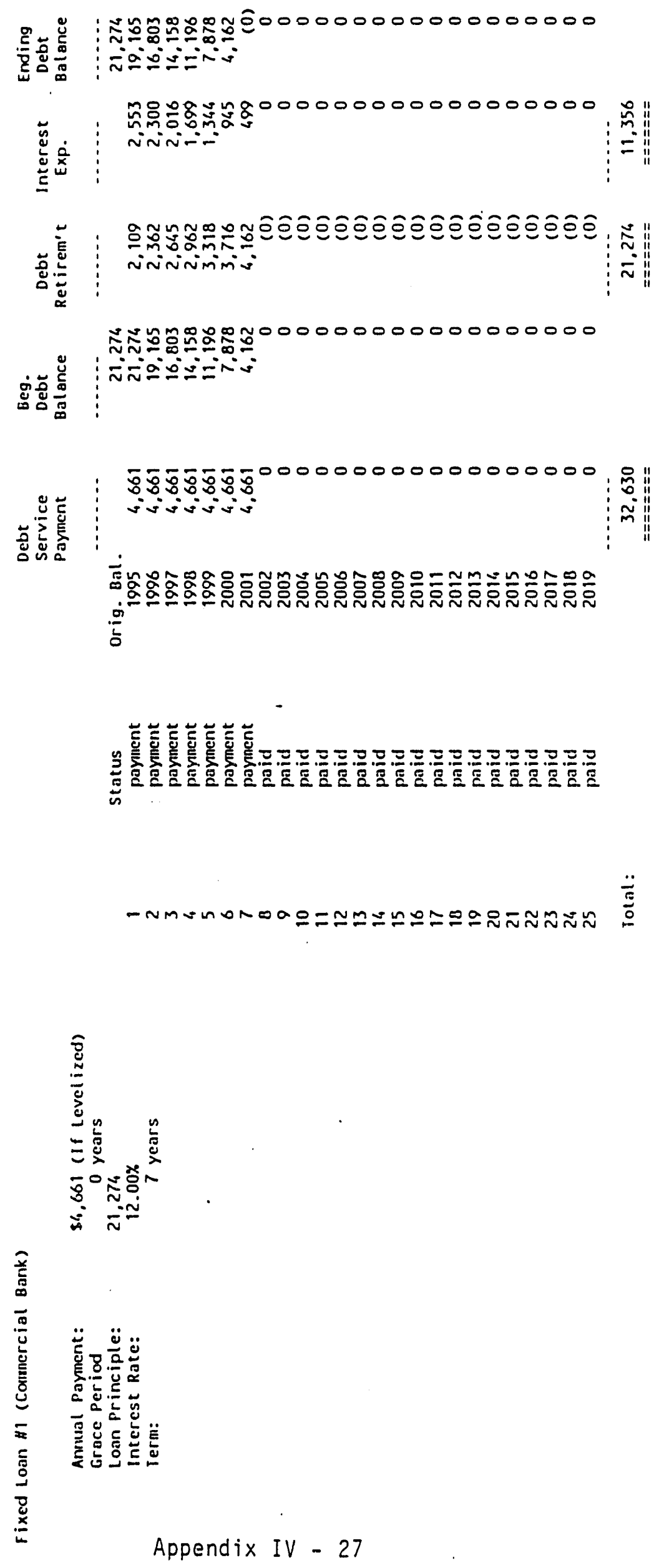



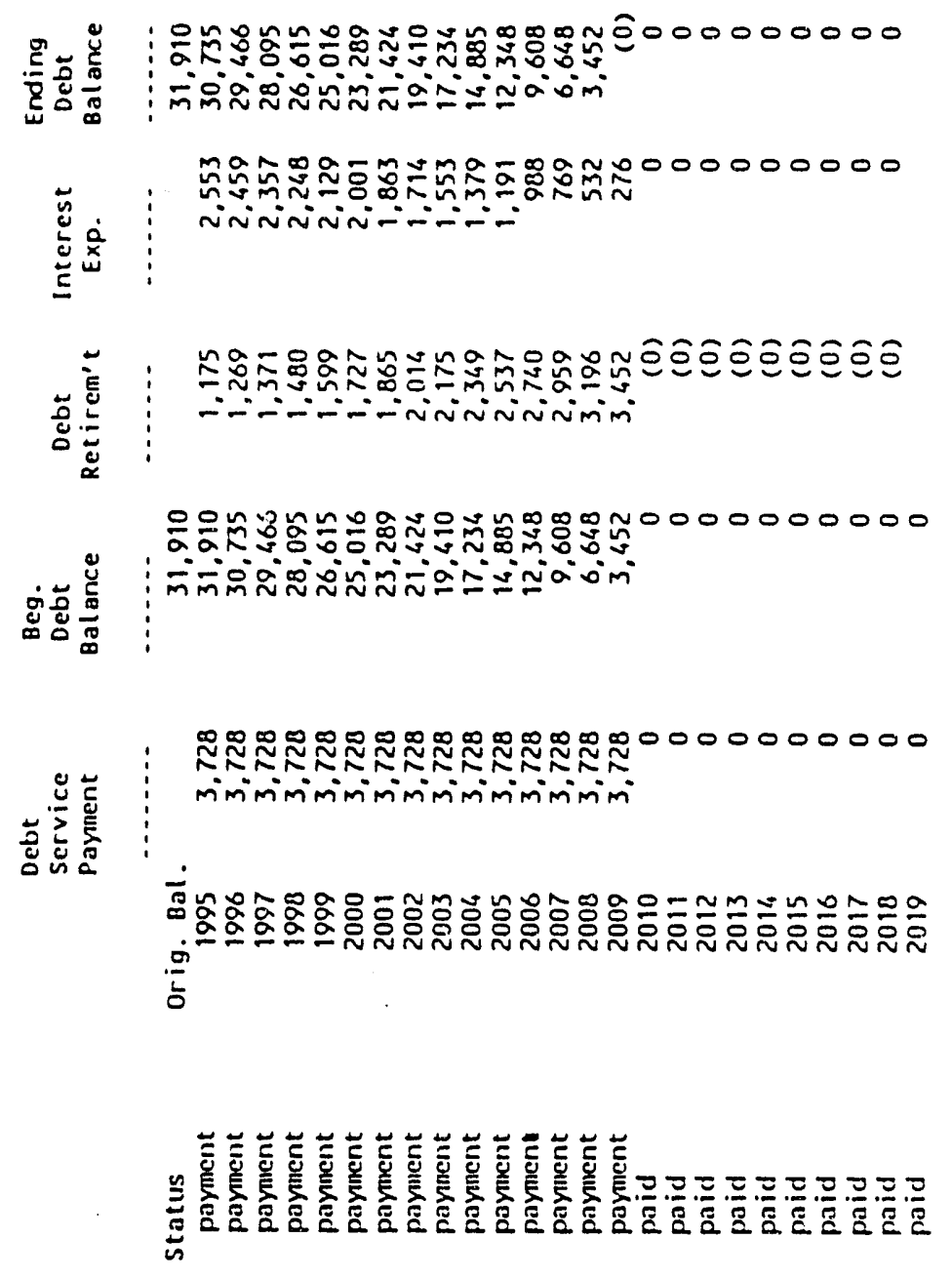

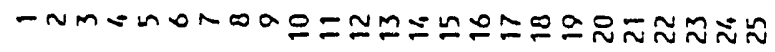
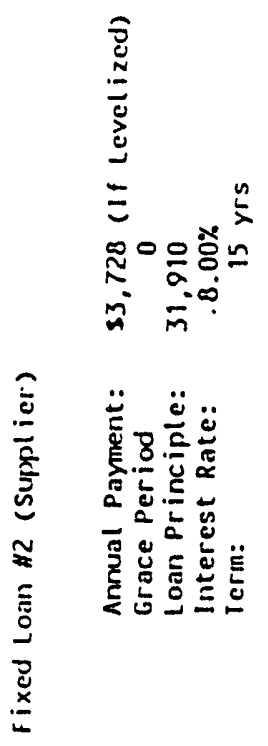

Appendix IV - 28 


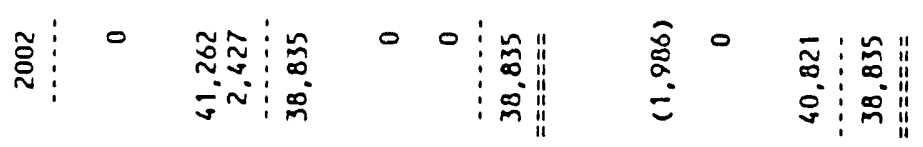

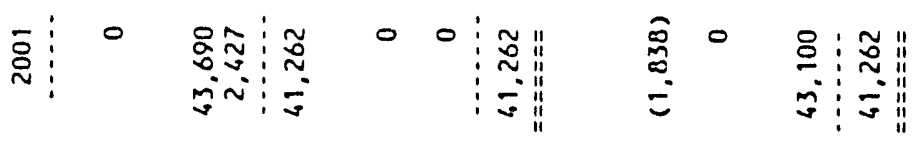

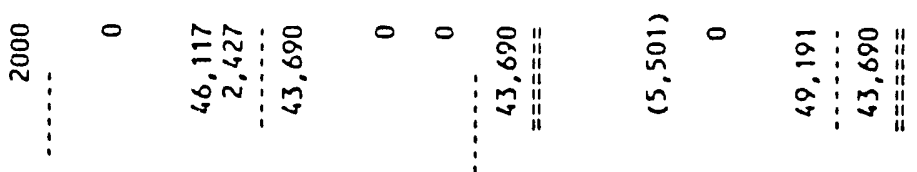

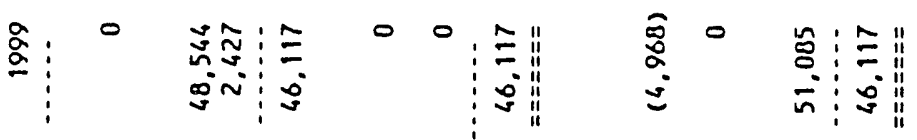

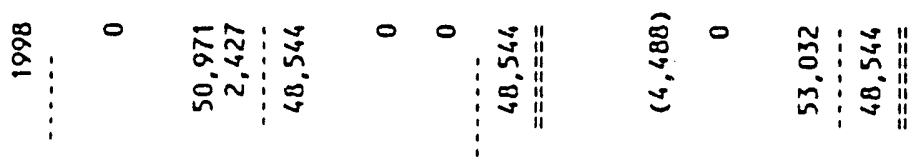

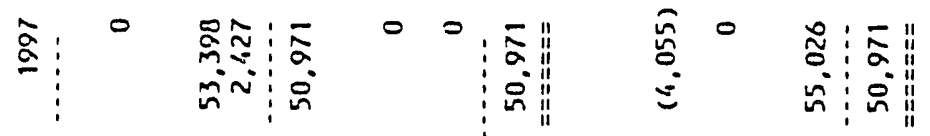

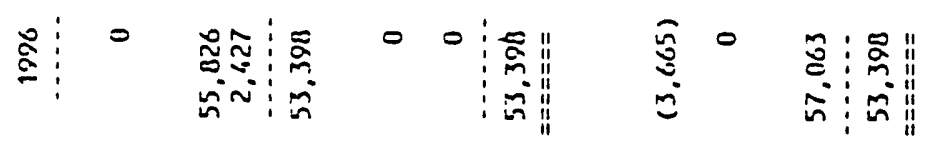

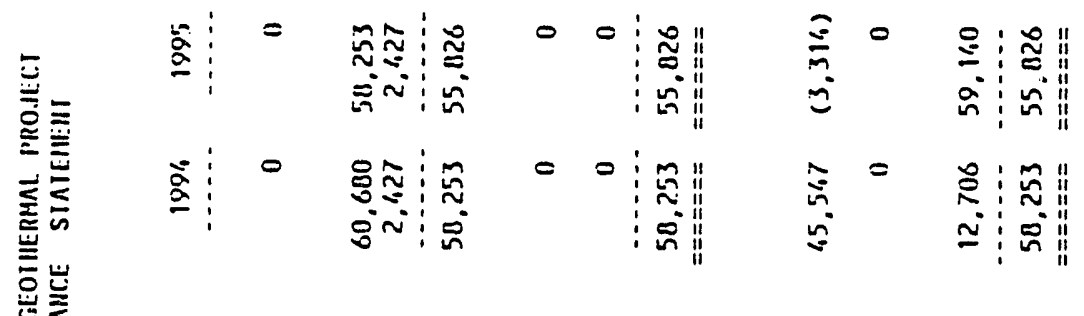

$$
\begin{aligned}
& \leq
\end{aligned}
$$

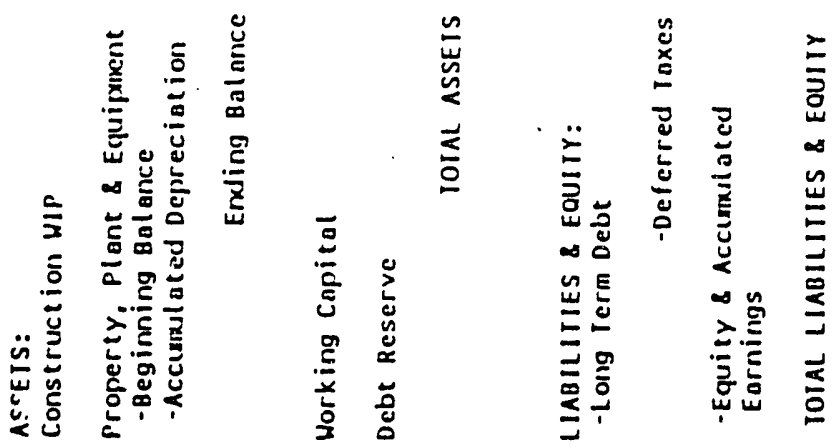


完

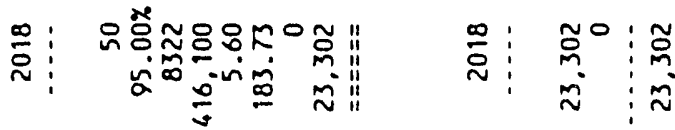

交:

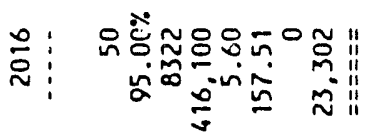

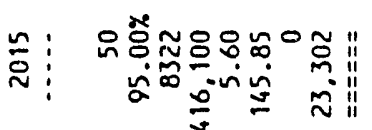

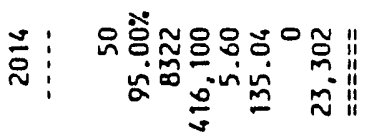

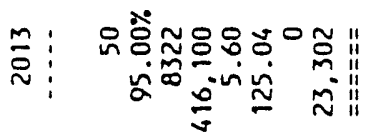

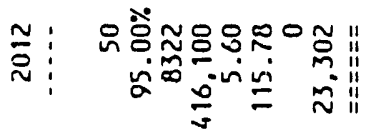

훈

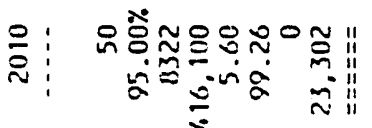

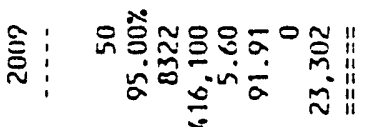

雚

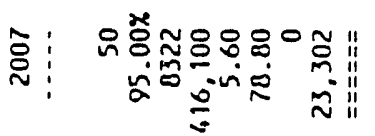

号:

享

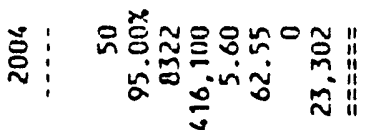

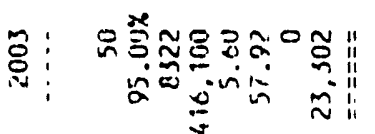

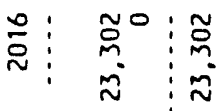

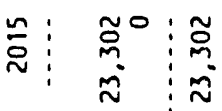

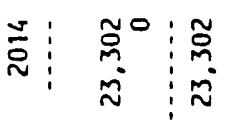

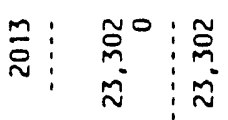

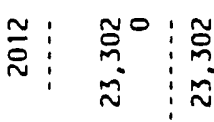

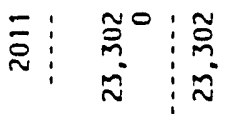

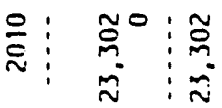

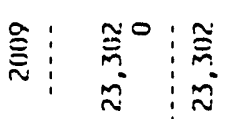

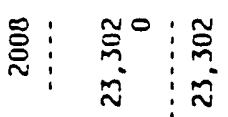

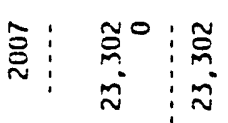

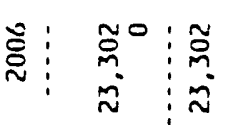

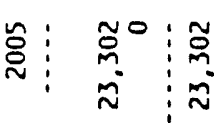

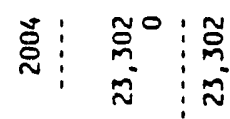

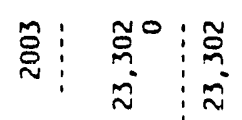

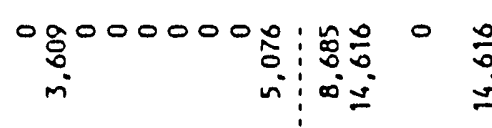

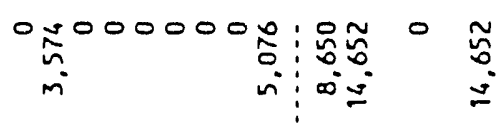

赑0000000:

0

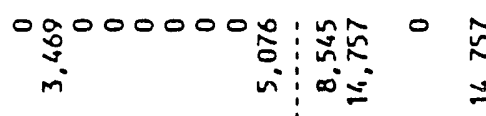

mi

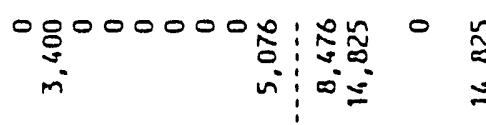

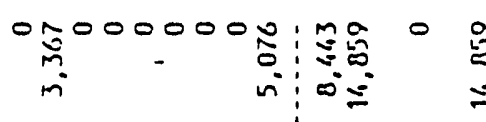

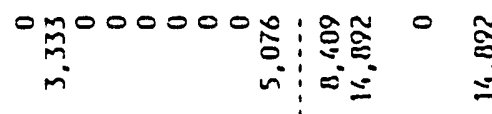

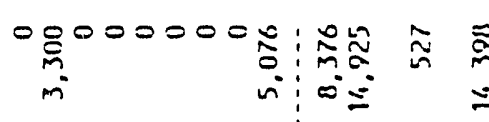

0 赵0000000:

筩000000落:

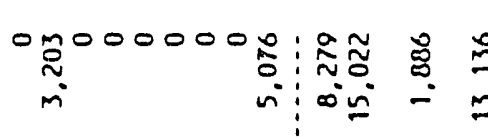

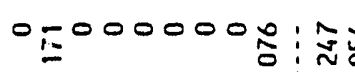

mi

聇0000000:

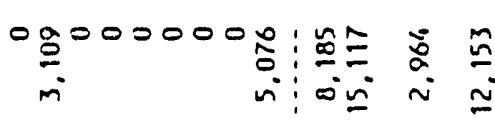

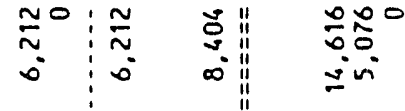

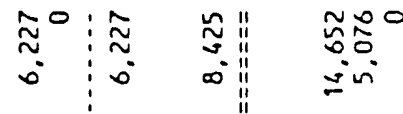

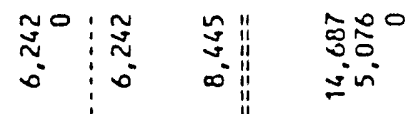

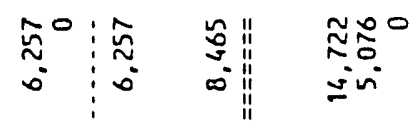

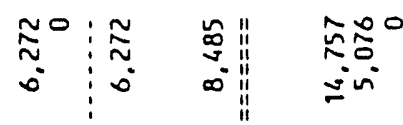

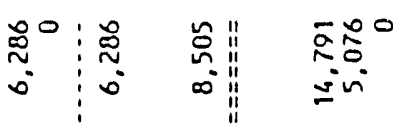

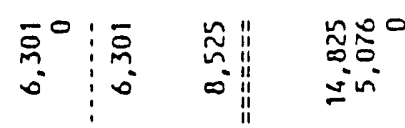

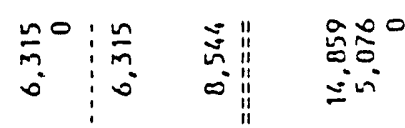

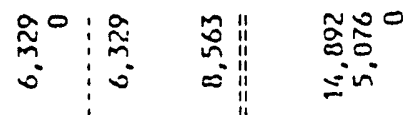

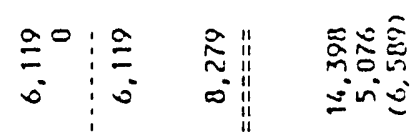

๙

mivi

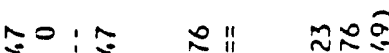

ตูก๊

in in ril mivi

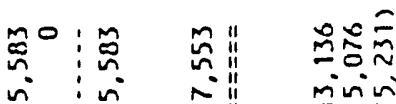

miniv

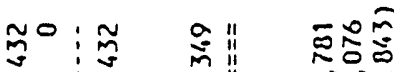

กิบ

苾运

inis

뜽ํำ 


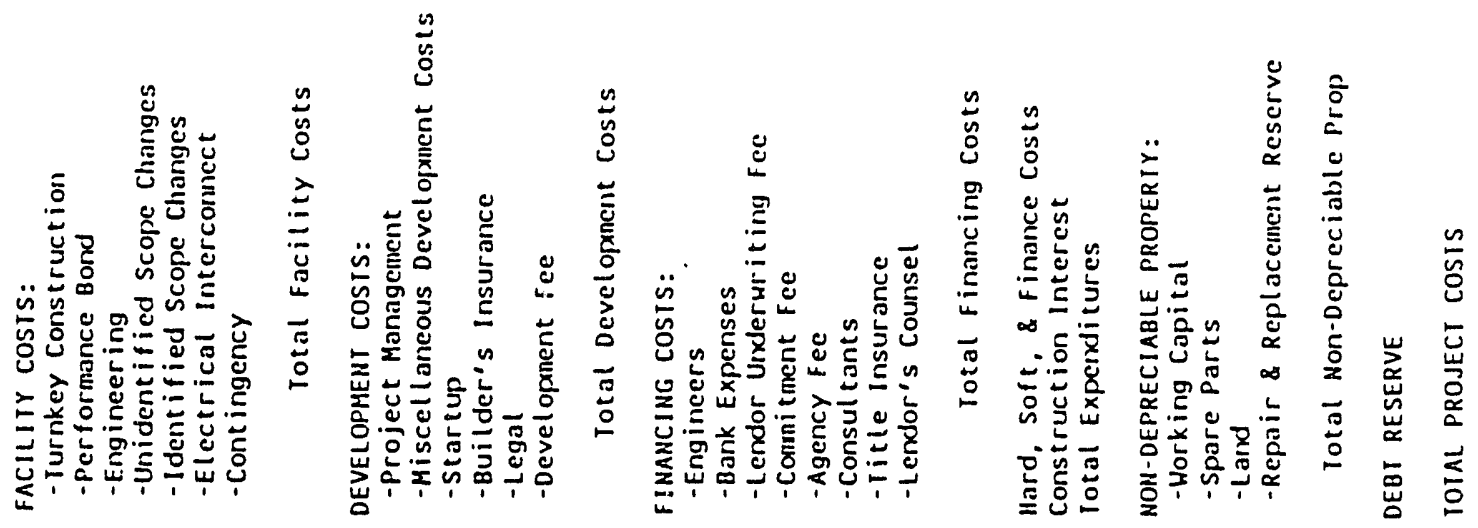




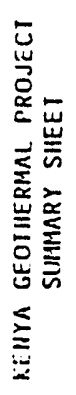

䓀咅

荅

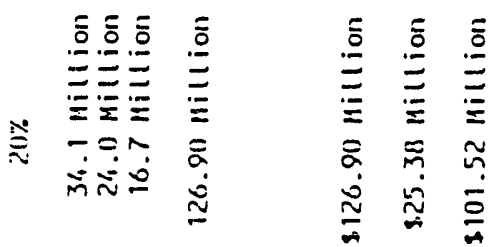

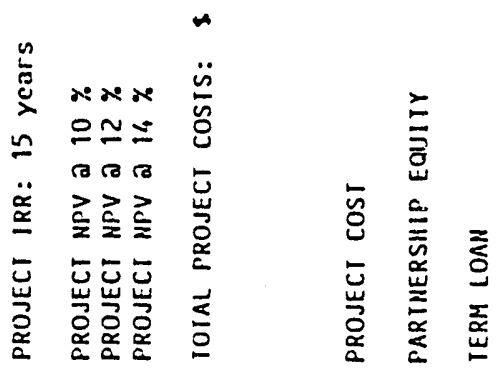

Appendix IV - 32 

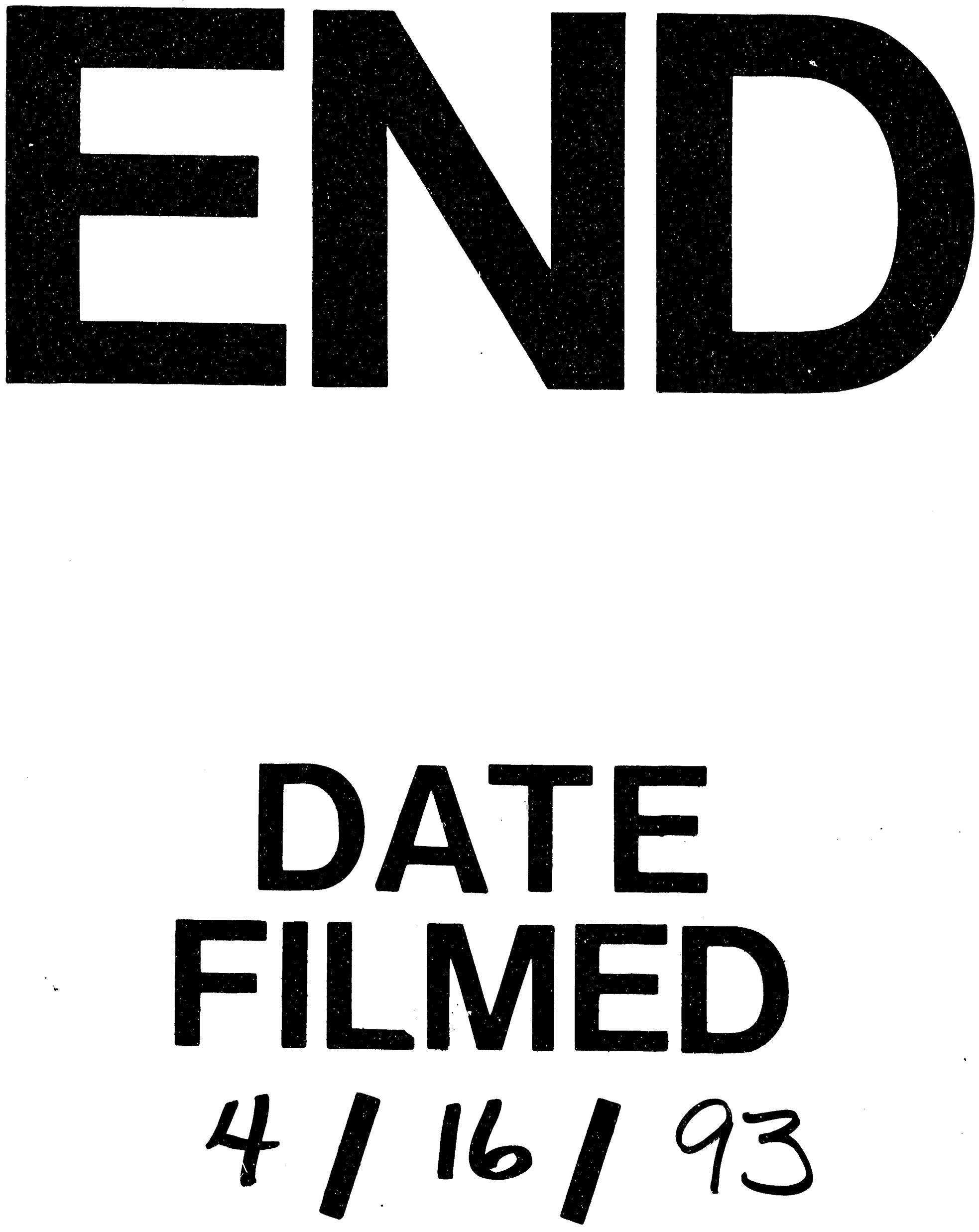

